


C. -1 
NOVAE SPECIES

QVADRVPEDVM

E

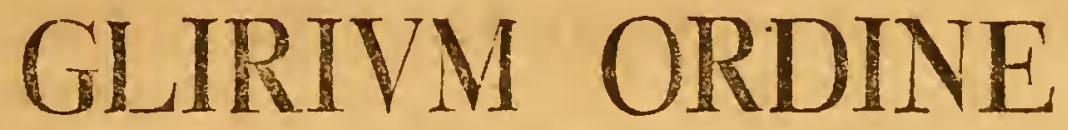

CVM

\section{ILLVSTRATIONIBVS VARIIS}

COMPLVRIVM EX HOC ORDINE ANIMALIVM

$$
\text { A V C T O R E }
$$

\section{PETRO SIM. PALLAS}

$\triangle C A D E M C O$ PETROPOLITANO.

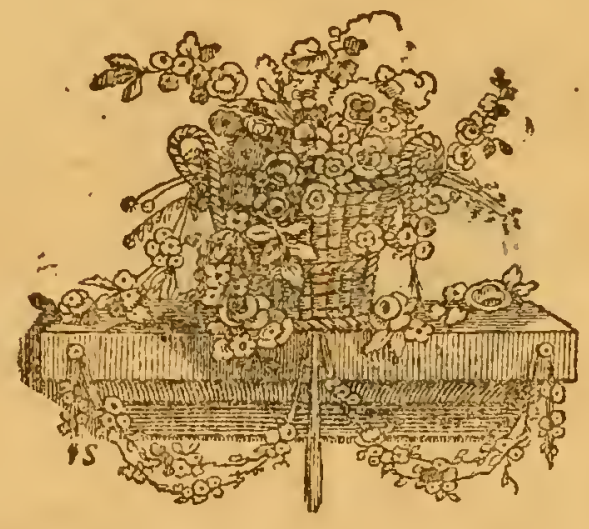

E R L A N G A

SVMTV WOLFGANGI WALTHERI. CIJ IS CC LXXVIII, 


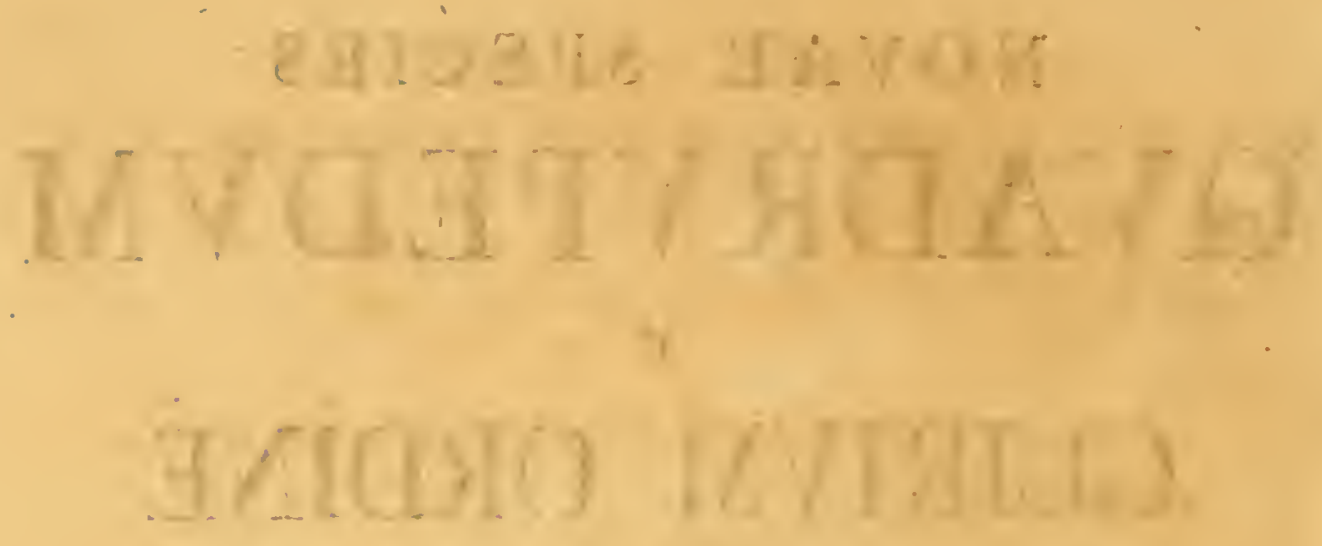

SENEC. natural. quxet, lib. III. prefo

Confumfers fe quidam, dus afta, reguns externorkm, componum, queque pulf, invicens arifine funt populi. Quanto fatizus eft fus mala extinguere, quan aliens palleTis tradere? Quanto potins Nwwinis opera colebrare, quan Philippi aut Alexasndri hatrocinia, ceterorungue qui cxitio sentiun clari - pefles fuere mor. salium. - -

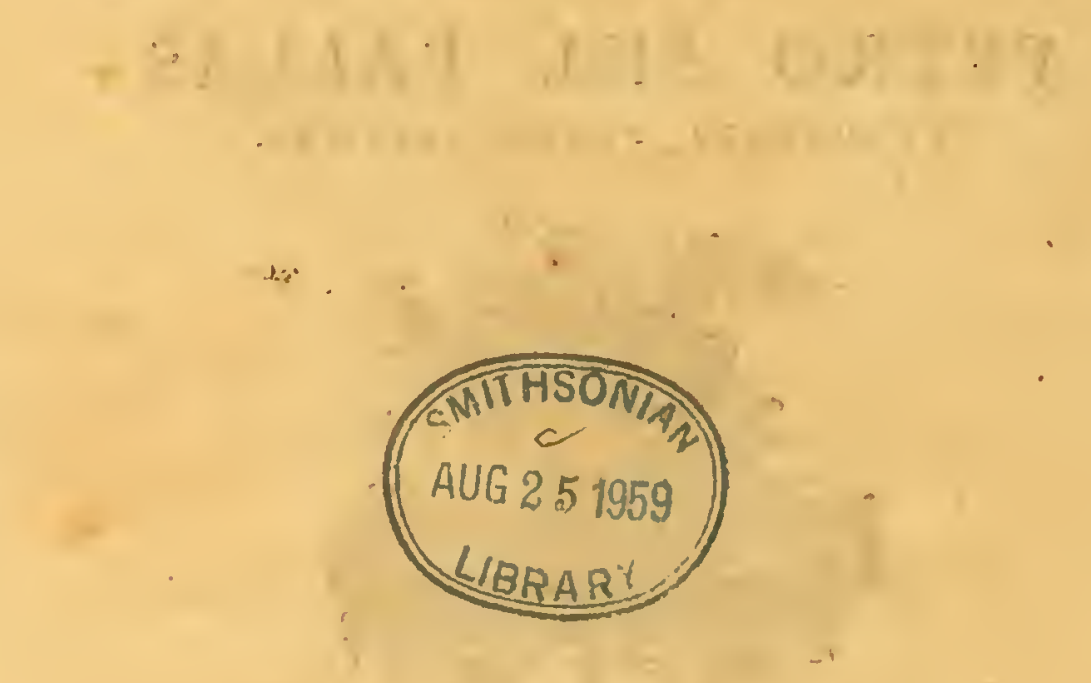




\section{AMICIS ET PATRONIS SVIS, \\ VIRIS ILLVSTRIBVS AC CELEBERRIMIS,}

DN. HENRICO GVIL. LIBERO BARONI DE RENGERS, CONSILII BELLICI IN BELGIO PRAESIDI, CET.

DN. PETRO IONAE BERGIO, MEDICO ET BOTANICO SVECO,

DN. MART. TH. BR V̈NNICHIO, zOOLOGO DANO,

DN. IOHANNI BVRMANNO, ET

DN. NICOL. LAVRENT. BVIRANNO,

BOTANICIS AMSTLLAEDAMENSIBVS,

DN. DRV DRVRY, ENTOMOLOGO LONDINENSI,

DN. I. FRIDERICO HENNERT, MATHEMatico VLTRAIECTI"O,

DN. ALEX. BERNH. KOELPIN, MEDICo ET bOTANICO STETTINENSI,

DN. GVilelmo VAN DER MEVLEN, physioPIILO AMSTELAEDAMENSI,

DN. AVGVSTO FRIDER. PALLAS, FRatri, MEDICO BEROLINENSI,

DN. THOMAE PENNANT ARMIGERO, zOOLOGO ANGLO,

DN. IOHANNI CHRIST. DAN. SCHREBER, .200LOGO ET BOTANICO GERMANO,

DN. DANIEL. CHRIST. SOLANDER, zOOLOGO ET BOTANICO SVEO-ANGLO. 


\section{HASCE MONOGRAPHIAS}

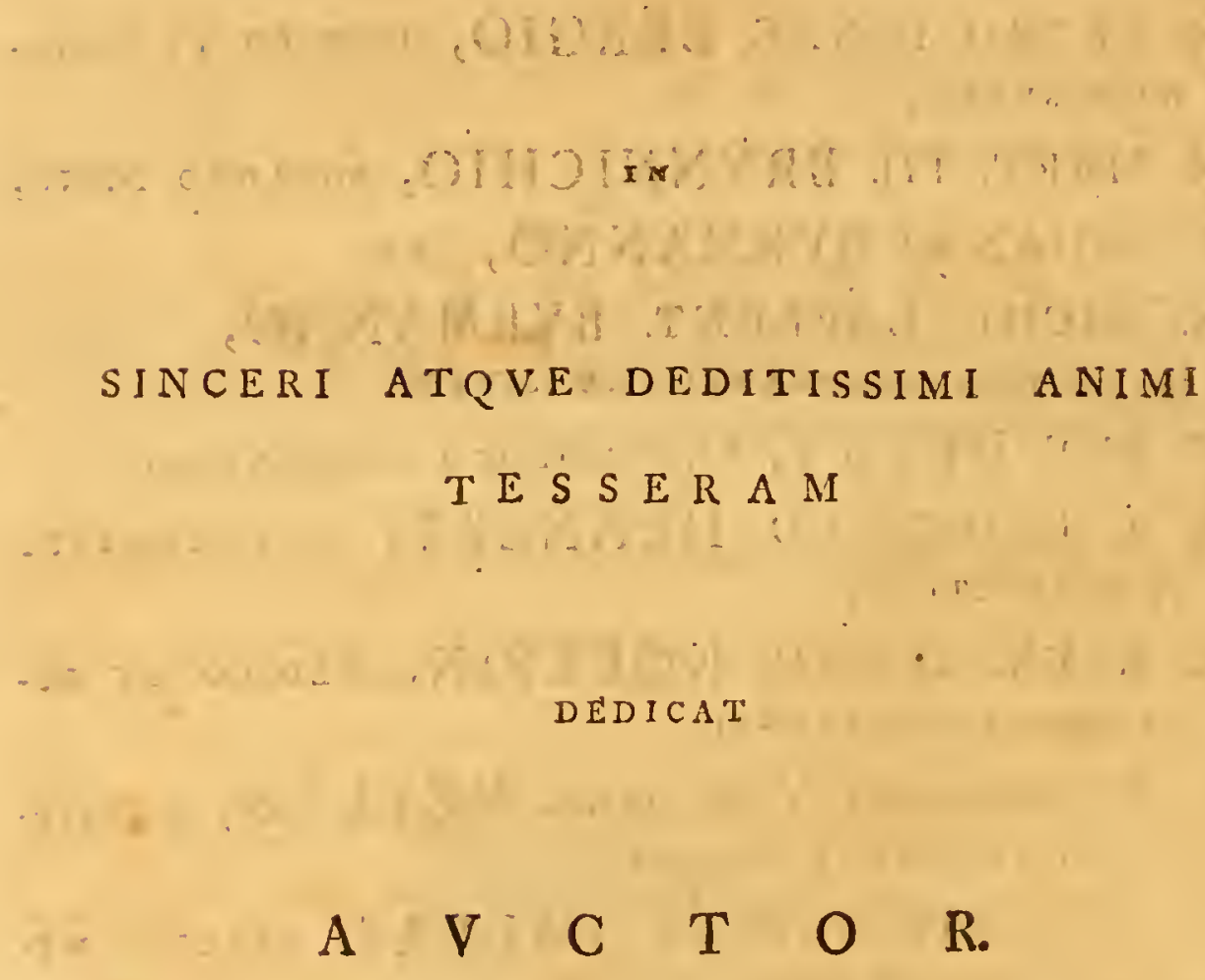




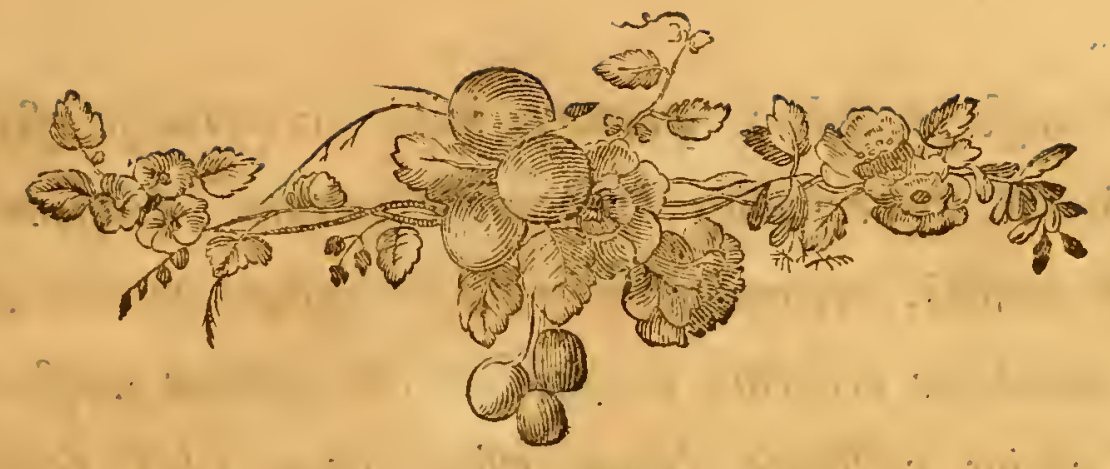

\section{P R A E F A T I O.}

A

nimalinn, quce in boc opuscula continentur, plurimorunn defcriptiones accurate et icones bonce bactemus defuerunt. Qunni igitur Vir celeberrinus atque meritis de univerfa Scientia naturali clarus, Dn. Ioh. Ch. Dan. SCHREBER, opns illud egregium zoograpbicum moliretur, cujus priora volumina applaufu publico in lucem prodicre, nuibique boc femper in votis fuiffet, ut fub aufpiciis talis Viri, pro fublevandis fcientice naturalis ftudiofis et profcribenda compilatorum farragine, tale opus confifteret: aid augendusn illud qualemcunque obo- 
IV

lum conferre volui; quumque mibi GLIRIVM prafertim ordinem, imperfectius bucusque excultum, occafione itineris perati, novarum specierun fat infigni numero augere, minusque accurate cognitarnm complurium illuftrationes varias colligere datum effet, omne illud celeberr. SCHREBERO obtuli, ut fl forte defcriptiones meas, quce, addita prafertion anatome, fufiores funt, quam pro ejus scopo requiruntur, in futura Zoologorum commoda publicas facere vellet, iisdem iconibus, quas complendo splendido Operi, in quo laborat, fuppeditavi, infervire pufjent. Quibus quandoquiden non Solum benevole anmit Vir bumanifimus, fed etiam curam edendi ommen in sè amicifjume fufcepit, libenter bonorifica ejus opera utor, atque bec qualiacunque mea, faltim annicitice et in commune fudium ardoris teftimonio futura, ne in fchedis dintius lateant, in publicos ufus mitto.

Qucernnt aliqui, quor-fun accuratifima defcriptiones et minutiofe inprinis dimenflones ad exemplum D'AU. BENTONI exaratce; quibus multum utique temporis ima. pendendum eft, et patientice. Objiciunt mullun, vel non 
ubique cognitum effe incrementi terninum, neque exacte anius magnitudinis omnia unins fpeciei effe individna. His refpondeo: prinumn neceffarias effe in majoribus et rarioribus prafertim animalibus menfuras et curiofiorcm (non fuperfuam) per onnes partes defcriptionem, ut nibil ad eorum cognitionem defit. Qui otiofus noftros labores inSpicit, bunc ufun minime intelligit; fed qui ipfe naturam inveftigat, fcientian angere adlaborat, fpecies novas comparatione cum affinibus fabilive defiderat, is quidern nobis pro prafita opera gratias aget. - Qui enim ad obfervandum adjicit animum, ei etian (ut recte VER VLAMIVS) in rebus, qua vulgares videntur, multa obfervatu digna occurrunt. - Quam ego frepe animaliun, breviflunis definitionibus vel mancis defcriptionibus apud varios illuftratorum, adumbrationes ad inftar D'Aubento. nianarum defideravi, innnn quan fape in bis ipfis aliquid ad comparationem requifivi, quod Vir accuratiffinus vel slon vidit, vel dictu noin neceffarinn duxit. Quan uno pane ore conquerentes ubique andinns Zoologos parter et Botanicos, in dubia Specie brefitantes, non fufficere aulo- 
VI

runi, et novifjimi prafertim LIN NAEI ejusque imitato. rim breves et incompletas definitiones, imnno defcriptiones. Haud ideo dixerim onninan, a nobili quadrupedum, puliraque avium atque pifciumn clufe, ad minima usque chaotica animalcula, fpeciernm dandas effe prolixis verbis $d c$ friptiones, et vel micrometro merifurus explorandas. Cuivis claffi funs efto defcriptionnun modulus, et judicium, quid effentiale fit, quid fuperflunn aut minutiofunn, fecundum explorata in maxinne affinibus speciebus differentice momenta. Licet boc non annent, qui tumultarie Elenchos et Syjtemata et Fannas Florasque corradunt, vix vifis aut fugitive infpectis ditandas, ut novi multum oftentent.

Deinde fciant laboren recufantes fciali, menfuras dari non tanquan fixas magnitudinis speciei pricfnitce determinationes; fed effe proportionnm Specięi propriarunn nuduios, fune quibus, maxime in claffe quadrupedum, species, externa forma et colore fepe fimillima, difingui onmino non poffunt, ui exemplis multis probari poteft. Et fi ob. jicias, fufficere poft diligentes inftitutas dimenfiones, illas tantum cbartis mandafje, qure ad diftinguendas maxime 
Species faciunt; reponam, multas adbuc inter exotica animalia, notis noftris fimilia et identica credita, latere novas species, qua non fine menfurarun it totius babitus accurata comparatione diftingui poterant; et cum omnia omnizm climatum animalia comparafse non unins bominis fit, neceffe eft, ut conferantur Species feilfinn per plenas defcriptiones, que tandem ftabiliendre funt pofteritati.

Céterum optandum, ut Cel. SCHREBERI opus $\int e-$ cunda navigans aura per totam Zoologiam extenfun tan dem Splendeat, onnibusque, qui bric fcientia operam navare velint, proluceat, ne amplins trediofis repetitionibus opera et impenfae perdantur, Sed infcitiores etiam perfpicere poffunt, quid in commnthe bonum conferri a fingulis queat. Optandum, ut celeberr. Auctor per omnes claffes feliciter perducto operi non folum fufficiat, fed $\int e$ rius etian publica, jamulse parta gloria, fruatur. Optals. dum denique, ut Bibliopola, nobili raroque pro Naturali Scientia fudio et impendio celebrandus, non careat generoso fucceflu, et procerum atque principum cirortum pro opere magno aufu crepto librali retributione fruatur. 
VIT

Etenim, ut cum Divo GESNERO concludam, quamplurimos (vellem) intelligere, rem longe honeftiffmam effe, circa optima et pulcherrima mortalium Atudia bene merendo famam et gloriam fibi immortalem comparare. Quippe hoc nobiliffinum gloriæ præmium viros bonos et utilitatem doetrinamque publicam promo: ventes, eriam fponte fua, veluti umbra corpus, confequitur (Conr. GESNER in Epift. muncupator. ad GRAVIVM, Operi de Quadruped. oviparis prafixa). Dabam Petropolitano in Suburbio d. XV. OEtobr. M DCC LXXVII.

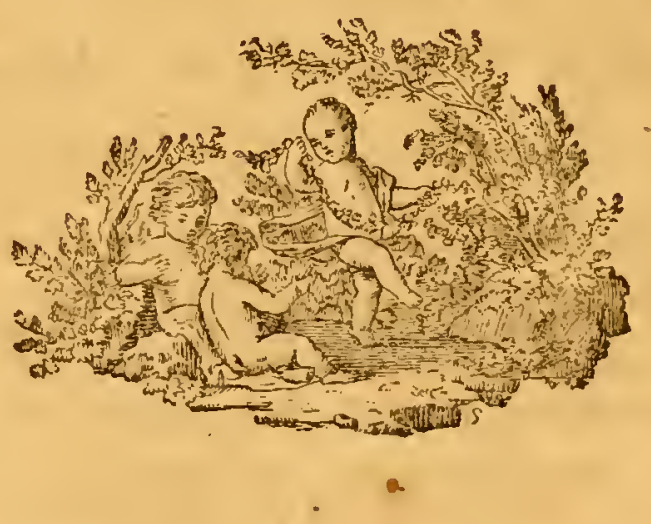




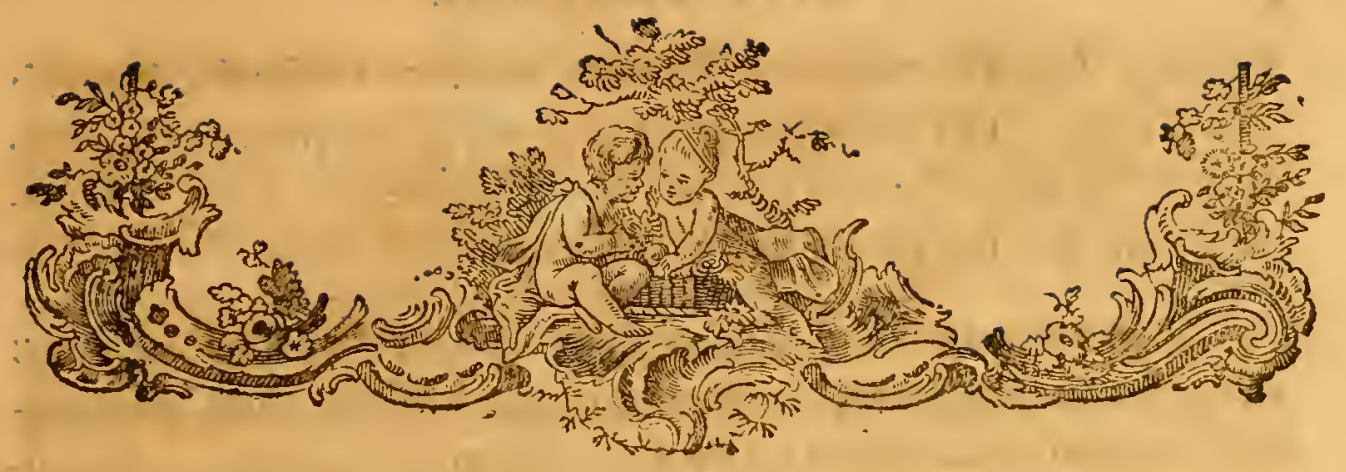

\section{E P V S \\ $V A R I A B I L I S$.}

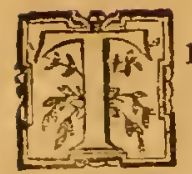

res Lcporum europæorum fpecies rectifime diftinxerat varro (de re ruft. lib.III. cap. I 2.) fcilicet vulgares, quos in Gallia transalpira et Macedonia majores fieri obfervat; , alterius, inquit, generis eft, quod in Gallia "nafcitur ad alpes; qui hoc fere mutant, quod toti candidi „funt; hi perrari perferuntur Romam. Tertii generis eft, quod , in Hifpania nafcitur, fmilis noftro Lepori ex quadam parte, fed „humile, (ut recte innuit) "quem Chnichlum appellant., ZooIngi plerique recentiores, non exccpto BVFFONIO, alpinos iftos, eosdemque borealibus regionibus Europæ, Afiæ et Americæ communes Lepores, qui hyeme toti evadunt candidi, et liquefcen-te nivi (ut jam plinivs habet) rutilefcunt, tantum obiter confideraffe videntur; quos accuratiore comparatione inftituta, cum 
vulgari Lepore campertris Europæ minime confundendos efte didiciffent. BRISSONIvs primum, atque differtius Cel. PENNANT, c propria et FORSTERI obfervatione, fpeciem diftinxe$\mathrm{re}^{a}$ ), de qua hic paullo accuratius dicam.

LEPVS variabilis, (quem nimis angufto nomine ilpimum ENNANTVs appellat, rectius algidus vel borenlis appcllandus) vulgari f. L. timido LINNAEI eodem fere gradu, quo $\mathrm{Cu}$ niculi, fimilis eft ad primum intuitum. Sed adtentus in magnitudine, proportione crurum, aurium, caudæ, colore denique æftivi velleris infignes differentias facile detegit. Dimenfiones accuratæ Leporis variabilis', quas infra $L$. Tölai comparatas fiftam, fpecie diverfum effe luculenter probabunt. Referam autem hic graviora proportionum momenta et aftivi velleris colorem defcribaim.

Lepus itaque oariabilis Europæum vulgårem, cujus Cel. D'AVBENTONVS menfuras expofuit, fere quarta parte totius longitudinis fupcrabat; caput habuit longitudine fere fimili paullo. ve majore, fed circumferentia cranii roftrique exilius, licet craffius, quam L. Tolai; aures quoque multo minores, nempe breviores capite, quum in Europæo longiores efie foleant; oculos paulo propiores nafo. Artus antici pofticique paulo breviores, proportione relativa licet fere congrua, brevior tamen refpective tibia, quam cubitus, contraque minor palma, quam planta L. europæo comparatx. In his autem proportionibus monendum

- 2) PEN $\mathrm{NANT}$. (yn. of quadrup. p. 249 . 1ab.23. fig.r. Zool. britann. ed.8vo. additam. p.40. tab. 47. fupra. FORSTER philof. Transalt. Vol. L.III. p.343, et
Vol. LXII. p. 375. ubi Lepus variabilis albus ex America aretoa adlatus defcribitur et a fpecie Americes peculiari (p.3\%6.) diftinguitur. 
eft, quod ab expertiffmis venatoribus accepi, nec tamen propria obfervatione adhuc confirmare potui: fcilicet proportiones artuum Leporibus in genere ratione fexus pariter et ætatis variare, ica ut Lepori quadrienni menfure relativa plane alix reperiri foleant, quam fefquienni; id quod ulterioribus infpectionibus ftabilicndum relinquo. - Canda L. variąbili multo minor, paucioribusque vertebris conftructa et omni, anni tcmporc alba, nullo areæ nigræ, in L. Europæo et Tolai adeo confpicux, difcrimine infignita, et hyeme tota glomo lanuginis laxo, albo fimilis, unde calamiftrariis pro infpergendo pulvere cyprio infervire folet. Non minus reliquus velleris color etiam aftate differt; in fenioribus quidem minus, qui magis plerumque lutefcunt et propius ad europæi Leporis colorem accedunt ${ }^{b}$ ). Sed vulgo color capiti, prefertim verfus roftrum obfoletius vel gryfeo-rufefcens, in vertice fufcis fenfim pilis mixtus; antribus fufcus, poftico latere omni tempore anni cano vel albefcente; cervix fufco-cinerafcens. Dorfirm fufcum, lanugine cancfcente, Iongiorum pilorum plurimis apice gryfeo-rufefcentibus; latera fenfim incanefcentia, et venter fubtus longitudinaliter fuliginofo-albidus, vel canus; collum tamen fubtus $a b$ ore ad pedes anticos, dorfi colore fufcum, vel paulo dilutius, apicibus lutefcentibus immixtis. Pedes, antici præfertim, antico latere gryfeo-rufefcentes; pofici primi albefcunt, immo frepe æfate candicant. Canila alba, vix fupra pilis aliquot $\mathrm{A}_{2}$

b) Non poffum non hac occafione mentionem facere Leporis, cujus exuvize male affervata e Cafanienfi, ni fallor regio. ne, ad Mufeum Petropolitanum mifix funt; æhivæ, infignis magnitudinis, fcd maximam partem alba, in capite fupra, dorfogue lorgitndinaliter ferrugineo in. tiucta, quo colore etiam artus et aures. extus, et cauda fupra levifime inumbra. tæ. Asrium apex plane concolor, nigre. dine plane nulla, 
fufcis inumbrata. - Inniores primo anno femper obfcurius fü fcercentes, magisque lanuginofi.

Admirandus vero maxime et fpecificus eft in Lep. variabill color byberni velleris, quod præter apices aurium nigro molliffimo veluto marginatos, et volas pedum lutefentes, totum nive candidius evadere, notum eft. Per omnem Scandinaviam ') eidemque finitimas Lapponiam Fennoniamque, dehinc in omni Ruffia et Sibiria borealiore, hyeme nulli, nifi candidi, Lepores vul-

- go occurrunt, quos et clima gelidum et faliceti humilis, quo præfertim aluntur, in frigidioribus et alpeftribus maior abundantia; intra hofce limites præfertim continuit. Abundant etiam in Scotix montanis ${ }^{d}$ ) et in Livonia ${ }^{c}$ ); ubi hyeme grifei Lepores nonnifi rarius apparent, et pro transfugis e Curonia Lithuaniave habentur. RZACZINSKY contra etiam in Lithuania et Polefia albos dari Lepores affeverat. - Ruffia licet tota plana fere fit, nullisque inde a Lapponicis alpibus ad Caucafum, et a Lithuanix fylvis ad Vralenfe jugum notabilioribus montibus elata, tamen eandem Leporum fpeciem hyeme candidam, uti Sibiria omnino tota, ufque fub arcticam zonam et in Kamtfchatkam, alit. Attamen in defertorum Ruffiæ auftralium xquore, verfus 50 latit. bor. gradum, fenfim rariores fiunt, multoque copiofior fuccedit fpecies hycme plerumque colorata, ex parte tamen, præertim lateribus, ita fepiffime albefcens, ut ab europæis Leporibus diverfa videatur. -

c) LINN. Faun. Ju. II. "1.25. r о TOP P I. satürl. Hiflor. von Norwegen Part.II. p.rg. L E $\mathrm{\text {M }}$ Nachr. von den Lappen $\cdot$. 97. Norvagicum minorem vulgaribus in Dania, folus PONTORP. DANY S ferjpfit. d) $P E N \mathbb{N}$ NT. 1. cit. et Ejusd. fir $/$ Tour in Scotland, ed.11I. p.84.

e) OLEARIVS itinerar. ed. ger\%. (Siefvic. 1656. p.156.) FR. CHR. I ETZ E phyficotheo!. Betrachtung liber die weigen Hafen in Lieflsnd, Liibek 1749.8vo. p. 45. 
Hanc, inihi vix dubium eft, varietatem vere hybridum effe productum, ex adulterio L. variabilis cum L. europro, autraliorem Poloniam atque Pannoniam occupante progenitam ex in iftis regionibus multiplicatam; quum, ob fummam horum animalium, corpore pariter et indole, affinitatem, proles ex utraque fpecie oriunda nequeat non focunda nafci. - Occurrunt etiam in media Ruffia, utut multo rarius, at vix unquam in Sibiria, hybridæ hujus natura Lepores, quos Ruffi gentili nomine $R u f f a k$ diftinguere folent. Sunt autem plerumque majores vulgaribus albis, et confirmata hyeme fervant roftrum fupra gryfeo-pallidum, verticem, cervicem totam, dorfumque medium xftivo colore gryfea, apicibus tantum pilorum albis; aures vero, apice late nigras, ca parte, qua compofito ad quietem animali exterius nudæe patent, gryfeas, reliquo albas habent; ut et reliquum, præter dicta, corpus totum album eft. Cauda huic varietati longior, quam L. variabili vero, fupraque (ut in curopxo) nigra; proportio itidem ártuum auriumque intermedia vere funt proportione: unde ambigura origo quam maxime confirmatur.

Horum Leporum hybridorum in auftralibus Ruflix, præfertim Rufia minore, quotannis maxima copia laqueis capitur, non propter carnes, quas Rufforum plurima plebs, ferc Tatarorum adinftar ${ }^{f}$ ), tamquam impuras refpuit, vel faltem fpernit; fed A 3

f) Hi non foli, fed Turce quoque et e G $\mathrm{mgr}$ ( $\mathrm{N}$ I jum. Itinerario (I'ol.IIl. Armeni a Leporis efu abhorrent et abfti- $p \cdot 328$.) orientales exiftimare leporina nent. Rationem adfert TAVERE- carnis efu homines reddi hecticos et va. Rvs hanc, quod credant femellam Le- letudinarios. In quo leporine carnis viporis menftrua pati. (Reizen verf. belg. tuperio præiverunt diætetici antiqui, ut Voh.1. append, p.3s.) Difcimus etiam Moyfes, Galenus, Aütius, Rafes, Da: 
propter pelles, quorum magna vis ad exteros mercatura defertuf, villo in pileariorum officinis infervitura. Notabile vero, meliores hunc in finem efle, quo magis funt gryfeæ, adeoque etiam pili naturam intermediam obtinere, quandoquidem alborum Leporum vellus ad pileos compingendos ineptum effe, fatis norunt artifices. Memorabile porro, etiam carnis naturam ex utroque temperatam efle: etenim albi ubique Lepores adeo infipidum et infulfum, pro delicatiori palato, probent ferculum, ut neque cum peffmis europxis comparari queant, immo Cuniculis pejores videantur. Et notavit hoc de alpinis Helvetix Leporibus jam waGNervs ${ }^{g}$ ). Contra, qui intermedio funt colore, laudabiliores in cibo mihi et aliis femper vifi, melioresque qui magis gryfei, et optimi in ma. ximc auftralibus Volgenfis deferti, ubi hyeme vix pallefcunt ulli. E quibus facile apparet, non poffe ambigua ifta individua, ut aliqui perhibent, pro xtate provectioribus inter albos Lepores haberi.

Adeoque pofito, quod mihi extra dubium videtur, Leporen variabilem a vulgari curopeo fpecie funditus differre; jam minus mira debet effe coloris in priori mutatio et ad nature normam redit. . Non enim varietatis crt, alpino vel boreali climate larvam mutantis, (cujus rei tamen in Sciuro vulgari et Muftela Gale, frigidiori tantum in climate hyemalem pilum variantibus, exempla habcmus) fed fpeciei infita indoles, uti Vulpis Lagopodis, ut Tetraonis Lagopi ${ }^{h}$ ). Confat etiam experimentis, Leporem va-

mis, apid nоCHA RTYM citati. At montanis, colorem hyeme non mutare aliter cogyitabant Romani. MARTIAL. pro certo accerifiern. Neque tamen in Xen. epigr.g2.

s) Hill. uatural Helvetice p. $17 \mathrm{~g}^{\circ}$.

k) Ermineum hic quoque nominaffem, niff illud in auttralioribus Afix, et Perfia Gernania, ubi Sciurus et M. Gale r. nivalis LINN. afivam habitum hyeme fervant, eadem Ermineo conftantia ob. fervatur. 


\section{LEPVS VARIABILIS.}

siabilem; licet domi educatum et probe calefactis per liyemem in conclavibus familiarem, tamen (ut et in Ermineo, M. Gale et Sciuro Rufix expertus fum) hyemalcm album pilum, licet folito paulo tardius, induere, lentius defluente aftivo, totumque albefcere, fi non corrupti fanguinis fuerit progenics. Quod vero oLEAn 10 narratum fuit, cjusmodi Lepores reftate captos et cellæ fubterraner inclufos, pilum gryfeum, poft aliquot feptimanas in album mutafie, fabulam omnino fapit, quandoquidem hybcrni velleris incrementum diu ante tempus a natura inftitutum, arte maturarc, extra humanas vires pofitum mihi videtur.

In quadrupedibus temperatæ atque frigidæ zonæ natura bis quotannis pilum novat; vere æftivum producens, brevem, plerumque rigidiorem, intenfius coloratum; autumno in hyenale vellus luxurians, largum, pilo plerumque denfiore, at tenuiore et molliore, lanugine intertexto factum et colore femper dilutius vel. albidum. Falfo enim fupra citatus (not.') Rever. IEтze pro infolita aliisque animalibus denegata proprietate habuit, Lepores variabiles bis in anno pilum mutare. Omnibus animalibus, etiam inter domeftica equis et vaccis, aliud ad hyemem fuccrefcit vellus, obfoletioris femper coloris, quam quod vere, defluente ifto, secens et lævigatum fubnafcitur. In fpontancis animalibus plerumque mutatio hyberna coloris multo infignior effo folet. Exemplum in Antilope Saïga et gutturofa, in Mofcho, in Equo He. miono ${ }^{i}$ ) dedi; Capreoli fibirici fubecaudati, aftate rufi, hyeme gryfeo-canefcentes evadunt; incanefcunt hycme Lupi, Cervi, Alces, maximeque Tarandi; Zibellina ipfa ct Martes aftate magis fufca, quam eadem hyeme, ut alia nunc relinquam.

i) Spicileg. Zoolog. Fafcic. XII. Nov. Comment. Petropol. Vol.XIX. p. 40\%. 
Qui explicaverit caufam, quæ hyemale vellus largius, tenerius, lanuginemque copiofam producit, quam xftivum, videtur etiam poffe divinare, quare quibusdan animalibus hyeme candidus pilus in locum colorati fuccrefcat. - GMELIN.v s fecundus ${ }^{k}$ ) nofter Patrui (in Mfis relictam) hypothefin fuan fecit, crediditque, ex jejunio hyberno rapacium aliorumque animalium, indeque orta macic et depauperatione fanguinis phanomenon albedi. nis hybernx pofle explicari. Mirum non perfpexiffe GMELINos plane contrarium huic cauffe effectum tribuendum efle, fi ullum in colore mutando habeat, quam ipfi tribuerunt. Non enim hyene, emaciato iam animalium corpore, albus enafcitur pilus, fed prodit is autumino fero, vel fub initiun hyenis, abundante tum maxime pabulo, vel faltem ab autumnali fagina adhuc florentibus animalibus. Contrario vere, quum per inopian et injurias hyemis maxime exhaufta funt corpora, tum quidem coloratam induunt veftem. Licet vcro hicce effectus etiam in inclufis animalibus, aquali femper cibo furtentatis, xque ut in fpontaneis accidat; ramen negari nequit faftidiun ante medium hycmis omnibus ingruere, venerea quoque organa alimentum ad fe rapere, ita ut fub vernale tempus conftanti lege nature macrefcant, et prefertim circa novi principium anni languent, quo tempore hyemalis pilus a fummo. perfectionis gradu fenfim declinare incipit et prima aftivi germina fuboriuntur. Immo didici experimento Muftelarum et Ermincorum, quas in cavea cnutrivi, tanto maturius prorupife aftivum pilum, quo magis languida et macilenta fuere animalia. Evidentiffi-

1) Reife durch Russland Vol.I. p. $3 S$. fcuri coloris evadat. Habui enim xitiJeq. Tenendum eft, ibi falfo de Strige vas aque candidas (practer fparfas luno: nyctea afleri, quod aftate fufci vel ob. las ct puncta) ut funt hyeme. 
dentiffine hoc requenti cafu difcitur: Anno 1768. ab initio Novembris Erminea et Multelas plures niveas, ut apud nos hyeme vulgo funt, diftinctis caveis nutrivi, voraciffima ambo animalia, ut qua frepe una die $\frac{2}{3}$ vel $\frac{3}{4}$ proprii ponderis digererent. Sub finem Decembris e Muftelis una (paulo tepidiore loco habita) agrotavit, faftidio pabuli et foctore forte caver debilitata, periitque initio Ianuarii emaciata. Inveni tunc per totum dorfum jam denfum fuccrevific aftivum pilum gryfeo-fufcum et deflucre hybernum. At reliqua animalia, prefertim Erminea, qux toto ad. huc Ianuario vigucre, ne pilum quidem mutaverunt.

Patet hine neque frigus pro cauffa albedinis hyberne adlegarí pofe, quum autumno jam praparatus fit et crumpat pilus hybernus (etiam in hypocaufto altilibus leporibus) mitiore aëris fub temperic, quam tunc, quum extrema hyeme, rigido adhuc celo, eftivus pilus in cute cxpeditur et jam crumpit, nullo adhuc externo calore fomentatus. Videtur itaque potius abundantia ct mitiori indoli fuccorum tribuendum effe, quod autumno largum denfumque vellus animalibus, ctiam pinguibus, licet his tardius; citius vero fanguineis, luxuriet, quo contra hyemis injurian dcfenduntur; penurix contra alimenti deberi brevem, imperfectum, rariorem, fimul tamen (ct ob id ipfum) crafiorem pilum xetivum. Poteritque forfitan biliofe fanguinis dyferafix, a nimis fubacto et exaltato fine renovatione cruore orte, tribui etiam color intenfior, in rufum luteumque tendens, $x$ tiva veftis; quemadmodum biliofo tempcramento, vel morbo, cutis hominum quoque colorari, ægroque vel macilento livida vel pallida evadere folet; bene nutritis contra et fucculentis corporibus atque temperamentis phlegmatico-fanguineis alba et tencra evadit, refpon- 
dente etiam fecundum temperamenta pilorum et capillitii colore, confiftentia, natura. Eadem ex ratione infantium lymphatica corpora flavos aut pallentes capillos generant, adultorum magis biliofa indoles fufcos et obfcuros facit; at nigricapilla gentes plerumque jam a nativitate furca complexione gaudent. Neque contradicunt experimenta GüNTHERI circa avium varias fpecies ex cannabe pinguefcendo nigras plumas adeptas '), immo potius in confirmationem fententix noftrx explicari queunt. Potert nempe ab olcofo alimento fuperfluo tandem dyfcrafia atrabilaris humorum oriri, et pluntationis tempore in peripheriam maxime expulfa plumas cum nutrimento tingere. Immo contrarius pilorum alborum in cicatricibus equorum nigrorum vel fpadiceorum proventus fimilem explicationem admittit: dum nova folidatie cutis textura tenerior, laxior, mollior (ncrvis quoque deftituta ${ }^{n}$ ), cenditiones infantix quafi reducit, et fuccos minus coctos, lymphaticos recipit. - Neque minus canities provectre ætatis, in homine pariter et animalibus domefticis, imminutx bilis et cruoris efficacir vel copiæ tribui poffe videretur, quum ea retas horum fanguinis elementorum elaborationem xque imperfectam ac in infantibus obtinet, aliis quoque phænomenis prodat. Animaliumque varietates albæ propter eamdem rationem indolis femper debilioris et habitus laxioris funt, quod. in Nigritarum prole lactea, cujus exemplum quondam Londini") vidi, prefertim liquet, de quo fimilibusque alibi, peculiari circa varictates animalium tractatione dicam.

[") Der Naturforfches Part.I. p.r. Seq. et Pait. $1 X$. p. 22 .

":) Vid. Tentanina medico - chirurgica Qe felici is aninantibus uteri extratione, dequé 'partium regeneratarknt' et cicatricis natura aute. IoS. CA V ALLINI. Flo. vent. iz6s. 8 .

*) Hujus elegantifimæ Leuccthiopiffe miror nullibi in publicis fcriptis factam fuiffe mentionem. Exhibebatur publice 
Quicquid fit, certiffmum eft, Lepores variabiles alieno fanguine non adulteratos, (ut in borealibus Ruffix Sibiriæque, quorum frigus vulgaris fpecies non perfert, univerfi funt) ineunte hyeme toto vellere ufque ad cutim albelcere ${ }^{\circ}$ ), ingruente vere pilo gryfeo variegato veftiri, neque apud nos ullos, ut perperam de fenioribus credidit BVFFoNivs: (Edit. min. Vol.XIII. p.2I.) xftate albos manere. Contra non folum fcriptorum, qui de Grœnlandia egerunt, teftimoniis $\left.{ }^{\prime \prime}\right)$, fed etiam $\mathrm{B} 2$

Londini füb finem anni $x-6$ r. fexdecim tunc circiter annos nata, et a Patre atque Matre. Nigrritis in lamaica infula genita dicebatur, de quo tanto minus dubitari poterat, quum nihil hybridxe ex albo nigroque parente geniture fimile preferot. Stature erat minoris, artubus et collo turgidulis, cute fanguineo-phlegmaticre tincturæ candida, labiis rubris et rubicundis genis vigens, vultu omnino Aethiopis, nafo quafiato, labris tumidis, fronte brevi, circunifcriptione faciei fubrotunda, notis variolarum fparfis cutem minus teneram diftinguentibus. Oculoram irides neque rubri nec cxfii, fed gryfeo lute fcentis erant coloris, neque vifus nocturnus, fed tamen apertie lucis intolerantia, quam profertim poft variolas ortam narrabant cuftodes. Cilia et /upercilia palli. de flava, et capillitiuni totum ejusdem quidem coloris (blond) pallide flavi, at penitus in denfifrinos circinnos cirparum, et duriufculam Aethiopis lanam ad amur. fim referens. Hebeti videbatur ingenio atque pudibunda fpectatores admittebar; faniffima cacteroquin et egregia corporis proportione. - Cognatos omnes niger. rimos Aethiopes habuiffe diccbatur. Creterum hasce varietates Acthiopum albas non magis morbofam naturam (quod BLVMENBACH 30 placuit) appellari pofie puto, quam ipfa Aethiopum nigredo morbus eft. E fporndicis vero ejus. modi prolibus integros populos fibi tales fingere et antiquitas et recentiorum credulitas amavit.

-) Equidem BARTNGTONvs in Aftor. anglic. I'ol.LXTI. p.11. de Lepo. re Americæ borealis, a variabili noftro, quem pariter inter Americana animalia eodein volumine recenfet $F$ o $\mathrm{R} S \mathrm{~T} E \mathrm{R} Y \mathrm{~S}$, diverfo, credidit aftivum pilım perfiftere, excrefcente longiori albo tectum; mi. hi vero is, quem obferiavit, nondum hyenalem pilum perfecifle potius videtur. Singularis effet hijus fpeciei proprietas, quod, referente $\mathrm{KA} L M 30$, in tempera. tioribus An:ericar feptentrionalis pilum hyene albo non mutaret; fi modo vere eadem in temperatioribus, quxe circa $\mathrm{Hud}$ fonis fretum, fuerit fpecies.

p) EGEDE Naturgefch. Granlands verf. gern. p. 86 . et CRANZ von Girenland Vol.1. p..95. 
e fcriptis ad quæltiones meas Miffionarii xöNIGSEER rẹponfis certo conftat, Lepores variabiles Gronlandix, quos preter aurium apices, præfertim interius, nigros, toto corpore albos; grandiores et carne meliores curopxis predicat laudatus Miffionarius, per totam pariter aftatem albos manere; cujus rei in Sibirix licet maxime borealibus nullum eft exemplum, neque in continenti Americes obfervari ex Famala Americe borealis a FORSTERO preftita apparet ${ }^{q}$ ).

Præter conftantem illam (apud nos) metamorphofin et climatis rigidifimi paticntiam, cum Cane Lagopode ctiam in eo convenit Lepori variabili, quod (minori licet frequentia) mafcatur in hac fpecie varietas tota fufca vel etiam aterrima, hyeme colorem haud mutans. In omni Sibiria et in Ruffia quoque hæc varietas, licet ubique rara, obfervata fuit, STELLE: Rvs vero in adverfariis reliquit, nigram, maximam, ut et fubfufcam varietatem Leporis fatis frequentem effe in confiniis Oceani orientalis, inter Ochotam, Tugir, et Vth fluvios. Servantur in Mufeo Acaciemia Pctropolitanæ pelles hujusmodi fufco-nigrix Lcporum, quarum una e Mofcuenfi regione miffa, altera cum compari ex Lenení tractu a Cel. quondam fiscueRo relata fuit. Similes vidi binas apud Gubernatorem Ircutenfem IIl. Adl. de в rili. fervatas, quas regiones transbaikalenfes miferant, : quæque tere chalybeati erant coloris. Meminit talium Celeber\%. MüLLER in enumeratione pellium fibiricarum '), et fufco-nigram pariter leporis pellem apud Mongolos

9) Loc not. $m$ ) citato p.376.

\%) Samml. vufs. Gefch. Tom. 3. p. 526.
MRIS SONIVs quad. epit. p.95. Lepo. rem sigruin diftinctam fpeciem fecit. 
vifam recenfet GERBILLONIVS ${ }^{5}$ ). Leporis nigri in Bornholmia capti exemplum e wormio, aliumque e thelauris Dresdenfibus affervatum memorat KLEINIVS'); qualem etiam in Cim-

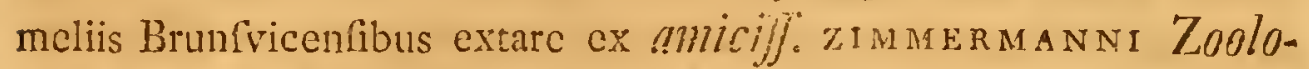
gin geograph. (p.187.) difco. Denique vivum Leporem aterrinum, in borcalibus regni Cafanenfis captum, media hyeme anni $1768-69$. obtinere fortuna mihimet fuit, cujus exuvia etiamnum in Mufeo Petropolitano fervantur, ubi foli diu expofiti in fubrufo-fuícum colorem degenerarunt. In hoc maxime perfpexi nigram varietatem in genere ad Leporem variabilem pertinere, ideoque frequentiorem in Ruflia et Sibiria, quan in reliqua Europa effe, ubi ifta, qua in medium hactenus prolata funt, vel que in pofterum curiofi obfervabune exempla, itideni ab alpino Lepore derivanda eflc, minime dubito, numquam a vulgari fpecie.

VARIETAS hæc migra femper folitam magnitudinem fuperat. Individum noftrum e maxinis et robutiffimis erat maribus "). Altres paullo minores adhuc habuit, quam in Lep. variabili vulgari folent effe. Hybermm vellus in toto corpore erat atrum, pulcre nitens, cum obfcura tamen brumnea vel rufefcente tinctura, quam dein folis ardor in Mufco prapollentem reddidit. Subtus magis hirtus, magisque rufefebat. Caput aterimum, fufcicullus tamen pilorum alborum in utraque bucca, fed in dextra

\section{B 3}

s) Apuí nu HAt.DE p.377. All. Longitudo capitis ad aurium intergem. Hijor. der Reifon IPII. p.7\%3.

2) Quadrupcdum Lifposilio p.52.

*) Dimenfiones tartur fequentes adnotatas incenio:

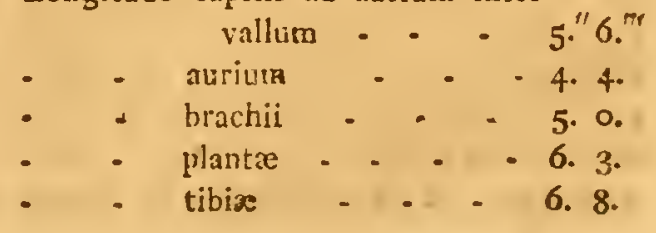


exilis. Labium fuperius ad fifturam et angulus nafi canis exiliter fparfa. Atrres pilo hinc inde albo in exteriore margine verfus bafin -et in medio marginis interioris, apice vero pilo teneriore (ut vulgo eft), quafi velutino et aterrimo diftincta. Myftaces tencriores, quam in varictate Leporis noftratis hybrida, cui vellus hyeme femigryfeum effe dixi. Per latera quoque et in regione fcrobiculi paftim pilus albus intermixtus, at in toto corpore conliftentia velleris minus mollis, quam in Lcporibus albis; quod in omnibus pellibus nigris pariter obfervo. Lanngo ubique fub pilo latens e fufco vel nigricante cancfcit, verfus cutim fenfim albicantior. Solere pedum lanam folidam crifpam, gryfo-cineream fervarunt (quod in Cuniculis quoque cicuratis atris obfervatur). Irides oculorum fuere obfcure fulva.

Leporis variabilis catuli nunquam alba in fronte nota, in eu: ropæis adeo frequenter obfervanda infigniuntur. Eadem tamen nota in Leporibus defertorum maxime auftralium, qui ad europaam fpeciem pertinent, circa Orenburgum v. gr. et ad Volgan obfervatur. Circa Aftrachaniam quoque captus fuit Lepus offeis cranii excrefentiis difformitcr cornutus, quale quid in reliqua Rufia et Sibiria nunquam auditum eft, adcoque in Leporc viriabili, quem propter pelles irmumerabili copia laqueis venantur, forte non accidit, ut contra inter europros cxempla nimis numerofa, quam ut in dubium revocari queant ${ }^{2}$ ), obfervari ctian feminis docent.

x) Leporum cornuta crania primus GESNERS ex iconibus a Kentmanno communicatis lecenfuit ide Quadrup. p. 6 ; t.). Leporina cornua linbet $M u / e u m$ Beslorianum p 3S. leq. tab.10. et I uN. STONVS, KLEINIVS, HIDINGE.
Rvs delinearunt. Plurima exempla la. boriofe collegit PAVIIN v's in Lago. graphia Seft. 2 . cap 3 . et aliqua recentiora citat amiciff. MA RTINI in notis ad BVFFON. germans. Voh.1ll. p. 153. not.s. p.17S. 
Inter calidifima animalia referendum efie Leporem variabi$1 \mathrm{em}$, repetitis experimentis didici. In albis et varietate hybrida femigryfea, hyeme adlatis, vivis calorem modo $103 \frac{10}{2}$, modo $104^{\circ}$ Therm. Fasenh. rigidilimo licet gclu, obfervavi, nunquam majorem, nifi in J.epore illo nigro, cui frigido æque loco detento infertum abdonini per vulnus thermometro gradus CVtus indicatus fuit. An ergo inter calorem animalem auctum et colorem infolitum aliquis nexus? - Nemo adhuc, quod fciam, calorem fanguinis in Nigritis thermometro exploravit.

Odor naturalis cavitatum inguinalium in Lep. variabili prefertim mafculis hircinus, cafeo melilotoïdi helvetorum affimilis; an fpecifice talis in Lepore curopæo foleat effe, non bene memini.

De migrationibus Leporis variabilis in oricntali Sibiria, pra: fertin ad Ienifeam et Lenam, quotannis obfervabilibus cadem, quæ I. BELL in itincrario habet, in Sibiria accepi. Videntur autem ex alpibus, quæ Sibiriam a meridic includunt, verfus campeftria et filvas borealiores pabuli cauffa migrare, et vere verfus meridiem in frigidiora montium juga reverti. In Rufia fimiles migrationes obfervari audio, ubi vicini funt alpeftres traćtus: fubinde in aliquas regiones hyeme copiofiores adventant, quam alias. Nulla tamen regularis et inftructis phalangibus migratio intelligi debet, fed vaga et incerta, qualem frpe Sciuri, deficiente in aliqua regione hyberno pabulo (Agaricis et nuculis Cembre) per Sibiriam -inftituunt.

Lepores America borcalis ulteriorem adhuc eluciciationem merentur. Species, quam BARRINGTonvs a Lcp. variabili diftinctam ftabilivit, itidem hycme albefcit, fed aurium caudeque 
apice cinereo, uti proportione conftanter diftinguitur. Eadeni

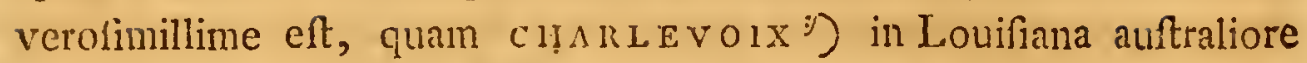
hyeme tantum canefcere fcripfit; neque differunt quæ de Lepore Caroline commemorat I. BRICKRLL ${ }^{2}$ ). Videntur tamen plures adluc in calidioribus America dari fpecies analogx, et diftinctas duas in California dari, relationes habent ${ }^{a i}$ ), quarum faltem una a cognitis fpeciebus divería efie debet. Lepus brafilienfis ecaudatus a mARCGRAF10 folo memoratus ${ }^{\text {bi }}$ ), et Capenfis fpecics, vix e picturis cognita, et Patagonia cuniculi apprime adhuc illuftratione indigent. Immo forte in media quoque Alia aliquæ hujus gencris fpecies adhucdum latent. Ex diario cnim quodam na. nufcripto

y) Les Lièvres \& Lapins font ici comme en Europe, excepté qu'ils ont les jambes de derrière plus longues. Leurs peaux ne font pas d'un grand ufage, parce qu'ils muent continuellement. L'hyver ces animaux grifonnent \& fortent rarement de leur taniére, on ils vivent des plus jeunes branches de boulena. En été ils font roux, си a RLEv, Vol. III. p.135. On troure (en Louifrane) des Lapins, qui ne fe terrent point \& qui fe setirent dans le crenx des arbres. Les Négres les en font fortir par le moyen de la funcé. DU m ONT Mlzmoir. Jur Loui. fiane Vol.1. p.86. - Le Lapin eftextremement commun dans la Louitiane: II a cela de particulier, que fon poil eft ce. lui du Liévre \& qu'il ue fe terte point; fa chair eft blanche, fans fumet, mais delicate. - LE PAGE DU PRAZ Hif. de la Louificne Vol.1I. p.94.

$\Rightarrow$ 1. в R I CK EL L nat. hill. of North. Caralina p.s26. The hedge conier never burrows under ground, but continually frequent woods \& thikets \& if you ftart \& purfue on of then, it generally runs up as far as it can into a hollow tree, in which care the hunters mike a fire \& fmoke the tree, which brings it down \& moft conmonly fmuthers it. - Pur. fucd \& taken by the dogs - theirs bladders are found ready to burft. They hide their young - from the difcovery of the buks, as the europaen Rabbets do \& are of the fame fize \& co. lour. At certain fenfous of the year great Bots or Maggots breed betwixt the fkin \& the flcifh - They eat much after the fane manner as thofe in Furope do, but 1 never obferved any of them fo fat.

"ara) Nathrichten von der Halbinjel Californien von einem Priefler der Gejelifchaft lefu (Mannheim 1773. 8) p.63.

bb) Lepus brafilianus BRISSON. guad. epit. p. 97. 
nufcripto, itineris per deferta mongolica Pekinum fufcepti, perfpicio dari in auftralioribus ejus deferti fpeciem cognitis minorem, quæ in arundinetis circa lacus verfari dicitur; quod a natura reliquorum hujus generis animalium infigniter recedit.

Quidnam fit Cuniculus ifte rufficus, quem Cl. p ENNAN T (iquadr. p.252. tab.23. f.2.) indigitat, fateor me penitus ignorare. Videtur potius angorcnfis effe varietas, vcllere fefe exuens; corte in ruffico Imperio nihil ejusmodi, neque ulli cuniculi reperiuntur, nifi a domefticis peregrinis haud dudum in urbibus multiplicati.

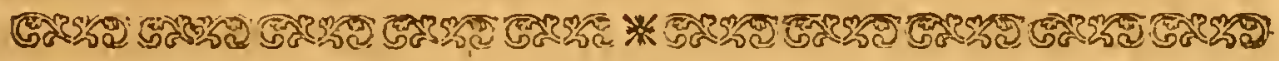

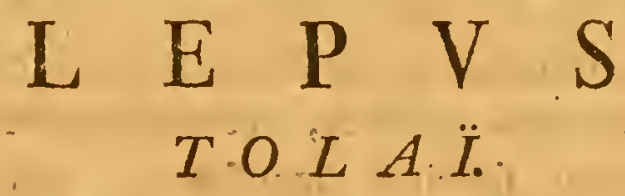

Tlluftrabo nunc aliam Leporis. fpeciem, quam pariter Zoologi hactenus imperfecte norunt et dubiam aliqui exiftimarunt. Poft messerschMidivm ${ }^{a}$ ) obfervavit illam GMELINvs, isque unus notitiam ejus, licet brevem, publice ${ }^{5}$ ) rcliquit; in qua et cuniculos fodicndi morem falfo tribui et caudam icone nimis protractam repræfentari video. - Gmelini verbis Epitomator BRISSONII (quadr: p.97. Jp.8.) hanc fpeciem adoptavit, neque neglexit PENNANTVS. (Jym. of quadr.p.2.53.) Sed

CMesserschmidivs in Xé fetur in Cetal. MIuf. Petrop. Tom. J. nio Ifidis Sibir. et in Hodegetico MSto, Cuniculum dauricum caudatum vel Tolai Mongolis dictum ap. leporini GMR L. in Nov. Comm. Petrop.

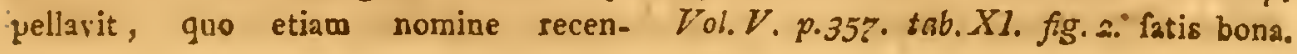


BVFFONIVS in additamentis (bif. nat. Vol.XV. p.I38.) varietatem Cuniculi europxi videri cenfuit; cui nuper $C$ el. z. IMmermanN (Jpec. zool. geograph. p. I9I.) affenfus eft. Adcoque ne alios auctoritate fua fectatores agant, haud crit fuperflua comparativa noftra hujus Leporis defcriptio, quem inter Mongolos et Calmuccos ufitato nomine Tolai appellabo, nullam cæterum additurus iconem, quum animal, præter proportiones, parum ab europæo Lepore differat, et Gmelinianm icon fufficere poffic vidcatur.

Mongoli atque Tungufi difcrimen inter hunc et Leporem variabilcm, quem illi Sclinghacbà, hi Unöggee appellant, non folum hyeme, quum hic evadit albus, Toolai vix colorcm nutat, fed etiam xftate, quum uterque fimili fere vefte gaudet, optime callent. Potelt etiam quilibet, venationis vel parum peritus, jam exinde utramque fpeciem dignofcere, quod, inftinctu diverfo, Lepus variabilis ad morem curopæi, per ambages fugit, nec facile latibulis fe condit; Toolai contra recto curfu ferri folet, et quamprimum poteft, rupium hiatibus, vel alienis cuniculis fere tutatur. Certum tamen eft, cundem numquam propios $\mathrm{ex}$ induftria cuniculos effodere, ut Cuniculorum mos eft, neque nifi periculo preffum abfcondi; potius in aprico, inter Robinix et Salicum pumila virgulta verfari anat, e quibus præcipuum illi alimentum. Caterum in montibus apricis; campisque rupertribus vel arenofis circa Selengam, ubi Lepus rupeftris (Kamennoi Sä̈z) inter Ruffos audit, uti per omnem quoque Mongoliam atque Davuriam, nusquam deeft, frequentior ibi Lepore variabili; ad feptentrionem contra Baikalis non obfervabilis. Tempus œefti et ${ }^{\circ}$ partus commune cum Lepore variabili fervare videtur: 
etenim fub Aprilis exitum utriusque femellam habui fœtam, eodem fere graviditatis gradu. Et quum in his foetubus multo infignior appareat differentia, præfertim in capitis proportione, addo pro comparatione in Tabula $I V$. Leporis variabilis fig. I. et Lep. Tolai fig.2. fœtum, fubæquales ambo et naturali delineatos magnitudine.

Differentiæ Leporis Tolai, quibus ab affinibus diftingtuitur animalibus, e defcriptione minutim perfpici poffunt; quandoquidem vero haud valde confpicux illæ funt, dicam hic fummariter: effe multo majorem Cuniculis vel naximis, et L. variabilem xquare, immo fuperare; caput habere eodem et Lep. timido longius, fed quoad cranium multo anguftius, licet roftro pæne craffiore; aures paullo longiores, quam L. variabilis, fed proprio capite fere breviores habcre, adeoque paullo minores Lepore timido noftrate; eædem non toto apice, fed tantum margine fummitatis nigre funt. Artunn proportione L. variabilem proxime refert, præter cubitum et tibias paullo breviores, palmasque et plantas minores, et pedes tenuiores, femora vero paullo longiora: quibus infigne præfertim a Cuniculo difcrimen innuitur, cui propter fodiendi neceffitatem antici artus robuftiores et poftici breviores funt, quam in reliquis affinibus, itemque a Lepore timido europro, cui artus multo longiores. Canda in L. Tolai utique longior quidem multo, quam L. variabili et $\mathrm{Cul}^{2}$ niculo, utplurimum tamen proportione paullo brevior, quam in L. timido europæo, paucioribusque una vertebris conflata; fimillima tamen huic quoad aream nigram infignem, qua fupra tegitur. Interanea æque parum in omnibus his fpeciebus differre vifa funt, ac inter tres fubfequentes novas Leporum fpecies ecaus 
datas, qux tamen adeo non magis in unum conjugi merentur.

Non certo conftat, quoufque ad occidentem per deferta Afiæ L. Tolai fpeciem propagaverit. In cafpicis utique defertis deeft. Quum a boreali climate alienus videatur, credibile eft, meridiem verfus tanto latius evagari et in Indiam forte ufque reperiri. Certe in deferto magno Gobëenfi ubique ad Tybetum ufque vivit, Tangutis nomine Rangzvò notiffimus, interque lunæ maculas confecratus.

\section{E S C R I P T I O \\ LEPORIS TOLAI.}

Tab. I. fig. 2.

Magnitudo circiter Leporis timidi et variabilis, eosdemque proxime habitu et fructura refert.

Caput oblongius, magis compreffum, exiliusque, quam iisdem. Labii fuperioris lobi ufque ad dentium bafin connexi, lobulo intermedio nudo, rugofo, molli. Nafus latus, convexus, futura pilorum bicruri poftice inclufus, albidus.

Dentes primores fupcriores fulco, interiori angulo propiore exarati, inferiores plani, læves.

Myftaces fex ordinum, multo copiofiores, majoresque; quam in L. variabili; fetis nigris, extremo albicantibus, quarum pofteriores aliquot capite longiores, rigidæ. Verruce fupraciliares binæ, bifetæ, ut in Lep. variabili, fed longioribus fetjs; parotica bifẹta. 
Oculortun proportio vix diverfa; palpebre margine (non ut ifti nigræ, fed) fufcefcentes, fuperior pofterius, inferior antrorfum tantum pilis longis nigris ciliate. Periopbthalmizmn femicirculare, limbo fufco, fed linea limbo parallela granulata. Ir $i$ des dilute fulva, fubradiate (at in Lep. variabili luteo-fufcx). Halo circa iridem fufcus.

Aures paullo majores, quam in L. var. in maribus capite tantulo longiores, in femellis breviores, intus magis nudæ, nec fummo apice toto, fed tantum margine apicis, paulloque ulterius, atro; cæterum ftructura fimiles, nifi rigidiores, minusque patulæ.

Corpus forma affinium, alvo minus gracilefcente. Artus. antici breviores, quam in L. timido; vix longiores, ac L. variabili; poftici etiam, quam in hoc, breviores. Pedes in gencre minus villofi, immo quoad offa tenuiores et graciliores (unde ineptitudo animalis ad cuniculos fodiendos a priori patet); nec villi fubpedales adeo largi laxique, præfertim in plantis.

Cauda (in L. variab. brevicula, tota, etiam æftate, alba) noftro longitudine proxime ut in L. timido, femellis tamen paullo brevior, fupra plaga longitudinali atra.

Genitalia omnino ut in L. variabili, eademque L. timido fimillima. Membrum maris e papilla ano adfidente, eundemque fere inftar operculi claudente, exferendum; area ante preputium lata, nuda, veftita cute fubargenteo-nitida. Scrotunil tumidum, inter femora compreflum.

Femina vulva labiis nudis cutaneis ab ano continuatis, apice villofa et intus glandulofa, pendula inter adfantem utrinque 
finlim Iunatum parvum, ad caudam tendentem, quorum quiliber intra cavitatem nudam velut atrizm, hiat; adfidente in ipfo hiatu tuberculo glandulofo, albo, centro perforato, febum coaguli finile eructante. Cavitas alia utrinque inguinalis, plica fubvillofa ab atrio finuum difcriminata.

Papillas mammarum in femina gravida, cui ubera ab armis ad inguina continua turgebant, tantum fex inveni, 2 in medio abdomine, 2 ad marginem thoracis, 2 thoracicas intra armos $c$ ).

VELlVS leporino fimillimum, capiti dorfoque pallide gryfeo fufcoque mixtum, intus lanugine albidum, tum fufcefcens, cxtimo pallide gryfeum; longioribus pilis partim apice nigris, partim nigri apice albis, qui in dorfo medio crebri funt, verfus latera albidiora rarifimi. Corpus fubtus album, gula alba, collum fubtus lutefcens; aures convexa parte et antico margine, ut et cervix lutefcenti-albida. Circumferentia oculorum et oris albefcit. Artus lutefcentes. - In byemalibus color fimillimus, nifi dilutior, circaque clunes et femora canefcens, auribus albicantior; vellus largius et clegantius, læve, pilis circa collum, perque latera et femora longis albis fparfum. Altitudo velleris in dorfo ad 1." 4."' longioribus pilis $1 . " 6-7 . .^{\prime \prime \prime}$ in ventre fere 2."

\section{MENS VRAE.}

Dabo hic menfuras comparatas Lep. variabilis et L. Tolai ex feminis adultis codem-tempore gravidis, quibus additre funt proportiones maris, e pofteriori fpecie, junioris, fed turgidis jan ad generandum genitalibus.

5) In Lep. variabili codem gradu gra- les, qux in Tolai exant floridifimze vida non apparuere glandula mamma. albxe. 
Pondus in Tolai hyberno feptem fere libranum rufficarum, in femina gravida Aprili cæfa $8 \frac{1}{2}$ librarum; in Lep. variabili eodem tempore et loco gravida tantum 7 librarun deprehenfum fuit.

Longitudo tota a nafo ad anum - - capitis

- - cauda fine villo fefqui - pollicari

- - diftantix oculi ad nafum -

- - - - ad aures - -

- - fiffuræ palpebrarum - -

Circumferentia oris

|L.unvinh. fon | Tolni fem. | Tolaimaris.

2.' 4." 2." 2.' 4." 4." 1.' 9." 5.",

0. 4.10 .0 .5 .1 . 0.4 .7$.

o. 1.10 .0 .3 .6 .0 .4 .1$.

o. 2 O. O. 2. I. O. 2.3.

O. I. $2 \frac{4}{4}$ O. 1. $1 \frac{1}{2} \cdot 0.0 .11 \frac{1}{8} \cdot$

o. 0. 9. O. O. $8 \frac{1}{3} \cdot$ O. O. $8 \frac{1}{2}$.

o. I. 3. 10. 1. 3 . O. 1. 6.

roftri rer labium inferius 0.3 .7 . $0.3 \cdot 9 \frac{1}{2} \cdot 0.3 \cdot 8 \frac{x}{2}$.

capitis inter oculos et aures 0.7 .0 .

d) Diftantia inter utriufque oculi canthos,

filo

- - - - - circimno

Longitudo myftacis fumma - -

- - aurium ad verticem. - -

Circumferentia aurium bafi - -

Circumferentia aurium bafi - - O. I.IO.

Latitudo eorundem media - - - 0. 2. 2.

Diftantia aurium in vertice - -

Longitudo colli

Circumferentia ejusdem

O. 1. $9 \frac{1}{2}$ O. 2. 1 .

O. I. $7 \frac{1}{2} \cdot$ O. I. $5 \cdot$ O. I. $2 \frac{\mathrm{T}}{2}$.

०. 3. 6. 0. 4.4 .

o. $4.3 .0 .4 \cdot 8 \cdot$ o. 4.10.

०. $3.4 \cdot$ o. 3.6 . - - -

O. 2. $2 \frac{1}{2} \cdot$ O. $2 \cdot 4$.

o. 2. 4. O. 2.6.

o. I. O. O. I. O. O. I. O.

0. 2. $4 \frac{\mathrm{T}}{2} \cdot 0.2$. 5 . 0.2 .5 .

o. 4. 1. O. 4. O. O. 4.0.

- thoracis ad armos - - 0. 9 10. 0.9. 2. 0. 9.9.

- in corpore medio - - O.l1. 4. O.I1.10. 0.10. 8.

- corporis ad ilia - - 0. 9. 8. 0.10. 4. 0. 8. 3.

Longitucio artuum anticorum a funma fpina dorfi ad extremos ungues extenfo pede Longitudo pofticorum artuum extenforum

a trochantere -
- - humeri figillatim -
-

क) Hrec minor in Lep. variabili, quod revera autem latius, ut e proxime fequenhuic roftrum fupra inter oculos planius, ti menfura patet. 
Longitudo antibrachii

- - palnæ cum unguibus

- - unguium majorum

Circumferentia brachii ad flexuram

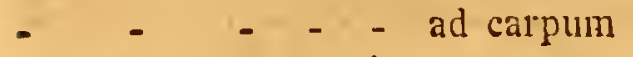

Longitudo femoris

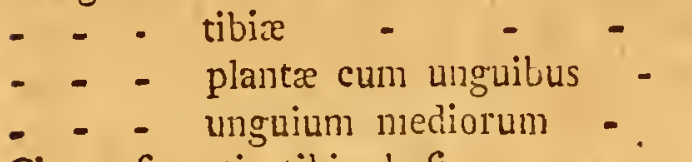

L.variab.fem.| Tolai fem. Tolai maris.

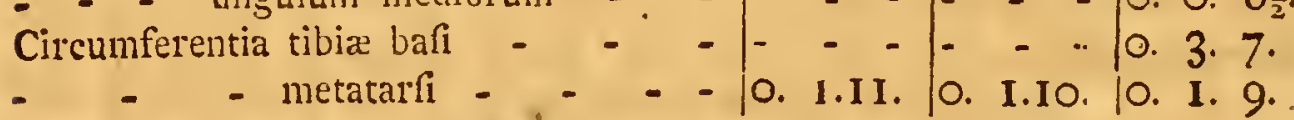

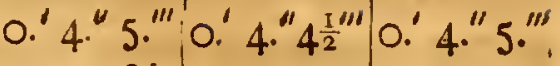

O. 2. $8 \frac{1}{2}$. O. 2. 4 . O. 2. 4 .

o. 1. 9 .

- O. I. $\frac{1}{2}$. O. O.II. O. I. $\frac{I}{2}$.

- 0. 1. $8 \frac{1}{2} \cdot$ 0. 1. 6. 0. 1. 5 .

०. 4. 6. 0. 4.10. 0. 4. 9.

- o. 5. 2. O. 4. $9 \frac{\mathrm{I}}{2}$. O. 4.I I.

-

o. $5 \cdot 3$.

o. $0.6 \frac{1}{2}$.

Ex his menfuris patet, Lep. variabilem, cujus aliquas proportiones cum I. vulgari, hudfonio et cuniculo comparatas dedit BARRINGTONVs, quique vel americanus vel fcoticus fuit, noftratibus et maxime fibiricis, inter quos Mangafeenfes præfertim eminent, minores effe; L. Tolai vero inter maximos hujus generis collocandum effe et europæum Leporem fere fuperare.

\section{A N A T O M E.}

Palati rugæ 14. poftice binarcuatæ, caruncula interruptæ. Molares in quavis ferie quini, infia pofticus parvus. Lingua bafi gibba, carunculis fungiformibus tantum binis ad fauces.

Hepar quinquclobum, lobis 4. fubæqualibus, quorum laterales, mediorumque bifidus dexterior (fub quo cyftis amygdalæ mole) fubtus margineque incifuris variis multipliciter diffecti. Spigclianus compreffus, femiorbiculatus.

Ventriculys in L. Tolai, variabili et timido ejusdem formæ. Inteftinnm tenue XI. pedum. Ccecum diametro ad fummum binol- 
bipollicari, longitudine ab ileo $1 . !$.." præter appendicem vermiformen glandulofam $4 . . "$ 9." ; qua craffitie digiti minimi; plicæ rugis cœci intus refpondentes læves, nec fimbriatæ. - Cellula ad infertionem ilei globofa craffo infidet, intus glandulofa alba. - Coli pars prior trifariam (ad 8.") cellulofa, cellulis uno latere latioribus, hinc $1 .^{\prime} 3 . "$ uno tantum latere cellulatum, totumque intus granulofum, glandulis in extrema parte fenfim obfolefcentibus. Inteftinum excretoriznn quadripedale, amplitudine digiti.

In Lep. variabili proportio et ftructura inteftinorum fere cadem; cellula huic glandulofa ad infertionem ilei oblonga, et glandulofa ejusdem appendicisque vermiformis fubftantia tenuior, quam in altero.

Ren dexter in L. Tolaï paullo anterior et minor finiftro, qui circiter columbinum ovum æquat.

Teftes in mare majores renibus, turgefcentia tempore vel toti vel tantum epidydimide in fcrotum emiffi. Veficula fpermophora mole nưcis, fubglobofo - didyma, hyalino - rutilefcens, femine gelatinofo (med. Aprilis) plena. Penis ad anum exfertus, glande fimplici, fubulata, apice incifa, fubrugofa.

Femina grivida, quam diffecui, in dextro com, tres, in finiftro duos continebat foctus... At Lep. variabilis femina, co. dem tempore cæa, tantum a finiftro latere tres conceperat, dextro cornu ad fuperfetationem adhuc patente. Fetus hujus vix provectiores, capitis proportione multo majore; ceterum placenta atque membranarum in utraque conftitutio eadem. - Ovaria in utraque erant oblongo-cylindracca, magna, diffectaque intus. 
totidem monftrabant fungos $\mathrm{f}$. corpora lutea, quot ab eo latere foetus, obductos communi parenchymate luteo, molli. - In finum vulvæ producitur corpus cavernof fln bicrure, fubulatum, fub quo urethra, longum a bafi I." 3. "I craffitie pennæ corvinæ: ab hac clitoride, penem mentiente, et ovariorum mole, Mongolorum fabula: "Marem Tolai parere fœtus et teftes intus condere.",

Pulmonum dexter quadrilobus, infimo azygo, finifter trilobus, quorum duo fuperiores per membranulam cohærent.

SCELETI ex mafculo, cujus menfuræ relatæ funt, dimenfio: nes addam:

Longitudo cranii ab alveolis anticis ad tubcrculum oc-

$$
\text { cipitale - - - - } \quad 3.11 \text { 5." }
$$

- - maxillæ inferioris - - - - 2: 1 2.

- - dentium primorum fuperiorum - - - 0. $4 \frac{\mathrm{I}}{2}$.

- - - - - inferiorum - - - - o. $6 .{ }^{3}$

Latitudo cranii per zygomata - - - . - I. $6 \frac{1}{2}$.

- - - inter orbitas - - - - 0. II $\frac{\mathrm{T}}{2}$.

- - occipitis - - - - - - I. 0 .

Longitudo vertebrarum colli fimul _ _ _ - 2. 6.

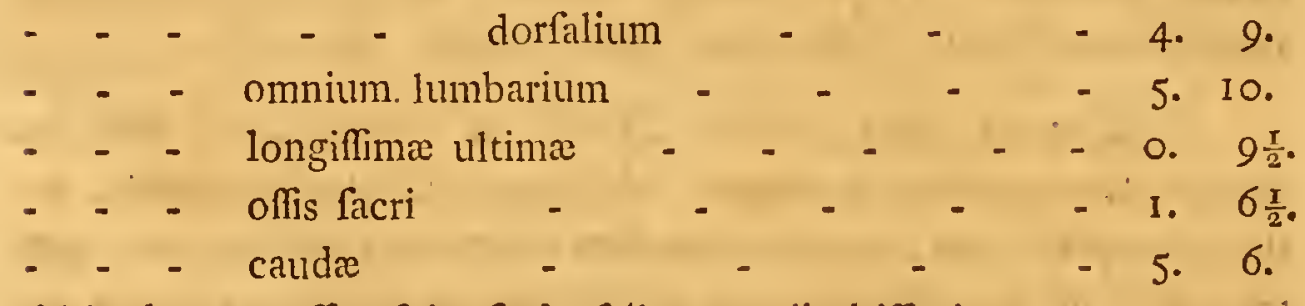

Altitudo proceffus fpinofi dorfalium tertii altiffimi . - $\quad 0$.

- - - - transverfi lumbarium feptimi - - 0.9.

Longitudo coftæ primæ - - - - - - o. 10.

= - - feptima longiffima - - - 4. 0. 
Longitudo ultimæ fpuriarum

Latitudo fumma coftæ quartæ .

Longitudo claviculæ

- - fcapulæ

- - humeri

- - cubiti

- - olecrani a cavo articulari

- $\quad$ - radii

- - carpi

- - metatarfi medii

- - ,- phalangis primæ

- - - - - fecundæ

- - unguis cum articulo

- - phalangis pollicis

- - - unguis pollicis cum articulo

- - ofium pelvis tota

- - ${ }^{e}$ femorum a trochantere

- - patellæ

- - tibir

- - - fibula ufque ad coalitionem

- - calcanei pedis

- - metatarfi medii

- - phalangis primæ

- - - - - fecundie

- - unguis cum articulo

Coftee numero I2, quarum 7 veræ, et ex fpuriis 3 per cartilagines adnexe." Vertebrce lumbares 7 , quarum portrema $\mathrm{D}_{2}$

- c) Eminet autem trochanter ultra collum femoris $3 \frac{1}{2} \cdot{ }^{\prime \prime \prime}$ et collum cum capite femoris exferitur ad $5 \frac{1}{2} \cdot ! !$ 
longifinia; - facrum quadripartitum; cauda, connumerato apice, I5 verticillis compofita.

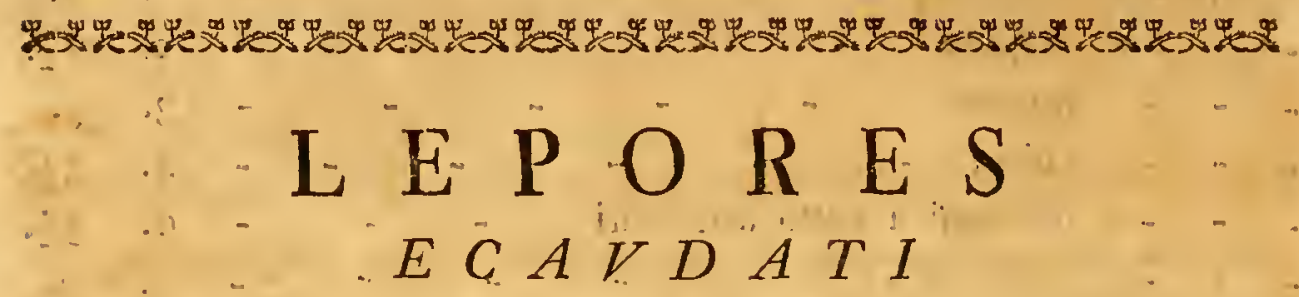

NOVA GENERIS COGNITI PHALANX.

$\therefore$ uriofiffrma tria nnimalcula in itinere Ruffo-fibirico detexi, quæ licet characteribus cxtcrnis et internis Leporibus antea. notis cóngenera fint; tamen habitu, ftructura, morumque momentis variis, petuliarem confituunt hujus generis phalangem. Reliqua, quotquot Leporum nomine Zoologi recenfuerunt, animalia magnis auribus, pofticis pedibus elongatis, ad faltum compofitis, caudaque notabili conveniebant. Contra animalcula, qui hic fum illuftraturus, - neque ultra-juftum proportionem anirita funt, nec- pofticos artus elongatos babent, canda. wero penitus carent. - Interna anatonne inter fe ceque fonilia funt, uti Lepores auriti: moribns etiam fimilibns gaudent, inque cuniculis prefertim vitam tranfigunt, quod ex aurita phalange fere folos Natura Cuniculos jufferat. - Cæterum fi dentinn nume-" run atque formam; fuperiores præfertim incifores fulcatos et minoribus dentibus duplicatos, fi naturam velleris, fi mune. rum digitorum, in palmis quinarium, plantis quaternarium, fi denique formam cranii et intefinornm genitaliumque gene-i ralem difpofitionen perpendas, - auritas fpecies fplendide referunt. Sunt etiam, ut ifte, lafiocnema (quemadmodum op. 
riants vocavit), digitos fcilicet et foleas pedum totas fubtus denfis -vilis opertas exhibent. $e$

Sed habent Lepores noftri ecaudati aliqua,. quibus Caviámun generi (Spicil. Zoolog. Fufcic. II.) adfines redduntur. Vt cnim taceam habitus externi et proportionum analogiam, étiam caudæ defectu confimandam, vocemque crebram et argutam, ab auritis Leporibus alienam: etiam coftarum numicro $\mathrm{Ca}$. wia noitre capenfi funt, proximi, et claviculas hubent, ut Cavia omnes, perfectas, non (ut auritis funt) imperfectas. Adcoque poffet hinc hypothcfeos transmutatorum in America animalium fautor BVFFONIVS hæc potius animalia pro parentibus Caviarum Americes venditare, neque amplius torrere animun Lepores auritos Caviis comparando, : qui non folum; ut Ipre ingeflit, antiqui orbis omne clinn, fine notabili metamorphofi tulerunt (bift.nat. Vol.XIV. p.372.) ' fed ctiam, ut nunc fatis conftat, in America quoque formam confervarunt. Sed non eft ea Naturie rerum paupertas, ut depravatione formarum varie. tatem fibi quærere velit; eftque, ut omnia probant, imaginaria hæc fpecierum transmutatio.' - Verofimile quoque, in Ame. rica boreali vivere vel unam e noftris, vel afinem faltim Leporis ecaudati et vocalis fpeciem, e P. chAR.EvoIX quodam loco rciditur ${ }^{f}$ ). Nequaquam autem Aperea marcgrafin et Caviæ americane reliqua', ullo modo cum Lepufculis noftris, erunt confundendre.

Quemadmodum Leporum auritorum fpecies ægerrime definitione brevi inter fe diftingui poffunt, ita etian fpecies ecâdata

\section{$D_{n} 3$}

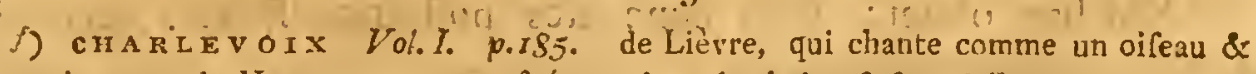
Dans le pays de Hurons - une efpéce dont la chair eft fort delicate. 
externis notis, vix nifi a colore defumendis, determinari queunt: Videntur, donec novæ innotefant, fpecies Leporum fic definiri polfe:-

LEPVS (elropátls) apicc aurium capite longiorum, caudaque a. Auriti et plerumque caudati. fupra atra.

LEPvs (Tolaï) auribus apice nigro marginatis, cauda fupra - atra.

LEPvs (unriabilis') apice aurium atro, cauda concolore alba. LEPVS (budfonius) apice aurium caudxque cinereo.

LEPVS (capenfis) auribus ...., cauda rufa.

LEPVS (Clniculns') auribus apice atris, cauda fubconcolore, cruribus pofticis trunco brevioribus.

LEPvi (Tapeti) auritus, collari albo, cauda nulla.

$$
\text { b. Reptabundi, ecaudati. }
$$

LEPvs (prifllurs) ecaudatus, fufco gryfeoque mixtus, auribuis fubtriangulis, albo marginatis.

LEPvs (Ogotona) ecaudatus, gryfeo-pallidus, auribus ovalifubacutis concoloribus:"

LEPvs (alpinns). ecaudatus, rufefcens, auriculis rotundatis, plantisque tifcis.

Sed hæc obiter; ipfas nunc tres poftremas fpecies accuratis defcriptionibus illuntremus. 


\section{E P V S \\ $\begin{array}{lllllllll}P & V & S & I & L & L & V & S \text {. }\end{array}$}

Nemo-ante mean in Novis Commentariis Petropolitaris 1 (Vol.XIII. p.53I. tab. I 4.) publicatam, tunc imperfectiorem defcriptionem, lepidifimum hocce animalculum noverat; nec quisquam Collegarum, qui fe itineribus in Ruffico Imperio confumferunt, illius mentionem fecit, præter $C l$. LEPECHIN, cui in Itinerarii Vol.l. (edit. ruff.) p.420. nomine a me indito allegatur. ' - Ipfe, poft priman ', editan, notitiam, Leporis purfli naturam cognofcendi occafionem habui crebram, varia ad mores ejus pertinentia in Ttinerarii Vol.I. p.I55. docui, et pleniorem anatomen, e variis fpeciminibus collegi. Completam itaqué. hiftoriam ejus et defcriptionem fiftere nunc poftum. :

Leporis pufilli patria funt maxime aufraliora montium Yralenfium promontoria, herbidi colles et convalles apricæ. Inter Kamam et Samaram fatis frequens ${ }^{n}$ ), ad ipfam licet Kaman deficiat; obfervatur deinde pafim inter colles Samaram et Rhymnum diftinguentes et fecundum ominem Volgam, ad Ilowlam ufque fluvium Tanaï fubcuntem. Nusquam autem frequentiorcm audivi, quam in lætiffima regione montofa Rhymni ct $\mathrm{Vï}^{\prime} \mathrm{fl}$. origines interjacente. Datur etiam pafim ad Irtin fluviun et inter apricos montes 'metalliferæ regionis ${ }^{b}$ ) fub alpibus altaïcis fitæ non

(a) A Kama verfus auftrum procedenti. bus primum circa Ik fluvium, ubi Cytifus fupinus crefcere incipit, Lepores pufilli quoque exaudiuntur. PAII. Reife III. Theil. p. 498 .

b) Lit. citat. Vol.11. p.533. 
deeft. Vltra Obum vero certifime nufquan datur, nec ultra LVtum gradum verfus boream vivit, fylveftribus humidisque regionibus hinc exclufus, quemadmodum ad Iaikum et Volgan defertum torridifmum; limofun et falfugine fqualidum limites fpeciei, ab Vrali jugis auttralioribus, tamquam prima patria, fefe diffundenti, pofuerunt. Siquidem læto herbarum proventu felices convalles, vel colles vepretis obfitos, ,.. nemorumque margines præfertim amat, et ibi prefertim occurrit, ubi in aprica regione Cytifus fupinus, Robinia frutefens et Cerafus pumila abundant, quorum flores, frondes et corticem, ficut et fylveftris mali, pro pabulo religit.

Solitarium eft atque adeo abditæ vitæ animalculum, at ægerrime capiatur, et vix a nilleflno rufticorum, qui nocturnam ejus vocem audiunt, eminus vifum fit. Quum tamen antra ejus hyberno tempore fupra nivem confpicua fapius pro Ermineorum cuniculis imponant, adeoque decipulis horum cauffa ftatutis non raro capiatur Lepus pufillus, pon potuit venatorum cognitionem fuffugere, et nomina etiam varia inter plebem iftarum regionum abtinuit. Ad Volgam et Samaram, ubi Mus Iaculus deeft, LepufcuIi terreftris (Semlanoi Saërfchik) cognomine inter Rufros cluit; alii a voce nomen Tfchekzifchla et Tfchekalha adinvenerunt.

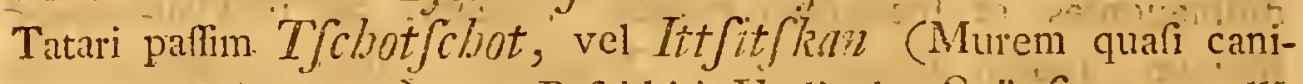

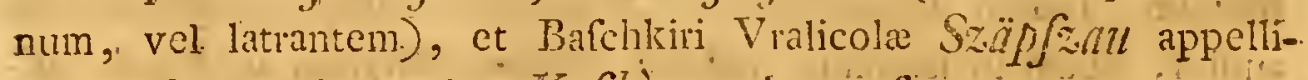
tant. Calmuccis nonine Kuflì cognitum eft.

Eligit in habitaculum sulgo locum vèl in plano depreffum, vel accliven, ficcum, firmo cæfpite obductum, fruticulis quomodocunque cinctum vel obumbratuini? In collibus et convallibus occidentale prefertim clivorum latus amat. Ejusmodi in 
locis fodit cuniculum, quem apertura tres fere digitos admittens; et obliquiter in terram penetrans, multumque ante illam egeftr terræ prodit, ad fruticum plerumque radicem delitefcenten. . Mares et juniores, aut qui novum fodiunt antrum, fimplici aditu; ad duos, tres, quatuorve pedes in terram producto, quem nidus vix diftinctus terminat, contenti effe folent. Sed occurrunt ( $f e-$ niorum forte animalium et maxime feminarum), latibula, ubi circa varios, non longe abinvicem diffitos frutices, bini, terni pluresve cuniculi apparent, anfractuofis inter radices ductibus inter fe communicantes, ita ut nulla ibi diligentia animalculo potiri liccat, innumeris ad fugam patentibus viis. Frequentiora funt antra bivia, externis canalibus non ita longe a fupcrficie coadunatis. Certifimum fignum delitefentis in tali antro animalculi prebent excrementa pilularia, quæ piperis fimillima vel minora hinc inde fub vicinis fruticibus, vel in parvulis ad id ipfum erutis foveolis accumulata, repeciuntur. Scilicet ne crebra fui veftigia inimicis, feris præberet animal, certis excrementa locis deponit, non teme»e fpargit, naturali lege, quæ, forte fimul fruticibus pinguefaciendis infervire videbitur. - Verno tenpore in locis, ubi hyemavit L. pufillus, apparent cafpiti infeulpti femicanales ramofe difcurrentes, quibus per nivem exitus varios exercuit animal, nulla autem ad hyemen foni promptuaria in hac fpecic unquam obfervata funt.

Sed tædiofum foret occulta Leporis pufilli antra in vepretís quxrere, immo reperta frep vix ab aliorum animalculorum antris dignofci poffent, nifi ipfe fui proditor effet, et voce peculiari, quam prefertin poft occafum folis, primaque aurora matutina crçbro iterat, quæentes ad antra quafi advocaret. Ab iis enim (ut Cuniculi) numquam longe difcedit. Vox e fonis fimplicibus, 
coturnicis alias graviorem fonum amulantibus, equa per intervalla ter, quater, imino frepe fexies iteratis conftans, tanta eft proportione ánimalculi, tamque longinqua per fpatia exaudibilis, ut admirari fatis nequeas, præfertin quum in pneumatopais organis nihil infoliti, nilhilque: magni apparear; folumque forte hoc inter quadrupedes animalculum paris fere molis aves, coturnices atque luffinias, quarum vim vocalen miramur, quantitate vocis æquat. Exauditur illa vox, ab ignaris frepe pro avis cujusdam fono habita, etiam interdiu, fed nomifi pluviofa et tonitrua tempeftate. Tum fubinde toto tempore antemeridiano clamantes audivi; audi-vi a quarta pomeridiana ad vefperam vocales. Id vero rarius accidit; folemne tempus edendr vocis utrumque diluculum. Hyeme non exaudiri certum eft; reliquo omni tempore anni, etiam frigido jam per Septembrin autumno, crebro fonat adeoque nón cftro adftricta eft. 'Vtrumque fexum vocalem effe xque certo fcio; videtur autem vel fexui vel xtati tribuendum effe, quod roces prafertim intenfitate varient; quibusdam adeo' robuftæ, ut ad femimilliare gernanicum facile exaudiantur. Mares habui, qui domi in ciftula claúf, fubinde mane et vefperi clamitabant, ipfoque eo momento comprehenfi, vocen inter manus continuábant, caput inftar canis latrantis projicientes. Femina, quam - unicam vivam alui, eadem nocte, qua capta eft, et voce exaudienda fuerat, pullos domi edidit, totoque deinde, quo apud nie fuit, tempore filuit.

Capti Lepufculi nooftri manibus tractari ftatiu patiuntur, intràque dicm homini adluêfcunt, ita "ut familiâres fere, depofito timoìe, evadant.- Mitifima funt ánimalcula, debilia, tranquilla, vix feniores manum, "qua retinentur, interdum morfitant, imbell 
conatu. Dormiunt parum, et dum quicfcerent, nunquam oculos çlaufffe vidi, .immo vix unquam nictitant nift nựo digito tangatur oculus. Quum vulgo conglomerato corpore (ut Tabula. J: noftra exprefium eft) fedeant, quietem contra capiunt extenfo atque terræ adpreffo corpore, capiti adplicatis auriculis, quemadmodum Lepores folent. Animalculum corpore in globum colle: cto fedens cavam manum exacte replet; extenfo vero corpore totius craffifima pars caput videtur. - Incedunt L. pufilli clumbi et fubfultante greffu, fed propter brevitatem pedum, maxine pofticorum, neque celeriter currunt, nec nifi. inepte exfiliunt. In pofticos pedes raro eriguntur; palmis vero caput, et ore vel. lus crebro demulcent, feque pectibus fcabunt, propter infeftos, fed minutiflimos et albos velleris Pediculos. Facile aluntur frondibus memoratorum fruticum, casque præfertim teneriores, ut et flores atque gemmas amant; decerpunt folia fafciculatim, atque fenfim, ut Leporcs, commanducant. Pctant fxpius, quam Citilli, in campis tamen rore contenti, quippe ab aquis fare remotiffimi; frequentius et urinam mittunt, fed limpidam et incdoram. Totum quoque animalculum odorem omnino nullum fpargit; quunque et cxcrementa globularia, quæ tantum diluculis et nocte dejiciunt, fere ficca prodcant, omni refpectu mundiffma dicenda funt. Interdiu per intervalla paftes quicfeunt, tota vero nocte vigilant, vagantur, diverticula quærunt, et unguibus etirm fefquipedali et ultra altitudine fecundum parietes enituntur: : No. ctu ctiam plurimum comedunt et exccrnunt. Marcs una incluf tum morfu fe invicem affultabant, et iracunduli fubgrunnicbant.

Femina gravida (de qua fupra) d. $\frac{30 \text { Aprll. }}{11 \text { Maji }}$ adlata, capta fucrat in nido molli gramine referto, ad quem quatuor ducebant carz $\mathrm{E}_{2}$ 
les, ftatimque in carcere ex oblato golfypio raptim fecit cubile; in quo piillos fex nudos, nigricantes, cecos peperit; quorum ipfa placentas cum funiculo ad umbilicuin ufque omnes abfumfit. Catuli pro mole matris magni, fexto fere die pubefcere et poft octavum apertis effe oculis et circumreptare coperunt. Excitati, vel accedente matre', avicularum inftár pipiebant. Interdiu hos fepius lactabat mater, deinde" goffypio curiofe tectos deferebat, in alio carceris angulo" quiefcens; nona die cafu evafit, unde fenfim debilitata proles, vellere jam matri fimillima facta, intra octiduum onnis periit.

Varietatem coloris neque fecundum individua, nec.per anni tempus fere ullan obfervavi, licet hyeme captum habuerim, e quo prior (in $N$. Commm. Petr.) deferiptio nata eft. Vnico mafculo majori et forte. feniori nafum pedesque brunneo - fufco colore diftincta vidi, vel propter xtatem, vel ex foli forte natura, quemadmodum opptanvs Lepores quoque vulgares in terris nigris fufcos, in rubris rutilos effe dixit.

Minutum adeo animalculum ad hyemem ferendan innato calore prefertim egenum erat; et utique inter calidiffima animalia L. pufllum effe, thermometro didici, quod in duobus temperiem ( $104^{\circ}$ Farenh.) fere $88^{\circ}$ de LiIsliane fealæ indicavit. Idem tamen calor etiam Leporibus majoribus proprius eft, et a Sciuro (qui ad $105 \frac{1}{2}$ Farenh. $88^{\circ}$ ' de'I'lsl. calet) etiam fuperatur. 


\section{LEPVS PVSILLVS. \\ D E S C R I P T I O \\ LEPORIS PVSILLI. \\ Tab. I.}

Moles Ratti aquatici; habitus inter Lepores et Cavias medius.

Caput oblongius, quam congeneribus, vellere largo tumidum; rofrum leporinum. Nafus fufcus, totus villolifimus, vix narium limbo et fulco labii nudo. Labia exacte conniventia, fuperius tumidulum, profunde bilobum, et ad nares fere ufque.

Dentes primores albi, fuperiores duplicati: exteriores arctiffime convergentes, fulco profundo exarati, acic acute emarginati, unde communis acies tridentata (Tab.IV. fig.4.); dentes fuccenturiati (fig.5. a.) minuti, retufi. Incifores inferi lineares, extus teretiufculi, interius oblique truncati.

Myftaces crebri, ordinibus fere quinis fparfi, quorum infimus e pilis albicantibus, duobus poftremis prefertim longiffimis. Pili fupraoculares tres breviores; paroticus folitarius, extremo albicans; gularis tenerrimus exalbidus.

Oculi roftro paullo propiores, minufculi, vivo extrorfum turgentęs, ut in murino genere; irides obfcurc fufco-lutex; palpebrarum limbus fufcus; perioplbtbalmium plica ab anteriore cantho prolixa, medio margine fufca.

Alrviculde majufcula, triangulo-rotundatx, fufcæ, anterius villis longiufculis, ad fuperiorem marginem pallidis obumbratx; limbus auris explanatus, gryfeo, dein fufco, denum ipfo mar$\mathrm{E} 3$ 
gine albo fimbriatus; concha ampla, anterius lamella lunulata (Tab.IV. fig.3. a.), cui oppofita interius lamella feniovalis (b.), apice fubpilofa; fuperior margo quali involutus et adnatus conftituit infindibnllnm $(c$.$) oblique patens.$

Truncus gracilis, reptabundus, exilis, craffitie 'fubrquali. Calla nulla. 'Artus breves, etiam poltici.

Paline pentadactyle, pollice remotiore, brevi, digitis 2 exterioribus degradatis. Plante tetradactyla, extimo præfertim breviore. Vingritculi ommium pedum tenues, arcuati, acuti, pallefcentes, pilis fere abfonditi. Solece pedum, ut in Leporibus auritis, pilis confertis, mollibus, horridulis hirfutifima; pofticæ ad calcaneos ufque villo fubreflexo fufcefcente; anticæ albido, teneriure.

Vellus mollifimum, largum, proque tantillo animale prolixum, at lævigatum. Lanugo interior ubique denfa, longa, recta, tenerrima, fufcefcenti plumbea. Pili fubpollicares, majore parte lanugini concolores, extreno recti, rigidiufculi, fupra pallide gryfei, fed apice nigrefcentes, unde capiti, dorfo et artubus extus color fere Lcporum juniorum fimilis, nifi nigrior; ina latera extremique pedes pallide lutefeunt; fubtus corpus canefcentialbidum, gula cana, nafus et labium utrinque albicant.

Scrotim mari turgidum villofum, ad chmes fere prominulun, ad infam onl aperturam, pilis fub apice coccygis arcte conniventem. Papillas mammarum in mafculis tantum duas "utrin.que, inguinalem et abdominalem invenire potui. 


\section{$\begin{array}{llllllll}M & \mathrm{E} & -\mathrm{N} & \mathrm{S} & \mathrm{V} & \mathrm{R} & \mathrm{A} & \mathrm{E} .\end{array}$}

p.ONDVS in variis a $3 \frac{x}{4}$ ad $4 \frac{x}{2}$ uncias variafle obfervavi antate; hyeme vix $2 \frac{1}{2}$ unc. fuperat.

Longitudo $a b$ apice nafi recta ad anum

- -. - a nafo ad apices unguium palmæ fecundum

corpus extenfe

$\therefore \quad-\quad-a$ nafo ad unguium plantæ retrorfun exten-

\section{fx apices}

- - - capitis ad nuchan

Diftantia oculi a nafo

\section{- . - a bafi auris}

Apcrtura et diameter oculi

Longitudo auricula

Latitudo auris inter angulos fumma

- - - - bafi

Circumferentia bafeos auiriculæ

Longitudo maximorum myftacis pilorum

Diftantia inter nares

- $1:-$ - inter oculos filo

. - . - - circinno

- - inter aurium bafes

Circumferentia integri oris

.. . . $\quad$ roftri per marginem labii inferioris -

$\therefore \ldots . . \quad$ - pone myftacem

$\therefore$ - - capitis per oculos.

- _ _. . - ad aures

Longitudo colli

Circumferentia colli 
Circumferentia thoracis ad armos

- - - abcominis ad femora - - - 3. 3.

Longitudo antibrachii - - - - o. 9 !

- - palme ufque ad apicem unguium - - 0.8.

- - unguis medii longiflimi - - - - o. 2.

Latitudo palmæ.

Circumferentia carpi

Longituda tibir

brachii

- - - plantæ a calcaneo ad apicem unguium

Latitudo ejusdem ad baGn digitorum

Circumferentia tibix fumma

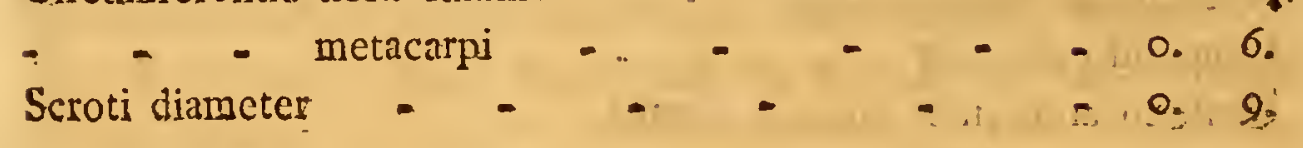

\section{A N A T O M E.}

Tab. IV. f fg. $4 \cdot 9$.

Palatum rugis craffis, transverfis, rectis circiter novers; anterioribus hine inde interruptis, pofticis 2 medio confluentibus.

Pellis tenuis, poftice femoribus et tibiis, itemque circa coccygem tenerrima et firmiter adnata, reliquo corpore laxiar. Detracta pelle animalculum vix Muftelam mole excedit. $P$ inguledo aliqua alba, grumofa circa collum et inter fcapulas $P_{Q_{-}}$. ratides intervallum ramorum maxillæ explentes, rubicundæ, fimul granorum quatuor. Ex inguine tractris ivafculofus cum fibris fecundum abdomen adfendens, cum glandula lymphatica 
albida oblonga, vix femen Lini æquante, qualis in Muribus folemnis eft.

Panniculus fubcutaneus tenuis, e fafciolis fubaxillaribus ortus, dorfum obtegens; Platy fmamyoïs ab angulis oris ufque ad claviculas per collum fubtus totum extenfus. Mivfuli præfertim bráchiorum, poftici fcapulæ et reductores femorum totius corporis robuftiflimi, nec parvi pectorales.

Abdominis aperti fœetor naufeofus, qualis muribus brachyuris vulgo obfervatur. Omentun fupra vifcera nullum apparet, et vix inftar fimbriæ ventriculi arcu adhæret.

Hepar (Tab.IV. fig.6.) tripartito - multilobum; pondere drachm. 2. gr. 4. Lobus finifter (a.b.) oblongus, verfus epigaftrium defcendens, convexo-planus, ad dorfum craflior et pro rene excavatus (b.); cui proxime fubtus adftat labulus Spigelianus $(c$.$) femiovalis, arguto margine ventriculo applicatus$ ejusque in naturali fitu finum feu minorem arcum replens. Media portio (d.e.g.) amplior, fubrotundo-ovalis, ufque ad fpinam bifecta, intercalari lobulo transverfim bipartito (d.); cui adpofita cyftis (f.) exigua, delitefcens. - Dextra pars hepatis (b.i.k.) minor, trifecta, lobo intermedio (b.) Spigeliani fimili, reliquis ( $i . k$.) triquetris, acutis, conjunctim cavum pro recipiendo rene ejus Iateris efficientibus.

Ventriculus (fig.7. a.b.c.d.) in nredio amplior fereque recto angulo incurvatus, fundo furfum tendente $(b$.$) , anguftio-$ re, obtufo; pylorica parte fenfim ab œfophago (a.) adtenuata, ad ipfum pylorum recurva (d) plica intus diferiminante ultiaum 
cavum magis glandulofum. Figura naturali magnitudine delineata; menfuras reddit fupervacaneas.

Lien (f.) exiguus, oblongus, laxiore membrana ventriculo adnexus. Pancreas (e.) fubtriquetrum, portioni pylorica ejusdem longitudinaliter adplicatum.

Inteftinorum oflicina maxima; temle ab initio 'duodeni (d.g.) ad infertionem ilei (l.) 3 pedes $5 \frac{\mathrm{r}}{2}$ pollices explet; jejunum (i.) medio tenuius, duodenum ad pylorum fubampliatum, ilcon fefquipollicari ab infertione diftantia $\int e c c \iint u \operatorname{ceco}(k$. peculinri, ut in avibus quibusdam, finuatum.

Prope infertionem ilei appendix lnmbricaris (m.) teres, longitudine 8."' intus glandulofa et lacteo fucco plena, quam (aque ut appendicem cœei) clyymus excrementitius haud intrat.

Ccecum ( $N . \%$.) quinquepollicare, in cellulas annulares contractum, e tenuiflima membrana factum; cxtremitate definens in appendicem vermiformem (n. o.) glandulofam, hamatam, fere liberam, I." $4 . " 1$ explentem.

Coli pars prior (N.p.) ceco fimillima, nifi amplior et fubdifcreta, 1." го." explens, extremitate faccata ( $p$.$) producit$ infundibulum ( $p . q$.$) arcuatum, fenfinque adtcnuatum, lxve,$ quod pofteriori colo $(q . r)$ inferitur. Hac altera coli pars bipollicaris prater ligamentum mefentericum (priori parte et caco commune) duobus aliis inftructum, in triplicem effingitur (fere coli humani adinftar) cellularum ordinem; quorum duo, in minoribus ligamentorum intervallis, cellulis crebrioribus et anguftioribus conftaot, tertius amplioribus; totum hoc inteftinum extus glandulis albidis punctatum. 
Vltima hæc pars coli, trifariam cellulofa, adtenuatur fenfim; tribusque ligamentis longitudinalibus in unicam fafciam, mefenterium legentem coadunatis, eflicit portionem (r.s.) uno ordine cellulofam, fibris robuftioribus annulatam, 3." 2." longitudine, in cujus modulis excrementa pilularia cffinguntur.

Ifinc breviffima curvatura reflexum inteftimm, fit aguabile, et per varios flexus novem cum dimidio pollicum longitudine continuatum (s.t.), ano terminatur, ubi veficulam r. cloacam peculiarem (Fig.g.b.) efrormat, ut in avibus.

$\mathrm{H} x$ craffi inteftini portiones variae interna quoque ftructu$r a$ egregic differunt. Cacum totum ct vaftion pars coli $(n-p$.) intus capillata cirrhis feu villis mollifimis, ad $3 \frac{1}{3} . "$ longis, apice fubclavatis, per rugas internas (qux cellulas interfinguunt) fimbriatim difpofitis, qui totidem tæniolas inteftino infixas mentiuntur (Fig. 8. A.); - Portio infundibuliformis (p-q.) intus vcluti reticulo, transverfe diductis arcolis, obtenfa, finubusque in quincunces folitis, externe quoque pellucentibus lacunofa (Fig.8. B.) - Inteftinum tandem trifurian cellalof $n m$ glandulisque adfperfum, intcrius totum villofum, $p a$ pillis pulpofis, mollibus, conico-acutis, inæqualibus, apparet (Fig. 8. C. a.).

Renum (Fig.9. a.a.) dexter paulo minor, craflior, anteriorque finiftro; uterque laxius peritoneo inclufus. Glandule renales (b.b.) flave, dextra ovita, finiftra oblongo - cylindrica, arta fuppofita. - Vefica urinaria infignis (d.), areteribus (c.i.) non verfus collum, fed ipfi fundo infertis fingularis. - . Teftes Majo floridifimi (e.e.); veficula spermatica! $\mathrm{F}_{2}$ 
ovatx (f.f.). Glandula Comperiance (g.g.) infignes, utrinque adfidentes bafi penis (i.) per anum exferendi.

Diaplorngma perobliquum, tenuifimum, centro triangulari, antice emarginato, hyalino, ruribus anguftis.

Oculi bulbus fere globofus, ater; glandnla craffa, alba, fundum orbite explente. Lens cryftallina dimidia fere totius oculi mole, fpheraque vix depreffior, ut in muribus.

scelaton (Fig. 4.5.) naturali magnitudine delineatum proportiones omnes accurate reprefentat. Craninm, ut reliqua compages, proxime ad Cuniculi fceleton accedit; configuratio ollæ, hiatus anteorbitalis, ubi cavum narium tantum membrana claufum, zygomatis latitudo et figura, altitudo maxillie inferioris ejusque proceflus adfeendens unicus, latiffmus, pone zygoma adarticulatus, molares transverfim fulcati, numero et figura omnia ut in Cuniculo. - Vertebraram dorfalium proceffus fpinofi exigui, reclinati. Sterni articuli quatuor, inter manubrium et enfem intermedii. Coftarmil paria feptemdecim, quorum decem fpuria et ex his tantum quatuor per cartilagines ultimæ veræ adnexa. Vertebre lumbares $\mathrm{V}$; facrum triarticulatum; $\operatorname{coccyx}$ verticillorum, connumerato apice, VII. Claviculc longa, perfecta, fecus ac in leporibus auritis; at fcapularum forma fimilis, acromio valde producto, extremitate tenui, extrorfum obliqua. Ifchia valde producta apice tuberofa. $O S$ fa pubis jufta fymphyfi coarticulata, quod non in fequenti. Fibula tibir paullo ultra medium coadunata.

Menfuras feeleti hic inferere nolui, partim quia icon pro: portiones omnes ftrictim imitatur, partin quod illas majori cum 
fretcu infra juxta menfuras Leporis Ogotone collocatas infpiciet Lector, ubi differentias inter fpecies adeo aftines indicabunt.

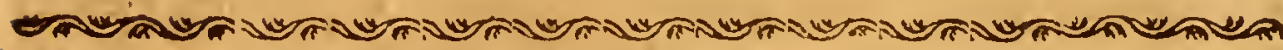

\section{E P V S \\ $\begin{array}{llllllll}A & L & P & I & N & V & S .\end{array}$}

orporis ftructura Lepori pufillo fatis fimile, aft propter fingularem cconomiam maxime admirandum animalculum eft, cujus primam mentionem, et nomen Lepori alpino, feci in Itinerarii mei IIdo Volumine (appendic. p.70I. n.2. et p.569.) icone etiam (Tab. $A$.) quanquam non fatis fida, adjecta. Nemo eorum, qui Sibiriam ante me naturx ferutandee cauffa adicrant, juftam hujus animalis cognitionem retulerunt; inmo vix quisquam attente illud obfervafle videtur, nifi forte $M E s-$ serschmini") Muftela disurica canda carens, corpore breviore et craffore, pilis in dorfo rufefcentibus - Ocbodona daurica amminos (in Catal. Muf. Petropol. p. 343. N.I I 4. I I 5.) hæc potius, quam fequens fpecies, fuiffe dicenda fit; quod, poltquam fpecimina Mufei perierunt, in fufpenfo manet. Eft tamen Lcpus alpinus apud omnes gentes venatorias Sibiria notifimum animal, quod propter nullam aliam rationem, quam quia montes afperrimos, et inaccefos fub nivalibus jugis fcopulos colit, obfervatorum curam cffugit.

$$
F_{3}
$$

2) In Hodegetico MISto MESSER- rini, fifularis, physivora; fed defcriptio

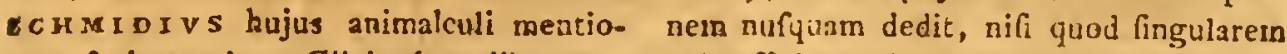
nera fecit nomine: Gliris faxatilis, amm coli oflicinam ibi ruditer adumbrarit. 
In Vralenfibus alpibus nulla ejus fama eft; primum et copiofe deteximus illud ad latera altifimorum montium Altaïci tractus et in monte præalto Kolywanenfis regionis, cognomine corulei, (Siraja Sopka) celebrato. Conftat etiam extra Sibiria fines, in magno jugo Altaïco, talibus locis ubique abundare hanc peciem, et orientem verfus fecundum univerfum alpeftrem Sibirix fitum, ad ultimum ufque angulum Afiæ ct in Kamtfchatkan ${ }^{b}$ ) ufque frequens eft. Vltra Icnifeam, ubi frigida regio, etiam in minus elatis rupibus fylva cinctis occurrunt Lepores alpini, ut v. gr. in monte haud longe a Krasnojaro oppido, fupra pagum Lodeika fito, ubi omnes fiffuras occupant, itemque in fl. Manæe tractu, immo verfus boream adufque inferiorem Tungurkam pervenerunt, et ad omnein Lenam, falcim Iacutiam tenus, copiofe vivunt.

Singulare eft Lepores alpinos numquam in locis planis et apricis vivere, fed montes colere afperrimos, fylvofos, fimul herbidos et humore abundantes, ut etiam circa torrentes a nivalibus alpibus defcendentes frequentius obferventur. Solent vel inter fasa cuniculos effodere, $\mathrm{vcl}$ in naturalibus petrarum fiffuris nidos condere, et fecundum loci naturam modo duo pluresve fimul, modo folitarii vivunt, ita tamen, ut femper, ubi aptum montis fitum invenerunt, inagna frequenria adfint, copiofius, quo. altius in mediam alpium regionem adfcendas. Narrarunt mili venatores, etiam in truncis arborum cavis et proftratis caudicibus. interdum nidufari. Diebus prefertim pluviis, aut quanda nebu-

b) In pofthuma STELTERI et KRASCHEN I N I I O VII deferiptione Kamtfchatkx nulla quidem exprefia mentio Le. poris alpini, fed quum pelles ex illa Peninfala ace eperim, verofinillime cum Citillie animalculum noftrum ii coufuderunt. 
las circa fe colligunt montes, interdiu difcurrunt, in prominentibus faxis excubant, et frequenti fiftulatı (projecto capite edito et vifo præfertim homine increbrefcente) exaudiuntur, qui illis eft fimplex, argutus, pafferini fubfimilis, et avicula fonum ita mentitur, ut milhi fæpius impofuerit. Sclopo explofo in latibula quidem promptifime rcfiliunt, fed denuo ftatimque prodire haud verentur, quafi nullo timore perculfi, quod de animale inter frequentia tonitrua vivente minus mirum. Sercno cœlo interdiu latebris haud exeunt, fed diluculis tantummodo audiuntur.

Eo maxime notabilis eft hujus animalis indoles, quod $a b$ Augufti circiter medio naturæ inftinctu quodam, duo pluresve concives fimul communi opera felectarum herbarum et graminum acervos, curiofe ficcatos, modo fub fcopuli imminentis tegnine, inque fiffuris rupium, modo circa arborum trnncos congerant in hyeinalem commeatum. Apparent tunc circa corum habitacula cxfpiti infcalpti tramites confpicui, quos laboriofa animalcula continuo difcurfu excavarunt. Vidi, quomodo herbas primum ad præruptos fcopulos fparfas quafi apricare folent; deinde vero, Septembri potifimum, exficcatum fœnum in acervos conoïdcos compingunt, ad iplum fepe antrorim introitum vel prope, ducto. que $a b$ antro ad acervum cavo tramite, quem dein nix fuperincumbens fornice obtegit. Ocurrunt hujusmodi accrvi, vbi plura fimul animalcula operata funt, humana fere altitudine, et octo, pluriumve pedum diametro congefti; frequentius tamen funt tri-; pedales circiter. Mira et neceffaria induftria, quum diuturna in hifce regionibus hyems et altæ nives, omnem aliam fuftentandæ vitæ viam animali, quod non fopitur et parum tamen habet. virium, pracludere neceffario videatur. 
Curiofius obfervavi herbas a Leporibus alpinis Septembri menre congeftas, et inveni maximam partem felecta gramina fylvatica et alpeftria mollifima, inque ftatu vigoris decerpta, quæ ita lente ficcata effe folent, ut foenum viridiffimum et fucci plenum exhibeant. Culmi fpicaque nullæ, fed puriffimo gramini immixtæ parcius herbæ variæ, pleræque amaræ vel acres, quafi pro fimulo et condimento hyenali. Copiofiora inter has agnovi folia Anemones patentis, Veratri nigri, Delphinii elati, Thalictri minoris, Serratulex coronariæ, Vmbellatarum quarundam, Epilobii anguftifolii, et Equifetum ramofum; pauciora Crepidis fibiricæ, Serratulæ alpinæ, Geranii fibirici, Anemones vernæ, Atragenes alpinæ, Orobi lutei ct tuberofi, Cypripedii minoris flore guttato; Trollii, Vrticæ, Actæx, Sanguiforbæ, junioresque Populi nigræ faolones. Caules earum tantum fpecierum, quæ fucculentiores, parvaque et fefilia folia habent, cosque abrófis extremitatibus minus folliofis, infimaque parte emarcida in penum adfumunt. Majora. folia, ut Crepidis, Serratule, quafi ex propofito in glomerem. complicata reperiuntur. Vix ulli occurrunt flores, plantarumve fummitates. Circa foni acervos, interque herbas ad folem adhuc ficcantes copiofe fatis excrementa globulofa depofita indenias, nulla habita puritatis ratione; quumque frep ante abfolutum fonifecium turbentur vel a feris devorentur opcrarii, pafim in fcopulis invenire eft relictas herbas excremrentis mixtas, que fimul cum eó, quod vere redeunte ex collectis promptariis reliquum fit, egregie conferunt ad alium naturæ fcopum, præparandam videlicet inter faxa fertiliffimam humum, alpeftrium et petrarum plantarum vigori neceffariam. 
Hæc animalis fœnifecia et acervi præcipuam illi inter venatorias gentes famam pepererunt. Etenim uti Muris quædam fpecies pro his populis radicum variarum promptuaria colligit, hominumque palato et ventriculo famulatur, ita Lepores alpini incuriæ eorundem hominum, fæno in folitudine alpina pro equis prxparato, fuccurrunt. Itaque venantes, qui propter Zibellinarum capturam cum equis fuis longe in defertas montanas fylvas procedunt, nive jam omnia tegente, Lepufculorum acervos, propter altitudinem facile inveniendos, diruunt, felectifimoque eorum fono equos fuos roborant. Atque ifta fibi exitiali hofpitalitate meruit, ut apud omnes Sibirix gentes proprium nomen obtinuerit inutile alias et defpectum animalculum. Sic Tataris Krasnojarenfibus et Tomenfibus Scbádak vel Sádıjak, Koibalis, Beltiris et reliquis Kusnezenfibus Kilbe, Kirgifis et Altaïcos montes difpalantibus Dycekulak (auris cameli), monticolis Sajanenfibus e Samojedica ftirpe Taibáfcbta, Arinzis Schállagai, Kamarchinzis Péve, Ortjacis ad Kaafum fl. Pljulmann, Burætis Tatfcherganà, Tungufis transbaikalenfibus Piika vel Péika, eidem genti ad Tungurkam Hénniani, Iacutis a fono vocis Tfibifs, itemque Dans-kybla (i. e. animal petrarum) vel Agàs (i. e. Senior, propter vocem pro tantillo graviorem), Korecis Tfchikultfh (itidem a voce), denique Ruffis in Kolywanenfi tractu Sjengftave: (fœnifecus), vel Kamennaja $K n, c b k a$ (felis petreus), ad Ienifeam et in orientali Sibiria $P i / i^{2}$ chníclọ (fiftulatrix) folemniter appellatur. Aliqui etiam Rufforum improprie nomen Iemulranka, ad Cirillum pertinens, pro Lepore alpino detorquent. - Iakuti dicuntur etiam vere adhuc relicto ab hyemali penu Leporum alpinorum fono pro alendis equis et vaccis uti. 
Hominibus in cibum haud cedit Lepus alpinus, fed præcipua eft prada Zibellinæ, maximeque Muftelæ fibiricæ ${ }^{c}$ ), qui propter hujus efer dulcedinem nondum extra alpeftrem tractum Sibiria regnum protulife videtur, vixque nifi in regionibus, ubi dantur L. alpini, occurrit. - Infeftantur hi etiam ab alio inimico, minus fevo quidem, fed frequentiffmo et incommodo; oEsTRVM volo, cujus adjeci defcriptionem "), cujusque Larve in plurimis horum animalium, nodo folitaria, modo dua, tres, plures$v e$ in eodem individuo, in folliculis panniculi carnofi fubcutaneis, extus hiantibus adolefcunt, atque Augufto vel Septembri fponte clabuntur. Nidulatur hac progenies incerto loco, in lateribus, clunibus, immo pedibus, frequentiusque in inguine feu laxa ante femora in peile, rarius in dorfo; ct folliculorum aperturam, dum. adhuc latent, adeo infignem cxtus efficiunt, ut ea dilatata cxprimi manu queant, liberoque externi aëris aditu fruantur. In Le. poribus auritis noftratibus tales hofpites obfervari, numquam audiri; fed in Carolincnfibus Oeftri quandam fpeciem fubcutaneam crefece, c relatione r. BRICkELL (fupra in $N^{T}$ tal $^{2}$ ) ad Lep. variabilem adlata) fatis apparet.

c) PA I L. Rei/en E'.II. append. p. zor. 13. $I$.

d) OEsTRVS leporimus, totus ater fubpilofo-glaber, facie alarumque crulitore margine lutefcentibus. - Magnitudi. se eft Mufce canarix et facies cminus fimilis. Corput facie fubinflata pallidum, vertice, oculis, antennis, papillaque oris fufco-nigricantibus; collmn: excentricum, ori approximatum. Coiprs glabrum: tho. rax fupra opace niger punctis atris quatuä pariun, duplici ferie transverfa po. Ltis, quorum media antica oblongata.
Scutelluwis prominulum, apice pilis fpar. fum. Aodomen atrum, polito-nitidun; fubtes opaco-variegatum. Pedes pilofi nigri. Alr fufcre, bafi margineque craffiore lutefcentes, puncto exiguo difci, litutaque parva ad bafin, nigris. Squamce fubalares albac, halteres albo capitulo. Prodiit in hypocaufto Infectum medio la. nuarii e LAR VIS Augufto enucleatis, brevibus, rugofis, mollibus, fpiraculis poftice 2 nigris cauez truncatx. Vid. Tab.11. jig. infra $A$. Larve, $B$. Infect abfoluti. 
Velleris colorem in L. alpino hyemc mutari nequaquam credo, habui enim fero autumno xftivis fimillimos; quemadmodum colnr etiam omnibus femper idem vifus eft, fine varietate ulla. In Altaïcis equidem æftate arcolam fubinde unam vel alteram in dorfi vellere albam notavi, fed ex cicatricibus œftrorum forte tribuendx funt, quæ, ut in equis quoque folent, albos pilos gencrarunt. - Infigniorem magnitudinis varictatem fecundum regiones oblervavi. Maximi in fua fpecie funt, qui ad Altaïcas alpes vivunt, pondus libræ cum quadrante æquantes, immo fuperantes. Longe minores circa Baikalen et in alpinis Davuriæ, omniumque minimos deprehendi, quos in Krasnojarenfi regione, a Mana præfertim fl. copiofe habui, utpote quí numquan dimidiam libram, immo plerumque vix uncias quinque explebant. Forte majores evadunt, qui in clatiore alpium regione et in locis longiore reftate gaudentibus vivunt.

Numquam potui vivum obtinere Leporem alpinum, ut mores curiofius obfervarem; adeo enim inter rupes delitefcunt, ut fodiendo adtingi nequeant; decipulis autem ad idipfum conftructis numquam fucceflit captura. Cæfos copiofiffime, fed tantum fub exitum æftatis, diffecavi, in quibus nunquam præfens focturd inventa eft; aft vidi fentel (fub finem Iulii) floridum fanguiferis venis uterum et mammas turgidas, ut paullo ante illud tempus, et nifi plurics in anno, tardius quam Lepores pufilli parere videantur.

Differt hæc fpecics a L. pufillo facie, et, lit ita dicam, thlyyfingrumia capitis magis ftupida et fera; velleris natura rudiori, pilo minus lavi et breviore, ne. de colore diverfffimo; luteorufefcente, foleisque pedum nigro villofis dicam; altribus porre

\section{G 2}


perfete rotundatis, fere infundibuliformibus, nigris, virque ora albidis; cirtelris lumbaribus tantum quatuor, ficralibus et coccygeis una numerofioribus, quam in L. pufillo. In viferum quoque et intertinorum proportione et confornatione aliqua eft diverlitas. Atque in univerfum magis a $\mathrm{L}$. pufillo diferepat hec fpecies, quam fequens, in qua characteres diftinctivi in figura, proportione, numeroque partium argerrime deteguntur.

\section{E. S C R I P T I O

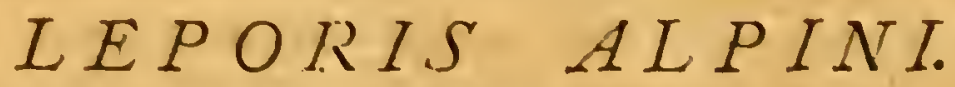

Ta6. II.

Mugnituto in majoribus Caviam Cobayam fubaquat.

Crput oblongius atque tenuius; roftrum minus obturum et productus, quam in Lep. pufillo. Os leporinum; Jabin mediocriter turgidula; margine nigricante pubefentia, fuperum incifura ufque ad nares bipartitum. Nitjis villolus, fufeus, folo lepto nuido.

My/faces infigniores, quam pracedentis, nigri, fex ordinibus digelti; pili utrinque duo in palpebra luperiore; feta elongata fub rygomate; exilis, folicaria fub gula.

Dintis primares fupra paullo robuftiores, fulco ex incifura magis interiori-angulo vicinis, unde apicis exterior angulus productior, neque denticuli-acicm terminantes aquales, ut in L. pulllo; dentes quoque fuccenturiati pallo magis inter fe diftantes. Mrolures numero et forma fimiles. 
In funco oris utrimque fecundum linguem lamella longitudinalis, fubcartilazinea, invegra, nifi portione pofterius per incifiram diftircta.

Oculi medin fitu inter nafum et aures, mirufcuip, niz̧r; palpebrarum quoque limbo nudo nigzo.

Aures magnæ, rotundate, care, rudiufcule niste; ;ṕa ora albo pubefcente, intus villis ratis: merge anierior vefus bafin infundibuliform:- tubulofus; lamalla rotundàz rucia ex igfo finu auris, oppofizaque major et prominentior in corcha transterfalis, quz, fimul cum villis pallioiz circa bafin, aperturam auis obumbrant.

Corpus minus elongatum et ventricriflis guam I. pufillo. Artus breves, neque poftici mulio longiones. Digitsrum numerus, ut in eodem; pollex palmarum brezior. Srilee omnium pedum to: denfifimo tomento atrn veftice, medio canefcertes.

Cauda omnino nulla; fedente vero animalculo coscigis aper, cum adfidente utrinque glomere pinguedinis ciriurcula, prominentian media clunie feu tuberculum convezum fup:a anum efficit.

Vulva freminis et auls intra orificium commune, bilabiato. confrictum. Mamma dua inguinales anie femora; Gue fupra fpurias coftas, duze thoracica verfus collum, armis paullo enterio:es.

Maris genitale, ut in L. pufillo, ez ani apertura protrucirur. Simus inguimales in neutris willi.

\section{$\mathrm{G}_{3}$}


Vellus haud prolixum, rudiufculum, ad Marmotze pilum accedens, longitudine in dorfo ad fummum 8."I Color mixtus, in capite dorfoque lutefcens, pilis longioribus nigris infufcatus, obfcurior vertici; parotides, latera, clunes fine pilis nigris rufentclutea; fubtus color obfoletius lutefeens, gula fumma cinerafecntc. (In krasnojarenfibus atque davuricis color paullo magis rufefcens.). Vtrinque fub parotidibus verruca extus pilis breviffimis ftrictim veftita areolam efficit peculiarem (qualem in Iumbari regione utrinque Cricetus habet) vellere delite!centem, at facile confpicuam, cujus in afinibus fpeciebus nullum veftigium.

\section{$\begin{array}{llllllll}M & E & \mathbf{N} & \mathrm{S} & \mathbf{V} & \mathbf{R} & \mathbf{A} & \mathbf{E}\end{array}$}

Ex Altaïcis etian femine ad $1 \frac{x}{4}$ libram med. pondere acce: dunt; daurici intor 4 et $5 \frac{\pi}{2}$ uncias variant; Krasnojarenfes a $3 \frac{\mathrm{r}}{2}$ ufque ad unc. 4. cum $>$ drachmis pondus, nec ultra, obfervati funt. Atque horum longitudo tota a fummo nafo ad anum non ultrn 7." capitis 1." II."' fuit. - Accuratiores menfuras ex Altaïca femsella recenfebo, ut et vifccrum anatomen; fceleton c krasnojarenfi fpecimine fubjuncturus.

Longitudo a fummo maro ad anum

-... capitis a nafo ad nuchan

\section{Diftantia oculi a nafo} - . - ab aure

Fiftura palpebrarum Apertura oculi

Circumferentia oris Intervallum narium Pili myftacis longiffimi 
Circumferentia roftri ante myftacem fine labio inferiore $2 . "$ I."I

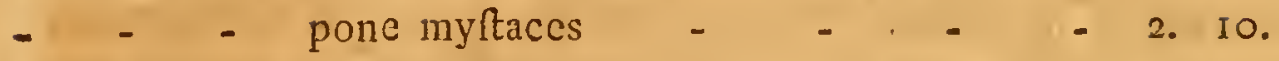

- - - capitis trans oculos - - - - 3. 3.

- - - media inter oculos et aures - - 3. 8.

\section{Auris longitudo}

- Latitudo fumma -

- - circumferentia bafi

Longitudo humeri
- - brachii feu cubiti

- - - totius palinæ

- - - unguis medii palmarum

- - - femoris

$-\quad-\quad$ tibiarum

- - totius plantx

Circumferentia colli

- - $\quad$ thoracis ad armos

- - - medii corporis

- - $\quad$ - abdominis ad femora

- - - brachii

- - ad carpum

- - $\quad$ - tibiarum fuperius

- - - ad calcaneum

- - metatarfi

\section{A $\quad$ N $A$ A $T$ T O}

Tab. IV. fig. 10.18 .

Circa collum, dempta cute, glandilla utrinque duæ, major et ante illam minor, falizales; tum alia glandula thymi fimi- 
litudine, et infuper lymphatica, mole tritici. Panniculus. carnofus ut in Citillo.

Hepar (fig. IO.) latum, explanatum, quinquelobum: Portio finifra e duobus lobis (a.b.) magnis, fubovalibus, profunde difciflis, inque ipfa intima incifura foventibus $c y$ ftidem (f.) parvan, flaccidam, vix pifo ampliorem; Dexterior portio (c.) craffior, irregularis, bis incifa, lacinia finifteriore bicorni, cornibus fubriquetris, media lata in aciem complanata, dexterrima linguiformi; lobus dexterrimus fimulque dorfa. lis (d.) triquetro - excavatus reni incumbit; Spigeliamus (e.) linguiformis, arcum ventriculi explens.

Lien (fig. I I. a.) exiguus, femiovatus, extremis productiufculis, ventriculi fundo per.. omentum, a dorfali latere adnexus.

Ventriculus (fig. I I.) requali extenfione lunatus vel femicircularis, utroque fine rotundatus, pylorum verfus paullo contractior, fundo argutius incurvato, cujus finui infertus œfophagus. Intris plica fupera in medio, cavum fubbipertiens. Icon, it et Hepatis, naturalem magnitudinem exhibet.

Inteftimum tenue (univerfum 6 ped. 5 poll.) calami fcriptorii capacitate, ad $5 .{ }^{\prime} .9 . "$ proprio mefenterio innexum, tum 2." 6."' fpatio appendici cœci fit comes, dehinc bipollicari menfura ipfi cœco, quo in loco dotatur area glandulofa, craffa, oblonga ( $6 . " \prime \prime$ ad $\left.4 .{ }^{\prime \prime \prime}\right)$; denique anfractibus laxe inter coeci gyros pergens inferitur craffo. (fig. I 2. a.) Simls Ilei, in L. pufillo commemoratus, huic nullus. 
Ad ilei infertionem appendix lumbricalis (b.) glandulofa cœco infidet (craffior, quam L. pufillo) calami fere cygnei craffitie, longitudine Io."' obtufa, alba, fufflata intus favaginofa; chymum nullum admittens, fed albo muco turgida. Eidem adfidet infuper Cellula (c.) ceci, itidem glandulofa, capacior quam in L. daurico. Glandulce duæ albæ, mole fabæ, in finu primæ curvaturæ cœci.

Cacum portione prima (d.d.) cui commiffum ileon, ad I." 4. "laxius, dein per 8." amplifimum, cellulofum, tunc ad 2." 10."I adtenuatum atque obfolefcentibus fenfim rugis fubæquabile, demum terminatur extremitate lumbricali (e.f.) mucofo - glandulofa; quæ longitudinem $2 . "$ " $6 . "$ "' et calami fcriptorii craficiem explet; un. de tota cœci curvatura emergit $14 . "$ " $8 . ! !$

Infundibulum cœci $(g \cdot)$ bafin feu infimam hujus cellulam excipiens, amplitudine fere cœci incipit, adtenuaturque incurvatum, longitudine tota 3 poll. intus tota fuperficie favaginofum, five fi॰ nubus reticulatum, ut in $L$. pufillo.

Colon (b.) trifariam cellulofum tripollicare, extremo adte nuatum continuatur intefino excretorio primum (i.) per 3 poll. Atrictius moniliformi, excreta in globulos cogente; dehinc æquabili $(k$.$) quod fefquipedalem longitudinem ufque ad anum abfolvit,$ eoque tractu ileo ex parte comes adhæret.

Ren dexter multo anterior a I 6ma ad ismam coftam (finifter tantum a $17 \mathrm{ma}$ ad $\mathbf{3} 4 \mathrm{mam}$ ) extenfus, forma diverfi. Glandula renales lutefcente-albæ, vertici renum interius adfidentes, dextra plana facie incumbens, finiftra oblongior et fubteres. Vefica nuce majore capacior, oblongata, ureteribus prope fundum pervia. 
Vteils in unica femina, fub exitum Iulii feeta, adhuc crae tumidulus, venis floridus, cormuluss ad minimum bipollicaribus, in fenicirculum anfratuofe arcuatis, verlus ocaria imis lumbaribus vertebris adfidentia, qua oryzam munditan aquant.

Diaploragna parum obliquatum, area tendinea migna, cordata. Pulmo dexter quadrilobus, quarto fpinali azygo, fummoque lobo reliquis majore; finifter trilobus. Thymus magna, alba, bicruris, fummum thoracis occupans, pericardio appofita.

In scelete: Cromilum magnitudine et convexitate oflum nafi, forma oblonga, 1tructura zygomatis et maxilla, cellula lacrymali ante zygoma, hiatu palati anteriore, opontisque palatini anguftia cum leporino convenit. Contra magis cum Ratti cranio congruit altitudine et craflicie minore roftri, defectu proceflus fupriorbitalis, critta occipitali transverta infigni, formaque deprefiore olls. A l. pulilli cranio difiert forma tota, prefertim olla, imagis deprefia, maxilla minus alta, roftro magis coartato, oflibus nafalibus brevioribus, tympanis offeis minus gibbis. Occiput ollw in genere adeo deprefium, ut quaflitum videatur, bregmatibus poftice totis hiulcis, cum carina litgittali, in criftam transverfam occipitalem, admodum produfam, definente. Imprefiones temporalium quoque mufculorum infignes; ifthmus cranii inter orbitas longior, magisque coarctatus, quan in L. pufillo, proceffu nullo, proter tuberculum pro infertione malleteris. Zygoma, nifi proceflu retrorfum productiore, fimile leporino; fed caverna lacrymalis minor et fimplex. Hiatus fublacerus, maguus olla cranii utrinque fubtus ante tympana, ubi fimul cranii lamina tonuifima; (hiatus rero ille in Lep. pufillo longe minor, limiliorque feneftrie lubquadratx, marginibus deterninatis). Molares ubique quini, forma ful- 
cisque transverfis fimillimi leporinis; ut et inciformm fructura fimillima (Fig. I 3.).

Cofte 17, quarum feptem veræ, hinc quatuor adpenfx, fex ultimæ rectæ, mufculis inhærentes. Stermnın officulis intermediis tantum tribus, ita ut coftarum verarum paria quatuor priora manubrio, ejusque ct articulorum corporis mutuis commifuris, quintum medio tertii articuli, et duo ultima eidem verfus enfis comniffuram, inferta hæreant. Spina lumbaris rigidifima, vertebrarum tantum quatuor; fed ultimæ fex dorfales iftis adfimilantur procefiibus a dorfo arrectis, latis. Sacrum c vertebris 5; quarum priores duæ iliis cöarticulatx. . Coccyx internodiorum 8, preter apicem cartilagincum. Pubis olfa non in fymphyfin coëunt, fed intervallo diremta per liganentun cohrent, in femina fublineari, in mafculis breviore. If chiorma angulus acutior, retrorfum productus. Clavicula majufcula, humcrali extremitate latiufcula, plana. Scapula angulo inferiore fublunata, crifta longitudinali vix ad $\frac{2}{3}$ continuata, hinc acromio longe protenfo. - Menfur Ils, c minori varictate, in tabula comparativa ad L. Ogotonam infra fubjuncta fuppeditabo.

\section{L, E P V S \\ $\begin{array}{lllllllll}O & G & O & T & O & N & A\end{array}$}

$Y^{\top}$ enio ad ultiman noftram fpeciem Leporum anomalam, que cum Lepore pufillo (fi colorem negligas) fummam habet fimilitudinem, immo tantam, ut cam, nifi loco, moribus, inftinctu et voce differret, pro varietate iftius, climate transbaikalenfium regionum transmutata et adaucta libenter declaraffem. Sed, præter

$\mathrm{H}_{2}$ 
ifta, etiam in proportione et forma partium characterum minutiorum haud parum, inftituta comparatione occurrit, quibus aque, ac velleris teneritudine atque colore, a L, pulillo funditus diftinguitur; $\mathrm{ab}$ 2lpino autem tota facic ita, ut iple L. pufillus, difircpat.

Lepus, cui Mongolicum nomen, Ogotónd'), pro triviali relinquo, prorfus mull sibiria in regione occurrit, quam in montofis ultra Baikalem Lacum, ubi vulgatillims eft, atque per omne Mongolorum defertum, maxime in Goheënli fic dicto cremo, rque frequens efle dicitur. Exoptatillimum habitaculum prebent montes rupeltres ad Selengam, Tfehikojum et Drhidim crebri, qui bafi arenofa, ex fatifente faxo derivanda, diflume. In his pariter et convallibus, ipfisque inliulis Selengre fl. arenofis tanta vivunt copia, ut vix ullibi antra animalculorum fiequentiora-viderim. Rarius ad Ononem, fimilibus licet locis, obiervantur. In rupetribus pasfim inter lapidum acervos delitefeunt, at lubentillime in folo arenoro cuniculantur. Alstra duplici vel triplici introitu cxtus patent, canalibus oblique concurrentibus ad nidum gramine molli ftratum atque haud profunde politum. Femina amnoliores complures in vicinia cuniculos paratos habere, et ex mo in alterum fecuritatis gratia transfugere oblervantur. Vidi fiepe intra parrum circuitum conplures hujusmodi cuniculos diftinetos, inter quorum oftia confpicui crant tramites, ab animalculi ditcurfi ficti; in omnibus recenter cxpurgatam terram, et in omnibus (profertim vere) congefta folia invenias: unde difficillime diftinguitur is, in quo animal vere deliteficit, pluresque fiepe frultra fodiuntur a quarentibus. Cacterum

r) Rufi in transbaikaleufi regione nomen aliud nefciunt quam Kisuserso: Krot, quod Rattum rupeltrcm ligniticat. "Mu"ftela mungalica, cauda carens, corpore ,brwiore - Ochodons mungalica MES. , SEKSCH M DII, in Catal. Muf. PC. tropol. Vol.1. F.j+3. no.112. fine dubio hxe tuit. 
ratio cuniculorum prene eadem eft, quam in L. pufillo defcripf, funtque itidem proportione animalculi (patiofi. Agnofcuntur facile excrementis (piperis mole) globulofis ad vicinos frutices paffim coacervatis; quibus tamen interdum fubterraneam in cuniculo camcram peculiarem refertam inveni, quæ pro hyberna forte cloaca fervierat.

Noctu præfertim vagatur Ogotóna, neque tamen non interdiu apparet, faltim vere atque autumno, et nubila tempeftate. Inclufi tota nocte inquietifimi lemper erant, vix tamen unquam edito fono; fpontancorum vox præfertim matutina exauditur, inftar pafterini fiftulatus bis terve iterati, acutiffime ftridula, et a voce Leporis alpini facile dignofcenda, Lep. pufilli vero clamori neque robore, nec modo comparabilis; in pullis femiadultis, fub finem Iunii crebro adlatis, pipitum acrem et argutum, brevem, fimplicem pro voce notavi.

In convallibus et infulis prefertim teneriorem corticem Cratægi, quem Pyrum baccatnm Lisnafvs appellavit, et Vlmi pumila virgulta rodere amant. Vere tamen plerumque meras plantulas arenarias, Alyffi montani cauliculos, ficcaque folia Pulfatillx, prafcrtim vero cuniculis infarctas deprchendi a radice revulfas plantulas Veronicæ incanæ, quæ fub nive quoque virere et hinc primum in Sibiria lanigeri pecoris vernale pabulum præbere folet. Congerunt autem primo vere, præfertim ante ingruens frigus, prædictas plantas, totumque frepe canalem is cffarciunt, unde præfagium tempeftatis in transbaikalenfi tractu certifimum.

Eodem inftinctu Ogotóna noftra autumnali tempore circa cuniculos colligit acervos earundem, quas modo dixi plantarum, ne poftea, quum

\section{- jacet aggeribus niveis informis, et alto \\ Gelu terra late}


annona prematur; eoque inter Mongolos et Dauuria incolas cclebratiffma et notifima evarit. Meminit horum acervorum GERB ILLoNıvs Icfuita, qui Mongolica deferta cum Sinarum imperatore pcragravit ${ }^{f}$ ). Vidit eosdem atque Muri Jaculo (qui torpet hyeme, nec pabulo indiget) perperam tribuebat GNELINvS ${ }^{B}$ ); idemque alio errore in Flora Sibivica (Vol.III. p.I 5.) pofuit: Iaculos in campis Ononenfibus prefertim Ceratocarpum in accrvos fuos congerere, quum neque ulla in regionibus, ubi Ogotonx (íeri acervorum auctores) vivunt, minimeque onnium ad Selcngam, Ceratocarpi planta creleat, neque aridifima illa et fpinofit planta unquam animalculo noftro pro pabulo videatur infervire poffe. Dicere voluit, vel faltem debuiflet: Ogotónam plantulas pro pabulo hyemali congeftas, cum gramine, in clegantes acervos himifpharicos, $\mathrm{Ce}$ ratocarpi formam exprimlentes, pedali circiter altitudine et diametro compingere. Ejusmodi acervi jam Septembri, in locis animalculo frequentibus, crebri confpiciuntur; vere autem, quum primum folutre nives, jan vix amplius apparent, neque preter fparfas reliquias et ingeftas cuniculis herbas $\mathrm{ex}$ iis quidquan fupereft.

Initio Aprilis diffectionibus genitalia floridifima in utroque Ogo. tona fexu inveni; adeoque eo fere menfe eftri.tempus incipit. Iu-

f) Memorat glires in deferta Mongolico, Olubri menfe innumeros, qui magisos herbarum feu forni acervos pro. pe cuniculos congefterant in Lybcrnum pa. bulum: Apud DU HALDE et in Samm. lung aller Reifebefalw. I'ol. IVII p.616.

g) Nov. Comment, Petrop. I. p 357. feq. ubi fequens locus, ad laculum rela. tus, Ogotone nottrac convenit: "In fu, turaun hyemem.. GMELIxvs inquir, "miro et fagaci fibi modo profpicit. Fœ„uum eo tempore fecat, quando arefiere , incipit, illudque in acervos cogit rotun.
„ diufculos. quorum finguli pedem latitu, dine ct altitudine xiquant, foum bene "ficcatum fuis importans cuniculis. Cum „, hace aninalcula innunera copia in campis "virant, adeo, ut propter infignem cu„, niculorum, quos efiodiunt. copiam, per " campos iltos (Onuncnies) proficifienti. "bus, ratinne equorum, continuo tita. "bantiun, perpotuas moleftias creent, "juxta has moleltias multa voluptate per. "fufus fum . quando innuneros hujuemodi „, foni acersos. qui pluriman partem $C_{\varepsilon}$. "ratocarpo confabant, intueri licuit. ", 
nio excunte jam fatis adultos pullos venatores nici crebro adtulerunt. Neque tamen hi fatis mitefcebant, ut manibus tractari potuiffent, et cum adultis fatis dit inclufi, femper timidifimi manferunt; prompto rapidoque huc illuc difcurfu fugientes. Sunt enim vividiffima et ngiliora L. pufillo animalcula, ceteroquin huic futis moribus fimilia, fitu prafercim conglobato corporis, motu narium et labiorum mafticatorio (Leporibus omnibus frequenti), morfuque imbelli. Fiftulatum licet a captivis numquan audierim, fubinde tamen noctu, forfitan pugnantes, fonum Leporis rulnerati barritui fimilem ediderunt.

Infertantur pauperculi a Falconibus minoribus; a Picis caudatis, quæ in arbuftis cuniculis prodeuntes cuftodiunt; et vefpertino tempore a Strygibus. Præcipua ctiam præda funt Felis Momnl dicta, mongolicis in defertis frequentioris, ut minores feras fubterraneas, Putorium, Ermineumque non dicam. Verum 'numquan ab Ocftri larvis obfideri hane fpeciem obfervavi, licet plusquam quadragenos tractaverim diverfo tempore anni.

Differentia præcipua inter Ogotónam et $\mathrm{L}$. pufillum (quen te:neritudine velleris et tota facie proxime imitatur) patet e prioris magnitudine, pedibns robuftioribus, colcre diverfifimo, hyeme eftateque conftanter pallidifimo; Alritum circumferiptione et conformatione alia, dentinm primorum crenis inæqualibus (dum exteriores anguli aciei, etiam quam in L. alpino, productiores), porro e defectu fum coci in ilco, fimuque contrà glandulofo-infigni, preter appendicem lumbriciformem infertione ilei adfidente; et denique veficularum feminalinn fabrica magis compofita, quæ univerfa, præter minutas multas differentias, fpeciem diftinctifimam, facie licet fimillimam declarant, ut e fequenti defcriptione pleinus conftabit. 


\section{E S C R I P T I O \\ LEPORIS OGOTONAE.}

Tab. III.

Magritudo inter L. alpinos maxinos et L. pufillum media, quæ minorem circiter prioris varietatem æquat. Facies et ftru. ctura pofteriori fimilior.

Forma capitis quae in L. pufillo; my/taces parciores, brevioresque, plerique albidi, fuperiores fufci; Pillts fupraciliaris geminus, longior in buccis, fub gula nullus.

Oculi paullo majores; quam in L. pufillo, pupillis magnis; iridibus fufcis.

Aures oblongo-ovales, fubacutæ, per ambitum pallido-pilo: fe, intus nudæ, fufcr; margo anticus verfus bafin dilatatus, pla. nus, nudus, introrfumque cavo conchæ adnatus, nec alteri margini occurrens; lobus intus femi-ovatus, tenuis, transverfus, fupra finum meatus anfractuofum.

Trancus brevis, artusque etiam poftici humilcs, ut in præcedentibus; offa robuftiora, quam in $\mathrm{L}_{\text {. pufillo. Palmarum pollex }}$ remotior, brevis; plantarum digiti duo interiores fubxquales, proximus longior. Vinglıes nigricantes; folece pedum villofifima, cano - albefcentes.

Calda nulla, coccyx tamen ad fenfum fub cute prominulus. In maribus fcrotum ante ani et genitalis communem aperturam, teftibus eftri tempore emergentibus, turgidum.

Vellus levigatum, e pilis longis, teneris, ftrictis; Color corporis fupra gryfeo-pallidus (pilis extremo albidis, medio gryfeo. luteis, ad cutem.fufcis), intermixtis pilis pauciffmis fufcis, maxime 
in tractu dorfi media; flubtus corpus album; artus exterius flavefcenti albidi, cluncs margine lutefcentes, tibiæ ad calcancum luteæ. Prceterea triangulum lutefeens fupra nafum, circunferentia-oris alba, at collum fubtus cinerafcit. Villi fubalbi circa bafin aurium:

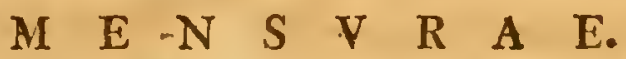

Powdus in marculis fenioribus $6 \frac{\mathrm{r}}{2}$ ad $7 \frac{\mathrm{T}}{4}$ uncias, feminis 4 ad $4 \frac{2}{3}$ unciarum.

Longitudo tota a nafo ad anum

- - capitis

Intervallum nariun

- - a nafo ad oculum

- - - inter oculum et aurem - _ . - - o. $8 \frac{1}{2}$. Palpebrarum fcifura

- $\quad$ - apertura

Aurium longitudo

- $\quad$ - latitudo

Circumferentia roftri per labium inferius - - - o. Ir.

- - - capitis inter oculos et aures - - - 3.5 .

Intervallum oculorum filo

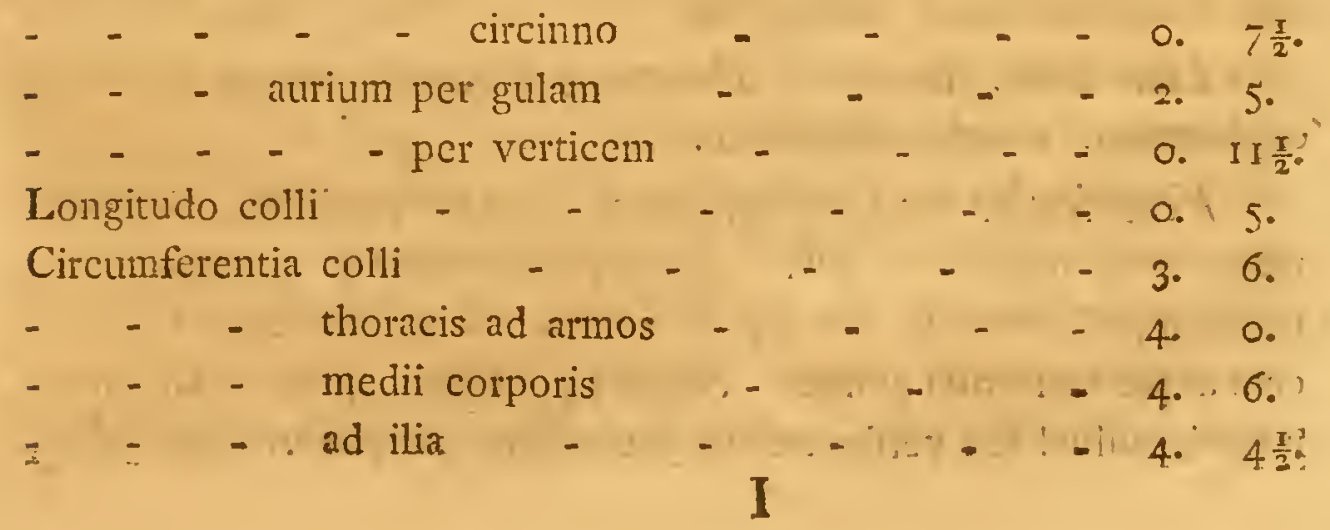


Longitudo humeri

-.. - brachii

- - palma cum unguibus

- - - unguis longillimi a pollice tertii

- - femoris

- - tibiæ

- - plantæ totius

- - unguis medii

\section{$\begin{array}{lllllll}\text { A } & \mathrm{N} & \mathrm{A} & \mathrm{T} & \mathrm{O} & \mathrm{M} & \mathrm{E} \text {. }\end{array}$}

Tab.IV. fig. $14 \cdot 16$.

Menfurce et pondera vifcerum c mafculo $6 \frac{\mathrm{r}}{2}$ unciarum.

Ruga palatinx is priores crân, pofteriores fenfm confertiores et obfoletiores. 'Lingua bafi, ve'ut carne duplicata, explens molarium intervallum. Ad fauces glandulæ fungoïder 3 , in triangulum.

Hepar (pond. drachm. I. gran.20.) feptilobum, varie incifum; lobi duo medii oblongi, explanati, magni, dexterior major, $c y / f i$ dem fubtus fovens; huic proximus dexter dorfalis, fubtus excavatus, angulis incifus, bafi exferens lobulum laciniatum; finifier major mediis, oblongus, explanatus, ad cujus bafin lobulus dorfalis. minor, multoties incifus, mucronatus et excavatus; lob. Spigelininis femiorbiculatus, compreffus.

Lien exilis, linearis. Pancreas fecundum arcum ventriculi explanatum, margine lacinulato.

Ventriculhis-fundo adfcendente, - ad $6 \frac{1}{2} ! \prime \prime$ producto, circumferentia arcus-maxima $3^{\prime \prime} 7^{\prime \prime !}$. Inteftinulnil temule tota longitudine 3 pedes 9 poll. explet; per 9 poll. extremos comitans cœci appendicem atque craforum glomer. - Sinus ceectls ilei, quem in L. pufillo notavi, nullus! fed verfus cecum paullulum exampliatur ileon f Fig. 
T4.a.). Ad infertionem ejus, præter appendicen (lit.b.) lumbriciformem glandulofam ( $7^{\prime \prime \prime}$ longum) adnat alius adhuc (lit.c.) finus five facculus muciferus membranaceus, longitudine circiter $3^{i \prime \prime}$, qui Lepori alpino minus productus et laxior five cellula fimilis, L. pufillo plane deeft!

Ceecum (litt.d.d.d.) a faccata extremitate ufque ad finem extremitatis lumbriciformis (d.e.) novem pollices explet; amplitudinem habet digiti et extremitate ifta glandulofa ${ }^{\prime \prime} .7^{\prime \prime \prime}$ xquat.

Colon incipit camali incurvo $(d-f$.$) , qui infundibulum voca-$ ri minus, quam in prioribus fpeciebus meretur, eft enim amplitudine fubæquabili, longus I" ${ }_{1} 1 \prime$, verum intus pariter lacunofus. Pars coli trifariam cellulofa $(f . g.) 5^{\prime \prime} 4^{\prime \prime \prime}$. - Intefrimum excrementitium (g.h.) fimplex, ufque ad curvaturam renalcm (ubi globuli formari incipiunt) $7^{\prime \prime}{ }_{2}^{\prime \prime \prime}$; hinc rectius fecundum fpinam defccndens $2^{\prime \prime}{ }^{\prime \prime \prime \prime}$ globuliferum. - Interna crafforum ftuctura perfecte, ut in 1. pufillo cxpofita fuit; villi intra cœcum prælongi. - Ajcarides, ut in eodem, frequentes, majufculæ, fpeciei quan LINnarvs $A$. pollicarem vocavit.

Ren dexter (Fig. I 5.a.) anterior, craflior, finifter oblongior. Vefica (lit.c.) ovato - ampullacea, parva; ureterious prope fundum infertis.

Teftes (lit.d.d.) in mafculo (feptem cum quadrante unciarum, fub finem Aprilis incifo) renibus majores, axi I'". Epididymis quafi gemina, minor (lit.e.e.) plana, lunata, cum fuperiore alterius extremitate plana coalcfcens; major (lit.f.f.) teftem ambiens (longa I" $8^{\prime \prime \prime}$ ) poftice in caput incraffata c canalibus groflioribus conglomeratum, e quo duchs deferens (lit.g.g.) initio glomeratus, continuatur. - Hi ductus ad veficæ collum in fimplicem 
ubulun uniti (lit. l.o). - Tificula' fimimules bipartite, porrione merapue e variis intettimulis ramolis conglomeraca, interiore

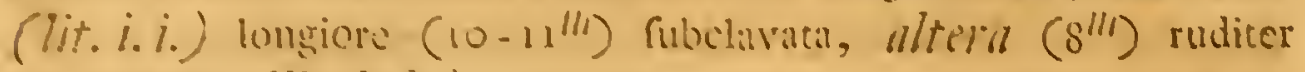
minllciformi (lit.k.k.).

P'onis ab itthmo tous (lit.l.l.) tancum g'll aquat: glans furbulito acuminata, apice peruti. Mllfollus (prater ifehiadicos pe-

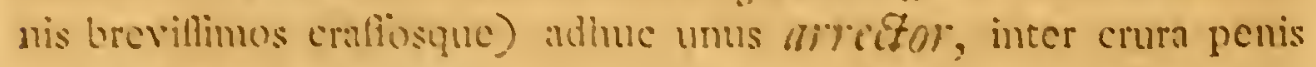
orus, ce tymphyli pubis infertus, quem in Leporibus omnibus inveni. Is muliulus genicale maris naturaliter per orificium ani retrorfiun extertile, in ercetione antrorlum adducit (ut in Camelo).

In lòminis ut crlls vere floridus; longiendo vagina ill cornumm ulijue ad cxtremitatem adtemmaso-glomeratam $2 "{ }_{t}^{\prime \prime \prime}$.

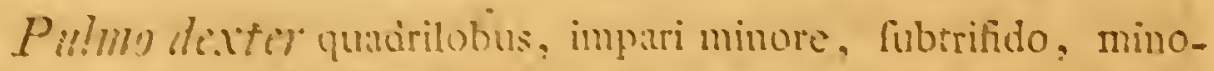
re deu laciniato: fiviftry trilobus: in urroque luperiores oblongi, cxpmat, medii trisusti, wntrortum mucronati, infimi tripuetro-ob-

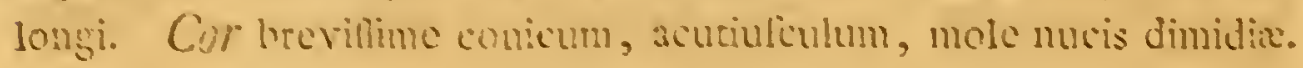

SEELETON C maleulo juniore, quinq̨ue fere unciarum pondus, et longitudinem -" j" $^{\prime \prime \prime}$ ingunte, deliribo:

Cranbisim toemin ohlongius, magis lave et convexius, quan in L. alpino, magis tamen pottice denrethu, quan in L. pufillo, ca. rima figitcali infigni. lthmus fromtalis inter orbitas umpliores longior, qquaw in I. alpino, et piene anguttior. Zgrgomata paullo minus arcuata, longiora, angultiora. Iliarus lacrymales aque nagni, ut in L. putillo, majores quam alpinc. Roltrum paullo longius, quam in utroque, robultius quam L. alpino. Olia nafalia longiora. Incilors argutius convergentes, exteriusque acutilime product, fulco as incorioreu margineu proximo. Maxilla inferior mincs lata ct 
robufta, quam in L. pufillo, magis quam in L. alpino. Molares ut in duobus affinibus.

Cofte 17, in nonnullis 16 parium; veræ 7 , omnes ad interfectiones ferni inferta, quarum pratcr manubrium et enfem intermedix quatuor. E fpuriis coftis utrinque tantum tres veris appenfw, reliqux 7 apice molli mufculis intextx. Veitelrce lumbares 5, facri 4 , quarum fola prima cum offibus innominatis connata; coccy $x$ rotularum, cum apice 9. Offis inmoniziliti foranen ovale triquetro-ovatum; if́chion ultra foramen ovale productius, quem in prioribus duobus.

Scapula triangulo-lunata, ut in L. pufillo, crifta medii difci verfus inferiorem marginem inclinata, acromio $5^{\prime \prime \prime}$ longo, plano, fubflexili. Femora craffiora, quam in pufillo; tibix teretiores, humeri pæne tenuiores.

Dimenfones fceleti cum affinibus fpecicbus comparatas fequenti tabula exhibeo:

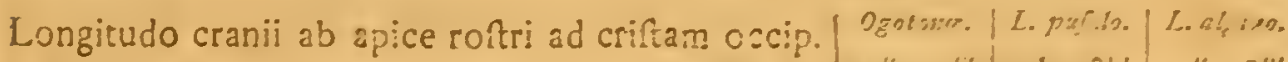
transv.

Latitudo ollæ ante tympana

- - per ipfa tympana

- - per zygomata

- . ifthmi inter orbitas

- - cranii pone zygomata

- - roftri in medio

Alitudo roftri

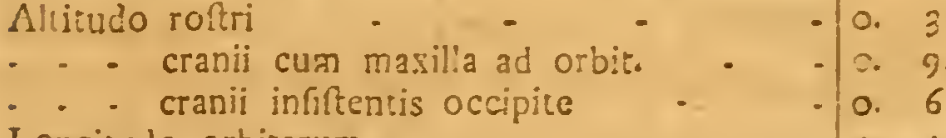

Longitudo orbitarum

- proceffum zygomatis retro protedfrum

- - offium nafí

La:icudo offum nafi

Longitudo roftri a molari primo

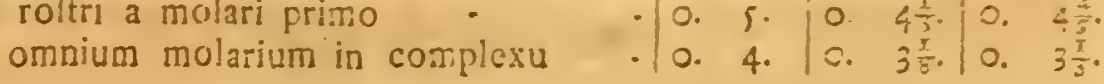


Diameter foraminis occipitalis

Longitudo maxillae ad proceflus pofticos bafis

Alcicudo a margine bafilari ad fummum proceffus

Incifores prominent

$$
\text { articularis }
$$

Longitudo vertebr. colli fimul

Harum longiffimæ poftremæ

Longitudo vertebr. lumbarium fimul

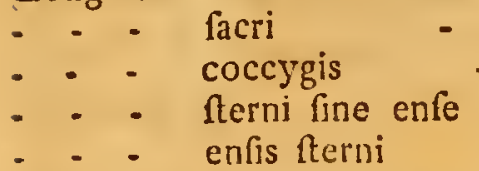

Cofta longiffima feptima

Longitudo claviculæ

Ejusdem laticudo fumma

I.ongitudo acromii

- - . bumeri

- - olecrani feparatim

- - offis metatarfi medii

- - phalangis prinæ

- . - - fecundie

- - oflium innominatoruns

- . folius ilej ab acetabulo

- . foraminis ovalis

Ifchion ultra foramen ovale productum.

Longitudo femoris

-. t tibiac

- - fibula ufque ad coalitionem

- - ofis metatarfi medior.

- phalangis primæ

- . - . fecundæ

(*) Notandum Leporis alpini menfuras na altaïca cranii longitudine aequant $2 . "$ e juniore minoris varietatis fpecimine de- I."' et omnibus proportionibus ampliora fumtas effe. Mlaxima ejusdem fpecimi- atque robuftiora offa habent.

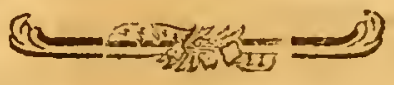




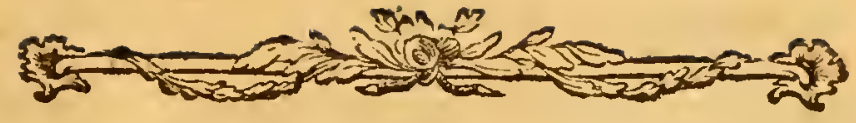 \\ D E \\ G E N E R E M V R I N O IN VNIVERSVM.}

Percipe exwitigenis quam fint variata figuris - Lucret. 1. II. 335.

A udivi viros in hiftoria naturali non fpernendam famam adfecutos, qui noftro ævo credunt, faltim quoad quadrupeda, Naturæ divitias obfervatorum numero pæne exhauftas iam effe. Hos unico murino genere convinci poffe puto, multa etiamnum inter terreftria quoque animalia latcre. Si enim unica Ruffia atque inclementi fub cœlo rigens Sibiria, tot in unico ifto genere fpecies, quot illuftraturus hic fum, certæ plerasque regioni addictas fuppeditavit, quas antea nemo adtigerat, quotnam concludendum eft per feliciorem Afiam, per vaftifimam \& ignotam interioribus Africam, Amcricam duplicem (unde, demtis Caviis, vix unicam fpeciem hucusque rite defcriptam habemus), terrasque fub auftro fitas, animalcula produxiffe Naturam, ut ferarum minori turbæ alimentum effet paratum. Hucusque vix unam \& alteram exoticam Peregrinatores commemorarunt, quum pauci remotas mundi plagas adierint, qui propter parvitatem defpecta animalcula attentione digna cenferent, vel pro Mufeis affervarent; prætercaquam quod propter fubterraneum et nocturnum vitæ genus eadem rarius, aliis magis publicis occupato, obviam fiunt. Mihique ipfi inexpectatum fuit adeo variam 
fecundum regiones, in parvis et imbellibus iftis animalculis, deprehendiffe Naturam. Praeter pauciores enim, quas videbimus, per omnem Afiam difperfas fpecies, aliæ vel arcticis terris, vel certis defertorum regionibus occidentalibus, vel orientalioribus, addictae funt. Quoque numerofiores fpecies in his frigidioribus detcxi, eo majorem adhuc varictatem in magis auftralibus calidisque terris latere, fuadet celebrata feliciorum climatum in quo. vis viventium genere foecunditas. Quin certus pane fum, etiam per Sibiriam atque Tatariam, ubi tot fpecies fors obtulit, plures una adhuc latere. Aliquot enim Murium notitias pauicis phrafibus contentas in Xenio Ifidis Sibirice MSto reliquic MESSERSCHMIDIVS ${ }^{\text {) }}$, quae noftris fpeciebus conciliari nequeunt. - Eft ergo etiam in minuta et defpecta plebecula Quadru. pedum maxime protea Natura; neque negligendam effe hujus pullitiei hiftoriam admonemur infignibus damnis, quibus meffes, funifecia, promptuaria hominum multac afficiunt, \& migrationes, quibus fape totas regiones invadunt atque hoftiliter devartant.

Vt $\int p e c i e s$ Murinm, qune jam per noftras numerofiores crunt, rite diftinguamus, ommes, quæ vulgo notæ auctoribusque varie indicatre et denominatæ funt, hic primum ordine, fimul cum novis, recenfeba, fpecificas differentias breviter indicabo, et in naturalcs phalanges genus totum difpefcam.

a) Hujusmodi eft: Chologoud \& Oike. Chologond Mhungulis Davuriae; Tumsulis Tfchingeroh; Lonsker Lapponibus circa Surgut. An Lemmus? Glis riparius, fi major, certe minorennis, totus e cinereo. fuitigtnofo rufefcens, dórfo inten/ius nigro, brachyurinos, pedibus ubigue pentada.
Aylis, clariollis preditus. MESSER. S С M D T. Itemque: Glis montanusbrachyuriuos, anterius polleriusque pentada: Alylus. kI V D. et: Mus montanus vei riparius e cincreo rufus, brachyurinos, anterius 4, 5 dactilus poflerius. I I S D. 
In prima, propter eminentiorem molem, ploalange nobis erunt Mures alpini feu Marmotce cum affinibus. Ex toto habitu, corpore magis craffo, capite grandi, gibbo, obtufo, auribus minutis vel mullis, dentibus grandioribus non bene tectis, caudx brevitate \& villofitate, internis denique characteribus, præfertim cœco ampliato, \& genitalibus, tanto differunt a frequentiore Murium habitu \& ad Caftores pæne accedunt, ut fingulari genere conftitui poffent, nifi infigniores deeflent characteres, \& alia phalanx quarundam fpecierum habitu nimirum ad has accederet. Conveniunt inter $\mathrm{fe}$, vita diurna \& fopore hyberno, voce, moribus.

Secunda plalanx continebit Mures fubterraneos, capitis mole \& figura ad Marmotas accedentes, qui dentibus primoribus maximis, latis, denudatis, fupra infraque in cuneum acuatis, aurium defectu, palmis plenius pentadactylis forforiis, cauda breviffima vel nulla, \& more tandem, inter fe conveniunt; hyeme vero, faltim non tota, torpent, fed colligunt pro penu radices.

Hos immediate fequitur pbalanx Murium Cmiculariorum brachyura, grandiufculo fed aurito capite, dentibus pedibusque parvulis inftructa; qui tota hyeme vagantur, vel congefta in latibulis penu vivunt, quorumque plures migratorii. Ex his aliqui, præfertim M. Lemmus \& affinis ejusdem M. torquatus, palmis pentadactylis fofforiis habituque propius ad præcedentem phalangem accedunt.

Quarta phalanx habebit Cricetorlm affincs fpecies, omnes brevitate corporis, artuum atque caudx, arguto capite, buccis utrinque faccatis, promptuariis \& vita vix nifi fummo frigore fuppreffa, confpirantes. 
In quinta elegantifima erunt fpecies letbargica, vellere mundx, colore \& habitu omnium lepidiffima, infigniter auritæ \& caudatæ, cauda pilis veftita, frepius flöccofa vel lanata, pofticis artubus plerumque magnis defultoriæ, qux omnes levi frigore fopiuntur, totamque hyemem lethargo tranfigunt: eoque anomalæ fpecies, qua Bipedes incedunt, omnino referri debent. In Sextam denique pbalangem relegantur vagabunda illæ fpecies, auribus majufculis, cauda longa, fubnuda, amnulis fquamata agnofcendæ, quarum vix ulla frigore obtorpefcunt, licet plerreque acerrimæ tempore; brumæ lateant.

Iam Species videamus, in quibus enumerandis, ut ex determinatione phalangum patet, exclufa penitus effe debent animalia in Spicilegiis Zoologicis quondam fub nomine generico Covia fegregata.

\section{I. \\ MVRES SOPOROSI.}

I. MVS (Marmota) capite gibbo auriculato, canda villofa brevi, pal. mis tetradaetylis, corpore fulco, fubtus rufefcente.

Mus alpinus PL T N. hifl. nat. 1.VIII. c.37. GESNER. quadr. p.743. R A I. quadr: $p_{0}=2 \pi$.

Marmota alpina BR IS S ON. quadr. p. 165.

Mus Marmota LI N. Jy/f. XII. p. Sr. fp. z.

Niarmote BVFFO N, hiff. nat. VIII. p. =20. edit. mir. XVII. p. zo. taú. $=S$. I. oc, in Alpibus helveticis, italicis, Pyrenxis circa altiona juga, locis infolatis.

2. MIVS (Monax) capite gibbo auriculato, roftro corrulefeente, cauda longiufeula villofa, palmis tetradactylis, corpore gryfeo.

Cuniculus bahamenlis CA TESB. carol. II. t. 79 .

Monax f. Marmota americana EDWARD. av, tab. roq.

Glis fufcus в R IS SOx. quttr. p. 115 .

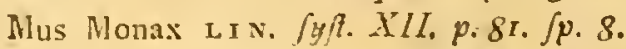

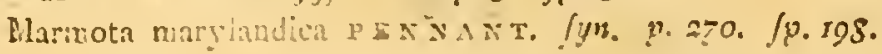


Loc. Americæ feptentrionalis calidiora, Virginia, Carolina, infulæ; neque conftat an fopiatur in illo climate.

3. MVS (Arctomys) capite gibbo auriculato, cauda brevi villofa, palmarum ungue pollicari, corpore gryfeo fubtus luteo. TAB. $V$.

Bobak vel Swifcz rzaczinsis. polon. p. 235. nvFfon. hift. nat. XIII. p. 136. 6 d. min. XXV1. p. 177. tab. r8. mala.

Glis flavicans, capite rufefcente B R IS S O N. quadr. p. 116 .

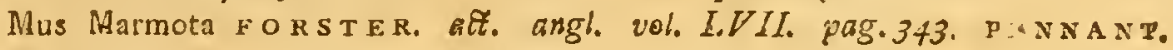
fyn. pag. 268 .

De hac fpeciatim agetur.

4. MVS (Empetra) capite gibbo auriculato, cauda villofa brevi, pal. mis tetradactylis, corpore fupra vario fubtus rufo.

Marmota quebckana PENAANT. Jyn. p. 270. Jp. 199. tab. 24. f. 2. bona. FORS TER Att. angl. vol. LXII. p.378.

Hæc Canadæ, totiusque borcalis Americæ inquilina fpecies mihi quoque in exuviis aliquoties vifa eft,' a prioribusque ommibus diftinctifima, ut e requenti patebit defcriptione, ad fpecimen Murei Leydenfis condita:

"Magmitudo Caviæ Pacæ, feu inter Marmotan \& Ci„, tillum media; habitus plane Marmotæ vel Arctomyos; Iongitu„, do circiter pedalis. Caput retufum, fupra fufco-nigrefcens, , lateribus albicans. Dentes prinores magni, nudati ut in „Marmota, nec antice fulvi. Auricule parvæ, fubnudx, ro„2 tundatæ, vix pilo longiores. Verruce plures fparfe, fu„perciliares bifetæ, paroticæ bifetæ, pilis albidis diftinctæ, gu„, laris unifeta. Corpus fubtus totum artusque rufo-ferruginea; „fupra corpus fufcum, extremis pilorum e gryfeo-albicantibus „) undulato nebulofum. Pedes extremi brunneo nigri, unguibus „fufcis; palmae fine veftigio pollicis. Canda bipollicaris „, cum dimidio, dorfo concolor, apice nigrefcens. 
5. MVS (Citillus) capite gibbo, aurieulis nullis, callda brevi villora, corpore vario. TAB. IT.

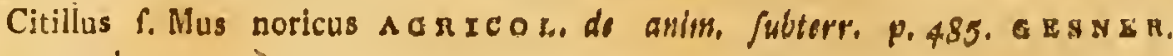
quadr. p. 737.

Cuniculus germanicus B R IS S O N. guadr. p. zor. 12.6.

Mus Citillus I I N. Jy/. XIl. p. So. Sp. 4. mantif. plant. II. p. 523. p A L L. Nov. Cons. Petrop. $X I V$. p. 549. t. 2T, f. T. 2.

Marmota auribus carens EEN NANT. fyn. p. 2z6. n. 203 .

I. Warmota cafanenfis EIVSD, p. 273. nr, 20r, tab. 25. f. r. pefims.

Mus Suslika g v ldexs t. Nov. Com. Petr. $M I V . p .3 S g$. t. 7 . pellima.

Cricetus orientalis G MELIN. jum. Ititur. 1. p. 3o. tab. 5. peflima.

Hujus deinde monographia fequetur.

\section{II. \\ MVRES SVBTERRANEI.}

6. MVS (Typblus) ecaudatus, palmis pentadactylis, inciforibus fupra infraque latis, oculis auriculisque nullis. TAB. VIII.

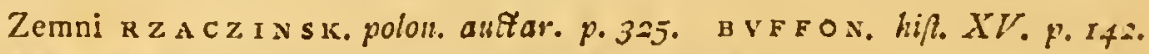

Marmota podolica PEN NANT. fyn. pag. 27T. 11. 204.

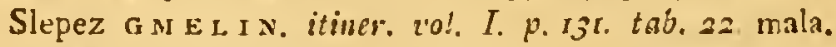

Spalax microphthalmus G V D E AS T. Nov. Com. Petrop. XIIr. F. qog. t. S.

9. mala.

Mus oculis minutiffimis, auriculis caudaque nullis, corpore rufo-cinereo I ЕРЕС н, ibid, p.504. tal. 15. f. r.

Hre quoque fingularis fpecies infra defcribetur.

7. MVS (Afpalax) brachyurus, inciforibus fupra infraque cuneatis, auriculis nullis, unguibus palmarun elongatis. TAB. $X$.

Mus Myofpalax LA m A N. aft. holmienf. 1773 .

Mus Afpalax PALL itin. III. append. p. 69:

Sequetur etiam hujus defcriptio.

8. MVS (capenfis) brachyurus, inciforibus fupra infraque cuneats, auriculis nullis, palmis pentadactylis, ore albo. TAB.VTI.

Cricetus ко о L в. capenf. p. 15 S.

Zandmoll belgartim M A S o s. att. angl. vol. 66. p. jo4.

Itidem hoc libello defcriptione qualicunque illuftrandus. 
9. MVS (talpinus) brachyurus fufcus, inciforibus fupra infraque cuneatis, auriculis 1ullis, palmis pentadactylis fofforiis. TAB. AT. A.

Mus talpinus p A r r. Nov. Com. Petrop. XIV. p. $569 . t_{0} 2 I_{0}$ f. 3 .

"De quo pariter plura in Monographiis dicemus.

\section{V. \\ MVRES CVNICVLARII.}

10. MVS (Lemmus) brachyurus, auribus vellere brevioribus, palmis pentadactylis, corpore fulvo nigroque vario, fubtus albo. TAB.XII.

Lenimus OLA I M. feptentr. p.358. GESNER, quadr. p. 73r.

Animalculum hirfutum OL E A R. muf. p. 20, tab. 12. f.6.

Mus norvegicus vulgo Lemning w ORM. muf. p. 32I. R A I. guadr. p. 22\%.

Cuniculus norvegicus BR ISSON. quadr. epit. p. 100. n. 5 .

Mus Lemmis LI N. att. holn. 1740 . fig. mala. Fyf. XII. p. 80. Sp. 5 .

Lemning BVFro , hil. nat. XIII. p. 314. edit. min. XXVII. p. 120.

Marmola lapponica PENNANT. fyn. p. 274. 11. 202. tab. 25. f. 2, mala.

Quamvis tot auctoribus dicta, accuratiorem mereri videbatur defcriptionem, quam fuo infra ordine fiftam.

II. MVS (torquatus) brachyurus, auribus vellere brevioribus, palmis pentadactylis, corpore ferrugineo vario, torque interrupta albida, linea fpinali nigra. TAB. XI. $B$.

Novum hunc præcedentis in Sibiria conterraneum poftea notioren faciam.

12. MVS (I.agurus) brachyurus, auriculis vellere brevioribus, palmis fubtetradactylis, corpore cinereo, linea longitudinali nigra. $T A B$. XIII. $A$.

Mus Lagurus PA L L. itin. 11 . append. p. 704. Sp.9.

Defcriptionem infra videbinus.

13. MVS (Jocialis) cauda femunciali, auriculis orbiculatis brevifimis, ' palmis fubtetradactylis, corpore pallido, fubtus albo. TAB. XIII. B.

Mus focialis RA LL-itin. I1. append. p. z05. n. 10.

Mus novus GMILIN itin. Il. p. I73. t. II.

Fufius dein e defcriptione cognofcendus. 
14. MVS (arvalis) cauda unciali, auriculis vellere proninulis, palnas libbtetradactylis, corpore fulco.

Mus agreftis, capite grandi, brachyurinus. RA

Campagnol в VFFON. hif. nat. VII. p. 369. edit. min. XIV. p. 224. tab. $4 \xi^{\circ}$

Mlus campeltris brachyurus minor is $\mathrm{R}$ is SON. quadr. 9. 125. epit. p. 125.

Mlus campeftris brachyurus PENNANT. Zool. brit. p. 107. Jynopf. p.305. 4.233.

Pcr omnem Europam \& Rufiam, etiam frigidiorem, frequentifima fpecies, in campis, vepretis, ripis, hortis, agris, cultis noxia, ad horrea vix accedit. - In Sibiria orientali ultra Obum non datur; obfervatur tamen ad Irtin \& in borealibus Obenfis regionis, circa Berefovam, germanicæ fimilis. Vidi etiam ex Hylcania relatam. - Hanc, fub titulo Muris terreftris, cum M. amphibio confundit LINNAEvs \& deinceps $M$. amphibium, cx aliorum falfa defcriptione palmipeden creditum, pro diftincta fpecie ponit.

In campis Ruffix incultis, ubi femina colligunt M. arvales, lubenter circa fæni acervos \& in præruptis voraginum vel riparum, locisque herbidis nidulantur, cuniculis oftio duplici, immo triplici, rarius uno, in pedalem vel-fefquipedalem, fœminis facpe bipedalem profunditatem effoffis, vix pollicem admittentibus, qui varie flexuof \& obliqui ad nidum conveniunt, pugni facile capacem, ramentis graminis molliflimis effarctum, in quibus mediis pulli conduntur. - Aprilis initio circa Samaram nidos cum pullis majufculis cœcis, \& ufque ad medium menfis etiam gravidas fre. quentes habui matres, qux læpe ad XI drachmarum pondus accedunt, \& foctus (juniores quinque vel fex) ufque ad duodecim (octo fxpe dextri, quatuor finiftri cornu) continere folent. Interdum molæ hypenemiæ inter reliquos foctus. 
Minores \& præfertim mafculi 5 vel 6 drachmas æquare foicnt. Lomgitudo tripollicari paulo major; cauda (ut \& caput) vulgo circiter pollicaris, pilis tenuifinic veftita. Dentes primores flaviffimi, fuperiores latiufculi, ftria obfoletiffima, fepe vix nulla. Auricula complicatæ, vellere vix emergunt; unguiculus pollicis in plantis vix notabilis. Canda proportio multum variat et quibusdam vix duas tertias partes pollicis, in folita corporis magnitudine xquat.

Infeftatur Acaris minutis. Folia alni aratro agris inculcata his muribus adverfari quidam perhibent. Noxios in Ruffia præter folitum fuiffe, gregariosve appartiffe non audivi; fed ubique difperli nocent.

15. MVS (aconomus) cauda fubfefcunciali, auriculis nudis vellere molli latentibus, palmis fubtetradactylis, corpore fufco. TAB.XIV. $A$.

Mus economus patx. itin. III. p.692. n. 4 .

De hoc infra videbimus, ut \& de fequentibus.

16. MVS (gregalis) cauda fefeunciali, auriculis vellere longioribus, palmis fubtetradactylis, corpore cinerafcente.

17. MVS (rutilus) cauda unciali, auriculis vellere longioribus, palmis fubtetradactylis, corpore fupra fulvo, fubtus cano. TAB. XIV. $B$. An Mus gregarias i. in s. $f y / l . X 11 . p .8+\int p .16$ ?

Ill. SCHREB E aflerit per litteras fe nunquam talem, qualom LINNAEvs fub adlegato nomine defcripfit, fed Murem potius agrarium noftrum, cum Illuftrifimo iro communicaffe. Deferiptio autem Linneana mihi proxime in hane fpeciem, deinde curatius defcribendam, quadrare vicictur, quod etiam ideo crederem, quia Mus rutilus, ut borcali Sibirix, ita \& Ruflix communis eft, fi modo varictas ejus, quam $\mathrm{cx}$ Rufia defcripturus fum, non pro diverfa fpecie fit habenda. Potuit tamen Miris arvalis varietatem voluifie LINNAEVS, femperque per brevem ejus adumbrationem, dubium fynonymon illud manebit. 
18. MVS (alliarius) cauda unciali, auribus majufculis fubpilofis, corpore cinereo, fubtus albido. $T A B . X I V$. C.

Diftinctifima, licet tantum e binis fpeciminibus cognita mihi fpecies, de qua poftidea.

19. MVS (faxatilis) cauda longiufula, auribus vellere majoritus, palmis fubtetradactylis. TAB. XXIII. $A$.

Nova nobis defcribenda fpecies, quæ cum fequenti, propius ad Myofiras accedere quodammodo videtur.

20. MVS (amplibius) cauda longitudine dinidia corporis, auribus vix vellere prominulis, palmis fubtetradactylis.

Mus marinus AEL I A , hifl. an. lib. IX. cap. 4 r.

Mus major aquaticus RA r. qucdiv, p.21\%.

Mus aquaticus BRISSON. qucidr. Sp.12.

Rat d'eau в VFFon. hifl. nat. VIl. p. 368. edit. min. XV.p. 197. tab. 43.

Nus amphibius L $1 \mathrm{~N}$. $\int y / 2 . X 11 . p .82 . \int p \cdot 11$.

Mus paludofus LIN N. mantiff. plant. II. p. 522 (Varictas tota atra)?

Mus terreftri affinis GMELIN. itim. 1. p.151. tab. 29. f.1. pefima.

Mihi etiam "Mus agreftis major macrourus Gefneri RAI. "quadr. p. 2 I9. vix aliter quan ex hac fpecie natus videtur; quum Murem aquaticun fuum raIvs e notitia WILLVGHBEII pedibus palmatis dotatum crediderit, in quo LINNAEvm habuit fectatorem, qui vorum Murem amphibinm fub nomine Muris terreftris fatis dilucide defcripfit, \& a M. amphibio diftinetum pofuit.

Quandoquidem hanc fpeciem, in Europa licet communem, præter BVFFONIVM \& DAVBENTONVM vix quisquam illuftravit, cadcmque per totam Rufiam atque Sibiriam, usque ad orien= talem occanum, fub omni climate, a mari cafpio ufque ad occanum glacialem, abundat, variasque patitur varietates, non poffum non quædam ad perficiendam hiftoriam ejus pertinentia, hic addere. 
In temperatioribus \& auftralibus Rufliæ, circa Iaikum \& Volgam, fubfimilem europæx colore atque magnitudine ubique obfervavi. Superant duarum, \& fæpe trium unciarum pondus $æ-$ quant. - In Sibiria multo majores funt, fenfimque ad orientem $\&$ boream, cum frigidiore climate, crefcunt. In aquofis camporum Ifetenfium, Ifchimenfium, Barabenfium, ubi quammaxime abundant, mafculi robuftiores a $4 \frac{1}{2}$ ad 5 uncias, feminæ fere quatuor æquare folent. Huic varietati longitudo ad 6 poll. Io lin. cauda $3^{\prime \prime} .8$.' . quare folet. Ad Ienifeam \& Obum verfus arcticam plagam inter fex \& octo uncias variant, ejusdemque magnitudinis pelles ad Lenam in pelliceas veftes confuuntur, Iacutis, fub nomine Kuter, affate in deliciis. Per Sibiriam non infrequens occurrit varietas, præfertim in potiore fexu, tota atra, (qualem in Mure arvali BVFFonivs, ego vero in hujus magno numero nunquam, ob(ervavit). Aliam varietatem ex Obenfi regione, ubi frequens effe dicitur, accepi \& ad Ienifeam obfervavit MESSERscinidivs, qux folito colore e gryfeo fufcefcente europæos referunt, fed macula magna alba, irregulari, "in medio dorfo fupra fcapulas, fimulque litura fepe parva alba fterni infigniuntur. Mares in omni regione robuftiores, majoresque \& nigriores fominis, verfusque polteriora pilis horridiores; fominas magis lutecentes obfervavi. Mares infuper plerumque labium inferius, ipfiusque apicis caudx pilos albos habent, quod non in fœminis. Pedes nudiufculi \& fquamulofi omnibus, conftanter fiffi; palmarum unguis pollicaris brevis, phalange vix notabili. Cant$d a$, licet pilofior quam myofuris, diftinctis tamen annulis circiter 130. fquamata. Alı\%s nudiufculæ, vellere plane abfconditæ. Dentes primores latiores magisque fulvi, quam in reliquis hujus phalangis omnibus, quibus ad fodiendum cæfpitem egregie utitur, \& aliquam $C_{a}$ ftoris fimilitudinem refert. 
Amat paludes, loca humida lutofa circa lacus \& flumina, prafertim ubi typha crefcit, cujus radices amat. In depreflis cxfpitem, inftar Talpx, canalibus percurrit, crebris oftiolis terram egerens, nec ultra fpithamæ profunditatem penetrans, ne radicibus, utpote laboris premio, fruftretur. Expulfus ad aquas confugit, inepte natat, potius in fundo ambulare amat, at vix ultra dimidium minutum fub aquis durat. Pifcibus infeftum ellic vix crediderim, abundat cnim magis circa lacunas pifce carentes, fi modo cæfpitc lato cingantur, \& nunquam pifeem olet. Videtur in hoc injufte a BVFFONIO alisque taxari, qui \& antra minus recte defcribit. (Forfan a Mure decumano illata damna fxpe huic tribuerunt aconomi). Captus in poftica erectus palmis dentibusque cum ftertore fe defendit. Canes villatici \& aquatici vix ullam Murium fpeciem acrius hac ipfa fectantur, \& odorem promptifime fentiunt, qui feminis, aftri tempore vernali, fortiter mofchatus eft. - Infeftatur Acaris fcutulatis fingularibus.

Quum nullum non Sibirix clima ferat Mus amphibius, verofimillime ctiam in Americam transfretavit; videcque in Carolina a Caftore mofchato diftinctas duas dari Rattorum aquaticorum fpecies ${ }^{a}$ ), quarum faltim unam vix dubitari poterit hanc ipfam effe. - Quousque ad auftrales regiones cvagata fit, ignoratur adhuc; intra Rullicum Imperium limites non invenit.

a) I. B R I CK E L natural hifl. of NorthCarolian p. 130. poftquam de Caftore molchato (MH/k rat) egic:"The Mar (hrat, fo called ,from frequenting the marlics, differs from "the former, being lets and of a darker co. "lour, but is more hairy and larger than the „common Houferat. It is a very deftruetire ,and milchierous animal, efpecially to corn ,. S all matser of finit - Porroque addit: "The Waternt is found here the fume as ,in England, , - 


\section{IV. \\ MVRES BUCCATI.}

21. MVS (Cricetus) buccis facculiferis, corpore fubtus aterrimo, cica. tricibus lumbaribus detonfis. TAB. $X X V$. fig. I. 2.

Cricetus A GRICOL. Jubterr. p. 486 . G F.SNER. quadr. p. 738 .

Mlarmota argentoratenfis uR ISSON. quadr. p. IIZ.

Mlus Cricetus r.IN. Jyfl. XII. p. 182. $1 p 9$.

Hamfter вVFFO N. hifl. nat. XIIl. p. nI. edit. min. XYVI. p.15I. tab. 14. opt. S V L ZER. monogr. gcrman. $17 \%$. c icon.

Narmota germanica PEN NAN T. fyn. pag. $27 x$. 14.200.

Delineatur etiam, fed male, apud GMELINVM jumiorem (itinerar. I. p. 33. tab. 6.) \& varietatem atram dedit Cel. Lepecirin itimerar. Vol. I. p. 3 IO. tab. I 5. bona. Circa hujus quoque animalis hiftoriam aliqua fupplenda, etiam poft egregium SVLZERI opufculum, reftant.

Per auftraliorem Ruffiam campeftrem præfertim locis cultioribus (ubi minoribus a feris tutior eft) abundat; datur tamen (ncc infrequens) per totum etiam defertum Tataricum, camposque auftralioris Sibirix, adufque Ienifeam (non ultra). In defertis fporadicus vivit, \& maxime løca amat, ubi abundantior Glycyrrihizæ proventus, cujus femina colligit. Arenofum vitat folum, depreffaque irrigua averfatur. Magnitudine, pro pabuli natura, fexu, xtate, admodum variat; marcs femper longe majores, pondere a libra medica, ad uncias fexdecim, quun contra fremina vix 4 vel 6 uncias fuperare folent. $\mathrm{Per}$ Volgæ tractum agris idoneum, maxime in Cafanienfi regno, circaque jugi Uralenfis auftraliora promontoria, \& in Ifecenf denique provincia non infrequens eft varictas atra, co. piofa vero in regione circa Simbirsk \& Ufam oppida, quæ promifcue cum vulgari coit, \& in eodem fxpe cum vulgaribus nido, plerumque tamen tota familia nigra, nafcitur. Diftingui- 


\section{DE GENERE MVRINO IN VNIVERSVM.}

tur vulgo ambitu oris, nafo, auricularum margine, palmis ultra carpos, plantisque ad medios plerumque metatarfos albis, fape ctian apice cauda albo. In quibusdam roftrum totum albet, frons cancecit, \& albedo maxilla inferioris per collum longitudinaliter cxtenfi. In Uralenfi jugo rariora occurrunt fpecimina hujus varictatis, magnis in dorfo maculis candidis, irregularibus infignita, imo vifus eft pane albus, maculis magnis atris varicgatus, fingulari naturx lufu. - In onni varictate, etiam quum perfectifimum vellus, obfervatur ad poftremum dorfum, pone renalem regionem, utrinque quafi. cicatrix, five arcola folito vellere deftituta, pilis brevifhmis fufcis veftita, in largiore vellere vix confpicul, nif flatu dimotis pilis. In ommibus quoque umbilici arcola nuda, finuque ceeco, intus pilofo \& febifero, cavata.

Anatomen genitalimm mafculcrn!m in Criceto perquam fingularim, nemo pro dignitate dedit; candem igitur $\mathrm{c}$ diflectis pluribus, eeftro venereo ad primum veris teporem turgentibus, fupperaddam. Valde enim (ut in muribus facile ommibus) genitalia effreta a repletis, vencreoque orgafmo floridis differunt. Totum criceti mafculi apparatum TABVLAEXXV. figura prima exprefli. Gloms penis (lit. a.) collapfa, valde fingula. ren, inflata per venam penis dorfilcul, formam acquirit, quam, utpote turgentis veram figuram, ad Lit.t. $A$. a fronte $\& B$. a latere delineari curavi. Eft fcilicet fubclavata, ad obtufum angulum inclinata, extus tota tencrrimis fetaceis aculcis (qui in collapfa non apparent) hifpidata, extremo hians voragine qux limbo inferius bidentato cingitur, \& intra quam prominet, fub urethre orificio, officulum glandis. Lit. W V. retractum preputium indicant; 'c $c$. vero glandulas duas clavatas, incurvas, folliculaceas, prixputio ad marginem infertas \& febum cructantes. 
$d d$. funt erectores penis crasfifimi; $c e$. glandula Comperiance; $f$. ifthmus urethrce cjaculatorius, mufculofus; gg. Veficnlce feminales magnæ, criftatx; $b$ b. veficularum, qux paraftate fuccedance videntur, par primum; ii. \& $k k$. carundem par fe. cundum \& tcrtium; ll. folliculi parvi, utrinque ad collum veficæ fupra infertionem ductuum deferentium feffiles; $m 7 n$. d $l l-$ ctus deferentes verfus infertionem crafisfimi, licet exiguo lumine; $11 \%$. caput inferius epididymidis, quod fundo fcroti adnatum cft; 0 . caput cjusdam fupcrius; $p$. ductus Grafiann infignis; qq. corpus teftium; $r r$ vafa fpermatica; s. maffa adipofa teftes defuper in ferotum extrudens, lobata. Autumno, quum hæc organa omnia flaccida \& in cxiguam molem tcnuata funt, foli ductus defcrentes cadem, qua verc, crafitie deprehenduntur.

Eaque occafione propter affinitatem conformationis adjeci figuram glandis e genitali Cuftnris, quan nullibi rite delineatam invenio. Itaque Figura 2. ad $A$. ipfam glanden denudatam \& per venas infatam cxhibet, a latere vifam, cylindraceam, papillofam, limbo fungiformi crènulato, difco planil. fculo lævi, in cujus medio fub apcrtura carunculari urethræ eminent lacinix binx, apice dentate, quibus apice refpondet offlchlanm glandis, quod lit. $b$. fubtus, $c$. a latere, $d$. defuper fpectatum reprefentat.

Cxtcrum in Criceto omenta lnmbaria, qux in Marmota \& affinibus adeo infignia, nulla funt, fed pinguedo larga totam regionem lumbarcm, \& rencs a dorfo incruftat, octuplo vaftior ipfis renibus, \& omentulum fingulare teftes defuper fovet. Ea pingucdo fere copiofior vere quam autumno.

Calor in Criceto variabilis, ut in omnibus hujus generis; qux hyeme fopiuntur. In vividiffimis Martio, tempeftate adhuc 
fubfrigida effofis, fanguis interdum ufque ad $103 .^{\circ}$ Farenh. qui circiter 91. de .L'Iflian. æquant, calebat; alias vix ad $99^{\circ}$ \& in iis, quos hyeme, loco frigido detinebam, vel aqua frigida antris expulfos accepi tantum ad 91. Far. - Nunquam tamen in ciftulis frigori expofitos obdormiviffe deprehendi.

Inter Ruffos fertur Criceti carnem ficcam, pulveratam, equis ex arena propinatam, habitum corporis pinguem fubito inducere, mangonibus utilem, fed poftea in marafmum lethalem verfurum; de quo fit fides penes auctores.

22. MVS (Accedula) buecis facculiferis, auriculis finuatis, corpore gryfeo fubtus albido. TAB. X'VTII. $A$.

Mus mi.ratorius pa L. itin. II. append. p. 703. "1. 5 .

In deferiptione deinde elucidabitur.

23. MVS (pharus) buccis facculiferis, corpore caudaque fufco - cinerafeentibus, fubtus albis.

Etiam infra peculiari defcriptione illuftrandus.

24. MVS (arenarius) buccis facculiferis, corpore cinereo, lateributs fubtusque albo, canda pedibusque albis. TAB. XVI. $A$.

Mus arenarins PALL. ittn. II. aupend. p. z04. n. . .

Videatur \& hic inter fpeciales deferiptiones.

25. MVS (fongarus) buccis facenliferis, dorfo cinereo, linea fpinali nigra, lateribus albo futcoque variis, ventre albo. TAB. XVI. $B$. Mus fungorus p a L L. itin. 1l. append. p. z"3. n.6.

Sequetur hujus quoque accuratior deferiptio.

26. MVS (Furmnculus) buccis faceuliferis, corpore fupra gryfeo, ftriga dorfali nigra, fubtus albido. TAB. $X V . A$.

Furunculus myodes, Orochzoifach Mlungalorum м еS S в в S н м. Xen. Ijid. MStum. Muf. Petrop. vol. I. p. 3+3.n. 10g.

Mus barabenfis p A t. L. itiin, 11. append, p.zo4. Sp.8.

Cum prioribus quatuor fpeciebus antea ignorata \& dein $\mathrm{cx}$ profelfo defcribenda. 


\section{V. \\ MVRES LETIARGICI.}

27. MV'S (7aculus) cauda longifima apice pemnata, nigro alba, pedibus pofticis maximis, pentadaetylis. TAB. XX.

Cuniculus f lepus indicus V rias dictus A L D R o v.quadr. dig. lib. 1I. p 396. Alak-dífga Mungulo-daurica, Abalak Indorum m ES E E S c H M. Hodeget. MISt.

Cuniculus minor caudatus dauricus Alachtacha Mongolis M ES SERSCH. Mil. Petrop. I. p 37t. Mr., 123 .

Cuniculus pumilio faliens g a e. Nov. Com. Petr. I. p. 35r. t. g. f. r.

Cuniculus cauda longitima в R ISs. quadr. epit. p. 103. $\int p .9$.

Lepus terrettris \& MELIN. itin. vol. I p. 26. tab. s. mala.

Jerboa fibirica PENNANT. (yn. p. 295. $n 223$.

Plenam tandem hujus \& fequentis hiftoriam dabo.

28. MVS (Sagitta) cauda longiffina, apice fubpennata nigro - alba; pedibus pofticis longiffimis, tridactylis. TAB. XXI.

Gerbo D E B R V Y N, oricut, $p .396$. ic.

Gerbua EDWA R D. av. $t .2 r g$. H A S S L Q V IS T. ad. holm. vol. XIV. p. 129. tab. mal. itin. p. 198 .

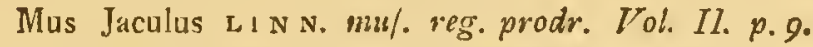

Mus Sagitta P A L L. itin. 11. append $p .706 .11 .12$.

Jerboa rgyptia PENNANT. fyn. $p$ 295. n. 222. tab. 25. fig. 3.

Diftinctifima, a præcedentis varietatibus \& fequenti, fpecics.

29. MVS (cafer) cauda longiffma, apice floccofa nigra, pedibus pofticis longiflimis tetradactylis.

Gerbo major A L L a m a N D. mollogr. 1776. Suppl. Buffon. tab. 15.

Capenfis fpecies, cum Marmotis, ex murino genere maxima, antecedentibus duobus vere affinis \& congener; quum contra male a Zoologis recentioribus nonnullis huc referantur Lemir Spectrmm, (Le Tarfier виғFоn. XIII.p. 90. ed.min. XXVI. p. I I6. t. 9.) diverfifimx fabricx animal, Moluccanis infulis proprium, nocturnum, Belgicis Podje dictum (Muf. Schlofferian. p.2. $n r .24$.), de quo fufrus alibi; \& Didelphis faltatoria Cell. BANKS \& solandrr. - Ipra hac a Cel. alda- 
1) AND illuftrata fpecies tranfitum facit ad fequenten fpeciem, unde Mures ifti bipedes feparato genere tradi nequeunt.

3०. MVS (longipes) cauda longa veftita rufa, corpore fulvefcente fubtus albo, pedibus pofticis majufeulis, pentadaetylis. TAB. X'FIII. $B$.

Serpentum pabulum S Е В A E thef. 1I. tab. $=9$. fig. 2.

Mus longipes L IN N. mur. veg. rol. I. p.g. Jy/f. vat. XII. p. 84. Jp. 19.

Mus meridianus PAII. itin. II. p. zo2. append. n. 4 .

Hanc, licet haud dubie fynonymis indigitatam, fpeciem pieniorem defcriptionem pofcere credidi.

31. MVS (tamaricinus) cauda longifima, 'veftita, fufco - fubaminlata, corpore gryfeo cinerafcente fubtus albo. TAB. XIX.

Mus tamarifcinus P A L L. itin. II. append. p. zo2. fp. 3 .

Etiam hanc inter defcriptiones fpeciatim illuftrabimus.

32. MVS (Nitedula) cauda longa, fubfloceofa, corpore rufefente, fubtus albo, area oculorum nigra.

Nitela P I I x. hifl. nat. lib. V1II. cap. 57.

Mus campeftris feu agrarius A L D R O v. quadr. dig. p. 45 r. icon.

Glis f. Mus avellanarum major BR ISSO $\mathrm{N}$. quadr. cp. p. II 4 .

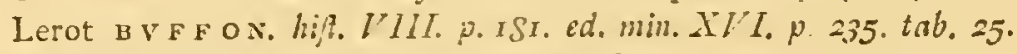

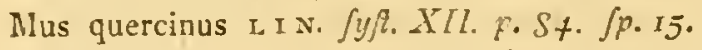

Sciurus hortenfis PEXNAXT. Jyn. p. 290 .

Apud Ruffus tantum in quercetis Cafanienfibus, ad Volgam \& in Parva Rufia notum animalculum, in cavis truncis \& $\mathrm{Pi}$ carum nidis non infrequens, etiam ubi deeft Corylus. Cauda omnibus aliis congeneribus villofore, minus tamen, quam in fequenti fpecic.

33. MIVS (Glis) cauda longa villofiffima, corpore cano, fubtus albo.

Glis PLI I. hif. uat. 1. VIII. cap. 57. GESNER. quad. p. 550. RAI quadr. $p_{0}=29$. is R I s s o x. quadtr. ep. p. 113.

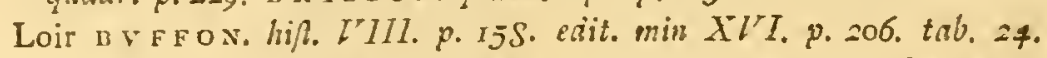

Sciurus Glis Li wx. fy/l. XII. p. S7. /p. S. PEN N AN T. Jyn. p. $=89$.

In Rufia minore \& ad Volgam in quercetis \& faxorum fiffu. ris idem qui per omnem Europam auftralem; at in Sibiria nuf 
quam datur, licet in auftralibus Afix wideatur ufque ad Chinam continuari, interque Chinenfum picturas zoographicas occurrat. Hic ipfe eft animal Polonis \& Carno-Slavonis Pouch, dictum, quod BVFFonivs (liff.nat.vol. $X V . p$. I 43.) e rzazcins10 inter dubia recenfuit; idemque Germanorum Billich vel Pillich, quem recte cum Pouch conjunxit in tritifino Lexico II ÜB BERVs.

34. MVS (avellanarius) cauda longa, fubfloccofa, corpore fulro, gula alba.

Mus avellanarum minor RAI. quadr. p.29r. EDW A D. av. tab.266. Z006. britaini. tab. 45 .

Glis - Mus avell. miror BRISS ON. quadr. epit. p. 115. Jp.3.

Mus avellanarius zin N. fy/l. XlI. p. 83. 1p. 14.

Mufcardin B VEFON. hif. nat. VIII. p. 193. edit. min. XVI. p. 25o. tab.26. pulcherr.

Sciurus fomnolentus PENNANT. Tyn. $9.291, n .219$.

Mihi nunquam oblatus, præterquam in Anglia, ubi frequentiffimus \& in foro proftat, pro deliciis pucllarum altilis; licet BVFFONIVS e defcriptione RAIl, (qui fufcefcentem varietatem indicavit) in Anglia non dari putet. RAII tempore apud Anglos nondum videtur domefticus fuific, ut hodie propter lepiditatem eft, aque ac Lacerta aurata (Guermfey Lisard). Si enim fuiffet, certe indicafet ra Ivs. - Molares huic fpeci. ci ubique quaterni, prino quovis minimo. Nafus nudus in apice roftri; pedes nudiufculi, palmis fine pollicis rudimento tetradactylis. Cauda longitudine totius animalis, denfis hirfuta pilis. Variat colore fulvo, vel flavo - rufefcente, vel (immixtis pilis fufcis crebrioribus) gryfeo-fufcefcente, fubtus omnibus pallido. Gula alba. - Vagatur noctu; tota vero hyeme, licet in temperato Angliæ climate, conglobata dormit, ægre excitanda \& fomnolenta, etiam in loco calido. Avellanas duriffimas, quamvis vi- 
ribus imbecille, nullo notio erodit. Unguiculis in omni plano, etiam fupino, facile adhæret. - Eandem in America dari vix credas; fimilis autem videtur fpecics lethargica ibi vivere, quam fub nomine Anglis pro $M$. avellanario ufitato (Dormonge) recenfet I. BRIClELl nat. hift. of $N$. Carolina i. I3I.

35. MVS (betulinus) cauda longifima nudiufcula, corpore fulvo, fafcia dorfali nigra, auribus plicatis. TAB. XXII. fig.I.

M. fubtilis PALL. itin. Il. append. p. zo6. n. IT. B.

In betuletis Sibirix cum fequente, fed rarius obfervatus, pofteaque delineandus, totius generis facile minimus, \& vere fpecie diftinctus.

36. MVS (vagus) cauda longifima mudiufcula, corpore cinereo, fafcia dorfali nigra, auribus plicatis. TAB.XXII. fig.2.

Mus fubtilis PALL, itin. II. append. p. z05. Jp. 1 I. $_{0} \alpha$.

In betuletis campeftribus totius Tatariæ magne frequens, \& cum precedente, licet cauda ad fequentem phalangem referenda videatur, attamen propter torpidam a frigore indolem inter M. lethargicos referenda.

37. MVS (ftriatus) cauda longiufeula fubnuda, corporis ftriis plurimis parallelis, albo - guttatis.

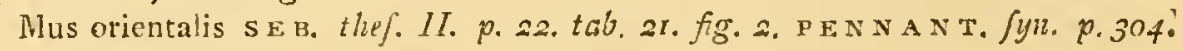

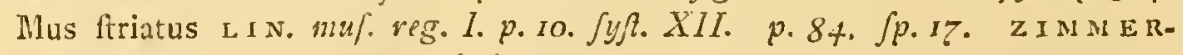
м A N. Zool. geogr. p. 5,6. Jp. 22 .

Pulchra fpecies, mihi nunquam vifa, \& vix nifi e Mufeo SEBAE cognita, quam tamen in campis circa Caucafum dari ex auditis fufpicor, \& ex habitu huc refero. Dubium tamen, fateor, circa hanc fpeciem incufit mibi, inter animalia e thefauris SEBAE in Mnlezm Petropolitanum translata, fub nomine M. indici ftriati, quod etiam Catal. Muf. preclandati p. 445. recenfet, inveniffe animalculum, quod certiflime Sciu- 
ri getuli pullus eft tenerior, cauda adhuc nuda murem mentiens.

\section{VI. \\ MVRES MYOSVRI.}

38. MVS (Pilorides) cauda longiufcula, fquamata, truncato - obtufa, corpore albido.

Mus albus ceylonicus B R I S Son. quadr. epit. p. 122. $\int p .8$.

Nlus amphibius* javenfis z I M M E R A A N. zool. geogr. p. 325 .

$\beta$. Piloris r r f o N. hil. $X$. p. 2. ed. min. $X X, p .3$.

Cavia mofchata P EN NANT. Cyn. p. 247 .

Caftor Piloris z I M $\mathrm{N}$ R M. Zool. geogr. p. 509 .

Specimen hujus fpeciei Ceylonicum, quod ab Americanarum infularum incola $\beta$. differre haud credo, quondam vidi \& breviter defcripfi in Mufeo Mercatoris Anzfeladamenfis C. P. MEIER lectillimo. Mole M. decumanum fuperabat, \& non multo crat inferior Cavia Cobaya 1. Porcello. Auriculce magnx, nudx, albæ; palma tetradactylæ cum verruca pollicari; planter pentadactyli, iffre, pollice craffo. Canda linearis, truncato-obtufiffima, quadripollicaris, fquamofa nuda. Color albidus, in dorfo leviter gryfeo-ferruginefcens, fubtus cinerafcens. - Acieoque fimillimus is, quos in America obfervarunt itineratores.

39. MVS (Caraco) cauda longa fquamofa obtufiufeula, corpore gryfeo, plantis fubfemipalmatis. TAB. XXIIT. $A$.

Species fequenti fimillima, e China in orientaliorem Sibiriam difperfa, quam figillatim illuftrabo.

40. MVS (decunanus) cauda longiflina fquamata, corpore fetofo gryfeo, fubtus albido.

Rattus fylveltris BRIS SON. quadr. epit. $p, 1 \geq 0$.

Rattus norvegicus Zoolog. britann. I. p. 99.

Surmulot в VFFON. hift. nat. VIII. p. 206. edit, min. XVII. p. I. tab. 27: Rattus gryfeuS PENNANT. Jyr. p. 300 . 
Hrc fpecies omnium hujus generis teterrima, ferocifima, nocentifima, certe cum aliis Indiarum noxis in Europam maritimam \& luxuriofam invecta eft \& nunc per Rufliam ufque omnem frequens, in Sibiriam tamen nondum penetravit. - In 'oppidum Jaïcenfe ante non multos annos, migratione legionatim facta, a parte occidentali adventavit ${ }^{a}$ ). Accepi poftidea, fimili migratione, ex occidentali item deferto, Aftrachaniam perveniffe autumno anni 1727 . paucis diebus ante terra motum $\frac{2}{13} \&$ $\frac{3}{14}$ Octobris ejus anni ibidcm \& ad omne Cafpii lacus occidentale littus obfervatum; credulisque hæc migratio inter portenta præfaga peftis, quæ iftam urbem deinde (A. I727-29.) vaftavit, habita fuit. Tranarunt eo tempore magnis turmis alveum Volgæ \& domos ita defubito infeftarunt, ut nihil ab iisdem tutum fervari potuerit. Mufculum tamen Afrachanix (qux aquis undique fepta eft) etiamnum deeffe GMELINvs jun. auctor eft (itin. 2. p. I62). - Ratti noftri decumani an illuc ex Europa, vel a meridionalibus terris venerint, non pronuncio; dantur certe in Perfia (unde farctos mifit GMeLINvs) \& ibi credo, inquilini funt, nidulanturque per Hyrcaniam in antris derelictis Hyftricum, qui colles arenofos, buxo (Camelis lethifero) confitos incolunt. Domeftici tamen ifthic vulgo non obfervantur, licet Racti vulgares \& Mufculi in habitationibus infeftifimi fint. - Petropoli, ubi immenfa Ratti decumani copia, etiam æftate in domibus abundant \& prolem educant, feniores vix ullis venenorum vel decipularum dolis eradicandi; efficaciffime tamen fugantur Cuniculis altilibus, quorum odorem, falutari antipathia, non amant, ut ipfe expertus fum, \& incolarum multi experiuntur; dum interim Mufculi cum Cuniculis amice vivant.-

a) PALL. Reife durch Rusfland. I Theil p. 304. 
Pondere M. decumani non raro octo unicas, immo fere libram medicam rquant. Afferes aliquot pollices craffos una nocte perrodunt; gallinas necant. Hyeme zellere largiori, fubtus pulcre candicante nitidi funt, fupra femper fetofiore atque hirto. Pedibus licet penitus fills, optime \& iponte natant. Palmo callo pollicari, ut in Ratto; cauda annulis fquamofis infra 200. Sunt hi verofimillime Mures cafpii, non multo minores Ichncumone egyptio, acerbi \& robore dentium infignes, quos in terra cafpia certis temporibus infinita multitudine accedere, perennibusque fluviis intrepide innatare, caudas inter fe mordicus tenentes, proditum reliquit a clianvs (bift. anim. lib. XVII. cap. I 7). Incertius, an migrationes Murium in Ponto \& Aegypto obfervatx, de quibus idem Lib. VI. cap. 4I. per eandem vel aliam fpeciem explicandæ fint?

4I. NIVS (Rattus) cauda longifima fquamofa, corpore atro, fubtus canefcente.

Mus domefticus major f. Rattus G ES NER. quadr. p. . 73r. R A I. quadr. p.21T. Rattus в R IS S ON. quuadr. cpit..p. 11 S.

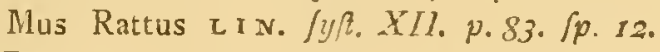

Rattus niger PE N A N T. Jyn. p. 299.

Spccics vel originis Europæx, vel ex America infulis illata, licet plures, \& omnium novifime Cel. ZIMMERMANN (in Zool.geogr.p. 223. (eq.) ex Europa potius in Americam transvectas contra Ill. L INNAEVM fuftineant, quod mihi etiannum dubitabile videtur; certe in Sibiriam nondum penetravit, immo vix Volgx tractum cgreffa eft orientem verfus, \& apul antiquos, licet Mufculi frequens mentio, nulla occurrit Ratti._- $\mathrm{Co}_{0}$ lore fingulari atro, \& pilo minus rudi a precedenti oppido diftincta, mole longe inferior; immo variat magnitudine. In de. fertis ad inferiorem Volgam regionibus varietas minuta, fape 
vix fex feptemve drachmarum pondus fuperans, aftatem ruri tranligens, in ripis preruptis maxime abundat. In fortalitii $\mathrm{Cu}_{\mathfrak{u}-}$ ricynenfis fuburbiis primo Mus fylvaticus in domibus autumo apparet, hune depellit minuta ifta Rattorum varictas, hos denique Mus decumanus. - morANDi calculos tabulares cryftallinos in vefica urinaria Ratri femel tantum obfervavi.

42. MVS (fylvatictus) cauda longa fquamofa, corpore gryfeo lutefcente, fubtus lateribusque abrupte albo.

Nus agreltis minor (iES N F R. quad): p. Z33.

Mus domelticus medius RA I. quadr. p. ars.

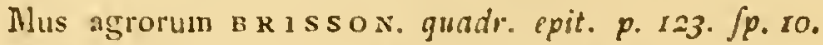

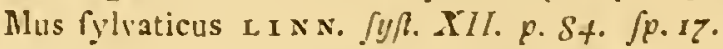

Rattus campeftris PENXAXT fyn. p. joz. Zool. britann. tab. 49 .

In borealibus aque ac temperatis, locis clivofis ficcis fylvarum, lucorum \& arbuftorum pafim frequens, cuniculans canali uno obliquo, duobus perpendicularibus absque egefta terra, ulnæ fiepe profunditate, folitarius. Hyeme ad horrea \& frumenti acervos veniunt frequentes, multumque damni inferunt. Magnitudine fecundum loca variant: in cultis, ubi fegetis beneficio grandefcunt, ad femunciale accedunt pondus; in defertis \& fylvis uralenfibus vix tres' drachmas fuperant. Cauda ad corpus ut 5 ad 6 circiter. Color (in ficcioribus, temperatis) fupra cleganter gryfeus, fubtus albus, linea ad latera difterminante paulo intenfius gryfea. In frigidis, gryfeo fufcoque magis mixti. Totum candidum circa oppidum Simbirsk ad Volgam obferravi. - In Sibiria ultra Irtin \& Obum mihi vix occurrit hee fpecies; attamen GMELNYS circa Ienifeam oppidum Auren huic aftinem ") autumno campos, hyeme granaria vaftantem, obfervavit.

Rattus

n) Defiriptionem MStam GMELXN ,cialis, pilis longis quidem, fed arete ad-

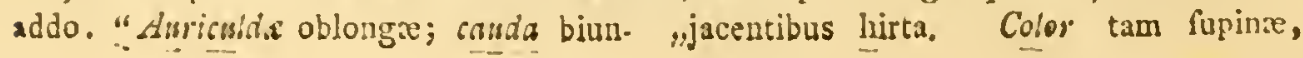


Rattus mefforitis PENAANT. $\int y n \cdot p \cdot 303 \cdot n \cdot 23$ I. non nif minufeula Muris fylvatici varietas eft; contra dimenfiones Ratto campetri apud Amidif. PENANT adtributas, mihi in M. fylvatico nunquam tantas obfervare licuit.

43. MLS (NIufutus) cauda longifima, fquamofa, corpore fufco, fubtus cinerafcente.

Mus Sorex II RIS S. qquadx. pp. p. 119

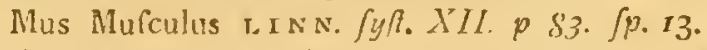

Souris rvFFON. hilt nat. VIl. p.309. cd. min XV. p. 175. tab.39.

Species per omnem Europam \& Afiam, fub omni fere climate inquilina, \& a nobis verofimillime in Americam invecta, ubi hodienum minus frequens Ratto. Variat interdum colore atro Ratti, itemque maculis trunci magnis albis, in folito colore; rarius tota candida oculis rubicundis. Videtur omni tempore anni generare: fub finem Decembris fepe \& adultiores pullo6 \& matres gravidas in codem loco obfervavi. Calidiffimi animalculi fanguinem ad 107. imo 109. Farenh. fervere, minuto thermometro fæpius expertus fum, media quoque hyeme. - Mammæ fex pectorales, quatuor ventris; quaruin duæ fere inguinales.

44. MVS (agrarius) cauda longa, fquamofa, corpore lutefente, ftriga dorfali nigra. TAB. XXTV. $A$.

PALL. itin 1. append. $p$.

Alia fpecies murium g melin. itin. I. p. 15r. tab. 29. f. 2. pefina.

Hæc fpecies defcriptione \& icone, quam dabimus, notior erit, antea non rite illuftrata, licet frpe noxia, \& in Germaniam quoque migrafie obfervata. Berolini circa annum (fi bene memini) 1754. tanta copia cum $M$. fylvatico hyeme „quam pronæ partis rufeícens, gula exce- „polteriores 5. digitos habent. - Agilli"pta alba. Myflax pilis albentibus compo- "mus, perpetuo rufpatur., „Gitus. Oculi majufculi, Pedes anteriores 4. 
ufoute in urbem aderant, ut fub ponticulis interdiu turmatim \& fine timore difcurrentes viderim.

45. MYS (mimutus) cauda longa funamofa, colpore fupra ferrugineo, fubtus albido. TAB. XXIV. $B$.

P A L L. itin. I. append. p. $45 \%$. $n$ \%

In hac phalange, immo præter M. fubtilem in toto genere minima, neque hoc iplo multo major, ut deinde videbimus.

Supereft ut de dubiis Murium fpecicbus difpiciamus. Non quæram, quosnam mures Antiquiores fub nominibus Gingilix, Zegeria, Giligrns, cet. intellexerint. Inter recentiorum fpecies, haud tane copiofis, folus fere Mus norvegicus senA (thef.ool.II. p.64. tab.63.ffg. 5.) vere \& ablolute dubius manet. LINNAEI dubia fynonyma fupra uteunque redegi; \& MESSERSCHMID 1 o brevirer, \& obfeure indicatas fpecies adtuli (Not.a.). - Vix autem dubito in America adhuc plures fupereffe nobis ignoratas fpecies. Id faltem analogia fuadet, proterquam quod aliqux jam imperfecte indicate proftant; ut aqua-

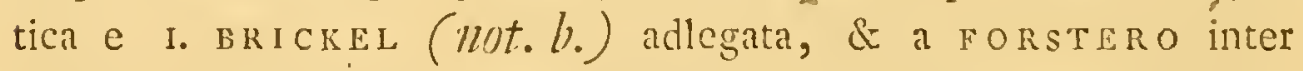
Animalia borealis Americe recenfitæ. - Vix plures ex Africanis novimus. - Itaque eos, qui Hiftorix naturalis caufa peregrinantur, excitari vellem, ut diligentiorem in animalculis fubteraneis navent operan; qux licet defpecta, tamen ufu, quem in aconomia Nature preftant, noxisque quas homini inferunt nequaqum fpernenda funt, \& ftudiofos non indignis, circa mores atque vitæ genus, inventis ditabunt.

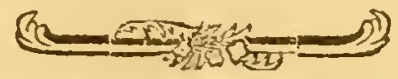




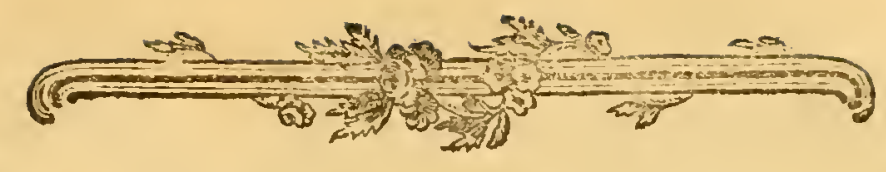

\section{A R C T O M Y S}

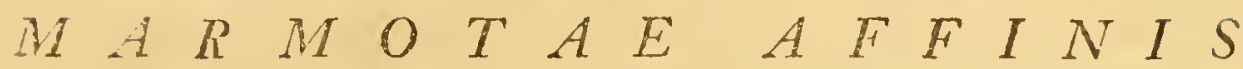

\section{R V S SO $\mathrm{OSI}$ A T I C $\Lambda$.}

Marmota alpina Eurosx primus BRIssonivs \& poft cum Ill. BVFFON ${ }^{a}$ ) diftinxerunt animal afine, quod ante illos Zoologis, obfcurum fuerat, quodque KLEINIVs etiam (in hift. nat. Muris alpini Prodomo biftorice avimm adnexa) cum Alpicolarum Marmota confudit. Nomine BVFFonIvs ufus eft polonico (Bobak, rectius Bobuk), quod Malorollis \& Cofaccis Baibak vertitur, quum notior \& propric Rullis ufitata appellatio fit Sfuròk ${ }^{b}$ ). Polonis RzACZINSKYo prodente etiam Smiftels a voce nuncupatur. Tataris vulgo Sunir vel Smmer \& Sugur o compellatur, quod forte Rusficre, quam diximus, appellationis radix eft. Mongolice Tarbagàn ${ }^{d}$ ) audit, quæ vox in Sibiria orientali etiam apud Rufios inoluit. Tanguticum denique nomen $B \int c h \dot{d}$ fonat. - Habet hoc animal, nobis vacuo nomine Arctomys appellandum, quod, preter modo dictos auctores, pauci memorarunt, tantam cum Marmota fimilicudinem,

\section{$N 2$}

i) BRrsson. quadr.p.165. BvFFon. rye ed.II. Vol. II. p. S4o. e relatione hifl.nat.vol.Xlll.p 136. edit.min.XXVI. Angli Ioh. W INTER Zoorik fcripfit, p. $17 \%$ tob is. mala. PEN N A T. Jyn. quod anglico ore Surik pronunciabitur. quadr. p. 268 . denuo, F ORSTERo præ. ") Sogur RUBRUGUIR voy. en Ta. eunte, Arctomyen cum Marmotahelvetica tarie p. 25.

commifcuit, ut fecerat KLEINIVS.

d) Perperam Tarbiki GER B I I I ON IO

b) WIISEN. Noord - en Ooft-Tata: apud D U HALDE p. 305. 
ut nif conftantibus notis, ungue pollicari, vellere \& vita genere differret, pro ejusdcm varictate haberi poffet. Inclinavit in hanc fententiam BVFFoNivs, idemque Monacen feu Marmotam americanam non magis difinetam fpeciem putavit, inmo Citilum quoque ex GMELINo nomine fibirico (Ierrafchka) iniroductum, eodem fere redigit. Sed qui has onnes fpecies viderit, ut ego vidi, fatis perfuafum habebit dintinctinimas efic omnes. Hoc de Aretomye \& Citillo e deferiptionibus noftris, Marmotæ alpeftri comparatis patcbit. De Monace autem Americano CATESBAEI atque EDWARDSI icones ") \& defcriptiones, locusque natalis hujus fpeciei calidus affatim probant. Denique cum PENNANTo ${ }^{f}$ ) fuftineo, Marmotam parvam canadenfem, quam fupra Empetram cognominavi, neque cum Marmota alpeftri Helvetia, nec cum Aretomye vel Monace, imo ne cum Citillo quidem, cui facie, colore \& magnitudine pro. xima eft, fpecie efle confundendam $f^{*}$ ).

Arctomys non, uti Marmora, in alpeftribus elatis, fed in clementioribus, apricis montium tractibus vivit \& meridiancs fitus fequitur. Obfervavi is prefertm in regionibus abundare, ubi colles fchifto cotaceo vel arenario horizontali, omnium mi-

e) С А т в S н. carol. Il.tab. 69 . append. 28. EDIVARIS av tab. IOf. PEN N A T. Jyn. p. 2\%o. n. 198. Marmota marylandica.

f) Murmota Quebecenlis PEN NANT. fyn. p. 270. n. 199. Sifleur LA n ON T A N it. I. p.233. Ill. B V F F O I V mihi hanc fpeciem cum Monace confudifle videtur, neutra forte oculis vifa. Potuit STELLE. R V s eadem in America parte, quam adtigit, audita, Citillus ibi vivere credidifle.

$f$ i) Peculiare ex murino gcsereanimal, quod juga moutiun Atluticorum Africa colit, \& Marmotis rel Citillo affine vide.

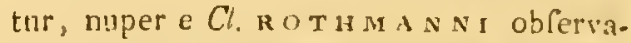
tione primum innotuit, qui Murem Gunds arabico nonine $\operatorname{cog} n o m i n a v i t$, breviterque determinar it: "nasuitudine cuniculi, cau"da abbreviata, pedibus omaibus tetrada,etylis, corpore toto teliaceo rufefcente, ,auriculis truncatis, apertura larga ovasa,.,

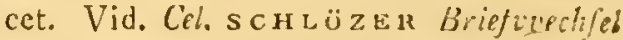
Vol. 1. ^.339. Accuratiorem \& fufurem hujus a. inalis def riptionen omnes Zoa. logiae fautores mecnus optabunt. 
nime featuriginofo confant; poft hos amant calcareos \& margaceos alliores \& ficciores montes. Sed ab arenofis, fylveftribus, udis, \& omni deferto falfuginofo, nudo abhorrent. - Abundant primo in collibus a Carpathico jugo per Poloniam \& Ruflam auftalcm fparfis. $\Lambda d$ Boryfthenem maxime in regione inter Su. lam \& Supoy fluvios abundare dicuntur ${ }^{g}$ ). In clatis camporum N 3

g) Defaription a'Ukranie par le Sieur de BiAUnLAN (Rowen 1660. 4.) p. So. feq. Lacum ubi de Aretomye luie dixit, apponam: "Entre les riviéres (de Sula \& "de Supoy, qui tous deux fe rendent dans , Ie Nieper) Re trouvent de perits animaux, "quils appeilent en leur langue Bobaques_,ils fe retirent dans terre comme les I.a. ,pins \& a mois d'Octubre ils font leus re"traites dans leurs tanieres, dont ils ne "Fortent qu' a la fin d'Avril, auguel temps "ils courent ia campagne pour cherclice "leur vie \& paffent ainfi l'hyver dans ter. ${ }_{2}$ rc \& mangent ce qu'ils ont amafié l'ćté, ,ils dorncut lougtrmps \& lont lort ceco. "nomes, "yant un ecriain inftinet de faire „leurs provifions; en furte yue l'on diroit, "lu'ils out des tilia es parmi eux, carceux ,qui font pareffenx, ils les font concher "fur le dos, \& leur chargent fur le ventre „une graude poignéc l'herbe fèclie, que le „, Bubalis ticut embrafie de fes pattes \& pour ,phise propres ent parler de fes mains, car "ces animax r'en aident prefique comme "le'; finges des lours, nuis les antres la trai"nene par la uuecue julques à l'entrée de "leur tanier, \& antrf cot animal leur fert ,de traine:us, \& de'à lui lont porter l'her"be dans leur cachettes: je les ai veuës "plufieurs fois fare ce mefnage \& me fuis „arreté par curiofité à les contempler des ,.jouruées entieres, \& inefinc j’ay fait fouyr ,jufques daus leurstaniéres, pour ioir leurs „apartemens, \& j'ay trouvé force trous, "feparés comme par petites clianbrettes, ,les unes font leur nagazins, d'autres „leurs fervent de cimetierre \& de fepuleres, „Ou ils retirent lenrs morts, \& les autres "font appliujués à quelque ufage particulier. ,IIs logent huit ou dix mefnages enfenble "\& ont chaqu'un leur demeure à part, ou „,ils vivent avee grande police \& leur re„publiçne ne cede en rien a celle des mou"ches \& des fourmis, dunt on a tant éferit. "J'adjoufteray que ces animaux font tous ,hermaplurodites \& eftans pris jeunes au „mois de May font faciles a apprivoifer; "ils ne couftent pas plus au marché d'un ,fol ou fix liarts, j'en ais nourry pluficurs, "\& font jolis dans la maifon \& donnent ,autant de plaifir que feroit un finge ou un „efeurcul, \& mangent mefine pafture \& "mefine forte de nourriture. J'oubliois à "dire, que ces animaux font fort ruféz, ,, car ils ne fortent jamais qu'ils n'envoyent „une fentinclle perduë, qu'ils pofent fur "quelque éminence pour avertir les autres, "pendant qu'ils font à pafturer, \& lorfque "la fentinelle apperçoit quelqu'un, ulle fe „adrefle fur les pieds de derriere \& fifle, par 
aufralium inter Boryfthenem \& Tanaïn, maxime ubi tumuli fepulcrales abundant, func frequentifimi; quia in his tumulis mollem terram facile fodiunt, \& exaltato fitu cuniculi contra meteoricas aquas tutas fe norunt. Abundant porro in toto illo collium tractu, qui a Tanaï fecundum Choper fluvium verfus Volgam pergit, ubi licet copiofe capiantur, copiofiores tamen quam ullo alio loco, fereque innumeræ vivunt, prafertim in regione rivorum Kamenka \& Sawalla, ubi colles calcareis ftratis altiores Schifto arenario confant \& graminofo cæfpite funt vefiti. In montibus calcareis fecundum Volgam Cafaniam fere ufque, minus tamen frequentes occurrunt; crebriores in promontoriis cotaceis circa Uralenfis jugi partem aufraliorem, in fumina Sok, Kincl, Samara, Iaik \& Saknaram fparis. Dcinde magno intervallo per Sibiriam mili non appertierunt, ob borealio. rem fitum, quem favente quantumvis regione, fugiunt. In auftraliore deferto tamen, per magnam Tatarim, clementiora ju-

„ce fignal ils s'enfuyent tous dans leur „fort \& elle aprés, \& y demeurent autant ,de temps qu'ils penfent que le monde „foit paffé, avant que de reffortir. La di. ,ftance de ces deux rivićres de la Soul. \& „Supoy, n'eft pas plus de fix liencis, \& „du Nieper jufqu'aux confins de la Mofco. ,vie 11'eft pas pluś de 15 à 20 licués de di,ftance, là ou fe trouvent ces animaux qui ,vivent.comme j'ay dit \& ne s'en trouve ,point ailleurs. 11 ne fait pas bon galoper ,en ces quartiers là, parce que tout cela eft ,plein de petits trous, (comme eft me ga. ,renne) les chevaux les rencontrent fous ,leurs pieds, tombent \& font en danger „,de fe rompreles jambes, \& j'y ais été pris ,plufieurs fois. Les payfans les chaffent en
„May \& Tuin en cette façon; ils jettent ,cinq on fix fceaux d'eau dans leurs tanié,res, ce qui les force de fortir. \& mettent ,un fac on un filet à la gueule da tefnier „ou ils fe prennent; les perits, tant privés "qu'ils font, ne peuvent oublier leur natu„ral \& au mois d'Oetobre, fi on ne lesti, ent attachez, ils fe terriflent dans la mai,fon \& fe vont cacher pour dormir long,temps, \& peut-eftre, quiles laifieroit fai„re, ils dormiroirent fix mois entiers, com„me font les Lerots \& les Marmottes. Les „miennes y ont été quelquefois bien deux ,femaines, \& aprés les avoir bien cher,,chées on trouvoit un trous, que je faifois "fouyr pour les reprendre \& je les trou. ,vois comme toutes fauvages., 
ga ubique occupant, iterumque intra Rufforum fines circa Altaï. ci juģi promontoria, ad Orientem Irtis fluvii, reperiuntur, parciores primum ad Ubam, frequentifimi circa Tomum in Kufnecenfi regione. Ultra Ienifeam denuo, ad Bä̈calem ufque, intra Sibiriæ terminos, propter fylvofam locorum naturam, haud vifuntur; fed numerofifimi funt in transbaikkalenfi regione, circa Selengæ collaterales fluvios, in planitio Bargufinenfi, \& in Davuria campis, maxime circa Argunum fl. \& Lacum Dalay. Dicuntur ctiam in montibus apricis ad Lenam, maxime vero in Kamtfchatka ${ }^{k}$ ) dari. Apparet in univerfum hane fpeciem vix ufque ad $55^{\circ}$. latitudinis borealis vivere; contra in montofis interioris Afia late ad aufrum difpaiari, e nomine, quo Tangutis noti funt, eque Bucharorum \& Sinenfium relationibus didici.

Cuniculos fodiunt profundiffimos, ideoque in ficcifimis tantum collibus habitare poffunt. Plures vulgo fimul communem aditum habent, qui obliquis flexibus ad duas, tres, pluresve orgyas in profundum tendit, tumque in ramos, ad fingulorum incolarum nidum ducentes, finditur. Hinc inde laterales etiam reditus in lucem emergentes obfervantur. Multi tamen unico canali contenti funt, quod prefertim Cofaccorum dolus probat, nivalem aquam ex altiori loco in cuniculos dirigentium, quo nullis lateralibus fuffugiis preparatis, eodem oftio prodire coguntur. Perfodiunt cxterum non folum mollem terram, fed etiam lapidofa firata; unde ad Uralenfes montes metallifofforibus famulantur, qui circa antra eorum crebro indicia cuprex minere, in ftratis horizontalibus latentis, legere folent. Magnos enim. comminutorum ftratorum cumulos egerunt, ut regiones, ubi abun.

h) íraschenintiof Defor. Ler Befchr. dir Lürder. Fimatch. Kasintfch. Ed. rus/.vol.11. p. 21S. STEL- p. I26. 
dant, fape tota inde colliculofie appareant. Ubi difficilior \& fixofia regio, ibi maxime communi labore fodiunt, $\mathbb{E}$ in uno antro fape 20 vel quadraginta Aretomyes fociatim vivune, commun gamdentes exiru, rerlus nidos ramilicato. Hoc maxime obfervatur in Davuria, ubi ideo Tungufi magno fepe labore (fumo prins, ad fuffocanda animalia copiofe immilfo) cas familias effodiunt. - In molliori contra folo diftinctis cuniculis firpe folitarii, rel pauci in familian coacti virunt; femper tamen, ubi aphum tumulum invenerunt, plura in exiguo fpatio antra invenias. - Nidos prefertim autumo, purillimo \& tencrrimo feno tanta copia infarciunt, ut ex aliquor diverticulis equus per noEtem fatiari poffit. Entue communis fima, collectun fub fe fonum in dorfum fponte provolutos quafi vehiculo tenere, fociorumque cauda mordicus apprehenfi, rel etiam dentibus cum focia concatenatis ad antra trahi. Quo quidem KLEINII (loc. cit. p. 234.) impedimentum a directione pilorum contraria objectum removetur; res tamen iptit fide dignifimis teftinoniis, ut credatur, indigeret.

Interdiu, maxime dum Sol matutinis \& meridianis horis calet, antris cxcurrunt, prbulantur, colludunt, numquam timen longe a latebris difectunt. Homine vel fera confpecta ad antra gravi et inepto curfu refugiunt, ubi ad iplum oftum creeti, vel ti propius iri videant in aditu cuniculi fedentes, procaculi s cum crebro fittulatu, plerumcue pre timore geminato, aufeultant, ita ut prope accedere ventorem patiantur, \& filopo demum explofo, fepe morientes, in antrum refiliunt. Plerumque criam in regionibus, ubi copiofis familis vivunt, unum ad comrune antrum excubias agentem videas, dum reliqui fub dio paicuntur; ut qux ST UMpFIvs apud GESNERUM (glladr: p. 7 46.) 
p. 746.) de (peculatore Marmotarum expofuit, etiam in hanc fpeciem quadrent.

Aretomys pabulo mere vegetabili fruitur \& ab omni carne (qund in familiaribus mulertics erperius fum) abhorret. Amant plantas oleraceas varias, \& avidius reliquis campeftribus plantis depafcuntur Polygonum aviculare, Atriplices, Chenopodia, I'lan. taginem, Millefolium, \& parcius Serpyllum atque Salvias. In Ruffia auftraliore Bitum virgatum cjusque baccas ita præferunt, ut his inde baccis nomen a Rufis inditum fit (Surrotfciog'e Fagroly). In Davuria Iridum variarum pumilarum radices vere fodiunt \& copiofe cuniculis ingerunt. Domi detentæ Brafficam \& panem impenfe expetunt, \& lac avidifime, fine ullo tamen murmure, potant, cui \& recens captæ ftatim inhiant, eqque maxime mitefcunt. Aquam oblatam nunquam bibunt, neque fi nullus diu potus offerretur, fitire funt virx. Sed propriam lambunt urinam, \& in campis pofitæ humum pinguem a pluvia madidam avide vorare funt vifæ.

Eo vero gradu focialia funt animalia, ut etiam plura $e$ diverfis regionibus \& Camiliis angufo fpatio incarcerata, licet plures fint mares, vix inter fe rixentur, recens admiffos dentibus teneriter vellicando quafi deofculentur, atque ita facile adfuefcant, ut etiam in laxiore deinde loco liberiores communi confenfu fpelæa cavare \& confertim cubare foleant, neque de pabulo difceptare velint, etiamfi alter alteri palmis prehenfam offam fæpe ante os preripiat: quafi omnia inter animalia fuæ ftirpis comcommunia efre velint. I Iinc etiam in regrionibus, quas cuniculis fuis idoneas experiuntur \& ubi herbæ ipfis gratæ abundant, copiofi fine pugnis, immo familiatim in communi fubterranen la. byrintho cohabitant. Qua indole præcipue differunt a Citillis, 
alias fimillimis, fod minime fociabili animo dotatis. Sunt antem hi carnium, ut videbmus adpetentes; contra Mlarmote, mere plycivors, illud cum animalibus ruminantibus, alisque folo resetabili mutrimento vicam lutencancibus commune habent, ut gresariam vitam amont, propecopue pafcua munquam invidiolia pugnent.

Arotumỵs videtur tardius paulo, quam Cicillus, prurirc. In codcm cnim climate, dum hos (incunte Aprili) jam venere occupatos obfervabam, ittorum accopi marcs, quibus coftes, intra abdomen adhuc latentes, vix turgelecbant. Attamen in aultraliore Rullia, ubi ver maturius, Immio menfe jam pullos dimidiam matrum molem aquatntes copiole habui. Oblervavi matres in tumulis plerunupuc cum unico pullo; verofmillime tamon plures pariunt: oftonarus cnim mammarum numerus pro paucis pullis nimius forct. Interim sravidas nunquam procurare potui, ut de furcuum numero cercior clïam. Sint autem mulco copioliores in hac finceie fomina, quam mares; unde licet paucos pariant, valde camen multiplicare necellario debent.

Quamvis por climata non minus varia, quam Citilli, difperla vivat, tamen vix ullis rarictatibus, certo non fecundum resiones, ludit hec fpecies, fed mbique cjuedem fere pili, coloris :tque magnitudinis occurrit. In orientali sibiria pilum, ut ommia hujus ecros animalia, largiorom habent; fe Kufnecenfes, at palliceos ufus profertim expecitx, magis nigricances tint, abundantia longiorum pilormm; fod cadem varietas mihi eciam ad lamain E Choper H. pathim oblata elt, nigredine circa capur incenfiore lingularis \& plerumque robuftior.

Ea qua in dometticis, quas frequenter alui, quaque etiam Moleuam et Pctropolin lepiditatis gratia adferuntur, oblervari 
poffunt, non abs re erit expofuiffe. Captæ, ctiam adultæ, intra paucos dies privæ fiunt, juniores autem ftatim familiares. Sunt tamen mares paulo ferociores feminis, neque mordax ingenium plane deponunt, cujus fexualis indolis contrarium in Citilli deferiptione videbimus. - Homini ita fenfim adfuefcunt, ut fponte accedant, blanditias requirant \& præfertim fedentes fub pectore \& gula feabi amant, voluptatem etiam pandiculationibus teftantes; fi vero fub axillis titillentur, morfitatione levi \& fubgrunnienti murmurc. In dorfo, quantumvis blande, tangi timent, \& $f_{1} \mathrm{cx}$ improvifo id fiat, cum grunnitu fere porcelli fugiunt, vel in poftica faltim eriguntur, quod etiam adtonitæ vel iratæ faciunt \& acutiffimum fimul fiftulatum iterant. Sedentes palmis fefe præcipue defendunt, quibus infeftum quoque baculum removent, raroque mordent. Clunibus etiam curiofx crebro infident \& comeftilia omnia palmis retinentes depafcuntur. Aeftate voraces funt; fed pinguiores, præfertim hyeme, parciffime comedunt. Quæ primum captæ immodice lac ingurgitarunt, ægrotare \& diarrhœam inde pati folent; adfuetæ nonnili parce codem utuntur. Pane lubentius fecalino nigro, deinde Braffica \& pomis precipue ali volunt. - Excrementa, quibus curvato trunco elataque cauda fe liberant, femper in certo conclavium angulo deponunt, leporinis fimilia, globulofa, fabis æqualia; veriffimumque eft certa in antris diverticula pro cloacis, in focictate viventium communibus, fervirc. Urinam vero propriam omnem ore haurire folent. - Territis curfus faltabundus ineptus, crecta cauda, \& ita rufticus, ut in obvia ubique inpingant. Per humiles fiffuras contra, ubi vix caput oblique transmittcre qucunt, reliquo corpore in planum dilatato facile \& dexterrime enituntur, validæ in genere viribus \& ad ictus cafusque, ut vitæ genus requirebat, ro- 
butta. Pedibus pofticis fe crebro fobunt, os rero palmis demulcere rarius vituntur. Dormiune ledentes in clunibus, trunco in globum curvato, rottroque intra palmas of femora ulique ai alvum rcondito. Si nullas invencrint latebras, e ftuppa \& lana congeltis nicium conficiunt, quem aliqunndo circa menliv fulcrum artificiole implectere vilix funt, quaris velpera denuo fternentes \& adomantes. Noitu, if frigida ett, fepe in lectos cubantium, a terra licet clatos, magno lito labore adicendunt ${ }^{i}$ ) ue calore fruantur. Imo fio cicuratam, quam dominus lub tentorio xitivare coaens lecum habebat, libere in campis ambulantem cunculum fibi parafe, in quo interdiu per intervalla fomnum capiebat, nofu vero in tentoria ad cubantes homines accedebar, tragulis fefe interens. Eadem adpropinguante amtumno pelliceos centones, Ituppam \& lanificia \& tentoriis furabacur, nidoque ingerebar; quod \& in domibus vireness faciunt, gua fape tota reltate ragie, non ante de cuniculo cogitant, quan monente illo anni sempore. Scio duplici exemplo domefticam Aritomyn in abdito quodam loco tacite parato cuniculo delisuile, totamque per hyomem pro amifia habitam, vere teperte in domo denuo apparuitio, fed magis efferatam \& priftna faniliaritacis ohlitam.

Appare hine non fola caloris deminutione, quam initio ausunn nondum fentum, vel hypocauti faltim heneficio fallere pollone, renienre hyome condi \& fommo dedi Arítomyes rque as Alarmotas, fed inltincitu quodam a plenitudine peniente, que Lrios quoque in latbula \& fpontaneum jojunium cogit. In

i) Fabulas de Atciomye explołens cui con tolum inspitilima fuat, fed loca

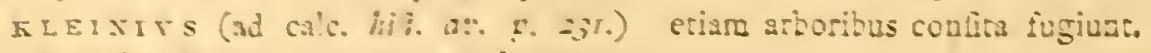
ipte filo nüruit, das abotes fordere, 
cubili bene calefacto, ubi latere nequeunt, fervarz non cbdormifcunt, neque a cibo plane abftinent, fed (quod in prepriis \& alienis obfervavi) mane, poft meridiem \& vefperi per quadrantem circiter hora cxtra nidum ambulant, ad homines accedunt, \& canis inftar palmis ad genua crećtx cum murmure demulceri fe poftulant; parcifine autem oblatum cibum gutant \& quafi naufeantes abjiciunt. Plurimum tomporis \& totam præfertim noćtem profundo fopore opprefla tranfigunt, infigni fæpe cum ftertore.

Arćtomys femella quadriennis, pinguifima, quam hycme 1768. familiariflimam alui, \& in qua (conclavi ad 120 \& $125^{\circ}$ Scalce de L'Ifliance calente) thermometrum inter inguina infertum ultra 10.. calefeclat, d. IV Deccmbris, infigni tum regnante gelu, experimenti gratia in frigidifima camera ad portam domus pofita, undique claufa \& obfcura, vixque $\sigma$ ad 8 pedes lata, includebatur. Rofit primo portam \& inquietifima fuit; $c x$ objecta deinde fuppa nidum in angulo paravit, e quo nonnif raro prodibat, præbitum panem rarifime appetens. Infequentibus diebus frigus, quod VI \& VII Decembris ad I68. port XIX vum cjusdem menfis, aquilone penetrantifimo fiance, infra I70. ftetit, bene tulit, folito more viguit, nido fubinde exiens, pixfertim quando iranf́cuntes homires exaudiret, quos cla. ro fibilo appellabat. Nec quidquam de familiaritate fua, pa. rumque de calore amift. Initio Ianuarii, majore \& confaniore frigore rarifime nido cxiic $\&$ vix quidquam comedore voluit, femper tamen extra fomni tempus vegeta. D. XVI lanuarii frigus tandem ad $187^{\circ}$. mercurium depreflit, \& tamen non obtorpuit animal, fed in nido fedens \& cum familiaribus, qui infpiciebant, colludens, folitam alacritatem fervarit. Nidus ta. 
men haud calebat, fibique relicta obdormifcebat facile. Continuante per biduum xquali frigoris gradu paulo torpidior evafit, xgrius fomno excitabatur; attamen \& tunc, pluribusque poftea diebus, nido expulfa ambulabat, \& alvi faburram, licet vix quidquam gubtaret, quotidie fere deponebat, interdum quoque afferes rodere audita eft. D. XXX Januarii, quum nihil mutaretur, inter femora detentum thermometrum inter 108. \& $109 .^{\circ}$ caloris dedit; d. vero 1 Februarii, quum tandem animal mactare conftituifiem, per vulnus abdominis infertum ad $93^{\circ}{ }^{\circ}$. (feu Scale Farenheitianæ $100 \frac{1}{6}^{\circ}$ ) calentem demonftravit; ut igitur frigore ultra menfem continuo calor maturalis, quem media xftate in domefticis exploratum femper circiter $92^{\circ}$. (Farenh. 102 ${ }^{\circ}$ ) deprehendi, vix duobus gradibus imminutus fuerit \& depreffus ad. gradum, quo xitate recens captas, macilentas calere aliquoties obfervavi (100-100 $\frac{1}{2}^{\circ}$. Farenh.)

Perfpicitur hinc facilc non quadrare in Arctomyn, faltem domi educatam, qux circa animalia hycme torpida, præfertim M. quercinum, afferuit BVFFonIvs: "calorem fanguinis iis non „effe multo fupra temperiem aëris externi, immo fæpe inferio,rem, Hoc unicum doleo, defuiffe hactenus occafionem experiundi, an Artomys recens capta, quæ nondum domeftica vita \& fermentato pabulo alterata eft, a frigore externe adplicato citius, quam domi educata, adficiatur, eodem modo atque in Citillis experimentis adftruendi locus erit. Et licet dicendum fit Citillos fpontaneos externo frigore calorem cito aunittere, nunquam tamen tanto gradu, quo BVFFONIVS perhibet, amittunt \& temperatiore aëre cito ad calidorum animalium teporem redeunt. - In Glire Romanorum, qui in cella glaciali omnium citiflime \& una rocte in globum convolutus obtorpefcit, \& in- 
tra aliquot horas calore aëris æftivi revivificari poteft (ut ipfe fum expertus), tamen fanguis, aliquot poftquam refocillatus eft horis, ä̈re vix ad $120^{\circ}$. ( $68 \frac{5}{5}^{\circ}$. Far.) tepente, ad $96_{2}^{\circ}{ }^{\circ}$. utriusvis Scalæ, adeoque multo magis atmofphæra calet. De Vefpertilionibus, qui hyeme plane obrigefcunt, idem valet: in V. Noctula v. gr. die fubfrigida plurics exploratum calorem fanguinis ad $90^{\circ}$. (102. Far.), in Pipiftrella, matutinis horis dum aër effet

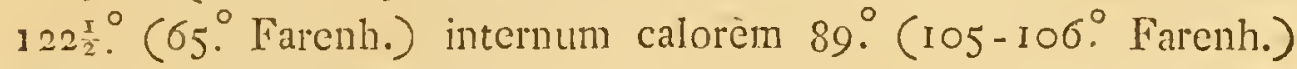
notavi. De experimentis in Erinaceo captis alibi dictum eft ${ }^{k}$ ) $\&$ in pofterum dicetur.

Supereft ut de modis capiendi Arctomyes quædam addantur. Lepidifimus eft dolus Calmuccorum, qui ad antra, qua habitata obfervarunt, circa introitum clavis ligneis adfigunt faccum e funiculis equino pilo tortis \& in rete rarifimum implexis, magnitudine quæ exacte capiat animal, cum apertura in extremitate robuftiore funiculo in circulum firmata, ea amplitudine ut caput transmitrere poffit. Aretomyes, ftupida ut funt, antris cxcuntes faccum fine timore ingrediuntur, pedes per laxas retis areas, caput vero per deftinatum collare exferunt; quo facto in facco, quafi ftudio infertæ, hærent, neque extricare fe amplius poffint, \& fic a venatore manibus prehendi, conftrictoque poftice facco vivæ quocunque deportari poflunt. - In auftraliore Ruffia aliud exercent lethiferum hæc animalia decipiendi artificium: nempe femicanalis vel canalis ligneus cuniculi oftio adaptatur \& firmatur, fupcrius in medio incifus, ubi oblique imminet trabs in cuncum acuata, cæfpitibus fupra impofitis gravata, quam horizontale lignum, àlio ante aditum perpendiculari retentum, incifuræ infeftam fuftinet. Exiturum animal re.

k) Nov. Comment. Petrop. Vol, XIV. p.57\%. feg. 
tinaculum aperturam impediens rejicit, quo liberata trabs per incifuram inciciit atque animali in ligneo tubo hærenti lumbos frangit. Hunc apparatum in Icone noftra $(T a b . V$.$) cxprimi$ curavi. His ita copiofæ capiuntur Arctonyes, ut adipem, ad coria emollienda unguentum præftantifimum, duabus haftulis in Libran, \& pelles $5 \mathrm{vel} 6$ haftulis, optimas nigrefcentes $8 \mathrm{vel}$ denis, venditent. Comeduntur etiam carnes, non folum a Calmuccis, fed a Cofaccis ctiam \& Maloroftorum plebe. Et ipfe expertus fum, notavitque misserschMIDIvs, coctas pariter \& aflatas fatis fapidas effe, præfertim qua non nimia pinguedine, quam flavam habent, fracida fucrint. Utique guftu proxime ad Lepores accedunt, quorum externe quoque hircinum odorem fere amulantur. Calmucci pinguifimos in deliciis, immo fere pro medicina habent. Contra Tatari Mahometani non foluni a carne abftinent, fed ctiam hofpitio Arctomyes colunt, unde in collibus, qui funt in vicinia pagorum Tataricorum, maximopere multiplicantur. Habent cnim vicinian horum animalium inter auguria felicifima, interque peccata numerant, ut Hirundinem vel Columbam, fic \& Arctomyes occidere; quum contra Citilli circa domum nidulantes iisdem pro deteftabili omine habcantur. Iakuti, Koræci \& Ruffi auftraliores pellibus Arctomyum frequenter in veftimentis utuntur, robuftillimis pilumque tenaciter retinentibus. - Omnibus vero partibus fuis vilia funt $\&$ defpecta animalia.

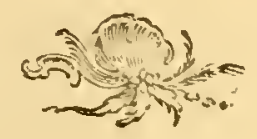




\section{E S C R I P T I O \\ MURIS ARCTOMYOS. \\ Tab.V. E $1 X$. fig. r. 2. 3. $\left.{ }^{*}\right)$}

Mngnitudo Marmotæ alpinæ. Caput depreffiufculum; roftro craffo, brevi, obtufo, nigricante; vertice plano, buccis parotidibusque gibbis.

Nafus, cum ambitu oris, niger, cano fubtiliter pilofus, nudiufculus, fupra gibbus.

Labium fuperius ufque ad nafi feptum nudum ftria canaliculatum, bilobum (Tab.IX. fig. I.) Dentes prinores magni, detecti, fupra infraque rotundato - truncati, fuperiores majores, ftria obfoleta exarati, albi, inferiores extus fulvi. Molares fupra utrinque 5, infra quatuor. Linguı craffifima; palati rugæ prominentiffimæ, circitel 12, quatuor priores integræ.

Myftaces exigui, fparfi, nigri, quinque ordinum. Verraca utrinque fupra canthum oculi anticum, pilis nigris plurimis fparfa. Verraca parotica transverfalis triplex, fecis tribus majoribus. Subgularis tripunctata, medio pilo albo, lateralibus bifetis nigris,

Oculi minufculi, ad verticem utrinque prominuli, palpebris medio cute albida nudis. Periophtbalminam breve, vix corneam adtingens, vafculofum, caruncula fufcefcente produ. ctum. Irides brunnex, \& albuginis halo fufcus.

Aurium meatus pellc connivente claufi; atriculle fupra aperturam parvulæ, óvatæ, craffæ, molles, gryfeo-albido villofe, pilis marginis longioribus.

*) Icones citatæ $T a b .1 X$. naturalem magnitudinem referunt, 
Corpus breve, depreffufculum, ventricofifimum, extenfo animali latum, quaffatum. Artuls breves, cutis a cubitis verfus thoracem \& a genubus verfus hypochondria laxe tenfa. Verruca unifeta in ulna exterius verfus carpum.

Palme fubpentadactyle, pollicis phalange breviffima, latente, ungue mutico, prominulo (Tab. IX. fig. 2. A.); vola callis pulpofis, ftriato-vorticofis, magnis, tribus ad digitos, unico fub carpo, maximoque itidem carpino ad pollicem (ibid.B.). Plante pentadactylæ digitis tribus mediis fubæqualibus, fubtus (fig. 3.), ufque ad calcaneum nudx, callis tribus ad digitos, duobus obfoletis fub metatarfo pollicis \& obfoleto ad tarfum digito extimo refpondente. Digiti omnium pedum ad medium nudiufculi, annulato-fubfquamati, pilis rigidis pronis fupra mngzles longos, teretiufculos, fubtus planos, nigerrimos; in pofticis breviores \& fubtus excavatos.

Canda breviufcula recta, rigidiufcula, teres, fed pilorum difpofitione depreffa, vivoque animali pilis difticha, pilofifima, remotis tamen pilis, ut in Muribus plerisque fquamulofa, annulis circiter centum.

Vellus minime denfum, fatis ftrictum, rudiufculum, (in domefticis hybernum laxius \& mollius) fubtus rariffimum prefertim fub armis \& in alvo. In capite rigidiores pili ftrictifimi, nitidi. Pili corporis vix pollice longiores, ubique terni pluresve fafciculatini, per punita vel poros cutis cinerafcentis, ftriisque fubreti. culatæ, difpofiti. Sutura velleris fub gula brevis \& a pectore pet, abdomen longitudinalis.

Color roftro \& circa oculos niagis minufve fufco-nigricans, inter myftaces fubferrugineus; parotides pallidæ, gula ferruginea, reliquum corpus infra \& artus interiore latere ferruginco. lutefcen- 
-tia; fupra gryfeus, pilis longioribus nigris, vel furcis apice gryfeo-pallidis magis minufve inumbratus. Cauda bafi fubtus ferruginea, majore parte lutefcens, a medio picea, apice atra.

Alltis a cauda remotus, vulvæ propior anxio, animali tribus quafi papillis extrorfum turgens. Fllog angufta, bilabiato-protuberans, connivens, clitoride nulla, raphe obfoleta verfus anum continuata, antice pilis fafciculatis, reclinatis. Mammarmm papillæ obfoleix, ab inguine ad coftarum marginem ferie valde divergente utrinque quaternæ, xquidiftantes. Mas pene extrorfum vix prominulo; teftibus plerumque in abdomine latentibus. Odor naturalis hircinus, leporino fimilis.

\section{E N S U R A E.}

Pondus adultorum vulgo vili. ad $\mathrm{x}$ librarum medicarum, in maximis Davuricis maribus xIv. feminis xu $\beta$. obfervavi.

Mas octolibris ad Selengam defcriptus longitudinem habuit $1^{\prime} \cdot 9^{\prime \prime} .6^{\prime \prime \prime}$. caput $4^{\prime \prime} .8^{\prime \prime \prime}$. cauda fine pilo 6". $2^{\prime \prime \prime}$. Accuratiores menfuras addo e femina pinguifima, domeftica, ad Volgam diffceta :

Longitudo tota a nafo ad anum - _ I. 3. - 10."' Alritudo antica ad fcapulas _ _ _ _ o. 5. 6.

- - gradientis poftica - - o. 5. ०. Longitudo capitis ad nucham - $\quad$ o. 3. 10. Circumferentia roftri per labium inferius - $\quad$ 0. 5. 4.

Intervallum narium Diftantia oculi ab extremo roftro - - o. I. 3 - inter oculum \& aurem - - O. I. - - - - \& meatum auditirun - o. 1. 
Longitudo fisfuræ palpebrarum Apertura oculi

Diftantia iner utrumque oculum filo directa $0.0^{\prime \prime} 70^{\prime \prime \prime}$

○. ०. 4 .

O. I. 11 .

0. 1. 7:

o. 6.1 .

०. 0.7 .

O. O. II.

o. 0.11 .

○. 2. $1 \frac{\pi}{2^{3}}$

o. o. IO.

o. 6.10.

I. 0.2 .

I. 4.4 .

I. I. 6 .

o. 4.4 .

o. 1. 0 :

○. 0.8 .

○. 0.8 .

o. I. 8 .

०. 2. 10.

०. 4. 0 .

o. 2. 5 .

०. 2. 2 .

0. 2. 4 .

o. $0.5 \frac{2}{3}$

○. 3. $1 \frac{\mathrm{T}}{2}$.

o. 3.4 .

o. O. $3 \frac{2}{3}$.

०. 4.1 . 
- ad calcaneum

Latitudo palma ad bafin digitorum

- plantr

Dentium primorum inferiorum longitudo

- fuperiorum

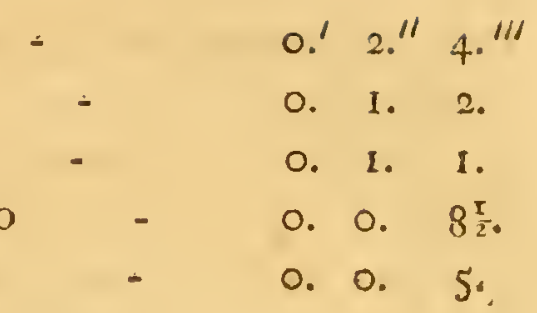

\section{A $N$ A $\quad \mathrm{T}$ O}

Tab. IX. fg. 4.5.

Interanea præfertim e fæmina pinguifima, cujus menfuras modo dedi, defcripturus fum, nifi ubi diverfa monuero. Panviculus carnofus extra pinguedinem, in dorfo robuftifimus.

Omentun ampliffimum, expanfione femicirculare, longitudine $4 \frac{1}{2}{ }^{\prime \prime}$. latitudine dupla, arachnoïdeum, ftriis adipofis, ramofis fubreticulatum, ambitu, præfertim finifterius, pinguiflinum; totum vero non per abdomen expanfum, fed verfus hepar reduplicatum, finiftrumque bypochondrium circa lienem effarciens, pondere folum $4 \frac{x}{2}$ unciarum. Onzenta duo peculiaria a lumbis orta, abdominis latera foventia \& fere ufque ad umbilicum producta, digiti imo pullicis craffitie pinguedine effareta, fenicircularia, verfus pubem connexa cum onnentulo quafi quarto f. pinguedinis lobo ante veficam collecto, priorumque intervallum ad umbilicum fere ufque explente. Tota dorfalis regio a renibus ad pelvim craffa pinguedine incruftata, quæ fimul cum omentis lumbaribus ponderavit a finiftra parte $6 \frac{1}{2}$ unc. a dextra $8 \frac{x}{+}$ unc. Preterea lobus pinguedinis cardiacus aderat, \& diaphragna adipe incruftatum; unde ex tota alvo collecta pinguedo (in animali $9 \frac{\mathrm{r}}{2}$ libras pendente) ultra libram \& 7 uncias æquavit, lardo mollior, albifima, levifima. - In feris autem pinguedo femper parcior, 
prefertim wtute, ut lipe ex omnibus omentis vix aliquot uncie costicimurur.

Hon ir tripartum, pondere 8 une. cum drachma, lisanentis nembramens robuttis lutpontum. Lobormm fivgyer maximus,

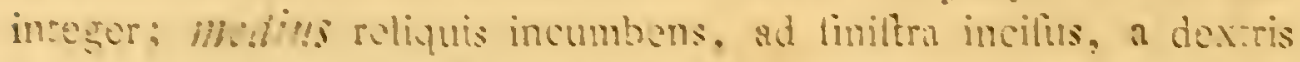

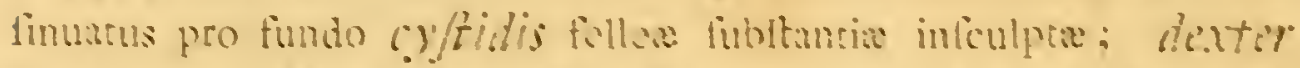
ittis minor, tritidus, portione fupera ovali, diangragmati adponta; altera trifusara reni impolial ceria (loco spigeliani lobuli) in ventriculi linu bimucronas. Membram robuth, pinsuedine defticuta, circa Inbulum ulcimum bihnellata, loco omenti minoris: purius

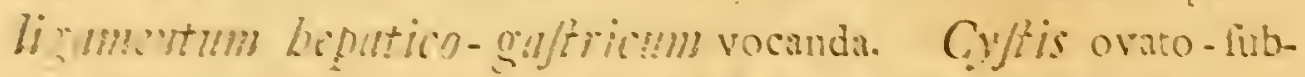
slobola; ductus bilarus vix 9"' detantia a pyloro inferca.

Liv" riquerto-pritinatius, interms linguiformis, ponders = drachmarum, longic: $=" 10^{\prime \prime \prime}$

Paveriss acins laxius fparlis fexpollicari longitudine, fecundun incettinum, exrentum.

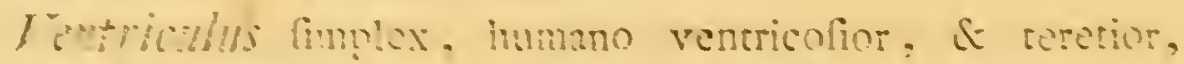
tunicis conthus crathuliulis a mufulofis. Oifophogils canofilimus, intus haginubimalier plicarus.

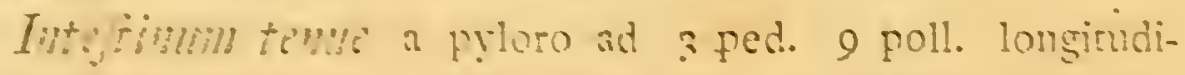
nam fojunum (1mecum) rafulolus; hine + ped. 3 poll. lle-

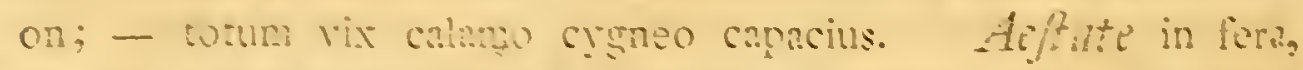

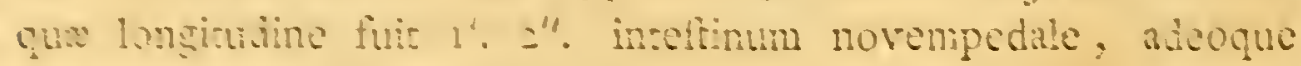
hy̆mali lonsils, inveni.

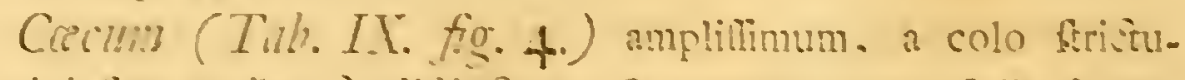
ra (cui inlorum ilson) dilimitum, facchtum, extus ftris \& venis celluhum, inds feptis (qua thiis rapondent), maxime in parte anguttiore prominentibus, quati concameratum; $\mathrm{ex}$ his plice anndars infigniores quingue vertus infertonem llei. 
connexa \& in curvaturam coadunatx in anicam prominentiffmam, qux crecum a colo difpefcit, \& valuulam ilei oftum exacte claudentem ipfa conftituit. Longitudo ceci a fundo ad ftricturam per majorem curvaturam $8^{\prime \prime}$. $G^{\prime \prime \prime}$. circumferet ta faci $7^{\prime \prime}$. ad initia coli $4^{\prime \prime}$. $6^{\prime \prime \prime}$.

Colon fefquiquadripedale ufque ad anum; portio prima (9".) ampliufcula, duodeno defeendenti adglutinata; fequer: (9".) ex parte parallela priori, fed anguftior \& excrementa in parvas moles diftribuens; tertia reduplicata globulos perficiena.. itidem (per $5^{\prime \prime}$.) parallela; unde reliquum inteftinum $\left(l^{\prime} . \tau^{\prime \prime}.\right)$ fub ventriculo defcendit ad anum.

Renes unipapillares; dexter dimidia fere longitudine anterior, uterque fefquidrachmali pondere paulo major.

Uterus fœminæ vix a vagina diftinctus; Crmmua longit. 4 ". $3^{\prime \prime \prime}$. Cecundum omentorum lumbarium marginen decurrentia, extremitate poliicari recurvata, cui fubtenfa membranula vafculofa, fed hiatu feneftrata. Ociltin lincaria, exilia, ad finem cornuum longitudinalia. Gevitalia maris $(f i g .5$.$) proportione multo mi-$ nora, quam Citillis, verum glande (a.), glandulis gelatinofis urethræ prope anum adidentibus ( $b b_{\text {. }}$ ) ctiam extra œftrum turgidis, \& a protata (c.) veficulisque feminalibus (dd.) diftinctiffmis-utique fimilima.

Thymnts totam fummam thoracis cavitatem ante cor explet, truncis vaforum majorious circumfufa, acinofa, pancreatis fubftantire fimilis, fed vafculofior, venis c pulmonali finu irrigua, parcifima pinguedine mixta; pondere femunciæ cum fcrupulo. - Ejuscem naturæ Clandula utrinque fingularis fub mufculo pectorali majore fupra thoracem explanata, difcoïcca, angulo fub armos producta, paulo minus vafculofa, acinisque denfius cohærentibus, fingula pon- 
dere circiter 3 drachmarum; quibus vafa magna a mammalibus \& fubclaviis accedunt. - Largior thymus atque glandularum thymo analogarum apparatus in omnibus, quæ fopiuntur, animalibus obfervabilis, atque hyeme magis floridus, ufum earum in fubigendo humores confiftere, eo magis probabile reddunt, quum lethargus ifte animalium ex parte, ftatui fotus in utero quam maxime comparabilis videatur, fotibusque pariter thymus in univerfum florentifima reperiatur.

Pericardinm robuftum, pinguedine aliqua ad diaphragma fuffultum. Cor mediocre, vix tres drachmas excedens. Truncus carotidis \& fubclaviæ dextræ communis, cum carotide finiftra baf pæne confluens.

Pulmones minufculi, cavum fere tantum dorfale, a thymo vacuum occupant: finiffer fimplex indivifus, dexter in tres lobos ufque ad vafa diffectus; impar lobus a dexrris quidem truncis vafa recipit, fubftantia vero plane diftinctus eft \& tertins quafi pulmo, a dorfo cordis in finiftram maxime partem extenfus, bifulcus, minorique portione fpine dorfali adnatus.

In Sceleto cofte duodecim; fermum quatuor conftans offibus, præter cartilaginem craffam terminalem, mucrone enfiformi productam.

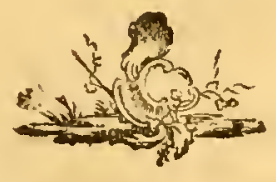




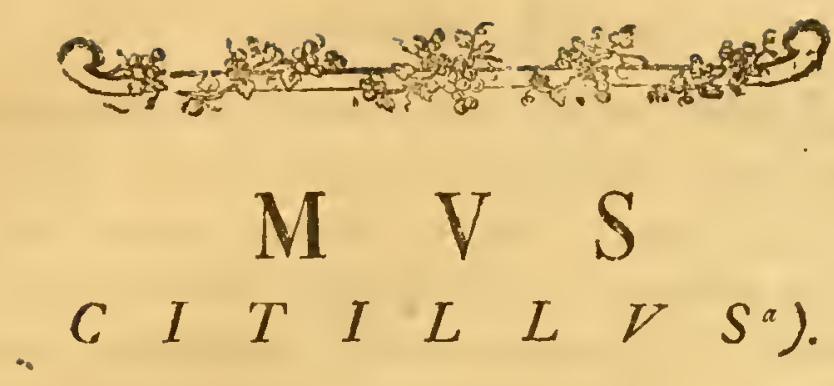

itillus, quem primus AGRICOLA, hoc ipfo \& Mitis norici nomine, difierte defcripfit, etiam antiquioribus haud videtur incognitus fuiffe. Etenim credibile eft Mur is ponitici appellationem, latius deinde ad Sciuros \& Ermineas quoque fignificandas extenfam, ftricto fenfu ad Citillum pertinuife. Quæ enim Muri pontico apud ARISTOTELEM \& PLINIUM ${ }^{b}$ ) tributa legimus, quod nempe condantur hyeme \& quod cibos remanducare foleant; deinde PLINII locus, ubi Murem ponticum juxta Mures alpinos collocat: Citillo magis quam alii cuicunque animali conveniunt. Deinde Citillorum noftrorum exuvias antiquitus in veftimentis adhibitas, eosdemque illos fuiffe mures, quo-

a) Dedi hiforiam Citilli in Nov. Coms. ment. Petrop. Vol. XIV. hic vero multis pofterioribus obfervationibus \& curatiore defcriptione auetam fifto, quam nec ibidem propofita duplex, neque $D^{\prime} A u b e n t o$. niana (в V F F O N. hifl. nat. XV.p. 195. Seg. fuperfluam reddunt.

. b) "Sunt etiam ex dentatis utrinque „nonnulla qua ruminent, ut Mures pontici,, A R I T To T. hill. anim. lib. IX.cap.5o. fub finem. - "Pontici mures fimili modo, ut "pecora, remandunt, PLIN._- "Glires „etiam latent in ipfis arboribus, pinguef. „cuntque per id tempus vehementer; item "Mnres pontici generis, AR I S T O T. hif. as. Vib.VIII. c.1\%. "Conduntur hyeme \& "pontici Mures, hi duntaxat alibi (i.e.exteri): , quorum palatum in guftu fagaciffi„mum quonam modo anctores inte „rint; miror. Conduntur \& alpini, P L I N. hife. nat. lib.VIII. cap. 37, GESNER V S nullo, ut mihi videtur, fundamento in pofteriore loco PLINII: albi loco alibi legendum effe cenfuit, \& additamentum gloffariorum ad ARISTOTELIS locum, quo M. ponticum albi coloris effe innue. batur, a G A z A jure neglektun, reftituit. Verum abufive Ermineos fub $M$ pontico. rum nomine barbaris temporibus venifle inde liquet, qund neque hyeme lateant iftre neque certe ruminent Noll magis re. Ete apud ISIDORVM \& HERMOLAVB 
rum pellibus Scythas veftiri Ivstinvs ${ }^{\circ}$ ) prodidit; id pæne irrefragabili argumento confirmant HESYCIIVS \& VARINvs, qui genus muris fylveftris, cujus pelles in vettibus adhibebantur, Parthica lingua ópwe appellari fcripfere; voce cum hodiemo Tatarorum Symron \& Calmaccorum D flymmbura, quibus propric Citillus indicatur, evidentiflime analoga. Inmo forfitan \& AELIANvs, quum in Ponto mures fupplicationibus ab agris averti refert, de Citillo eft intelligendus.

Poft agricolam \& ALBERTVM M. qui Cencodyli nomen, a Germanico Zycbel vel Zy/el cfictum, Citillo applicavit, Citillorum progenies in europxis terris adeo fuit exftirpata, ut ad noftra ufque tempora vix ullum defcriptorem autoptam invencrit. Recenfuit tamen citillos inter Silefix animalia sCHWENKFELDV, \& in Bohemia aliisque Europæ locis abundafie conftat, unde hodierna demum cultura fugati funt. In Polonia vero, prefertin minus cultis Podolix \& Volhynia, etiamnum vivere kzAczinsky (bift. nat. pol.p.235.) teftis eft.

Campeftres auftralioris Ruffix totiusque Sibiria regiones $C_{i}$ tillos inter frequentifima animalia numerant. Abundant in de. ferths omnibus ab Iftro, fupra Euxinum Pontum, Mrotidemque \& Cafpiam paludem, por magnam Tatariam patentibus; abundant in apricis totius Sibirix, ad Amur \& Lenam ufque fluvios; abundant ctiam in Kamtfhatcx ericctis, quod non foltum $\mathrm{kR} \Lambda$ SCHNNINIKOFII ${ }^{d}$ ) \& STELLERI teftimonio, fed pellibus quoque inde transmifis certus affirmare pofum; immo Korxcorum gens hodicnum, ut antiquitus Scythæ, pellibus Citillorum cle$V_{G}$ :i nomen, Sciuris borealibus, hye- thre(inter Riphreos montes \& Pontum) me canefcentibus on nino proprium, pro "pellibus ferinis aut murinis utuntur.

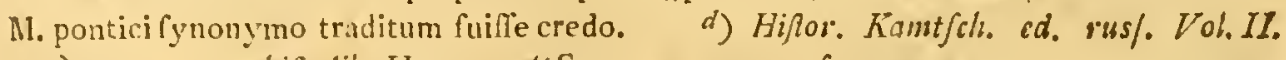

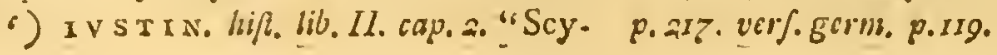


ganter variegatis ad feftivas veftes utitur. Denique STELLERVS ${ }^{\circ}$ ) in infulis inter Kamtchatkam \& Americam fitis, præfertim Schumagini dicta, magno numero Citillos in montibus apricis fibi obfervatos fuiffe reliquit. - In Ruffia verfus boream ufque ad Occam fluvium, \& in Cafanienfi regno ctiam ultra Kamam ad $56^{\circ}$. fere latitudinis habitant; in Sibiria ufque ad fylvofum regionem, frepe ultra $57^{\circ}$, imo ad Lenam, in rigidiffmo Sibiria climate, ulra $\sigma_{2}{ }^{\circ}$ prefertim circa Iacutiam \& Verchojancnfe oppidum $^{f}$ ), indeque ad Sinum Penfhinenfem ufque \& fecundum omnia hujus Sinus littora, in montanis apricis vulgares funt. In meridionalibus Afia Citilli longe ultra fines Ruffici imperii fpeciem propagarunt: per magnæ Tatariæ Campos ufque ad Bactra \& Indos frequentiffimi funt; in Perfia campeftri etiam ad auftrum Tauri inquilinos effe teftimonio DE BRVYNII confat ${ }^{\circ}$ ), cujus locum Cel. pennant perperam cum Polonorum Zemin, ad Typhlen noftram infra referendo, confudit \& peculiarem inde fpeciem condidit ( $\int y$. quadr. p. 277.). Videntur etian Ermellinæ gryfex boreali Chine communes, quarum mentionem fecere Ieflite Miffionarii ${ }^{h}$ ), meri effe Citilli.

e) STELLER Befchr. von dem Lande Kawutch. p. 126. ubi tamen male Citillus cum Lepore alpino, fub nomine Piflchucha intelligendo, confunditur.

f) G M E I I Reife durch Sibirien I'ol. II. $p .4+3$. In STELLER I chartis invenio Citillos ad Lenam non ultra oftum Aldani fl. ad boream inveniri, plopter pracoces \& acerrimas hycines, Dari autem in Iacutenfi regione tautum ab ea parte fuminis, in qua oppidum conditum eft, non ab altera, licet folum haud di. uerfum \& caden ibi pabuli abundantia. g) Reize over Molsovie door Perfie en Indie p. 430 . icon. p. 431 . quam, licer peffimain \& e farkta pelle factan. pro Citilli adumbratione nemo non agnofcet gnarus. Nomen vero additum, Zits.jan, Tata. sorum eft, pro umni murium genere fignificando commune. Corrigendus hinc etiam Amicisf. Z I M M R R M NN Zooiog. geogr. p. $524 . \& 6=r$.

h) Hifoire generale des voyages Vol. IT p. 565.6003 .

Q 2 
In tam extenfa, per diverfifima climata, diverfasque fitu \& natura terras, patria mirum non eft Citillos fedentarios plus, quan animalia fpontanca reliqua magis vaga, varictatibus, pilo, colore, magnitudine valde difcrepantibus ludere, quas quum in peragratis regionibus diligenter obfervarim, fufus hic perfequar, antequam mores animalculi exponam.

Maximos \& pane dixerim monftrofos Citillos paffim ad inferiorem Iaikum in campis fqualidis, Salfolarum \& Anabafcos abundantia fecundis, prefertim circa rudera tatarica Saratfchik obtinui, ubi in tumulis \& clatiore folo profundiori, verfus ca. fpiarum vero paludum initia, propter lumiditatem locorum, minime alte effoflo cuniculo habitant. Fomina, quas inde habui (licet plerumque in hac fpecic femina mare foleat efle minor) magnitudine parum a Marmota aberant, \& erane colore uniformi, c gryfeo-flavefcente, in dorfo fubcinerco, cauda villofodifticha ormati, pilo rudi attque peflimo. Indolem fimul prodebant ferocifimam, $c x$ antro pulfi iracundia fibilabant, nec fuga falutem quærebant, fed grandes canes morfu impetebant, neque demordebant facile, fed clautis oculis e vuinere pendebant, ululante pre dolore cane. In nulla alia regione tantos unquam vidinus, licet in infignem magnitudinem ad Samaram \& Irtin cxcrefcant, iftis tamen minime xquiparandam. Neque hoc mirabile videretur, nifi in iisdem pane defertis fimul obfervaretur omiet.s pygnlea \& omnium, quas vidi, minutifima. Habco Citillos vix Murem aquaticum aquantes, totosque flavefcentes, pilo mollifimo veftitos, cauda brevi, pilofo-tereti, qui circa la. cus falfos inter oftia Iaïci \& Iembre fl. fitos, \& in promontoriis editioribus littorum M. Cafpii capti fucrunt Menfe Martio, quo tempore nulla adhuc junior proles nata clle potuit, preterea 
quod adultos effe pygmeos aliis quoque notis conftabat.-Simillimos iftis, vel tantillo majores ubique in deferto limofo circa oppidum Iäcenfe, \& inde verfus tractum arenofum Naryn, primo itidem vere copiofe cepimus; eaque varietas a plurimis collatis individuis convenire vifa eft: vellere gryfeo, obfoletius guttato, fubtus pedibusque exfolete lutcfente, cauda brevi, terctiufcula*). Longitudine tota xquabant feptem (ad fummum 8.) pollices, cauda dento pilo $1^{\prime \prime} .2^{\prime \prime \prime}$. - Circa minorem Vfen, medii deferti rivum, ubi magis arenofum \& aridum folum, minuti. ores his \& plane Gurjevenfibus fimiles, colore xquabili, flavefecnte - pallido, cauda pollice breviore, occurrebant. - In arenis fuctuantibus medii deferti, Naryn dictis, haud majores, fed magis cincrci, profundiffmis cuniculis in arca humida delitefcunt.In omni deferto Aftrachanenli ad utrumque Volgæ latus, \& circa Kumam atque Sarpam, ubi æqualis terræ facics \& Iaïcenfis fimilis, haud multo majores dantur, vix femilibres, toti gryfeocincrei, fquamatim variegati, fulvedine plane nulla, cauda brevi, fed diftiche villofa feu pennata. - Cauda itidem criftata \& femilibres, fed uniformi colore pallido lutefentes, necquicquam variegatos, longe ab hinc circa Tarci lacum exficcatum Davuriæe \& ad Onon-Borfa rivum, in defertis montanis, aridis, glareofis, Mongolix finitimis frequentes obfervavi, cosque in tota Sibiria minimos.

Pulcberrima Citilli varietas circa Tanaïn \& in Cafanienfi regno, ad median Volgæ regionem a parte occidentali, Sarato. vam fere ufque, in campis herbidis conftans \& vulgaris eft. Habet illa magnitudinem mediocrem, pondus unciarum circiter decem,

*) DE BRVYNI I figura, utcunque ru. reprælentat. dis, perficum Citillum hifce fatis fimilem 
caudam brevem, nigricantem \& teretiufeulam, colorem in dorfo gryfeo-fulecfentem, puntis albidis pulchre guttatum, ita ut propter elegantiam pelles proceribus etiam ad exornandas veftes fubinde expetantur. Hujus varietatis iconem Tabula $F$. B. B. proponimus. Notabile eft eandem ultra Volgam mullibi obfervatam fuife, neque in citeriore \& aultraliore Sibiria (ubi diverfit plane Citillorum facies) occurrere; ultra Lcmim ${ }^{i}$ ) vero denuo vulgatifimam efle, unde pelles, qux in frigida illa regione pilo altiore \& denfiore luxuriant, confute Ircutian \& Kjachtam deferri, ac Chinenfibus fatis caro, imo carius Sciuris cincreis, vendi folent. - Sed neque cirea Baikalem, nec in Kamtichatka fimili elegantia preditos invenias. - Cel peNNaNe, qui notabili hallucinatione $\mathrm{Ci}$ tilli duas, ex uno animali, fecit fpecies ${ }^{*}$ ), aultriacam vel bohenicam a CRAMERO miflam varictatem ex pelle deforipfic fumilliman Cafinienfi atque trans-lenenli noftre, pulcrius guttata; refteque BVFONIVS a PRNANTO acceptam pellem auftriace valictatis cum Cafanienfi, e Ruflia accepto aninualculo, conjungendam judicavit, lieet in diftinguendo utroque a Citillo AGRICOLAE, non minus erraverit ${ }^{\dagger}$.

i) Iacstenfes Citilli, quorum adumbra-

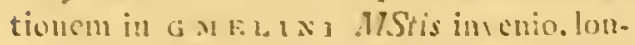
gitudine plus mimns pedali, cauda quadrun. ciali, colore in dorfo cincrafeente, luteo immixto len perdicio, fubcus Intefiente. fixp in rufum vehementer inclinantes, ha. bentur. Tales pelles, Samarienfibus fimiles, etiam inter confuras, quac lacutia mittuntu:, obforvan: pulchertimos suttatos e regrionitus verlus Uchotam S. L thll. mitei accepi. ex fue tnulto magis attimanth. E copiosi :s ce Lenculi regrione ad Sinenfium emporiun deforuntur.

*) Synop\%. quacir. p. - $\div 3$. Marmotam Cafauicnfem, \& $p \cdot--6$. Marmotam liue auriculis, quuxe funt unum idenqque animal, tançum diltinetas fpecies pofuit; feduetus, ut puto. exemplo BV FFo 1 \& $\&$ deferiptione perfunctoria in FORSTER I rhapfo. dica lizund loigrnli (Phil.Trans/. vol. Ll'TT. p.3.43.11. 15.) exlribita, qua Citillo anriculac parva rotundata, cx deturpatis forfitan exwiis tribuntur, qua reccuti nulla funt.

1) в в F́ovirs in additumentis ad hiltorian quadrupedum l'ol. .l. $/ 5.159$. 
Inter Amici fato functi Cel. FALKI collecta animalia fervatur in Mufeo Petropolitano Citillus, qui e magnitudine, colore, \& maculofa pelle Cafanienfis videtur, fed'apprime notabi1F eft area irregulari magna atra, pectus totum inter anticos pedes, aliaque abdomen inter femora occupante; ut pæne adultcrium cum Criceto fufpicarer, nifi reliqua figura a folita norma plane non aberraret. Interim peculiarem mentionem mereri vifum eft hoc fpecimen, quod mihi fimilem varietatem, in permagna Citillorum integrorum \& innumera pellium, ex omnibus rufieci Imperii regionibus, copia, obfervare nunquam contigit.

A Volga ufque ad Baikalem, diverfiflima licet climatis natura, minus tamen variant Citilli, \& in toto illo fpatio media circiter (inter fupra expofita extrema) magnitudine, Sciurum paulo excedente, \& fubfimili quoque pelle, caudaque fciurex inftar villis difticha infignes, ubique reperiuntur. Majores ex his \& pulcherrimi (Iibra, inmo 1efquilibra fæpe majores) funt, quorum in campis herbidis circa Samaram aliquot centena individua tractavi \& mactavi, \& viva quoque alui, ad obfervandos lepidifimi animalculi mores tunc otiofus. Talem Tabula noftra Sexta exprcfi. - Pcllis dorfi (in hac varictate) cano fufcoque mixta, perdicei, fæpius undulati vel fubfquamati coloris; fed la-

Murem noricum feu Citillum A G $\mathrm{R}$ I coJAE \& atciorum, nonine Zilel diftinxit ab animalculo p.I44. nomine Sonflik pro. pofito, \& p. 195. a Cel. D'A VBENTONO defcripto; potuiffet tamen, collata graphi. Ca AGR I COLAE defcriptione cum fpeciminibus fuis, facilc perfpicere, unum idemque tractari animal; quo utique PF.NNA N T I hallucinationem antevertiffet. Si addas eundem y VFIONIV M (hifl. nat Vol.XIII.p.337.) Citillum Lenenfem (Tevrafchka) e G M EI I N I itinerario diftincte recenfuifle, habebimus in Ejus Opere triplicem in unico animali errorem. Poffent \& alia recenferi, e quibus perfpicias melius effe propriis, quam alie. nis oculis obfervare, quod Virillaftr. ope D'A BENTONI plerumque fecille vide. tur. 
tera capitis pedesque intenfe ferrugineo-lutea, faturatiore \& prene rufa litura fupraciliari, fuboculari, \& utrinque ad nafum; collum fubtus lutefcens, \& corpus pronum pallidum; cauda villis pulchrc pinnata, lutea, pilis longioribus cano fufcoque mixtis fimbriata. - Similes Samarienfibus, neque colore nec vellere deteriores, alunt tractus omnis Samare \& collateralium fluviorum, agri circa Ufam ad occidentem Uralenfis jugi, campique Ifetenfis provincix, ab ipfo ejusdem jugi defcenfu orientali, ad Irtin ufque, \& pars borealior Barabenfium camporum, maxime Obo fl. contermina; nifi quod his color luteus circa caput \& in pedibus obfoletior. Et fateor fimilis fere horum Camporum ubique facies, folum nigrum, cæfpitofum, ficcius, herbarum plerumque fimilium proventu lætifimum. - Circa Ui fluvium ex his paulo majores occurrunt. - In deferto fecuindum omnem Irtin fluvium partim arenofo, partim limofo fqualido, paulo minores \& obfolete guttatos obfervavi, colore inter Lenenfes \& perdicinos f. undulatos quafi medio, facie tamen, magnitudine \& cauda his fimiliores, quippe pondus plerumque libræ cum una alteraque uncia, \& longitudinem 8: ad ro pollicum æquantes, cauda (dempto pilo) I". IO'"., pilis fere pollicaribus criftata. - In campis denique montanis circa Ienifeam (ubi paffim in faxofis quoque frequentes delitefcunt), \& in arenofa planitie infulisque Kali vulgari confitis, Selengæ fluvii, itemque in montanis circa Ingodam Citilios ubique obfervavi circiter felquilibres, longitudine $10^{\prime \prime}$. excedentes, cauda (quod mirum) multo longiore, fine pilo $3 \frac{T}{2}$ pollices æquante, villoque plus quam pollicari pennata; caterum Samarienfibus vellere dorfi eleganter undulato fimiles, fed colore ubique dilutiores, circa caput ex albidos, luteis lituris plane nullis, corpore fubtus pedibusque fere 
fere totis albis, ut vix humeri leviter lutefeant \& in feminis (multo minoribus) hypochondria; cauda tamen intenfe ferruginea, \& quafi linea per longos villos ambiente nigra, ambituque demum albido fimbriata. - Atque horum fimiles pelles, in dorfo licet paulo faturatiores, interdum obfolete guttatas e Kamtfchatka accepi.

Patet igitur varietates Citillorzm, qux recundum regiones fuas conftantes deprehenduntur, adeoque a loci, pabuli, foli natura omnino pendent, præfertim tres ftatui poffe. In herbidis perfectiflninam illam mediocrem, mndulatam, caudaque pennata infignem, ultimo loco expofitam; qux in frigidiore \& alpeftri Sibiria albidior evafit, paffim magis minusve guttata apparet, ad Selengam autcm maxime longitzdine candae eminet. - Deinde guttatam, ad prioris maxime poftremas varietates (etiam albido proni corporis colore) accedentem, cui minus villofa \& exilior cauda, quæque (cum fub climate adeo diverfo, ad Lenam fcilicet \& Tanaïn, \& in campis eorum, qui primam alunt, fimillimis, imo ad Volgam folo flumine diremta, gignatur) difficillime explicari poterit. - Denique in calidiffimis \& torridis regionibus fluvefentem vel ad primam colore varic declinantem, cui cauda quoque ifti fimilis eft, fed ftatura plerumque minima, vel rariori exemplo ad giganteam molem, pabuli forte cujusdam (forte animalis) beneficio adaucta.Ha tamen omnes varietates moribus \& natura, paucis, quæ monebo, exceptis inter fe conveniunt.

Citilli, præter fylvas \& paludofa loca, omni fere regione temperatiore \& aprica contenti funt. Maxime abundant in campis \& collibus ficcioribus, elatis, incultis, cæfpitofo vel limofo folo \& herba breviore vel rariore dotatis. Non defunt neque 
in aridifimis, falfuginofis, ctian fubhumidis, prafertim aufralioribus; neque in fabulolis, ubi tamen minus vulgares, nec nifi deprefli colume, ubi arena magis tabilis. Circa vias publicas plerumque fiequentes habitant, ob fecuritatem puto in minoribus feris, ibi majorem. - In Sibiria neque a rupeftribus locis $\&$ montibus faxofs, apricis abhorrent; frigidasque ultra Lcmam \& Kamtichatce planities ufque eccuparunt. - In quibusdam locis, nefeio an pabuli vel foli aptitudine adleti, mira cxiguo in circuitu copia confertim habitant: talis eft regio circa Samaram

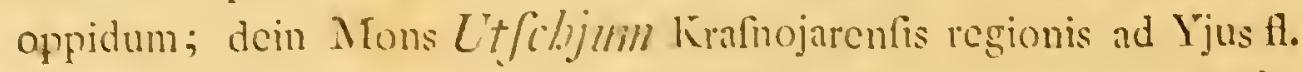
totus antris Citillorum a clementiore Iatere foraminulentus ${ }^{\prime \prime}$ ); talesque infulir Selengar. Ubique tamen aptis locis e copiofillimis funt animalibus, \& nifi culta loca minus amarent, inter agris noxia haud infimum locum occuparent.

Seniores, rel qui feniorum defertos cumiculos occuparunt, facile produnt foramina duo vel tria ampliora ceca, ad aliquot pallus, vel multo fape minus dillita, fpithame plus minus in profunditatem pervia, quorum umum, praterito antumno obturatum recens egelta terra indicat. Norus, quo co anno utitur animal, canalis anguftior eft reliquis \& cxacte animalis magnitudini folet effe proportionatus; nullam ibi terram egctam videas, fat nihil prater rotundum aditum, in tertam dircetione ab initio pernendiculo plerumque proximal deficudentem \& herbis fiepe ita obumbratum, ut lynceo vix oculo dectegi queat. Antra mafculorum proportione majora, in media varictate tres digitos transverfim junctos facilc admittunt, dum fominatum aditus vix 2 digitorum diametro patcat. Canalis rario gradu obliquata directione in tcrram penetrat, in folo ficciore magis precipiti, in dem) Pall. Reije IIur Thicib p.6-6. 
preffioribus \& fubhumidis clementiore inclinatione, ad duum, trium, quatuorve \& quod excedit (certe pro majoribus) profunditatem; ea quoque lege ut nulto profundior \& anfractuofior femper fit foeminx cuniculus, quam maris. Ulterior pars obliquius deinde pergit \& poft varios fape anfractus dilatatus in cameram fornicatam oblongam, vel fubrotundam, pedalis plus minus diametri, depreffiufculam, culmis ficcis graminum comminutorum molliter ftratam, \& weftate undique, præter aditum, claufam. In fqualidis ad Irtin, infra Septem palatiorum regionem, Citilli, licet mediocris magnitudinis, antra præter morem profundiffima, orgyali ductus longitudine \& fefquiulnari ad minimum profunditate, nido fpatiofo, graminum ftuppolis radicibus referto terminata colere inventi funt, præfertim matres, quæ prolem jain educaverant. - Iuniora animalia vel, quod fxpe fit, quæ novum proxime clapfa xftate cuniculum paraverunt, unicum cum egefta terra veftigium, preter folitum aditum, indicat. Nempe per obliquum cuniculum terram fubire folet Citillus, humum retro egeftans, donec nidum fatis fpatiofum excavavit. Sic xftate plures, opere occupatos inveni. Verfus hyemem vero novum 2 nido ordiuntur canalem, quem ad cæf́pitem tantum perducunt, tandemque egefta c nido terra tritum tranfactæ xftatis cuniculum replent \& obturant, nunquam tamen ita pleniter, ut non cœca extus veftigia antiquatorum canalium fuperfint, \& numerum annorum, quibus habitatum fuit antrum, indicent. Quem vero ad cxfpitem perduxit novum exitum animal primo vere, quum defluxere nives \& extima vix terræ crufta refoluta eft, ex hyberno torpore refufcitatum pertundit, inque lucem exit, favente forfitan in emollicnda terra aëris inclufi tcmperic, a fopito animali utcunque tepefacti. - Hæc omnia e copicfis 
vario ftatu, loco \& tempore anni pro obfervatione coram me fulfoflis Citillorum antris, \& modo quo capta animalia nova antra parare vifi funt, clare intellexi. Inveni ctian fepius juniores a matribus expulfos in derelictis aliorum, $\mathrm{vel}$ parvis pro tyrocinio captis cuniculis delitefientes, quos fiepe relinquunt \& multum paflim terse cgerunt. .

Exitum igitur perfecti cuniculi conftanter unicum habet $\mathrm{Ci}_{-}$ tillus, \& quotics novum fodit, obturat antiquum, circulantis forte aëris impatiens, quem contra Cricetus \& mures varii duplici apertura conciliare fibi ftudent. Ea vero œconomia perniciofiffima Citillo, non folum quando rapaces Muftele irrumpunt, fed etiim quando effoditur, vel aqua antro infunditur. In priore cafil vidi Citillum, dum defuper foderetur, tumultuario canali a nido in oppofitam parten effugere tentafie, ut fape intra breve tempus ultra fpithamam fefe in duram terram condidifet $\&$ vix inveniretur. Facilius \& proruptius aqua exturbantur, cujus tamen in profundioribus feminarum antris, folo prafertim bibulo, fiepe quinque \& plures amphore requiruntur, donec prodeat animal, quod fenlim altius \& altius adfecndens non nifi ultima necellitate coastum in apricum tandem prodit madidum \& a geliditate aque ita perculfum, ut vires ad fugam plerumque defint; quam alias dum viget, incpto licet \& fubfultante curfu, fatis expedite tamen capelfit.

Citilli femper folitarii in cuniculis vivunt, nec nifi veneris tempore femina lubinde in cuniculo maris deprehenditur. Contra mares mordacis femine cuniculum propter anguftiam fubire ipfi nequeunt, cavente forfitan natura, ne carnivoro, quem deinde cxponam, appetitu ad deftrucndam fobolem follicitentur; quod Muribus albis incarceratis accidiffe fcio. - Primo mane 
\& oriente fere folc antris excunt, totaque die, fi ferena fuerit, interpofita fubinde quicte, ufque ad folis fere occafum vagantur, pabulantur, infolantur \& in aprico colludunt mares cum fæminis. Inter fe vero occurfuntes cjusdem fexus Citilli, præfertim mares, acriter etiam pugnant, unde non paucis digiti palmarum cicatricofi caudaque præmorfa obfervatur. Feminarum in campis fiftulatus crcbro exaudiuntur; mares taciturni plerumque ambulant. Ilomine vifo ftatim ad antra refugiunt omnes. Videas etiam paffim prope antra in talos erectos \& excubantes, ubi quantocyus periculum ingruit, edito folito fiftulatu in cuniculos conduntur. Subfrigida \& humida tempeftate rariffine foras exeunt; domi etiam detenti omnis frigidioris aëris \& humoris impationtiffimi apparent, tremebundi latcbras quxrunt, \& cœlo turbido majorem partem diei dormiendo tranfigunt.

Vix vidi animal, quod facilius Citillo cicurari poflit. Mares omnes, etiam feniores, unam fere intra diem, juniores aliquot horis, non folum catenule adfuefiunt, fed \& ita manfuefcunt, ut coram hominibus ambulare, pabulari, lavare, ludere haud reformident. Immo poft aliquot dies, domefticorum inftar animalium ad hominem fponte accedant, feque manibus demulceri \& tractari patiantur, vel e digitis cibum legant. Præbent itaque exoptatifimum pucris ludibrium, qui aqua cxpulfos, funiculisque laneis, quos non facile rodunt, alligatos ubique trahunt. Feminæ contra, prefertim feniores; uti natura funt mordaciflime atque fubdolx, ita nunquam feritatem plane deponunt. Hinc GMELINVM, qui adeo mordaces Citillos fcribit, ut irritati ctiam fponte morfu impeterent, Iacutix folas feminas domi aluiffe concluderem. Arctomyes contra noftrates, etiam feminx \& adultx, intra aliquot dies manfuetiffmx ficri omnes folenta 
Multos domi alicui Citillos, moresque animalis fimplicifimos \& innocuos otiofe contemplatus fum. Noctem femper totam fopiti quiefount, a prima jim vefpera torpiciuli. Sape \& interdiu, pluvia maxime \& procellofa tempeftate, plenoque ventre fopiuntur. Dormiunt, clunibus infidentes, conglobato corpore, palmis \& capite inter projecta femora reconditn, more prorfus Artomyos \& Marmota, quibuscum fumman totius ftructura, indolis \& faciei fimilitudinem habent, ngiliores tamen, minusque ftupida milhi vifie. Somno plerumque adco profundo torpent, ut agre excitentur, dormientes fubinde in latus provolvantur, imo cx altiore loco decidant, jaceantque, fiepe aliquot minutis, quafi cxanimes.

Ambulant, fubfultim currunt, in clunes vel talos varic criguntur circumpectantes, corpore extenfo \& divaricatis cruribus eniti atque anguttias quasvis, fi modo caput transmittant, perrepere polfunt, cibum minutum \& herbas ore humi colligunt, majores oftas dentibus fublatas in palmas accipiunt \& fedentes rodunt, - omnia uti Marmotis. Lepidillimum eft videre poft paftum, vel quandocunque os vel pedes inquinarunt, qua dilisentia \& munditici cura non folum os \& facien, imo totum quoquc caput, palmis lingua delibutis permulceant, pofticis pedibus feabendo pulveren e vellere cxcutiant, \& palmis hypochondria \& ventrem quafi peetant. In genere etiam fabi $\&$ manibus foveri atque demulceri annant, interque feabendum pigrefcunt \& ofcitabunda pandiculantur, prafertim poft fommum.

Quibus tamen in captivitate delitefere permittebatur, ii minus cicures evadebant, quam in aprico detenti. Vinculis liberati clecta quacunque latebra, prafertim feminx, lanam, pilos, foni \& herbarum quicquid conquirere poternt, aut fi talia de- 
effent, ligna, chartas, limumque fornacum propria opera comminuta in nidum congerebant.

Cictrati mares raro, nifi perterriti vel irati, fiftularem fo. num, qui Citillis proprius eft, acutiffimum, hiante ore edunt; mecila varictas plerumque fimplicem. Fœminæ clamofiores funt, vocemque debiliorem, magis querulam \& argutam fxpius iterant, iracundia, impatientia, aliterve turbatx. Mirum vero, effe varietatum \& locorum etiam quoad vocem differentias. Circa Sa. maram \& in Ifetcnfi provincia varietas media fimplici, ut dixi, fono fiftulare folet. Ad Irtin in eadem fonus brevior, acutior, fxpe geminatus, rarius triplicatus, ctiam maribus. Ad inferio. rem Volgan minoribus fxpius iteratus fonus. Denique minuti, circa Iä̈cnfe oppidum obfervati, fonum octies deciesve continuato repetunt, ut infuetis pro avicula infolita imponant. Eæque fecundum determinatas regiones conftantiffimæ differentiæ. Præterea iracundi grunniunt Citilli, quod Marmotæ potius blandientis eft, \& fæminæ, quando deprehenf commordent, felino fere more fterunt \& fibilant. Famclici \& fubirati frepe dentes acuendo collidunt, quo ftridorem (quafi Gryili ftriduli volantis) eliciunt, uti Glirium multis folemne eft ${ }^{n}$ ).

Pabulum cicuratis meis ufitatifimum fuit triticum, fecale, avena, panis. Ilerbas infipidas \& teneriores omnes depafceban. tur, prefertim Polygenum aviculare, Trifolia, Cytifos, Robiniam fruticantem, Tetradynamas, cet. In Sibiria orientali etiam baccas Empetri, Uvæ urfi \& radices varias in alimentum conquirunt \& nidis ingerunt. Raro fitiebant, \& denegato diutius

n) Sciurus, quem Koz в ro referente dentibus collifis, quam cauda fonum ede. Belgæ ad Promontorium B. Spei Murem re, credibile eft. ftridulum (Ratelmaus) appeilant, potius 
potu urinam propriam lambebant; fecus, fi aqua prefto effet. In campis, ubi ab aquis remoti vivunt, folo rore \& calcti humore fitim tolerant. Bibunt lambendo \& parcillime. Nivem oblatam femper recufarunt, quam Sciuri, calidiore funguine $x$ ftuntcs, ctiam hyeme aque preferunt \& avide vorant. Contra Citilli, ut Marmotx, perdite amant lacticinia, iisque ultra modum ventrem replebant, ut frepe inde agros, fluxu ventris conflictatos, imo pereuntes viderim. Neque aquam curabant lacti adtucti; \& e campis modo adlati lac oblatum, ftatim atque deguftallent, lubenter hauriebant, eoque maxime circurabantur. Pretcrea fipe panem butyro illitum, placentulas butyratas, carnes coetas \& aflatas, imo lardum comederunt cicurati. Et quidem pingtia impenfe amare vili funt; famclici vero nihil, nifi maxime contraria reçufabant, immo exerementa, quæ rattorum fere fimilia, oblonga funt $\mathbb{\&}$ in nidis quoque parcius reperiuntur, propria devolarunt.

Naturalem Citillis carnivorum appetitum ineffe, licet mirum videri debeat, certum tamen eft. Murium \& avicularum reliquias in antris Citillormm invoni \& captivati oblatas cum plumis aviculas, quafi amonam benc notam, ftatim arripicbant $\mathbb{E}$ femper a cranio primum impetebant, excfoque cercbro fenfim ad alin tendebant, fiepe totas prater alas \& caudam confumere vifi. Verofiuillime itaque Citillos in campis \& murium copiam minnere, $\mathbb{E}$ alaudarum aliarumque humi nidulantium pullis codem infinctu infeftos clle, idemque patrare, quod in arboreis aribus agit Sciurus ftriatus; unde non fine fundamento, licet vix probe cognita caufa, inter rapacia \& carnivora animalin apud bVFFoxiva (ormithol. ool.I.p.6I.) relacus eft.Qummque in regione circa inferiorem Inikum, ubi gigantei re- 
periuntur Citilli, aves hydrophila \& alaudx copiofifime humi nidulentur; nonne inde forte derivandum infolitum, ex abundantia animalis alimonix, incrementum?

Cum Marmotis in co queque convenit Citillo, quod to'a hyeme, finc nutrimento cxterno, in antro torpeat. I'rimis plerumque Septembris dicbus, quo fere tempore frigora, fulcem nocturna, primulum incidunt, cxitum antri fui xftivum claudit terra, ut dictum eft, e novo canali, inftinctu mirn, pro maturiore inftanti vere cxitu, ad cxipitem ufque parato, egefta. Eo tempore pinguiffimi funt, totique adipofo cortice quafi incruftati, coque iam pigri arque tardi, quippe \& naturaliter fomnolentze indolis. $\Lambda$ ccedens frigus adhuc pigriores reddit, in cuniculis coërcet \& ad fomnum difponit fenfim; tandem, poftquam frigoris caufa cuniculum obturavit animal, inclufus aër prioribus caufis junctus plane torpidos \& immobiles facit. Ninuitur caior, torpore ceffat fenfm refpiratio, unde lentior fanguinis circulus \& forte primaria caufa fuporis \& fine alimento vita; quum contra in calidis, hyemem in aprico ferentibus animalibus, ipfoque præfertim homine, a frigoris ftrictura potius intendatur calor fanguinis, aliquot fepe (ut quilibet in feipfo experirı hyeme potent) gradibus, perinde ac in frigide febrium paroxyfmo fupra natu.. ralem temperiem auctus effc folet. - In Citillo fummus fanguinis calor xeftate conftans effe obfervatur circa 91. fealx de l'Iflianx (ultra $103^{\circ}$. Farenh.); fed quando infufa aqua frigida c cuniculis torpiduli proturbantur, frepe non ultra $106^{\circ}$ ( $(8,435 \mathrm{Fr}$. $)$, immo nonnulli vix ad $110^{\circ}$. ( $80^{\circ}$. Far.) indicarunt. In cella glaciali aliquor dicbus detentis \& dormitabundis factis gradum coln. ris circiter $130^{\circ}$ ( $56^{\circ}$. Far.) pertitiffe expertus fum. IIre a $\mathrm{S}$ :maram experimenta capta funt. Vidi dein ad Irtin, Junio men- 
fe circa initia gelido, Citillos, qui aqua antris affufa exturbati fuerant, nocturno unius noetis aëre plane obtorpuiffe, ita ut mortuorum inftar flaccidi, claulis pertinaciter palpebris \& vix dolore ad leves motus excitabiles effent. Mane, aëre ad 12I. ( $67^{\circ}$. Far.) jam calente, illorum interanea adhuc ad $130^{\circ}$. frigebant, fed jam incipiebant refpirare primulum, \& cordis paulo evidentior fubfultus, ter circiter intra duo minuta fecunda, perfentiebatur. Eadem tamen aëris temperie regnante, imo frigidiore tẹpeftate, ad Selengam fub fincm Martii jain copiofe prodeuntes vidi Cicillos, Solis radiis excitatos; fed quos tunc aqua gelida perfufos aëri frigidiufculo vix hora fpatio expofui, ni cito refoverentur calore, fine reditu vitæ obriguife vidi. Hre tamen omnia de Citillis nondum domeftico alimento imbutis, fed e campo adlatis valent. Obfervavi enim, ut in Aretomye dictum eft, etiam Citillos domi pinguefactos contra frigoris vim robuftiores reddi; quod in Erinaceis tamen mere carnivoris, licet diu domi alitis \& pinguifimis aque ad familiarifmis factis, nunquam locum habet. Krafnojarii initio Januarii (1773.) obtinui Citillum marem feniorem, qui per autumnum domi pane altilis, pinguifimus evaferat; hunc per diem noctemque \& quod cxcurrit in ciftula pervia aëri ad $180^{\circ}$. ( $4^{\circ}$ infra. Far.) frigenti detentum, nequidquam vivacitatis \& vocis naturalis anifife, neque calorem fanguinis infra $95^{\circ}$ ( $98^{\circ}$. Far.) imminutum fuiffe obfervavi. Quod an fermentato alimento autreque pinguedini \& fanguinis phlogiftice na ura tribui debeat, aliis judicandum relinquo. - Inde forte eft, quod neque GMELINvs Jacutix domi educatum Citillum, lacte potifinum, pane \& carnibus altilem, obtorpuife viöit \& quod, eodem referente, in granariis ibi colonorum hybernanies neque hyeme eadem vaftare definunt. - 
Experimentum diutius producere abitus, quem tune e Sibiria paraball, prohibuit.

Prodcunt ex hybernaculis Citilli primo ftatim vere, poftquam nives defluxere, adeoque fecundum fitum locorum cirius tardiusve. Ad Samaram plerumque ipfis Aprilis initiis, feriusve in depreflis vel borex obverfis clivis, ubi- Icntius pereunt nives vel nivalis humor colligitur. In Aftrachanenfi deferto jam fub finem Februarii; in infulis, tepidaque \& arenofia convalle Selengæ ipfis initiis Aprilis prodibant, terram vix in fuperficie ad aliquot digitos transverfos degelatam pertundentes; at in campis ad Chilok, \& verfus Baïcalem fitis, aquilonem verfus inclinatis multo tardius. - Ubique prodeunt macilenti, tantum in iliis, axillis \& omentis parca relita pinguedine, quam autumno copiofiffime collegerant. Debet ergo, licet torpida circtilatione, continua fieri adipis in fanguinen reforptio, inque cruorem \& alimentum corporis abfumtio. - Ventriculum \& inteftina tunc invenias vacua \& ufque adeo contracta, ut etiam fuflatione vehementi vix ad dimidium folita capacitatis diftendi queant; etiam cacum, quamvis hoc fub finem quoque hyemis femper fufcæ faburræ aliquantum contineat. Primis temporibus, ob hanc ipfam ftricturam, Citilli nonnifi parciffime cibum capiunt, cavente $\mathrm{Na}$ tura, ut lente a diuturno jejunio defuefcant. Nihilo tamen fecius, hyberno fomno \& diæta quafi præparati, ftatim atque exeunt tumidis teftibus mares, floridoque utero fenina in venerem ruunt. Videas tunc in campis ubique per paria colludentes. Quum hæc glacie adhuc flumina tegente fiant, facile perfpicitur quomodo per regiones magnis fluminibus diremtas fpecicm propagarint Citilli; immo glacie abrepti: etiam in infulas mari cinctas transfretare potuerunt: cujus exemplum, præterca quod 
stellero, ut diximus, obfervante in infulis verfus Americam fitis occurrunt, habetur in Maris Cafpii infula arcnola, medio littori inter Volge Rhymnique oftia oppofita \& a tractu deferti nrcuofo quafi avulfa, quam Calmucci a mira copia parvulorum Citillorum ibi obverfinte Surminil (Citillorum locum) appcllarunt.

Videbimus in deferiptione Citilli, hoc Animal, Marmotis alias fimillimum, buccis faccatis (minori licet gradu) ad Cricetos accedere. IIæc quidem ftruetura in animalculo tota hycme torpido, cuique commeatus congerendi nulla necchitas, fupcrflua videri poffet. Attamen ad verna \& autumnalia frigora fubinde, poftquam antris jam prodicre Citilli, incidentia, ufum in is effe, \& prefium tempettatis animal tunc in buccis alimentum ad antrum congeftare, ut fine famis periculo durante frigore delitefcere queat, precipue in Sibiria, omniuns vero maxime ad Selengam, inque Dauuria perfpexi. Ibi Citilli, fine dubio propter congeftandi habitum a ncceflitate (ob veris intempericm) crebriore natum, folliculos buccales folito (pre reliquis regionibus) multo ampliores \& facile pollicem vel faltem digitum majorem admittcntes, ad medium ulque collum cxtenfos habent, qui in Ruficis (calidioni in regionc parco ufu oblitterati) vix fabam capiunt. Vidi iltos (Aprili), ingruentibus frigidis dicbus, cffoflas raliculas \& germina Taraxaci aliarumque planiarum in nidos congeftalie, ef tune vix ullum racuis, plerosque refertillimis facculis cepinus.

Quamvis primo vere vis fullulare incifft herha, tamen cito admodum pingucfeunt. In rentriculis verno tempore diffeExtuin athuc non bene diftentis plerumque nil nifi gramen, germina varia \& fruticum cortices commanducatos inveni; contentaque ventriculi naturaliter in hoc animalculo non folm, naus 
feofi nihil fpirant, quod tamen plerisque animalibus folenme ert; fed gratiffmum quoque, fubvinofum, vel quafi virgarum betulæ concifarum odorem fpirant, ut in 'Tetraone 'Tetrice \& Lagopode pariter obfervavi. Ipfum tamen animal $\mathrm{cx}$ ore, Aretomyos inftar, ferinum quiddam redolet; toto ceteroquin corpore omnis fetoris expers, nec nifi co turpe, quod æftate adulta pediculis peculiaribus, tencræ Cimícum domefticarum progenici fmillimis, fcatcre folcat. Cllmable ani vel finus, quós prefertim iratum vel anxium animal extrorfum in triangularem formatn (Tab.IX. fig. S.b.) protrudit, ne oftri quidem tempore ullum odorcm produnt, nifi debiliffmum hircinum, quem avide fcctantur canes.

Cicures mares, quos primo vere captos Samare alebam, adlatas quotidic c campis fominas avide cxcipicbant, palmis \& ore permulcebant, totoque corpore velut deofculabantur, continuo fiftulante \& quafi leviter repugnante fomina; quan tandem reluctantem palmis mediam vi (ut genitalia extrorfum turgefcerent) complexus mas fecum in latus profternebat \& cute cervicis mordicus apprehenfa, plantis circa femora fominæ adhærens, intortis clunibus fubigebat, inquietam \& paffcrum frmili voce fubinde ftridulam, donec claufis utriusque oculis poft unum alterumve minutum peragereur opus. Poft congreffum piger mas eandem vix amplius curabat fominam, raroque in novam ca die venerem fuficere videbatur. Iam pregnantes quoque fominas, odore forfitan dignofcentes, intactas dimittere folebant. Alui marcs, ensdemque mitiffinos, c magnitudine pro anniculis mihi habitos, qui ad venerem torpebant \& inepti videbantur; fed an hoc lege naturx? non dixerim. Fœminas oftri tempore menftruari, nunquam obfervavi. $\Lambda$ dnotapit tamen STELLERVS in 
adverfariis: Jacutos fub finem Aprilis feminarum inter Citillos veftigia e fignis fanguimolentis dignofcere; fi modo non aliena veftigia ad Citillos fuerint relata.

Femina domi detenta $\&$ a cicuratis maribus fecundate omnes intra vigefimum quintum vel trigefimum a congreflu diem pepercrunt, quod circa Samaram in. initium circiter Maji incidit. Idem fere tempus de Lenenfibus prodidit gmelixvs. Sed in deferto Aftrachanenfi, ubi fepe ante initium Marcii jam copulantur, pariunt verfus initium Aprilis; ita ut medio Martii gravidas, fub medium Aprilis vero jam adultos pullos, dinidia matrum mole vagantes, fmul alias nutres gravidas foctubus vix fabam aquancibus obfervaverim. Unde vel plus fimplici vice in anno parere, rel non omnes codem tempore ceftro perciri apparet; $\mathbb{E}$ forte anniculæ tardius maritantur. Pariunt in gencre nudos \& ceecos pullos, fatis informes, albidos \& pro matris nole grandes, trinos, quatcrnos \& ad fenos, imo octonos ufque. - In pramagna Citillo ad Saratfchik primo vere capta (gigantew varietatis) emoryones per utrumque cornu matricis diftributi ufque ad xir. inventi funt, mole jam Muren domefticum xquantes, licet adhuc valde immaturi viderentur; fimul in medis, inter perfeformm embryonum utriculos, intervallis quatuor aderant embryones quafi emarcidi, vix $\frac{3}{4}$ poll. longitudine, utique non fuperfectatione natos, fed fubtracto forte alimento \& a majoribus quafi elifos ac fupprellos. An hujusmodi male nutritis partubus forte debeatur pygmea Citillorum varietas in isden, ubi. gigantea vivit, locis interdum obferrabilis, in furpenfo relinquo. Satis tamen verofimile eft varietates animalium atque avium, in quibusdam prefertin fpeciebus crebriores, male nutritis partubus, aque ac Nanos pulchellos, quos huma- 
num genus vidit, deberi. Immo fimile forfitan phænomenon in Lepore fuperfotationis, (in hoc tamen animali etiam per fructuram poffibilis) famam peperit. Sic Gallinæ, aves aquati. cæ variæ, maxime Pelecani, nimia fœcunditate exhaufæ, ova in eodem nido cum folitis, frepe dimidio minora pariunt \& minutam inde progeniem excludunt.

Pulli Citillorum celerrime adolefcunt, ut menfrui jam parum a dimidia mole matrum abeffe foleant. Tardius tamen, \& non ante xfatem, matris deferunt cuniculum, fibi profpicientes. Colore \& pilo adultis fecundum regiones fimillimi funt, fed mo. lc capitis \& ftultitia, dum extra antra vagi occurrunt, facile dignofcuntur; caque multi pereunt \& in pradam rapacium cedunt. Domi detentæ matres pullos adhuc teneros \& cocns, exturbato fponte nido quem paraverant, derelinquebant, ut plerumque frigore \& inedia perilent. - Cæterum incrementi celcritas æque ac geftationis tempus vitæ brevitatem fatis arguit, quo nimia Citillorum multiplicatio inhibetur, præertim quum vix nifi biennes, faltem mares, generare verofimile fit.

Minuunt etiam Citillorum numerum infenti animalculorum Subterraneorum hoftes, præfertim nocturnæ feræ, canpeftria habitantes, Putorius, Ermineum, Muftela, quorum facillima \& certa præda funt; etenim in antro fimplici aditu inftructo effugium non darur \& noctu præfertim fomnolenti opprimuntur. Mares tamen plures perire haud dubito, quum fint minus pugnaces \& antra capaciora habeant. Extra antra interdiu pabulan. tes Citilli a Falconibus variis, etiam minoribus, imno juniores a Cornicibus famelicis crebo dilaniantur; in Infula fupra memo. rata Maris Cafpii etiam ab Ardeis crebro devorari fcio, 


\section{DESCRIPTIO \\ MVRIS CITILLI. \\ T:L. I\% $\%$} cabitur.

Mignitudo fecundum regiones varia, ut menluris indi-

Coput crallius, minusque deprellum, quam in Aretomỹe, roftrum magis conicum, parotides minus gibbie. Thtix inter orbitas convexas, planimiculus. Nifili nigricuns, conpexus, fubtili veluto pubefecns, nudus tantum circa moris lunulatis, fipto camaliculato dircmets.

Labium fupcriss ulque ad nalum bipartitum. Bucce laxir, ante molares nerinque finmatix, plica ad primum molarem duta difereta, in Volgenfibus vix arellina capaci, fominis majori, in Sibiricis uque ad collum faccato finu.

Dintes primores fiperiores convexi, parum Iutefentes (rix in feminis), truncati; inforiores albi, lubadtenuati, apice rotundari. Molmas (non ut in plerisque gliribus detrito lamelloli) red acutius lumanis tuberculoti, infra media corona excavati, utrinque quaterni; fippra accelturio antice minore, fubconico, quini ab utralue parte: poltremus utrinque lupra infraque mijor: \& tota dentium facios cmmiormm iidolom aliqualiter indicar.

MTy/faces nigri, capite breviores, minus ordinari, quinque fere ordiniblis per latera roltri convexa frarli. Supra canthum oculi anticum feter nigne to ferie fere transwerlia fita paro-

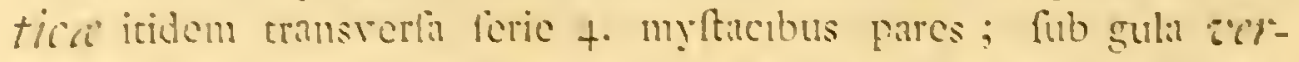
rmen!ll lets tribus tenellis albis. Antibrablinhl in medio cxtus pilo longo folitario, \& tribus verfus carpun interiusque minoribus. 
Oculi magni, prominuli; palpebra margine nudo fufcæ, ciliis nigris; perioplstbalmiii loco caruncula canthi unguiformis, fufca, fubcartilaginea, membranæ latiufculæ, laxx inharens. Irides brunneo-fufcæ; pupilla ampla, ctiam ad lucem longitudinaliter ovalis.

Auriculce nulls; Meatus auditorii nudi, anfractuofi, pofterius margine crafo, pilofo coronati, qui quafi prafectx auricula cicatricem refert.

Curpuls reptabundum, depreffum, minus ventricofum, quam Marmotis, flexile. Pellis tenuis, laxa, maxime plicis verfus artus dilatata.

Artus minus roburti, quam Marmotis; pnlma tetradacty1a, unguiculo pollicari conico, magis (quam in Arctomye) prominulo; plante pentadactylæ, tribus mediis fubæqualibus. Ungures infignes, nigri, compreffi, acuti, in palmis longiores.

Callal proportione, fecundum varietates, diverfa, pofticis artubus plerumque brevior, linearis, murino more fubannulata, fed tota pilis longis veftita, in plerisque varictatibus fciurea inftar difticha criftata, \& pro lubitu animalis magis in pennatam formam expanfilis.

Vellus molle, breviufculum, lrvigatum, piiis fafciculatim difpofitis, vix femipollicaribus, lanugine inter pilos fupra albida, in ventre fufca. In capitc pilus rigidiufculus, ftrictiffimus, poftice. fenfim mollior, laxiorque. Suturre brevis fub collo, infignior a cardia ad pubem, longitudinales.

Colnr fecundum regiones maxime variabilis. In mediscri perfectiore varietate fupra (ad inftar plumarum perdicis) canocinercoque mixtus, undulato-fubfquamatus $\int$. magis minusve fubguttatus quibusdam, magisque vel minus gryfeo-flavefcente im$\mathrm{T} 2$ 
butus, prafertim junioribus \& feminis. In occidentalibus temperatis huic varietati facies ufque ad aures tota (excepto vertice dorfo concolore vel magis cano) luteo-ferruginefcit, intenfius nafus, litureque fuperciliorum \& fub oculis; collum \& quatuor pedes lutei, reliquum corpus fubtus flavefecnti pallidum. - In frigidis orientalibus facies ommis \& corpus fubtus totum albicant. - Varictas guttata fupra gryfeo-fufcefcens, guttis diftinetis albidis, fubrqualibus maculata, facie exalbida, lituris tantum circa oculos, nafoque rufefcentibus. - Auftraliorum color e gryfeo vel cinereo magis minus ve flavicans, obfoletiflime undulatus, vel guttatus, imo in maximis aquabilis; fubtus fordide pallidus, ferruginefente ficiei colore obfoleto. - Cauda villi plerisque fulveicentes, anmulo fufco notati, cxtremo canefcentes; unde expanfa linea per ambitum fufca, cannque fimbriata apparet. - In guttatis cauda minus villofa, tcretiufcula, fufcefcens, pilis longioribus pallidis. - In feminis cauda femper villofior.

Anls caude proximus, intra orificium finmbus tribus febaceis inftructus, (Tab. IX. fig. 6.) comprefo abdomine his ipfis fimbus extrorfum fubverfis \& turgentibus tripapillaris (ibid. $f i g$. S. ...)

Sirotum mafculis nudiufculum, fufcum; Prepntium fubftrictum. In fominis en!lua ano proxima, labiis tumidulis extus convexa, ovalis; clitoride intra labiorum commifiram latente, exferili.

Milm!malmmm papilla numero variant: plerumque duo paria femorilia, totidem abdominalia, par fupra coftarum fpuriarum cariligines, \& par ad ad armos, aderque duoder? $\alpha$; in aliis ab axillari finu ad inguina urinque vil. aquidiftantes, adeo. 
que fexdecim; aliis uno pari minus f: quatuordecim. - In maxima varietate tantum decem, pectorales Iv. totidem ventrales, \& 11. inguinales. Papilla tempore prolis magnx, conicæ, fufcx.

\section{ME NS V R $\Lambda$ E.}

Mediocres mares plerumque libram medicam pluribus unciis fuperant, \& adulti ad libram cum novem decemve un. ciis accedunt; fentince nunquam uncias IX. vel X. pondere (nifi gravidx) excedunt. Maxima varictatis feminx (quas folas habui) quatuor libras medicas explebant. - Minuti contra in deferto calpio fappe vix quinque vel fex ad fummum uncias xquant.

Menfirns proportionum ex utroque fexu comparatas e Samarienfibus Citillis dabo, mare fexdecim, femina novem unciarum, verno tempore adhibitis, adultis.

Longitudo tota a nafo ad anum Maris. Feminae. Longitudo tota a nato ad anum - - 9." 9.1" - 9.1 . 2.111 Alitudo ftatura antica - $\quad 3.6 . \quad$ - 2. 9.

Longitudo capitis ad nucham - - 3. 4. -2. $7 \frac{\mathrm{r}}{2}$

Circumferentia roftri pone nyftaces - 29.

- capitis iriter oculos \& aures - - 4. $90 \begin{array}{lll}-4 & 6 .\end{array}$ Intcrvallum narium $\quad \cdot \quad$ 0. $1^{\frac{3}{4}}-0.1^{\frac{3}{5}}$. Latitude nafi - . $\quad 0 \quad 5 \cdot-0.4 \frac{3}{5}$, Diftantia oculi a nafo . $\quad$ 1. $0 .-0.11$. - inter oculurn \& meatum auditorium : 0 . $9 .-0.8 \frac{1}{2}$. Fiffura palpebrarum - $\quad-\quad$ - $0.5^{\frac{2}{3}}=0 . \quad 5$. Apercura iculi - - $\quad$ 0. $3 \frac{1}{3} .00 .2 \frac{5}{6}$. Intervallum oculorum anticum filo - $\quad$ 1. $33^{\frac{3}{4}}$ - - 1. 2 .

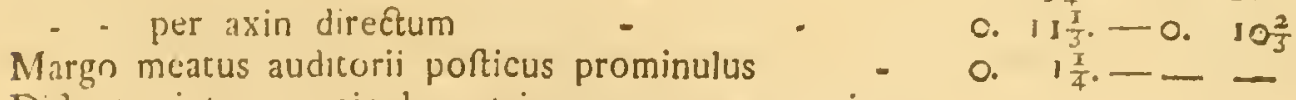
Dittantia inter prominulos utriusque meatus margines, filo Fadem per directum axin Lougitudo colli

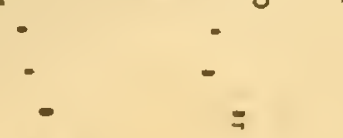

T 3
I. $4 \frac{3}{3} \cdot$ I. 3 .

1. $2 \frac{1}{2} \cdot-1$. $\frac{3}{4}$.

1. 0.1 . 0 . 


\section{Circumferentia colli}

- thoracis ad armos

- in ampliflima parte thoracis

- veneris medii

- - ad femora

-) L.ongitudo cauda fine pilo

Exluperantia pilorum caudie

Diltantia ani a cauda - prapucii ab ano

Longituito rulva ano contigur

Circumferentia cauda bafi

Longitudo ancibrachii

Circumferenia cjusdem bafi

- carpi

L.ongitudo palma cum unguibus

Longitudo unguis longiflina palmx

- cibia

- planta a calcaneo ad apices unguium **)

Circumferentia tibia bafi

- tibia ad calcaneun

- mecacarli

Longitudo unguium planta
Maris.

2." $5.111-2.113 .11$

5. 2. - 4 .

6. 4. - 4 .

0.

5. 4. -4 .

5.

4. II. - 4. J.

2. 10.2 .10$.

I. I $\frac{1}{2} \cdot$ I. $1 \frac{\mathrm{r}}{2}$.

o. $2 \frac{\mathrm{T}}{3}$. 02 .

o. $10 \frac{2}{3} .-1$

$-$

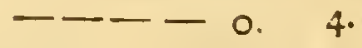

0. $7 .-07$.

I. $6 \frac{2}{3} .1 .5$.

I. $9-1.4 \frac{3}{3}$.

- $11 \frac{1}{2} .0 .10 \%$

3. 2. - 1. 2 .

o. $3 \frac{4}{5} \cdot-03 \frac{4}{5}$.

I. $8 .-1.7 \frac{\pi}{5}$.

I. $11 \frac{\mathrm{I}}{2}$. -1.9 .

2. 2. - 1. 9 .

०. I1. - 0 10.

I. $0 .-0.11$.

o. $2 \frac{3}{5} .-0.2 \frac{3}{5}$

\section{A N A T O ME.}

Tab. 21. fig. 6-10.

Pillis tenuis punetis intus fulcis, a pilorum falciculatosum radicibus pellucentibus. Plnguledo vere tantum circa inguina, anum \& tenuis circi alvum \& fub axillis fupereft. At

*) Erequentior ad Irtin sariebas e fpecimine femineo $\times 1 \frac{1}{2}$ unciarum, fequentes edidic proportiones: Long. tota 8 " $6 / 1 \prime$ c:ipitis 2.11 1." caudx $1 . " 1$, $0 \frac{1}{2}$. exfuperan. tia pili g."Il palma 1." plantie 1." 6."IAli Serpisis omnium proportiones conlideunt ut Mafculo ferquilibri aunotavi, fci. Jicet: Longirudine toca $10.11-\frac{1}{2} /, 1$ caput fuir =." $\mathbf{5}$."l longitudo cande $3 . "$. 6."ll aduititia pili infuper $1 . / 2.11$ - In g1!sta. tis at ocidentem: $T$ "olgae: Longitudo tota 9." caudre $3.1 /$ 3."I pili infuper $6.1 /$ pon. dus $X$. unciarum (pinguiniìmo).

**) Notari vellem, quod magnitudine tantum ilantarum utrumque fexum differ: re obfersarim, palmis in ftatura creterum valde insequali paribus, ut fcilicet femins fodiendis profundis ruis cuniculis habilior eflet \& robultior. 
in autumnalibus tota præfertim dorfi fuperficies cruftra pinguedinis valde olcaginofe obducta, circa collum, per pofticum dorfum \& in inguinibus craflifima, ad tres fxpe uncias rquante, preter omenta, qux, licet ampla, tamen ob laxitatem pinguedinis vix unciam fuperare folent.

Panniculns mufculofus extra pinguedinem fubcutaneus; per torfum to:um \& latera expanfus, fafcia utrinque fub axillis ortus \& poftice gemina fafcia fupra caudam infertus, in medio dorfo firmilime pelli adglutinatus. Tenuis expanfio mufcularis pone aures utrinque orta per colli latera explicatur. Sub oculo utrinque glandula lunata, glomerata, fubcutanea. - Ad ipfum exitum vaginæ teftium ex abdomine, glandula infidet lymphatica, (Fig. S. gg.) male cannabis, pinguedine involuta, quæ vulgo in muribus magis verfus hypochondrium remota, panniculo carnofo inhæret.

Glandulce thymo analogx utrinque circa collum, \& fub mufculis pectoralibus latiflime, ut in Marmotis; thymmos item maxima.

Abdominis aperti fretor, ut in isdem, infignis. Omentunn ventriculi raricularum, circa ipfum ventriculum revolutum; lumbaria magna, pinguifima, omnia vifcera, valvarum inftar, a latere obvolventia.

Hepar tripartitum, pondere (in Mare vernali cujus menfuras dedi) $5 \frac{2}{3}$ drachmarum. Lobnls finifter maximus, integer, femiovalis; medins ligamento, incifura \& folla inferne profunda, venam recipiente bipartitus, cytidenque fovens; dextering bipartitus, utroque triquetro - acuto, \& pro rene recipicndo excavato. Prxtcrea Spigeliamns lobulus compoficus c duabus ligulis oppofitis, obfolete triquetris, apice rotundatis, baf 
cöadunatis, quarm dextra major. - Cojis magna, globofo: sdecumaca, repleta bile viridilima, fape fomidrachma pondere. Duftus bilurius vix n." a ftrictura pylori diftantia inteltino infundicur.

Lien ruberrimus, triquetro-depreflus, utroque apice obtufus, longit." $1 . "$ 1 $\frac{1}{2}$ " latitudine lumma $6 . "$ pondere firupuli cum fex granis.

Fentriculus omento ufque ad dorfum totus, prater areolam a liene fecundum fundum occupatam, involutus, forma haud infolitus, ut in Artomye, circumferentia inflati, in jejuno amplifima 2." $8 . "$ at in faturis fiepe ultra $3 . " 6 . "$ "

Intifinum temue totum fore tripedale, iefiuiquadruplum animalis; in qua longicudine pro duodeno $3 .^{\prime \prime} 6 .^{\prime \prime}$ jejuno difincto s.", ilco fere bipedalis portio. Circunferencia tenuis inteftini in jejuno vix 9." in puftis ad I." 2."

Crcuml (Tib. II. fig: 7. 1.) ficcatum, quale in Aretomye, fed exeus venis vix evidenter, incus plane non cellulatum. Circumforentia parcis amplilima 2." 10. " longitudo filo per arcum a fundo upque ad fricturam, $(b$.$) cui inferitur ile-$ on (d.) circumducto 5." $4 . "$ "

Colon amplo initio $(b-c$. cerco contiuuatum, fenfimque adtemuam, a prima curvacura (e.) ilco anguftius, ultra fecun. dam (f.) demuo fenfim laxius, rectoque continuatum. Longitudo ab initio ad primam curvaturam $-. " 6 . "$ " hinc ad fecundam 6." $6 . " \prime$ inde ad anum $6 . "$ qui orificio (ut dictum cft) triInuaco (fgo. G.) vel tripapillari (fog. S. \%.) ad ipfan cauda bafin (17\%.) effunditur. Portiones reduplicate coli omnes inter fe parallelx, figmoïdeo Alexu in dextro hypochondrio verfus dorfum repolita, arcu denique rerfus rectum finiftum tendentes. 
Renes fimplices. Vefica urinaria ovata, capacitate ovi fturnini, longitudine rr."l vel minor (Fig. 9.i.)

Cientalia mafculina (Fig. 8. in fitu) proportione multo majora \& flcridiona, quan in Arctomyc, cujus alias fabricam, heic c Citillo fufius defcribendam, accuratifime reforunt. Penis (Fig. 8. 9. a.), qua cxfertus praplitin (b.), cylindricus, coronatus glande agariciformi, latcribus prominentiore, fubtus foflula bipartita, (Fig. E.d.), quam fuperminet bulbulus fupra cordatus mollis, fubtus fubdidymus, mucronatuo afice fubcochleariformi, fupra laretbre orificio longitudinali canaliculatus (Fig. q. a.), fuffultus afjiculn fingulari (Fig. I I.), cujus apex unguiformis, hine concavus (a.) tnargine fubtiliffime crenulatus, bafis craflufcula apici corporum cavernoforum innata.Nervi dorfales penis duo robuftifimi (fig. 9.cc.), ab iliacis oriundi.

Cr.pona cavern!g (Fig. 8. a. 9. a.dd.) Iongitudine s." 2." cylindro communi in crura brevifima (dll.) divifo (fig. S.ll.) Bulbus uretbra (fig. 8. 9. ee.) magnus, didymus, glanduiofus, extus ftrato obliquo mufculofo obvolutus, intus fiffula excavatus ( Fig. I O.a.), qux antrorfum ductu in urcthram continuatur, poltice recipit ductus e folliculis 1, feudoparaftatis (fig. 8. it. 9. $f f$.

Hi glandularum Cowperianarum analogi extra peivim cat:die utrinque adfidentes, pifo majori æquales, duri, fphærici, cr ftant membrana albida, crafiufcula, fortiore, refertifisio $m$. tenaci, gelatinx tragacanthæ fimillimo, macerationc in aqua : mefcente, perque ductus \& urethram pariter, ruptoque for liculo crumpente (fig. 9. F.) - Dučtus horum follicu. excretorii molliores, cylindrici, folliculo circumficxi \& adius 
(fig. I O. b.), facile tamen cultro feparandi (c.), $9 \frac{\mathrm{T}}{2} \cdot{ }^{\prime \prime \prime}$ circiter longitudine.

Iftlmus urethræ $(f g \cdot g \cdot g \cdot)$ cylindricus, fingularis, extus mufculofus, intus (fig. IO.d.) plicis obliquis utrinque circiter denis, fupra infraque in jugum longitudinale pinnatim concurrentibus concameratus. Huic fuperius collum vefica $\left(f_{.}\right)$ intus longitudinaliter rugofum infunditur, pone quam aperturam ifthmi cavum duobus cacis fimbus definit, quibus adfidet profitata (fig. 9. \%.) parençymatofa, ovata, \& ipfis finubus implantantur veficulæ feminales. Oefrri tempore cavitatem ifthmi totam farctam inveni maffa fpernatis, febi confiftentia, oblonga, ab impreffionibus plicarum quafi erucxformi.

Veficula feminales (fig. $9 . k k$. I o.e.) conftant inteftinulo crifpato \& corpufculo triquetro, quod reflexum inteftinulo adhæret, itidemque ex inteftinulis glomeratis compactum, videtur. Ductus deferentes (fig. 9. ll.) inter veficulas feminales ifthmo inferti, tenues.

Teftes (fig. 9. $n m$ ) oblongi, majufculi, plexu pampiniformi \& valis ferpentinis infignibus. $\quad V$ ll $\int a$ fpermatica (on.) in omentis lumbarilys decurrentia, quibus ramulos impertiunt. Enidinymidis ( $f i g .9 . m m$ ) caput oblongum, per ductum infignem tefticulo coharens; medium gracillimum, circiter pollicare, ductu anfractuofo conftans; venter ovatus, in fcroto feu vagina teftis mufculofa adnatus, a quo ductus deferens oritur. Turefcentibus organis primum epididymis in fcrotum elabitur, fubfequente demum tefte integro ( $f g .8 . f . f$.

Fumince clitoris terminata officulo unguiformi, denticulato, denticulis recurvis. Vteri cormna fubflexuofa, fecundum omentorum lumbarium marginem adfcendentia. In focundatis 
(quinto poft congreffum die) in pelvim retorta \& anguinis flexibus collecta, nodisque obfoletiffmis diftincta. In gravidis ad lumbos repofita, partubus nodofa, extus longitudinaliter fibrofa, interna tunica vafculofifima; omenta fimul vafculofiora fed emaciata, venis præfertim turgidifinis, quarum una e cava, altera ex iliaca, tertia fecundum uterum e pelvi adfcendens, omnes arcubus communicantes. - Embryommm membranx te. nuiffimæ, hyalinæ, fubtilifinnis rarisque vafculis; placenta orbicularis, craflufcula, margine obtufo, tumidulo, latere foctum refpiciente concavo, omnes a latere cornuum omentis adhærente \& vafa refpiciente adnatæ. Canales communicantes inter uterum \& placentam evidentiffimi, capillo humano pares. Ex umbilico cmbryonis, prxter venam \& arterias, figillatim oriuntur vafcula per chorion diftributa.

Mammales glandulce ad fingulas papillas orbiculares, diftincte, a vafis mammariis irrigatæ, quæ fub pectorali orta ufque ad femora longitudinali filo decurrunt, occurruntque vafis ex inguine ad proximas mammas adfcendentibus.

Pulmones proportione magis extenfi quam in Arctomye; finifter minor, tenuior et pro corde loboque impari excavatus, tantum antico margine in medio incifus. Dexter in tres lobos, præter imparem, profunde difciffus, quorum infimus maximus; impar lobus a dorfo cordis ad finiftra repofitus conftans portione magna, triquetra, falcata, finiftro pulmoni applicata, parvuloque fubovali lobulo ad fpinam hærente.

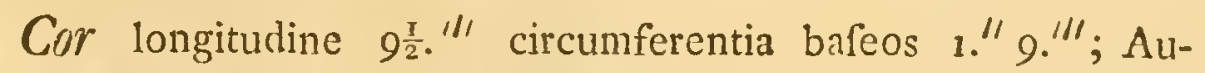
ricula finiftra parvula. Ex arcu norte trunci duo, quorum dexter major.

Sceleton præter proportiones, præfertim vero craffities $\mathrm{V} 2$ 
\& forma cranii, (Fig. I I.) omnium ex ordine Glirium prow xime Sciuro affimilatur. Frons inter orbitas leviffime excavata, fimul plano arcuato verfus roftrum item arcuatum \& cona vexiufculum, minusque verlus occiput declivis. Na/i offa antrorfum latifima, robuftifima, convexo gibba ultraque incifores prominula, pro fulciendo nafo foflorio. Proceffus fupraciliares valde retrorfum, ad ipfa offum temporalium confinia, re. moti, triquetro - fubulati. Zygomata robufta, oblique ancipitia, latiufcula. Olla cranii convexa occipite folo plan:ufculo. Maxilla inferior lata, robuftifima, bafeos proceffa prominentifimo extrorfum diftorto, \& pro mufculorum infertione. tuberofe acuto.

Epiftropliceus crifta lata rotundata prominens; dor falinm vertebrarum tertia fpina reliquis longiore, pofterioribus fenfira minuenda; lumbares procefribus fupra latis, retrorfum fenfim majoribus. Cofte XII. quarum reptem verce, \& fpuriarmm tres cartilaginibus adnexæ; longiffima octava. Stermmm, præter manubrium triangulare, carinatum \& enfem cartilagineum, e qui tuor ofliculis teretibus compofitum. Lumbares vertebra feptem; fucri quatuor, candice a 16 . ad 20 variant. In omnibus. vero fumma cum Arctomye fimilitudo.

Proportiones fceleti e fequenti tabula optime perfpicientur; qua Samarienfis varietatis marem \& feminam comparate defcripfi: Longitudo cranii a prarupta facie occipitis ad finem offium

$$
\text { Maris. Feminae. }
$$

\section{nafi}

Lativudo olle pone zy:gomata

- fumma ad arcus zygomatum

- minima inter incifuras orbitarım

D.ftancia inciforum a molaribus

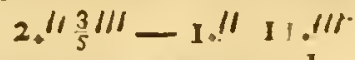

I. 1. - - $11 \frac{1}{2}$.

s. 5. -1 .

o. $4 \frac{4}{5}-0$.

0. 2. - 0 .

0. $7 \frac{1}{2}-0$.

4.

$4 \frac{\mathrm{T}}{\mathrm{S}}$.

2.

7. 


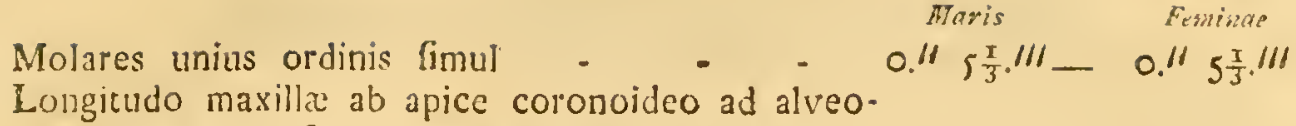
los inciforios Altitudo ramorum maxillex perpend. Longitudo vercebrarum colli fimul

- vert. dorfalíum collectim

- vertebra dorfi duodecimæ

- vert. lumbarium fimul

- longiffima tertiz

- facri

- caudæ fexdecim articulorum

- coitr longiflima

- fterni line enfe

- enfis

- claviculic

- Ccapulz

Latitudo fcopulæ

Longitudo oflis humeri

- ulna

- radii metacarpi medii digiti - -

- phalangis prima

- fecundx

- terminalis condyli cum ungue

- phalangis pollicis

- ejuldem unguis

- oflum pelvis tota

- oflis femoris

- tibiæ præier malleolos

- fibula demum adnatx

- calcanei

- meiatarfi medii digiti

- phalangis prinix

- phal. lecunda

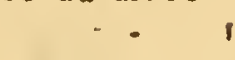

1. $2 \frac{\mathrm{I}}{2}$. $\quad$. 3 .

0. $\frac{\mathrm{I}}{2}$ - 0.6

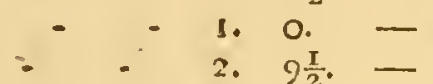

2. $9 \frac{\mathrm{I}}{2} \cdot$

○. $3 \frac{\mathrm{T}}{3}$

2. $5 \frac{2}{3}$.

c. $4 \frac{1}{2}$.

o. $10 \frac{2}{3}$.

०. $10 \frac{\mathrm{r}}{2}$.

2. $4 \frac{1}{2}$.

o. 3 .

2. $4 \frac{x}{2}$.

O. $4 \frac{T}{4}$.

o. $11 \stackrel{2}{\longrightarrow}$

3. 6. - 3. 2.

J. 5. - I. 3 .

I. $5 \frac{x}{2} \cdot \quad 1.6$.

o. $3 \frac{\mathrm{I}}{2}$. - 0.3 .

0. $10 .-0.9$.

1. $1 \frac{1}{5}$, 0. $11 \frac{\pi}{2}$.

0. $7 \frac{1}{3}$ - - . $6 \frac{\pi}{3}$.

I. $4 \frac{1}{2}$. 1. 3 .

I. $7 .-1.4 \frac{5}{2}$.

I. 3. - I. $\frac{2}{3}$.

○. 5. - C. $4 \frac{\pi}{2}$.

o. $3 \frac{1}{2}$ - o. $2 \frac{2}{3}$.

O. 2 . - $0.1 \frac{3}{5}$.

(). $4 \frac{2}{3}$. $0.4 \frac{1}{4}$.

O. 2. - $0.1 \frac{\pi}{3}$.

○. $1 \frac{1}{2}$ - $0.1 \frac{3}{2}$.

I. 8 1. $6 \frac{1}{2}$.

I. $8 \frac{1}{2}$ - $1.6 \frac{3}{4}$.

I. $7 \frac{3}{5}$ - 1. 6 .

I. $5 \frac{1}{2} \cdot$ I. $4 \frac{3}{5}$,

O. $4 \frac{2}{3}$ - 0 . $4 \frac{2}{3}$.

D. $7 \frac{\mathrm{r}}{5},-6 \frac{5}{\mathrm{~g}}$.

○. $3 \frac{1}{2} \div$ 0. $3 \frac{1}{3}$.

०. 2 . 0.20 


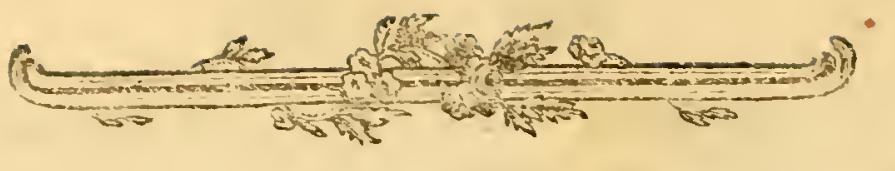

\section{V S \\ T $Y P H L V S$.}

Diu caca \& oculis orba credebatur Talpa, cui primus BIDLovs, refticuto quafi vifu, cœcitatis notam ademit. Animal quod hic defcribimus, omni fpe luminis excidit, totoque fenforio organo externe orbatum, folum Talpa coccius, inter hactenus nota quadrupeda quatuor fenfibus contentum efle debet. Forte tamen fociam miferiæ aliquando inveniet Talpan capenfem a), aut fi quam forte hujus quoque murini generis aliam fpeciem coecam, Natura alicubi terrarum produxcrit.

Ante nuperrima ab Academia Petropolitana procurata itinera phyfica, Zoologis nondum notus erat Typhlus; vix enim notitia dici poteft imperfecta illa apud RZACZINSKIVM mentio, quam BVFFoxio adoptatam inter fynonyma Typhli in elencho fpecierum recenfui. Mihi non prius in manus venit, quam cum regiones inter Tanaïn \& Volgam, redux e Sibirico itinere, peragrarem. In omnibus enim ad orientem Volgæ fitis regionibus, adeoque por univerfam Sibiriam deeft.

a) Talpam auratam volo, quæ in Pro- vos der Meulen benigne fuppeditatum; montorio auftrali Africes patriam fixit, in quo preter deutium ftructuram \& nuapud SE 1 A M rero pro fibirica quondam merum, inter Talpam noftratem \& Soricem defcripta fuit; unde me toto durante fere media, oculorum externa reftigia itinere defiderio fui exercuit; donec tan- plane nulla detegi pofiunt. Neceffe dem reduci mihi procurarit fpecimen, antem ut aliquis in recenti rel liquore affabre farctum fed capenfe, Amicifl. affervato animale denuo inquirat.

Nii. Lour. Burmansus a Nobil. Willieino 
Frequens contra in terris ad occidentem ejus fluvii fitis a Syfrano ufque ad Sarpæ confluentem, quoufque nempe folum humofum et cæfpitofun invenit; a limofo enim falfoque per defertum cafpium regnante adeo evidenter alienus eft, ut nullibi in hanc planitiem defcendat, licet in ipfo margine collium ad Sarpam per convalles frequens vivat. Secundum Tanaïn omnem, præterquam in arenofis, habitat, \& cum Citillis, magifque localibus Marmotis usque verfus fontes ejus \& Rælk oppidum pafim obfervatur. Datur etian per omnen reliquam Rufiam auftealcm, \& herbidos huic fimiles campos confinis Polonix. Inque has regiones planas (prima mundi ætate fub æquore torpentes) a primæva patria Carpathico jugo defcendiffe videtur, \& altiores collium atque terrarum tractus fecutus, fontes quidem Tanaïs fuperavit, inter eum atque Volgam in auftrale intervallum fenfim propagatus, fed ipfum Volgæ alveum nimis borcali ambitu prodeuntem fuperare non potuit, quum a frigidioribus regionibus abhorreat, flumina autem, propter fubterraneum vitx genus, trans. gredi nullatenus queat. Pari itaque ratione ab occidente Viftulæ, ab auftro Danubii alveo exclufus, in Europæe occidentaliora regna pervenire non potuit. Efque adeo infigni firmamento hypothefi quæ juga montium primaria ab initio mundi habitata fupponit; quemadmodum etian (ut alia multa nune tranfeam) Leporis pufilli circa uralenfia promontoria, Lep. alpini \& Muris Afpalacis (quem ftatim videbimus) circa magnum Sibiriæ jugum alpeftre localitas, vix aliunde explicabilis videtur. Immo haud fcio, annon fingularis diverfitas inter Citiilos folo Volgæ alveo differminatos, cujus e folo vel climate rationem nullam reddi poffe fupra indicavi, fimiliter $\mathrm{e}$ diverfarum ftirpium, antiquitus fub diverfiffimo colo multis fe- 
culis viventium \& mutatarum, propagationi tribucnda fit; fic nempe, ut Citilli guttati \& brachyuri a Carpathico, majores variegati criftata cauda confpicui a fibirico jugo ortum duxerint, utroque populo thminis nunc limite fegregato, \& antiquitus impreffum habitum, ftaturam, colorem utcumque retinente. Hujusmodi exempla localium circa palmaria juga animalium innumera (fi hic effet locus) adlegari poffent, \& illufriffinum prabet univerfa America tot peculiaribus quadrupedum fpecicbus habitata; imo \& Africa multis ab Afa diftinctis animalibus idem loquitur, adco ut etian imperium Leonis vix extra Africam, Tygridis nondum extra Afiam prolatum videamus.

Vice genere Mns, Typhlols Talpa fimillimus cft, licet genere, forma \& victu alienillimus. Continuis nempe fub cxfpite cuniculis, fepe per infignia fpatia procedit. A primario cuniculo paffm collaterales fodit ramos, angulo frepe concurrentes, propter quærendas \& rodendas radices. Terram c canalibus fimiliter per aliquot ulnarum incervalla factis oftiis egerit, ut cumuli lupra ipfas aperturas duum fape ulnarum circumferentia \& infigni altitudine exifant, e quibus facile nofcitur. In captis obfervavi: animal petifimum latis atque nudatis dentibus tcrram duran, radiculis intertextam rodendo, \& roftro (velut aratro) fublevando ac trudendo cavare, folutas moleculas palmis fatis imbellibus fubter fe rejicere, plantisque propellere, integras vero fubinde terre moles clunibus antris extrudere retrogradum. Eaque ratione celerime fe totum defodit. Aliquoties recentifimis egeftre terræ cumulis proditum animal fodiendo cepi, ubi nondum labyrinthos effecerat. Promtilimo autem ibi quoque labore opus eft; namque inimicum fentiens fatim perpendiculariter 
perpendiculariter in profundum fe defodit penitus, ut nonnif mollitic terræ, qua canalem fupra fe opplevit, prodatur. - Captus morfu acerrimo, at propter coccitatem facile evitando fe defendit, eoque extra terram continuo minatur, fublato aufcultans capite, ut in icone noftra (Tab. VII.) expreflum eft. Nihil autem omnino nifi fenfu vel auditu percipit, \& Talpa cocior incaffum furit. Dum laceffitur ftertit, vel quafi mulitat iracundus, dentibus more generis frendens, nullo unquam alio, licet ad mortifera vulnera, mihi fono exauditus. - Sponte alias non raro ex antris prodit, matutino præfertim tempore, \& durante oeftri periodo etiam interdiu, ut in aprico cum focia conveniat. Sporadici enim vivunt, nec ullibi adeo frequentes ac certis in regionibus Marmotæ, imo vel Citilli. - Hyeme torpidum haud fieri Typhlum continuati in ferum ufque autumnum labores probant; Novembri menfe in auftralioribus fodientem cepi. Parant autem illo tempore profundiorem, circa arbufta vel arbores nidum \& molli radicum ftuppa replent. An vero quidquam pro hyemali cibo colligant, vel an profundiores tunc radices fectentur, non determino. Fortaffis etiam rigidiffimo demum gelu obdormifcunt \& fonno faturi mediam hyemem tolerant, quod tamen parca, etiam autumnalibus pinguedo \& glandularum thymo analogarum (quas animalia hyeme fopita magno apparatu habent) defectus improbabile reddunt. Gratiffmum alioquin pabulum radices Chærophylli bulbofi, graminumque cæfpitantium præbent. Iliud præfertim ubi crefcit, vix unquam cumuli horum animalium defunt, unde potiffmum in convallibus \& depreffis camporum occurrunt. Sed alias quoque radices promifcue rodunt, non fine proclilectione fapidiores feligentium. Herbas vero qualefcunque oblatas ut \& 
lumbricos recufant omnes. - Dicendum quoque de nominibus popularibus, fub quibus apud Rufos aliosque notus eft Typhlus. Et vulgo quidem rufice fummo jure Slepez, id eft Coecus, appellari folet, eodemque fenfu a Calmuccis volgenfibus Sfócbor - rómon vocitatur. - Eft vero in Vcrania ufitata alia appellatio, quæ Singkö̈ - St chenjae audit, cujusque derivatio fuperititiofa eft. Credit enim vulgus illum, qui Typhlum manibus fufiocaverit, eorum digitorum, quibus animali vim adtulit, tactu poffe curare fcrophulas \& glandulas circa collum induratas, qua ruffice Sbelefy \& apud Ukranos Salofy clument, unde abbreviatione adjectivum Sinfkoi - cum additione Stfchenae (catulus) effecerunt. Itaque decantata virtus Regum Gallix apud Ukranos admodum obvia \& vilis eft, nec fpero minus efficax, fi quid imaginationis vires in iftos morbos valent.

\section{DESCRIPTIO \\ $M \dot{V} R I S T Y P H L I$.}

Tab. VII.

Moles Citilli mediocris. Caput magnum trunco latius; fupra planum, fubtus mandibula gibbum, utrinque a nafo ad tempora corio incraflato carinatum, pilisque rigidis convergentibus criftatum, criftis fimul cum nafo femiellipticam aciem, planum verticis terminantem, conftituentibus, ita ut defuper infpectum caput formam fpathe rotundatam referat.

Nafus latus, cartilagineus, utrinque verfus criftam myftaceam angulo molli rugofo dilatabilis, depreflus, retufus, fupra planus, facie tranfverfim lanceolata, fubtus ufque ad incifores nudus \& declivis. Nares fubtus remotiffimæ rotundæ; fciffura lunata verfus marginem excurrentes, ftria fepti latifimi nulla. 
Os hians, dentibus plane exfertis. Incifores utrobique maximi, lati, ceftriformes, extus plane albi ${ }^{b}$ ); fiperiores breves, usque fub nafum denudati, nulloque labio vaginati; inferiores longinimi, labio laxe circumjecto bafi vaginati. $L a-$ binnn fuperius pone incifores tumidulum, villofum; os utrinque non occludit, fed ad fulcum a palato verfus incifores excurrentcm devexum eft, \& poftice papillari tuberculo coarctat hiatum oris verticalitcr oblongum, lingllaque exferenda femiobturatum. Palatmm anguftifimum, antice rugis circiter ternis obfoletis, inter molares lævigatum. Molares ubique terni, fubdidymi, teretiusculi, corona obfoletius detrita.

Myftacum loco pili longiores, teneri fupra infraque criftam lateralem capitis fparfi, fubtus copiofiores. Pili gemini medio inter criftam myftaceam \& porum auditoriun.

Oculornm apertura plane nulla, ne in detracta quidem pclie detegenda, licet adfit rudimentum utrinque oculi, papaver zo granulo minus, membranulis \& mufculo cutaneo obteEtum.

Alricula nullæ; pori auditorii minufculi, furfum directi, comiventes, vellereque latentes, armis proximi; adeoque

Collnm fere nullum, nifi levis difinctio capitis a trune?

Trulicus cylindraceus, fpina recta rigidiufcula cxter fus, Artuls breviffimi, poftici haud longicres, extremitate albidi, nudiufculi, digitis præfertin palmarum fere glabris, tenellis.

Palme mediocres, pentadactyix, fiffe, digitis divcigen. tibus, plica tenera bafi connexis, verfus ungues adtenuatis,

b) in his, pro conftitueudo peculiari talpimun fenfin ad Lemmum degenerans, genere, non fatis virtutis effe, fequentium fatis probat.

fpecierum feries, per M. capenfem \& 
mediis fenfim longioribus, at pollice reliquis breviore, magisque adnato. Ungues omnium xquales, breves, conico - obculi. Vola palme verfus carpum dilatata, cartilaginea, plana, villo rigidiufculo, deflexo circumvallata, verfus digitos biconvexa mollis. Litura fufca ad carpum extcrius.

Plantre minores, unguibus paulo longioribus, digitis ultcrius concretis, lateralibus multo brevioribus, folo apice exfertis. Solere ufque ad calcaneos nudx, molles, villis inflexis utrinque obvallata.

Canda nulla; vcftiginm papillare nudum, milii magnitudine, coccygis locum indicat. Anns in areola lanuginofa, nudiuscula connivens. Praputiunn ano proximum, parvum, papillare. - In Famina mammas, ob crebrum vellus, pram ter binas inguinales, invenire haud potui.

Vellhs in toto corpore denfiftimum, molle, lanuginofum, intus fufcum, extus fupra gryfeo - cincreum, altitudine $6 . "$ fubtus cincrafecens 5."' Caput magis cancfeit, fupra roftrum \& in crifta myftacea pilis rigidioribus argentatis, quiles etiam pedum fimbrias deflexas conftitumt. Labinm inferius albidolanuginolum, \& in quibusdam litma alba frontis \& abdominis. Villus fub gula conflut in futuram cvidentifimam; \& abfole. tillima alia fubtus longitudinalis.

\section{E N S V R A E.}

Pondus in defcripto mafculo unciarum octo cum didrachma. Longitudo a fummo nafo ad papillam pone anum fitam $7 \cdot " 7 \frac{1}{2} \cdot 11$ - capitis ad nucham Altitudo verticalis capitis

Lacitudo capris maxima cum criftis nafi cranliverfa Intervalluna narium Diftancia inter marginem nafi \& incifores

1. 4 .

I. 6 .

2. I.

o. $7 \frac{\pi}{2}$.

c. 2 .

o. 3 . 
Diameter nafi nudi fuperne

Longitudo inciforum fuperiorum

Eorundem latitudo communis

Longitudo inciforum inferiorum

Eorundom latitudo

Circumferentia oris

Extenfio criftx myftacea a nafo

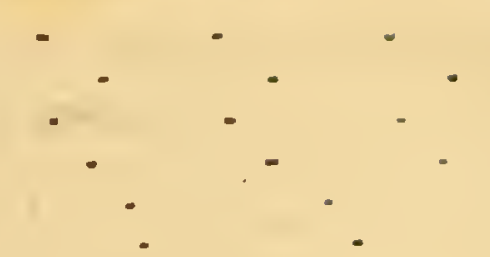

0 $113 \frac{\pi}{6} .111$

o. 2 .

Diftantia pori utrinque auditorii a nafo

- utriusque per verticem

- cadem per gulan

- eadein dirceto axi

Circumferentia roftri ad lab. infer.

○. $2 \frac{\pi}{6}$.

o. $6 \frac{\pi}{2}$.

0. 2 .

- capitis ante aures

- colli

- thoracis pone armos

- in medio trunco

- ad femora

Longitudo antibrachii

Ejufdem circumferentia ad cubitum

- - ad carpum

Circumferentia carpi

Longitudo palmæ cum callo volæ

- digiti medii cum ungue

- unguis

Latitudo palmx ad digitorum bafin Longicudo femoris

- tibix

- plantre a calcan. ad apicem unguium

- digiri medii cum ungue

- unguis

Circumfercntia tibix ad genu

- al plantam

- metatarfi

Latitudo plantic ad digitos

I. 10.

1. 5 .

I. 10.

1. II.

2. 4 .

I. 6 .

3. 8 .

4. 3 .

3. 7 .

40.

4. 1.

3. 6

I. 3 .

1. 7 .

O. 10 .

I. $\frac{2}{3}$.

O. $1 \mathrm{I}$.

05.

- $1 \frac{\pi}{8}$.

o. 5 .

I. 0 .

o. 11 .

I. I.

- $5 \frac{2}{3}$.

o. 2 .

I. 5 .

o. $\% \frac{x}{2}$.

- $10 \frac{1}{2}$.

O. 4 .

\section{A N A T O M E.}

Tab. $1 X$. fig. $12 \cdot 14$.

Cottis tenuis in abdomine, fed in dorfo Mufculo $\mathbf{~} u$ taneo maxime incraffata, circa clunes carnofifimo. Pinguedo in toto animali (autumno) parciffina, pauca circa collum, alas, 
$\&$ in tractu inguinis, cui medio inhwret glandula lymphatica, murino generi propria, fecalino grano hic minor atque tenuis. $M u$ fenli circa fcapulas \& humeros validiffimi, crafta carne facti.

Orbitalis folfa cranii maxime mufculis oppleta; reliquum fpatium occupat Corpus album, ovale, depreflum, cui infidet grammlum nigrum, oculi analogum, vafculis pedunculatum, cui nulla refpondet apertura incraflati corii. Quare ergo illud oculorum rudimentum produxerit Natura? dicant caufarum finalium patroni.

Omentum curtum, macrum circa ventriculum; mefenterinn quoque macilentum, glandula unica oblonga.

Hepar magnum, fubquinquelobum, pondere fere 4 drachmarum: Lobi fuperi tres, dno maximi, explanati, ovales, tortius intermedius minor lunatus, cui a dextris infculpta $c y$ ftis, mole pifi fubrotunda, intimo finu latet. Lobus dexteryimns in duas lacinias fere bipartitus, portione altera lunata reni circumflexa. Lobulus Spigeliamus tripapillaris. Lien linearis, longus, tenuis.

Ventriculus infracto curvatus (Fig. I 2.). In ipfo arcus majoris gibbo aca magna ovalis, glandulofa (litt.a.) extrorfum craffata, cujus diameter longitudinalis Iı."' transverfus per convexitatem filo 1." I. ' Hac intus molli parenchymate fuccifua, limbo feu ruga alba membrana nervea coronata. Finndus ventriculi (litt. b.) conicus, fibris longitudinalibus robuftis: ftriatus. Antrun pylori (litt.c.) ventricofum.

Drodeni initum $(c-$ d.) amplitudine digiti minimi, a ftrictura pylori arctifima fubito dilatatum, agnine glandularum miliarum circa infertionem ductus bilarii notatum; dein adtenuatum, jejuno calamum cygneum, ileoque anferinum capacitate 
\&quante. Tota tenuium inteftinorum longitudo 2 pedum \& undecim pollicum, vel animalis quadrupla.

Cecum $(f i g$. I $3 . A-$ b.) maximum in finifto hypochondrio conduplicatum, unde arcu verfus pelvim fasto caco apice (litt. b.) in dextro bypochondrio definit; totum ab infertione ilei (litt. a.) cellulis magnis quatuordecim veficulo. fum, quarum cxtremæ fubobliqui, quafi fpiram mentiuntur; apex longitudine 6." reflexus cellulam oblongam, fubacutam refert; totius longitudo per arcum 9." 3." circumferentia maxima 3." 2."' xquat.

Inteftinum spirale oblique ftriatum (litt. c.) in laxos anfractus compofitum, longitudinis 6." 5." Excretorizm feybalis moniliforme longitudine $10 . " 6 . " 1$

Renes forma folitx, fere oppofiti; glandulce renales globofæ. Genitalia autumno exilia, ut teftes vix granum fecalinum xquarent. $V e f i c a$ majufcula, nucis juglandis mole, admodum fibrofa.

Pulmonum dexter trilobus, finifteri ndivifus. Cor mediocre. Sceleton (Fig I 4.) multimodis fingulare. Craninm (fig. I 4. I 5.) majusculum, robuftum, forma trigonoidea, occipite latiffmo trincato, angulis maftoïdeis prominentifimis. Os nafi robuftifimum, ultra inciforia prominulum, fornicatum, impreffione longitudinali obfoleta, fed futura nulla divifum. Offa frontis \& bregmatis parva longitudine fubrqualia; occipitale latifime adfcendens (usque ad a.fig. I 4.). Tympora (Fig. I 5. aA.) offea planiufcula, apertura cxterna cxigua; biatus ad offa petrofa in bafin cranii vix ulli. - Maxilla robuftiflima, proceflu bafeos (litt. bb.) craffo obtufifima, interius $(c c$.$) condylifero, exterius incifo.$ 
Fertebre brevifime colli firmifime cöarisculata, nee mi: nimum flexiles, folo atlante mobili; Dorfales cofteque XIV. in aliis XIII. harum fecunda infigniore fpina prominens, fequentes fenfim humilioribus, imbricatim recumbentibus. Cofta prima robuftilima, verfus fterni manubrium (folito magnis atque carinatum) latißima; fecunda quoque crafiufula; offava veris pane adnumeranda, longifima cartilagine ad enfis bafin inferta; reliqua fpuria, prater ultiman, invicem coharentes. Corpus fterni quinquearticulatum, enfe ofleo fubulato terminatum. Vertebra lumbares V. vel VI. fecundum coftarum numerum; facri V. coccygis totidem, connumerato ctiam apice.

Scapulamm magnitudo \& forma ad ftructuram Talpæ declinat; itidem bumnerormm, cubitique longifimo craffoque olecruno (lit. e) inftucti, quod etian talpino robuftus. Clavicula tamen $(f f$.) Soliti forma \& tenuitate, licet longiores quam in ullo fere alio animali, vefpertilione forte excepto. (leilicet 8." prater partem cartilagineo - ligamentofam verlus fternum ad $3 \frac{1}{2} . "$ extenfan. Artus poftici multo minus robufti. O/fa pubis (ob exiguitatem foraminis ovalis lanceolati) latifima, inter fe diftantia, anguftoque \& elaftico ligamento (lit. g.) connexa; hine pelvis apertura amplifima atque dilata. bilis tranfinittendo videlicet grandifimo fartuum capite. Fibula inferius tibix adglutinata, at fubdiltincta.

Menfuras fceleti (naturali magnitudine delineati) e juniori animale addo:

Longitudo cranii a bafs oecipitali ad fummum marginem oflis

$$
\text { nafalis circinno }
$$

Latitudo fumma cranii poltice ad zygomata - - I. 2.

- minima inter orbitas, eadenque fere roftri - $0.4 \frac{\mathrm{T}}{2}$. Longitudo oflis nafalis

o. $\frac{1}{2}$ 
F.jusdem latitudo antice Longitudo maxilla a proceffu crafto ad alvcolos inciforios directc 1. I. Fjufdem altitudo a bafi ad fummitatem coracoidei proceflus 0.7 . Longitudo omnium vertebrarum colli - - - o. $7 \frac{2}{3}$. - vertebrarum dorfalium - . . I. 10. - vertcbrarum fex luabalium - - - $\quad 1.3 \frac{2}{3}$.

- offis lacri - . . . . . $009 \frac{\frac{1}{2}}{2}$.

- coccygis - - - - - 006.

- fcapula a cotula - o. I I.

Fadem a lummo proceffu coracoide -

. Fjufdem latitudo

Longituda offium bumeri

Diamcter capitis humeri

- condylorum

Longitudo radii

- cubiti cum olecrano

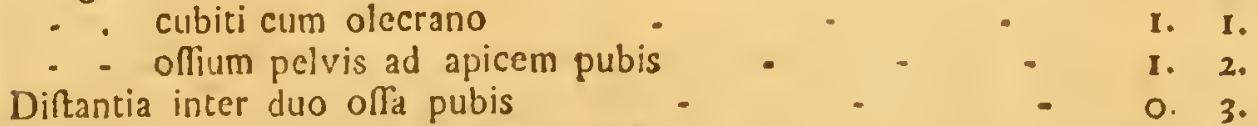

Longitudo offium femoris a trochantere - - - o. I1.

- tibiaruas

- fibula

$\cdot$

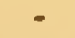

o. $10 \frac{1}{2}$.

o. $S$.

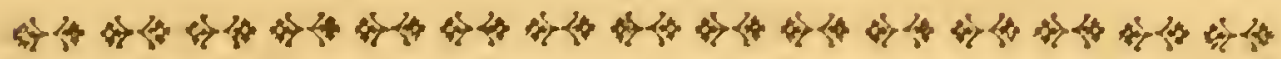

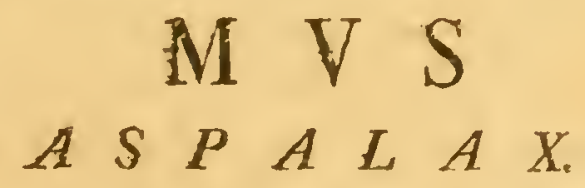

Q 0 uum fingularem hance fpeciem an. 1772. in Dancira oba fervarem, ignorabam candem prius a Cel. LAXMANNo circa Aitaïca promontoria inventam \& Acrdemice Hnlmaieng oblatam fuiffe, in cujus Actis (pro anno 1773. Part. I I. p. I 34. fub nomine Muris ${ }_{2}$ yofpalacis defcriptio externa cum icone prodiit. Mentionem ejus quoque factain invenias in opufculo, quad fub titulo: Sibirifche briefe prodiit (icettingse

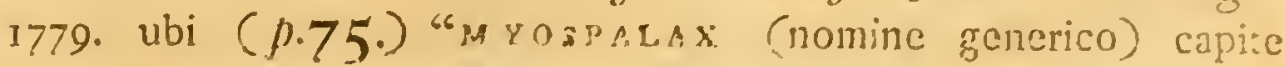


brevi (non roftrato) plantis non calcancatis, dicitur. Videturque, e relatione LAXMANNi, cundem cum Citillo confudilie

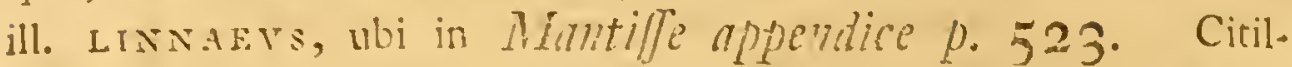
lum vita genere Tilpa amulum facit, quod in hune minime quadrat.

Vita genere \& fodiendi norma Mhs Afpulax cum Typhlo \& fpeciebus mox defcribendis convenit. In tranfalpina prefertim Dauuria, ab Ingoda ad Argunum, frequeniflima ejus veftigia in acclivibus montim, folo nigro vel fimiore arena tectis, occurrunt. Contra ad Vdam \& Sclengam, cisalpinos fluvios, eundem nunquam obfervavi. Rarius ad Abakanum apparuit; Cel. LaxMANeve autem in convallibus campisque inter Ticharyfch \& Alci fluvios invenit, ubi cumulos ejus maximos pro talpinis habitos neglexcram. Videturque in hoc ultimo loco, aque ac circa Abakanum, Erythronii potifimum bulbis delectari, \& ideo forte ftatura multo eft majore, quam in Dauuria, ita ut Typhlum longe fuperet. In Dauuria cum Lilio pomponio prefertim abundat, licet fine dubio alias quoque radices, prafertim Iridum, depalcatur, quas actis cuniculis offendit. Fodit autem canaiestuperficiei terre vel cefpiti paralle los, reeto _plerumque tractu, \& fiep peraliquot centenas orgyias continuos, quorum direction em crebris magnisque (etian dauurico) curnulis egeltaterra indicat. Hine difficillime capitur, mihique poltinumerairritatentamina vix femel iterumque aratro cele-riter circumacto proturbatum animal obtimere contigit. Tungufo - Dauuris Moron-Zokór appellacur, quod Ccecmmt fignificat. Vere tamen cacus non eft, fed parvitate oculorum cratlis palpebris profunde immerforum, vellereque connivente latentium, multotamen magis, quam in Talpis, confpicuorum eognonem meruit. A Rullis in Sibiria nomine

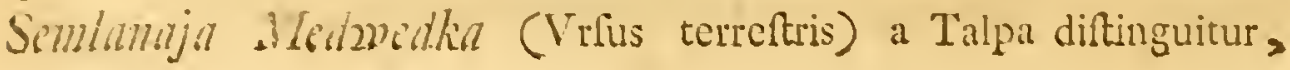


quam Sufedka femlanaja (Lcmurcm fubterraneum) ibi cognominare folent.

Captus $\Lambda$ palis voce exili, ftridula, brevibus fonis iterata conqueritur. Auricularum defectu, habitüque corporis cum Typhlo convenit; fed oculorum apcrtura \& præfentia caudæ, licet nudæ, potius M. capenfem \& talpinum æmulatur. Nafi tubere fofforio prominente, convexo, callofo, palmarum unguiumque magnitudine \& robore, iftos omnes vincit; adeoque nec folis palmis, ut Talpa, ncque nafo \& capite præcipue fodit, ut Typhlus, fed utroque æque valet; contra minus, quam Typh. lus, dentibus utitur primoribus, quos etiam minores habet, quippe ad faxofum folum, quod colit, aliis potius, quam his inftrumentis roborandus. Singularis eft in Afpalace forma unguium in aciem comprefforum, ita ut inftar cultellorum incidendis radicibus apti fint; præterea proximus pollici unguis tenuitate fua fe diftinguit a reliquis, quemadmodum in Pholidoto f. Nanibrachyura quoque obfervabile cft. Convenitque unguium ftructura actioni palmarum, quæ femper incurvatæ fodiunt, ita ut tres ungues longiffimi medii perpendiculares imo retrorfum vergentes, aciebus fuis obvia lacerent, tenuisque illc, aciei medii adplicatus, candem quafi muniat \& acuat; omnes tres verfo cum lateralibus conicis in triangulare roftrum quafi convergant. - Caeterum utique pertinet ad Murinum genus, eidemque \& Typhlum adjungere jubet; eftque mere rhizophagus, nihil (præter vitæ genus) cum Talpis commune habens: ut potius Sorices his affines dicendx fint, quam ille Afpalax nofter. Egctis copiofe cumulis \& fubruto cæépite utique, ut $\mathrm{C} c l$. LAXMAN obfervat, folum aptum feminibus plantarum variis præparat, in œeonomia Naturæ affiduus hortulanus; fed preftant hoc, quodlibet fuo more,

$$
\mathrm{Y} 2
$$


animalcula fubterranca omnia, multoque valentius Apri \& ferx cuniculariæ majores, quarum circa derelicta fpelæa plerumque rarifimæ occurrunt plantæ.

Deferiptionem Afpalacis ad exuvias imperfectan dare coactus fuiffem, nif, dum hae fcriberem, e Kolyvanculi regione pulcherrimum, maximumque fpecimen mafculum, liquore affervatum mififet Anricifjmis 10 1r. Leve, rei metallavice ibidem Confliarius dignifinums ct adtentifjimns, a quo illud dudum expetieram.

\section{DESCRIPTIO \\ $M V R I S$ AS PALACIS. \\ Tab. VIII.}

Facies Typhli, quam altaici prefertim mares longe fuperant, dum daurici codem minores effe folent.

Caput crafium, deprefliufculum, roftro brevifimo, obtufo. Nafus latiflimus, folforius, retufus, fupra corio convexo, callofo, nudo loricatus, ultra incifores productus, antice nudus, fubdidymus: Nares inferæ, fepto Iatiffimo, vix impreflo, integerrimo remotæ, rotundulæ.

Labimm fuperius fub fepto cxfolete finuatum, plane nor incifum, verfus finus oris laxos craffifimum, inque palatum pone dentes conniverts. Dentes primores multo minus lati, quam in Typhlo, convexiufculi: fuperiores nudati, paulo la: tiores, ceftriformes; inferi intenfius colorati, convexiores, rotundati, labio mobili vaginati. Molares ubique tres, truncatodetriti, fuperiores vix ultra palatum prominentes; inferiores ma jores, finguli qnafi e tribus tabellis conferruminati.

Latera roftri minime carinata, convexa, fparfa my/tacumz pilis creberrinis, albidis, velleri labiali immixtis. 
Oculi minuti, fatis tamen confpicui, profundius Iatentes intra apcrturam palpebrarum (quæ funt craffiffimx, rugofx, pubefcentes) vix granum milii. admittentem.

Aures quafi truncata, tubo meatus cartilagineo breviffimo, poftice paulo productiore, undique villo cincto, prominulx.

Collum brevifimum, inter humeros lacertofos fere delitefcens. Corpus breve, depreffum, informe. Cauda brevis, teres, obtufa, nuda, cute rugofa obducta, albida.

Artus humiles, fed robuftiffimi, prxfertim antice, pro fodiendo introrfum valgi. Palme maximæ, folforix, ufque ad metacarpos nudx, pentadactylæ: digiti tres intermedii magni, unguibus maxinis, robuftiffimis, compreflis, acie exteriore acuatis; horum interior elongatus quiden, fed reliquis tenuior, fubulatus, acutiffimus. Digiti laterales breves, unguibus curtis, oblique truncatis, pollicari fubbidentato. Plante usque ad calcem nudx, vix dorfo pubefcentes, pentadactylx, palmis longe minores: digitornn extimus breviffimus; intimus paulo major; eidem vero proxinus longiffimus ungue paulo majore inftructus; reliqui gradatim decrefcentes. Unigues plantarum mediocres, obtufunfuli.

Vellus totum molle, laxum, rudiufculum, fere quale $M$. amphibio; fupra extus gryfeo- cinercum, fordidum, intus fufcum; fubtus fufco - cincreum, canefcentibus pilis inumbratum. Capitis vertex magis gryfeus, litura in quibusdam longitudinali alba. Prceputium maris ab ano parum remotum, craffum, raphe fubtus longitudinali \& utrinque plica collapfi. fcroti craffa, arcuata, ad anum coeunte, intra quam quafi finus utrinque retractus, villo brevi, fubferruginco intus hirtus. 


\section{E N S R A E.}

Pracipue ex altaïco nuper accepto, qui in fua firpe gigas videtur, menfuras dabo. Dauricum fpecimen vix longitudine tota $5 . "$ 3." æquavit.

Longitudo tota a fummo nafo ad anum - - $\quad$ - 8.118 .11

- capitis

- cauda ab ano

Latitudo nafi nudi filo

- Cepti jnter nares

Altitudo nafi antice a margine labii

Diftantia oculi a nare

- aures ab oculo

- inter oculus filo per verticem

- inter aures per verticem

Diameter auris externa

- inter aures \& oculos

Circumferentia capitis ante oculos

- colli vix diftincti pone aures

- thoracis ad armos

- - in medio corpore

- - alvi ad femora

Longitudo antibrachii

- palmir

- unguis'medii

- tibir

- plantæ

Circumferentia carpi

- metatarfi

\section{A N A T O M E.}

Tab. $2 X$. fig. 16 .

Hepar feptemiobum, maiufculum; lobo finifterrimo \& portionis fuperincumbentis lobo dexteriore majoribus, \& pofteriore quidem maximo; dexterrimus lobus directione ad diaphragma parallela bipartitus, fuperiore portione obrotunda, gibba, inferiore triquetra, pro rene excavata. Lobi fpigeliani duo: in- 
ferior linguiformis ad dorfum productior, ligulatus. Cy/tis fellea inter duos lobos incumbentes mediocris, flaccida.

Ventriculus major, quam in Typhlo, forma M. talpino fimillimus, fed amplior, brevior, fundo minus producto, capaciore, obtufiore. Intus cavum, verfus antrum pyloricum - plica annulari, crafla, papillofa, papillisque mollibus, confertis dentata, biloculare; plica imperfecta fimplex ad finiftra cofophagi. Area magna, orbicularis, glandulofa, in parte maxime gibba arcus majoris.

Inteftinum tenue 2 pedum 10 poll. - Cactum in ceilulas valde turgidas divifum, ut in M. Typhlo, fed apice vix adtenuatum \& fpiraliter intortum, prorfus ut in M. talpino. Cellule coeci XV. in ampliore parte annulares, in extrenitate fphrrico - veficulares, terminale cum proxima fubconfluente, ovali. Longirudo cocci ab infertione ilci ad apicem ro." circumferentia fumma 2." so." pars infundibuliformis infra infercionem ilei tefquipollicaris. - Irteftinum Spirale ampliufculum, in triplicem curvaturam arctifime conglomeratum, tripollicare, intus plicis craflis, obliquis, ad mefenterium inque oppofito laterc longitudinaliter connexis, \& extus tranfparentibus, ftriatum. - Intejínintm excretorium, fcybala in oblongas moleculas efformata continens, I pedis ro pollicum.

Tborax brevifimus, conico - exampliatus, coftis robuftiffimis Nil. parium. Pllmo dexter quadripartitus, fuperiore lobo depreflo, dorfali, orbiculato, medio paulo majore, triquetro, inferiore maximo; quarto a:ygo clongato - triquetro, vix bafi connexo, inter cor \& dorfum in finiftum cavum pectoris. protenfo. Pulmo finifter minor, integerrimus. Cor ovato breve, obtufilimum, languine in molem glandis turgidifimum, 
longitudine 11." circumferentia bafeos 2." 2." fubftantia ventriculorum valde extenuata, dexterioris fcre membranacea.

Ofja pedum anteriorum e daurico fpecimine naturali magnitudine in т в в а $I X$. ad fig. 16. delineata funt, ut cum fceleto Typhli comparari queant.

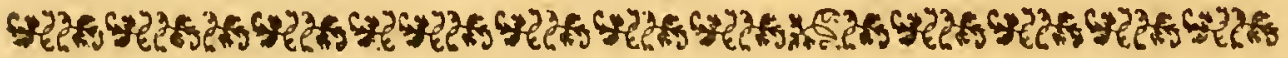

\section{V S \\ $\begin{array}{lllllllll}C & A & P & E & -N & S & I & S \text {. }\end{array}$}

Infero fpeciem, inter rutheno - afiaticas, africanam, cujus E fpecimen Cel. \& Amicifinn n. L. bvrmanno debeo. Eaden eft de qua korbivs") fub nomine Criceti dixit, quæ tamen a belgicis Promontorii bonæ fpei colonis propric Talpa arenaria (Zandmoll) appellari folet, quia maxime in arenofis verfatur, dum Talpa aurata firmiore illius. regionis in folo cuniculos agit. Quanta horum Murium in campis arenofis ibi fit copia, e nupero massovi bortulani itinerario capenf patet, in quo tamen nomen (Landmoll pro Zandmoll) vitiofe feriptum eft '). Refert ille cuniculos horum animalculorum adeo frequentes \& profundos cffe, ut itinerantium equi in hora frepe decics ad humeros ufque incidant; victitare radicibus Ixiarum, Gladiolorum, Antholyzarum \& Iridum, quæ mira copia ad Promontorium proveniunt; \& magnitudinem fepe cuniculi aquare, unde \& in cibo quibusdam adhibetur. - Kolbivs modum

a) Befchrciöung des african. Forgebtirges p. 158 .
9) Psilofoph. Trans. Fol. LXVI. for 1776. Part. 1. p. 304. 
modum eosdem capiendi defcribit, dum cuniculus remoto terræ cumulo aperitur, \& bombarda ftatuitur flo, radice adligata inefcato, explodenda, ut animal, quod omni mane fexta \& meridiana hora antra fua expurgare, novisque cuniculis augere folet, arrepta radice fe ipfum occidat. Primam animalis no. titiam habui quondam $\mathrm{ex}$ iconibus animalium capenfium, quas Celeberr. IoH. Bvrmañvs fervat. Iis Mus capenfis depingitur mole majoris Criceti, \& colore, quem kolbIvs in. dicat, fufco - canefcente feu cinereo. - Specimen tamen, quod, rogatu meo, Amiciffintis s. L. в vrmannvs procuravit, licet e dentibus adultum vidcatur, multo tamen minus eft \& colore gryfeo rufefcente, maculisque albis diverfum, imo forte ob id ipfum affervatum; unde pro loci pabulique natura vel accidentalibus caufis variabilem fpeciem exiftimo. - Sup. plebunt ejus hiftoriam, quibus felicem paradifum capenfem adiré fortuna non invidit.

\section{DESCRIPTIO $M V R I S C A P E N S I S$. Tab. $1 X$.}

Magnitudo (in meo fpecimine) M. Typhli. Caput gibbum, obtufum; nafo lato, truncato, nudo. Myftaces tenues, fparfi albidi, longioribus pilis fufcis.

Dentes primores magni, albi, læviffimi, fupra infraque lati, inferiores tamen convexiufculi; fuperi plani, magis porrecti, quam Typhlo, denudati pro exaranda terra. - Molares ubique terni, teretiusculi, truncati, xquales.

Labium fuperius pone primores dentes utrinque in palatum contractum, contiguum, pubefcens. 
Oculi minufeuli. Alnies externa nulla, nifi lobulus meatum poltice coronans, apice villofus.

Corpus breve, deprediufulum; Aitls beres, roburti, extremis pecum nuduculis. Palma majores, pentadireylar, disito cxtimo pollicen non aquante, proximis duobus longillimis. 7 lggus mediocres, fubulati, in plantis obtuluteuli. Plantumon vole nute, margine pilis dellexis, ad calcancum exterius clongatis, fimbriatte.

Callda brevillima, obtufa, pilis confertis, longis, albis penicillata.

Tilllls molle, dentum, ad cutem fufeum. Ambitus oris atque nafi totus late allus, ulterius area tranfierfil ufque ad genas nigricat, in qua palpebrat albe; occiput fufco-rufefecn- te mixtum; area aurum utrinque alba, parotica ferruginea. Corplls in (meo fpecimine) fupra totum obfolete rufefens, Iateribus pallidius, fubens fordide albicans. "Arill afymmetrica candida a mediis lumbis dextrum hypochondrium tegens, perque abdomen ad alterum ulque femur producta. - Hanc IC) burmamiana non cxhihet; fed ambitus oris albus, fufco cinctus ut in nottro pecimine, $\mathbb{S}$ artus albidi; reliqui corporis color fufco - corulcicons, fuhtus albidus.

\section{MENSVRAE.}

E ficcato fipecimine inperfectinima tradi poltunt:

Longitudo tora circiter

- capicis ad nucbam

- caudie fine pilo (6.1/1 excedente)

Longitudo palax cum ungurbus

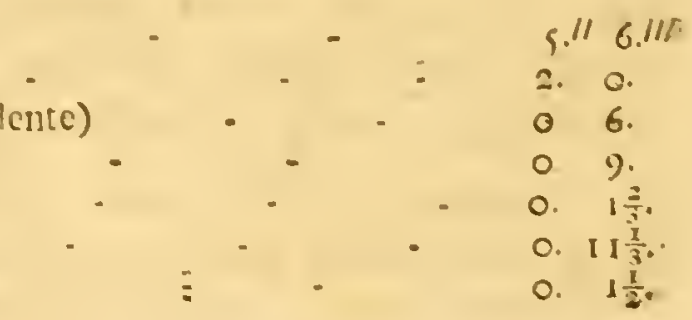

- unguiun longiorum palma

- plancia cum ungubus

: : unguitas longrorum plantio 


\section{$\triangle N \wedge T O M I C \Lambda$.}

Tab. IX. fig. 17 .

Craminm multum fimilitudinis habet cum cranio Typhli. Bafis vero feu ncciput multo minus latum; roftrum ante zygomata brevius, teretius. Zygnmata antice minus robufta; poftice lata bafi radicata, os occipitale poftice planum, non ufouc ad mediam ollam productum, nec devexum fed breve, ad criftam necipitis transverfam definens; contra bregmatum ofra anguftiora, fimul oblongo - quadrata. () /fa nafi non ultra dentes producta, fed abbreviata ut in M. talpino, futuraque divifa, anguftifima antrorfum. Maxilla brevifima \& robuftifima, bafers angulo latiffimo rotundato, quafi ala extcrius ab utroque ramo defcendente.

Longitudo cranii a bafi occipitali ad extrcmum offum nafalium circinno

$111.3 \frac{2}{3} \cdot 11 \%$

Longitudo ab occipite ad extremum marginem inciforum fup. porrectum

Latitudo cranif fumma pone zygomata

- per ijáa zygonata

- inter orbitas minor

- cadem antcrius ubi frontis latera paullum protuberant

Longitudo offum nafalium

Latitude corundem poftice

- - - antice vix fupra

I.ongitudo maxilla ab angulo rotund.

- inciforum infer. ultra masillam

- - - fuperiorum

I.atitudo inciforum, ultra

1. $\left\{\frac{r}{2}\right.$,

o. 8.

I. 0 .

○. 4 .

O. $4 \frac{2}{3}$.

- $\int \frac{1}{2}$.

- $2 \vdots$.

o. 1 .

I. 4 .

o. 7 .

o. 2 .

o. 2 .

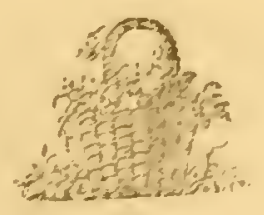

$\%=$ 


\section{(-3)

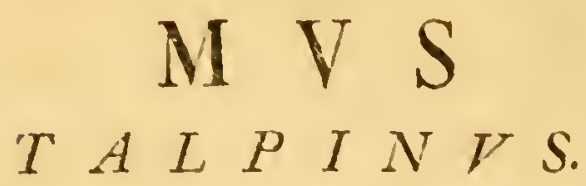

P'ideor milhi hane filtem Murim fofioriorum fpeciem folus obfervalle, atque deferipfitie; $\&$ quia copiofo habui $\&$ diligenter obfervari, poterit nunc accuratius deferibi.

Frequens elt per omnem Rulliam campeltem atque temperatiorem, ab Occa fuvio ufque ad defercum Aftrachanenfe; frequens circa Vralenlia promontoria \& in campis lietenfibus, Ifchimentibus; vix ultra Irtin \& faltem non ufque ad Obum. Amat folum cafpitolum nigrum, naxime palcua, circa ipfos pagos frequens; rarilime in arenofis vel limofis terilibus obfervatur. In fylvolis etiam \& gradu LV. borealioribus dect. Viderur contra cas maxime regiones amare, in quibus Phlomis tuberofil crelicit, vixque dect ubicuncue hujus eft proventus; quemadmocim ejusdem quoque \& Lachỵri cfculenti tuberibus captos optime fuftentavi. - Asnofcitur prafentia Mruris talpini e parvis, vis fpithamali diametro, terre cumulis, per intervalla, ficundun traftum canalium, quos lub vel in ipfo cafpitc multarum orgyam Iongitudine terebrat, egeltis. Inde ctian apud sulticos non an rulicum Sembleroikn (quod terrfoftoren diminuive fignifieat) commeruit. - Hifec fuis canalitus continuo latet, valpari \& lub auroram maxime novo operi intentus; nec inde exit, nifi dum terram evarrit, vel ut altri tempore conforien quarat, vel denique quum locum victus caula mutar; quod ubi fecit, ablentia animalis ex aperto in fine cuniculi oft.o facile anolicicur, alins cnim aperture omnes molliter fu- 
peraccumulata terra curiofe claufæ deprehenduntur, quæ quo recentior eft, co certiori eft indicio prefentix animalculi. Solitariam hic ubique vitam agunt, rarifimeque extra antra confpiciuntur œftro præfertim perciti; locum itaque potiffinum diluculo vel in tenebris mutare credibile eft. Ad claram enim lucem oculis haud bene uti videntur, quod in captivatis facile perfpicitur, altcrique, inter Rufforum plebem ufitatæ appellationi (Sljepuftchonka, Cocculus) \& Tatarice (Sucher - tfkan, Mus cœcus) anfam dedit. Nequc, fi interdiu frequenter exire folerent, ruri agentium obfervationem effugerent, quum inepto curfu vix celcrius incedant, quam fub terra fodiunt.

Hyeme non obdormifcunt Mures talpini, fed locum cæfpitofum fub denfis arbuftis quærunt, vel fub foeni acervis delitefcunt, ibique durante hycme numerofis buc illuc ductis canalibus cibum quxrunt, profundiorem in foco parantes nidum, quem gramine molli replent pro cubiculo, \& fæpe diverticulum, quod collećtis gracis radicum tuberibus replent. Talia hybernacula paffim vidi, præfertim in locis, ubi fœnum acervatum fteterat, ideo confpicua, quod ibi in -ipfa fuperficic cxfpitis fulcos labyrinthicos exfculpunt.

Capiuntur autem facile, ficubi in locn recentiffimis terræ cumulis animal prodente matucino feu vefpcrino tempore opperiaris, dum expurgando cuniculo novisque canalibus cavandis operam navat, quod plerumque poft auroram \& diluculo vefpertino ingruente facit. Ad oftium, quo terram egcrere tunc confpicitur, fufpenfo paffu accedendum eft, \& aufcultanduin donec ad oftum veniat. Quoties enim aliquantum terræ intus accumalatum eft, retrogadum clunibus ad oftium everrentem videas, \& intra canalem frpius fe agilitate mira vertentem, us 
extra aperturam circumfpiciat \& auram captet. Tumique defixa per corpitem fpathe acic canalis intercipiendus, ut cfinginm in labyrinthos defit, revulfoque calpite animal manibus prehendi queat. Inmo ipio in oltio, dum circumfipectat, digitis coptum vidi, unde ficile apparet, quam male oculis ad lucem utatur.

Ciptivos diutius radicibus alui in ciftulis terra femiplenis; line terra enim cito agrotant. Cibum, ut alii Mures, palmis ori admovet; isdem fortiter fodit, dentibus exfertis tantum radiculas pramordens, vel duriora obltacula rodens; terram pal- mis fubmovet, plantis retro fe accumulat, tum clunibus propellit. Videntur ftatim cicures, fed ftupiditate potius \& cecitate, fomperque fuffodere fe tentant \& fortiter ciftam, qua includuntur, rudunt. Vocem edunt raran, pipientem, inftar murinorum pullorum, rel ariculie oro emergentis. Dentes re. ro inter rodendum fepillime frendentes conterunt \& acuunt. Habui fpecimen, cui dentes inferiores cafu erant prarupti, unde liperiores longinime \& circinnatim exerererant; qualem cafum in Lepore etate prorecto delincavit RIDixgEl, \& in Cuniculis frepius obfervar, cosque tandem inanitione interimere AT parifina docent "), cujus \& ipre exemplum in Belgio vidi: Cumiculum ferum fuperioribus dentibus rerfus palatum recurvis, inferioribus longilimis circimnatis. - Eoque iefellitur utique fententia mVNTEr, qui dentes fuccrefere negat, quum tamen ipfo incremento, aque ac roftra avium, unguisque \& cpidcrmidis fubltantia, fuppleantur atque luftententur contra adtritum continuum; idque a Natura preparatum lupplementum etiam muper, eleganti experimento, in duobus Sciuris, qui mollibus cibis cuttriti, dum rodendo dentes adterere

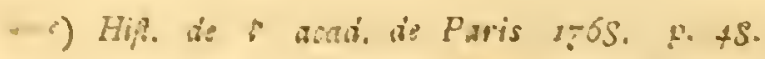


non poTent, nimio corum incremento tanden pericrunt, confirmatum leginus in Diario Berolinenfi (Fournal litteraire 1775. Maj. .7un.)

Iam fub finem Martii vel Aprilis initio venerem exercent M. talpini, coque tempore glandulæ circa genitalia, prafertim in focminis, fortiffimum odorem zibethicum, qualcm fere So: ricis mofchati cauda, fundunt; anus cum vulva communi tumore glandulofo, olido prominct, quem ctiam graviditatis initio, quum turgefcunt jam mammx, perfiftere obfervavi. Catulos tres vel quatuor pariunt; an plus quam femel in alno, haud dixerim. Non fane multum pullulant, neque adhuc in regionibus, quas occupant, parum cultis, noxii obfervantur. In Germania enim hanc cffe fpeciem, quæ fub nomine Muris folforii (Räutmauls) nocet, jam non fuftineo, \& affcrui prius fimilitudine cunulorum deceptus, quos potius Mus amphibius in hortis Germanorum ad quærendas radices fodiens efficit, quique frepe fatis fimiles funt Muris talpini laboribus. Vidctur Mus talpinus circa Uralenfe jugum primam patriam habuiffe, in cujus clementioribus collibus hodicdum prefertim abundat, indeque fpeciem occidentem verfus fpargi flumina forte prohibuerunt.

Varictas in hac fpecie tantum quoad colorem obfervatur, eadem fere, quam in Murc arvali delineavit BVFfonivs, quamque in M. Milufulo frepe obfervavi, \& in Criceto atque M. amphibin fupra expofui. Nempe a folito colore murino aberrantes obfervantur toti atri; hujusque varietatis (in Ruffia rarioris, in Ifetenfibus vero campis \& apricis Urali frequentiffimx) aliquos obfervavi labiis oris \& lincola abdominis ante genitalia longitudinali, albis notabiles. Aliquantum \& 
magnitudo variat, a pabulo vel climate: in campis ficis, colliculofis ad inferiorem Volgam, ubi Tuliparum præfertim bulbis pafcuntur, infigniore funt magnitudine, pondus duum fere unciarum rquantes; fimul colore, ut folun regionis, admodum diluto, verfus pofteriora fere gryfeo - flavefcente, in capite tamen fufcido, differunt.

Cætcrum Mus talpinus dentibus, ut in defcriptione dice. tur, M. Typhlum \& præfertim capenfem; forma etiam tota, nafo truncato, cauda brevifima, potius hunc refert; quem tamen palmarum magnitudine \& robore vincit, \& cum $A f-$ palace feriem ad M. Lemmum ejusque affines continuat, nullo generico intervallo exiftente.

\section{DESCRIPTIO

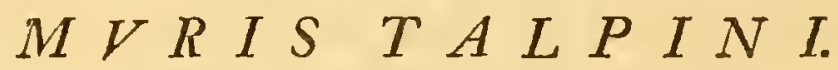

Tab.XI.A

Mägnitudo Muris amphibii minoris, \& aliqua cum eodem fimilitudo, præfertim capitis.

Caput grande, breviculum; roftrum craffum breviffmum; retufum; lateribus hirfutiffimum.

Nafus truncatus, fubdidymus, fufcus, nudus; mares comniventes, diftantee.

Labinn fuperius ufque ad nares late bipartituum, dentes fuperos ufque ad bafin detegens, lateribus tumidulis pone eosdem ad palatum convergens, quod continiatio utriusque labii contigua pubefcens ibi totum occupat. Inferius labium craffum, vaginale.

Dentes primores fupra nudi, quafi extra os protenfi, longi, plani; inferiores obfoletius tetraëdri, paullo longiores; apice rotundati. Molıres fupra infraque terni, antici majores, omnes $_{s}$ 
omnes æqualiter detriti \& argute lateribus ftriati, ut in muribus vulgo funt.

Myjaces nigri, mediocres, iparfi, deorfum vergentes, quinque fere ordinum. Terrucula fupraocularis tripilis, uno longiore; paranica \& gulnris unipiles, pilis teneris, gulx incano. Pili cani longiores circa inferius quoque labium fparfi.

Oculi vertici nafoque propinqui, minuti, vellare fere latentes, nigri. Almimm apertura mediocris, pofteriore margine prominulo, albido marginata, vellere abfcondita.

Corplis breve, ventricofum; Artus breves, proportione robuftifimi. Pedes nudiufculi, albidi, omnes pentadactyli. Palme validx, latæ, pollice brevi, proximo vix breviore quam medius, a quo reliqui gradu decrefcunt; calli ad digitos tres cxigui, majores 2, ad pollicem \& fub carpo, in vola nuda. Plantarum digiti laterales breves, medio \& huic proximo interiore fuperantibus. Palmæ plantæque exterius, ufque ad digitos, pilis longis, rigidiufculis, deflexis confertim ciliatæ.

Cauda breviffina, teres, truncata, vix in alto clunium vellere prominens, pilofa.

Vellus murinum, tenerum, molle, xftate in ventre \& fub armis rariufculum, fub hyemem undique denfum; denfiffimum circa caput, verfus clunes altifimum, pilis longioribus crebris vellere extantibus. Color capiri roftroque furco nigrefcens, buccis fubgryfeis, mento albido; dorfi fufco - niger, vix fummis pilis gryfeis mixtus, verfus latera fenfim magis gryfeus, fubtus artubusque canefcens. Varietas tota atra, nigredine Ratti fubexfoleta effe folet, pedibus cancfcente pilofis. - Valgaris color quibusdam magis fulcus, aliis dilutior, gryfeo - flavefcens, idque in varia ætate. 
Mammulce in feminis tantum fex; in mare nullum papillarum veftigium. Preputium breve, ano proximum, plica verfus anum decurrens. Anlls fub ipfa cauda.

\section{E N S VRAE.}

Pondus ab unciali cum duabus drachmis, ad biunciale. variat, fecundum regiones vulgo tribus circitcr drachmis unciam excedit, in utrolibet fext.

Proportiones e mafculo adulto, ponderis uncixe cum $2 \frac{\mathrm{x}}{3}$ drachm. adfcribo:

Longitudo a fummo roftro ad anum

- rećliffima

- cauda ufque ad anum

- capiris a nafo ad nucham

Diftantia oculi a nafo

- auris ab oculo

Fiffura palpebræ extcrior, quie veram oculi diametrum cxcedit

Apertura oculi, non ultra

Intervallum oculorum filo

- per axin

- aurium filo

- - - per axin

Circumferentia maxilla fuperioris folius pone dentes

- capitis trans oculos

- ad aures

- colli

- thoracis pone armos

- medio corpore

- ad femora

Longitudo antibrachii

- palinx

- digiti medii cum ungue

Latitudo paima ad carpum

- ad digitorum bafin

Circumferentia antibrachii ad bafin

- ad carpum

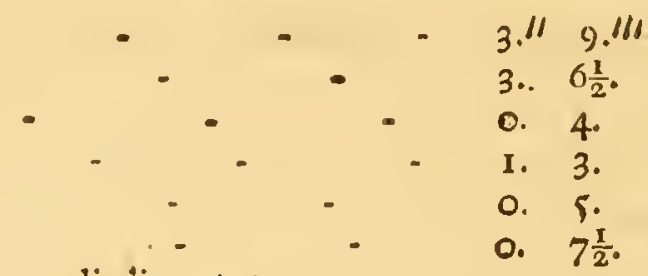

o. $1 \frac{\pi}{4}$.

o. $0 \frac{2}{3}$.

o. 6 .

O. $4 \frac{4}{5}$.

o. 10.

o. 9.

J. I.

2. $1 \frac{x}{2}$.

2. 7 .

I. 10.

2. 8 .

2. $1 \mathrm{I}$.

2. 10.

o. $6 \frac{\mathrm{I}}{2}$.

o. $5 \frac{1}{2}$.

o. $3 \frac{1}{2}$.

o. $2 \frac{1}{2}$.

o. $3 \frac{1}{2}$.

Q. 9 .

c. $4 \frac{1}{3}$. 
- mecacarpi

Longitudo tibide

- plantex

Circumferentia tibix ad bafin

- ad tarfum

- metacarpi

Latitudo metacirpi

- ad bafin digitorum

Circumferentia cauda bafi

Longitudo dentium fupcriorum

- inferiorum

Laticudo fumma corundem

Intervallum narium

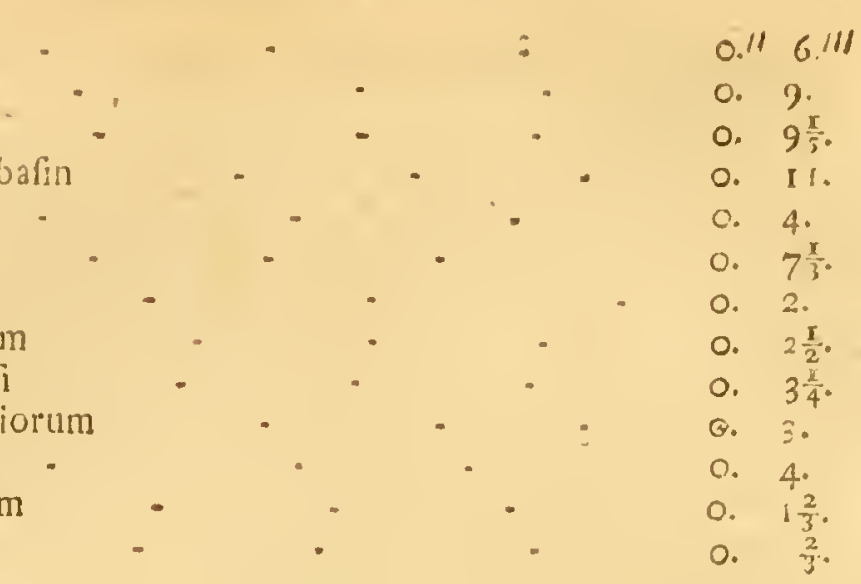

A NATO ME.

Tab. XVII. fig. 3 4. 5.

Cervix mufculofinima. Pingaledo ctiam autumno parca; tantum circa inguina, fub armis \& in finu fterni collceta. In inguine utrinque glandula una feminis lini mole, altera vix grano milii par, paulo anterior. Glandula tenues, cxplanata circa collum. Odor circa anum ambratus, licet glandulx infigniores haud apparcant.

Omentunn margo ventriculi membranaceus, minime expanfus, anguftiffimus. Crecum in dextro hypochondrio convolutum. Omenta lumbaria nulla, \& nulla intus pinguedo.

Hepar majufculum, feptemlobum, fub medio diaphragnate pofitum; lobi duo fuperi magni, craffi, profunde difciffi; finifter fuccuborum explanatus, dexter parvulus; renalis Itmatus, impares fubtus bini, forma fere licnis lingulata produci. Pondus hepatis femidrachmale cum aliquot granis. Cyftis biliria plane nulla. Lie!l a dorfali latere ventriculi, longitudine 5." latus 2."

Ventricullus reniformis, facen pylorico magis recurrato capaciore; fundo cylindracen, obtufo (fig. 3.) Arcus major a fundo ad py!orum 2." 5." Iongitudo fundi ad ofophitgum 4:." 
Inous coven divitum plich inligni, s medio srou nunori lunatim deficnente, timplici, cilinet.

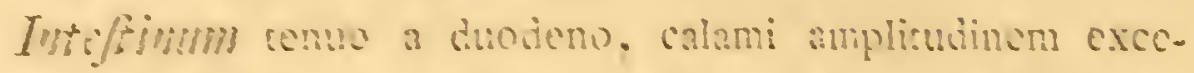

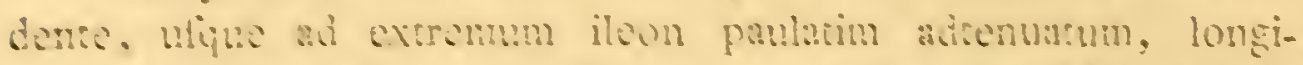

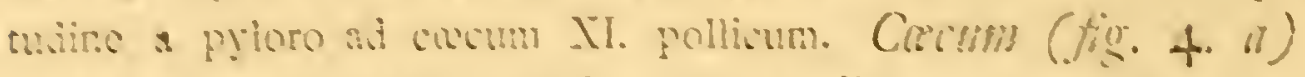

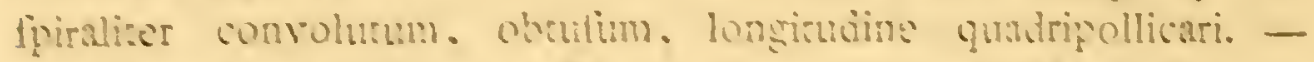

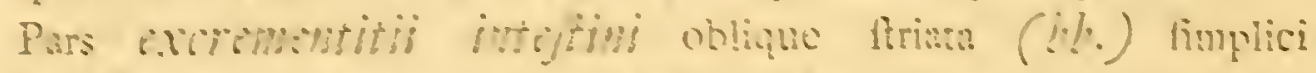

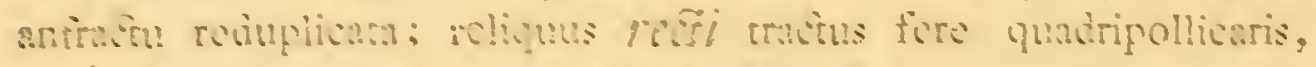
excrements non in modulus colletis, fod contimus replets, contr. morem hujus seneris, yuod lixitati gloneris in inirio

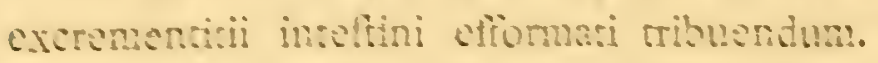

hepgs fere oppotid, dexer vertice tantillo anterior.

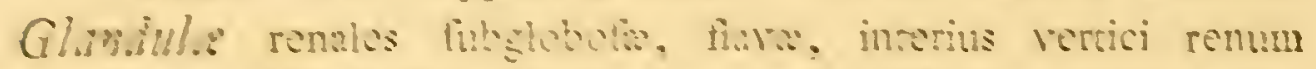

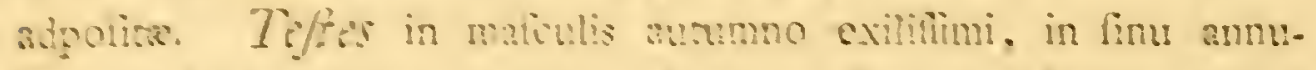

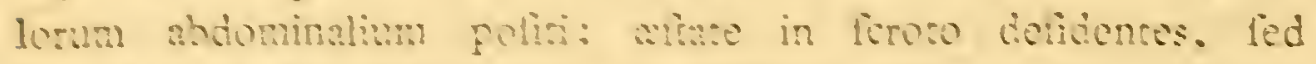

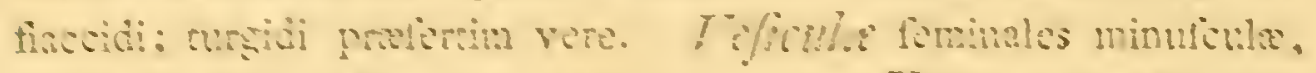

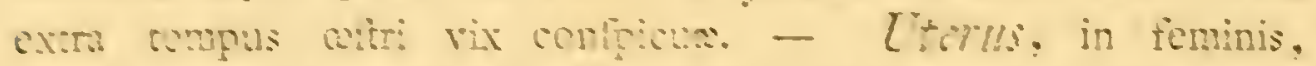
whe su rers: cominus exprestis, merabranula cum uretoribus deculinniots coheress.

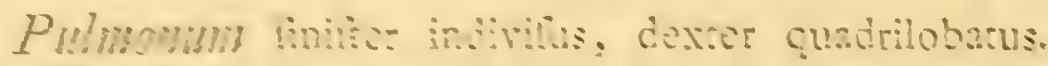

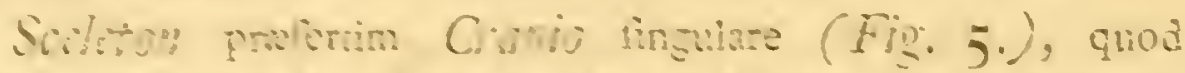

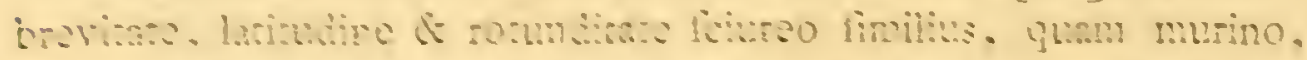

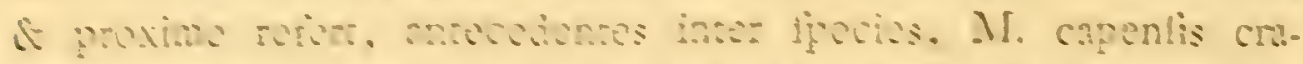

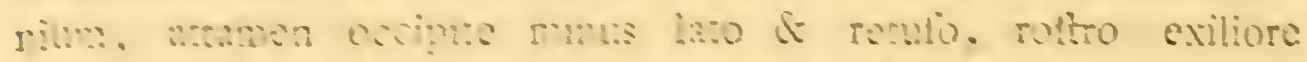

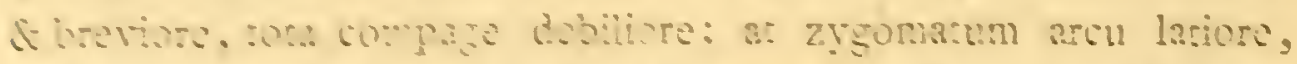

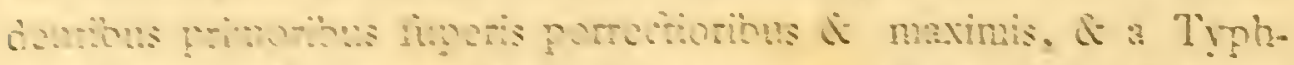

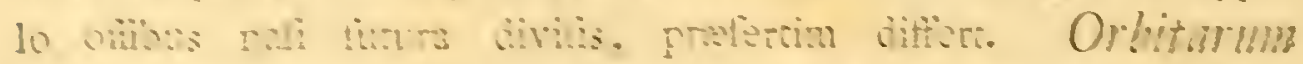

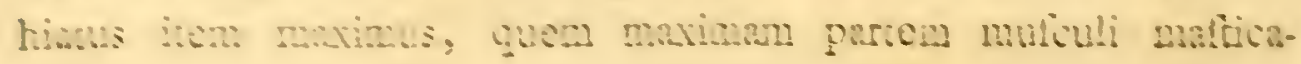


torii opplent, oculi bulbo, cum fubftrata glandula, fere extra orbitam, ad anticam zygomatis radicem remoto. Tympana itidem depreffa, oblonga, proportione exigua. Maxilla inferior forma \& robore parum diverfa.

Vertebrarum nulla proceffu infigniore prominens. Drrfales 13 , totidemque coftarum paria, quorum vera 7 . ultimæ brevifimæ. Stermm officulis tantum tribus intermedis, enfe prælongn. Lumbares vertebræ 6. Salcrum ex unica lata, alteraque cylinárica coalitum. Cauda vertebris cylindraceis, præter apicem 13. compolita. Ifchia lata, - Jymphyfis pelvis acutius angulata, folida. Artunm priorum offa robuftiora pofticis, nulla tamen infolita ftructura, nifi quod bumeri crifta verfus caput prominentifima, clavicnloque longæ \& robufta. Pnilicis palmarum phalanx ab ungue diftincta, oficulo brevirfimo infidens.

Longitudo crarii ad alveolos inciforics - ad fiem offum nafi - - e. Iı.

Latitudo ejusdem fumma per zygomata : . o. $6 \frac{2}{5}$.

- minima inter orbitas - - o. $2 \frac{x}{2}$.

- roftri offei ad ipla zjgomata - - 02.

Altitudo verticalis crani maxilæ infitentis - - 08 . 0

Longitudo inciforum faperiorum - * 04.

- maxil a a furm:s condylis ad alveolos - - 09.

- inciforum inferiorum - . 0 s.

- omnium vertebi. colli - - - c. $5 \frac{\frac{5}{2}}{2}$

- omnium vertebr. dorfalium - . $\quad$ r. 0 .

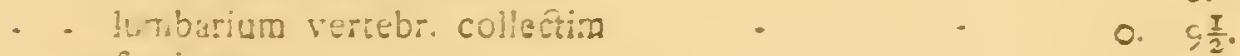

- facri - - o. $2 \frac{\frac{1}{2}}{2}$.

- cauda - - 0. $11 \frac{\frac{1}{2}}{2}$.

Latitudo a lantis panlo ultra - . - o. 3.

Longitudo offum innominatorum . - : : $08_{\frac{x}{7}}$

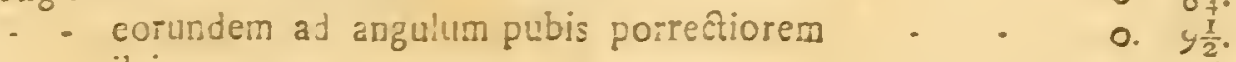

- ilei - . O $4 \frac{4}{5}$.

- foraminis ovalis - . 0.2. 
Latitudo ejusdem

Longitudo fterni manubrii

- corporis ejusdem

- enfis

- clavicularum

- fcapula

Longitudo oflis humeri

- cubiti cum olecrano

- olecrani ab articulari cavo

- offis metacarpi medii ultra

- phalangis prima medii

- - - fecunda

- - - pollicis

- femoris

- tibir

- fibula femiadnatr fere

- offis mecacarfi medii

- phalangis prima medii

- . - fecunda

- calcanei

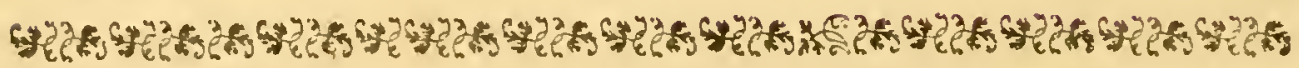

\section{$\mathrm{MVS}$ \\ L E M MVS.}

emminn migrationes admirandie celeberrimum reddidere, \& tamem bona ejus icone hucusque caruit Zoologia, licet Europæ inquilini animalis. Dum igitur hanc fuppedito, \& dum de varietatibus hujus muris per reliquas terras fub arcto fitas obferrabiles agendum eft, non inutile credidi fimul collecim referre, quæ circa Norvagicorum mores \& migrationes paflim fcripta extant, atque auctores, qui de Lemmis egerunt, recenfere. 
- Primus Lemmos celebravit Olans Magmus (Feptentr. cap. 20.) quem antiquiores Zoologi exfcripferunt omnes, do. nec wormivs proprio tractatu ") inque MTufei fui defcriptione, non fine aliqua credulitate, accuratiorem animalculi hiftoriam propofuit. Fecerunt dein ejusdem mentionem SCHEFFERVS (in Lappon. illus $r$ p. $3+6$. ) \& OLEARIVS (in Mureo gottorpino) \& Olig. I асова Evs (in Min. regio bafiniens.p. 6. fez. I.). Iconesque worMI exferipfit vaLENtinvs (in Amplitbeatr. zootom. t. 38. \& Muf. muecor. edit. germ. vol. II. tab. 27. f. 3.). Fuliorem deinde \& fidam Lemmorum hiftorian communicavit Nob. Panl. r. YcAvT (Actor. angicor. val. XXI. an. I699.n.251.p. 110.) Denique nuperis temporibus cognitionem eorum redintegravit i perfecit Ill. Linnarvs (Actor. bolmienl. 20l. II. I 740. edit. germ. p. 75.), fupplementis auxit Pet. Ifoegstroem (lbid. vol. XI. I 749. p. I 9 feq.), variaque contulere GVNNERVS in notis ad librun LEEMII (Nacbricliten un den Lappen p. I 2 I. feq.) \& pontoppidanvs (bift. nat. Norveg. verf. germ. vol. II. p. 58. feq.) Quam vero Italus Albert. moncali dedit Lemmi hiftoriam (Giomale d' Italia fpettante alla fciema naturale Tom III. p. I 89.) tota e recentifimis Suecorum relationibus compilata videtur; dum contra BvfFonivs (bift. nat. vol. XIII. p. 3 I 4. ed. min. XXVII. p. I 20.) neglectos in his dudum worMIVM \& scheffervm exfcripfit. Novam nuperime, fed Hormiand haud multo meliorem, e farctis pellibus iconom propofuit Cel. pennant (fyh. quadr. tab. 25. fig. 2.).

a) Olai woRMIr hiforia aninalis Hafi. 1/53. 4. cum Icone forma \& ma. guol in Norvegia a mubibus decidit cet. culis inordinatis peccante, feflimas 
Quandoquidem Lemmus præfertim migrationibus fuis ineleruit, de modo \& ratione harum inprimis e collatis auctorum relationibus dicam. - Accidunt hæ migrationes non quotannis, nec fapius, certisve vicibus, fed plerumque vix femel intra decen. nium, immo, quibusdam locis \& periodis, adhuc rarius. Infolita horum animalculorum in defertis alpinis inacceffis multiplicatio, defectus pabuli vel prærens vel inftans populofæ reipublicæ, fenfusque futurarum tempeftatum multis, prefertim murini generis, animalibus infitus, potifimum pro cauffa mirabilis hujus tranfmigrationis haberi poffe videntur. Egregie ad hoc facit judiciofa HOEGSTROEMII obfervatio: Lemmos potiffmum autumnis migrare iis, quos infolite ftrenua in alpinis regionibus infequitur hyems. Aeftate anni MDCC XLII. poftquam ex alpibus demigraflent, codem revertebantur, at in Umenfi Lapponiæ diftrictu autumno anni fubfequentis verfus orientalcm planitien defcenderunt, infecuta in ea parte alpini jugi tigidifima hyeme; dum contra in borealiore Lapponia, prefertim Iulcnfi, ubi mitior eadem fuit,'non migrarunt. Addit jden, finili modo alia quoque animalia, præfertim -Erminea, brumalem exceffum præfentire atque aliorfum transmigrare, quod illum obfervatio annorum [730 \& 1744 . docuit. - Attamen pabuli pariter defectum migrantia pafim animalia fedibus, fuis depellere, notifimæ per Sibiriam, e magno jugo linitropho, verfus fylvas \& planitiem borealiorem, variorum animalium migrationes argunt, ut inde quibusdam annis Lepores ${ }^{b}$ ) verfus boream, prefertim circa Ienifeam \& Tomum fluvios turmatin defcendant; aliis, autumno ingruente Sciurorum mira copia migrantium vis appareat, quos e colore nigricante pellis, non ejus regionis, quam occupant \& peragrant,

1) Vide qux fupra in Leporis variabilis hiftoria fufius expofui $p \cdot 15$. 
\& peragrant, prolem, fed e frigidiffimis alpeftribus jugis adventitiam effe, facile apparet ${ }^{c}$ ), quosque propter nucleorum Cembræ \& Agaricorum annonam in diverfas regiones hyematum abire, vulgo nota res eft, quandoquidem iftis præfertim nucleis promptuaria fibi replere, \& Agaricos, quos amant ${ }^{d}$ ), in ramorum fpinis \& furculis circa nidos copiofe defigere folent ad futuram neceffitatem hyemalem providentes. Immo etiam Lemmorum migrationes pabuli autumnalis utplurimum defectui deberi, Norvegorum fuadet opinio, qui credunt Lemmos patrias alpes tunc relinquere, quando certis ventis aridisque æftatibus alpinæ regiones exuruntur, ut propter victum in herbidas planities defcendere cogantur, quod Cel. BRvNNICHIvs in litteris monuit ${ }^{e}$ ). De aliis murum migrationibus in Muris aconomi hiftoria ftatim dicetur.

Quæcunque demum itinerum Lemmi fubfit ratio, mirabilis utique eft, nec facile fine peculiari inftinctu \& intelligentia explicandus, confenfus quo Lemmi ex integra regione congregati, ftructa vellut acie, ex alpinis in vicina plana defcendunt, re. ctoque, quem inftituerunt, tractu pergunt, nullis neque periculis, nec obftaculis difturbandi. Confentiunt enim auctores, qui de Lemmis egerunt, omnes, eos in agmina collectos rectiffima. directione incedere, ita ut, a longo fuccedentium ordine, radicitus exefo gramine, tramites cæfpiti velut infculpti

c) partas Reife Vol. II.p. 660.

d) Flor. Lappors. p. $36 \%$.

e) Excerptum e litteris Amici adpono: "In regione Norvegiæ auftrali (vul"go Syndenfield's dicta) perraro apparet "unus \& alter horum murium (Lemmo. "rum). Tribus iftis annis, quibus inter "Fodinas Kongsbergenfes fui occupatif. "fimus, nec ego, nec ullus alius talem "vidit. Aliquot tamen ante annis ibi "apparuiffe nonuullos, retulit mihi ami"cus, qui ipfe eos vidit. Anni præte"riti (1775.) menfibus Februario \& N!ar. "tio licuit mihi facere iter ad Nidrofiam "ufque; frepius rogavi de iftis muribus , apud rufticos alpium, qui afferuere, eos 
appareant plures, parallelo fitu, unius duorumve dodrantum law titudine \& aliquot frepe ulnarum (ut RYCAvT habet) abinvicem diftantia, unde campi, per quos inceffere, fpeciem arati agri præbeant. Agmen præfertim diluculo \& noêu migrat, quiefcit interdiu \& regionem ubi fubftitit, ita devaftat, cafpitem exedendo, ut exufta videatur. Quidquid obftaculi in via occurrat, nequaquam declinant, non ignes, profundas voragines, fcaturigines, torrentes, paludes, lacus, fed audacter rectaque pergunt, unde frpe multa eorum millia in undis prefertim pereunt, \& mortui ad littora reperimntur. Si frumenti vel feni acervus obftet, rodendo viam faciunt, rupes, quas tranfcendere nequeunt, ambage circumeunt, ut dein priftina directione via ad eandem plagam pergant. Si lacum tranantes affequaris \& contis remisve agmen disjicias, non fugiunt retro, fed directe natantes pergunt, \& ordinem turbatum fat cito reftituunt; immo (GVNNERo referente) objectum quoque navigium tranfcendere conantur. Non timent. obvium hominem, \& in curfu inpeditæ in poftica arriguntur, cum latrante quafi grunnitu pugnaces, ita ut ad genua fere exfiliant, objectumque fcipionem ita pertinaciter mordeant, ut cx eo pendentes jactari poflint; nec nifi xure ex ordine dis-

„fub nive degere $\&$ a vulpibus conquiri; , ipfos autem videre tume non contigit. „. Dicnnt eos valde efle irncundos, ita ut in ,Folticos erecti tam firmiter mordeant in. , ftrumentum, quo eos inquietalerit ali„qnis, ut patiantur fe clim ligno a terra ,elevari. Cibun vix colligunt pro hycme, ,vagabundi fub jpla nive, ubi procul du. „, bio ex Lichene ivunt; ld certume eft, quod ,per xeltatem graminivori iunt; line, ubi "procedunt, quafi cxufti apparent campi. „De raigrationibus eorum nil didici,pre. ,ter ruigata anctorum, quod fcil, linea "reit: loctm mutent; forte hoc ex rento "pendet, quando aridis reltatibus, exuftis "alpinis, graminifcras planities petunt. „Singilare eft, in quo pluacs confentiunt, "quod fimul venientes fimnl abeunt, tan "fubito, ut nitil de iis amplius audiatur ", in circumjacentibus. _- Hre funt orn, nia, quæ pro tempore de is haben; "fcripfi dudum ad amicos in Noriegia ., feptentrionali, ut me de iis erudirent, ncct. Hæc BR VN NICHIVS. 
turbatæ latebras tantem quærunt. - Lemmos interdum ftructa acie inter fe concurrere prælio, folus prodidit MONCALLI, quod dicit Lappones pro belli Suecia imminentis præfagio habere, etiam fic, ut credant, fi ab oriente venerint, cum Rufis, fi ab occidente, cum Danis bellum portendi.

Directionem migrantium HOEGSTROEM circa finum bothnicum verfus orientem ad ipfum finum effe obfervavit, \& LINNAEVS quoque afirmat; at RYCAVT ab oriente seftivo verfus occafum hybernum migrare dicit, licet de obfervatis anno 1697. in Tornëenfi Lapponia loquatur, in qua præfens HOEgSTROEmivs obfervationes fuas collegit. Forte directio vix ad jugum, unde defcendunt, in genere transverfa feu rectangula effe folet; ut utraque obfervatio per turmas e diverfis borealis jugi dorfis, pro vario horum fitu diverfa viæ directione migrantes, conciliari forte queat. PONTOPPIDANI hoc etiam relatio confirmat, qui ex alpibus Norlandiam a Suecia difterminantibus, ubi patriam Lemmorum ponit, per eandem provinciam \& Finmarkiam oecidentalem verfus oceanum migrare perhibet; uti ad orientem per Suecorum terras, adverfa directione verfus Bothnicum finum tendunt.

Lemmi in Scandinavia, cujus borealibus in alpibus præfertim pullulant, tantæ funt faruræ, ut inter affincs brachyuras fpecies magnitudine primatum fibi vindicent. Habui ex Suecia fpecimen a Celeb. Petro lona e ERgio transmiftum, habui fpecimina tria Norvegica a Cel. BrünNichio procurata, qua magnitudine \& colore inter fe \& cum icane altera noltra (Tab.XIl. A.) omnino conveniebant. Contra c Iapponia Rur. fica, ubi fapius migrantes obfervantur $\&$ fub nomine Peftrufchla (Variegatulis) noti funt, adlatos vidi \& ex Obenf regione B b 2 . 
fpecimina habeo, longe minori ftatura \& colore quoque diverfo, ut ex icone Tab. XII. B. cum priore collata \& defcriptioni bus comparatis conftabit; neque tamen hic a Norvegicis fpecifice diftincti funt. Et quandoquidem in vicina Scandinavize Lapponia ruffica, (ctiam circa Kolam) non talcs reperiuntur, quales e Norvegicis alpibus per Lapponiam fuecanam verfus orientem migrare folent: confirmatur inde, haud ita longe a paternis fedibus exercitus iftos procedere, fed in vicinas planities difpergi vel maximam partem perire, fluminibus aut, maris finu, verfus quem plerumque agmen dirigunt, demerfos. Eadem quoque LINNAEI \& aliorum obfervata innuunt, qui migrantes immenfis copiis mures, non folum antequam ab alpino jugo ad finus Bothnici littora perveniant, plerosque itineris cafibus \& ferarum dente perire-tradunt; fed \& reliquos, licet vix centefima fæpe migrantium pars, non in diffitas regiones abire, fed infequente xftate reduces, denuo verfus alpes, eodem ordine \& perfeverantia pergere HOEGSTROEMIVs teftatur, numero equidem in tantum deninuto, ut fepe vix obfervatus fuerit reditus.

Difcimus ex eodem, in campeftribus, quorfum migrarunt, fparfim habitare Lemmos; nee fociabiles videri; in alpibus vero illis annis, quibus migrationes accidunt, paucos admodum refides obfervari. LINNAEVS, qui Lemmos in alpina patria obfervavit ipfe, adeo copiofos ibi habitare dicit, ut rarum terræ tuber fine antro videas, quod folet effe latitudine manus, fed vix altitudine digiti, raroque pluribus commune deprehenditur. Tota illos hyene vagari \& BR obfervatum eft, unde Marmotis adnumerari nequeunt, nec penum fere ullum collisunt. Monet eciain RYcav's, hyeme 
fub nive latentes tamen apertum fervare fpiraculum, ut lepores aliaque hyeme non fopita animalia. - Mihi palmarum \& unguium magnitudo, \& horum in "mafculis fingularis conftitutio in peculiares fines deftinata videtur; ut faltem cæfoiti \& radicibus fodiendis adaptatas credam.

Pariunt in fuis cuniculis quinos aut fenos \& quidem cos: cos catulos, fed maculofa jam pelle (GVNNER.) Vif etiam in ipfa migratione occupatæ matres peperifle, \& pullum alium ore, alium dorfo fuftuliffe; quod \& RYCAVT \& LINNAEVS prodiderunt. Forte igitur pluries in anno pariunt, unde tanto facilius mira mul. tiplicatio \& migrantes exercitus intelligerentur, compenfata diminutione, quam in fedibus fuis a Cane Lagopo, Ermineo, aliis: que feris patiuntur; Lagopis præfertim, arctica regionis civibus, foli fere a Natura in pabulum deftinati, ut etiam migrantes has femper feras pediffequas habeant, felicioremque accolis fua cum pernicic adferant venationem. - Inde vero nec virulentas Lemmorum carnes effe patet; quod aliqui ex co concluferunt, quod canes fola Lemmorum capita comedere, intactis reliquis, \& aves rapaces, plerumque fola exta deguftare audiverunt. Magieque veneni fufpicio tollitur, dum Lappones totos Lemmos fine noxa comedunt, Scirisque fapore fimiles adfirmant. Ex his de ortu atque parria Lemmorum jam ita conftat, ut hodie nemo amplius e cclo deciduos wormo credere velit. Vere tamen ex alto deciduos fieri plebs etiamnum perhibet, immo, fi LEEMIO credimus, vere decidunt; quod vero paradoxon felicifime explicavit Venerab. GVNNERos eo, quod a Corvis, aut, dum aquas tranant, a Laris raptus Lem. mus volanti fubinde avi elabitur; quod \& vcipertino tempore Strygibus contingere, faciliusque pro miraculo imponere poteft;

$$
\text { B } \text { b } 3
$$


quemadmodum ipfe GVNNERVs vidit Echinum cx aëre in faxum decidenten, quem fupervolans Cornix amiferat, credulus autem aliquis e calo pluife contenderet.

De Lemmis Imperii Ruthenici, quos a Mari albo ufque ad Obenfem finum, maximeque in boreali parte jugi Uralenfis abundare certo fcio, pauca relatis fuperaddi pofiunt, nifi quod magnitudine, ut dixi, \& colore infigniter a Scandinavis differunt. An hoc majori regionis frigori, folo nunquam degclanti, aliisve caulis tribuendum fit, incertum relinquo. In Sibiria, ctian tempcrata \& pafcuorum abundantia felici, Armenta cum Equis \& magnitudine \& robore, formaque decreverunt; tamen neque hoc frigido lecorum climati adfcribere vellem; notum enim is China quoque \& felicifima India peltmam cfle progeniem faltem cquorum, \& armenta Sibiric parvula in frigidam Kamtfchatkam translata ibi pulcherrimam acquifiverunt faturam. Nollem ctiam propter iftorum animalium decrementum, \& quod Tunguros, Buretosque exiles \& imberbes profert eadem tellus, concludere (ut in Americam iniquus duce bvFFoN10 fecit PAVVIVS), ommia in Sibiria pejora nafci, licet id pari ferc argumentorum numero fpeciofe polfet cvinci. Dum contra aliis animantibus gigantcum, fi curopxis comparentur, incrementum cadem largiatur Sibiria, v. gr. Alcibus, Cervis, Tarandis, Talpis, Erinaceis, Scinis, alisque. De quibus ali bi fufius dicendi locus crit.

Caterum Lcimmos, uti \& Cequentem Muris fpeciem, in Obenf regionc xque vulgarem, fed in Lapponia munquam obfervatam, certis periodis ex Vralenf jugo modo lenifeam, modo Petíchoram verfus transmigrare atque venatorum fortunam vel augcre vel minucre, fequacibus feris, etiam inter Samoje- 
đas \& reliquos maris glacialis accolas notiffima res eft. Iidem quoque tradunt Tarandos Lemmis inhiare, fimili appetitu ut Cervi ferpentibus vefci dicuntur, qua non de nililo fama eft; fed rque pro medicamento hoc iis effe crediderim, ut ovibus funt aranex, vel phalangia, qux avidifime hoc pecus conquirit. - Studiofus, qui Lemmos \& Sequentis fpeciei Mures ex arctica ad Obum regione retulit, in tractu ibi montofo antra copiofiffima, fed perraros Mures obfervavit; dicebantur autem tunc demigrafe, unde illo quoque anno parcior Lagopodum venatio fuit. Obfervavit autem cuniculos fub cumulis \& tuberibus cæfpitofis canali continuo connectente complures cameiss, in quibus Lichen rhangiferinus erat congeftus, quem LINNAEvs etiam in Lemmorum ventriculis reperiri afferit.

In orientaliore Sibiria Mures migratorios per terras arcticas ufque ad Lenam notos \& Lagopodum duces procurare mihinet non potui, adcoque - an ibi Lemmus, vel altera noftra fpecies (M. torquatus), vel ab utraque diftincta ex cadem affinitate degat \& peregrinetur, - pronunciare non aufim. Scd Iob. Geo. GMELINI inter pofthumas chartas feriptam obfervationem addam, c qua confabit, Nures ad Lenam migratorios non forma quidem, féd colore, a Lemmo \& iviure torquato, admodum differre. Et licet hycmale vellus ga E$\mathbf{L I N V S}$ in Lenenfibus obfervaverit, unde credere quis pofiet, Lemmos quoque, ut alia aretoa animalia, hyeme albefcere, tamen hoc a Suecis, \& Norvagis obfervatoribus non adnotari vix potuiffe credendum eft. Itaque, tanquam de dubia fpecie, Lemmo faltem \& M. torquato proxima, ipfa GMELINI verba apponam: 
„Mures, inquit, duos, qui Ifatidum (Canis lagopodis') „pabulum funt, campeftres, brachyuros, curante Iacutenfi Can„cellaria duos e Schiganenfibus hybernaculis ad Lenam adla"tos habui. Mediæ fere magnitudinis funt inter Murem do"mefticum vulgarem \& Rattum; roftro gaudent nec acuto, gnec obtufo, ad rictus latera retis albentibus munito; auriculis „brevibus, fubrotundis; corpore latiufculo, brevi \& fere æqua"liter lato; cauda brevi eaque longis pilis, parallele cum „cauda difpofitis hirta. Ad anteriores pedes quinque digiti „appenduntur \& totidem ungues albi, robufti; ad pofteriores "quatuor tantum \& totiden ungues albi pariter, anterioribus "multo infirmiorcs "). Pili plurimam corporis partem occu„pant fatis longi, qui a radicibus ad tres quartas totius pilo„rum longitudinis, five quoad abfconduntur a fociis, cinereo, "partem quartam, que extrema eft et patet, candido "colore infigniti funt; adeoque color muris, naturaliter fpe. „ctati, totius candidus eft. Malæ tantum, \& ductus fecundum „mediam roftri longitudinem cinerco, mentum nigrefcenti colore "gaudent. - Dimenfiones individuorum, quæ defcripfi, hæ funt: ,Ab extremo roftro ad initium caudæ $\quad 3 \frac{\mathrm{T}}{5}$. poll. par. „Longitudo capitis "Latitudo corporis circiter „Caput per aures transverfim latum „Oculorum canthi interni diftant , $\mathrm{Ab}$ extremo roftro ad medium inter oculos ,Spatium diftantia

" Cauda, una cum pilis ultra officula coccygis „prominentibus
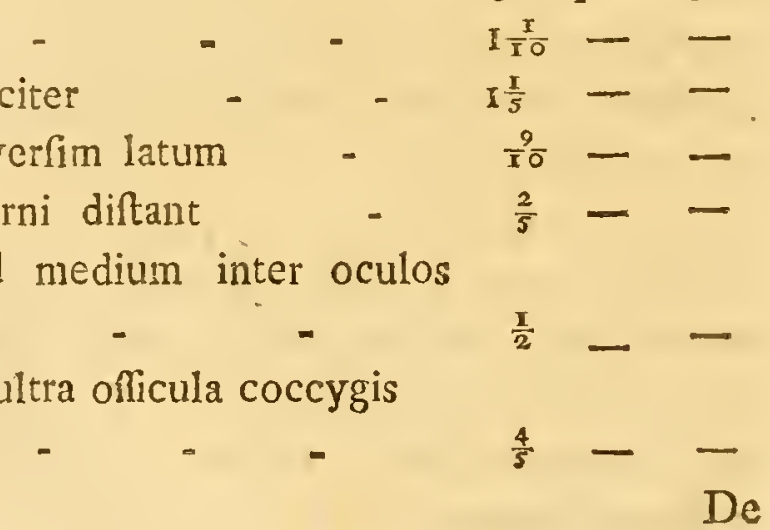

a) Digitorum numerum forte in palmis quaternarium indicare voluit $G M \mathbb{E}_{\mathbf{L}}$. 
„De partibus internis, nihil habeo quod dicam; poftquam „enim mures regelati erant, interna omnia fanie fuere cor„rupta. Quæ tamen difcernere valui, non differre videban"tur a confueto naturæ in - hoc animalium genere ordine. "Incedunt gregatim \& in regione inferiore Lenæ fluvii atque „ad littus maris glacialis, ibi propinquum, perææe obfervantur. "Adveniunt ex improvifo, fub autumni plerumque tempus, ex ", improvifo etiam abeunt. Ifatidi earum regionum in efcam "cedunt, ipfr non nifi radicibus mufcorum vefcentes. - An "Mures (addit GMelinvs) Ienífeenfibus Ifatidibus pabuli loco „, infervientes iidem fint, non poffum decidere, quia nullum „éorum exemplum vidi. Quantum vero ex venatorum defcrip„tionibus oralibus colligo, præter magnitudinem, qua Ienifeen"fes excellere dicuntur, notabilem differentiam dijudicare non "valui. Dicunt etiam duo ad Ienifeam obfervari genera $f$ ), , in omnibus quidem, præter colorem, fimilia, qui in uno ge"nere totus candidus fit, in altero nigto, albo \& lutefcente "varius. - Muri norvagico WORMII hic mus admodum cog"natus effe videtur. Vt enim olavs MAGNvs colorem „eorum varium defcribat, dantur, ut dixi e venatorum rela;, tione, etiam in his regionibus colore vario præditi; præterea „Olai defcriptio æflivo tempore concinnata videtur, quo co"lor in multis animalibus frigidas regiones colentibus alius eft, „quam hyberno. Dubium tantum, movet capitis figura acu"minata, quam OLAvS de mure norvagico prædicat "(falfo), „, reliqua enim attributa, ut generatio eorum e nubibus, pugna

f) Forte Lemmum \& Murem tor- grantes apparent; fed color albus requatum noftrum intel!exerint relatores, pugnat. qui in Obenfi quoque regione ambo mi. 
, inter fe \& cxtera, quæ Lapponum ingenio, non oLA 1 digna ,effe cenfeo, nec difcufionem mercri videntur., Hucufque GMELINVS.

Fere minus ego dubitarem ad Lemmum referre Murem e terris Hudioniis transmiflum, quem in Atis anglicis ${ }^{\circ}$ ). Forstervs breviter adumbrat. Quantum cnim ex imperfecta mutili fpecininis delcriptione liquet, fibiricam varietatem Lemmi migratione, magniturdine, "colore fufco \& fulvefcente mixto, ,fubtus fordide albo, capite lato, linea per medium verticem „, fufca, per dorfum obfcurius continuata, auriculisque minutis, , plane refert. Adeoque effet Lemmus fere univerfo orbi arctico communis.

Aliorum obfervationi relinq̧uo Mures campeftres, quos breves, craffos in Groenlandia dari ANDERsonivs ${ }^{h}$ ) adtigit, Mirum tamen Amicum, quem e Groenlandia hofee Mures procurare rogaveram, inde a Colonix Lichtenfels miffionario $D \%$. noenigener refponfum tuliffe, Rattos terreftres $A n$ derfonii in Grocnlandia nullos efle, imo nullos omnino Mures ibj terrarum inveniri. Si tamen dentur, verofimillime Lenmorum funt e profapia. - Contra illi Mures, quorum in Iflandia aconomiam, penum e collectis baccarum cumulis, migrationem, navigationem, cet. in Itineribns oLAvI \& poVELSLNI1 ${ }^{i}$ ) relata legimus, potius $M$. ceconomo noftro quam Lemmo aftines videntur.

g) Pinilofophical Trunlo vol, LXII. p. 350 .

i) Nachrichten von lslasi. Groeuland, cet. p. 563. i) OLAFSENS L, POVELSTN' Reife durch Ifland verfion, germ. vo! $I_{\text {a }}$ p. 91,117 . 


\section{DESCRIPTIO \\ $M V R I S$ LE $M M I$.}

Tab. XII. A. ct B.

Proxime omnium fpecierum mihi cognitarum (præter M. torquatum) ad M. Lagurum facie \& fabrica accedit. Sibirica \& lapponica varietas magnitudinze paulo fupra Murem terreftrem; Norvegica, plus duplo major, ad molem Muris anphibii mediocris accedit.

Caput majufculum, ovatum, breve, ob villofitatem horridulam admodum crafium apparet. Roftrinn obtufiffimum, maSo craffo, rotundato, æque ac labia denfifima lanugine veftito. Nares fub protuberantia nafi delitefcentes, fepto breviffimo, fulcato, nudo; Labitm fuperius tumidum, ufque ad feptum fifium.

Dentes prinnores fupra latiufculi, extus convexi, interiure margine lutefcentes, pofterius ad dimidiam longitudinem canaliculati; acie terminali leviter excavata, inferi longiores, obtufiufculi, tantum apice lutefcentes. Molares ubique terni, anteriores fenfin majores, trifulcati, omnes detriti.

Myftaces capite breviores, rigidiufculi, fetulis infimis albidis, fuperioribus in fibirico nigricantibus, in notvagico brit fufcis, extremo albidis. Seta fupraciliaris folitaria vel gemella.

Oculi minufculi, medio inter nafum \& aures. Alit $\%$ culce exiguæ, vellere latentes, capiti appreffie, rotundatx, margine meatum coronantes, apice fufco fubvillofx. Intra auriculam margo alius quafi valvúlaris, crafius, atrium meatis ampliufculum cingens.

Colltm latitudine capitis, depreffum. Truncus breviufculus; Artuls breves, robuft, fere ut M. talpino, prefertim anterioncs. 
Palnne majufculæ, pentadactyle, $m$ guibus lutefcentibus, valde compreffis, quaternis fubulato - incurvis, fubtus vix fulco canaliculatis; pollicis brevifimi ungue craffiore, compreflo, apicc oblique detruncato \& veluti prærofo, ita ut inferiore margine ad volam acuto mucrone promineat, quo verfus folum directo lacerandis radiculis aptus videtur. In Mafculis ungues palmarum majores, tres exteriores maximi, verfus apicem obtufum \& fubunguliformem incra/fati, interior folus fubulatus, pollicaris bimucronatus (Tab. XVII. ffg. Io.)

Planta pentadactyla, unguibus omnibus in utroque fexu fubulatis, tribus mediis longioribus, pollice breviore. Vole palmarum plantarumque ufque ad callos bafeos digitorum pilis canis rigidulis hirfutiffmæ; digiti nudiufculi, fubimbricati, pilis circa ungues denfioribus ipfosque ungues fubæquantibus.

Uropyginn, ut in M. talpino, productius, fubtus genitalia gerens; fed anns fub ipfam caudæ bafin, ceu tubulo, eductus. Cauda plantis brevior, craffa, cylindrica, obtufa, pilis proftratis, rigidulis denfius obfita, præfertim apice penicilliformi.

Genitale Maris fub imo uropygio, ad fcrotum nudiufculum, preputio prominens. Femince clitoris recumbens, preputio maris haud minor, pubefcens, conica, interiore latere raphe bipertita, obtegens oftium vaginale rugofum, ani tubulo producto fuppofitum. Papillas mammarum duas thoracicas, duas remotiores femorales, binasque inguinales tantum inveni; octonas numeravit LINNAEVS.

Color: in Norvagicis (Tab. XII. A.) pulcre variegatus; vertex inter nafum albidum oculosque ater, lituraque atra $a b$ oculis utrinque ad aures longitudinalis; occiput tegit 
area lunata, liturata, cum flavedine lutefcens, in Senioribus exalbida; hănc excipit area magna, oblongo - quadrata, a bafi cervicis ufque ad medium dorfum continua; reliquum dorfum cum flavedine fulvefcit, fufco fubnebulofum, vellere fcilicet tantum extimo colorato, tecta parte fufco. Latera capitis, gula \& corpus fubtus totum alba, trunci lateribus e fulvefcente fenfim in album obfolefeentibus. Cauda pedesque canefeenti alba. Altitudo velleris $8 \frac{\mathrm{T}}{2}$ ad $90^{\prime \prime \prime}$

In Lapponicis (Tab. XII. B) præter fafciam utrinque fufcam, ab ipfo nafo fufcefcente per oculos \& aures poirectas, lituramque verticis longitudinalem fufcam, vellus fupra omne extus fulvum, pilis raris nigricantibus afperfis, \& in cervice aliqua fufcedine mixtum, verfus latera flavefcens, fubtus. pallidum; gula late candida. Altitudo velleris $6 \frac{\mathrm{t}}{2}$ ad $7^{\prime \prime \prime} \&$ in utraque varietate vellus molle, fed lævigatum.

\section{E N S V R A E.}

Norvagici \& Obenfis Lemmi menfuras comparatas addo; ut melius differentia magnitudinis elucefcat. Pondus in animam libus liquore affervatis explorari haud potuit.

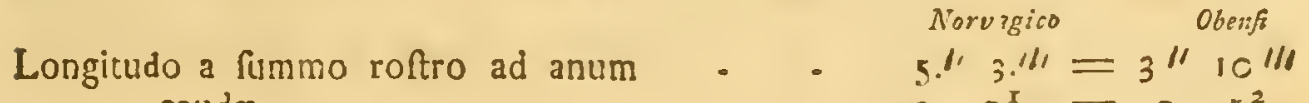

- caudx

- pilorum caudam excedentium

Circumferentia caudæ

Longitudo capitis a nafo ad nucham $\quad 0.5 \frac{1}{2} .004 \frac{\frac{5}{4}}{2}$

. $5^{\frac{1}{3}}=1.2$.

Difantia oculorum a lummo nafo - $\quad 0.7 \cdot=0.5 \frac{1}{2}$.

Intervallum narium

- inter aurem \& oculum

Oculorum fiffura

Longitudo auricularum

Earundem laticudo

Circumferentia capitis pone myftaces

o. $\frac{2}{3} .=0$.

c. $6 \frac{3}{5} .=0$

0. 2. $=0.1 \frac{\pi}{2}$.

0. $4 .=03 \frac{2}{3}$.

: inter oculos \& aures

$$
\text { C c } 3
$$


Intervallum inter oculi utriufque canthum

$$
\text { Noruagico }
$$

Obenfs

Circumferentia colli

0." 6"1'. = 0 oll 5.111

Longicudo colli

Circumferentia thoracis ad armos cadem qua medii

Congitudo horis

$$
\begin{aligned}
& \text { colporis } \\
& \text { o humeri }
\end{aligned}
$$

\section{- antibrachii}

- palmæ cum unguibus

- unguis maximi in feminis - in mafculis, quitus planta tota ad $7^{\prime \prime \prime}$

Circumferentia antibrachii ad bafin

- carpi

Longitudo femoris

- tibie

- planta cum unguibus

- unguium longiflimorum

Circumferentia tibix

- metatarfi
2. $1 \cdot 1 .=2.6$.
0. 3. $=0 \quad 2 \frac{x}{3}$.

3. ०. $=2.8$.

D. $6 \frac{\mathrm{T}}{4}=0 . \quad 5 \frac{4}{5}$.

0. $2 \frac{2}{3}$. 0.2 .

0. 4 . -

o. $10 .=0.8$.

०. $6 .=0.5$.

o. $9 .=$

๑. $11 .=$

0. $10 .=0.8 \frac{1}{2}$.

0. 2. $=0.1 \frac{2}{3}$.

0. $11 \frac{\mathrm{l}}{2}$. $=0.8$.

0. $6 .=0.5$.

\section{A N A T O ME. \\ Tab. XV11. fig, 6. ro et 우.}

Cutis utrinque in regione parotidum \& maffeterum per arean ovalem, qua cxtus pilis albis denfifimis veftita \& tumiduli eft, incraffata, firmatur fibris ligamentofis firmifime implexis, ita ut medio craffitiem in minoribus $1^{\text {"l }}$ in majoribus féquilinex adxquet; quo fodientis caput \& glandulas colli defendere voluit Natura.

Totum collum infra $a b$ una ad alteram aurem ambeunt \& capiti xquant glandule thymo fubfantia analoga, in complures utrinque fub amre minores lobos, unumque majorem lunatum fubdivifx. Cervix plerisque pinguifima.

Hepar quadrilobum, crafum, lobo finiftro ampliore, difcoïdeo, dextro craffo, difformi, fuperincumbentibus duobus in difcum convexum cöaptatis, quorum dexter major \& quos in- 
terjacet Cyftis fellea minufcula, libera. Lobus Spigelianus f. quintus fubtus perexiguus.

Ventriculas fundo minus, quam in M. oconomo \& affinibus productus, totus membranaceus, plica intus ad afophagum dexteriore, verfus arcum majorem exfolefcente fubbilocularis, \& a plica ad pylorum paulo crafliore fubftantia fubglandulofus. In cibo repletis vel inflatis (fig. 6.) fundus amplior, in famclico ventriculo ( $f g .7$.$) aretifime conftrictus.$ Cbymzls in fibiricis fufcus, lutefcente mixtus; in norvagicis miculis albis mollibus a comefto lichene mixtus.

Intefinmm tente in majore Norvagico bipedale cum 4 pollicibus. Ceecum (fig. 8. b c d.) ab infertione ilei $(a-b$. circiter quinquepollicare, forma ut in $M$. fociali, arcuatum, fubcellulofum, extremo adtenuatum, apice (d.) cylindraceo, inflexo. Continuatio craffi $(b-e$.$) coeco paulo anguftior,$ cellulofo - contorta, circiter bipollicaris. Inteftimum dein spirale $(e-f$.$) (quantum in nulla alia fpecic) fpiris cir-$ citer fex confertis pergit circa cundem axin tortis, reditque fpiris circiter quatuor exterioribus, ftriatis, priorum mediis circumpolitis, a quibus continuatur $(g-b$.$) rectum initio$ (ad pollicis fere longitudinem) itidem ftriatum, dein cxampliatum, excrementa molecularia continens, totum circiter pedale. At fpirale extricatum 9 pollices æquat. (Hæc e majori va. rietate).

In minore inteftinum tenue bipedale, ileo non multum fupra quartam partem confituente; rectum cum friato i3 pollicum.

Ren dexter fitu paulo anterior. Teftes in forotum remiffi, fundoque cremafteris ep:didymide adnati. Supra teftes 
Ma/fa adipofa agariciformis, emboli inftar canalem fcrotalem obturans, abdominique obvertens planum excavatum. $V e f i$ cula fpermatica tantum binx, infignes, anfractuofo - circinnatx. In Mafculi pene vix 9."' a radice longo, glans cylindrica, brevis, calycis inftar excavata, intra quem prominet officulum, phalangis latentis apice adarticulatos gerens ftylos tres offeos, minutos, mobiles, fub quibus orificium urethræ Fig: 오.).

Pulmonum dexter trilobus medio lunato, minore; $f$ nifter bilobus, inferiore fere mediaftino; uterque parvulus, prout thoracis cavum in hac fpecie anguftius. Cor minufculum, ventriculis parum carnofis, dexteriore præfertim tenuiffimo, flaccido.

Sceleton: Cranium amplitudine ollæ proxime ad $\mathbf{M}$. talpinum accedit, fed eft fere robuftius, præfertim zygomatibus, dentiumque fitu \& reliqua circumcæfura potius cum Muris arvalis cranio convenit ( $f g . g^{\circ}$.) Olla latifima, fupra plana, offe utrinque temporali verfus orbitam quafi crifta protuberante; ofla bregmatum parvula, duplo anguftiora latitu. dine cranii, trapeziformia, minora adhuc, quam in M. capenfi. Zygomata robuftifima, antice latifima obliqua lamina, orbitas protegente radicata, medio latodilatata, poftica radice tenuiffima. Maxilla ad molares tubcrofiflima, procelfu coronoideo tenuiffimo, condyloide \& angulari productifimis.

Vertebrarum apophyfes prominentiores nullæ præter criftam epiftrophxi. Coftarmm tredecim paria, feptem vera. Stermum officulis quatuor intermediis. Vertebra lumbares VI. maximæ. Sacrum biarticulatum, primo tantum innominatis coarticulato. Cauda vertebra XII. connumerato apice. 
Offa innominata parva, fed fymphyfi coëuntia. Artuntm offa anticorum paulo robuftiora; palmarum pollex phalange brevifima (præter unguiferam) ad carpum feffilis. Fibulde ultra medium a tibiis diftinctx.

Longitudo cranii ad extr. offa nafi

In Norveg.

Obenfo

Latitudo inter orbitas

1." 3.111 - I. 0.

- ollæ pone zygomata '

0. $1 \frac{3}{4}$. - $1 \frac{4}{5}$.

- inter arcus zygonu. fumma

0. $6 \frac{3}{4} .-0.5 \frac{4}{5}$.

- - roftri ad zygomata

०. 9. - 0. $7 \frac{5}{3}$.

Longit. offum nafi eademque roftri offei - 6. $4 \frac{3}{5}$ - o. $3 \frac{1}{2}$.

Diftantia molarium

- molar. ab inciforibus fere Longit. inciforum fuperiorum

Q. $2 \frac{3}{4}$ - 0.2 .

o. $4 .-0.3 \frac{\mathrm{T}}{3}$.

o. $2 \frac{x}{2}$ - 0.2 .

0. 5. - 0.4 .

○. $2 \frac{3}{4}$. - O. $2 \frac{\pi}{4}$.

o. $3 \frac{\pi}{3} .-0.3$.

- maxilla ad condylos

- colımna vercbr. colli

- - = dorfí

- - lumbaris

- facri

- caudx

- offum innominatorum

Longitudo ilei ad cotulam

- foram. ovalis

Latitudo ejusdem

Longitudo fterni fine enfe

- enfis offei

- claviculæ

- fcapularum fumma

- humeri, fere

- cubiti

- offis metacarpi medii

- femoris

- tibiæ

- calcanei

- offum metatarfi medior.

- cofta longifima fept.

D d 


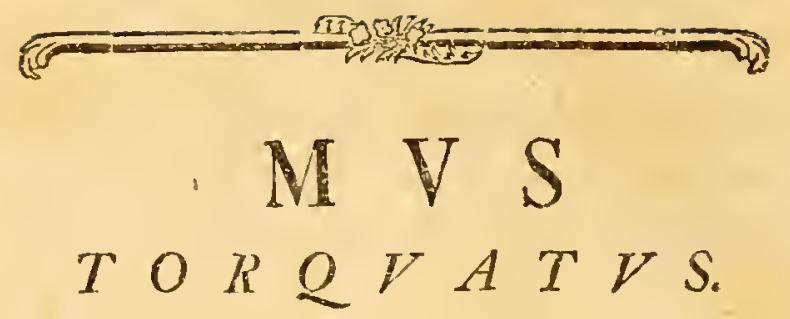

$\mathrm{H}$ anc fpeciem a Lemmo diftinetiflimam \& varietate hujus Sibirica fere minorem e regionibus ad Obum fitis arcticis accepi, ubi frequentior Lemmo obfervatur, ita ut quibusdam annis omnia borealium paludum tubera. occupet, Samojedis autem referentibus migrat, iisdem annis, quibus Lemmi. Hinc in calvis Montium Uralenfum per arcticam regionem crebri apparent horum murium cuniculi, a nido fub cæfpitofo tubere latente plurimis canalibus pervii, a quibus quafi femicanales, cæepiti mufcofo infculpti, \& hinc inde infra fuperficiem. delitefcentes contimuantur. Lichene rhangiferino \& nivali etiam hi nidi repleti, attamen Polygoni vivipari etiam tubera inibi seperta funt. Plura de moribus \& natura hujus animalculi difcere non potui, cujus fpecificæ differentix, in affinitate cum Lemmo fumma, preter maxime alienum colorem \& velleris mollifimi confiftentiam, e figuris \& defcriptionibus, utriufque comparatis facile perfpici poffunt.

\section{DESCRIPTIO

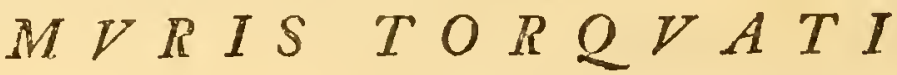

Tab. XI. B.

Mngnitudo M. arvalis majoris, feu Lemmo ejusdem regionis circiter æqualis. Forma aflimilis.

Rofrnam fere obtufus \& labia vix non tumidiora; flperins ufque ad nafum difcifum, \& naflis fulco argute divifus, fupra pilofinimus, fufcus. Myftaces fparf, nigri, longi- 
tudine capitis. Dentes primores albi, fuperiores minus lati, quam in Lemmo, neque acie excifa.

Oculi paulo majorcs, quam in Lcmmo xquali. Atrium lobulus breviffimus minimus, apice ferrugineo - villofus, e vellere plane non (adcoque minus quam in Lcmmo) proininulus.

Corporis \& artuum proportiones fere ut in Lemmo. Pedes robufti breves villofiores, quam in codem, foleis totis villofifimis; ungutes robuftiores, cathetoplateo - lati, mucrone tenui falcato; in plantis minores; piloque fere latentes. Palma robuftifima fubpentadactylæ, pollicis papilla, verfus volam inclinata, ungue minutifimo, ad papillæ bafin.

Cauda brevifima, fufca, obtufa, extremo fetis rigidis, albis fubpenicillata. Anus fub cauda tubuliformi productiufculus. Preputiun parum remotum, plica crafla verfus anum continuatum.

Vellus mollifimum, læve, tenerius quam Lcmmo. Color fupra ferruginco \& gryfeo lutefcente, in aliis, gryleo pallido \& fufco - ferrugineo undulato - nebulofus; tractu per mediam fpinam magis nigricante; latera pallefcentia. fubtus totus e pallido fordidius albet. Nafus nigro villofus, traEtu fufcefcente a nafo per frontem longitudinali, areas myftaceas albefcentes interftinguente. Area transverfa in regione aurium brunneo - ferruginca, pone quam collaris utrinque litura pallida, fuccedente denuo plaga humerali brunneo - ferruginea. Artus albido fufcoque mixti, foleis albo - villofifimis.

M E N S R R E.

Pondus e fpeciminibus liquore adfervatis detcrminari non potuit. 
Longitudo tota a nafo ad anum

- capitis ad nucham

- caudie fine pilo

- exfupcrantium pilorum

Diftantia oculi a nafo fere

\section{- a aurs ab uculo}

Fiffura palpebrarum

Longitudo lobuli feu marginis atricularis

Circumferentia capitis ante aures

- colli

- thoracis ad armos

Circumferentia medii cöporis

- corporis ad ilia

Longitudo antibrachii

- palmie cum ungue ( $\left.1 \frac{3}{5} / 11\right)$

- tibiarum

- planta cum ungue (1 $\left.\frac{1}{4} . / 1\right)$

Lorigitudo palmæ ad carpum

- palma digitis

- planta ad digitos
$3.111 .11 !$

I. 0

o. $4 \frac{1}{2}$.

o. $2 \frac{1}{2}$.

o. S.

o. 4 .

c. $1 \frac{1}{2}$.

○. $\frac{2}{3}$

I. I I.

I. 10.

2. 3.

2. 5 .

2. 3.

o. $\left\{\frac{1}{2}\right.$

ว. 6.

o. 6 .

०. 7.

c. 2 .

o. 3 .

o. $2 \frac{\pi}{4}$.

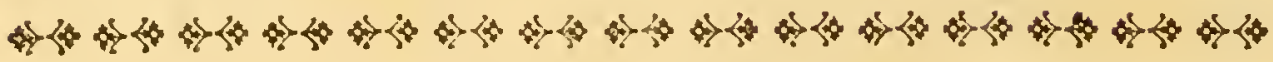

\section{V S \\ $H V D S O N I V S$.}

In Hiftoria Lemnii mentionem feci Muris Lemmo quam maxime afinis, quem forstervs in Actor. angl. vol. LXII. p. 379. inter animalia e terris Hudfonis transmiffa recenfuit \& e mutilo fpecimine imperfecte defcripfit, verofinillime migratorium. Iam poftquam typis illa tradita fuere, per Amiciff. Mercatorem Petropolitanum Dh. H. W. WeBER, e Labradoria Americes a Miffionariis Fratrum Evangeliconum inter alias animalium exuvias, obtinui pelles horum murium complures, e quibus diftinctam, Muri torquato noftro apprime 
fimilem, unguibus in altero fexu etiam magis, quam in Lemmo, monftrofis memorabilem fpeciem agnofco, quæ Americæ id cft, quod L.cmmus Europe \& M. torquatus Sibiriæ arctica, quamque etiam magis iftis cum Lenenfi Mure, cujus deferiptionem Gmelinianan inferui, coïncidere fentio.

Magritudo e pellibus maximos I.emmos Norvagicos fubxquafe videtur; Habitus 'omnino eundem \& M. torquatum refert, velleris natula potius pofteriorem.

Myfaces tencri, incani, bafi fufcefcentes. Oculi minufculi, roftro propiores. Meatus anditorii vellere abfconditi, margine cutaneo poltice prolixiore coronati, loco auriculi.

Pedes breves, foleis quoque hirfutuli: Palma robuftiores tetradnetyle, pollicis rudimento nullo, plante pentadactylac. Poftici pedes in utroque fexu unguibus fubulato arcuatis, tribus mediis fubæqualibus. Palmarnm angyes duo medii in maribus? (majores pelles funt) maximi, craffi, compreffi, extrcmo bifidi, ita ut fit unus mucro fupra alterum, \& quidem inferior junioribus obcufus, fubcallofus (Tab. XXVI. fig. A.), at fenioribus, maxime in dextra palma, uterque mucro comcus, fubitqualis, acutus, ut quafi duorum unguium invicem fuperadnatorum robuftifimam fpeciem finguli ungucs exprimant (fig. B.). In feminis r. minoribus pellibus (fig. C.) ungues omnes ") tenues, fimpliciter fubulati, ut in maribus quoque lateralcs.

*) In unica pelle \& quidem dextro A. \& in duobus minoribus \& colore tantum latere, ftructuram fig B. expref. minus pulchris, palmæ funt ut fig. $C$. fam obfervo; in tribus obtinet forma fig. exprefium eft.

$D$ d 3 
Conda brevifima, $3 \frac{1}{2}$."' fine pilo, obtufa cylindrica, fetulis rigidis $3-4 . "$ ut in afinnibus penicillata, canefcens.

Fellus mollifinum, etiam M. torquato \& Sciureo hyberno mollius, natura Sciuri volantis veilus optime referens, lanuginofum, $6 . "$ circiter altum. Caput fupra, dorfumque totum cano - cincrea, furco fubncbulofa, medio dorfi tractu in quibusdam magis fufcefcente; latera longitudinaliter \& abrupte ferruginefcunt, abdomen, fenfim c pallido vel cano albidur. Colli latera, paroridesque incenfits ferruginea; area aurium ferrugineo fufca. Fei cano albidi, ungues albicantes.

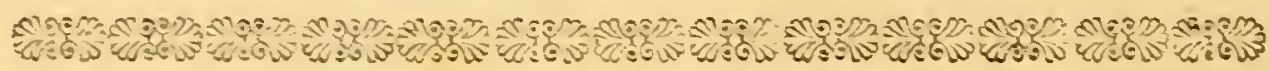

\section{V S \\ $\begin{array}{lllllll}L & A & G & V & R & V & S \text {. }\end{array}$}

$\mathrm{D}$

e hac Mimis lepida fpecie fama inter Nomadas magna Tatarix, quod magnis interdum cohortibus migrare obforventur, unde is vulgo D foilkis - Zivchan (migratozius Mus) audiunt; neque enim hoc nomen cum RYTschlorro (itinerar. part. III. p. I3.) Muri fubtili, qui colori huic noftro fruilis eft, foli tribui debet. Mihi ifta migratio ideo verofmilis videtur, quia Mures Laguros in defertis circa - Iaïkum, ubi primos invenimus, $\mathbb{E}$ ad Ienifeam nonnif raro, ad Irtin vero in fimili deferto, preferim in arenolis circa fortalitium Shelefenka \& ince Iamyfchevam ufque, incredibili multitudine \& quafi in eam regionem congregatos, ubique cuniculantes obfervavi. Suadet hoc etiam habitus, quo inter 
11. brachyuros omnes proxime ad M. Lemmum \& torquatum accedit.

Mus Lagurus campos aridos, arenofos quidem, fed limo firmatos amat; non enim in fabuletis \& mobili glarea occurrit unquam, ubi ncque cuniculos apte inftruere polfet, neque forte gratum præ aliis pabulum invenit. Mihi maxime cum Iride pumila abundare vifus eft, cujus quoque radices, fructusque nondum maturos, avide incarcerati rorabant. Mfultas tamen alias plantas fimul crefcentes in pabulum adhibent vo. raciflimi, etiam falfas \& amaras, ut Abfinthium ponticum \& maritimum, itemque fubvirofas, ut Afclepiadem fibiricam; Euphoroiam folam recufant. Gratum contra pabulum illis frumentum, floresque \& femina varia, panis, faccharum, imo carnes coetr; \& fi plures fimul incluferam, mortuos vel enectos focios devorabant, deglupta pelle cranium \& ofta a carnibus fubriliter depurantes. Aliarum quoque fpecierum Mures, viribus æquales, imo fuperiores mordaces cnecant \& vorant; indeque forte eft quod in regione, ubi M. Laguri abundabant, rarifime alios invenerim, nif in depreffioribus locis quos ifte vitat.

Cuniculi M. Laguri conftanter bifori, pro fexu \& forfan pro ætace varia prnfundicate; altero aditll fpichamali, vel ultra, Iongitudine oblique ad nidum tendente, quo terram egerit, altero perpendiculari, transverfe palmæ, raroque plus spichamali profunditate. Nillls anguftus, fubrotundus, graninibus eorumque ramentis refertus. Canales vel $c$ diverfo ad nidum concurunt, vel citra nidum uniuntur. Srepe marem cum femina in eodem, frequentius in diftinctis, fed admodum vicinis cuniculis habitantes inveni. Fodere vix necelle eft, ut 
capiantur; fi cnim canis ad hec inftudus in altcro cuniculi aditu cum folito ftertore olfaciat, ftatim altero canali fu. gientes excunt; at curfu parum valent. Quando mares plures cum feminis inclufi, pugnabant continuo, \& cum frequentipipitu invicem mordicabant, donce robuftior exagitatum diu comparem interimerct atque Caribæo more ftratum hoftem devoraret. Feminam tunc illam, que alterius focia fucrat, peflime habet victor \& fipiflime fubigit, quafi pugnæ premium, ectam gravidam. Sunt \& alioquin falacifinn, neque certum eftri tempus fervare videntur, vel faltem fapius in amo gignunt: namque ad Iaïkum jam ad primam germinationem (Martio) inventum cum fex adultis pullis nidum accepi; ad Irtin Majo puili jam adulti a matribus difcefferant, propriaque latibulit raptim effofis antris haud profundis ordiebantur; matres vero denuo gravidate crebro occurrebant; \& ad Ienifeam Septembri denuo pullos ninorennes inveni. Femina (qua cauda paulo breviore \& pondere tantillo majore a mafeulis differunt, minus vero pugnaces videntur) prurientes odorem mofchatum, quem etiam in M. aconomo obfervavi, fatis infignem fpargunt. - Mares, quando capti a primo terrore refipuerunt, procacilfmi funt \& mordaces, in poftica erceti pugmant, ftrident collifis dentibus \& morfui inhorent muti. Omnes dormiunt Marmota inftar convoluti clunibus infidentes; Marmotarum ctiam ineptos motus \& tarditatem imitantur, facicque fubfimiles funt; fed frigido aëre minime torpefcunt. Sine terra vel arena incarcerati cito languent \& vellere fiunt horridi; dum addita arena depurant fefe \& corpus curant, ut fubterreftria animalcula facile omnia. 


\section{DESCRIPTIO \\ $M V R I S L A G V R I$. \\ Tab. XIIL. A.}

Magnitudo infra M. arvalem. Caput minus \& oblongius, raftro obtufiffimo, labiis hirtis tumidulis. (Facies ftupida). Nuf $u$ is folo fepto didymo \& narium margine nudus. Labium minus profunde bilobum, fub nafo ftria divifum.

Dentes primores ut in M. arvali, fupcriores (vix lutefcentes) plani, acic vix excavata. Mnlares ægre dividendi, videntur tamen ubique quaterni, poftico minore.

Myftaces capite breviores, canefcentes, quinqque ordinum. Seta fupraciliaris fubfolitaria, gularis gemina, \& parotica utrinque folitaria; nulla ad carpum.

Oculi auribus paulo propiores, haud vero majores, quam in M. arvali. Altricula minutx, rotundx, planæ, capiti adpreffæ, vellereque fere latentes, nudiufculæ, fufcæ.

Truncus clongatus; artuls breviores, multoque exilinres, quam in M. arvali; extremis fufcidis, canefcente fubpilofis. Palmue parvæ, tetradactylæ, callo infigni mutico loco pallicis, cum papilla fere cornea, arrecta, notabili, ad ipfum carpum. Snlece molles, nudx, callis ad digitos vix notabilibus. Digiti, ut in muribus vulgo, fubtus incio papillofi, fupra fubannulati. Plantee ufque ad callos digitorum bafilares, ternos, villofix

Cauda fere omnium hujus generis breviffima, vellere vix emergens, cylindrica, obtufa.

Vellıs mollifimum, largum, lave, fupra pailido - cinereum, crebris pilis fufcis mixtum, in junioribus dilutius $\mathrm{fcu}$ magis cancfeens; fubtus \& in extremis artubus fordide cinerafcente albidum, Linea nigra a vertice inter oculos inE e 
cipiens, ufque ad caudam continua, medio dorfo latior. Velleris altitudo fupra pafim ad $5 . "$ "

Anus fub ipfa cauda. Scrotum mafculis fub cauda tumidiffmum; preputinm papillare albidum. - Vulva feminis prurientibus \& poft partum tumidis undique labris, ad ipfum anum prominentifima, antice papilla infigni, biloba, pilofa, fub qua oftium urechres intra vaginam connivens. Mammce inguinales utrinque duæ, poftcriores viciniores, vulva proxima; remotifima hine utrinque fub armis, cæterun in lateribus nulla. Papilla omnium areola infigni, rugofa nuda cinctre.

\section{E N,S V R A E.}

Pondus drachmarum ufque quinque cum dimidia, feminis plerumque minus, licet videantur paulo majores effe maribus.

Longitudo a fummo roftro ad ortum caudre

- capitis ad nucham

- caudr in feminis

- . - in mafculis ufque ad

- pilorum caudam exfuperantium

Circumferentia caudre Diftantia oculi a nafo - auris ab oculo Palpebrarum filfura - apertura

Longitudo aurium ad externam bafin .. . ad verticem

Lacirudo aurium explanata Circunferentia roftri Laticudo fepti narium

Circumferentia capitis inter nculos \& aures

Diltuntia inter canthos ocuiorum filo

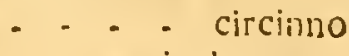

$=$ : zuricularum

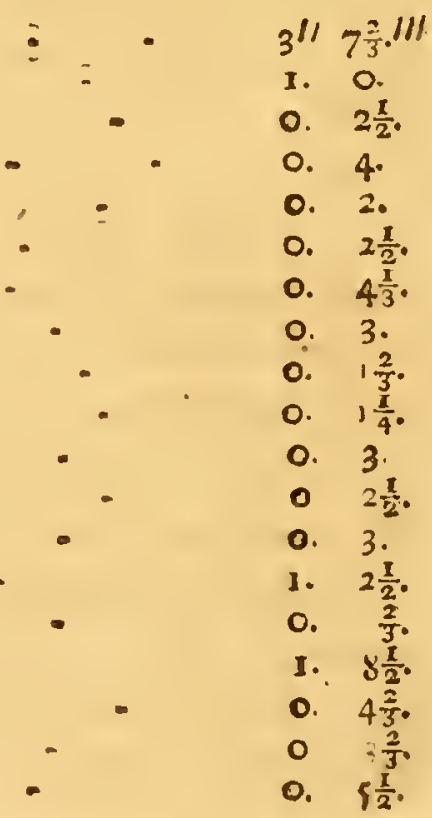


Longitudo colli

Circumferentia ejusdem

- thoracis pone armos

- medii corporis

Eongitudo antibrachii

- palmæ cum unguiculis fere

- tibiarum

- plantis

- digitorum palmx \& plantie circiter

Circumferentia carpi.

- metacarfi

Diftantia mammas thoracicas inter \& inguinales

- $112 \frac{2}{3} \cdot 11$

I. 7 .

2. 4 .

2. 6 .

o. $\quad 5 \frac{\pi}{2}$.

o. 4 .

o. $6 \frac{r}{2}$.

c. $5 \frac{1}{2}$.

o. 2 .

○. 33.

o. $3 \frac{1}{3}$.

I. 4 .

\section{A N A T O M E.}

Tab. XVII. fig. 12. - 13.

Pro anatome \& menfuris fceleti adhibitum præfertim fuic fpecimen mafculum, fupra enumeratas femella menfuras proxime referens, fcilicet longitudine $3^{\prime \prime} 7^{\prime \prime \prime}$ capitis $I^{\prime \prime}$ pondere fere femunçiali.

Tractus pinguedinofus inguinalis, cum lymphatica glandula antefeminali exigua, ut in reliquis congeneribus. Pinguedo fub armis multa in altilibus, fponte vix ulla. Glandulce 2. largæ circa collum.

Hepatis (fig. I I.) lobus finifter maximus (lit. a.) portio media (lit. b.) in 2 lobos fubxquales fecta, in quorum fciffuræ intimo receffu continetur Cyftis fellea minuta, flaccida. Dexterior lobus (lit. c.) obrotundus; quintus renalis, triquetro - lunatus (lit.d.); Spigeliani duo (lit.e.) linguiformes fubdiftincti.

Lien oblongus, longit. $5 \frac{x}{2} \cdot "$ altera parte latior ufque ad $2^{\prime \prime \prime}$.

Ventriculus (quem fig. I 2. inflatum, I 2 b. jejunüm exprimit) ftrictura bilocularis, intus plica craffa diftinguente, 
quæ limbo longis \& albis lacinulis ciliato fluctuat; Portio finjftrn Atriis albis annularibus.

Inteftimum tenue 9. pollicum, pennx corvine capax. Cecum (fig. I $3 a$ - b.) magnum, cellulofum, fpiraliter convolutum, in gyros 2 \& quod excedit. Inteftinum fpirale $\left(a-c_{0}\right)$ in anfractus quatuor arcte conglobatum, priores duos ampliores, reliquos ftrictiores, \& tertio quafi intra quarti finum collecto. Inteft. excrementale $(c-d$. cet.) novem pollicum, molecularibus fecibus moniliforne.

Renes inferiore vertice acuti. Genitalia maris haud infolita, neque magnitudine nec forma a proxime affinibus difcrepantia, ut moles virtuti non femper refpondeat. In femina glandulæ duæ albse molles ad bafin labiorum vulve anterius, \& duæ item albæ grano milii vix majores, pone anum adfident. Uteri cornua gravidata ufque lupra renes extenduntur, longitudine fere pollicari; in una femina moleculas lividas feu primordia partus in finiftro cornu 5. in dextro unicam, in alia duas in dextro, in finiftro tres inveni; unde fecuræ numerus folitus colligi poteft.

Sceleton: Craminm brevitate, amplitudine ollæ, zygo. matum convéxo arcu, \& craffitic proxime ad M. talpinum, aceedit, fed fabrica roftri offea, dentium directione \& proportione plane $M$. arvalem refert; Inter cranium M. Lemni \& M. Laguri fmilitudo perfecta, ęa fere fola differentia, quod olla temporalibus offibus utrinque verfus orbitam proceffi. papillari acuto, non crifta rotundata promincat. Offa bregmatım fimiliter parva, in medio fupra difco ollæ trapeziformia, \& futurarum difpofitio eadem ut in Lemmo. O/fa $n a f_{z}$ antice convexiora, fornicata. Maxilla inferior in regia- 
ne molari extrorfum item tuberofa, fed proceffu angulari minore.

Fertebrarmm nulla proceffu infigniore prominens, preter carinaw epiftrophai. Coftarmm tredecim paria. Stermuni ut in M. talpino. Vertebra lumbares VII; facrimm biarticulatum; cauda vertebrarum. VII præter apiccm. Innonzinatı exigua; \& pubes ad fefquilineæ intervallum maxime in feminis diftant, intercedente ligamento.

Longitudo cranii ad extr. offa nafi Laticudo inter orbitas

- olla pone zygomata

- inzer arcus z5gomatum fumma

- - rottri ad zygomata

L.ongitudo roftri offei \& offum nafi

Longitudo molarium collectim

Eorundem diftantia ab inciforibus Longitudo maxilla ad condylos

- columnie vertebrarum colli

- - - vertebr. dorfi

- - - lumbaris

- facri

- caudx

- offium innominatorum

- - - iliacurum ad cotulam

- foraminis ovalis

- Rterni

- enlis

- clavicula

- fiapula longit. fumma

- hunieralis

- cubici

- offis metacarpi medii

- nffri femoralis

- tibar

- calcanei

- oflis metararli maximi

- culta longur. feptimæ

E e 3 


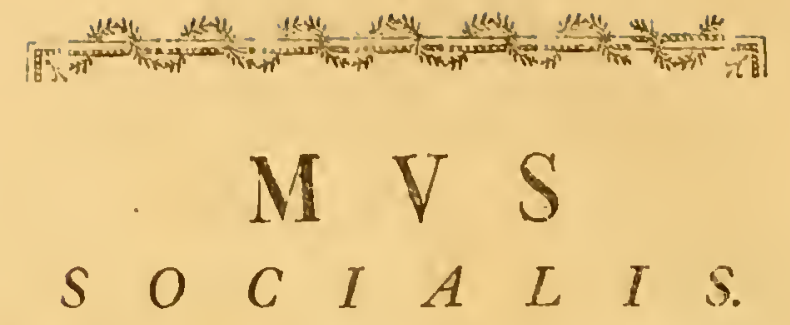

1urem rocialem appellavi a) elegans atque tenellum ani-
malculum, quod auftralibus defertis, apprime arenofis, addictum videtur. Primo intuitu \& vita genere parum a $M$. gregali (poftea defcribendo) diverfum diceres; fed fola velIcris natura tantam prabet difcrepantiam, quantam locus \& clima in nulla animalium fpecie producere valent. Etenim in M. gregali duriufculi funt pili, immo duriores, quan in $\mathbf{M}$. arvali europxo; at in M. fociali contra omnium hujus phalangis mollifimum ac tenerrimum vellus. Deinde, negle§to licet colore omnibus aliis pallidiorc: capitis (ut ita dicam) phyfionomia, auricularum forma, corporis ftatura brevis \& teres, caudx tenuitas, hanc fpecicm ab onmibus aliis fplendide diftinguunt. Preterca proportionum differentix multe funt, quas collatis menfuris reliquarum fpecierum quilibet facile inveniet. $\Lambda \mathrm{M}$. arvali noftram fpeciem non folum color \& vellus plane diverfa, auricularum pedumque (qui ifti nigrant) albedo, horumque fine fquanis tenella lavitas, fimul iftorum forma, proportio, craffiufcula fubftantia; cauda brevior, tenuior \& itidem albicans, deinique capitis craflitics paulo major \& vitæ genus, cxteris ferc paribus, diftinguunt.

Mures fociales quibusdam deferti cafpici (inter Volgam \& Rhymnum) locis, præfertim arenofis \& fimul herbidis, circa valles \& deprefliora loca copiofintimi, quafi caftris cona) 'P A L L. Reifen Wat. II. append. p. ร05. N. ro. 
fertis habitant. Maxime abundantes obfervavi circa Rhymnum inferiorem \& fecundum convallem Bogyrdai, arenofam, xftate ficcam, vernis inundationibus e fluvio aquas ambituofo per defertum tractu deducentem; cujus elatas ripas cuniculis atque egeftæ arcnæ cumulis adeo crebris obfidebant, ut vix veftigio fupereffet locus integer. Neque vero in borealioribus ifto tractu (50. ${ }^{\circ}$ latit. bor.) fitubus, nec in orientalioribus Tatarix defertæ (v. gr. ad Irtin) obfervati nobis funt; quamvis circa Mare cafpium ad auftrum latius habitent, circaque Aftrachaniam mihi, GMLLINo autem in Hyrcania b) occurrerint. Cujus fubalpinas prafertim regiones incolere a Sociis Gmelinianis accepi.

Fodiunt ad fpithamæ circiter profunditatem, canalibusque frpe octonis vel pluribus, arenæ egeftæ cumulo externe ftiparis, permeabile folum reddunt, circa nidum, fæpe infigni profunditare effollum, in quo remper per paria, vel cum familia habitantes deprehenduntur. Victitant radicibus, plantisque variis, neque vero Lappx calyces appetere credibile eft, licet hos in antris (forte cafu) copiofe inventos fuife GMELINVS referat. Wihi potius Tuliparum in deferto paffim provenientium bulbos requirere vifi funt, quorum effofforum tallæ \& veftigia in locis, ubi frequens $M$. focialis habitalt, nunquam defunt. Immo fere is tantum Iocis habitare noftros dixerim, ubi Tulipa Gcfneriána fponte provenit, qua deficiente in Tatariæ orientaliora deferta non proceffit. - $\Delta d$ Rhym-

b) Mus micruros GMELIN. itiucrar. eundem Murem prius circa Aftrachaniam vol. 1IT. p. 500 tab 57. t. 2. pefilma obfervatum $1 \mathrm{DEM}$ in Itin. vol. II. p. icone haud diftinguendus, fed e trans. 173. tab. 11. defcripfit, \& quod perfico mifís a GMELINo farctis pellibus pro in icone fere Soricis dentes tribuit M. fociali agnitus, neque obftat quod pictor. 
num preferim vere abundant, autumno rarius apparent, \& vel migratione quadam (ut inter accólas faua eft) locum mutant, vel in recondita magis \& arbuftis tecta loca delitefcunt. Dicuntur ctiam fub foni acervis hybernare; domeftice tamen nunquam obfervantur. Siccum femper folum maxime requirunt; dum contra $M$. arvalis in iisdem regionibus \& ufque in Pcrfiam obvius, prata \& folum cafpitofum amat Crterum, quandoquidem numerus horum murium a Putorio Ermineoque, a Cornicibus in famelico deferto procaciffimis" \& a Colubro Bero iisdem locis frequenti, multum minuitur, necefle eft ut fecunditate fumma ftirpem fupplcant, alias multo minus frequentes obfervarentur. Tempus autem generationis tardius, quam in reliquis fpecicbus, incidere, e ftatu genitalium verno tempore captorum concludo.

\section{DESCRIPTIO \\ $M V R I S$ SOCIALIS.}

Tab. XIII. B.

Magnitudo paulo fupra M. arvalem mediocrem. Caput eodem craffus \& obtufus, trancus paulo brevior, artus robutiores, canda tenuior.

Nafirs pilofus, latiufculus, concolor. Labia carnofifima, fuperius ufque ad nafum divifum. Dentes primores fulvi, fuperiores convexi, acie utrinque fubexcavata. Molares ubique terni, poftici minores.

Myftaces longiufculi, ferc rigidiores, quam M. arvali, albidi; punctun fuperciliare bipile, gula bipile \& pilus geminus ad carpum utrumque. 
Oculi remotiores a nafo, quam in $M$. arvali, medio inter nafum \& auriculas fiti, pauloque majores.

Auricula minus latæ, magis nudæ, ovali - infundibuliformes, albidæ, margine tantum pubefcentes, fubftantia craffiufcula conftantes.

Corpurs breviufculum, teres, \& velut obefum. Artus paulo breviores, quam in $\mathrm{M}$. arvali.

Palmce fubtetradactyla, verruca pollicari paulo evidentius unguiculo incruftata, quam in $M$. terreftri; digitus medius tantillo longior, calli fubpedales quinque. Plante paulo craffiores, \& ufque ad callos fubtus pilofiores, digitorum proportione $u t$ in $M$. arvali. Omnium pedum digiti lævi, nec fquamulofa cute obducti, albidi: Unguiculi albicantes.

Canda albida brevior, fereque tenuior, quam $\mathbf{M}$. arvali, fod magis pubefcens, ut annuli multo obfoletiores numerari haud queant.

Vellus tenerum, mollifimum, æquale, læve, fed largius, quam $M$. arvali, altitudine 5."' \& ultra. Color fupra, præter nafum fufcefcentem, totus c gryfeo pallidus, lateribus fenfim albidior, fubtus \& extremitatibus candidulus; lanugo tamen etiam fubtus plumbei coloris. Dorfales pili partini extremo concolores, partim apice fufci. - Perícum fpecimen, quod fub oculis habeo, dorfi colore intenfiore, gryfeo - lutefcente, lateribus flaventi - pailido, ab Aftrachanenfibus \& Rhymnicis differt.

Uropygium fub cauda paulo ultra femora productum, \& anus ad ipfam caudæ bafin longitudinali apertura connivens. 


\section{MENS V RAE。}

Pondus circiter sex drachmarum. Menfurce M. arvali fubrquali comparatæ, omnes, præter capitis \& trunci longitudinem xqualem, majores prodierunt; diftantia vero aurium $\mathrm{ab}$ aculo integra linea minor.

Longitudo a fummo nafo ad anum

- caudæ fine pilo

- pili caudæa apicem excedentis

- capitis ad nucham

Diftantia oculi a nafo

\section{- auris-ab oculo fere}

Palpebrarum fiffura

- apertura ultra

Longitudo auricularum ad extern. bafin

Latitudo auricularum

Circumferentia roftri pone myftaces

- capitis inter oculos \& aures

Diftantia inter oculos, filo

- eadem circinno

- aurium, filo, fere

- eadem circinno

Latitudo fepti inter nares Longitudo colli

Circumferentia colli

- thoracis pone armos

- medii corporis

- abduminis ad ilia

- bafeos caudie

Longitudo ancibrachii

- palina proxime

- digitorum yalma mediorum

- tibix

- planta

- digitor. plant. med. ultra

Circumferentia carpi

- tibiæ ad calcem

- : metatarfi

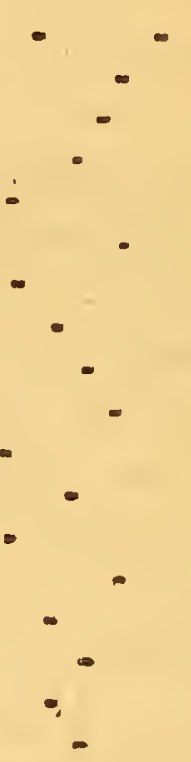

3." 5.111

o. $9 \frac{\pi}{3}$.

o. $I \frac{1}{4}$.

1. $1 \frac{2}{3}$.

o. $4 \frac{1}{2}$.

o. 4 .

c. I $\frac{1}{2}$.

o. 1 .

o. $4 \frac{x}{3}$.

o. $2 \frac{2}{3}$.

- $3 \frac{1}{2}$.

I. 4 .

I. II.

o. $4 \frac{1}{2}$.

o. $3 \frac{1}{2}$.

c. 7 .

o. 6.

o. $\frac{\mathbf{I}}{2}$.

o. I $\frac{3}{4}$.

I. $1 \frac{1}{2}$

2. 4

2. 6 .

2. $4 \frac{T}{2}$.

D. $3 \frac{3}{5}$.

- $5 \frac{3}{4}$.

o. 4 .

o. 2.

o. $8 \frac{\pi}{4}$.

o. $7 \frac{\mathrm{I}}{3}$.

o. 2 .

o. 3 .

o. 3 .

o. $3 \frac{1}{2}$. 


\section{A N A TO M E.}

Tab. XVII. fig. 14. 15.

\section{culam continens.}

Hepar lobis folitis, in mediorum fiffura cyftidem minuf-

Ventriculus (fig. I4.) ftrictura minus arcta, quam in M. arvali, bilocularis, intus lævis, plica etiam ifthmi ad arcum minorem lævi, fimplici. Filum a cardia per arcum majorem. circumductum, ufque ad pylorum, aquavit $3 . "$ " $3 . "$ Circumferentia maxima ventriculi J." 9."'

Intefinum tenue longitudine novem pollicum. Ccecunn (ffg. I 5. $a$ b.) amplitudine digiti, fubcellulofum, in laxam fpiram compofitum. Longitudine ab infertione llei (lit. a.) 4." $2 \frac{1}{2}$." Inteftinum fpirale (lit. c.) in artum glomum tribus fpiris compofitum, quarum extima cœeco continua, amplior, intima centro emergit, intermedia continuatur inteftino oblique ftriato $(d t$.$) \& excrementitio, quorum longitudo 5 . "$ 8." at fpirale explicatum circiter 2." $9 .{ }^{\prime \prime \prime}$

Ren dexter ultra duas tertias longitudinis anterior altero. Fefica mole fabr. Veficulce feminales xfate flaccida, mediosres, apice circinnato - incurvæ.

Cor pifo minus. Pulmo dexter quadrilobus, uno imparc; finifter bilobus.

Palati rugæ 3 craffæ ante molares, inter molares 5 . tenues, obfoletiflima, interruptæ. Lens cryftallina oculi, ut in multis muribus, fere perfecte globofa.

Sceleton: Cranimm fere, ut in M. Mufculo, nifi quod olla \& zygomatibus magis arcuatis, paulo latior roftroque fere brevius; fimillimum Cranio $M$. aconomi, \& a $\mathrm{M}$. gregali plane diverfum. Coftarm XII. paria; Sterni interneüia F $f 2$ 
officula quatuor, quorum 2 pofteriora fubcoalita. Vertelire lumbares tantum V. mediocres; facri III. conule XIV. minuta.

Longitudo cranii

Latitudo olla pone zygomat3

- inter arcus zygomatuma

- incer orbicas

Longitudo inciforum fupcriorum

- oflium nali

- mandibulie a condylis

- incilorum inferiorum

- vertebrarum colli collcktim

- . dorfi

- - lumbariun

- Cacri

- cauda

- vertebra cauda max. epcina

- clavicularun

- feapula

Laticudo ejusdem Longitudo humeri

- cubiti cum olecrano (1."'I)

- ollium inummutorum

- ilei ab acctabulo

- foraminis ovalis

Lacitudo ejusdem

Longitudo femorum

- c cibiarum

- fibula, quosque diftincta,

- metatarli medii

- plalangis prime

- . fucunda

- unguis cum articulo d" 10.111

o. $5 \frac{3}{3}$.

o. $\left\{\frac{3}{3}\right.$.

o. 17.

0. $1 \frac{4}{5}$.

o. $2 \frac{4}{5}$.

o. 6 .

o. 2.

o. $3 \div 2$

0. $4 \frac{2}{3}$.

0: 6.

o. 3 .

1. $\frac{x}{4}$

3. I.

(ai 3.

o. $3 \frac{3}{5}$.

- $2 \frac{5}{5}$.

o. $4 \frac{1}{2}$.

o. $5 \frac{\pi}{2}$.

o. $5 \frac{1}{2}$.

o. $3 \frac{1}{2}$.

o. $1 \frac{x}{3}$.

o. $\frac{2}{3}$.

o. $\left\{\frac{1}{2}\right.$.

o. ?.

o. $3 \frac{1}{2}$.

o. $2 \frac{3}{5}$.

C. $1 \frac{1}{2}$.

o. $\frac{3}{4}$.

o. $\frac{4}{3}$. 


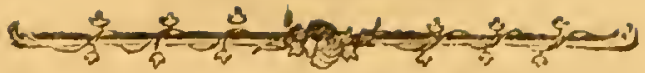 \\ $\mathrm{M} \mathrm{V} \mathrm{S}$ \\ $\begin{array}{lllllllll}O & E & C & O & N & O & M & V & S\end{array}$}

Venio ad fpeciem notatu digniffimam \& Sibiriæ forte peculiaren, quæ prima facie \& colore adco fimilis oft $M$. arvali, ut nifi obfervata primum mira occonomia \& accurata deinde proportionum \& anatomes comparatio diftinctam probaffent, facile tanquam varietas negligi potuiffet. Primum omnium in campis Ifchimcnfibus \& ad Irtin adtentionem meam excitarunt hi Mures per fingularcs fub cæepite cavatas cameras, in quibus habitantes offendebam. Dehinc frequentes circa Obum, Tfehulymum \& Ienifeam, maxime vero circa Baïkalem \& in Dauuria tranfalpina, (ubi maxime mores \& habitacula corum fcrutatus fum) obfervavi. Vniverfin pafcua \& prata humidiora, interque montanas convalles amant, neque in fylvis \& alpinis defunt; abhorrent contra ab arenofis, aridis, elatioribus, ubi fequentem contra fpecien copiofiorem in iismet regionibus offendas. Pro nido cameram fub ipfa cærpitis crufta, immo locis humidioribus in tubere quodam terræ, fere fupra campi fuperficiem, excavant fubrotundam, depreffofornicatam, transverfæ palmæ profunditate \& pedali diametro, m)llifimo \& comminuto gramine farctam, a qua cuniculi circum plures, in ipfo cæfpite frepe ramofi, in fuperficiem exitu laterali pervii, patent oftiis vix digitum admittentibus, pro antiquioribus domiciliis fæpe ufque ad trigin a; vel ubi panciores funt, $a b$ oftiis faltem vix, quas fulcoruin inftar excfo cæfpite cavant, ramofe quaquaverfum fparguntur, per quas in

$$
F \text { f } 3
$$


fua rura excurrere poffint. Alii a nido canales fubterranei ad duas pluresve in ambitu fub plano cxfpite cavatas cellas feu promptuaria tendunt, nidi capacitatem fpithamalem adhuc excedentes, quas radicibus vạriis, pro victu, provida replent animalcula, fumma diligentia \& magno laborc ab ipfo veris initio hanc penum conquirendo. Tantum laborem fubterraneum vix credas debcri animalculis, quibus-parve \& imbclles palme, dentes haud robutt, \& vires in fluxo corpore exigux, immo imbecilliores, quam multis aliis congeneribus longe minus laboriofis. Et tamen adeo fpatiofa fpelæa vix unquan plura duobus animalculis, conjugali fide junctis, immo fepe tantum unicum parat \& inhabitat, nifi quum autumno familiatim occurrunt, quo in cafu fipe circa fpatiofiorem nidum ufque ad octo vel decem promtuaria diftincta inftituere \& radicibus variis replere dicuntur. Mihi autem tales familias videre ipfi non contigit, fed unanimes de is retulerunt Tunguf Dauurie, qui ex profello antra horum animalculorum. autumno plena quxrunt \& e promtuariis (ob molliticm fuffofi cefpitis pede vel fcipione facile explorandis) levi labore collectas radices in fuos ufus domefticos deportant. Affeverarunt iidem ex unius frep familie promtuariis interdum ultra viginti \& triginta libras recentiun radicum effodi, ut non incaffum inveftigentur Nomadibus agris hortique cultura carentibus. Suntque hujus præfertim \& Muris gregalis promptuaria (quæ Urgàn, murem vero incolam Kutughmi vocant) notiflima Tungufis pariter \& Burætice genti, quibus bulbi \& radices pro cibis hyeme condiendis, Sanguiforba vero radix pro theæformi infuro expetuntur ").

9) Id falfo de Marmotis intellexit 50.) cujus errorem etiam ab A MMAN. GMELINVS (Reife in Sibir. vol. II. p. No (firp. stuth. p. I6o.) repetitum video. 
Etiam Krasnojarenfes Tatari, imprimis Saçaici, qui promtuaria Murium $K y$ lym appellant, hunc ufumfructum haud negligunt, fed otiofi pauperculos mures impigre parto commeatu fpoliant; idemque ad inferiorem Ienifeam ficri in GMELINI Flora Sibir. val. III. p. 46. notatur. At vero Apri, omnium crudeliffimi hoftes, \& promtuaria irrumpunt, \& ipfos mures cum nido \& pullis commanducare haud vcrentur.

Radices, quas M. œconomi indagant \& colligunt, funt in campis Ifetenfibus atque Barabenfibus prafertim Phlonidis horminifoliæ tubera \& Biftorta vulgaris radices; in Dauuria \& Krafnojarenfi tractu Polygoni vivipari (Tunguf. Mykir) \& Sanguiforbæ vulgaris (Tung. Scloyddul), quibus noxias admifcent Chærophylli temuli radices, magnitudine \& forma Sanguiforbæ fimiles, fed albedine externa \& tenacitate (a fufcis \& fragilibus iftis) facile dignofcendas, quo etiam criterio Tungufi ab efculentis feligunt. Certo tamen etiam hæ virofa radices Tnuribus in efcam cedunt, \& ipfe femirofas in nidis inveni; Tungufi vero perhibent temulentas radices a Muribus loco inebriantis colligi feftisque diebus cxhilarandis infervire. Radices omnes optimas \& recentifimas legunt mures, duroque labore parvis in cæfpitem tenaciffimum actis cuniculis atque foveolis eruunt, fibras \& fufformium apicem atque germen in loco abrodunt, ipfisque bi- vel tripollicares radices depuratas retrogradæ per vias cæfpiti infculptas ad promptuaria trahunt, quibus confertim, modo promifcuæ, modo felcctim, in. geftx reperjuncur. Vere primo plerumque unicam cellam adhue plenam radicibus, reliquas cum prærofis reliquiis vacuas inveniebam. Mares etiam tunc rotaque xftate multi folitarii vagantur, vel cuniculos antiquos derelictos incolunt \& adap. 
tant; quorum paffim in pratis, ubi radices gratx copiofe proveniunt, tanta eft copia, ut equitanttibus inde frequens periculum, equis per cæfpitem in vacuas cameras pede inciduis atquc collabentibus. Cæterum hæc fpecies nunquam, quod fciam, domeftica evadit.

Differentia magnitudinis inter mares \& feminas, in bac pariter ac in fequenti fpecie adeo infignis eft, ut femina fxpe ultra decem drachmas, immo fefquiunciam, mares vix renas vel feptenas drachmas æquent. Videturque femina laboriofior effe, \& in penu paranda præcipuas partes agere. Vere primo etiam in borealioribus coëunt; tunc femina mofchi fortem \& haud ingratum odorem fpirat. Medio Maji adhuc cecos in Dautria pullos inveni, frep tantum binos vel ternos, drachmali circiter pondere. Verum vix dubium eft pluries in anno pullulare; qui enim alias tanta horum murium in campis effet copia, quum feris \& avibus facilem in prædam cedant.

Calor Canguinis licet haud ultra $97^{\circ}$ Farenh. $\left(96^{\circ}\right.$. de L'ICl.) his muribus obfervetur, tamen nullo frigore torpe. fcunt, \& regiones Sibiriæ etiam maxime boreales \& orientalcs non reformidant. Etenim ufque circa Berefovam ad Obum habentur \& ad I.enam (ubi Iacutis Kutujacb audiunt \& ipfa miferarum caro delicata \& pinguis offa reputatur, quam collectis in fua promptuaria Hedyfari cujusdam ) efculentis radicibus condiunt) ad Lenam, dico, ultra Iacutiam borean verfus abundant. - Bantur etiam in Kamtichatka, eademque funt

b) Hedyfarum fol. pinnatis, pinnis pendulis; floribus racemofis, ochroleucis, linearibus, leguminibus articulatis, glabris, congeltis. Flor. Sib. vol.IV. p. 28. tab. Ir. 
funt murium fpecies, de qua, fub nomiaibus Kamtechaticis, Naufffchitfch \& Tegultfchitfch, mira fed vera retulcrunt. STELLERVS ${ }^{c}$ ) atque KRASCHENINIKOFIVS ${ }^{d}$ ). Dubitaram circa hane fpecien diu, neque enim in STELLERI chartis ulla harum, reliquarumve ejus Peninfulie murium defcriptio extabat, quia Vir alias diligentiffmus natuiali (ut ipfe excufabundus notavit) antipathia inde a cunis ab adfpectu murium horrebat. Sed procuratis nuper e Kamtfchatka pellibus, reliquisque momentis collatis, nullum jam dubium fupereft Murem oconomum effe intelligendum. Radices, quas in Kamtrchatika colligunt, præter Jilii Kamtfchatici bulbos, rubo idaeo forma fimiles \& Ccmbræ pumilæ alpinæ nucleos, STELLERvs fequentes adnotavit: Anacampferotis, Biftorta, Vlmariæ ricini folio capfulis hifpidis "), Sanguiforbæ, atque virofas denique vel Napelli $f$ vel Anemonis cujusdam acris; quas omnes, felectis hisce venenatis, Kamtfchadali autumno magna cum lætitia ex antris colligunt pro domeftico ufu, \& muribus, quos amicos

c) Befchr. v. Kamtfchatha p. $I \geq 9$.

d) Dofiript. Kamtfchat. edit. ruff. f $^{10}$ vol. J1. p. 226.

e) Spiræa fol. multifidis angulatis, fruCibus rectis, hifpidis, petiolis appendiculatis Flor. Sibiv. vol III. p. rg2. n. 55.

f) Murem Napelli radicibus vietitantem Gloplographus AVICENNAE atque MATTHIOLVS adtigerunt. Pofte. rior in Commentar. ad Diofcor. lib. $1 V$. cap. 73 (edit. venet. 1554. p. 481.): "Ant, inquit, ," in eaden confeftione (Avicen. "næ) fortafle Mus ille interponitur, qui "Napelli radicibus viEtitat, a nobis plu"ries inventus in Ananienlibus nontibus, "quod etiam Mus ifte Napellus mors I
" ab AVICEN N A dicatur, quoniam iisdem "contra Napelli venenum polleat viribus, "quibus \& ejusdem nominis planta,.. $C f$. etiam A LD R O V. de quadr. dig. vivip. Lib. II. c. 31 .p. 436 . - Aconitum pro noftro. rum Murium annona indicat etiam Flora Sibir. vol. III. p. 43. ubi quoque e STELLERO narratur, fimilis Tungufi. cæ, Kamtfchadalorum fuperftitio, Mures fcil feftis diebus is incbriari. In aliis tamen S T E L E R I fchedis Anemonoidem feu Anemonem ranunculoidem (Flor. Sibir. Vol. IV.p. 199 n. 40.) video in. dicari, quam \& KRASCHENINLKO. rivs ruffico nomine Ljutik fubinnuit. 
fuos reputant ideoque occidere nefils habent, in fpoliato antro munufcula varia ridicula relinquunt, illatum damnum quafi compenfaturi, \& favorem murum hife donis fibi conciliaturi. - Feruntur ibi Mures noftri aftivo tempore, dum in hyberno victu parando laborant, folis baccis herbisque vivere. Dicuntur ctiam lectas radices ferenis dicbus extra antra, laboriofa diligentia intolare, ne diuturna fub terra mora fitu corrumpantur - Accidit sterarko in vicinia cujusdan lacus fub dio pernoctanti, ut magnam bubillorum quorundan copiam in va. cuam ocream congererent mures, quorum reftigia fecutus detexit equifeti hyemalis bubos, quibus hac planta, in Kantfehaticis terris copiofilima, propagatur, quosque deinde, a Muribus edoctus, coctos paricer crudosque fapidilimos \& Kamtfchadalis quoque ufitatos expertus eft.

Certif]immm, licet fubdubie propofuerit KRASCHENINIKOF; \& non folum a folo strilero confirmatum, fed omnibus, qui it Kamtfchatka vixerunt notillimum eft, Mures economos certis annis e terris Kamtichaticis, ubi mire pullulant, demigrare, prouti hyperborcis Lemmis corumque affinibus folemne eft; allis denuo amnis magnis tumis fub autumnum adventare, infeçuente vulpium aliarumque ferarum cxercitu, quarum tunc feracillimam hycmen ingruere venatores latantur. - Ejus vero migrationis etiam per reliquam orientalen Sibiriam, maximeque inter Tungufos Daumrie \& Baikalis accolas fama eft norifima 8). Dicuntur Mures noftri ex is maxime autumno demignare pafcuis vel infulis, quæ prefentiunt hyeme vel infequente vere inundationem paffura. Vtique ad Turam Dauuria rivum per magnos tractus me ibi peregrinante inundatos, antra derelicta 8) GхокGI Riife p. 16r, 16:. itidem teftis. 
copiofifima, cum fupertite fæpe aliquo radicum appatu, inveni, licet in tota illa regione ne quiden unicus horum Murium indagari potuerit. Forfitan in Kamtfchatka fenfus aliquis ignis fubterranei in illa peninfula furentis, vel futurarum mens præcia tempeftatum, Mures $c$ fuis fedibus ad tcmpus fugat. - Quum abitum e Kamtfchatka parant, vere paffim onnes, præter fparfos, qui circa pagos facile inveniunt sutrimentum, maximis congregantur turmis, rectaque ad occidentem hybernum abcunt, interriti tranantes flumina, lacus, finusque maris objectos, plurimi licet pereant, aut fatigatione femianimes in adverfa ripa, mortuorum inftar, aliquamdiu recubent, donec ficcato vellere refumtisque viribus iter continuare potis fint. Multos in trajectu aquarum Mergi, multos Salmonum majores fpecics voraciffmæ rapiunt, neminemque inveniunt clementiorem illarum terrarum incolis Kamtfchadalis, qui jacentes ubi vident, tanquam colunos fuos \& rhizotomos, omnem $\mathrm{ab}$ is noxain avertere \& refocillare illos fudent. - Vbi Penfhinam fluvium fuperarunt, finum Maris circumgreffa agmina ad meridiem fenfim tendunt, ejusque anni, quo Kamtrchatka vere exceficrunt, medio circiter Iulio circa Iudoman \& Ochotam fluvium adventant. Obfervati fuere greges tanti, ue migrantes vix bihorio tranfeant. Redeuntes Kamtfchatkam Octobri falutant, reditusque incolis magna celebratur latitia; præter venationem enim ferarum fubfequentium, annum quoque tempeftatibus \& pifcatura felicem portendere creduntur, contraque omnibus infelix cenfetur abitus, quem crebra cxperientia docuit pluviofi \& procellofi amni effe prænuntium, praterquam quod neceffario venatoribus ferarum finul valedicentium petiuriam portendit. - E quo item migrationis elu-

$$
\text { G } \mathrm{T} 2
$$


cet caufra, quám fupra adtigi. Inter Kantfchadalos autem; fupertitiofam plebeculam, variæ circa hæc fabulæ: creduntque venationis ergo alio migrare mures \& frctum trajicere in tcftis Haliotiformibus, quas mare egerit, quibusque nomen Cymbæ murinæ fecerunt. - Fabulantur eosdem Murcs, dum . rurantur, penum fuam contegere virofis illis radicibus, quas colligere indicavimus, ut alias mures penum fuffurantes fallant vel deterreant. Fabulantur, ademto fub autumnum penu omni, Murem cujus is fuerat, ad incitas redactum defperatione in furcellato ramo fufpenfum occlufo spiritu vitam finire; quæ quidem fabula apud Iacutos quoque \& Tungufos obtinet, indeque forte orta eft, quod Lanii pro preda captos mures in fpinas \& furcatos ramos defigere foleant; quibus vifis creduli fponte vitam finire excogitarunt. Certe ob hanc ipfam fuperftitionem Kamtfchadali nunquam penum omnem Muri auferunt, fed ipfarum, quas invenerunt, radicum aliquantulum relinquunt, $\&$ offam ficcatorum ovorum pifcium addunt direptos, confola. turi. - Interim STELLERvs \& ad Lenam GMELINvs obfervarunt, tardius adventantes, vel quibus promptuaria ablata, in domos etiam hyematum venire, inque promptuariis incolarum damnofos fieri; quod non in Sibiria reliqua.

E novifima quadam relatione Celturionis scHMaLEv?, qux in Opufallis Societatis litterarice Mofcuenfis h) impreffa extar, perfpicio Murium anno 5772. tantain in Kamtfchatka fuife multitudinem, ut circa Avatfcham \& Bolfchcrezk arborum cortices abroferint, \& in domibus atque promptuariis frumentum, limo in oppidulo Kamtehaticenfi inferiori mercibus in mercatorum tabernis infigne damnum intulerint. Sequenti

h) Opyt trudof wolnajo rolijfkajo Sobranias vol, I. p. ar 
anno jam multo minor fuit turba, difperfæque magis copiæ. $\mathrm{Vt}$ videantur in Kamtfchatkam undique mari claufam, ex magno Sibiriæ fpatio migratione temere fufcepta congrcgari, tanta frequentia, ut deficiente fenfim pabulo, vel fupra indicato fenfu denuo oborta migratio multo magis in fenfum cadat.

Varietas Kamtfchatica muris œconomi, cujus exuvias habeo, fibiricos maximos æquat, fimillima vellere, auriculis, forma, proportione pedum atque caudæ. Sed aliquantum differt colore, qui his muribus omni tempore anni idem confintit. Sicut enim e borealioribus paulo nigriora folito habui fpecimina, ita Kamtfchaticæ, quarum fex pelles accepi, magis e fufco lutefcunt, dilutiote colore, quam in reliqua Sibiria, præterquam quod ad Tfchulymum fubfimiles habui.

Caterum mihi haud videtur vero fimile, Murem œcono. mum ufque in borealem Europam migrationibus fuis extendi. Obfervata tamen etiam in Germania admirandæ Murium brachyurorum migrationes ${ }^{i}$ ), vix de $\mathbf{M}$. arvali intelligendx. Et dolendum neminem unquam accuratius defcripfife, vel comparafle fpecies murium, qui fubinde agmine facto Germaniæ agros invaferunt \& vaftarunt; quod in pofterum ut fiat, optamus. - Iflandici mures, quorum fupra memini, haud exiguam morum cum noftro $M$. œconomo fimilitudinem prodere videntur; fed horum quoque accuratior defideratur notitia. Nec magis novimus Mures qui in calidis Orientis, auftralibus-

i) M. brachyuri migrantes differte fectorum adfert Operis vol. II. $p$ 154. indicantur in Bremenfi relatione, quam feq. ROESELIVS occafione migrantium in.

\section{G 83}


que terris migrationibus fefe illuftrant ${ }^{k}$ ), ut hoc itaque genus multa fibi adhuc expectet fupplementa..

\section{DESCRIPTIO

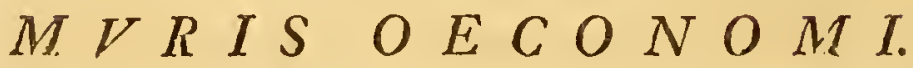

Tib. XIV.A.

Magnitudo fupra M. arvalem; facies perfmilis, nifi capite minore, minusque oblongo, artusque paulo robutiores, oculos minores, anticulas modo vellere majores, modo exiliores, vellere latentes, quo dimoto apparent nudx, con: choidex, cutacex, anterius fere deficientes, pofterius latæ, fubvillofx; lobulus tenuis, planus, extrorfum fubnarginaco. concavus, in ipfo finu bafeos a margine poftico productus, protegens atrium, continuatusque plica obfoleta circa atrium meatus ampliufculum circulari.

Nafus, ut in M. arvali; os anguftius; dentes fuperiores paulo latiores, ceftriformes, fulvifimi.

Truncus longior, quam in M. arvali, ventricofus. Palnice fubtetradactylæ, verruca unguiculato - conica pro pollice, cui fubjectus callus fubcomprefius. Extrema pedum fufcefcunt, digitis ammulofo - fquamatis.

Callah cylindrica, obtufa, tenuis, præter tractum fupra fufcum albido - pilora, maxime fubtus crebris longioribus-

מ) Conf.qux de Murium Aegyptiorum \& Ponticorum migratione habet AELIAN. hil. anim. lib. VI. cap. 4r. itemque de cafpiis lib. XV'IT. cap. $\tau_{0} \&$ de populis quibusdam Italix fede fua murium migratione pulfis, Lill. XIVII. cap. $f$ r. Eodemque pertinent Talpa, qua $\mathbf{H}$. RODOTO referente regis Affyriorum exercitum infeftarunt, lora fcutorum \& nervos arcuum erodentes. Vt multa alia omittam. - Videtur étiam Mus ille promtuaria condens in infula Francica oceani indici infeitus, peculiaris quædam efle rpecies (Foynge d'un Oficier francais.) 
que pilis; confpicue tamen annulata circulis circiter fexaginta.

Vellus luteo nigroque mixtipile, obfcurum, magis lu. tefcens, quam in M. arvali, medio dorfo nigricantius, fubtus a gula ad caudam canum (fupra fufcam lanuginem). - In junioribus color magis fufcus. Dilutior \& magis lutefcens maximis \& item Kamtfchaticis.

Fulva orificium in feminis inftar preputii prominulum, eademque fere diftantia ab ano.

\section{E N S R A E.}

Pondus mafculis paulo fupra infraque dimidiam unciam; iisdem longitudo circiter $3 . " 13$ ad $6 . " 11$ cauda $1 \circ \frac{1}{2}$. Femince integram unciam cum drachma una vel altera úperare folent; longitudine corporis $4 .^{\prime \prime} 2_{\frac{1}{2}}^{\prime \prime \prime}$ caudæ $1 \frac{1}{2}^{\prime \prime \prime}$ in aliis corpus 4." 5." cauda 1." $2^{\prime \prime \prime}$ - Femince majoris dimenfiones hic addam:

Longitudo tota a nafo ad anum

- capitis

- caudie

Circumferentia ejusdem Diftantia oculi a nafo Intervallum narium Diftantia aurium ab oculo Fiffura palpebrarum Apertura oculi I.ongitudo auricula *) - a finu bafeos Diameter lobuli antici Circumferentia roltri ante oculos - capicis inter oculos \& aures - colli

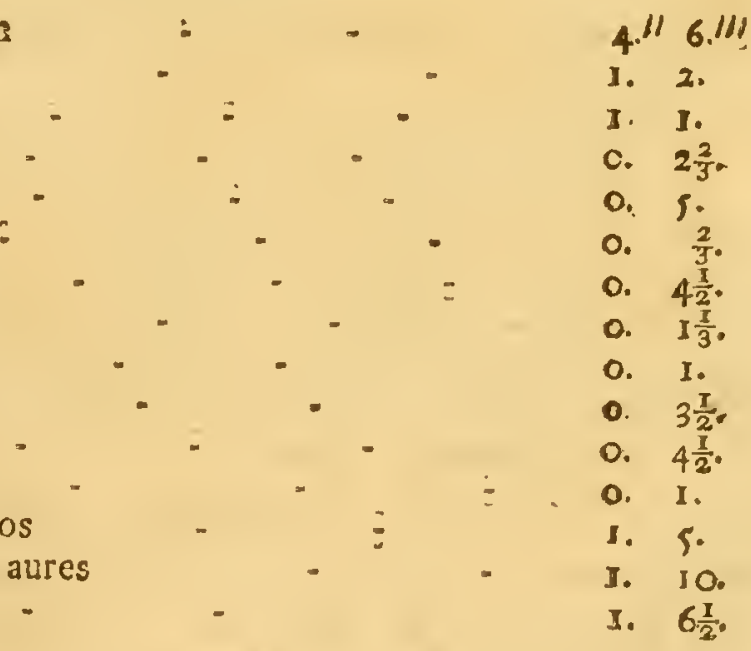

*) In quibusdam femiorbicularis, yix 2, "' alta, in latitudine $3 \frac{1}{2}$." 
Circumferentia thoracis ad armos

- . . meujio corpore

- alvi ad femora

Longitudo humeri ultra

- antibrachii

- palmie, cum ungue (1.III)

Circumferencia carpi

Longitudo femoris cilciter

- - tibize

- planta cum ungue $\left(1 \frac{x}{4}\right)$
$2 " 11.111$

2. 4 .

1. 9

- 5

- 7 .

$\circ$ S.

013.

- 7.

- s.

- $8 \frac{2}{3}$.

\section{A N $\triangle \mathrm{TOME}$. \\ Tab. XIVll. fig. 16. - 19.}

Fetor incifi abdominis, ut in $\mathbf{M}$. arvali, teterrimus, licet recentifimo.

Hepal (fig. 16.) lobo fniftro maximo (lit. n.), 2 medis (b.c.) cystidem (lit. d.) inter fe continentibus, dextro (lit. e.) exiguo, orbiculato, renali (lit.f.) lunato, \& ad hujus bafu duobus spigelianis (lit. g.) conftat. Cyftis fellea exilis, cylindracea, mediorum loborum dexteriori adnata. Lien oblonģus, planus, longitudine I1." Iatitudine 3.11

Ventriculus (fig. I\%.) fubtripartitus; pars finiftra (lit. a.) feu fundus, veficularis, oblonga; media (lit. b.) fubreniformis, fubftantia crafia, glandulofa; pylorica (lit.c.) libcordato - irregularis. Intus plica fiu valvula pyloricum cavum a majori cavitate diftinguens, lata, ciliata, mollis.

Intefinnm tenue XI. pollicum, amplitudine palfim calamum fcriptorium excedens. Cacrim (fig. I 8.) amplum, cellulofum, in fpiram convolutum, longitudine $4.1110^{\prime \prime \prime}$ adeoque brevius quam aflinibus; $a b$ infertione ilei (lit. a.) verfus apicem (lit. b.) fenfim adtenuatum, infra ileum fingulari 
modo lobatum (lit. c.). - Spirale inteftinum $(d d$.$) ini-$ tio ampliufculum, laxiore circulo arcuatum, tunc anguftiore breviorique circulo contortum, quem retrogradæe dux fpiræ obvolvunt, a quo glomere excrementicium inteftinum (lit. e.) pergit. Spiralis extricati longitudo 5." excrementitii 8." xquat.

In uno ad Tfchulymum inveni tenue inteftinum refertum tæniolis decem, fingularibus, quæ itineris cafu perierunt, antequam rite defcribi, vel delineari potuere. - Ilcum glandulofa area, orbiculari, infigni inftructum.

Ad vulvæ orificium glandula' duæ anfractuofe, lente majorcs, mofchato fortiffimo ichore fcatentes, quem per orificium vulvæ effundunt. Minimæ eadem mafculis ad præputium.

Sceleton: Cranio plane diffimili a M. arvali, inter orbitas latiore, convcxo, olla pariter convexa, latiore, depreffjufcula, roftro breviore in totum fimilior hac parte $M$. domeftico (fig. 19.). Molares poftici trifulcati, medii bifulcati, anteriores unifulci. Coftartlm XIV. paria, quo etiam evidenter a M. arvali differt; horum vera octo, 3 ultima confertim ád articulationem enfis inferta Vertebra lumbares fex, facri dux, caulde XIII. preter apicem. Offa pelvis parva, angulo pubis acuto \& retrorfum vergente, ubi late (prefertim feminis) diftantia offa ligamento in fymphyfin cohærent; hinc foramen ovale anguftum, lanceolatum. Menfuras fceleti in fpecimine femineo, quod unciam cum drachma fefquitertia pendebat, notavi.
Longitudo cranii
Latitudo pone zygomata paulo ultra
- inter orbitas ultra
- per zygomata
- - roftri ante zygomata
Longitudo offium nafi, fimulque roftri fere
1." olll
O. 5 .
o. $1 \frac{\mathrm{I}}{2}$.
๑. 7 .
o. 3 . 
Longimdo inciforum fuperiorum

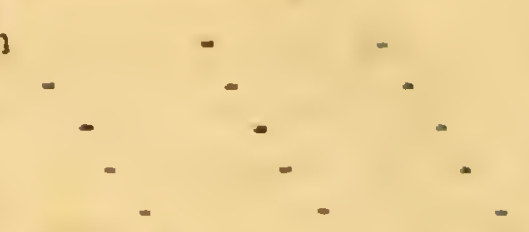

- - maxills a condyio

- vertebrarum colli

- . durli collctim

'. - . lumbarium

- vertebra prima longilima paulo vilera

- fucri

- caudia

- clavicularum

- Coppharum

Laticndo earundem

Longicudo humeri

- cubiti

- oflis metacarpi longilliui

- phalangis primie

- - - Ecundx

- offis innominati

- jlci ad usque accesbulum

- foraminis ovalis

- femoris

- ribia

- fibulx quousque diltinguicur

- calcanci

- ollis metacarti longillimi

- phalangis primic

- . - Recmadx

- Sterni praces enfers

- enlis

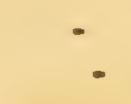


diftinctam conftantes characteres externi \& vitæ pabulique genus diverfum, extra dubium ponunt. Et quidem Murem arvalem generaline proportione corporis, natura veileris, nifi durioris, forma cranii, contarumque numero afimilatur; fed tamen accuratius comparatis proportionibus magis differt, quam ut a loco \& climate tantum mutatus videri queat, praterquam qund colore, pili rigiditate \& inftitutn vites \& vićtus plane differt. Id tamen monendum eft, M. gregalem tantum in orientali Sibiria dari, ubi M. arvalis Yuropes nunquan chicrvatur. - Contra a M. ceconomo, qui easdem regiones colit, pluribus notis differt: non in depreflis, graminofis, ut ille, fed elatis femper montiun \& camporum habitat; non colligit radices, quas in $\mathrm{M}$. reconomi hiftoria indicavimus, fed bulbos liliacearum, unde in maxime borealibus, uti lilia defunt, non occurrit; corpus denique habet minus e'ongatum, auriculas paulo majores, caudan paulo breviorem; maximeque cranin \& coftarum numero difcrepat. Minus adisc coïncidit cum M. fociali, licet colorem huic fintiem habcat; fed pilorum piane aliam indolem diverfasque proportiones, cofarum numsrum, vivendi normam, patriam, aliaque comparatis defcriptionibus perfpicienda. - Praterque enumeratas hafce fpecics cum nulla hucusque mihi nota facile confundi poterit.

Mus gregalis idem eft, quem in Baikalenfum anims: elencho fub nomine $\mathrm{N}$. Socialis, addita Tungufica anpollacis (Niri-Katfcham) recenfet Grorgr (Itiner.p. I62.) Mi. hi citra Obum nufquam vifi funt, primosque ad Tfetulyrum obfervavi, paulo lutefeentis coisris. Copiofintes funt in campis \& montanis apricis fupra Krafnojarum inter Yjus \& 1.4. feam $\mathrm{A}$. ufque ad $\Lambda$ bakanum \& altiora juga; copiofifima

$$
\text { I h } 2
$$


regionibus Transbaikalenfibus, precipuc Dauuria. Ibi fcilicet abundant, ubi copiofe crefcit Lilium pomponium \& Allium tenuifimum, cujus bulbi fatui, fubdulces, vix alliaceum faporem habcnt. His cnim bulbis (\& Trifolii Lupinaftri forte radicibus) precipuc victitant, hos colligunt in hyemis folatium. Eftque hæc fpecies murium, cujus Allia infipida colligentis mentionem fecit gmelinvs Flor. fib. I. p. 62. Senper, ut adtigi, clatum \& ficcum folum quærunt, vix in humidis pratis, infulisque fluminum, qux loca M. ceonomo frequentia funt, cuniculatur. Inde forfitan nec migrant; mihi faltem de horum migrationibus non conftat, licet verofimiles inde fiant, quod variis in locis fatis confertim habitent, pluresque frpius in uno antro, quod migratoriis muribus folemne eft. Dome. fticam vitam nunquam appetunt, fed Nomadica in libertate vivunt. Cameram pro nido, fere inftar M. cconomi, fub ipfo cefpite fatis fpatiofam cavant, oftiolis circumquaque plurimis foras perviam, ea differentia, quod terram oftiolis egeftam fupra cavum nidi quafi de induftria accumulent \& convexum tuber arte efficiant, quo pluvia defluat \& a penatibus arceatur. Circa nidum deinde, in quo familix integre (mater cum conjuge \& cjusdem anni pullis) degunt, ctiam promptuarịa cavata funt, ductibus a nido adeunda, quæ autumnili melfc bulborum lectiffinorum replent. Certum eft femper hanc fpeciem, non M. economum, in is faltem, quas adii, regionibus bulbos liliaccorum conquirere *). Inde concluderem Murcm hunc noltrum etiam in Kamtfchatka abun-

*) In regionibus ad Tenifeam, circa mis profundos) iu antris murium reper: Abakanum pracertim, ubi Erythronium tos fuifle audisi.

abundat, nunquam hujus bulbos (ni. 
dare, \& Lilii Kamtfchatici aliorumque bulbos ibi legere, quos sTELLYRvs (utramque fpeciem confundens) inter $M$. œconomi cibaria, promifcue cum reliquis radicibus, huic pofteriori gratis, recenfet. Inter miffas quidem e Kantfchatka pelles nullam M. gregali fimilem inveni; id tamen nihil probat, quum iftx pelles tantum in regione Portus Bolfcherezlkienfis collectæ fuere, in depreffis pratis. - Neque frigiditas regionis repugnat, quum montofa Dauuria non fit tepidior Kamtfchatka, immo Mures noftri ufque ad Ienifeenfe oppidum, fub prefrigida latitudine pofitum, obfervati fucrint; nempe quousque dulces bulbi proveniunt, quos etiam Tunguf ex huius maxime fpeciei antris autumno pro cupediis effodiunt.

Magnitudo in M. gregali fecundum fexum utique variat, ut in M. œconomo, fed minus conftanter, minorique gradu. Plerique Mares multo minores funt feminis; attamen dantur, aliqui, quorum magnitudo ad majores feminas accedit. Habui etiam feminas minoris ftaturæ, an juniores?

Duos Mures e Dauuria effarctos accepi, quos equidem pilus \& color, ut \& pleræque proportiones a $\mathbf{M}$. gregali diftingucre vetant, quos tamen filcntio tranfire haud poffum, licet fpecificam dignitatem e folis exuviis \& imperfecta obfervatione largiri nequeo. Poterunt in pofterum melius obfervari \& fi dítinctæ fint curatius, etiam per anatomen, determinari.

Horum alter magnitudine xquat $M$. gregalis maximas feminas \& a Studiofo $N$. sokolof ad Argunum, circa Soktui, loco herbido captus fuit in cuniculo, qui $M$. gregalis videbatur. Mordaciffimus fuit, quod M. gregalis vulgo non audet; pugnacem quoque teftabantur palmæ cicatricofæ \& mutilæ. Exuviarum, quas etiamnum fervo, præcipua differentia eft in If h 3 
dentibus primoribus robuftis, intenfe luteis, it quidem fuperioribus acie Sua communi medio in angulum argute acuatis, ut figura 20. tabulice XVII. exprefi; ceterum fulco obfo. leto, ut in M. gregali vulgari exarati funt. Videtur etian hæc mucronata dentium acies attricu orifi poruiffe, \& forte fenio provecti robuftiori \& pugnaci indoli tribuenda venit. Attamen aliæ adhuc differentia quædam curata comparatione pa. tefcunt: auricule, quantum e ficco judicare licet, paulo ma jores funt \& plane nudx; plante proportione breviores; velleris color e prilicle gryfeo cinereus, dilutior, quam in M. gregali, lateribus albicantior, neque roftum fufcefcente fupra tractu infignitum, fod uniformiter cinereum. Reliqua ita conveniunt, ut vix dubitem varietatem dicere. Longitudo exuviarum tota 3." $10 . "$ caudre 9."' capitis . I" $2^{\prime \prime \prime}$ planta $7 \frac{7}{7} . "$

Altermm, de quo dixi, fpecimen itidem laudato Amanuenfi debco, qui afirmabat fe Mures conftanter tales plurics, in humidulis ad Argunum pratis, circa Soktui \& Zuruchaïu obfervaffe. Cunicuii, in quibus deprenfos reculit, maxime fingulares funt, \& diverfam fpeciem arguere videntur; nifi dicas Murem gregalem forte nova domicilia condentem talia moiiri. Canales funt longiffimi, in ipfa fere cæépitis fubftantia flexuofe decurrentes, ramofi, labyrintinici, crebris oftiolis (quibus terram egerit) pertufi, in quibus duobus tribusve locis ampliori fpatio herba pro nido congefta, nullumque profundius diverticulum apparet. Hujusmodi cuniculos ipfe pluries ad Ononem \& ad Abakanum inveni \& miratus fum; nunquam vero incolam comprehendere datum fuit. Mus, quem canaliculorum anctorem affeverabat Studiofus, colore, itemque proportione artuum \& caudæ, M. gregali fi- 
millimus eft, \& magnitudine mediocres hujus fpeciei xquat. Videtur gracilior effe aflinibus, \& præfertim currens elongato corpore muftelam parvulam referre dicebatur. Dentes, auriculæ \& reliqua ut in M. gregali; Verruca etiarn acute unguiculata pro pollice in palmis. Vellus paulo rudius videbatur, \& color minus flavicans. Maxime infignis in recenti videbatur tumor externus glandulce lumbaris vel hypochondricæ, qux omnibus muribus in tractu fubcutanco, vafculofo. pingui folemnis, externe tamen in aliis haud apparet. Huic utrinque ante flexuram femorum quafi cyftis protuberabat, cum area externa velleris nudiufcula fupra ipfam. glandulam. Longitudo exuviarum, quas accepi, fuit 3." 8."' caudæ 9."' plantarum cum unguibus $7 \frac{1}{20}$ "'l capitis circiter 1." 1. $^{\prime \prime \prime}$ Coftæ in fceleto XIII.

Habui etiam aliquot fpecimina in borcalibus ad Ienifeam lecta, M. gregali affinia, in plerisque, etian colore fimilia, qua confervativo e liquore non facile fuit determinare. Videbantur a M. gregali differe: I.) Cranio minus oblongo, feu paulo craffiore \& breviore, prefertim roftro; facie magis. hirta; trunco (præfertim quoad fpinam lumbarem) longiore; a.) Dentibus primoribus M. arvali fimilioribus; molaribus paulo divcrfis, fupra utrinque $1 \mathrm{~V}$. cum accefforio fcilicet antice parvo, qui M. gregali deficit; 3.) humeris brachiisque paulo longioribus, robuftioribus, palmaque latiore, villofiore; quum tamen poftici artus vix differant; 4.) Vellere, quod obfcurius paulo habet M. gregali, fubtus fere albo. - $\mathrm{I}_{\text {- }}$ dem a M. arvali brevitate auricularum atque caudæ, magis: pilofe, craffic capitis majore, artubus pofticis brevioribus, 
anticis majoritus, eft. diflerebant. Menfure quxdam M. gret gali compluarat: lic habuerunt:

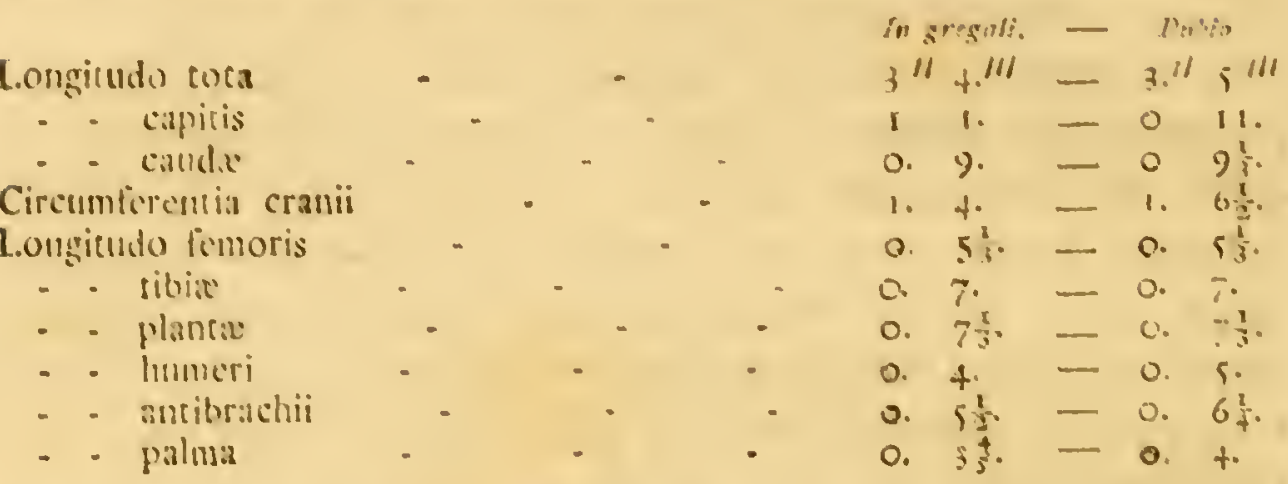

Mas igriur mihi dubias fuccics vel fi mavis varicates, indicalle linliciat.

\section{DESCRIPTIO$$
M V R I S \text { G } R E A L I S \text {. }
$$

Magritudo femper paulo infra M. aconomum conliftic, \& truncus tuntillo brevior, at longior, quan in Ml. Cociali.

Cuput magis hirtum, at habia minus crallit: M!y/fuces plerique nigri, non, ut in M. fociali, allhi. Aluricula mapores, ovales, plicatiles, tenues, vellere eminentes, apice fubvillolo - fulico.

Dent's primores lutefentes, fuperiores latiuleuli, fulco obfoletillime exarati, acie exearati.

Pedss robuttiores quam in M. fociali, nudiufeuli, fun foi: polmore lubetradactyla, callo pollicuri papilliformi, fulzunguiculate; calli duo fub enrpo contigui, verruciformes (in M. fociali diftuntes). Plontarmu digiti omnes unguiculaci, medii tres non plane aquales. 
Conda craffior, quam M. Cociali, pilis Inngioribus, pricfertim apice (nigrefecentibus) fetofo, annulis inter pilos circiter $\mathrm{XI}$.

Fillus rude, duriufeulum, minus lave, fed frictum. Color fupra gryfeo - pallelicens, pilis medio dorlo crebrioribus, nigrefcentibus obfufcatus: latcribus fenfin pallidus, pilis gryleis mixtus; fubtus pallidus lordideve allefecns.

\section{$M R N S V R \Lambda$ R.}

Pondus in majoribus (feminis) uncian cum didrachma squat, harumque longitudo 4." $6 . "$ cinudia $1 "$ explere folet. In maribus vulgo pondus 4 ad 7 drachumarum inveni; fequentesque menfure e fpecinine fex drachmarum petita funt:

Longitudo tota a nafo ad anum

- capitis

- culde fine pilo

- excedentium caudam pilorum

Diramia oc.lli a nafo.

- auris ab oculo

Fiffura palpclorarum

I.ongitudo auris

Fiusdem latitudo explanata

Circumferentia roftri ante oculos

- medio inter oculos \& aures

- colli

- thoracis pone armos

- medii corporis

Longitudo huneri in fecleto

- cubili

- palmic

- femoris in fecleto

- tibicc

- unguium in palm. \& $\overline{p l}$. 


\section{A N A T O IE.$$
\text { Tib. XVll. fig. } 200^{*}
$$

Interanea maximam cum M. economo finilitudinem prodiderunt. Ventriculus itidem medio glandulofus, intus plica fimbriata bilocularis. In ileo glandula conglomerata, orbicularis, infignis. Cacmm finillimum, fed paulo longius, nempe 6." 9." dum in M. oconomo xquali vix effet 5." 9."

Cofte in fecleto conftanter XIII. parium, c quibus vera VII. duo ima ad enfis bafin inferta. Spina lumbaris VI. vertebrarum longarum, quæ collectim $9 \frac{x}{2} . "$ xquant, at dorfalis 10." colli $3 \frac{1}{2}$." Os facrmm brarticulatum $2 !$ linear. Cantda ( . $^{\prime \prime} \mathrm{I} \frac{\mathrm{r}}{2} . "$ ) $)$ XIV. vertebrarum, quarum tamen dua priores, minus mobiles facro adnumerari poffunt. Ofju immominata longitudine $6 \frac{\mathrm{I}}{2} .{ }^{\prime \prime \prime}$

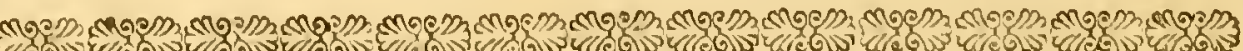
Ex

\section{$\mathrm{M} \cdot \mathrm{V} \mathrm{S}$ \\ $\begin{array}{llllllll}R & V & T & I & L & V & S .\end{array}$}

Dum plerique Mures brachyuri conftanti aconomia induftrii vivun, pabulum colligentes, certamque in condendo cuniculos legem fervantes; hic, quem deferipturus jam fum, mire degener, rapina \& cæde vagus vivit, nullam certam cuniculorum methodum obfervat, immo fiepe tuguriorum ru. fticorum \& granariorum fit parafita, quod inter affines nullus, Illum frequentilime in omni Sibiria transobenf, locis prefertim fylvaticis, ctiam alpinis frig dis, obfurvavi, immo e terris arcticis (ad ipfum Sinum Obcnfem capcum) habco, fed 
magis fufcidum. In Dauuriæ fylvis frigidis putridos truncos inhabitantem, alibi fub tignis cafarum rufticarum in terra raptim congefto nido latentem \& ctiam juftis aliquando, fed alicnis forte in cuniculis, autumno vero lub frumenti acervis, paffim inveni. GMELINVS ad Lenam obfervavit, dicitque Iacurix in domibus hybernare \& a Iacutis (communi cum M. œconomo nomine Kultujach) affatum comedi fcripfit. stellervs ad Ilgam \& Aldanum dari, reliquit; idemque ent, qui in Kamtrchatka fub nomine T chetanauftchu (Muris rufi) notus eft. crediturque collectas a $\mathrm{M}$. œconomo radices fuffurari ${ }^{a}$ ), \& maxima ubique copia in Kamtfchatkx fylvis, montibus, ericetis vagatur.

Per totam hyemen alacres funt \& fupra nivem difcurrunt, ubi veftigia mirum in modum in orbes $\&$ anfractus intricata paffim confpiciuntur. Frequentes etiam incidunt in decipulas carnibus inefcatas, quæ Ermineis fimilibusque feris capiendis ftatuuntur, unde carnarium \& omnivorum eorum appctitum colligere licet.

$\mathrm{Ex}$ omnibus iftis apparet, quantum $\mathrm{M}$. rutilus a fpeciebus affinibus differat, quod aliunde proportionibus \& colore fatis indicatur, in quibus momentis Sibiricos vix unquam variaffe vidi. Vnicum fpecimen e plaga arctica adlatum colore in dorfo ferrugineo - fufcefcente, obfoletiore, latera verfus lutefcente differre vifum ent, non proportionibus.

Sed obfervavi circa mediam Volgam, prefertim in Cafanienfibus \& Simbirlkienfibus agris, frequentem hyeme circa pagos \& granaria Murem ftructura \& colore apprimæ quidem

a) KRASCIENINIK OF. defcr. Kam. Befchr. von Kamtech. p. 129. not. a. techatk. edit. ruf. r. p. 226. S T ELLER 
fimilem, attamen paulo minorem Sibiricis, cauda proportione tenuiore \& longiore inftructum; cæteroquin etiam hic (præ* ter fulvedinem dorfi faturatiorem \& latius diffulam) vix di. verfus, neque fuflicienti jure pro diftincta fpecie habendus vi. detur. In plurimis hujus varictatis individuis pondus quatuor cum dimidia, vel quinque drachmarum vulgo obfervavi; lon. gitudo fuit $3 . " 4 . "$ " capitis 1." caudæ $1 . " 6$ - $8 . "$ - Et hisce plane fimilem murem quondam (Augufto MDCCLIX.) in Horto botanico Gettingenfi obtinui, cujus etiannum deferiptionem atque dimenfiones fervo, accuratiflime cum Volgenfi noftra var rictate coïncidentes. Mirumque quod in utraque caudam, multo licet longior effet quam fibiricis, totidem tamen vertebris conflatam invencrim, auriumquic formam \& proportionem. fimillimam. Itaque nullus dubito in occidentalibus obfervatos. iftos cum Sibiricis conjungerc, fpeciemque Muris rutili ab Europa ufque in finem Afix difperfam pronunciare, quamvis inter Volgam \& Obum medias per regiones vix obfervata nobis fuit, \& inter curoparos mures a mullo hucusque Zoologo difertc indicata.

\section{DESCRIPTIO \\ $M V R I S R V T I L I$. Tub. XIV. B.}

Magnitudo confantior, in utroque fexu fubrqualis, circiter $M$. arvali compar.

Rofrrum cum nafo hiffutifimum \& facies fere ejusdem. Myftaces tenucs, albicantes, longitudine capitis. Dentes ut in M. aconomo, paulove anguftiores, antice flavi.

Oculi vix roftro propiores, parvuli. Aures affinibus (M. gregale, arvali, cet.) majores, ovales, tenuius albo = mem; 
brantcex, complicatx, nudx (preter apicem vellere prominentcm cum antico margine ferruginco villofum); atrium meatus fpatiofum, iamella meatum protegente minus producta, quam is $M$. œcononio.

Palmæ plantæque trantillo majores \& robuftiores, quam nffinibus. Palmoe fubtetradactylx, ungue pollicari minuto, ut in $\mathrm{M}$. aconomo, paulove obtufiore.

Cauda (in quibusdam caliu detruncata) multo craffior, quam affinibus, longitudine (in fibiricis) minus abludente, pilofiffima undique, (paulo minus Volgenfibus, quibus annulos circiter 80. numeravi).

Vellus forc tencrius, quam in M. cconomo. Color a media fronte per dorfum ad clunes ufque uniformis late rufo. fulvus vix fummis longiorum pilorum apiculis fufcercentibus; latera dilute gryfeo - flavefcunt, ut \& roftrum, immixtis pilis fparfis fufcis; alvus \& gula fenfim albefcunt. Pedes albi, pilofiores quam affinibus. Cauda fupra tractu fufco, fubtus pallida lateribus flavidior. Lamugo vclleris ubique fufca.

Ubera feminis bina abdominalia, bipapillaria, valde confpicua notavi, nulla thoracict.

MEN S V R $\Lambda$ E.

Sibiricos pondere a IV. ad VII, drachmas variare obfer. vavi. Femina quae pondus VII. drachmarum aliquot granis excedebat, fequentes dimenfiones dedit:

Longitudo tota a nafo ad anum - $3117 \frac{\mathrm{T}}{2} .11$

- capitis

- coude fine pilis

- pilorum caudam exfuperantium

Diftantia oculi a nafo

- auris ab oculo 
Oculi claufi diameter

Intervalium narium

- oculorum filo

- - - circinno

Longitudo auris a bafi - a vertice

Ejusdem latitudo fumma Circumferentia roftri

- capitis

- colli

- thoracis ad armos

- - in medio corpore

- alvi ad femora

- bafeos cauda

Longitudo colli

- antibrachii

Longitudo palma cum unguiculis $\left(\frac{3}{4} \cdot{ }^{\prime \prime \prime}\right)$

- cibir

- planta cum unguibus (fere I.ol')
O $11: \frac{\pi}{3} \cdot 1 / \mathrm{H}$

o. $\frac{1}{2}$.

o. 4 .

o. $3 \frac{\pi}{2}$.

o. $5 \frac{1}{2}$.

c. 4 .

o. $4 \frac{\pi}{3}$.

r. 0 .

1. 4.

I. $\frac{\text {. }}{2}$.

I. $4 \frac{\pi}{2}$.

I. $S$.

I. $6 \frac{1}{2}$.

c. 3 .

o. 2 .

c. 6.

o. 4 .

o. 8 .

o. $8 \frac{\mathrm{T}}{8}$

\section{A NATOME.}

Tab. XVII. fg. 21.22.

Hepar fere ut in $\mathrm{M}$. aconomo, Cyftide exigua inter lobos incumbentes.

Ventriculus (fig. 2r.) naturali magnitudine (ut reliquorum vifcera) depictus, multo major, quam affinibus, oblon-

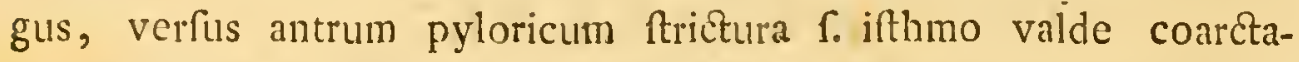
to bilocularis, cui intus refpondet plica valvularis , tenuis, non fimbriata. Pars pylorica ventriculi multo minor, inæquali - fublobata, ad majorem arcum fchto glandulofo, fubovali inftructa. Chymlis contcntus in hyeme diffectis plerumque lutum terreum, particulis rofis mixtum.

Inteffinum tenue longitudine $15^{\prime \prime}$ crafitie tenuioris calami. Crectlm (fig. 22. $a$ - b.) primum rectiufculum, extremo fubadtenuato, fubtrifpire, longitudine $4^{\prime \prime}$ apice obtufum. Inte- 
ftinum Spirale (lit. c.) tenue 2." 6. "I pofteriore medietate oblique ftriatum; excretorium (lit. d.) ufque ad anum 4." 6."

Sceleton: Craminm brevius, multoque convexius, quam in M. arvali \& economo, temporibus ad infertioncm maffeteris vix obfoletifine angulatis, zygomatum arcu latius divaricato, quam in iisdem; ifthmo inter orbitas roftro latiore, roftri proportione fere ut in $\mathrm{M}$. œconomo, fed maxilla ad molares haud gibba. Coftartum XIII. paria, quorum VII. vera. Stermi fegmenta intermedia IV. Vertebra lumbares VI. facri tres, caudie XVI. quarum priores in fibiricis admodum breves. $O / \int a$ artuum proportione admodum tenuia. Symplyy $/$ is pubis folida, neque angulis retrorfum directis.

Pro menfuris fecleti fpecimen pondere $6_{3}^{\mathrm{T}}$ drachm. longitudine 3. " 4. " cauda 127.

Longicudo cranii

Latitudo cjusdem pone zygomata

- incer orbiris

- zygomalum per arcus

- bafeos roftri

Longitudo roftri offumque nafi

- inciforum fi!periorum

- - - inferiorum

- maxilla ad condylos

- columnæ vertebris colli

- vertebris dorfilium collectim

- . lumbarium

- Tacri

- cauda in libirico

Sterni fine cnfe longitudo

- enfis fere

Longitudo clavicularum

Latitudo ejusdem

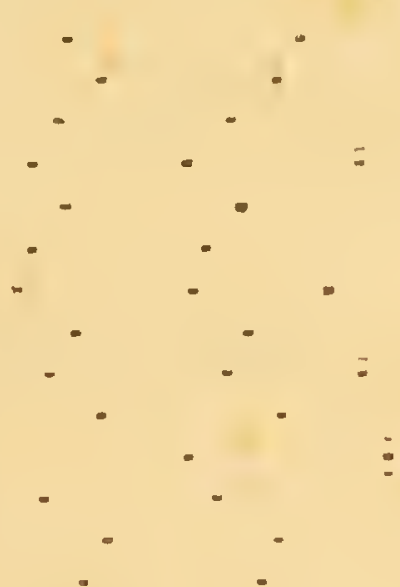

$0.110 \frac{\pi}{4} 11$

0. 5 .

o. $\mathrm{J} \frac{4}{5}$.

ว. $5 \frac{2}{3}$.

o. $1 \frac{3}{4}$.

D. $2 \frac{3}{5}$.

o. $1 \frac{\pi}{4}$.

o. $2 \frac{\pi}{3}$.

o. $4 \frac{2}{3}$.

ค. $3 \frac{2}{3}$

0. 10 .

o. $9 \frac{\pi}{3}$.

c. 4 .

I. $5 \frac{\pi}{3}$,

C. 5 .

o. 3 .

o. $3 \frac{2}{3}$.

0. 5 .

o. $2 \frac{x}{2}$. 
Longitudo humeri

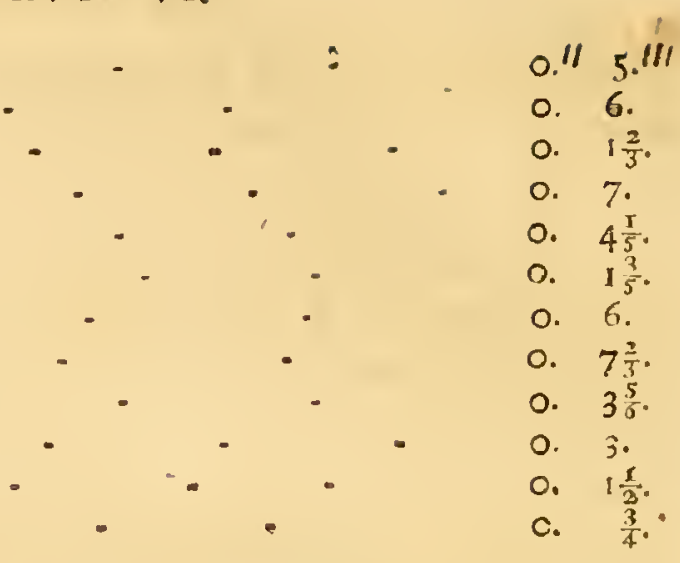

- cubiti

- oflis meracarpi medii

- oflum innominatorum

- ilei ad ufque acetabulum

- foraminis ovalis

- femoris

- . tibia

- fibula quousque diftincta

- oflis metatarfi medii

- phalangis prima

- - lecundx

$1 \frac{2}{3}$.

o. 7 .

o. $4 \frac{\mathrm{T}}{5}$.

o. $1 \frac{3}{5}$.

o. 6.

o. $7 \frac{2}{3}$.

$3 \sigma^{\circ}$

o. $1 \frac{\pi}{2}$.

c. $\frac{3}{4}$.

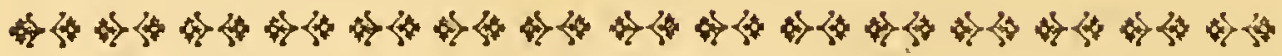

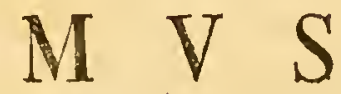

$\begin{array}{lllllllll}A & L & L & I & A & R & I & V & S .\end{array}$

Diu de fpecic Muris, quam Allii angulati aliorumque bulbos acri guftu præditos in cellulas fubterraneas congerere rufticis Sibirix, præfertim circa Ienifeam, Kanum \& An. garam, notiffimum eft, follicitus fui, donec tandem duo fpecimina liquore fervata e regione urbis Ienifex accepi, qux pro alliariis muribus mittebantur. Diftinctiffimam utique fpeciem loquebatur aurium præfertim magnitudo, qua plerosque Mures brachyuros vincit; color etiam cinerafcens fingularis eft, ne de myftacum longitudine, variisque proportionum momentis dicam. Verum an lrec ipfa fit fpecies qux fingulari ifto appetitu allia in victum adhibet, cujusque cuniculos propter Allia obtinenda fodiunt Ruffi \& gentiles Sibiriæ fylveftris; id equidem ex aliena fide tantifper trado, non affero, fpeciem diftinxifle contentus. 


\section{DESCRIPTIO \\ $M V R I S A L L I A R I I$. \\ Tib. $X I V . C$.}

Magnitudo M. aconomi. Habitus inter M. domefticum \& arvalem medius. Caput, myftaces longiores, aures magnæ patulæ Muris mufculi; truncus clongatus, cauda brevis, ftatura M. arvalis. - Myftaces albidi, majoribus fetis bafi furcis. Aures magnx, nudiufculæ, lamina interius fupra meatum transverfa, infigni, protegente; nullo antitrago ante meatum.

Pedes mediocres: palme tetradactyla, callo pollicari mollufculo, verruciformi.

Cauda proportione fere ut in M. œconomo, pilis ita veftita, ut annuli non appareant.

Vellus fubfemipollicare, inæquale, molle, frictum, in dorfo cinereum, pilis longioribus extremis gryfeo - fufcefcentibus; latera cincreo - albida, fubtus pedibusque totis albidis. Cauda, preter tractum fupra fufcum, alba. Aures fufcefcentes. Mammœ duæ pectorales, totiden abdominales \& duæ inguinales.

\section{MENS VRAE.}

Pondus in liquore conditis explorari non potuit. Longitudo tota a nafo ad caudam

- capitis

- caudæ fine pilo

- exfuperantium caudam pilorum

- pilorum myftacis longiff. Diftantia oculi a nafo - auris ab oculo Fiffura palpebrarum ultra Diftantia inter oculos circinno - aurium per verticem

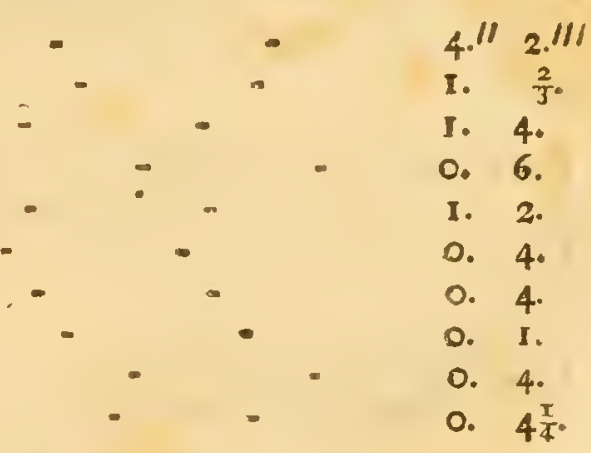

K k 
Longitudo aurium

Earundem latitudo

Circumferentia roftri

- capitis inter oculos \& aures

- colli

- thoracis pone armos

- medio corpore

Circumferentia corp. ad femora

- cauda

Longitudo tubix

- plantæ

- antibrachii

- palinæ integræ

\section{A N A T O M I A.}

In illo, quem defcripf \& diffecui, bepar morbofum fuic; in maximam molem auctum, præfertim lobis majoribus per melicerides tuberofis, lateralibus folis \& fuperis in naturali ftatu relictis.- Cyftis exigua, vacua inter lobos fuperos. Ventriculus bipartitus, ut in affinibus.

Sceleton: Crania fimile M. oconomo \& rutilo, fed omni parte oblongius, ifthmio inter orbitas roftro latiore, \& fronte non aqualiter convexa, fed verfus verticem plano impreffa (Tab. XVII. fgg. 22.*) Molares ubique tres. Coftarum XIII. paria; ftermum ofliculis intermediis IV. vertebrce lumbares. VI. facri III. caudæ XV. connumerato (ut in omnibus) apice. Symphy/gis pubis anguftifima, ligamento cohx. rens.

Longitudo cranii in defcripto

- roftri offumque nafalium

Latitudo ollix pone zygomata

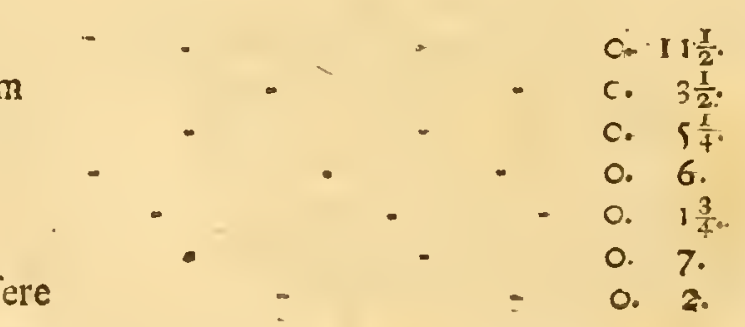


Longitudo inferiorum

- vertebrarum colli fimul

- . . dorfi collectim

- - lumbarium

- racri

- caudic

Longitudo fterni manubrii

- . - corporis

- - cnfis offex

- clavicularum

- Ccapulse

Latitudo cjusdem

Longitudo humeri

- offum innoininatorum

- ilei ad acetab.

- foraminis ovalis linearis

- femoris

- fibulix quousque diftineta

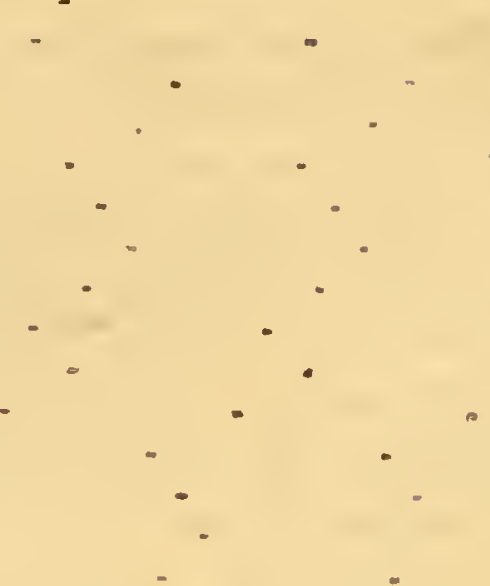

0 $113 \frac{x}{5} .111$

○. 4 .

I. $1 \frac{5}{2}$.

1. 0 .

o. $4 \frac{r}{2}$.

I. 10 .

o. 2 .

o. $4 \frac{x}{3}=$

o. $3 \frac{x}{3}$.

c. 4 .

o. 5.

- $2 \frac{1}{2}$.

o. $6 \frac{7}{3}$.

o. $8 \frac{1}{2}$.

o. 5 .

o. $2 \frac{x}{2}$.

o. 8.

o. 1 .

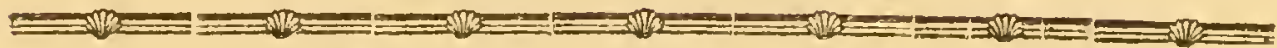

M V S

$\begin{array}{lllllllll}S & A & X & A & T & I & L & I & S .\end{array}$

Proprium transbailkalenfi regioni Mongoliæque defertæe effe autumo M. faxatilem, cujus preterea per Sibiriam nullibi veftigium inveni. Miro modo imbellibus plantis inter rupes \& faxa cuniculum fibi effodit, fiffuras humo repletas obfervans, quas gelu \& radicum vis vegetans dilatavit. Videtur in aridis, foloque nudatis montibus ex Aftragalorum prefertim feminibus victum legere. Obfervavi cuniculos ejus primum ad Udam, dein ad Ononem in montium, faxis afperrinorum, latere meridiano foli oppofito. Similibus iocis ad Argunum obferva. tus \& captus fuit. Eftque hic ipfe, cujus mentionem in Hod-. 
'getici MSto facit Messerschmidvs, nomine "Muris montani brachyuri, dauurici,..

Cuniculi confant canali majore oblique anfractuofo, per quem terram egerit; altero, vel duobus pluribusve fubperpendicularibus, inter rupes pariter anfractuofis, nullo terræe cumulo confpicuis, qui fipe fefquiulnari, immo biulnari tractu ad nidnm defcendunt, herba molli faretum.

Diftinetifimam effe fpeciem magnitudo, qua reliquos affines Mures fuperat, cauda longitudo paulo infignior, qua ad myofuros inclinat, aures majufculæ, aliaque probant. Quum autem defcriptio ad recentia fpecinina facta cafu perierit, ex affervatis exuviis, ut potero, defcribam.

\section{DESCRIPTIO}

\section{$M V R I S S A X A T I L I S$.}

Tab. XXIlI. B.

Facie fimilior M. fylventri, quam arvali. Magnitudo prioris qui majoris ftatura. Caput oblongum, roftro fubacuto.

Dentes primores, ut in priore, fuperiores fulvi, craff, acie curta; inferiores flavelcentes.

Myftaces tenues, nigricantes, capite breviores. Aures vellere multo majores, ovales, extremitate prominente villofre, fulc $x$.

Altus proportione majores atque robuttiores, (fere ut in Ratto), præfertim poftici, extrcmis nudiufculi, nigricantes. Palme unguiculo pollicari parvulo.

C.lluda vix dimidio corpori æqualis, tenuis, linearis, fquamoro - nudiufcula, pilis fparfis, fubrus albicantibus. 
Color Supra furcus, gryféo parcius immixto; latera magis gryfca; fubtus cinerafcente - albus. Roftrum fufcum, vix exili area circa nafum nudum albicante.

\section{MENS V R A E.}

Pondus recentis fuit uncix fere cum integra drachma.

Longitudo corporis

- capitis

- caudæ

- palma

- planta

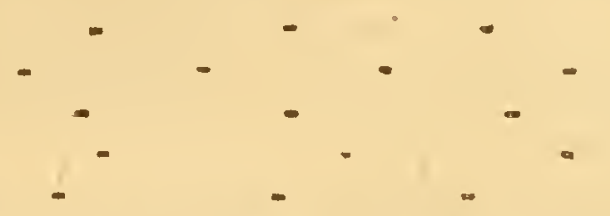

4." 0.111

1. 1.

1. 6.

05.

o. 10.

फन

\section{V S \\ $\begin{array}{lllllllll}A & C & C & E & D & V & L & A \text {. }\end{array}$}

Tnter mures buccarum facculis Cricetum referentes, quos in Afia boreali obfervavi, hæc fpecies magnitudine eminet, licet ab ipfo Criceto tantundem diftet, quantum a Lepore vulgari L. pufillus nofter. Eft autem apud nos rarior, auftraliorum forte regionum frequentior incola; immo unicum plane fpecimen hujus obtinui, a Rhymno fluvio adlatum, quod etiamnum in liquore fervo. Captus is fuit, a canc ad hoc inftituto, in colliculofa regione inter rivos Irtek \& Kindely, noctu cxtra antrum currens; unde \& hujus ftrctura, juxta cum reliquis moribus ignoratur. Accolæ Cofacci refurebant hunc murem interdum noctu migrare, ut quibusdam locis repentino cohortatim appareant, vulpium, a quibus infectantur, largam vena. tionem tunc promittentes. Sed dubito effe hoc vere de præ$\mathrm{K}_{3} \mathrm{~K}_{3}$ 
fentii fpecic inteligendum; potuerunt cnim hi minus adtenta de plebe homines M. Lagurum vel focialen, vere migrantes fpecies cum Accedula fine tertio comparationis oblata confudife. Non enim confentaneum videtur indoli Murium facculiferorum, ut in focictatem peregrinatoriam cö̈ant, quum fint mordaces \& viciniam confanguineorum vulgo haud ament. Debuifet etiam tunc fpecies hee noftra frequentior obfervari in illo deferto, quod in hec minuta animalcula corumque antra adtentifimus peragravi. Liceat ergo de ifta narratione tancifper dubitare \& pro fporadica fpecie M. Acccdulam proponere.

Diftinguitur a fequentibus fpecicbus facile magnitudine, auricularum forma fubemarginata, labiorum notabili craflitie, colore fubuniformi gryfeo. Caude crafitudine \& brevitate cums M. fongaro folo convenit, cum quo propter réliquam diffimilitudinem a nemine facile confundetur.

\section{DESCRIPTIO \\ $M V R I S A C C E D V L A E$. \\ Tab. XIIII. $A$.}

Magnitudo fere dupla M. arvalis. Caput majus codem, labiisque carnofifimis roftro obtufo.

Nifals rotundatus, pubcfeens, folo limbo transverfo fupra nares, prominuloque ad feptum utrinque margine lunulato, nudis.

Labizm fuperius alte bilobum, incifura in fulcum fepti inter nares profundum continuata. Labinm inferius \& maxime finus oris utrinque laxi, carnofiffimi, tumidi, unde adfpectus fingularis; ipfum labium inf. ad oris finum inflexum, connivens fupra aperturam utrinque ad mandibulam hiantem, 
qux ducunt ad faccos buccarum ampliffimos, colli latera, ad hunieros fere ufque occupantes.

Dintes primores fupra minufculi, extus convexi, lutefcentes, truncati; inferiores longi, fubulati, albidiores.

My/zaces tenues, vix capite longiores, quinque ordinum; anticis fetis albidis, longioribus nigris. Seta fupraocularis gemina, nigra; Pili aliquot longiores, albi fuib finubus oris. Verruca cum fetis circiter VI. albis fub antibrachio verfus carpum.

Oculi majufculi, medio inter nafum \& aures, palpebra fuperiore tota, inferiore antrorfum pilis nigris ciliata. Perioptbalmizm caruncula plana, fufcefcente prominulun.

Auriculce infignes, reclinatx, nudiufculx, fufcefcentes; forma oblongo - ovata, apice rotundata, \& poftico margine verfus apicem oblolete finuata.

Collum \& trumcus brevia, craffa. Artus breves., robufti, extiemo nudiufculi, albi. Palmce majores, tetradacty$\mathfrak{l}$, papilla loco pollicis fine veftigio unguis; Vola tuberculis tribus ad digitos, \& duobus parallclis, æqualibus fub carpo, quorum pollici. propius. magis prominulum. - Plantee pentadactylæ, pollice multo breviore, fubtus tubcrculis fub me. tatarfo fenis, in duo bafi obverfa triangula pofitis.

Caluda breviffima, cylindrica, vix extremo fubadtenuata; obtufa, fupra longitudinaliter fufco, ceterum albo - pilofa, ita ut fubtilifimi annuli numerari nequcant.

Vellas haud prolixum, læviufculum. Color in circumferentia oris late, ul-raque nafum \& verfus buccas albus; cetcrum fupra e lutefcente cinereus, pilis fufcis immixtus, fubtus albo - canefcens; cxtrema pedum alba. 
-4 amu itriuto - struta, ancrius prominens papilla crulta, orificio

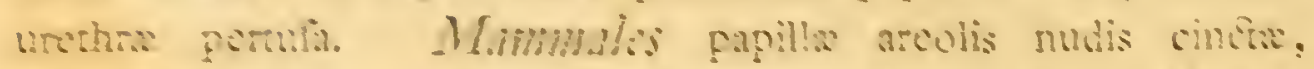

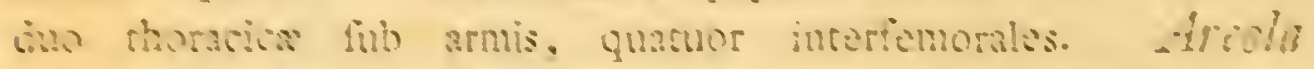

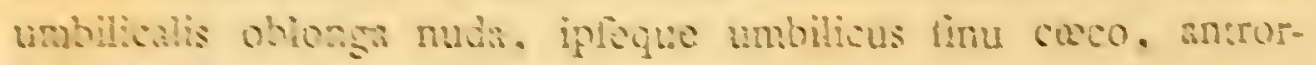
lim offuto nomets.

\section{$M E N S V R A E$.}

Pordess protimo uncim aquavit.

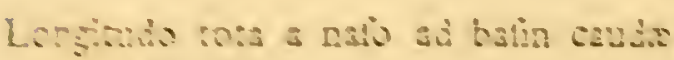

- ancisis

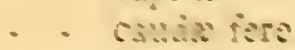

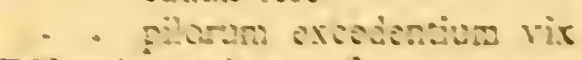

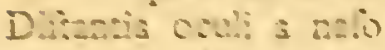
- endis at asulo

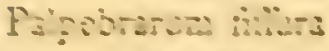

- - agertura

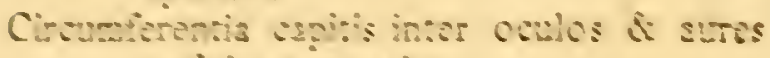

- rotai anse ocros

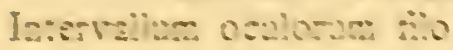

- - p parasia

- . zariug

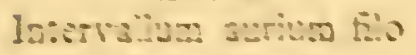

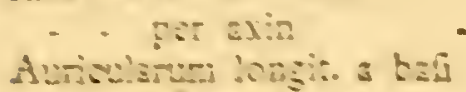

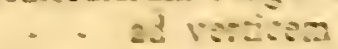

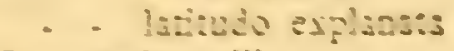

Ictionso ond

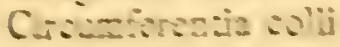

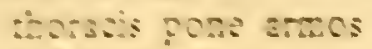

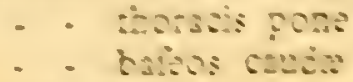

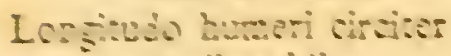

- - sasbrectio

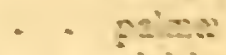

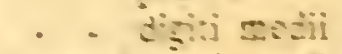

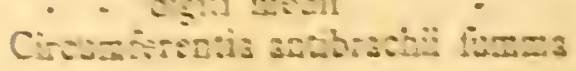
cis:
3." I $1 ., 11$

1. ร.

c. $s$.

c

a i.

c. 3

0. $=\frac{1}{2}$

o. 2.

$\therefore \therefore$

1. 6

a $\therefore$

c. +

a.

c. $i \frac{1}{2}$

o. 5.

c) 6 .

c.

2. 訾.

c. $\therefore$

J. IC.

$\therefore$. 9 .

o. $\frac{1}{2}$

a i $\frac{1}{3}$.

จ.

c. 6 .

o. 3 .

c. 9.

a 6 .

Lati- 


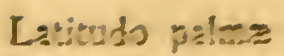

Longuge ficcoris cirsise:

- tiblarum

- planz

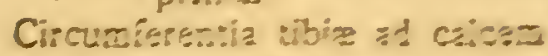

- . - ed fozar

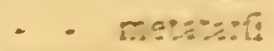

Laxieudo plas:e

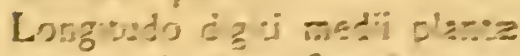

- necuar Copsivina

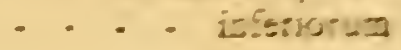

\section{A NATOMICA}

Fugiviza fectone ainosari: Hetar quinquaiobum, Cyfti dis reftzigio plare nullo; Ventriculum bipartum, portiose

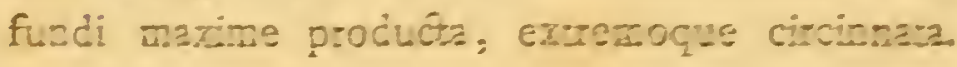

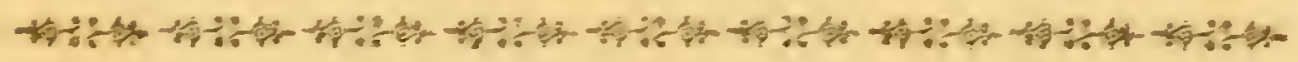

\section{MVS \\ $P \quad H \quad A \quad E \quad V \quad S$.}

$\mathrm{H}$

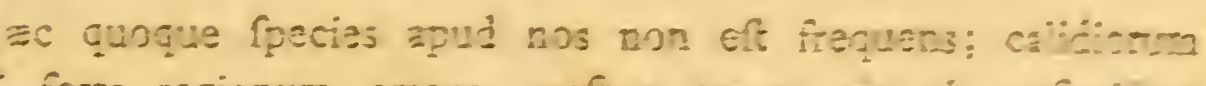

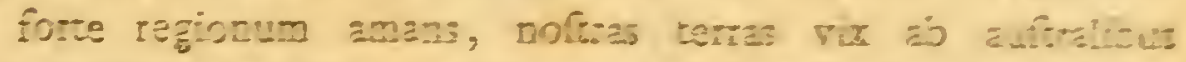

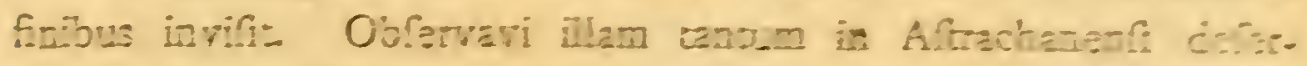

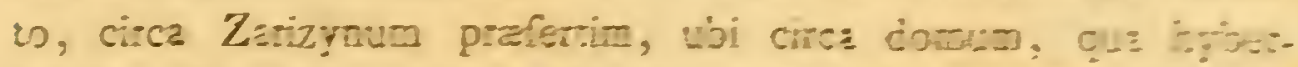
nabsu, in ipfo cempo haud longe a fábulis equeftions if an,

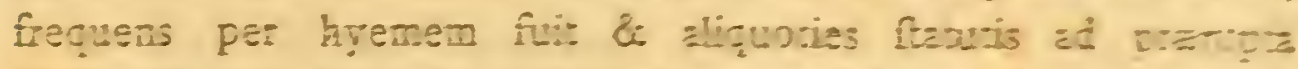
Volgenfis rip decipulis capta fith - Adporavit ej-a tein ch.

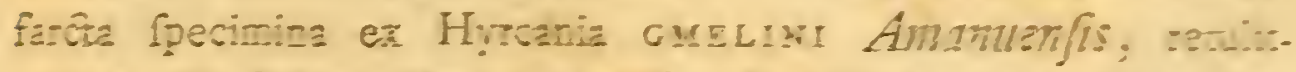
çue is alpefribus ilum sceuriffe, se fubinde circa pagss per. $\dot{L} \mathrm{i}$ 
farum domefticum hyeme ficri \& oryzan depopulari; unde iftic frequentior \& magis inquilinus videtur.

Quandoquidem mihi fub medium brumale frigus, Decembri menfe, plures hujus fpeciei, plenoque ventriculo capere licuit, fatis conftat cam hycmalem foporem non fentire, in eoque a Criceto difere. Verum antra cjus invenire, horum. que ftruturam indagare non fuit occafio.

Velleris teneritudine \& colore fimilem huic fpeciei videbimus M. arenarium, fed $M$. pheus multo largiore veftitus eft, \& ab eodem differt capitc-breviore, ioftro obtufiore, colore cano faturatiore \& ulterius per artus cxtenfo, cauda denique breviore. A reliquis fpecicbus bucciferis longius recedit.

\section{DESCRIPTIO \\ $M V R I S P H A E I$. \\ Tab. XV.A.}

Magnitudo fupra M. focialem; facic inter M. arenarium \& fongarum medius, capite oblongiufculo, obtufiore quam in M. arenario.

Nafus nudus, plica fupra nares inliectenda, fupra pilór. Labia craffufcula, ristu dilatabili, laxo; fuperius bilobum, fulcoque ad nares ufque divifum.

Myfaces $\mathrm{V}$. ordinum, capite longiores, e fetis nigris, cxtrcmo canis, ori propioribus albidis.

Oculi majufculi, limbo palpebrarum nigro. Anviculle integerrima ovales, majufculx, extremo (quousque complicatæ e vellere prominent) villofe, bafi prefertim intus nudx, albidæ; plica annularis, cxteriufque lamella breviflima, rotumdata, atrium meatus a concha diftinguunt. 
Corplus breve, craffum, depreffulculum, collo laxo, brevi utrinque faccato.

Artals breves, fatis robufi, teneri, albi, tenuiter villofi, volis nudis. Palma tetradactylæ, verruca cartilaginea, ungue dettituta loco pollicis; callis 2 magnis carpinis, altero conico, exteriore obtufo. Planta pentadactylx, pollice breviore; callis V. fub metatarfo, pentagono fitu. Unguiculi albidi.

Cildda albida, brevis, vellere tamen multo longior, cylindrica, obtufa, tenuiter pilofa, fupra tractu fufcefcente. Annuli circiter L. verfus bafin, ob denfiores pilus, haud conkpicui. - Praputium ab ano remotum.

Vellus elegantiffmum, altitudine $4 .^{\prime \prime \prime}$ tenerrimum, molle; Colore fere Gliris romani paulo fufcidiore, fupra nempe canocinerafcente, pilis longioribus nigris, a nucha per dorfum creberrimis pulchre obumbrato; frons \& roftrum magis cancfcunt; ambitus oris, corpus fubtus totum, artusque extremi nivea, \& albedo in lateribus, ac utrinque ad caudam paulo altius extenditur. Aures fufca.

\section{MENS VRA.}

Pondus paulo ultra fex drachmas in plerisque

longitudo tota a nafo ad ortum caudæ

- capitis

- caudæ fine pilo

- excedentium caudam pilorum

Diftantia oculi a nafo

- auris ab oculo

Palpebrarum filfura

- apertura

Circumferentia roftri pone myftaces

- capitis inter oculos \& aures

Longitudo auris ab externa bafi

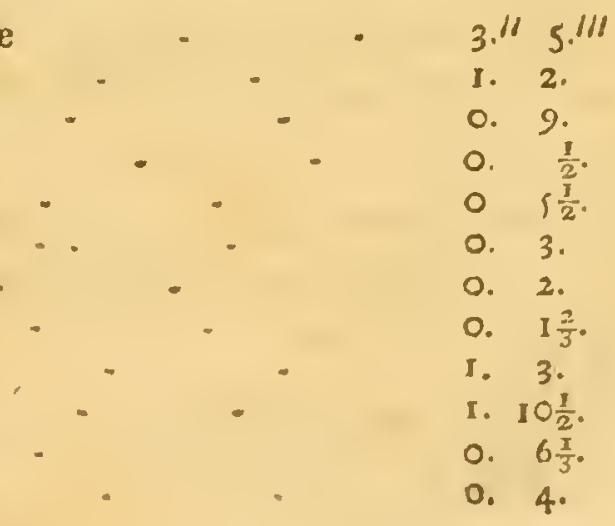

L. 12 
Intervallum narium

- canthorum oculi filo

- - per axin

- aurium per verticem

Longitudo colli

Circumferentia colli

- thoracis ad armos

- alvi

Longitudo humeri circiter

- antibrachii

- palmx

Circumferentia antibrachii bafi

- carpi

Longitudo digiti medii palmæ

- - femorum circiter

- tibir

- plantre

Circumferentia tibiæ bafi

Longitudo $\mathrm{d}_{\mathrm{i} g i t i}$ planta longifimi

\section{A N A T O ME.}

Hepar fexlobatum, Cyjfide omnino nulla: Labus dexterrimus triquetro. acuminatus, renalis; Jpigeliantus oblongus, rotundatus, fimplex. Pondus femidrachmale.

Ventriculus qualem in Mure arenario videbimus. In teftintım tenue XI. pollicurn. Cectum magnitudine \& forma prorfus ut in M. arenario, nifi quod apice fubinflexum, obtufum fine, acumine. Excrennchtitinm inteftinum 5." 6."

Teftes (hyeme) parvuli, femiexferti. Glans ovata, convéxa, obtufa, glabra, in genitali parvo.

Pulmonum dexter lobis 3 magnis \& minuto impari; $f$ nifter indivifus.

Sceleto coftarum XIII. paria; Vertebra lumbares VI. facri II. 


\section{(2as \\ M V S \\ $\begin{array}{lllllllll}A & R & E & N & A & R & I & V & \mathcal{S}\end{array}$}

Tertia fequitur fpecies Criceto penulis buccarum confimilis; cujus mores paulo otiofius obfervare potui. Fors illam in arenofis Barabenfium camporum ad Irtin fl. aliquoties obtulit, nec præterea ufquam. Primo inveni marem in fabulofis collibus Koptælye dictis, capaci antro delitefentem, ad aliquot ulnas in latus tumuli effoffo, cujus fundum occupabat nidus e radicibus, fibrofis Elymi arenarii confectus \& reliquiis leguninum Aftragali tragacanthoidis remixtus. Antequam ad nidum erat ventum, immiffa arundine fponte, quafi fomnolentus, prodiit incola, facileque captus fuit. Alia fimilia antra cum triplici aditu ibidem fodienda curavi, fed fruftra. In iisdem collibus crebras obfervavi fpicas Elymi abrofas, \& juxta culmum detonfis glumis jacentes; quod an hifce muribus, vel aliis, \& fequenti forte potius fpeciei tribuendum fucrit, in medio relinquo. - Paulo poft in folo limofo - glareofo, circa ftationem Gratfcheffkoi, fub finem Maji quinque cum matre pullorum nidum coram me effoderunt; fed e pullis tres mortui \& focti. di reperti funt, duo vegeti \& jam fatis adulti. Nidus triplex reperiebatur e molli ftuppa ignotæ mihi plante confare:natus, cui Alyfi montani filiculæ exefæ copiofe imnixtre fuerunt. Vivas iftas aliquamdiu alui. - Erant mordaciffimæ indolis; laceffiti ftatim in dorfum provolvebantur, dentibus minitabundæ, crebramque vocem Criceti vel Ermineæ. fubfimi- 
lem \& Catis gravem, etiam pulli, edentes. Cum pullis tenerioribus $M$. fongari in codem carcere detenti fatis anice quidem, fed diftincto nido vivebant, \& dum ifti familiariffimi evadebant, M. arenarii femper feri \& ab homine alieni manferunt. Aftragali tragacanthoidis legumina (ante maturitaten admodum , fucculenta) omnibus aliis feminibus pretulerunt \& lepide excavare callebant. Vagabantur tantum noctu, interdiu femper in nido latebant, diluculo prodeuntes. Curfu crant promptiores \& ommino agiliores M. 'fongaro, qui phlegma in. facic alieniflima, ut in moribus prefert.

Velleris teneritudine \& leucophao colore ad nullam, preter M. phæum, fpeciem M. arenarius accedit; ab codem vero fe diftinguit argutiore roftro, artubus totis albis, caudaque paulo longiore, fubadtenuata; magis adhuc a reliquis afinibus difcrepat.

\section{DESCRIPTIO \\ $M V R I S A R E N A R I I$.}

Tab. XVI. A.

Mognitudo fupra M. focialem, fed precedente paulo minor, imo brevior fere proportione magnitudinis.

Cnput oblongum, roftro producto, acuto; Nafus rubicundulus, pubefcens. My/taces cani, capite multo longiores, creberrimi. Pili tres fupraciliares.

Labia fricta; dentes primores lutefcentes; facculi bucceals ampliflimi, per colli latera dilatati.

Alutes magnix, ovales, patula, cano-pubefcentes, fufcidix. Oculortm majufculorum palpebre margine nigrefcentes. 
Truncus breviflimus, craffus; Artus humiles, tenuiores. quam in antecedente. Palmce fubtetradactylx, rudimento pollicis minutiffime unguiculato; calli fub carpo obtufi duo. Plantarnm digiti tres intermedii xquales; calli fub metatarfo quinque, codem fere ut pracedentis fitu; reliquum planta fubtus pubcicens. Ungriiculi albi.

Cauda tenuis, recta, nudiufcula, adtenuata, alba.

Vellhs altum, mollifimum, tencrum, fupra totum incanum f. cinerafente albidum, lanugine intus fufca; fubtus \& ufque ad media latera candidifinum. Pedes toti, caudaque alba.

MEN S V R A E.

Pondzis mafculi adulti drachmas feptem xquavit.

Longitudio tota a fummo nafo ad caudx ortum

.. capitis fere . . . . .

3." 8.111

- caudx

- exfuperantium caudam pilorum, paulo ultra

Diftantia oculi a nafo

- auris ah oculo

Palpebrarum fiffura

- apertura

Longitudo auris ab externa bafi

- - - ad verticem

Latitudo auris explanatæ

Circumferentia roftri pone myitaces

- capitis inter oculos \& aures

- colli faculis vacuis

- thoracis pone armos

- in nedin corpore

- abiominis ad femora

Longitudo bumeri

- ancibrachii

- palme a carpo ad ungues

- femoris

- tibix

- plantis

I. 2 .

0. 10 .

o. $\frac{1}{2}$.

o. $5 \frac{T}{6}$.

o. 3 .

o. 2 .

o. $1 \frac{4}{7}$.

o. 7 .

o. $5 \frac{1}{2}$.

o. 5 .

I. 5.

I. II.

1. 5

2. $2 \frac{2}{3}$.

J. 6 .

1. 6 .

c. $5 \frac{3}{4}$.

c. 7 .

o. 5 .

c. 7

c. 6 .

a. $6 \frac{3}{4}$. 


\section{A N A T O ME.}

Tab. XVII. fig. $23 .-28$.

Glandula circa collum infignes duæ, exiguæ fub armis. Hepar (fig. 23.) fexlobatum: Lobus finifzer maximus, remiorbiculatus; media portio biloba, dextro majore; finifter minor quaram orbiculi partem referens; renalis triquetro excavatus; Spigeliants unicus ad fpinam, compreffus, finum ventriculi replens. C $\quad$ J $t i$ s plane nulla.

Ventriculns (quem inflatum fig. 24. exhibet) bipartitus \& plica bilocularis, portione finiftra tereti, obtufa, reflexa; annulatim ftriata, dextra fubreniformi, inter quas medius inferitur ofophagus. Pabulum comeftum primo replet finifrum loculum (fig. 26.) conftricto \& vacuo pylorico, ut in fecto ftatim poft paftum evidenter obfervavi. - Contra in alio pridie pafto, inveni loculum finiftrum ftrictifinum (fig. 27. a.), pyloricum chymo extenfum (lit. b.). Sed an ideo ruminatio? Inteftimnn tenue XI. pollicum. Ccecmm (fig. 28. a $b$ c.) cellulofum, arcuatum, peramplum, obtufum; apice angufto, cylindraceo, inflexo, obtufiufculo mucronatum. Int. fpirale (lit. d.) tricurvatum, pergens in portionem oblique ftriatam $(d-e$.$) unde continuatur excrementitius canalis, fex$ pollices cxplens.

Rentes majufculi, dexter paulo anterior, infimam coftam adtingens. Glandule renales vertici renis infidentes. - Glans penis, cylindraceo convexa, truncata, e plica annulari orificii prominulis papillis binis officulo 'fuffultis fupra urethram, \& $l i$. gula minutifima fub urethra. Veficule projtatice anfractuofx utrinque ad collum veficx finguix; vefic. Seminales majores, cellulof 
tis minoribus, rectis, quæ omnes ex utraque parte coadunatæ confluunt, recipiuntque ductus deferentes fenfim incraffatos.

Cor mole ciceris. Pulno dexter trilobus, folisque vafis cohærens cum lobo impare triquetro - lunato, $i$ in aciem producto. Sinifter pulmo integerrimus. In Sceleto coftarum XIII. paria.

\section{$\mathrm{M}$ V S \\ $\begin{array}{llllllll}S & O & N & G & A & R & V & S .\end{array}$}

Cepidiffime hæc parvula fpecies toto habitu corporis, fubmaculofis lateribus, inter omnes penulis buccalibus inftructos proxime Cricetum vulgarem æmulatur. Hanc, pariter atque antecedentem, nullibi præterquam ad Irtin in auftralibus Barabenfum camporum inveni; ibi vero fæpius, in solo plerumque arido, falfuginofo, arenaceo. Plerosque (æftate) cuniculis primum cœptis, obliquis, nido adhuc deftitutis latentes vidi. Unicum inveni antrlim feminæ (d. $\frac{14}{2} \frac{4}{5}$ Iun.) cum feptem pullis adhuc cocis, cujus cuniculus primo ad aliquot ppithamas oblique defcendens cameram efficiebat rotundam, ramentis radicum \& herbarum ftuppa mollifima effarctam, in qua latebant pulli, \& crebræ filiculæ Alyfi montani, granaque Elymi arenarii erant admixta. Hinc alius canalis tendebat in profundum, ad aliud forte hybernum receptaculum, quo mater refugit \& propter duritiem fubftratæ fupcriori folo argillæ effodi non po- 
tuit. Pulli licet adhuc ceci, jam infigni erant magnitudine, pondere a drachmar. cum 15 gran. vellereque veftiti, \& altera ftatim die oculos aperuerunt. Hos diu vivos alui, pane nutriens \& feminibus variis, quæ e leguminofis \& Polygono, Atraphaxide, Elymoque defumta, quibus etiam captorum facculos (frepe ultra drachmale pondus collectis) refertos aliquoties inveni, maxime amare vifi funt. Admodum familiares facti funt, contra reliquorum affinium morem, ut tractari paterentur, e manu comederent, lac oblatum lamberent \& in menfam emiffi nunquam fugiendi ullam cupidincm monfrarent. In Ciftula cum arena inclufi tota fere die fodiebant, idque fumma agilitate; alias in ambulando multo lentiores \& ad omnes motus minus prompti, quam affines. Lavabant palmis, cibumque fedentes rodebant, ut affines omnes. Vagabantur femper interdiu \& vefperi, intervallis quieti relictis, nocte vero tota convoluti dormiebant. Vox rara, nec nifi laceffitis, tumque pipiens, Vefpertitionis adinfar. Vrina crebra \& fotida. Sub medium Augufti, præ pinguedine collecta, plerique perierunt.

Difinctiffima cæterum eft inter affines, colore, ftriga dorfali, areis albis, fufco cinctis lateralibus, cauda breviflima, craf$\mathbf{f}_{\mathrm{a}}$, obtufa cet.

\section{DESCRIPTIO \\ $M V R I S S O N G A R I$. \\ Tab. XVI. B.}

Mngnitudo paulo infra præcedentes \& ftatura breviffima. Caput craffus, roftro obtufiore, quam in $\mathrm{M}$. arenario, fere ut in M. phæo. Myjtaces capite breviores, tenues, creberrimi. Labia craffa, finu oris laxo, facculis buccarum refpondente. Dentes primores lutefcentes. 
Oculi majufculi, marginibus palpebrarum fufcis. Aures ovales, plicatiles, vellere longiores, cano - fubpubefcentes, flaccidiores, quam in M. arcnario, magisque membranaceæ.

Truncus breviffimus. Artus humiles, robuftiores fere quam in M. phæo. Pedes extremi, etiam magis fubtus villoro - pubefcentes. Palmce tetradactylæ, rudimento pollicis murico. Calli fub pedibus villo denifflimo, quo folcæ veftiuntur, latentes.

Cauda brevifima, teretiufcula, crafta, obtufa, pilofa.

Vellus molle, tenerum, fatis altum. Color fupra gryfeo - cinereus, ftriga nigra, a nucha ad caudam fere ducta; latera areis (ut in Criceto) fubintrantibus albis, defuper fufco cinctis \& intervallatis, quarum prior ab auribus ad fcapulas flexuofa, altera anguftior pone humeros, hinc triangularis ante femora, inter quæ \& caudau itidem arcolæ intercedunt albæ. Subtus omnia, pedesque toti \& apex caudæ candida.

\section{E N S V R A E.}

Adulti pondus paulo ultra quinque drachmas, vel $\mathrm{V}$. cun dimidio, effe folet.

Lungitudo tota a nafo ad anums

- capitis ad nucinam

- cauda exfuperantium vix

Diftantia oculi a nafo

- auris ab oculo

Palpcbrarum fiffura

- apertura

Longitudo auris a bafi externa - . - ad verticem

Circumferentia roftri pone myftaces

- capitis per buccas pienas poft oculos

$M \mathrm{~m}_{2}$

3.11 0.111

I. 1 .

o. $4 \frac{\pi}{2}$.

o. $\frac{\mathrm{T}}{3}$.

o. $4 \frac{1}{2}$.

O. $2 \frac{2}{3}$.

o. 2 .

o. $1 \frac{x}{2}$.

o. $6 \frac{\pi}{5}$.

a. 5 .

I. 0 .

1. 9. 
Circumferentia colli cum buccis plenis

- thoracis ad armos \& medio

- adominis ad femora

Longitudo femoris

- tibix

- planta paulo ultra

- humeri

- antibrachii

- palma

\section{A $\mathrm{N}$ A $\mathrm{T}$ O $\mathrm{M}$. $\mathrm{E}$.}

Tab. XV 11. fig. 29. -3 .

Folliculi buccarum pollicis craflitie \& longitudine. Glandula fuborbiculata, mole lenticulæ minutæ, ad bafin folliculi. Glandulce larga circa collum \& fub armis. Glandula exigua ad finum umbilici.

Hepar (fig. 29.) quinquelobum, craffum. Lobus finifer irregulariter femiorbiculatus; portio media craffior, biloba, dexter lobus ovalis, craflus, gibbus; dexterrimus triquetro lunatus, reni circumjectus, ad cujus bafin fubtus papillaris compreffus.

Ventriculus (fig. 30.) bilocularis, fundo inftar cœci producto, longifimo, cylindrico. Inteftimum tenue pollicum undecim cum quadrante. Cacum fimplicifimum (fig. 3I.) cylindricum obtufum; fpirale vix intortum, totaque craffi longitudo $\mathrm{ab}$ infertione ilei, ad anum IV $\frac{\mathrm{I}}{2}$ pollicum.

Cor mole ciceris. Pulmones tres diftincti: dexter trilobus, medius fpinalis, fimplex, triqueter, inter cor \& dorfum; finifter integerrimus.

Coftarmm XII. paria. Vertebra lumbares VI. facri III. caudæ $\mathrm{X}$.

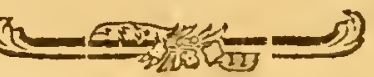




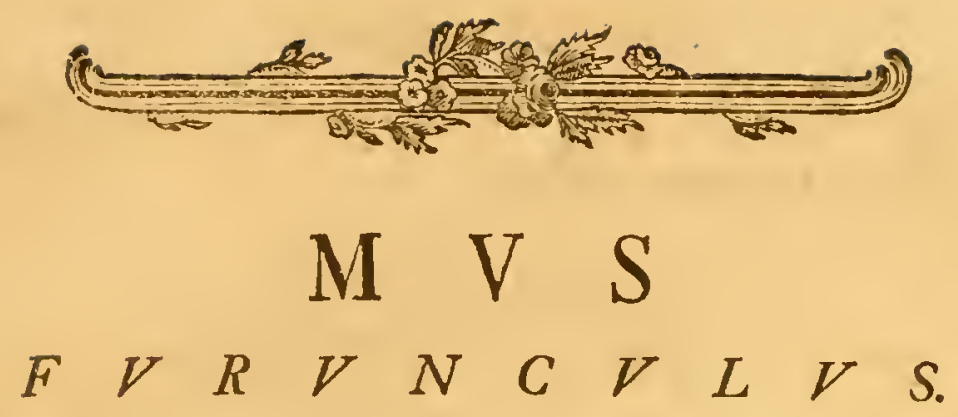

Sequens defcriptio ad recentia fpecimina parari non potuit, quum me abfente fuerint effarcta. Primus hujus fpeciei obfervatus fuit autumno in arenofa regione Barabenfium cam. porum, inter Barnaul \& Kafmala rivos, verfus Obum. Dein alios Studiofus legit in montanis campis inter Ononem \& Arguvum, circa Lacum Melaffatu. Fecit ejus quoque mentionem MESSERSCHMIDIvS ${ }^{*}$ ), qui hunc Murem. in campis circa Dalaï Lacum Dauuriæ fero \& frigido autumno obfervavit. De moribus nihil habeo, quod dicam, quum fpecimina tria, quæ habui, curfitantia in campis capta fuerint. Eft autem diftinctiflima fpecies, quæ forma proxime ad $M$. arenarium ftabit, fed minor eft \& colore, gryfeo in lutelcentem feu ci-

*) Hodegetici MSti ann. 1724. Sep. tembr. "Furunculus myodes, vix Mure " domeftico major, cauda brevifima, "vix 2 poll. decimales longa; penta"dactylus, bucca utrinque avellanæ in "molem fufflata, reminibusq̣ne Aftragali, "Átriplicis, aliisque minoribus farcta; , coloris in cinereo - rufi, ductu fpinali „nigro, prona facie tota albida, leviter "cinerafcente. Circa Dalai Nor. Mafcu"Ius drachmarum 1ll. cum gr. X. alius "drachm. 1II. cum fcrupulo... - Idem messerscha, in Xemio Ifilt. Sibir.
MSto n. 320. hre: "Furunculus myo. "des, Orochzo/ach Mungulo - Dauris, "(eine Ham/ermaus) facie \& pelle mu„rina, bucca utrinque avellanæ capaci, "pedibus ubique pentadactylis, cauda ve"luti præmorfa, anurinos," quod de alia forte, mihi obfcura fpecie intelligendum. Specimen vero MESSERSCHMIIT Mufeo Petropolitano illatum, quod in Catalogo ejusdem vol. 1. p. 343. n. 100 . recenfetar, nomine "Furunculi myodis Orochtfchofchach Mungalis MESSER. „, $\mathrm{C}$ H M., dudum periit.

M $\mathrm{m} 3_{3}$ 
nereum vergente, \& ftriga dorfali, caudaque inter omnes affines buccatos longiore, differt.

\section{DESCRIPTIO \\ $M V R I S F V R V N C V L I$. \\ Tub. $X V . B$.}

Facies Muris arenarii, quo minor. Caplat roftro itiatem acutiufculo. Dentes primores anguft, fuperiores fulvi, infericres flavefcentes. Myjtaces capite longiores, fufci albidique.

Oculi proportione majufculi. Alires majufcula, ovales, nudiufcule, verfus ambitum nigricante pubefcentes, ipfa ora terminali alba.

Statura oblongior pracedentibus. Palmce verruca pollicari unguiculato - obtufa. Circa carpi \& calcis articulum cólor gryfeo fufcus, faturatior quam in reliquo corpore, in barabenfi varietate; in daurica vix calcis articulus fufcefcit, antici pedes toti albi.

Canda paulo longior, quam in prioribus cunctis, adtenuata, alba, tractu fupra nigricante.

Vellhis tenerum, molle. Color fupra totus lutefcente gryfeus, in barabenfi magis lutefcens \& obfcurus; verfus latera fenfim pallidus; fubtus fordide albus, at in daurico imis lateribus, genis \& fubtus candidior. Striga nigra ab occipite per. fpinam longitudinalis, ad caudam tamen non perducta.

\section{MEN S V R A E.}

In exuviis, longitudo tota $3 . "$ 4." Caput I." Aures- 6."' Cauda 10 - I1" Plantæ 83."." xquarunt. 


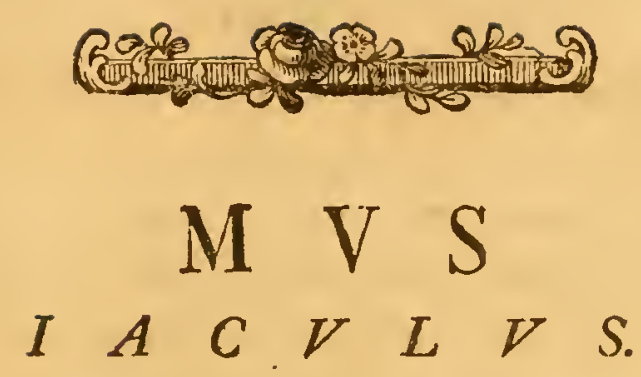

Ieres bipedes antiquorum, quos hac \& fequente Monographia defcribo, in fuo genere æque infolita forma funt præditi ac inter Lemlthres - illa fpecies $\left.{ }^{a}\right)^{j}$, quam -BVFFonivs perperam Muribus bipedibus affinem perhibet, Illius-

a) Le Tarfier в V F F o v, hijl. val. $X I I I$ : p. 87. edit. min. $X X V 1$. p. 116. tab.g. I, INNAEO intacta fpecies, atque Lemur-Spettrum aptifime appellanda. Quum plura rarifini hujus animalis fpecimina in lectiflino Mufeo Anici defunati SCHLOSSER I quond:Im examinaverim, non inıtile videbitus, fi refero quæ tunc adiotavi. Et quidem primum patriam, qua B VFFONIVM latuit, moneo effe extremas infulas Oceani indici, profertim Amboynam, unde nonnifi parce in B.lgarum Mulixa venit, \& ubi nomine Macaflarienfibus ufitato Podje notum eft. Dentes deinde paulo aliter, quam a D'Ay. BENTONo enumerantur, defcripfi: Pri. mores nempe fupra infraque tantum binos, majufculos, obtufos; hinc Caninos primarios fupres a primoribus, quibus vi:s longiores, remotos; infre magnos, primoribus approximatos; tum laniarios fecundarios minores nbique binos, quorum fupra anteriores minores. Habitu toto, demta cauda, proximus eft Lemuri tardigrado, itidem in fiso genere anomalo, nec tamen facile feparando. $V$ ub. tus roftro minus elongatus, quam in $\mathrm{L}$. tardo, nafusque latior; labiun inferius interne crenulatum; pili longiufculi in myttace \& fupercilis. Ois/i valde protuberantes, \& nifi fallor, nocturnæ vit'æ deftinati. Aures magnæ, oblongæ, nudx, fufcæ, exteriore margine verfus bafin quafi navicula duplica. tæ, interne rugis fupra tragum albidum tribus transverfis, quarum infima in lobulum feu lamellam produeta. Palmarum digiti proportione ut in manu humana; pollex non divaricatus. At in plant is pollex remotiflimus, longus, robuftus, apicis tuberculo magno, ungue minuto; Digiti duo pollici proximi eo. dem fere breviores, unguibus longioribus, falcatis diftincti; tertius longifimus, cum breviore quarto, ungue, ut in palmis, minuno, plano, fubacuminato inftructi. - Strultura tota etiam dentibus, conneetit Lemurum atque Didel. phidum genera in naturali ordine maxime vicina. - Cauda nudiufcula. Penis in medio ventre fubexfertus. 
que exemplo Cel. PENNANT.Yerboam indicam appellavit (Jymopf. 298.); vel ut inter Didelpbides - Kanguru dictum aufrale monftrum, quod fimili vitio Yerboam giganteam appellavit Amiciff. zimermanN (Zool. geogr.p. 526.). Quemadmodum vero hæc animalia ad naturalia genera facile reducuntur, nec ob folam crurum pofticorum longitudinem ab iisdem fegregari polfunt, ita Mures bipedes neftri adhuc magis per M. longipedem \& Tamaricinum, quos deinde proponam, cum reliquo genere Murino catenatim cohærent, neque poffunt genus diftinctum cfficere, fed ad fummum fingularem Murini generis pbalangem, quam nuper novo ex auntrali Africa adlato tyrone, magnitudine inter Mures bipedes eminente, auxit Cel. alramand in Supplem. ad Buffoniani operis edit. Amftelodamenfem.

Mures falii noftri (Iacullus \& Sagitta) toties jam ab Auctoribus obfervati \& traducti fint, ut mirum fit naturalem hiftoriam eorum adhuc in cunis effe, immo ne quidem certo, ante meas obfervationes, conftitiffe unius pluriumve fpecierum effent. Qui BVFFonil de iis collectanea evolvat '), incertitudincm circa notitiam animalculorum, qux toties ex Oriente inEuropam etiam viva adlata, toties ab itineratoribus vifa fcriptaque funt, potius anctam mecum mirabitur. Certiora hic tandem ex obfervationibus propriis traditurus \& animalculorum lepidifimorum mores illuftraturus, primum qua apud auctores promifcue ad utramque noftram fpeciem pertinent, exponere debeo.

Iam antiquitas, in parvis haud curiofa, hæc tamen animalcula fingularia mirata eft. Fecit Murium bipedum mentio. nem

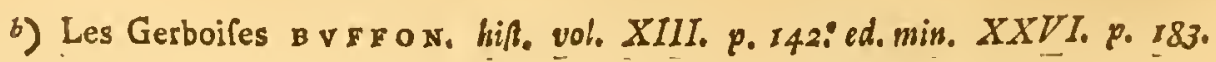


nem HERODOTVS '); egit de iis fufus \& duobus locis ARISTOTLLes ${ }^{d}$ ); differtius vero \& fufius, e THEOPIRASTO autopta, ut facile apparet, AELianvs (cripfit $\left.{ }^{e}\right)$. Ex iftis in farraginem fuam PLINIVS horum animalculorum mentionem, fed vitiofam, ingefit. Etenim e male intellecto ARistoteurs loco primum (Lib. X. cap. 65. Hift. natur.) fcripfit: "Aegyptiis muribus durum, ut herinaceis effe pilum, eosderts"que bipedes ambulare, ceu alpinos." l'bi etiam minus apte vifis conferens non vira, ideam animalis corrupit, quod non Marmota inftar refidere in clunes, fed duobus pedibus ambulare, priores recte dixerant. Eademque perfuafione ( $\mathrm{Lib}$. VIII. cap. 37.) pofuit: "Effe pares (Muribus alpinis) \& ", in Aegypto, fimiliterque refidere in clunes \& binis pedibus "ingredi, prioribus ut manibus uti., In quo non magis accu-

c) "Apud Afros r. Pœnos paftorales, " in Africa, orientem verfus, tria murium ", genera funt, quorum alii bipedes vo. "cantur, alii Zegeries pusica lingur, "quod in noftra pollet idem quod colles "(Brvo'), alii echines." IIERODOT. Hic fecundam rpeciem crediderim effe fubterraneam, colles egerentem, eam forte ipfam, quam nomine $M$. capenfis defcripfi, quaque verofimillime totius Africæ arenas colit; per Echines vero Hyftrices indigitari.

d) Primum de hit. sitim. Lib. VI. cap. "36. "Aegypitis muribus prædurus, pae. , ne ut herinaceis pilus elt. Sunt \& "alii qui ereti, bipedes ambulant; ha "bent enim crura pofteriora longa, prio"ra brevia., Deinde videtur de laculis intelligendus elle locus corruptus 'Ejus- "dem Operis Lib. VIII. c. 28. In Ara. „bia - - Mures etiam multo Soricibus ", autiores, quibus crura priora vel fpi"thamx menfura, pofleriora ad prinum "digiti nodum habentur. "Ubi vel vitium relatoris, vel librariorum errorem \& tranfpofitionem fubeffe, atque pro pri. oribus pedibus, pofticos \& vice verfa, legendum quis non videt.

C) AELIA N de animal. Lib. XV.cap. "^6. $\varepsilon$ verf. Gyll. In Aegypto audio bi. "pedes Mures maxima magnitudine efic, „, \& prioribus pedibus tanquam manibus "uti; eos enim breviores effe pofterioribus. „Hos videre memini; Lybici funt. ReEti , duobus pedibus gradiuntur, quum autem "infequentibus urgentur, faliunt. Hæc "T THEOPIIRASTVS prodidit., 
rate Mures bipedes Marmotis, atque has Melibus comparaffe PLINIVS dicendius eft.

Bocbartus (Hierozoic. Lib. III. cap. 33.) qui animal variis Scipture facra locis, fub nomine Sapban, inter Ruminantia quæ non habent bifidam ungulan recenfitum, per Murem Iaculum interpretari amavit, multus fuit in exponendis Auctorum Arabum locis, qui Iaculi (feu Aljarbun, ut ipfis appellatur) mentionem fecerunt ${ }^{f}$ ). Fateor autem profunda eruditionis Virum in hoc, quod evincere voluit, mihi non fa. latisfeciffe, neque argumenta, quibus priorum, Supbin biblicum per Lepores, Cuniculosve aut etiam Erinaceos explicantium, opiniones infirmat, omnia fatis valida videri. Magis verofimile accipio, animalis Saphan fynonymon effe $A l$ - Webro vel (ut inter dubia animalia ForsK ${ }_{A}^{\circ} \mathrm{LEVs}$ in poftbumis fcripfit) Uabr arabum; quod fi concedatur, minime dubito fub his nominibus Caviam noftram capenfen (Spicil. Zool.

f) $\mathrm{Ex}$ his aptifime DAMIR, cujus excerptum huc referri meretur: "Vocari ,etiam Dirs \& Duromchi i. e. haftatum, "nempe pro halta caudam habere, fimilem "caudre muris, quam furfum tollit, \& in ",cujus extremo eft floris fpecies; colo. „rem vero fimilem Gazella.," Porro de moribus animalculi veriffime (ut in (ra di. cemas) docet idem: "Aljarbuo parare 12. „tibulum fuum difpergendo terram, \& , domum fibi fodere ad flatus quatuor "ventorum. eamque feneftris inftruere, "quarum una Arabibus vocatur naphica, , alia kafia \& rohita; a quibus fi impe. , tatur exire per naphicam, \& fi a na "phica impetantur exire per kafiam; ant "per ralitam fi a kafia." Et quidem naphica (illuftrante BOCIARTO) hic dicitur latibuli foramen terra obtectum, quod \& metaphoris apud Arabes originem dedit. - Nec minus apte A L C A Mv S (eocem citante):, Damama, latibulum "Aljarbuo, \& terra quam colligit \& e "latibulo fuo effodit, ut ea complanet ", ejus aditım." Neque plane improbanda quae ex IBNOLGIAVZI adlata funt: "Aljarbuo domum non parat, nifi loco "duro \& fublimi, nt ah aquis \& ungula „tnta fit; nec eatr ftatuit nifi in tumulis "\& arboribus, aut petris, ne, cum ad „illam redit, aberrct., Quod tamen. utique fugienti fiepe accidit, nec folis catulis, a quibus apud D A I REM proverbium (Catulo Aljarbui magis errat) defumtum. 
Fafc. II. p. I6.) effe intelligendam, quam in boreali Africa $\&$ contermina Afia pariter dari cranium ejusdem in Sidonis antiquæ ruinis repertum (apud $I l l$. в vFFONivm bift. nat. $X V$. p. 205.) probat, \& in quam optime quadrant восиARTo citata graviari ${ }^{g}$ ) verba, domiciliumque Sepbanim in Pfalterio. 104. \& Proverbiorlin cap. 30. inter petras affignatum. Neque repugnat, immo fententiam meam confirmat potius interpretatio vocis Acbbar apud iesaïam cap. 66. per Arabicam confonam (Acbbar vel Alacbbar) marem Aljarbui defignantem ${ }^{h}$ ), ubi nomine Sapban non fuife ufum prophetam fic facile explicabimus.

Inter Europæos noftros poft reftitutas fcientias primus Ia. culi mentionem fecit ALDROVANDVs (de quadr. digit. lib. II. p. 396.) ubi fub "Cuniculi feu Leporis Indici, Utias "dicti, titulo icon Iaculi veri (plantis pentadactylis) ligno in. cifa, extat, acuratior quam recentiorum multæ, præfertim utriusque GMELINI icones, nifi quod auribus pro hac fpecie jufto brevioribus expreffa fit. - Longo poft Aldrovandum intervallo orearivs (itin. perfic. Lib. VI. p. 64.) eandem fpeciem majori ftatura ad Terekum vidit breviterque indicavit. Dein Cornel. de bRVYN alteram fpeciem, quam nomine $M$. Sagittæ poftea exponam, quamque e Getulia adlatam Venetiis fub nomine Gerbo in donum acceperat, fatis accurate depinxit (Reize door Klein - Afie, Delft. 1698. fol. p. 396. 12. 2 10.). - Neque plus præftitir Panl. Lvcas, qui ejusdem fpeciei bigam ex Aegypto vivas in Galliam retulit, ubi in aula regia biennio vixere (Voyage du S. $P$. Lucas dans la

g) "Alwebro eft animalculum fele mi"nus, fufci coloris, fine casde, cet. h) Achbar Mas Aljarbui, Alatjuda foemina apad Arabes audit. в о CHART. $\mathrm{N} \cap 2$ 
Grèce, cet. Paris. I7I2. 8. tom. II. p. 73.). Immo alii quoque complures itineratores, Zooliggos haud doctiores reddidere; ut TEXEIRA, qui chimæræ inftar M. Sagittam defcripfit; vel nievhofivs (Legat. batav. Part. II. p. 23.) qui Mures Chinenfibus circulatoribus faltare doctos, verofimillime Iaculos, adtigit; quorum etiam fit mentio aput E. Y șBRAND IDES (ith. chin. ed. belg. p. I 04.); vei denique STRALENBERGIVS, qui folus Iaculum Leporis volantis nomine produxit, \& pereira (apud witsen Nord - en Ooft - Tatat. Ed. II. vol. I. p. 200.) Cui Chinenfum Imperator nocturna ad illuftrem lunam venatione Cuniculorum longis cruribus falientium, quos sinice Tbeáo - Tu dicit appellari, delectari vifus eft.

Curiofus \& utramque, ut videtur, noftram fpeciem infpexit Accuratiff. sin wivs. Primum enim (itiner. verf. Gall.vol. I. p.32I.) Murem Sagittam fub Verbôce nomine in omni Mauritania, ad Oran ufque, nunquam in faxofis, fed in argillofis præfertim campis \& imprimis in arenis Saharæ, ubi arundines, laurcolam, aliasque ejus regionis plantas amat, frequentem \& Nomadibus edulem obfervavit, fatisque accurate defcripfit, nifi quod memorix (ut videtur) lapfu, Ariftotelicæ quam (mot. d.) citavimus tranfpofitioni finili, pedes anticos tridafiylos, loco poficomum poluit. Deinde (Vol. II.p.75.) circa Libanum mentionem facit animalculi lerbox prefertim crüribus prælongis fmillimi, in terra; fed plerumque inter rupes latentis, \& cuniculum xquantis, quod Daman Ifraël (Agnus Ifraël) Arabibus appellatur, $\&$, apud Profp. A I.pinvm (hiff: mat. egypt. lib. 4. cap. 9.) pariter commemoratum, haud dubiæe magna (de qua dicendum erit) Iaculi varietas videtur, 
quam tamen pro Bibliorum Sapban habendam effe minime confentiam.

Iaculi deinde medioris ftaturæ icones reliquis auctorum, quæ extant omnibus præftantiores, fedente in pofticis atque in anticos pedes demiffo corporis fitu, triplices dedic Nic. Franc: наум in Thefauro britannico (Edit. ital. vol. II. p. I 24. verf. latin. p. I 49. tab. I7.) Is vivum a Doctifinno sHERARDo animal habuit, cum aliis curiofis e Syria transmiflum, variaque circa indolem ejus adnotavit. Primis tribus integris menfibus, dum folis amygdalis, piftaciis, granisque alebatur, fine omni potu vixiffe, multum tamen urinæ reddidiffe vidit. Dein didicit etiam pomis, carotis, rapa \& herbis præfertim fatuis, fpinacia, lactuca, urtica, ut \& pane faccharato vefci; recufare autem rutam, mentham, thymum, aliasque odoratas, itemque cafeum \& lacticinia omnia. Oblatam aquam interdum avide haurire vifum eft, at non omni tempore. Maxime videbatur amare cannabis femen, \& arenæ impofitum multum ejus ingurgitabat, ut etiam inde gravius factun videretur. Cæterum erat manfuetiffimum, nec odore incommodum. Si воснarto, Saphan biblicum huic animali applicanti minus recte afferfus eft HAYMIVs, felicius videtur explicaffe HERODOTI locum ${ }^{i}$ ) per nummum aureum cyrenaicum, in quo diftincta expreffa eft Iaculi effigies ad radicem Silphii antiquorum fedentis, quod genus plantæ in $\mathrm{Cy}$ renaica regione abundans, in nummis Iovis Ammonis crebro occurrit.

i) In Melpomene cap. 9z. "Sunt "Tarteffiacis fimillimae,", „ præterea muftelæ, in Silphio nafcuntur, 
Ejusdem pentadacyle fpeciei, in Mongolix confinis; ubi alia nulla datur, obfervatæ infufficientem defcriptionem reliquit r. g. gmelin (Nov. Comm. Petr.vol. $N \cdot p \cdot 35 \mathrm{I}$. cum icone tab. XI. fig. I. pefima, fitu corporis coacto peccante publicatam), in co præfertim vitiofam, quod animalculo perperam Cuniculis adnumerato ${ }^{k}$ ) pedes pofticos tantum tetradactylos tribuat, referatque in hiftoria morum animalis, acervos feni, quos Lepori Ogotonæ in hyemalem commeatum Servire docui, ab hocce animalculo congeftari, ab codemque campos ononenfes fubrui \& equitantibus periculofos reddi, quod Muri œconomo \& caftrenfi potius iebetur. - Delcripferat eandem fpeciem rectius \& fure (ut folebat) MESSERSCHMIDIvs in Hodegetico fub Alak - dágce Mongolo - dauuricx, feu Abalák Indorum nomine; ea vero defcriptio nunquam lucem vidit, mihi in manufcripto codice perlecta. - Nuperrime etiam pentadactylum Iaculum defcripfit \& peffima item icone expofuit Sam. Gotl. gmelin (itinerar. Vol I. p. 26. tab. 2.) ubi obfervationes circa mores e pofthumis, ut videtur, avunculi fchedis excerptas, etian hallucinationibus ejusdem oneravit illa præfertim, quam Is circa foni, quos dixi, acervos commiferat, cciam in Florce Sibiricce, Vol. III. p. I 5. repetita.

Contra Murem Sagittam noftum poftice tridaftylum ex profeflo defcripfic HASSELQVist (ACtor. bolmienf. vol. $X I V$. verf. german. p. I 29. \& in Itinerar. palaft. verf. german. 277.) eamque folam fpeciem \& nondum adultam

1) Appellatur illi: "Cuniculus pumilio "faliens, cauda longifima,, Ibid. \& in "Mis. Petropol. Vol. I. p. 344.: jt, 123.
?) Pofuit magnitudinem infra Rattum; longitudinem capitis I poll. corporis $2 \frac{T}{2}$ poll. pedum pofticorum $3 \frac{\pi}{2}$ pollicum. 
ex unico plane fpecimine noviffe videtur, cujus adumbrationem diffufam fatis \& fuperfluam, iconem vero malam dedit, \& de moribus animalis admodum pauca docuit. Id folum ex ejus adnotatione difcinus, animal, preter triticum \& panem, etiam Sefami femina pariter oleofa amare; interdiu dormire \& in fomno fudare; circaque pyramides Aegypti \& verfus Arabiam maxime abundare.

Dedit hujus quoque fpeciei figuram non optimam, licet pictam ad vivum in Angliam adlatum animalculum, EDWARDSivs (av. tab. 2I9.) \& recte pedes porticos tantum tridactylos effe affirmavit. Meliorem iconem cum fida defcriptione nu. perrime Cel. pennantrs edidit (Syn. quadr. p. 295.tab. 25.f.3.) qui viva pariter fpecimina Londinum adlata fub oculis habuit, \& Zonam uropygii fufco - albam ab Edwardfio nimis argute expreffam, in fuis non videns, variet atem fubeffe credidit.

Ipre BVFFoN Ivs Murium faliorum notitiam e variis aucto. ribus tantum corrafit \& nihil novi addidit, quam quod, e GMELINI vitiofa defcriptione pedum, Iaculum fibiricum pæne fpecie diftinguendum putaverit (loc. cit. p. I 84.); Damin SHAWII contra cum $M$. longipede LINNAEI confundens, \& item male, ut fupra indicatum eft, Lemurem Spectrum (not. a.) in cognationem horum murium deducens (l. p.c. I 83.).

Poffum Zoologos Syftematicos ficco fere pede tranfire, quum nihil proprii habent. Etenim KLEINIVS \& BRISSONivs Mures falios plane prætermiferunt, tantum pofterioris Epitomator (Cel. allamand) e gMELINo Iaculi fibirici noti. 
tiam inferuit " ) LINNAEvs autem auctorum fynonyma omnia commixta ad unam fuam M. Iaculi fpeciem retulit.

Iam ex ipfo Naturæ codice edoceamur. - Murium faliorum in defertis mmediæ $\Lambda$ fiæduæ obfervantur fpecies abinvice diftinctiffmæ. Ex his altera, quam indicavi, DEBRVYN, LVCAS, SHAW, EDWARDS \& PENNANT haben`, fequenti Monographia fub M. Sagittae nomine defcribetur. - Altera, de qua hic dicendum eft, mihi fub triplici ftaturae varietate innotuit. Vulgatior magnitudo ea, quam ALDRoVANDVs, HAXMIVS, G MELINvs fen. delinearunt, quæque per Tatariam orientaliorem; Sibirixque deferta frequens eft \& in transbaikalenfibus regionibus fola datur. - Occurrit vero in collinis herbidis ad Tanaïn, - Volgam, Rhymnum \&Irin gigantea altera varietas, ubique tamen rarior, quam GMELINVs jull. indigitavit nec fatis magnam depinxit, \& quampropter proximam Cuniculo ftaturam Daman Ifraël A L P IN I atque sllAwI videri fupra monui. - Denique in auftralibus falfis verfus Marc- Cafpium, circa inferiorem Volgam atque Rhymnum, priori loco fimul cum gigantea, pofteriore cum media varietate, frequens datur tertia quædam familia pygman, majoribus tota facie, aurum pofteriorumque artuum infigni. longitudine, fimillima, tantum difcrepans halone circa nafum albo - fufco deficiente, caudaque (haud magis tereti) apice minus longe pennata, vix fummitate alba; cæterum fere fextuplo minor \& M. Sagittam non equans, licet primo verc sapta offium perfecta foliditate adultam xtatem haud dubic probet, dum contra e giganteis nonnulli omnia offa adhuc epiphyfibus in-

ii) Cuniculus cauda longiffima BRISSON. quadr, epit. $8^{\circ} \cdot$ p. zo3. 
inftructa exhibuerunt. Tres iftæ ftatura valde difcordantes varietates, quarum prior etiam aliis characteribus abludit, quas tamen fpecie diftinguere haud poffum, plantis pentadactylis conItantifime, uti colore \& plerisque forma internæque ftructuræ requifitis inter fe conveniunt \& a M. Sagitta, femper tridactylo, multis notis deinde exponendis differunt. Nulla datur (ad GMELINi $\int e n$. mentem) plantis tetradactyla varictas, quam in Transbaïkalenfibus, ubi uitra quadraginta medix varietatis animalcula, Mongolis procurantibus, meis manibus tractavi, faltem femel obfervare debuiffem. Neque messerschmidivs ejusmodi quidquam vidit. - In omnibus ceteroquin varictatibus iftis mores \& color eadem.

Mediocris ftaturæ Iaculi, ut funt copiofinimi maximaque terrarum fpatia occupant, imo in quibusdam regionibus, prafertim ultra Baikalem, \& totam forte per Mongoliam defertam foli reperiuntur, ita pro ftirpe primigenia haberi poffe videbuntur. Fateor tamen bos, ut e particulari defcriptione perfpici poterit, proportione aurium artuumque, forma capitis, craffitic \& rotunditate caudx, quibus omnibus potius M. Sagittam referunt, ita differre a grandibus \& pygmais, deferti tatarici Iaculis, ut eos fere pro diftincta vel hybrida fpecie declaraffem, quum tantæ \& tan conftantes differentix vix a climate aliisve accidentalibus caufis produci poffe videantur. Sed debuiffet tunc eciam pygmæa a gigantea varietate, licet forma fimillima, ob nimiam molis differentiam, fegregari.

Proxima ad occidentem noftrum regio, ubi vivunt Iaculi, defertum eft Crimenfe, vel Cherfonefo Taurica finitimum ");

") Vid MüLxER Sambl. ruff. Gefch. vol. IX, p. 43. e relatione IVNKERT. 
ultima ad orientem patria funt campi Argunum \& Ononem interjacentes. Ad boream non facilc LIII tium gradum in latitudinem egrediuntur; auftrum vero verfus haud nifi Tropici limites agnofcunt. Dantur ufque ad Indiam, inque planis fubmontanis Hyrcanix; dantur iidem in Syria, unde HAYMIO adlatos effe diximus ${ }^{\circ}$ ). Nullum tamen certum invenio teftimonium in Africa reperiri, quum Auctorum, qui Mures falios in Africa obfervarunt, vel ex Africa adlatos defcripferunt, omni- um loci ad M. Sagittam pertinere videantur; prater illos itineratores, qui fpeciem non diftinxerunt ${ }^{p}$ ). Et quum $M$. Sagitta intra Afiam minus late ad aquilonem \& orientem vivat \& calidiffimas arenas amet, torridis eadem regionibus aptior; Iaculus vero, qui frigidioribus herbidisque locis vigore \& magnitudine eminet, ad ferendos Africx ardores minus difpofitus mihi videtur. Neque, fi Daman Ifraël Arabum vere Iaculi gigantea fit varietas, quod poftere obfervationes confirmabunt, aliter quam in temperatis alpeftrium Syrix \& Arabix genitam effe crediderim; quemadmodum contra in depreflis, humidis falfis calidifimis verfus $M$. Cafpium minutam varictatem produci monui.

Iaculus in omni firmiore folo cuniculatur, adcoque per omne defertum limofo - arenofum Tatarix \& Boryfthene ufque ad Obum frequens habitat, non Solum editis et ficcis in locis, circaque tumulos \& prærupta, fed etiam in depreflis falfuginofis, ubi tamen editiora loca feligit, tantoque minori profunditate fodit. Attamen in fluitantibus arenis, quas M. Sagitta

-) GMELIN. jun. itinerar. Vol. IIL. periri in Aegypto, regione Nedjed, ad p. 40. utrumque littus finus perfici, inque defer.

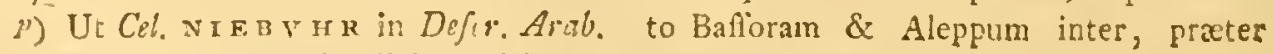
p. $16 \%$. qui Ierboam fimpliciter dicit re- alias regiones. 
amat, non xque vivit, licet in transbaikalenfum regionum arenofis, fed fimul faxofis, firmioribus, frigidulis, frequentius panc, quain ufpiam alibi occurat. Mirum fatis, quod cuniculos, adco iongis impeditum cruribus, ita prompte \& vix corpore ampliores fodiat animal. Sed fodit prefertim in molliori folo, capitc terebrans \& fuccuffibus elevans arenam, in durioribus dentium exfertorum ope comminuens \& folutam terram paimis removens, plantis retrorfum projiciens, unde ad oftium cuniculi fomper longo tractu egefta terra apparet, præfertim is locis, ubi recens domicilium fodiebat animal. Cuniculi plurium fxpe ulnarum longitudine, peroblique \& flexuofe in terram penetrant, vix ad fefquiulnam infra fuperficiem defcendunt, mido definentes capaci, ramentis herbarum mollifimis purisque farcto. Aditus plerumque fimplex, rarius ramo laterali bivius, \& interdiu oftium cum egefta terra extus apparens, in ipfo ranali arena ingefta obturatus effe folet; idque Mongolis tanquam certiffimum latentis in nido animalis indicium habctur \& me nunquam fefellit; dum contra aperti cuniculi femper deferti reperiuntur. $\Lambda$ nido plerumque exitum alium præparat animal in divcrfa tendentem, qui non in fuperfrciem oftio patet, fed integra terræ crufta claufus eft, quam animal, fi quando a folito aditu impeditur, nifu facile impellit \& faltu faluti confulit. Hoc dolo Iaculi perfæpe quærentium fere e manibus elabuntur", quod recte DAMrk Arabs, cujus locum e Bocharto (not. f.) retuli, obfervavit.

Iaculi interdiu fuis antris femper latent mirumque, animal quiod a levi frigore torpefcit \& in finu refocillancium eft, tamen diurni ardoris impatiens latere in cuniculo fomnolentum, \& oftium etiam obturare, ut in terræ frnu gelido cubili gau-

$$
\mathrm{O} \quad 0_{2}
$$


deat, noctu contra in orientalibus iegionibus fape perfrigida vagari alacrius. - In hypocaufto enutriti interdiu femper in latebrofo loco, vel nido intra carcerem congefto torpent, caput prioresque pedes conglobato ut Marmota trunco, inter femora condentes, flaccidis \& ftudio, ut videtur, in nucham circa caput complicatis (ne frigefiant) auribus \& vel clunibus infiftentes vel in latus, imo dorfum provoluti. Inquietati in fomno pofticis pedibus amovendo fefe aliqualiter defendunt. Protracti in lucem diu vix pedibus infiftunt, quafi ftupidi vel ebrii, mutique, nec aures facile vitali vigore erigunt, vixque ad faltandum excitari poffunt, carcere calidiore forfan lentiores redditi; Etenim in campis ftrepitu cuniculos fuffodientium facile ad fugam excitantur. Nocte contra tota graffantur, ciftæque inclufi afferes una fæpe nocte pollicares perrodunt, anguftis licet dentibus \& debilitate virium vix tantum valere videantur. Carcere emiff vividi \& erectis auribus procedunt, irritati manuve comprehenfi vocem catuli neonati fimilem cdunt, vel iracundo quodam ftertore fubgrunniunt, nifi qui homini jam adfueverunt. - In defertis fub occafum folis prodire folent, expurgato prius cuniculo, matutinis etiam horis donec rorem abforpfit oriens, apparent. Vifo periculo orgyalibus faltibus ftatim fugiunt, non recta, fed confufis ambagibus huc illuc fe vertentes, quo infectantes fatigant, \& cuniculum vel fuum vel alienum quodvis obvium antrum, quorfum fe fubducant, quxrunt. Sic frepe fatis diu circumfliunt, majores vix equo affequendi \& ita prompti omnes, ut continuo jaculabundos, vix cruribus terram adtigiffe credercs. Saltuum vis profertim quidem longis \& validis cruribus, ex parte tamen etiam caudic elateri debctur. Continuo nempe, 
quum bipedes ftant \& gradiuntur, cauda figmoïdeo flexu (ut Tabula noftra expreffum eft) curvata terre infiftunt; eadem exfilientes terram feriunt \& in ipfo laltu gubernaculi infar utuntur, ut faltus directionem mutent. Quantumvis alte \& fublata manu in terram projecti femper, æquilibrio caudæ in rectum protenfe \& fubremigantis, in pofticos pedes decidunt. Et licet impetu ruentes in anticos quoque pedes fefe fubinde excipere cogantur; ftatim tamen in crura denuo erigunt corpus. Quum nihil timent, modo Leporis inftar quadrupedes ambulant, alternatim in crura eriguntur, lepide circumfpiciunt, ftrictis auribus aufcultabundi; modo corvi inftar contractis brachiolis bipedes faltitant. Fodientes vel cibum colligentes in palmas fe demittunt, arreptas vero offas in palmas accipiunt \& erecti comedunt.

Cicurantur etiam adulti celerrime. Amant in finu foveri, femperque calidiorem angulum quærunt. Si frigidis dicbus vernis vcl autumnalibus fine tegmine nocturno exponantur aëri, facile \& plane obtorpefcunt, præfertim minores \& juniores, ut pro mortuis fepe habuerim \& fecaverim, nondum expertus in finu refocillari poffe. Præfentiunt etiam frigus \& pluviam tempeftatem, tumque maxime ftuppa fe involvunt, \& qui in campis funt curatius antra obturant; ficca tamen, fed nubila tempeftate, interdiu quoque vigilant \& extra antra verfantur, etiam in campis. - Sine terra anguftiore loco inclufi cito fiunt languidi \& confpurcantur toti; addita vero terra vel arena quafi e morbo convalefcunt, lætiores, agiliores, \& puritati velleris tunc magis ftudent, palmis os frpe curant, palmaque altera alterius brachii fordes lepidifine detergunt.

\section{$\begin{array}{llllllllllll}0 & 0 & 3\end{array}$}


Aluntur facile vegetabilibus fucculentis, variis, braffica; carotis, pane. E Citrullis oblatis noctu parenchyma totum, per unicam aperturam, fcite excavant, relicto cortice \& fcminibus, quod $\&$ in hortis, quibus hi fructus cum Melonibus coluntur, fape facere folcnt. Potum fic nullum requirunt, quum $c x$ alimentis humoris tantum capiant, ut etiam urinam copiofam (ad aliquot quotidic uncias) mittere pofint; quam tamen fepius lambentes vidi. Crudam etiam carnem appetunt \& avicularum vifcera herbis praferunt. Selengix, ubi multos uno carcere inclufos fervabam, omni fere mane (licet amice inter ie vivere viderentur') faltem unum mortuum exefis oculis \& cerc. bro, cranio per orbitas exinanito, offendebam. Mongolis atque Buratis fama fertur Iaculos noctu ad ovillas greges accedere \& ovium ubera fugere; in quo id certe veri eft, quod noctu lubenter inter greges lanatas verfari foleant, quas faltibus fipe difturbant \& perterrefaciunt.

In defertis occidentalibus ea prafertim loca colunt, quæ Tuliparum proventui vario favent, quarum ibi bulbis cffofis vefcuntur. Oleraceis tamen herbis defertorum, Chenopodis, Atriplicibus, Salfolis quoque \& Salicornis precipue vivunt, $\mathbb{E}$ a falfo forte pabulo minori ftatura nafeuntur. In regione transbaïkalcnfi, ubi conftanti \& media magnitudine ommes efle dixi, Iilii pomponii maxime buibis vivunt, quibus ibi vulgo inclufos alebam. Robiniz caragane etiam virgulta campeftria, inter que in arenofis lubenter verfantur, rodunt.

Invicen non folum feris minoribus fed hominibus quoque efcam prebert. Non folum enim ab Arabibus, quibus 
aliorum murium efus interdictus, Iaculi conceftus eft, comeduntur, immo in deliciis funt, ut etiam Iaculun in latibuls vendendi inter illos mos, \& quia hoc fepiffime fruftra foditur proverbium inde ortum fit ${ }^{7}$ ), carnesque ficcari foleant; fed ctiam Calmucci, Tatari paftorales \& Mongoli hujus offæ funt appetentes; atque pofteriorum præfertin pucri in capiendis Ia. culis funt exercicatiffini. Non folum enim antra dexterrime rimari \& deferta ab occupatis difcernere callent, ut vel fodi. endo, vel infufa aqua preda potiantur; fed etiam exfilientem Iaculum congregati plures objectis undique perticis impediunt, ut vix evadat unquam. Pellis tamen tenuiffima \& male veftita inutilis plane eft, folæque carnes requiruntur.

Nomen Mongolis pro Iaculo ufitatum Aluk-daagha (fic enim fribendum eft) neque messerschmidivs, nec BVFFonivs, qui in ignota fibi lingua Etymologum egit, recte interpretati funt. Prior per animal greffu mancum explicavit; BVFFONIVS, nefcio quam inter nomen Sciuri volantis rufficum (Ljetaga) \& Mongolicum Iaculi affinitatem quærens, Melferfchrnidium noftrum corrigere voluit \& "animal volans, fignificari ratus eft. Alak autem Mongolica lingua variegatum, Daagha pullum equinum defignat, ut fignificatio nominis Alak - dangha prodeat: Equulus variegatus. - Caimucci nomen Ialma impofuerunt Iaculo, magnam autem varietatem Morin - Ialna (equinum Iaculum), minorem Choin - Ialma

q) "Ut qui pro Aljarbuo emit foramen exitum animalis aufcultando, donec exejus, B OCHART. Modum Arabum la- agitatum eo refugiat, refert Panl. IV. culos capiendi ad claufum cuniculum poft cAs 1 . c. 
(ovinum) appellarunt. Bafchkiris pariter \& Kigifotataris Ialman f. Dfbjalman - Koirok audit. Runi vulgo Lepufculum terreftrem (Semlanoi Saëz) ad Iaikum Tufcbkantfcbik (Lepufculum), mediocrem vero varictatem fpeciatim Iemísrantfchik vocant.

- Videntur in calidis pluries durante xftate parere. In trans - baikalenfi regione, ubi vix Majo ver tepefcit, quæque omnium quas colunt Iaculi frigidifima eft regio, primis demum Iunii diebus pullos adlatos habui, jam aliquot, uncias æquantes, licet adhuc cœesos. In Cafpico deferto jam initio Maji pariunt, \& denuo Septembri medio circa Iä̈cum accepi pluries varictatis minoris fpecimina, mammis turgidis \& papillis laxis, rugofis valde prominentibus, ut qua haud dudum peperifle videbantur. Quam numerofa foleat effe proles indicare haud latago; ex numero tamen papillarum octonario infignior videtur ftatuendus pullorum numerus. Hyeme certifime tota torpidi \& fine ullo alimento latent, ideoque nec penum condunt. In Aftrachanenfibus tamen defertis fæpe jam medio Februarii, fi calicia contigerint dies ex antris gigantei \& .pygmæi prodeunt, ita tamen ut ingruente denuo frigore itcrum delitefcant.

\section{DESCRIPTIO \\ $M V R I S \quad I A C V L I$. \\ Tit. $X X$.}

Maximi Sciurum aquant, medii circiter Ratti funt mole, minuti M. fylveftri vix majores funt. Medios deinde figillatim defcribam.

Caput 
Caput oblongum, roftro producto, fed crafo et obtufilimo. Nafils quafi truncatus magnus, nudus, carneolus, cordatus, plica fupera cutis protegendus, fubdidymus, $\int e p t o$ lato, naribus forniculatis, lunatis.

Labium fiperiuls bilobum, fulco per feptum nafi ftria adfecndente divifum, dentes vaginans \& pone dentes in palati anteriorem partem didymam pubefcentem coalefcens; inferins circa dentes longe denudandos vaginale. Anguli oris interius - areola pilofa.

Dentes prinnores longi, tenues, leves, albi; fuperiores breviores, truncati, oblique exferti, inferiores fubacuti. Molares tuberculofi, majoribus fupra quatuor, antico minuto, infra tres ab utroque latere; pygmaeis ubique terni, magis detriti, pofticus femper duobus reliquis minor.

Myftaces longi nigri, extremo cannefcentes, per tumidula roftri latera ordinibus fere octonis fparfi \& radiatim divergentes. Setce præfertim tres majores angulis oris utrinque proximæ, ultra medium truncum pertingentes. Verruca fupraocularis tripilis, parotica unipilis, fubgularis diftincta nulla et vix aliquot pili albidi in labio inferiore prominent. In magnis pone myftaces utrinque pili nigri crebri, longiufculi, futuræ inftar collecti \& barbam quafi fecundariam conftituentes.

Oculi majufculi protuberantes, apertura obliqua, cantho anteriore adfcendente. Palpebrae externe pilis nigricantibus, longiufculis (inferior radiatim) lparfæ, laxæ, fuperior nigro - ciliata, inferior margine molli nudo. Periophtbalmii membranula linguiformis, limbo fuperiore fufco marginata. Irides luteo-fufcæ; pupilla fubcirculari. Albuginea lata. 
Aures capite longiores, femicylindraceo convolutx, ob. longæ, nudæ, tenerrimæ, fubdiaphanæ; venis pictæ, pilis fubtiliffimis margine adfpcrfe, anteriusque vellere tenui, lutefcentc, margine fufco veftiti.

Collum brevifimum; thorax exilior, macilentus; abdomen ventricofum, femoraque poftica ad truncum carnofiffima; uropyginm pone femora productum obtufum fub cauda.

Artus priores cxiles, brevifimi; palmee pentadactylx, pollice brevifimo, unggle craffo, obtufo inftructo. Volee nudx teneræ, callo carpino gemino, exteriore papillari, fubacuto. Artus poftici longitudine corporis cum capite; tibiæ præfertim \& metatarfus longiffima, nudiufcula, tenuiter pilofa. Plante pentadactylæ, digito medio longiore, lateralibus ad $\frac{x}{3}$ metatarfi remotis, ungue mediorum articulationem adtingentibus. Metatarfus ad calcaneum ufque fubtus longitudinalitcr nudus; fed pilis nigris, rariufculis; circumflexis utrinque fimbriatus; qualibus \& fpatium inter digitos, horumque bafis confperfa. Digitorum tantum 3. mediorum apices fub unguiculo comprefli, in orbiculum obfolete crenatum; callus unicus fub bafi digitorum mediorum. Vngues trium mediorum æquales.

Canda toto corpore longior, pedum inftar nudiufcula, breviffimis ftrictifimisque pilis corpori concoloribus, tenuifime veftita, tetraëdro cylindracca, extremitate pilis firmioribus diftichis pennata, lanceolata, bipollicari fpatio atra, extremo ad unum vel $2 \frac{\mathrm{I}}{2}$ poll. niveo (in pygmxis fummo apice).

Color (circa nafum in majoribus prinum albo, dein fufco halone) ceterum fupra gryfeo- lutefcens, pallidus, pilorum longiorum apicibis fufcis fubnebulofus, pofterius fenfim aucta fufcedine. In pygmxis mafus concolor. Latera pallent, vcr- 
tex cinerafcens; femora extus pallidifline gryfea, area transverfa clunium alba, fupra infraque furcefcente ftipata. Artus extremi, \& corpus lubtus totum candoris nivci. In quibusdam pygmais litura frontis alba.

Vellus breve, mollifimum, lævigatum, ut plurimum fex, reptemve linearum, circa clunes ufque ad ro." Suturce vellcris una fubtus a fterno medio ad mediam alvum longitudinalis \& utrinque a cauda fecundum femora marginalis.

Pygmais interdum fubtus litura magna atra in regione cardix.

Anus a cauda remotus, præputio tumidulo contiguus mafculis; Scrotum didymum, ad uropygii extremum protenfum, nudum, rugofum, fufcefcens. - . In feminis valva cum ano intra rugam annularem cutis communem, a fummo uropygio aliquot lineis remota, connivens labiis carnofis, intus rugofis, in lobulum communem productis, fub quo latet papilla clitoridea exigua. - Manme papillis rugofis conicis, aliquot lineas longis (lactationis tempore), areola rugofa cinctis; quorum 2 pectorales inter armos, 2 in margine thoracis, 2 in latere interiore femorum, \& $\&$ paulo viciniores ad pofticum marginem femorum, fub uropygio.

\section{MEN S V R A E.}

Menfuras hic primum dabo comparatas e majori \& minori varietate, quæ proportionibus conveniunt, \& quiden e majoris mafculo, Orenburgi diffecto, qui uncias feptem cum $6 \frac{1}{2}$ drachmis pendebat; \& e femina ad oppidum Jaïcenfe capta, fepten cum dimidia unciarum; \& denique e minoris femina in eadem regione capta, qua tamen multo minutiores ad inferiorem Jaikum obfervantur, primo quidem vere \& adultæ.

$$
\text { P p } 2
$$


Longitudo a fummo nafo ad extremum

$$
\text { uropygium }
$$

- caudr fine pilo

Diftantia oculi a nafo

- auris ab oculo

Palpebrarum fiffura obliqua - .

- - apertura circiter

Longitudo aurium ad verticem

Auris circumferentia bafi

- lacitudo maxima explanata

Circumferentia roftri poft myftacem Intervallum narium

- - inter canthos pofticos filo

- aurium

Circumferentia capitis per oculos

- ante aures per gulam

- colli

- thoracis ad armos

- - - in medio, ubi amplifimus

- uropygii pone flexa femora

\section{- alvi}

Longitudo antibrachii

- totius palme cum unguibus

- digiti medii cum ungue

- unguis medii

- tibiarum

- metatarfi a calcaneo ad articulos mediorum digicorum

- digiti medii

- lateralium medio proximorum

- lateralium extimorum exterius

- intimi cum ungue

Circı mierentia antibrachii ad bafin

- tibiz ad bafin

- metatarfi

- caude ad bafin

Longitudo fetarum longifimarum myftacis

\begin{tabular}{|c|c|c|}
\hline Ius varieta & majoris & in varies. \\
\hline Niare. & Fim. & minor. \\
\hline 6.119 .111 & $7 .^{11} 0.111$ & 4.113 .116 \\
\hline 10. I. & . 9 & 5. 1. \\
\hline 1. $10 \frac{2}{3}$. & 2. $\quad 1$. & 3. \\
\hline l. $\quad \frac{\mathrm{I}}{2}$ & 0. & 8. \\
\hline o. $\quad 5 \frac{\pi}{2}$. & 5. & 2. \\
\hline o. 5 & o. $\left\{\frac{2}{3}\right.$. & $3 \frac{x}{2}$ \\
\hline จ. $\quad 3 \frac{\mathrm{T}}{3}$. & ․ $3 \frac{3}{\overline{1}}$. & $2 \frac{T}{5}$ a \\
\hline 2. 0. & $\therefore 0$ & 10. \\
\hline 1. 1. & 1. $\quad 1 \frac{1}{2}$ & 7 \\
\hline 0.11. & I1. & $5 \frac{3}{4}$. \\
\hline 2. 3. & 2. 2. & G. \\
\hline 0.1. & 0. $\quad I \frac{\pi}{6}$. & $\frac{3}{5}$. \\
\hline I. $\quad 0$. & 0. & $8 \frac{1}{6}$. \\
\hline 1. $7 \frac{2}{3}$. & 8. & 0. \\
\hline $0.10 \frac{2}{3}$. & 10. & 6. \\
\hline 3. 7 & 8. & 2. \\
\hline 3. 2. & I. & 2. \\
\hline 2. 0. & 3. & 0. \\
\hline 2. 10. & $3 \cdot$ & 6. \\
\hline 3. 1 !. & 4. & O. \\
\hline 4. 8. & 4. & 4. \\
\hline 4. I. & 4. & 10. \\
\hline 1. 0. & 0. & 7. \\
\hline 0. $8 \frac{1}{2}$. & o. & $4 \frac{\pi}{3}$. \\
\hline O. $\quad 4 \frac{1}{2}$. & 0. & o. \\
\hline $1 \frac{2}{3}$ & $\therefore \quad 1 \frac{2}{3}$. & 0. \\
\hline 2. 7 & 2. 8. & 1. 5. \\
\hline 2. 6. & $4 \frac{1}{2}$. & $2 \frac{x}{3}$. \\
\hline 0. $10 \frac{1}{3}$. & 11. & $5 \frac{2}{3}$. \\
\hline כ. 2. & $9 \frac{1}{2}$. & $4 \frac{\pi}{2}$. \\
\hline c. 8. & 0.8 & $43^{\frac{\pi}{0}}$ \\
\hline 0.7. & 2. 7. & 4. \\
\hline 0. 10 & 1. 0 & $6 \frac{1}{2}$ \\
\hline 2. 2. & 2. $\quad=\frac{1}{2}$. & I. 3 \\
\hline 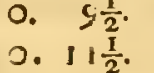 & $\begin{array}{ll}\text { ग. } & 9 . \\
0 . & 10 .\end{array}$ & $\begin{array}{ll}\text { o. } & 4 \frac{\pi}{3} . \\
0 . & 5 .\end{array}$ \\
\hline 2. 10 & 2.8 & 2. 2. \\
\hline
\end{tabular}




\section{DESCRIPTIO}

\section{VARIETATIS IACVLI MEDIAE.}

Huic varietati, quæ defcriptis auctorum e Syria \& Aegypto Iaculis optime relpondet; proportiones \& magnitudo proxime ut in M. Sagitta.

Differt a prius defcriptis Iaculis roftro paulo minus producto; myftacum fetis mulco brevioribus, vix ad media hypochondria pertingentibus; auribus fxpe tertia fere parte brevioribus, fed latioribus; palmarum digitis fure brevioribus; alropygio vellere magis tecto; canda multo craffiore, perfecte tereti, paulo breviore, in apice minus eleganter pennata, potius fubfloccora, flocco aliquousque lutefcente, dein .vix ad $5 .{ }^{\prime \prime \prime}$ nigro, fummoque tantum apice albo, ita ut in nonnullis albedo fere clifa videatur; artubus pofticis totis, prefertim quoad tibias \& metatarfos, paulo proportione brevioribus, digitis contra (ut in M. Sagitta) majoribus \& ungue medii (ut in eódem) proxime lateralibus paulo minore. Mongolicis hujus Varietatis Vellus (ut pro climate) largius \& denfius, color vero nihil differ, quemadmodum \& dentiznn primorum forma a M. Sagitta diverfifima, defcriptæ prius fimillima obfervatur. Operæ pretium eft accuratas hujus quoque Varietatis menfuras e Mongolico, folitæ magnitudinis fpecimine, qualia pondere generatim inter IV. \& V. ') uncias variant addere, ut melius de differentia, judicari queat.

Longitudo a fummo nafo ad extremum uropygium

- caudid line pilo

4." s."II

5. 0.

7) Dauricos tranfalpinos paulo mi- tra \& plesumque paulo infra quatuor pores ad Selengaw obfervatis, raro ul. uncias deprehendi.

P P. S 
Longitudo capitis a nafo ad nucham

Diftantia coculi a nafo - auris ab oculo

Palpebrarum fillura obliqua

- apertura circiter

Longitudo aurium a vertice

Auris circumferentia bafi

- latitudo maxima explanata

Circumfirentia roftri pone myftacem

Intervallum narium fere

- oculorum filo antice

- incer canihos pofticos filo

- aurium icem filo

Circumferentia capitis per oculos

- ante aures per gulam

- colli

- thoracis ad armos

- in medio ubi anplifimus

- alvi

- uropygii pone flexa femora

Longitudo humeri circiter

- antibrachii

- palma totius cum unguibus

- digiti medii cum unguibus

- femortm

- tibiarum

- metatarfi a calcaneo ad digitorum mediorum articulos

- digiti medii cum ungue (1."1/)

- lateralium medio proximorum ( $1 \frac{\mathrm{T}}{8}$.)

- latcralis extimi c. u. $(1, / /)$

- lateralis intimi c. u. $\left(1 \frac{1}{4} \cdot 1 / 1\right)$

Circumferentia antibrachii bafi

- tibia ad bafín

- metatarfi

- caudiz ad bafin

Longitudo fetalum longifr. myftacis
$=1.112 .111$

o. $7 \frac{\mathrm{T}}{3}$.

o. 2.

o. $3 \frac{T}{5}$.

o. $2 \frac{1}{2}$.

o. $9 \frac{\mathrm{r}}{2}$.

○. 7 .

o. $\int \frac{\pi}{2}$.

1. $6 \frac{2}{3}$.

O. I.

o. 9 .

I. I.

0. $6 \frac{2}{3}$.

2. $6 \frac{1}{2}$.

2. 5 .

2. 3.

3. I.

3. 4.

3. 6.

o. 5 .

○. 7 .

0. 5 .

○. $2 \frac{2}{3}$.

o. 11 .

I. 6 .

I. $2 \frac{I}{2}$.

o. 6 .

०. 5 .

․ $4 \frac{\pi}{2}$.

o. $4 \frac{\pi}{5}$.

o. S.

I. $2 \frac{I}{2}$.

o. $4 \frac{\pi}{2}$.

o. $6 \frac{r}{4}$.

2. 6 .

\section{A N $\Lambda \mathrm{T}$ O M E.}

Tab. XXV. fig. 1. - 4 .

Quum in memoratis varietatibus interna fructura parum admodum differat, e majoribus præfertim anatomica defcriptio 
hic dabitur Glandula fubcutaneæ thymo analogæ infignis, ut in omnibus hyeme fopitis. Circa collum tenuiter explanatæ duæ, fimul pondere gr. XI. - quatuor tenues fub pectorali \& fub axillis explanatæ, collectim pondcre gr. XII. Præterea (ne anteriora feilicet nimis onerata forent) ad fuperiorem introitum pelvis, intra abdomen, utrinque Glandula deprefla, fubrotunda, exterius craffa, intcrius in aciem comprefla; fubftantia \& facie fere fuprarenalium humanarum, in pinguedine omentorum lateralium nidulans. Similis, fed major \& oblonga, utrinque obtufufcula, triquetra, carina dorfali productiore explens finum longitudinalen lumbarcm, pone renes exteriusque ad proadas exiftentem; harum dextra apice circiter fub extremum renis definens; fod finiftra extremo fuperiore depreffo \& rotundato fecundum renem dorfumque infinuatur, major \& craffior compare. Harum pondus fingularum if ad I5 granorum; pelvinarum $8 \frac{\mathrm{I}}{2} \& 9 \mathrm{gr}$. Conftant glandulofo - lardofa fubftantia, calore oleum fundente, fed magis confiftente, vafculis infignioribus infructa.

Glandula iliorum tenuis in expanfione fubcutanea; $a b$ inguine adfecndente utrinque fita, $u t$ in reliquis muribus.

Omentilm inteftina fubtus tegens nullum, fed tantum tenuis \& fine pingui tunica circa ventriculum, ad lienem \& pancreas pinguedine. largiore collecta. Onenta lumbaria pingtiffima, infignia \& prefertim finiftum pollice quadrato majus. Pingucio verfus renes fpiffa renesque eadem coronati.

Hernia naturalis feu finus abdominis ultra pelvim in uropygium defcendens conicus, intus porco longitudinali, plim 
caque a vefica verfus abdominis mufculos excurrente didymus; circa veficam pinguedine oppletus, dein coci cxtremas, fpiras continens.

Ventriculus (fig. I.) ovato - oblongatus, fere reniformis, ufque ad finum pylori peramplus. Iftbmus pylori (lit. a.) ftrictuś, carnofior, cylindrico arcuatus, pennæ corvinæ craflitie, longitudine $3^{\frac{1}{2}}$ "II $-A$ cardia per arcum majorem ad pylorum 4." $1 \frac{5}{2}$." circumferentia ventriculi, ubi amplifimus 3." 6"l Chymus faburra herbida \& inlcctorum reliquiis mixtus.

Diodemum $(a-b$.$) calamo cygneo æquale, longitu-$ dine 2." 9." Iejumum fenfim adtenuatum 8." Ileum duodeno primum fere amplius, extremitate jejuno fere anguftius; longitudinem notare oblitus fum. Inteftinorum, membranæ tenuiffimæ.

Cectun (fig. 2. $"$ - b.) a ftrictura cui inferitur lleum (A.) ad apicem (b.) 9." $6 . "$ " in tres fpiras convolutum, fenfimque adtenuatum. Port cœcum cellula (lit. c.) eadem fere amplitudine, longitudine feptem linearum. Inteftinum dein oblique ftriatum $(d e f$.$) in aliquot fpiras primum con-$ tortum $\left(d e_{.}\right)$, poftea rectum $(e f$.$) , longitudine totum cir-$ citer 5." $4 . "$ Demun excretorium $(f-g$.$) bis conduplica.$ tum, tota longitudine 9 pollicum.

Hepar (fig. 3.) mediocre, bidrachmale, ruberrimum, tripartito - feptemlobum. Lobus finifter (a.) maximus, ovalis, fubtus planus, fupra dorfatus. Media portio profunde biloba (b.); finifteriore paulo minore, pro cyftide excavato. Dexterrimi lobi minores, craff, (litt. $c$ d.) Spigeliamus geminus (e.). 
Cyftis mole amygdali, ovata, bile tenui fufco - virefcente turgida.

Lien deprefo - triqueter, lineari lanceolatus, longitudine $8 \frac{I}{2}$. "I latitudine $2 \frac{\pi}{3}$. "I pondere granorum duum; dorfali lateri ventriculi adplicatus.

Pancreas bipartitum, portione altera ad dextram extremitatem lienis adpenfa, triquetra \& triangulari; altera pone ventriculum lineari, liene longiore \& tenuiore; pondere ambo ifthmo exili cohærentes gr. vj.

Glandvilce fuprarenales depreffx, dextra ovali - oblonga, propius reni fuo adplicata; finiftra remotior ex ovato-. linearis, long. $3 \frac{1}{2} \cdot{ }^{\prime \prime}$ latioris extremi latitudine ${ }^{\frac{I}{2}}{ }^{\prime \prime \prime}$

Renes oblongi, hilo infigni, maxime dorfali latere, finuati, ad dorfum fubangulati, dexter $\mathrm{XV}$. gran. finifter tantillo brevior, granorum XVII. ambo papilla intus unica, acuta.

Vefica urinaria mole ovi columbini, ab ípfo collo reclinata, extra pelvim projecta, ureteres iplo collo recipiens, membranis robufta.

Vulve apertura ano ita approximata, ut exterius unum orificium conftituere videantur, limbo pilofo conniventem. Distracta cute apertura vaginæ apparet fphincteri adplicata, retractior, rugofe collapfa, ruga ad orificium papillari, cum orificio urethræ effufo, infigni. Vagina longitudinaliter rugofa ad io." hinc canalis continuus ad $1 . .^{\prime \prime} 6 . "$ cormu 2. " 6. "I fecundum mefenteria lateralia decurrentia; ovaria fcre $2 . "$ " cylindrica, exilia.

Thorax pro mole corporis peranguftus. Diaphragma fubinfundibuliforme, ipfo centro tendinco, irregulariter triangulo, intra thoracein retracto. 
Pulmo finifter minor, indivifus. Dexter quadrilobus; medio mucronato, fecundum cor producto; inferiore majore; quarto azygo, poft cor latente, apice triquetro anguloque bafeos in ligulan producto. Tracbea cxilis.

Cor majufculum, ovatum, convexum, dextro ventriculo obfoletiflime compreffum, obtufflimum. Alricula fubæquales, integerrime, plane; dextra paulo oblongior. Longitudo cordis. 9." circumferentia bafi $1 . "$ 7."

Tbymus vix ulla in thorace apparet, propter ejusdem! brevitatem, \& ne xquilibrio noceret.

Sceleton, fecundum formam totius animalis anonalam, maxime fingulare, pofticis præfertim artubus, nec non cranio. Iconem tamen nullam addo, quod pleraque cum M. Sagittæ offea compage, (quam in tabula exprimi curavi) in Iaculo conveniunt, unde \& comparativa deferiptio fub iftius Anatonle dabitur:

Cranium fciureo Iatius, tenuius; olla b:aviore, ampliore; zygomate late \& prærupte arcuato, areu ante orbitas alio verfus frontem ramofum, officulo acecforio prope frontem latitudinem zygomatis adaugente \& orbitam protegente. Roftrum cranii tetragonum, breve, dentibus inciforibus antrorfum exfertis. Maxilla inferior tumidula, ramis extus craffo proceffu tuberofis, angulo perforato. (Tab. XXV.fig: 4 .) Ut evidentior effet differentia ftature inter maximos \& pygmaxos Iaculos, fig. 4. "Cranium majoris, \& fig. $4^{*}$ pygmæi, qui tamen non e minimis fuit, delineari curavi.

Colli vertebric (preter atlantem \& epiftrophæum, ro. buftiores) brevifime. Dorfales fine proceffibus fpinofis tredecim, totidemque coftarum paria, quorum feptem vera, ultimum. 
fpuriorum minimum; quod frepe elifum deficit. Lumbares vertebre rex, quatuor pofteriores procefibus fpinofis \& transverfis robuftis. Sacrmm quadriarticulatum, duabus prefertim vertebris pelvi coarticulatum, omnibus coalitis. Canda vertcbræ XXXI. quarum prima facro fubcoalita, proceffu fpinofo fupra craflo, reclinato infructa; 2 ad 5 proceffibus transverfis antrorfum directis, reliquæ cylindracex, ad articulos tubercu. lofæ, fine procelfibus, 7 ad II omnium longiffimæ, reliquæ fenfim imminutx \& adtenuatx.

Thoracis crates infirmæ, fubito exampliatæ. Sternumn in fceleto magnæ varietatis conftat manubrio, quatuor articulis, \& enfe offeo cartilagine rpathulato; in minuta varietate, articuli intermedii tantum tres, fubxquales, ultimo evidenter $\mathrm{e}$ duobus coalito.

Claviculce majufculæ, fatis robuftæ, fcapulce infignes. Antibrachinm humero longius, offibus diftinctifimis factum. Carpus ofliculorum octo; pollex unica phalange \& ungue conftat.

O/fa imnominata robuftiffma, in $M a / c u l o$ magnæ varietatis fymphyfi ad integrum femipollicem connata; in femimeo pygmeæ varietatis fceleto, fympliyfi vix unius jineæ, totaque fimul capacitate pelvis \& apertura amplinte. Differt etiam in his duopbus fecletis tota forma \& proportio offium pelvis, fed quun diverfi fexus \& etatis fint, nullaque nunc alia ad diffecandum fpecimina fuppetant, inde nihil concludere licet.

Femorlim offa in majori feeleto tantum $\frac{2}{3}$ tibiarum aequant, in minori paulo longiora vel tibix proportione breviores. Tibice femoribus multo robuftiores, fupcriore extremitate

$$
\text { Q q } 2
$$


crallifima, triquetræ, fibula extcriori angulo adnata, tantun aci $\frac{T}{3}$ totius tibix longitudinis divaricata. Tarfus conftat caIcanen maximo, pone tibix articulum prominentifimo, talo, cuboide \& binis innominatis. - Netatarjers trium mediorum digitorum conftat e folitaria fifula offea, $\frac{z}{3}$ tibiæ fuperante, extremo trifurca, tribus articulationibus prefinita, quarum media productior; digiti intermuedil duabus phalangibus \& ungue facti. Digiti laterales metatarfo diftincto, vix dimidium medii æquante, fed pollex unico tantum articulo cum ungue, gaudent. Interiori metatarfo firmando refpondet os planum, longum, tarfo adnatum eidemque. adnumerandum. Sub articulo bafilari metatarficorum lateralium utrinque ofliculum fefamoïdeum. Articuli metacarpi medii, digitis firmandis deftinati, fubtus trochleariformi incifura maxima, pro actione tendinum promovenda inftructi. - In magno fceleto offculum peculiare $4^{\frac{1}{2}}$ lin. longum, planiufculum, lineare, pro firmando tendine Achillis, calcaneo ligamentis adpenfum; quod in minori, licet feniore fpecimine, non obfervavi. Tab. $X X V$. fig. 오. offa pofticorum artuum majori minorique varietate mole naturali exhibet.

In magna varietatis mafculo fceleto, cujus hic menfuras apponam, epiphyfes offum omnium cartilagine diftincta, omniaque tenerioris ætatis indicia; contra in minuto, quod comparavi, ofla omnia folidata, \& futuræ cranii magis oblitteratæ:

Longitudo cranii ab oflum nafi extremo ad occiput

Latitudo olla pone zygomatå

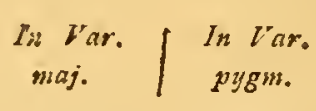

- per zjogmata poltice fumma

1."I 6."lll - O. I I. III

0. 10. - 0. 7 .

I. $1 \frac{\pi}{2} \cdot$ - 0. $9 \frac{7}{3}$. 
In maj.

In min.

Latitudo inter adfcendentes anticos zygom. trabes - minima inter orbitas

Longitudo offium nafi

Latitudo roftri ad zygomata

○. 11. - $0.7 \frac{\pi}{3}$.

Longitudo dentium fuperiorum

○. $5 \frac{2}{5} \cdot 0.3 \frac{\pi}{2} \cdot$

○. $7 \frac{x}{2}$. - 0. 4 .

- maxill fine dentibus

- dentium inferiorum

Columna vertebrarum colli

- dorfalium

- lumbarium

Longitudo facri

- Iterni offei

- cauda

- claviculæ

- fcapulæ

- humeri

- antibrachii cum olecrano

- oflis innominati

- ilei ab acetabulo

- foraminis ovalis

Latitudo ejusdem

- - fymphyreos

Diftantia inter ifchia

Longitudo femoris a condylo

- - tibix inter articulos

- calcanei

- tarfi

- metatarfi medii

- dig. medii phal. primæ

0. 4 - 0.2 .

०. $4 \frac{\pi}{3}$ - $0.2 \frac{\pi}{3}$.

I. $0 . \quad 0.7 \frac{1}{2}$.

○. $3 \frac{3}{4}$. - O. $2 \frac{\mathrm{T}}{4}$.

๑. $\left\{\frac{\mathrm{I}}{2}\right.$ - e. $3 \frac{\mathrm{r}}{3}$.

I. 8. - 0. 11 .

1. $\left\{\frac{T}{2} \cdot 0.10\right.$.

०. 9. - ०. 5 .

I. 4. - $0.7 \frac{\mathrm{T}}{2}$.

12. $10 .-6.10$.

0. 6. - 0.4 .

०. 9. - c. 6 .

0. 9. - 0. 5.

I. $0 . \quad-0.7$.

I. 7. - 0. $10 \frac{x}{2}$.

0. 9. - 0. 6 .

- . phal. fecundie

- - unguis

- - exterjoris phal. primæ

○. $\int \frac{3}{4}$. O. $2 \frac{3}{4}$.

o. 3. - 0. 2 .

o. $5 \frac{1}{2}$. - 0.

- - - - phal. fccunda

- - - - - unguis

- - interioris phal. primæ

o. 6 .

0. 5 .

- - - - phal. fecunda

- - - - unguis

- metatarfi digiti intimi lateralis

I. 9. - 1. 0.

2. $6 \frac{\pi}{2}$. I. 5 .

0. 6 . - 0.3 .

o. 4. - o. 2.

I. $9 \frac{\mathrm{T}}{2} \cdot$ 0. $10 \frac{\mathrm{T}}{3}$

0. 6. - o. 3 .

0. 3. - 0. $1 \frac{2}{3}$.

○. $3 \frac{\pi}{2}$. - O. $1 \frac{\pi}{2}$.

c. 5. - 0.2 .

- ejusdem phalangis

o. 2. - $0.1 \frac{\pi}{4}$.

$:=$ : unguis

Q q 3

- $3 \frac{r}{4}$ - C. $1 \frac{\pi}{2}$.

o. $5 \frac{1}{3}$. 0.2 .

0. 2. - $0.2 \frac{1}{2}$.

o. $3 \frac{x}{4} \cdot$ - 0 . $1 \frac{2}{5}$.

०. 8. - 0. $4 \frac{\mathrm{r}}{3}$.

o. 4. - O. $2 \frac{1}{2}$.

D. $2 \frac{4}{3}$. O. $1 \frac{\pi}{3}$. 
Longitudo metatarfi extimi

- phalangis ejusdem primæ

- item fecundæ

- item unguis In maj In mis.

0. $10 . \quad-0.4 \frac{3}{4}$.

o. $4 \cdot \frac{2}{3}$. $0.2 \frac{\pi}{3}$.

०. I. - o. $\frac{1}{2}$.

o. 3. - $0.1 \frac{\pi}{6}$.

\section{V S \\ $\begin{array}{llllllll}S & A & G & I & T & T & A\end{array}$}

A uctores, qui Murem Sagittam oblervarunt omnes in Hirtoria Iaculi excitavi. Sed præer BVFFonIvm nemo hane fpeciem a priori diftinguendam, effe cogitaverat, donec utriusque differentias in Appendice ad Itimerarii Vol. II. p. 706. ftabilivi. Dein Amiciff. pennant \& Zimmermann utramque fpeciem diftinctam adoptarunt.

Mus Sagitta, ut ex allatis auctoribus conftat, per omnem Mauritaniam \& Africx borealis arenas, in elatis Acgypti, \& Arabiæ Syriæque defertis vivit. Mihi in arenolis inter Tanain \& Volgam, \& frequentiflime in collibus fabulofis ad Irtin auftraliorem, a Jamyfcheva fortalitio ufque ad Septempalatia, ubi fchiftofi montes altaïci tractus incipiunt, obfervatus eft. Nullamque formæ, proportionum vel coloris varietatem in plus quam viginti fpeciminibus, æqualemque fere omnium magnitudinem notavi, qua Iaculi mediæ varietati paululum cedunt. Vidi femper in fabulofis locis \& mobili pane arena cuniculantes, ubi Iaculus vivere recufat. Cæterum cuniculi eandem omnino rationem, eundemque devii ad fugam exitus, oftio non 
hiantis dolum expertus fum. Tuliparum præfertim bulbis \& herbis fatuis victitat, eodemque more interdiu conglobatus dormit, noetuque vigilat. Saltus, licet cruribus paulo brevioribus, haud minores edit; itemque frigore torpefcit. Sunt autem paulo magis mordaces \& vocem turbati, vel capti, diverfam, flebilem \& exilem edunt. Cofaccis ad Irtin nomen Tarbagantfchik huic fpeciei adpropriatur', quod a male applicata \& deminutiva Marmotæ apud Calnuccos appellatione (Tarbagan) ortum ducit. In orientalioribus Sibiria trans Baikalem, ubi Iaculum frequentem efle dixi, Mus Sagitta, arenofo quanvis folo, nunquam obfervatus eft. Contra ad Irtin, ubi maxime abundat idem, media minorque varietas Iaculi mihi nunquam obviam funt facti; giganteam folam ad rivum Alë̈ Barabenfium camporum aliquoties obtinui, \& ufque ad Altaïca promontoria obfervari audivi. Ad Iaïcum M. Sagitta nunquam, interque Volgam \& Tanaïn multo minus frequens. obfervatur, quam Iaculi minores.

Differt autem a Iaculi varietatibus conftantiffimis \& valde confpicuis characteribus: capite elegantiore, nafo minore, cranioque minus lato; at zygonatum arcu antc orbitas adfcendente Iato, robuftiffimo; dentibus primoribus luteis, fuperioribus non oblique exfertis, fed verticalibus, exterius fulco infigni exaratis; anribus multo minoribus, my'facum fetis brevioribus; palmarum ungue pollicari feflili, obtuo; artubns pofricis parum brevioribus, quam in Iaculo magno, at mediæ varietatis crura proportione excedentibus; canda, ut in Iaculi varictate media, minus eleganter floccofa, at tetragona, ut in aliis ejusden Varictatibus; maxime demum defectu plenario 
digitorum in pofticis pedibus lateralium, ut nulta minutiora non referam, e defcriptione \& icone perfpicienda.

\section{DESCRIPTIO \\ $M V R I S S A G I T T A E$.}

Tab. $X X I$.

Magnitudo circitel majoris Ratti. Nafus ninor \& elegantior; labizm bilobum, ftria verfus nafum nulia exaratun. Cacterum forma capitis fere Iaculo fimilis, nifi quod minus craffa.

Dentes primores lutei, intenfius fuperiores, iidemque robuftiores quam in Iaculo, magis acuati, nec obliquati extrorfum, fed deorfum directi, extus fulco per totam longitudinem arati. Molares tuberculofi (ut in Iaculo grandiore), ubique terni, fupra cum accefforio antice minutifimo breviore obtufo papillari, ceterum poftici minores anterioribus.

Labinim fuperius pone dentes in palatum coalefcens, fed nudum; areola villofa interna buccarum exilis.

Myfraces per tumidula roftri latera feptem ordinum, fetis infimis majoribus, maximaque angulo oris proxima, dimidiam tamen trunci longitudinem non adtingente. Barbula pone myftaces nulla. Verraca fuperciliaris bipilis, parotica unipilis. Seta antibrachii verfus carpum.

Oculi magni, canthisque anterioribus oblique adfcendentes, ut in Iaculo.

Alnres milto minores, quam in codem, et capite bre. viores, oblongo ovatae, nudiufculac, tencllae, bafi et anteriore margine villofiores. 
Corporis forma proxime ad Iaculum accedens, at poftice minus ventricofa, neque uropygio pone femora produeto, adeoque hernia naturali nulla.

Artus antici parvi, paulo majori tamen, quam Iaculis, proportione. Pollex palmarum ungue infigni, craffo, obtuffilimo, fereque truncato, fubtus canaliculato, fed fere feffili, ante callum carpi maximum, fubtrituberculatum.

Artus poftici animalculo longiores; tibiis præfortim \& gambis feu metatarfo longiflimis. Planta tridactylæ, digitis fubæqualibus, fubtus rigide villofo - barbatis, lateralibus nullis; medii ungue minore, omniumque apicibus fub ungue compreffis, callofo - nudis, crenulatis. - Metatarfus hine a calce ad digitos ufque xqualis, cylindraceus, nudiufculus, fubtus fufcefeens, verfusque digitos fenfim villofus; callo ad digitos nullo, fed ipfa digitorum articulatione lubtus villofiflima pilis longioribus.

Cauda fubtetragona, flocco molliore minus eleganter (quam Iaculis) pennato, apice ad 1." albo, dein ad 1." nigro; craffior, plane ut in Iaculis mediis.

Color et natura velleris omnino ut in Iaculis. Area clunium transverfa alba, fufco ftipata a caudx bafi ufque ad flexuram femorum.

Manme in feminis quatuor parium; quatuor inter femora fubrquidiftantes, duæ thoracicæ ad coftarum fpuriarum cartilagines, et duæ fere ad articulum humeri pofita.

Vulva ano proxima, conftricta, antrorfum in areolam nudam, fubtrituberculatam effufa, ceterum labiis clitorideque nullis. Genitale maris exiguum. 


\section{MEN S V R E.}

$P$ ondus in adultis malculis trium unciarum cum $2, \&$ ufque ad 4 drachmas; feminis interdum ad 3 unc. 7 drachm. vel proxime 4 unciarum. Proportiones in omnibus ad Irtin lectis individuis et utroque fexu vix ullatenus diverfae, nifi quod cauda quibusdam brevior vel longior, proportione junioribus femper longior, quam adultis, Sequentes menfuræ funt Feminæ quae 3 unc. cum $5_{-1}^{\frac{1}{2}}$ drachm. pependit.

Longitudo tota ab apice nafi ad ortum caudx

- caudæ fine pilo

- pili exfuperantis

- capitis a nalo ad nucham

Diftantia oculi a nafo

- auris a cantho port. oculi fere

Longitudo fifurx palpebrarum

Apertura oculi

Longitudo aurium a vertice

- a bafi exteriore

Circumferentia aurium bafi

Latitudo auris explanatæ

Circumferentia roftri poft myftaces

- capitis per oculos \& maxillam

- capitis ad aures

Latitudo fepti narium

- nafi nudi

Diftantia oculorum filo antice

- - inter canthos pofticos filo

Intervallum aurium

Circumfercntia colli

- thoracis ad armos

- - - in medio trunco

- abdominis

- uropygi i pone flexa femora

Jongitudo dentium fuperiorum

- - . inferiorum

- pilorum in myftace longiffimorum

- antibrachii 
Longitudo palmæ totius cum unguibus

- digiti medii cum ungue $\left(2 \frac{2}{3} .111\right)$

- tibiarum

- totius plantix

- digiti medii cum ungue $\left(1 \frac{\pi}{3} .1 / 1\right)$

$\therefore$ - excerioris digiti cum ungue $\left(2 \frac{\pi}{3} .(1 /)\right.$

- interioris cum ungue $\left(2 \frac{4}{5} / \prime\right.$.)

Circumferentia antibrachii bafi

- tibix ad vafin

- - - ad calcaneum

- metatarfi medio

- cauda ad bafin

Longitudo a nafo ad extenfarum plantarum fummos ungues Diftantia ani a parte cauda nudata

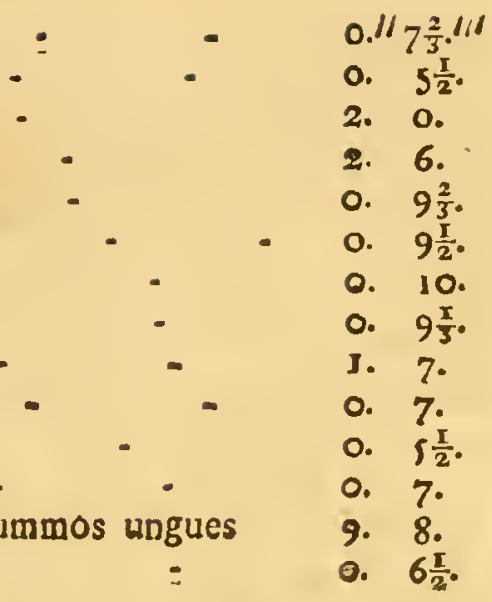

\section{A N A T O M E.}

Tab. XXV. fig. 5 .

Interanea plerisque momentis Iaculo fimilia deprehendi. Situs inteftinorum eo præfertim differt, quod coccum fymphyfin pubis vix adtingit \& cavum abdominis ante ipfam fymphyfin pubis definit. Ren dexter dimidia longitudine anterior, infimæ coftr contiguus. Vefica collo elongata, fupra pubem recumbens. Cornua utteri I." 4." longa.

Palatum tantum inter molares rugofum, antice caruncula tripapillari, dein rugis binis biarcuatis, hinc quaternis, fulco interruptis \& fubconvergentibus.

Pulmo dexter quadrilobus, uno impare, finifter femitrilobus.

sceleton $(T a b . X X V . f i g \cdot 5 \cdot)$ generatim proportione \& Aructura proxime ut in Iaculo. - Craninm paulo oblongius, quam in eodem, olla minus lata, \& depreffiore, aft inter orbitas latiore, roftro paulo productiore, circumcefura fere ad fciuream accedente. "Zygonna quoque minus exarcuatum, 
fed arcu ante orbitali adfcendente latifimo, robuftifimo, e poftica lamina latiore, finuata, anteriore trabecula firmiore ${ }^{a}$ ) compofito; eoque oculi, teneraque cranii compages ab impingente vi faltantis vel fodientis animalis defenditur. $O \iint a n a \bar{a}$ latiora, convexa, ut in fciureis. Maxilla inferior ramo trifida, exteriore tubere exili, angulo latius perforato, condyloïdeo proceffu productiore, quam Iaculis.

Vertebre. colli latæ, brevifima; folus epiftropheus fpina conico-compreffa erectus. Dorfales vertebræ duodenæ, omnes muticx; lumbares (ut in Iaculo) reliquis omnibus majores, feptenæ, longitudine colli dorfique fimul columnam æquantes, proceffibus a dorfo I- 3 fenfim crefcentibus, 4-7. magnis, latis, longiffime in feptima, ad 4 \& 5 latioribus; $3-7$ etiam proceffibus lateralibus antrorfum vergentibus. Os $\int a-$ crum latum, lamina utrinque offea tripcrforata alatum, qua.

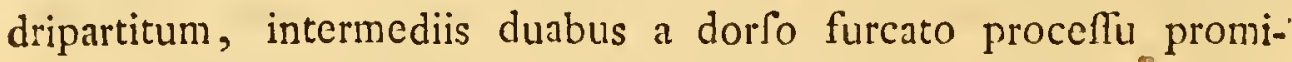
nulis, poftica proceffu inter furcam craffo, fubcapitato. Call$d a$ vertebrarum (numerato apice) $\mathrm{XXV}$. quarum tres priores proceffu dorfali furcato, et transverfis; lumbares fere adxquantibus. Reliquae cylindraceae, fenfim adtenuatæ, 6 -ad 8 longुifimx.

Coffre I2 parium, 7 utrinque veræ, quarum prima, ob longitudinem manubrii fternalis, remotiffima, poftremæ duæ communi fere infertione ad bafin enfis firmatx. Sterni oflcula 4 . intermedia.

a) Arcus anteorbitalis conficitur ramo ceffu fupraorbitali occurrente, \& denique zygomatici oflis verfus frontem adfcen- pofticis duabus lanellis offeis, inferiore dence, anguito fed crafiufculo, qui an- oblonga, fuper. minore triangulari. teriorem confticuit marginem, dein pro- 
Artulum priorum offa tenera, attamen paulo robuftion, quam in Jaculo. Pollex ad carpum ungue fere feflili.

Offa innominata majora fere quam in Iaculo, totiusque corporis (preter offa longa crurum) maxima: Ileon craffum, ifchia latifima, producta, arcus pubis fecundum fymphyfin anguftifimus (quod fecus in Iaculis).

Tibice femore multo longiores, ramo tenuifimo loco fibulæ, fere ad $\frac{x}{2}$. longitudinis pertingente. Metatar $/ 2$ loco fiftula fimplex feu gamba, ut in ungulatis ${ }^{b}$ ), cylindrica longa, extremo capitato - triloba, fubtusque pro tendinibus canaliculata. Digiti phalangibus duobus \& falcula compofiti.

Lorgitudo cranii a fine offium nafi

Latitudo ollæ fumma pone zygomata

- per zygomata poftice funma

- minima inter orbitas

- . inter arcus anteorbitales

Longitudo offium nafi

Latiiudo roftri ad zygomata

Longitudo dentium fuperiorum

Longitudo maxillæ fine dentibus - . dentium inferiorum

Colli-vertebre colle $2 \mathrm{im}$

Vertebræ dorfales collectim

- lumbares fimul

Os facrum

Longitudo totius caudie

- vertebrarum caudx longifimarum

- proceffus fpinofi longirf: lumbarium

- procelfus azygi oflis facri

- Aterni fine enfe

. . clavicularum

- . fcapularum

Latitudo earundem

\section{R $r 3$}

I.". $3 \frac{1}{2}$ III

o. $8 \frac{2}{3}$.

o. 11.

०. 5 .

o. $9 \frac{2}{3}$.

o. $6 \frac{1}{2}$.

o. 3 .

o. 3.

o. 8.

0. 3 .

o. $3 \frac{1}{2}$.

s. $\mathrm{I} \frac{1}{2}$.

J. $3 \frac{1}{2}$.

o. $6 \frac{3}{4}$.

6. 10.

o. 5 .

D. 3 .

0. $1 \frac{x}{2}$.

o. 8.

०. $4 \frac{1}{2}$.

0. $6 \frac{3}{79}$

c. 5 .

b) Unde recte Arabes pedibus Gazellæe comparaverunt. 
Longitudo humeri

- antibrachii cum olecrano

- oflis innominati

- ilei ab acetabulo

- foraminis ovalis

Latitudo ejusdem

Longitudo femoris

- t tibix

- fiftulæ metatarfi fine calcaneo

- calcanei

- phalangis primx digiti medii

- - - lateralium .

- phal. fecundæ in omnibus circiter

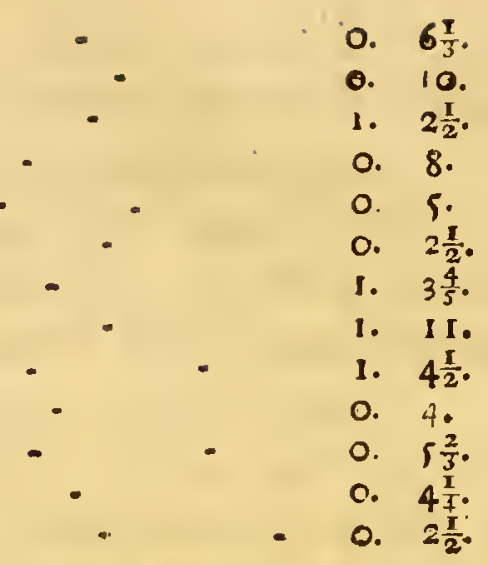

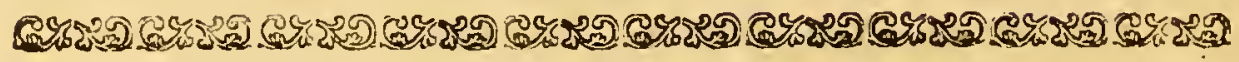

\section{$\mathrm{M}$ V S \\ $\begin{array}{llllllll}L & \dot{O} & N & G & I & P & E & S .\end{array}$}

Non fupcrvacaneum erit renovare memoriam fpeciei, quam crurum pofticorum magnitudo in hoc genere memorabilem, falisque modo defcriptis proximam reddunt. IIl. в $\mathrm{F}$ FONIVs ditifimus \& vere clafficus in quadrupedibus auctor, ne verbulo quidem ejus mentionem fecit, etfi fatis bene apud SEBAM delineata extat. Crederet hinc nonnemo fidem Sebance iconi non effe thabendam (thefaur. vol. II. tab. 29. fig. 2. Serpentum pabulum.), confirmante quamvis fpeciem Ill. Linnaeo (Sy/t. nat. XII. p. 84. Sp. I9. Mul. regis Vol. I. p. 9.) qui \& "Muris longipedis, nomen primus impofuit. - Sed vidi quondam Amftelodami è Mufeo sebae reliquum pecimen in collectione dn. Chr. Paul. MEIER, mercatoris, \& ibi breviter defcripferam; iconen quo- 
que poftea procurante Amiciff. H. E. D. SCHLOSSERo. Hinc non imaginariam $S E B A E$ iconem effe, fed minus bene, \& e fpecimine nondum adulto delineatam, confirmare poffun. Magnitudo iftius fpeciminis vix Murem fylvaticum mediocrem fuperabat '); caput \& poftica crura magna proportiohe excedebant; color laxi velleris erat lxtiffime luteo - ferrugineus, dorfo fufcidior, lateribus fenfim albefcens, fubtus \& artubus albus. Cauda minus veftita, quain in adultis poftea fpeciminibus obfervata mihi fuit.

Per Amanuenfem fcilicet, anno 1770. fecundum Mare Cafpium ad colligendas res naturales miffum, adlata mihi fucre duo fpecimina hujus muris, in confiniis deferti arenofi Naryn, fub latitudine bor. $46 \cdot \frac{1}{2}$. circiter graduum, feu in maxime auftralibus hujus fabuleti, haud longe ab ipfo mari, capta. Ambo fimul apparuere in loco aridiffimo ad meridianum folem colludentes; mares ambo \& ad diverfos cuniculos diffugientes fugiendo capti funt. Erant autem, ut mihi relatum eft, cuniculi triplici obliquo canali adeundi, ulnari circiter profunditate effofi, in arena limo firmata, ipfis animalibus fere concolore (uamque multo pallidioris \& exfoletioris erant coloris, dicto (pecimine SEBAE). In foco cuniculorum nidus aderat nullus, neque pabuli veftigium. Crefcit autem in arenis iftis vix quidquạm, præter tenuifimum Melilotum, Aftragalos quosdam macerrimos, Antirrhinum junceum, Tragopogon villofum \& Polygonoides ephedræ facie tovrnfFort. Notatum eft haec animalcula, licet infignis crurum longitudo fuaderet, non tamen faltibus fugere, fed murino more currere.

') Longitudinem obiter menfuratam ti $6 \frac{2}{3} . "$ palmæ $4 .{ }^{\prime \prime \prime}$ tibiarum $1 \mathbf{1}^{\prime \prime \prime}$ plan. notavi a fummo roftro ad ortum caudæ tæ $\mathbf{I}^{\prime \prime} I_{\frac{1}{2}}$." caudæ 3 . 2." 8 . "capitis s." 2 "' aurium $6 \frac{\mathrm{x}}{2}$ "." cubi. 
Mihi vix eft dubium aninalcula deferti cumani, quorum fub nomine Tfitsjam (apud Tataros pro denotandis muribus generico) imperfectam mentionem fecit sснов вRVs ${ }^{d}$ ) in memorabilibus RufJo-afaticis, \& e quibus, cum Citillo codem tatarico nomine apud $D e$ BRVYN male delineato conjunctis, Marmotam fuam Circafficam fecit PENNANT ( $\int y n$. p. 278. 21. 205.), hanc ipfam effe fpeciem. Ad veri quoque fimilitudinem accedit eundem Murem fub nomine Fird in deferto Saharæ, una cum M. Sagitta, vulgarem. \& efculentum indicafe sHAwiva (itin. verf. gall. vol. I. p. $32 \mathrm{I}$.); defcribit enim Fird colore \& magnitudine Sagittæ finilem, capite acutiore \& nafo toto hirfuto, pedibus minus inæqualibus, omnibus pentadactylis, cauda (quam in Ratto) breviore, fed magis veftita. - Omnino videtur Mus longipes nofter calidiorum tantum regionum effe animal, neque certe in borealibus defertorum Ruffici imperii obfervatus fuit.

\section{DESCRIPTIO \\ $M V R I S$ LONGIPEDIS.}

Tab. XVIII. B.

Magnitudo inter Rattum \& M. fylvaticum med:...

Caput oblongum, roftro productiore, quam M. fylvatico, (cui alias facie fubfimilis), obtufo \& carnofo. Nafis fofforius, gibbus, totus pubefcens, plica craffa, deflexa, mobili nares protegens (fere qualis in Citillo); Narium papillofo conniventium folus limbus \& feptum interjectum nuda.

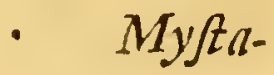

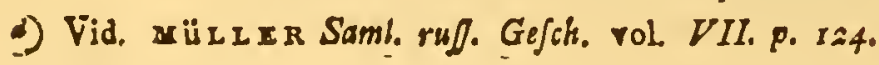


Myftaces fex, feptemve ordinum obliquorum, in tribus fummis ordinibus longiffimi, caput excedentes, nigricantes; inferiores albidi. Verrnca fupraciliaris bipilis, gularis pilo unico, tenero.

Os labiis carnofifimis, pubcfcentibus connivens, fuperiore bilobo, nec ufque ad nares adco profunde, ut in congeneribus, diviro.

Dentes primores lutei, fuperiores fulco piofundo exarati, apice crena incifi, inferiores longiores, obtufi. Molares fupra infraque terni, utrobique ferie brevifima inter congeneres.

Oculi majufculi, majores quam in M. fylvatico, palpebrarum margine nigricante.

Altres infignes, ut in M. fylvatico, paulove minores, tenerrime luteo-pubefcentes, ovales; intus ispto feu plica transverfa fupra foffam atrii, exteriore margine verfus bafin craffo.

Corpus poftice craffefcens, femoribus validis, carnofflimis. Artus antici majores quam in M. faliis, poftici minores, red grandiores, quam in ulla alia rpecie murini generis. Palma fubtetradactylæ, pollice breviffimo, fed lubtiliter unguiculato, adeoque evidentiore multo, quam in $\mathrm{M}$. fylvatico. Plantce pentadactylx; tribus mediis fubæqualibus, laterali utrinque dimidio breviore. Volae plantarum præter folos digitorum apices villofre, magis quam dorfum pedis; fed palmarum nudiufculæ, granulofæ, callo carpino gemino infigni, \& metacarpicis ad digitos minutis, ternis notatæ.

Cauda corporis circiter longitudine, craffa, cylindrica, fubadtenuata, tota pilis fulvis, fubtus albis, largiter veftita, extremitate laxius villofa \& fubfloccora. Ammuli caudæ inter pilos obfoletius apparent, numero circiter 200. 
Uropyginm fub cauda maxime fcroto prominet turgido, fubrugoro, nudiufculo, nigricante, poftica producta parte plane nudo, didymo; ano fupra gemellum tuber, epididymides continens, hiantc. Proputium breve, emarginatum, ante bafin fcroti antice incumbens.

Color fupra totus dilute gryfeo - fulvefcens, lateribus fenfim pallidior, pilis in dorfo omnibus fummitate fufcefcentibus, \& latente lanugine plumbea; Subtus animal candidum, ut \& circumferentia oris extremisque pedibus; fed jugulum \& hypochondria lutefcunt, \& ftriga fufco rufefcens, pilis brevibus denfis facta, a fterno per abdomen longitudinale. Cauda rufo - lutea. - In altero fpecimine meo dorfi color pallidior, in altero evidentius fufcefcens.

\section{ENS V R A E.}

Pondus fere biunciale.

Longitudo a fummo nafo ad ortum caudx

- ad fummum uropygium

- caudx fine pilo

- pilorum excedentium

- capitis a nafo ad nucham

Diftantia oculi a nafo

- aurium ab oculorum cantho pontico

Palpebrarum filfura

- apertura fere

Aurium longitudo ad verticem

- - ad externam bafin

- explanata latitudo

Latitudo nafi

Intervallum narium

Circumferentia roftri pone myftaces

- apicis roftri ante lab. inferius

- capitis inter oculos et aures

Diftantia oculorum filo per frontem

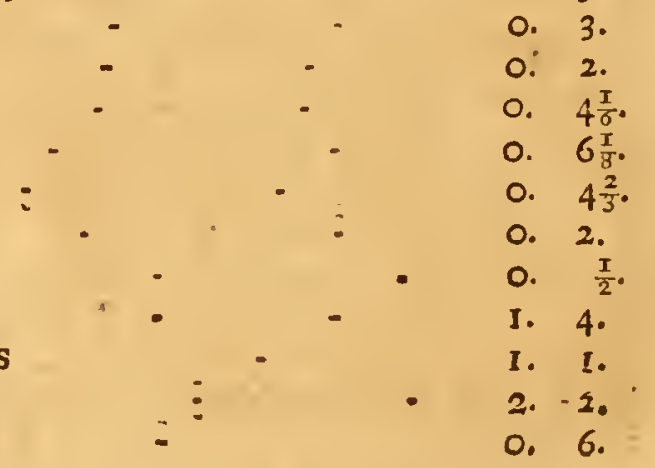


Diftantia recta per axin

- inter pof́ticos canthos filo

- - per axin

Intervallum aurium filo

Longitudo colli

Circumferentia colli

- thoracis ad armos

- - abdominis ad ilia

- Ccroti fub cauda prominentis

Longitudo fcroti a bafi praeputii

- praeputii

Circumferentia ejusdem

- caudae bali

Longitudo antibrachii

- palmae cum unguiculis

- digiti medii longiffimi cum ungue $\left(\frac{3}{4} . "{ }^{\prime \prime}\right)$

Circumferentia antibrachii bafi

- - carpi

Longitudo tibiarum

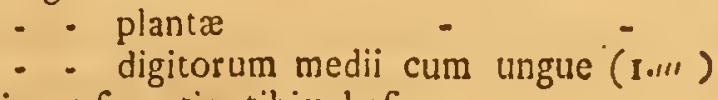

Circumferentia tibia bafi

- tibiæ ad calcem

- plantæe

Latitudo plantæ

- palmæ

Longitudo pilorum velleris in dorfo ad

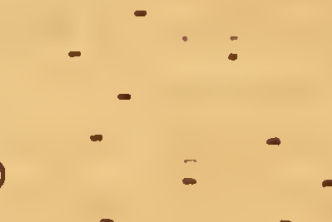

\section{A N A T O M E.}

Tab. $X X V$. fig. 6. - 8.

Subcutanece glandulæ inguinum, cum tractibus fuis vafculofis, infignes, grani triticei fere mole. Glandulce ad collum chylofe vix infigniores, quam in M. Mufculo. Subaxillaris mufcultes fubcutaneus infignis. Artuum pofticorum mufculi maximi, carnofifimi.

Ventriculhis (Tab. fig. 6.) a cardia ad pylorum per majorem arcum filo menfuratus $3 . " 2 . "$ "ii circumferentia amplifi$\mathrm{S} \mathrm{S} 2$ 
ma fere 2." intus lævis, præter plicam arcus minoris, dexterius ab afophago infignem, lunarem, craflam, papillis fubcallofis, majufculis crebram \& fubjentatan, unde ventriculus obiter bilocularis, utroque loculo ramentis herbarum viridium repleto. Inteftimm tentle longitudine so pollicum. Cœcum (fig. 7 a.) longitudine $3^{\prime \prime}$ amplitudine ferme digiti minimi, vix adtenuatum, obtufun, femicirculare. Stricturn ad infertionem Ilei, (litt. b.) ultra quam cellula exampliata (litt. c.), quam excipit inteftinum oblique friatum $(c-d$.$) ,$ figmoïdeo flexu curvatum, longitudine fere pollicis. Excretorium fexpollicare.

Teftes tumidi in froto, epididymide adnati. Veficula Seminales maximæ.

Diapbragma centro tendineo magno, ungulæ equinæ forma. Cor tefte ninus, \& vix pifo majus. Pulmo finifter fimplex, dexter quadrilobus, lobo impari longo, triquetroaçuminato, bafi dentato - laciniato.

Sceletoin a folita in muribus caudatis - cenformatione parum alienum. Craniam (fig. 8.) folidiufculum, olla inperforata rqualiter convexa, f:onte ad orbitas argute angulata, roftro perangufto, angulato, zygomatum anteriore radice latifima \& robufta, poftico margine ad frontem officulo peculiari, unguiformi appendiculata; tympanis maximis, fere ufque ad foramen occipitale exampliatis, folidiflimis. -

Spina dorfalis XII. vertebrarum proceffibus fpinofis; intermediorum infignioribus crects, anticis reclinatis; lumbaris VII. vertebrarum, quarum ultimæ proceffibus fpinofis \& transverfis infignioribus, inftuctx. Sacrlm triperforatum utrinque, adeoque quatuor vertebrarum, laminis latis coalefcentibus. 
utrinque alatarum. Cauda vertebrarum circiter XX. apex cnim in Ipecimine difiesto defuit. - Coftarum duodena paria. Sternnm manubrio robufto, carinato, officulis 4. intermediis, teretiufculis, \& enfe longiflimo, cartilagine fpathulato compofitum. O/fa itmominata ifchio latifimo, argute angulato. Fibulce ultra medias tibias, diftincta; offaque extremitatum in genere tenuiflima, fed rigida. Unguis pollicis in palmis officulo minimo fuffultus.

Longitudo cranii ab apice offium nafi Latitudo ollæ pone zygomata

- cranir fumma per tympana eademque zygomatum

- minima inter orbitas ad radicem zygomatum anticam

Longitudo oflium nafi

Latitudio eorundem \& roftri

- Longitudo inciforum fuperiorum

Longitudo mandibulæ.

- inciforum inferiorum

- vertebrarum colli collectim

$\therefore$ - omnium vertebrarum dorfi

- omnium vertebrarum lumbarium

- oflis facri

- Aterni mạnubrii

- a corporis

- enfis offei

- clavicularum

- fcapularum

- humeri

- cubiti ab articulo-

- - cum olecrano.

- ofium innominatorum

- ilei ufque ad acetabulum

- foraminis ovalis

Ejusdem latitudo

Longitudo offum femoralium

- tibiarum

- offium metatarfi mediorum

- offum metacarpi in palmis

: : fibule quoufque diftincta

I." 2 ."I

0. 7 .

o. $7 \frac{2}{3}$.

o. $2 \frac{3}{4}$.

o. 5 .

o. $1 \frac{\pi}{2}$.

0. 2 .

o. 7 .

0. 3 .

o. 4:

0. $11 \frac{x}{3}$.

0. $11 \frac{\mathrm{x}}{3}$.

o. 5 .

0. 2.

o. $5 \frac{\pi}{2}$.

o. 3 .

o. 4.

o. $6=$

- $6 \frac{2}{3}$.

o. 7 .

o. $8 \frac{I}{2}$.

o. $10 \frac{3}{2}$.

o. 6 .

o. 3 .

o. I $\frac{\pi}{3}$.

o. 10.

J. I.

D. $4 \frac{2}{3}$.

o. $1 \frac{2}{3}$

o. $7 \frac{\pi}{2}$. 


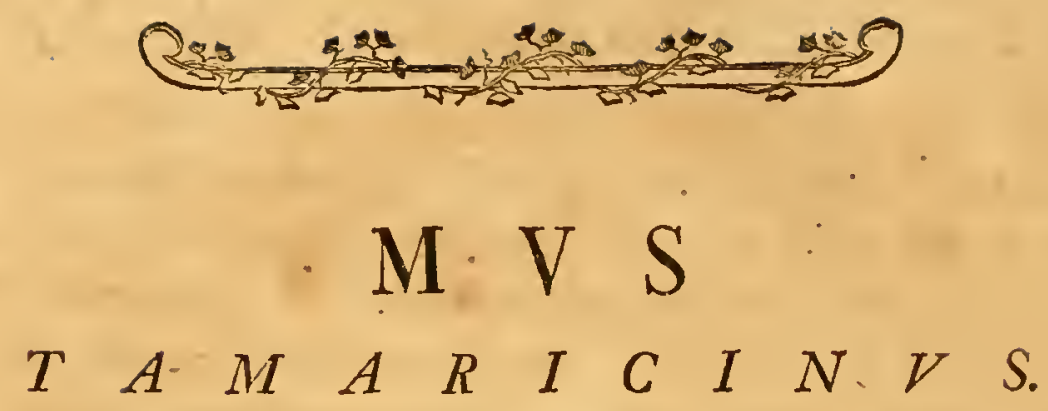

Hec quoque fpecies in maxime auftralibus deferti cafpici tantum obfervata eft, \& abinde forfitan per calidiorem Afiam frequens vivit. In depreflis falfis ad inferiorem Rhymnum, præfertin circa. Saratichikofka rivum Tamaricis gallicæ arbufto confitis, folitaria quidem, fed crebra habitat, indeque nominari poffe videbatur, quemadmodum Nitelam a quercubus, quas amat, cognominavit LinNAEvs. Soliti noftrx fpeciei cuniculi ad ipfas vulgo nodofas radices Tamaricis vifuntur, \& duobus oftiis feu canalibus, vix quatuor junctos digitos admittentibus, obliquis patent. Ad quosdam vix aliquid egeftæ terre apparet; ad alios, forte antiquiores \& crebro expurgatos, infignes cumuli. Profunditas cuniculorum tanta, ut 8. vel Io. amphoris aquæ infufis vix repleri queant. Immo vix poteft aqua exturbari animal, \& plerique quos habui, decipulis per noctem ante exitus omnes ftatutis capti fuere. Semper autem in decipulis mares, omnesque introëuntes captos fuiffe, notabile eft. Victum hos Mures e Tamarice capere vix crediderim; abundant vero in iisdem regionibus Nitraria, Salicorniæ, Salfolæ, Atriplices, aliæque maritimæ fucculentæ, e quibus aimpla alimenti materia. - De natura \& moribus haud quidquam difcere licuit, nifi quod noctivagos effe fatis conftat. Summa totius habitus fimilitudo, qua ad Nitelam . . M. quer- 
num accedit hæc fpecies, ad lethargicas feu hyeme fopitas referre jubet. Primo vere capti mares grandibus atque turgidiflimis erant genitalibus, externe tantundem confpicuis, ut in aliquo Sciuro exotico seBA delineavit. Hinc etian aftri tempus colligitur. - Cxterum inter majores \& pulcherrimas hujus generis fpecies hæc meretur collocari, præfertim quum primo vere nitido eft \& integro vellere (cujus confiftentia fere Nitelam. æmulatur), cauda etiam valde pilofa, fufcoque fubannulata infignis; quem ornatum cum venuftate vellcris æftate amittit. Genitalinm externorum mole congeneres facile omnes vincit, id quoque fingulare præferens, quod ante penem; per totam abdominis longitudinem, ad cardiam ufque confpicuus fit velleris, veluti pro facilitanda emiffone membri, fulcus latus, rafo quafi pilo lavigatus.

\section{DESCRIPTIO \\ $M V R I S T A M A R I C I N I$.}

Tab. XIX.

Magnitudo Muris decumani. Conformatione inter M. longipedem \& Nitelam medius videtur.

Caput oblongum. Nufus pubefcens, obtufus, convexus, fofforius, plica defcendente nares protegens, quarum feptum folfula impreffum, nudum.

Myftaces quinque ordinum, nigri, fetis longiffimis (ad I" I $^{\prime \prime \prime}$ ) extremo canefcentibus, anticis albicantibus. Verrucce fupraoculares tripiles, gularis bipilis, \& item bipilis pone carpos. 
Labinm fuperius bilobum, nec ufque ad nafum divifum; inferius craffum. Dentes primores antice fulvi, fuperiorcs fulco exarati, extremo obfoletius crenati, inferiores obtufi.

Oculi majufculi, furci; palpebarum margines nudi, furcefcentes. Altres nudiufculæ, ovales, infignes, margine leviter pubefcente fufco; intus plica obfoletiore transverfa ad atrium meatus.

Collum breve; tranci proportiones, ut in Nitedula \& affinibus; Artus fatis robufti, poftici longiores.

Pulma fubtetradactylæ, verruca pollicari obtufa, incruftata, infigni. Plante pentadactylæ, pollice breviore quam extimus. Digiti omnium pedum fubtus nudi, rugis velut incifi. Palmce callis 2 carpinis \& 3 fub metacarpo infignibus: Plante callis nudis ad bafin digitorum quaternis, reliquo ufque ad calcaneum fufco - villofe.

Cauda longitudine circiter corporis, e cylindrico leviter adtenuata, tota veftita, pilis præfertim extremo largioribus, annulis ægre numerandis, circiter 200. annulata.

Scrotum turgidifimum, nudiufculum, albidum, ovatum, poftice (una cum ano) inftar uropygii hemilphærici fubdidymi fub cauda protuberans, bafi pedunculatum praputio infigni, a quo rhaphe longius decurrit. Area lanceolata furca, minutiffimis, denfisque pilis pubefcens, a cardia ad hypogaftrium longitudinalis, ut in $M$. longipede.

Vellus mollius quam in Rattis, rudius quam Sciuris, ftrictum, longitudine in dorfo ultra 8. "' Color fupra totus gryfeo-lutefcens, pilis apice fufcefcentibus, lanugine tecta plumbea; verfus latera dilutior, poftice fenfim magis fufcefcens. Circumferentia nafi, oculorum, \& fuperciliorum macula, aliaque litura 
litura pone aures albicant. Capitis collique latera e canefcenti albida; ambitus oris \& fubtus corpus totum caudaque alba; Supra cauda cincrafcens, areis transverfis fufcis fubannulata, apice fubfloccora fufca. Plantæ fútuls longitudinaliter fufco: nigricantes, lituraque fagittato - oblonga cxterius in metacarpo', latiore parte articulo digiti ęxtimi contermina.

\section{ME N S R A E.}

\section{Pondlıs ad quatuor uncias accedit.}

Longitudo a fummo nafo ad ortum caudx

- cauda fine pilo

- pili excedentis

- capitis a nafo ad nucham

Diftantia oculi a nafo

Fiflura palpebrarum

Apertura oculi

Longitudo auris ad verticem

Latitudo auris explanatx

Circumferentia ejusdem bafi

- roftri pone myftaces

- capitis poft oculos

Diftantia inter anticos canthos oculorum

- inter pofticos canthos

- aurium per verticem

Longitudo colli

Circumferentia colli

- thoracis ad armos

- corporis ad femora

- . - in medio

- Ccroti fub cauda

Latitudo nafi

- - Septi narium

Longitudo fcroti a preput. ad anum

Circumferentia caudæe bafi Longitudo humeri
6."1 6."II

5. I.

o. 6 .

2. 1 .

o. II.

o. $4 \frac{5}{3}$.

- $4 \frac{i}{2}$.

o. $2 \frac{3}{4}$.

o. $7 \frac{4}{5}$.

o. $8 \frac{\mathrm{r}}{2}$.

o. 6 .

०. 9.

2. $2 \frac{\pi}{2}$.

3. 0 .

o. $8 \frac{2}{3^{\circ}}$

I. 0 .

c. $7 \frac{\mathrm{r}}{2}$.

o. 5 .

2. 8 .

4. 2 ,

4. 5.

4. 3.

I. II.

o. $2 \frac{3}{4}$.

o. 产.

o. 10.

o. 8 .

- $8 \frac{x}{2}$. 
Longitudo antibrachii

Circumferentia brachii ad bafin

ad carpum

Latitudo palmie

Longitudo femoris

- tibiarum

- plantarum digiti medii cum ungue (2."'j

Circumferentia tibix bafi

- ad calcem

- metatarfi

Latitudo plantx

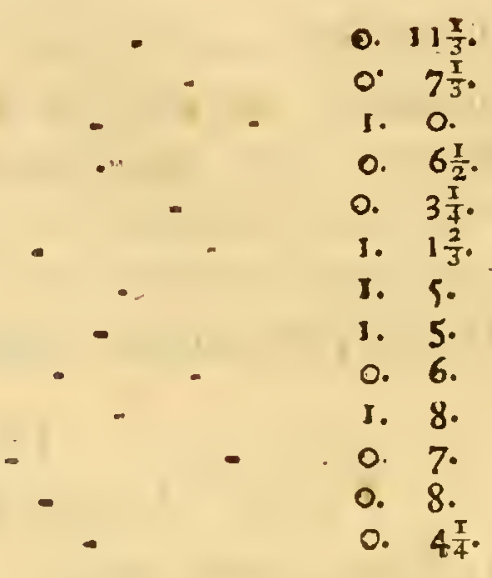

- $11 \frac{x}{3}$.

I.

o. $6 \frac{1}{2}$.

o. $3 \frac{\pi}{4}$.

1. $1 \frac{2}{3}$.

1. 5 .

1. 5 .

o. 6.

I. 8.

0.7 .

0.8 .

o. $4 \frac{\pi}{4}$.

\section{A N A T O M E.}

Tab. XXV. fig. 9. 10. 11.

Ventriculus (fig. 9.) latis carnolus, fundo toto fibris Iongitudinalibus externe evidentifime ftriato; intus membrana rugulofa æquabiliter obductus \& ramentis plantarum viridium refertus.

Cacum (fig. IO.) amplitudine digiti, in fpiram oblongatam compofitum, extremo fubadtenuatum, apice obtufo, fubdiftincto, veficulari (lit.. a.). Longitudo cœei in rectam extenfi 4." Continuatio crafi prinum in flexuram figmoïdeam arcte compofita (lit. b.), dein recta pergens, oblique ftriata $(b-c$.$) amplitudine 3 . " \sigma^{\prime \prime \prime}$ excretorialn intefinum anfractuofum 5." 6." At inteftini tennis longitudo tota 19. pollicum.

Omentum prolixum tenue, macilentuin. Hepar feptemIobato tripartitum; portione media incumbente biloba, in finu $c y$ fillem infignem continente; dexteriore lobo lato, magno; finiftro mucronato; fubtus papillari ad dorfum, \& duobus infuper pyramidatis, bafi coalitis. Dlıctus bilarius $\frac{\pi}{3}$ poll. a pyloro infertus. 
Renes ultra coftas fpurias, fere oppofiti; finifter tamen tantillo inferior. Teftes (fig. I I. a a.) mediocies, in facco tenui mufculari, epididymidzms capite inferiore adnato, plexu longiffino, laxe ambiente. Ductis deferentes ( $b$. b.) a tenui principio medio incraffati. Veficule feninales ( $c$ c .) duæ maximæ, turgidifima pelvim excedentes; duæ fuccenturiate ( $\left.\begin{array}{ll}d & d .\end{array}\right)$ faccidiores. - Folliculi Cowperiani ( $e$ e. $)$ ifthmo urechræ adfidentes, infignes. Genitale (litt. $f$. ) mediocre, ftructura glandis fere ut Criceto. Vefica arinaria (litt. g.) proportione parva.

Diapłragmatis centrum tendineum magnum, cordatum. Pulmo dexter quadrilobus, imo pone cor latente; finifier unilobus, integerrimus.

Coftce utrinque XII. veræ 7. fpuriarum adnexæ 3. liberx 2. vertebra lumbares VII. facri IV.

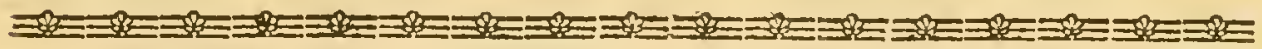

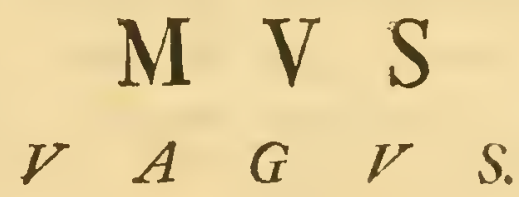

Per totum defertum Tataricum frequens, certisque temporibus migratoria effe videtur parvula Muris fpecies, quem a vitæ genere vagum voco. Primum obfervatus circa Iaïkum in deferti auftralioris arenofis; dein fxpius in arenofis item camporum ad Irtin oblati fuere, curfitantes omnes vefpertino temporc. Magno numero \& in ipfa forte migratione eosdem $T \mathrm{t} 2$ 
in Kirgifiorum deferto, montofis locis circa Irgis \& Kamifchli rivos, caftra noctu frequentantes obfervavit, mihique transmi-. fit Centurio, Nicol. RYTschkof, in cujus meo aufpicio perpetrati Itineris iol. III. p. I 5. nomine Tatarico DfbilkisSit. kan (gregalem id murem fignificat) indicatul; ut quod ex obfervatis fubinde confertis horum murium per deferta migrationibus ortum duxit. "). Nidulatur - in fifturis faxorum, antris aliorum murium derelictis, fub lapidibus, imo truncis quoque arborum proftratis vel excavatis. Quamvis ad Irtin Iamifchevam ufque \& in betuletis inter Obum \& Ienifeam ultra 57 gradum latitudinis obfervatus fuerit, in gelidis regionibus brevique æetate gaudentibus, tamen adeo impatiens eft frigoris, ut etiam Iunio menfe frigidulas aquilone noctes conglobatus (ut Figura noftra expreffum eft) perdormiret, gelidioreque aëre torpidiflimus redderetur. Eoque \& cyftidis bilarix prefentia, differt a Muribus, quos alias cauda habituque refert, myofuris mihi dictis, nulloque vulgo brumali gelu obtorpefcentibus. ${ }^{b}$ ). Eosdem tamen æmulatur appetitu carnario; etenim inclufum aliquando Murem hujusmodi, cum duobus ejus fpecici, quam M. minuti nomine defcribam, ambo intra unius noctis fpatiun enecaffe, exefoque cerebro \& parte thoracis mutilafie expertus fum; feminibus licet variis,

a) Conf. qux in Not, k. ad M. œco. nomum adlata funt.

i) Mus domefticas minor $f$. Mufculus media hyeme in domibus \& promtua. riis etiam frigidis vagatur, fummo ta. men regnante gelu vix apparet. Et hoc de vulgari fen naturali intelligen. duon: contra Murem candidiffimum, oculis corallinis infignem, hoc' proxime elapfo autumno Petropoli in conclavi captum habui, qui quoties aëri etiam non ad glaciem ufque frigenti per horam exponebatur, obtorpuit, vix fenfum prodens, calidoque reddita, pandiculatione \& ofcitatione multiplici prævia, reftituebatur. Erat tamen vulgaris fpeciei varietus. 
quæ alias amare videbatur, fuppetentibus. Scandit ceteroquin - egregie, M. avellanarii more, expanfis palmulis \& cauda quoque circumflexa fubinde fufpendit corpus vel adjuvat.

\section{DESCRIPTIO

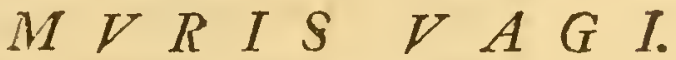

Tab. XX11. fig. : :

Magnitudo vix fupra M. minutum; facies $M$. agrarii.

Caput oblongum, roftro obtufo, nafo rubicundo. Nares diftantes, fepto lato, utrinque lunula nares marginante proninulo, medio depreffo, fed ftria convexa notato.

Labium fuperius haud profunde bilobum, obfoleta verfus nafum impreflione. Dentes primores utrobique lutei, fuperiores truncati. Molares fupra duo fubæquales utrinque, infra terni.

Myftaces teneri, cani, capite breviores. Pilns fupraciliaris unicus. Oculi mediocres, media inter nafum \& aures diftantia.

Auriculce (ut in M. fylveftri) infignes, ovales, nudiufculæ, anteriore inflexo margine exterius, areaque interius verfus apicem fufco - fubvillofæ.

- Artus graciles, teneri; pedes extremi nudiufculi, fubfquamofi. Paline tetradactylæ, verruca conica, extus callofa infigni loco pollicis. Plante pentadactylæ, verfus digitos fextuberculatæ, fubtus ufque ad calcaneum nudæ, utroque margine inflexis villis fimbriatæ. 
Canda corpore longior, adtenuata, paulo pilofior, quam in M. Mufculo, fed minus, quam in M. agrario, annulis cvidentiffimis circiter 170. fquamata.

Vellus mollifimum, læve. - Color fupra pallidocinereus, pilis nigris mixtus \& quafi undulatus, linea fpinali a nucha vel tantum a fcapulis ad caudam nigra (quibusdam vix a medio dorfo); Subtus e cano albicans fupra lanuginem fufcam. Artus extremi albicant; pili caudx, nifi fupra, cani.

Mammce 2 pectorales intra armos, 4. abdominales, quarum priores ad ipfum coftarum marginem, 2. inguinales ad bafin femorum; omnes pullitici tempore papilla infigni rugofa, areaque nuda valde notabilcs. Vulva cum ano intra orificium bilabiatum fere commune.

\section{ENS V R A E.}

Pondus in fibiricis paulo minoribus fere duum drachmarum obfervavi. His longitudo 2." I"' cauda 2." 7." capi-

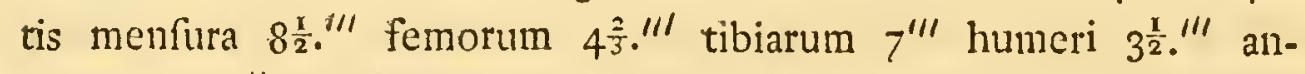
tibrachii 5." Ex hoc anatomen deinde, menfuras vero fubtiliores e fpecimine Jaïcenfi femineo, quod $2 \frac{\pi}{2}$ drachmas xquabat, apponam;

Longitudo a fummo roftro ad ortum caudx - caudx

- capitis a nafo ad nucham

Diftantia oculi a nafo -: auris ab oculo

Palpebrarum fiffura

Longitudo aurium ad externam bafin 
Longitudo ad verticem

Latitudo aurium explanata

Circumferentia roftri pone myftaces

- capitis inter oculos \& aures

Diftantia oculorum per axin

Longitudo colli

Circumferentia colli

- thoracis loco ampliffimo

Longitudo humeri

- - antibrachii

- palma

- femorum

- tibiarum

- planta

\section{A N $\triangle \mathrm{T}$ O M E.}

Tab. XXV. fig. 12. 13.

Glandulce circa collum \& fub armis largæ, ut in omnibus hyeme torpentibus. Glandula (an lacrymalis?) lumbriciformis, alba, duriufcula, longitudine fere $\sigma^{\text {"II }}$ tenui initio ex orbita prodiens \& fecundum collum utrinque extenfa.

Hepar conftans: lobo finiftro maximo, crafo, reliquos fimul fumtos fere rquante; media portione in 2. lobos fciffa, quarum dexterior major, fubtus peculiari foffa, fciffur: parallela continet cyftidem oblongo - anguftatam, exilem, flaccidan; lobo dextro fubrotundo triangulo, fubtus valde gibbo; quinto trapezoïdeo, aliquoties incifo. Lobulus fpinalis duplex, fubrotundus, altero majore.

Lien linearis, anguftifimus, Iongitudine $4^{\frac{1}{2}}{ }^{\prime \prime}$ " Iatitudine: vix femilinex. 
Ventriculus (fig. I 2.) fimplex, reniformis, fundo paulo ampliore, obtufifimo; ambitu maximo a pyloro ad œfophaguin $1^{\prime \prime} 2^{\prime \prime \prime}$ circumferentia fumma $9 . "$ "'

Inteftimum tenue rexpollicare. Cacum (fig. I $3 \cdot a \cdot$ b.) lumbriciforme, fummo apice (a.) inflexo, tota longitudine I" I"' Inteft. (lit. c.) oblique ftriatum arcuatum 10" Ex. cretorium (lit. d. cet.) 1." 6."'

Ren dexter paulo anterior, oblongior, minorque; finiAter latior. Glandulce renales ipfi vertici adfidentes. Cor-

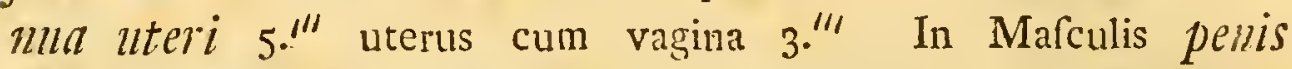
glande craffa, fubtus bilobo - fifla, fubtilifime papillofa. $V e$ ficulce Spermatica oblongo - adtenuatæ, craffiore extremitate extrorfum verfus pelvim reflexæ. Bulbus proftate teftibus major (tempore oftri vernali.).

Pulmo dexter quadrilobus, quarto fpinali lobo diftincto, per fola vafa cohærente; finifter integerrimus.

Sceleton: cranii forma vix a M. Mufculo recedit; ifthmus tamen inter orbitas multo latior, quam roftrum; roftrumque a bafi adtenuatum; tempora totunque cranium convexa, angulo eminente nullo; zygomata antrorfum lata; ofla nafi roftro longiona. Coftarmm XII. paria. Vertebra lumbares VI. facri II. caudæ XXXV. præier apicem tenuifimum. Pubes arcu tenui offeo cohærens. Menfurce oflum in fpecimine deferti Kirgifici fequentes fuerunt:

Longitudo cranii

Laticudo pone 7.ygomata fere

- - inter orbitas

- . per ipfa zygomata

- bafeos roftri

Longitudo roftri

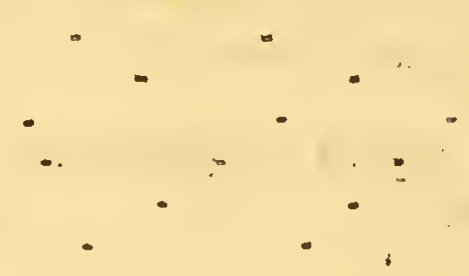

$0.118 \frac{2}{3} .111$

O. 4 .

o. 2.

๑. $4 \frac{\pi}{3}$.

จ. $1 \frac{\pi}{2}$.

o. $2 \frac{1}{2}$.

Longi. 
Longitudo maxillæ

- vertebrarum colli collectim

- - - dorfi fummaris

- lumbarium

- facri

- cauda

- fcapula

- - humeri

- cubiti

- oflium innominatorum

- ilei adufque cotulam

- femoris

- tibix

- calcanci

- oflis metatarfi longiflimi

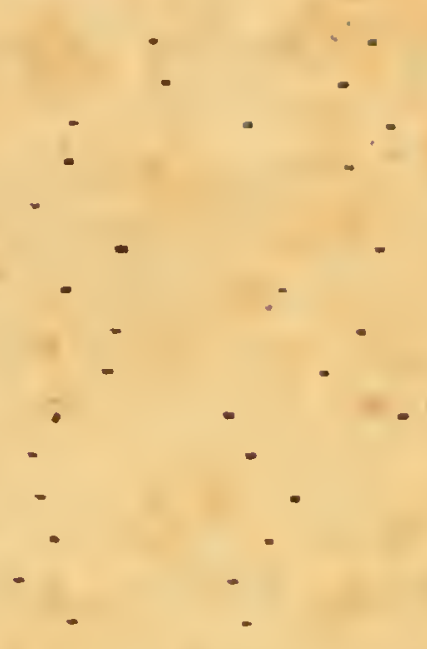

$0.114 \frac{1}{4} 111$

0. $2 \frac{1}{2}$.

o. 8 .

o. $5 \frac{2}{3}$.

o. $1 \frac{3}{4}$.

3. 2.

c. $3 \frac{2}{3}$.

o. 4 .

o. 5 .

o. $5 \frac{x}{2}$.

c. $3 \frac{\pi}{5}$.

o. $4 \frac{1}{2}$.

o. 6 .

o. $1 \frac{\mathrm{r}}{2}$.

o. $2 \frac{1}{2}$.

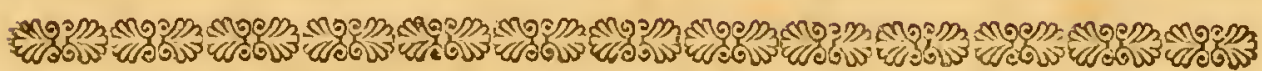

\section{V S \\ $\begin{array}{lllllllll}B & E & T & V & L & I & N & V & S \text {. }\end{array}$}

$\mathrm{H}_{\text {anc }}$ fpeciem, in hoc genere inter minimas celebrandam; primum credidi præcedentis ( $M$. vagi) effe varietatem, fub eoque titulo in Itinerarii Vol. II. appendice conjunxi. Sed occurrentibus poftea pluribus, colore \& parvitate conftanter diverfis, præfertim vero longiffimæ proportione caudæ difcrepantibus, fpeciem jam diftinctam pronunciare nullus dubito. Uti multo fubtilior, ita \& tenerior eft $M$. vago, ita ut vix LX. graduum Farenheitianorum temperiem ferat, quin conglobatus obdormifcat. Et frigidiore quidem aëre, præfertim noctibus, plane fit torpidus; fi minori gradu, tunc irritatus pofticis pedibus repugnat, lenemque foricinam vocem edit, $\mathrm{V} \mathrm{V}$ 
quam alias ciariorem, fed raram, tenerrime murinam habet.

Obfervavi hunc Murem præfertim in betuletis camporum Ifchimenfum, \& Barabenfium, inque fylvis inter Obum \& Icnifeam fitis - fporadicum. Semel in nido torpentem inveni primo vere, eratque is intra corticem betulini trunci penitus putridi, humique jacentis, c cujus ramentis lignofis ficcis cubile fibi paraverat. - Diu vivos alui, \& cicurantur facile, ut manibus foveri gaudeant. Currunt in omni plano, cxpanfis digitis hærentes, fimul juvante cauda magis adhuc, quam præcedentis, volubili circaque ramos inflexili. Vidi culmos'graminum robultiores fcandentes, quos corporis pondurculo vix flectebant. Et forent utique minimi inter omnes quadrupedes, nifi Mus minutus \& Soriccs aliqui de parvitate. certarent.

\section{DESCRIPTIO \\ $M V R I S \quad B E T V L I N I$.}

Tab. XXIT. Fig. I.

Magnitudo infra M. vaguns. Roftrunn acutius, nafo rubicuncio. Myftaces fere teneriores, cani. Alniculce paulo minores, plicatiles, fufcx, apice fubbirfutæ.

Corpus ftatura præcedentis; artus itidem tenerrimi, extremo nudiufculi albidi. Palme tetradactylæ, pollicis ver-

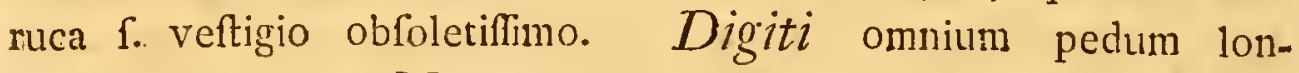
giores, quam in M. vago, tenuiffimi, divaricato = prehendentes. 
Cauda longiffima, corpore multo longior, tenuis, adtenuata, annulata, rarius pilofa, fupra fufca, fubtus albida.

Vellus fupra totum (ut in M. agrario) gryfeo - ferru- . gineum, pilis pauciffimis, fufcefcentibus infperfum, paulo magis rude, quan in M. vago; fubtus cinerafcente - albidum. Struga dorfalis atra a fcapulis vel ccrvice incipit, per fpinam lata, verfus caudam adtenuata.

MEN S V R A E.

Pondus drachmam unam cum fcrupulo in nullo fuperat.

Longitudo ab apice roltri ad anum

- capitis

- cauda
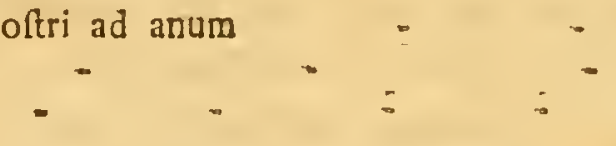

$2.113 \frac{1}{2} \cdot 111$

o. 10.

3. $2 \frac{r}{4}$.

\section{$A N \wedge T O M E$.}

Ventriculus fimplex feminum farinaceorum minutura refertus; circumferentia a pyloro ad cardiam per arcum majorem circumducto filo I." $7^{\prime \prime \prime}$ circumferentia ad œ

Inteftiminn tenue crafitie calami tenuioris, longitudine 7." 9." Cecei pars adfcendens r." 5."' portio defcendens, cui medio inferitur ileum 8." Inteftinnm ftriatum 9." excretosilum I." I0."

Teftes mole pif, fubglobofi; epididymides lineares, inferiore extremitate globulofa $10 .^{\prime \prime \prime}$ Veficulce feminales infigniter clavatæ \& incurvatx, cxtenfe $8 \frac{1}{2} . "$ ' æquant.

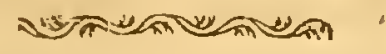

$$
\mathrm{V} \times 2
$$




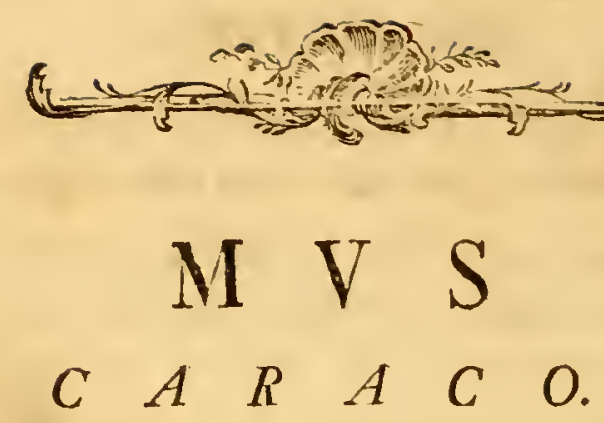

$S_{\text {atis diu furpenfun, me tenuit hac fpecies, Muri decumano }}$ f. Ratto fylveftri Europam infeftanti perfimilis. Prxcipue adtentionem excitabat, quod Mus ille decumanus, xque ac vulgaris Rattus, per ommem Sibirian ignorantur \& jugum Uralenfe nondum videntur transmigrafle. Non magis citra Ienifeam apparuit Mus Caraco, fed in transbailkalenfibus demum regionibus \& eirca ipfum hodie Baikalem abundat, quem borealem terminum nondum tranfgreflus eft. Comparatione igitur inftituta vidi a M. decumano diverfam, licet admodum fimilem, effe fpeciem, que forte ex auftralioribus Chinæ in Sibiriam noftram enigrare copit, vel orientalioribus $\Lambda$ fix regionibus propria femper fuit. Mongolis certe referentibus circa aquas \& lacus prefertim majores montanæ regionis, quam coIunt, frequens vivit \& nomine Cbarachy vel magni muris (Fike - Cholgonach) nota eft. Habet enim hoc quoque cum M. decumano commune, ut aquarum viciniam amet, inque ripis lubentius cuniculetur \& facile natet, immo magis hydrophila fereque amphibia cenfenda eft. In cultis autem regionibus itidem domefticum frepe vitæ genus eligit \& fine dubio in populofiore China nocentifima eft.

Difert a M. decumano capite minore, dentibns minus: robutis, fuperioribusque vix fulvefcentibus; proportionibus- 
nonnullis artulum, pofticorum præfertim robore, palmarum verruca pollicari obfoletiore \& molliore, digitis omnium pe. dum per plicas fubfemipalmatis, caluda longe breviore, truncum circiter æquante obtufa, cætcroquin fimili; pilo per totum corpus molliore, tencriore, minus hirto; vertebrarum denique numero; codemque fere gradu diftat, quo Rattus, nifi colore effet fimilior *).

\section{DESCRIPTIO}

\section{$M V R I S C A R A C O N I S$.}

Tab. XXI1T, A.

Magnitudo \& facies M. decumano proxima; fed caput proportione corporis anguftum, valde oblongatum. $R$ ()frum fuperiore maxilla maxime productum, ultra maxillam craffufculum, obtufum. Nafis majufculus, fepto lato, rugofo, nudo. Aures a nucha antrorfum remotæ, oculique auribus quam nafn propiores - infolitum adfpectum conciliant.

Myftaces copiof, rigiduli, fed capite breviores, quinque ordinum, fuperiores fufci, inferiores albidi. Verrnca fupraocularis bipilis; pili tres minuti in verruca gulæ.

Labiam fuperius ufque ad nafum refciffum. Dentes primores fuperiores lutefcentes angufti.

$$
\mathrm{V} \text { \ } 3
$$

*) Subdabito an huc tanquam varie- "nigrum, fubtus neutiq̨uam candidum; tas referri debeat, vel diftinetus fpecie "caudam breviorem quam in Sorice fuerit: "Glis riparius major vel monta- "vel Ratto, ceteroquin fimilem; pedes nus fylvefiris MESSERSCHMIDII " ubique pentadactylos; pondus in maf. Hodeget. anno $1724 ., M$ S Septembr. de "culo VI. fere unciarum." Nec plura quo circa Dalay. Noor Davurix obfer- reliquit; a $M$. amphibio tamen diftinxifrato breviter indicat: "Vellus undique re apparet. 
Oculi mediocres. Atrres majufculx, ovales, extus villofa, interius præfertim bafi nudx; tragis nullis, neque margine ullo meatus aperturam antice coronante.

Collnm craffitie capitis, longiufculum. Corpus retrolfum maxime ventricofum, femoribus carnofflimis.

Artus poftici majores. Pedes nudiufculi, fubfquamofi: Palnhe parvæ tetradactylæ, plicis fubfemipalmatæ unguiculo pollicari nullo; fed vermica papillaris, mollis, fubincruftata ad carpum. Planta pentadactyla, digitis tribus intermediis fubæqualibus, baf plica connexis, omnibus brevibus, præfertim pollice. Unghes parvi acuri. Volæ pedum glabre, anticorum callis 2. magnis fub carpo, 3. ad digitos, pofticorum callis 4. ad digitos, duobus fub metatarfo.

Canda longitudine circiter trunci, bafi ad femipollicem villofa, dehinc adtenuata, fed apice obtufa quafi præmorfa, minufque extenuata quam in Ratto \& $M$. decumano, quorum ftructuram ceteroquin craflitic \& fquamofitate refert, pilis tamen crebrioribus, minusque rigidis. Ammuli fquamulofi circiter 150. (at in Ratto decumano fere 200.)

Anls in ipfa bafi caudx; vulva ab ano remotiufcula, apertura rugofa, ante quam adfat papilla diftincta infignis, cutacca, extremo bilabiata, atque hiatu urcthre cava, ut hermaphrodite facile videantur femine. Mamma octo, duæ pectorales, totidem inguinales, quatuor alvinæ a pectoralibus remotiores.

Vellus fupra fufco - gryfeoque mixtum, fubtus cinerafcente albidum, minus rigidum, quam in $\mathrm{M}$. decumano, cujus colo. rem apprime refert; pedes fordide albi; cauda fupra longitudinaliter fufca. 


\section{E N S V R A E.}

Pondus inter fex \& feptem uncias variare folct.

Longitudo tota a fummo nafo ad anum

- capitis a nafo ad nucham

- caudie

Circumferentia caudx baft

Longitudo roftri ultra maxillam prominentis

A rictu oris ad fummum nafum

Longitudo myntacum

Dillantia oculi a fummo nafo.

- auris ab oculo fere

Fiffura palpebrarum

Auris altitudo ad externum linum

- ad verticem fere

Circumferentia roftri fuper. ante maxillam

- roftri pone myitaces

- capitis ad oculos

- - - inter oculos \& aures

Diftantia inter oculos filo

- per axin

- Marium f. latit. fepti

- aurium per gulam

- - - in vertice

Longitudo colli

Circumferentia ejusdem

- thoracis ad armos

- - loco amplifimo

- abdominis ad femora

Longirudo antibrachii

- palmæ

- - digiti medij (cum ungue I.")

Circumferentia antibrachii bafi

- carpi

- tibia verfus femur

Longitudo tibiæ

- plantx

- digitorum mediorum (cum ungue $\frac{2}{3} . " 1 \prime$ )

Latitudo plicarum inter digitos ad

Latitudo planta

Circumferentia tarfi.
6." 9.111

I. $7 \frac{2}{3}$.

4. 6.

0. $9 \frac{\mathrm{x}}{3}$.

c. $5 \frac{\pi}{3}$.

c. 7 .

3. 6.

o. 8 .

0. 4 .

○. $2, \frac{T}{3}$.

o. $6 \frac{1}{2}$.

o. 6 .

1. 5 .

I. $9 \frac{\mathrm{r}}{2}$.

2. 4 .

2. 8.

o. $6 \frac{\mathrm{r}}{3}$.

0. 6.

0. $1 \frac{\pi}{8}$.

I. $7 \frac{1}{2}$.

0. 7 .

0. 6 .

2. 6 .

3. 7.

4. 2.

4. 4 .

0. 1 I.

- $8 \frac{\pi}{3}$.

o. $3 \frac{\pi}{4}$.

I. $2 \frac{1}{2}$.

o. 7 .

2. 1.

I. 2.

1.3.

o. $5 \frac{3}{4}$.

O. I.

o. 4

o. $\frac{T}{2}$ 


\section{$A N A T O M I C A$.}

Glandula large circa collum. Glandula' dua inguinales, in temina quoque infignes. Interanea vix a Ratto direrlit.

Coffa XII. parium. Tertelya lumbares VI. fieri $I V$. caudx cum apice XIVII. quarum extrenas tenuillima, longillima feptima, cique proxima, $3^{\prime \prime \prime}$ circicer aquantes. Stemli verebre intermedix 11 .

Longirudo cranii decorticati

- versebrarum colli omnium

- . dorlalium

- . - lunbarium

$\therefore$ Pacri

- caudir

- Rerni manubrio

- . - parte intermedia

-. enfis line cartilagine

- clavicularum

- Rapularum

Laticudo earundem

Longitudo humeri

- cubiri

- curpi

- mecacarpi medii

- phalangis med. dig. prime

- . . lecundx

- unguis cum articulo

- olfis innominati

- femoris

- tibia

- tarfi cun caleaneo

- mesasarli medii

- phalsngis primie

-. - Pecunda

- unguis

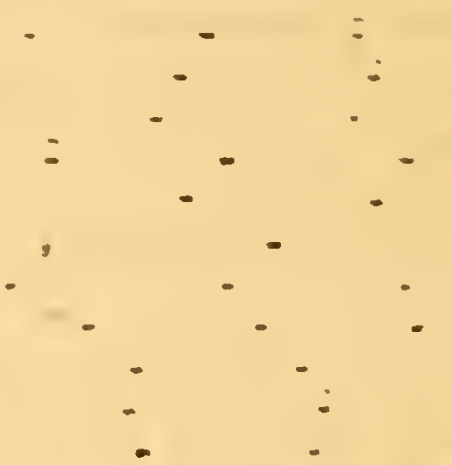

1." 111

o. $7 \frac{1}{3}$.

1. $9 \frac{1}{3}$.

1. $4 \frac{1}{2}$.

c. $9 \frac{1}{2}$.

5. 0.

o. 3 而.

o. $\$ \frac{1}{2}$.

o. 4 .

c. 6 .

o. $\$ \frac{1}{2}$.

o. $6 \frac{\mathrm{t}}{\mathrm{s}}$.

C. $9 \frac{3}{5}$

o. IT.

o. II.

o. 2

o. $1 \frac{3}{3}$.

c. 1 .

o. $\quad \mathrm{I} \frac{\mathrm{T}}{4}$.

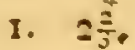

I. 0 .

I. 2 .

o. $5 \frac{1}{2}$.

o. 5 .

c. $2 \frac{3}{10}$

○. $1 \frac{1}{3}, 1$

0. $1 \frac{\mathrm{T}}{3}$ 


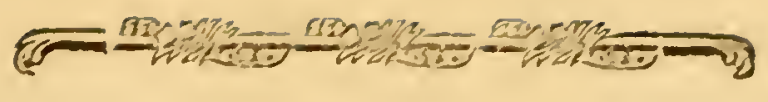

\section{$\mathrm{MV} \mathrm{S}$ \\ $A \quad G \quad G \quad A \quad R \quad I \quad V \quad S$.}

Wirum, hanc fpeciem, quam Germanix fegetes infeftare \& ibi nonnunquam gregatim adventare mihi certo conftat, quippe quam circa Berolinum quonḋam anno, migratione murium mire frequenti, puer ipfe memini vidiffe, quamauc Celeberr. schrebervs ad lisigarva a fe transmiftam in Litteris adfirmat, imo cujus SCHWRNKPELDYs in theristrophen Silefice diftincta definitione meminit "), hactenus inter dubias \& non defcriptas fuiffe. - In Ruffie \& Sibi. riæe temperate agro cultis regionibus ab Iftro ufque ad Ienifeam frequentifima eft. - Or:gine quidem fylveftris effe videtur \& habitu, viræque genere proxime ad M. fylvaticum accedit. Sed maxime pullulat circa fegetes \& cannabim, \& nufquam majore numero anparet, quam fub mergetum autumno in agris congeftorum cumulis \& fub frumenti acervis, quos ruftici harum regionum in campo prope pagos fub dis ftatuunt. Ruficum hine nomen Sbitnik, (Mus fegetalis) nactus eft. Et fic quidem ubique omnibus annis faris frequens \& frumento noxius eft, affociatus plerumque M. Mufculo, minuto \& fylvatico. Sunt tamen anni, quibus vel annona, vel humiditate aliisve caufis alicunde abactus, immenfis catervis quasdam frugiferas regiones inundat, \& agricoiarum fpem autumnalem voracirate fua minuit. Audivi hac de re frequentes pafim, in Cafanienfi præfertim regno, agris felicifimo, querclas; \& inter alia circa

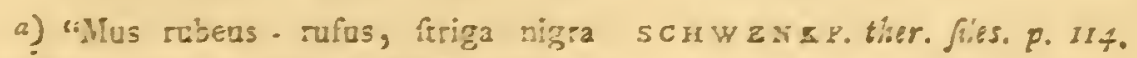
"do:fali, rentre albo, dentibus ful ris" 
annos 1763 . aut 64. tota regio circa Cafaniam \& Arfk oppidulum, verfus autumnun tanta vi horum murium infeftata fuit, ut non folum in agris \& fub frumenti accrvis turmatim habitarent, fed domos etiam (quod alias vix faciunt) replerent \& præ fanie coram homine panem e menfis furarcntur, inque ipfis pæne manibus audacter roderent; donec ingruente hyense difparuerunt**). In cultis inter Obum \& Ienifeam, ubi multo majores funt Cafanienfibus, autumno in agris \& prefertim novalibus abundantes, proprioque marte cuniculantes obfervavi. Fodierunt finguli fub ipfa molli terræ fupcrficie ductum longiffimum, fublevata \& paffim accumulata terra confpicuum, cum camera haud profunda', quam inhabitant, \& in quam ad penum hyemalem colligunt femina varia. Ibi vulgo quinque drachmarum pondus excedunt, quum Cafanienfes raro quatuor æquent; imo habui marem ad Tfchom rivum initio Seprembris (fcroto tunc tumidifimo \& uropygium fub cauda prominulum eficicnte notabilem) qui unciam integram \& cum $1 \frac{\mathrm{T}}{4}$ drachma ponderavit, muresque fylvaticos majores æquabat. In Sibiria maxime orientali deturne M. agrarius? mihi non certo conftat; in auftralibus defertis fylva deftitutis omnino deeft.

\section{DESCRIPTIO \\ $M V R I S A G R A R I I$. \\ Tab. XXIV.A.}

Paulo minor M. fylvatico; Mufculo longior atque gracilior, capite oblongiore, roftroque acutiore.

*) Vaftationes etiam a Muribus fyl- cap. I2I.) ubi propter glandes faginas, vaticis, huic fpeciei alfinibus, interdum Gliribus prefertim gratas, alios quoque committi, migratoria congregatione, ve- mures e longinquis regionibus Carniolix, rofimile eft. De his forte intelligendus Styrix atque Carinthix fylvas ingredier,

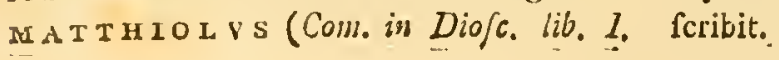


Nafus fupra hirfutus, fufcefcens. Buccae intus areola pilis pubefcente. Dentes antice lutei. Myftaces parciores, vix quatuor ordinum, nigricantes; pili fuboculares vellere parum longiores, fupraocularis longior, folitarius.

Oculi medio inter nafum \& auriculas. Auriculce paulo minores, quam in Mufculo, ovales, cave, intus gryfeo fubpilofx; tragus etiam minus prominens, marginis inftar; conduplicatæ auriculæ vellere latent.

Corpus gracile, longiufculum extenfo; artus fubtiliores, quam in Mufculo: palma tetradactylæ, unguiculo pollicari obtufo, minutiffimo, cum in Mufculo tantum fit callus convexus. Plantee pentadactyle, interiore parum breviore. Solece pedum nudx, vix margine ciliatx; ungules albicantes.

Catda dimidia totius longitudine, linearis, tenuior breviorque, quam in M. Mufculo, pauloque pilofior, annulis circiter XC. (at in Mufculo fere CC.) fupra longitudinaliter nigrefcens, cæterum albicans.

Color velleris (ad cutem fufcus) extus fupra gryfcoferrugineus, pilis rariffimis fufcis, vix inquinantibus, at in capite crebris; latera paulo dilutiora; fubtus ab ore ad anum canefcenti albus, pedesque extremi toti albi. Annullus furcus fupra calcaneum pofteriorum; Striga nigra dorfalis ab occipite, paulo citra caudam definens.

Scrotum œftri tempore maribus turgidifimum; tubere didymo, fufco, nudo fub cauda prominens.

\section{MENS VRAE.}

Pondus a $3^{\frac{\mathrm{T}}{2}}$ ad 4 drachmarum vulgo effe folet; fibiricis majus. 
Longitudo vulgaribus a fummo nafo ad ortum caudro

- capitis ad nucham

- caudæ

- brachiorum

- palmarum

- tibiarum

- plantre cuar unguiculis

Circumferentia capitis inter oculos \& aures - - - $\quad$. 9. - - thoracis

Diftantia oculi a nafo

- aurium ab oculis

Altitudo aurium

Latitudo aurium

\section{A N A T O M E.}

Tab. XXV. fig. 14. 16.

Omentum totumque corpus macilentum in omnibus; etiam autumno \& hyeme. Glandule inguinales cum tractibus fuis rubicundis in imis hypochondriis, proxime ante femora politæ. Glandulce paroticæ non ita difcoïdcæ, ut in $\mathbf{M}$. Mufculo, fed oblongæ, acinofæ \& rubicundx, pancreatis fimiles. Interanea foetidifima, facillime putrefcentia.

Hepar (fig. I 4.) tripartitum: Iobus finitter (lit.,a.) major reliquis, femi - difcoideus; medius bipartitus (b.c.) laciniis inæqualibus; dexter duplex, altero (lit. d.) ovato, gibbulo, altero renali (lit. e.) triquetro - pyramidato, pro rene excavato; Spigelianus (lit. f.) parvus, difcoidcus. Cyftis omnino nulla.

Lien triqueter, linearis, utrinque obtufus, 9 linearum longitudine.

Ventriculus (fig. I 5.) ampliufculus, reniformis, fubftantiis in medio, ad infertionem œfophagi difcretis, ita ut verfus fundum (lit. a.) tunicæ fint tenuiores, pellucidæ, altera dimidia pars (lit. b.) ufque ad pylorum glandulofior, rubicunda. Intus plica membranacea annularis duo cava interftinguit. 
Inteftimum tenue calamo anatino capacius, a pyloro ad cœcum pedali longitudine: Ileon jejuno paulo anguftius, in uno diffectorum continens Taniolatn tenuifimam, pollicarem.

Cactm ( fig. 16. $a$-b.) pollice longius, femicirculo curvatum, fubadtenuatum, obtufum. Inteftinnm oblique ftriatum (lit. c.) bis contortum; excretorinn tenuius, 3." 6."' longitudine, continens excrementa molecularia, oblongo - acuta, arenacea.

Coli cœcique figura accedit hæc fpecies ad Cricetum, cui etiam pars coli ftriata bis contorta, intus rugis obliquis magna e parte ftriatum (quod BVFFonivs bis notavit).

Ren dexter dimidia longitudine altior. Globnli fuprarenales lutei, milio majores. Teftes vix cannabino 1cmini pares extra oftri tempus; epididymidis capite extra abdomen defcendentes. Penis minufculus; Glans fanguinea, tripapillaris, papilla media prominula, acutiore, in quam inferitur officulum lineare, minutiffmum, longitudine glandis, circiter $\frac{2}{3} . "$ Glandule lumbares fupra medium vertebrarum lumbarium, inter ureteres.

Pulmo finifter indivifus; dexter quadrilobus, quarto impari, pone cor majufculum, renibus majus.

Sceleton ut in M. Mufculo.

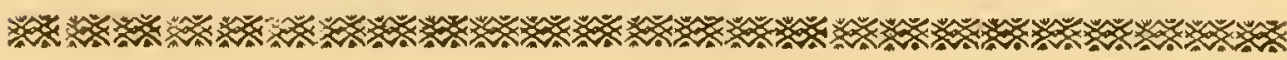

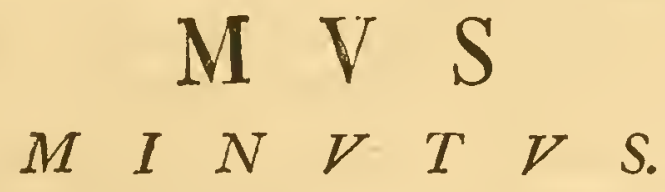

Minutifimum hocce animalculum an detur ufque in Germaniain, conterraneis meis obfervandum relinquo. In Ruthenico Imperio ubique datur cum M. agrario, neque mi$\times \times 3$ 
nore copia \& iisdem locis libenter vivit. Itaque autumno \& per hyemem fub frumenti acervis circaque horrea copiofe congregatur, in Ruffia $M$. etiam Mufculo, in Sibiria M. rutilo \& gregali fæpe in focietatem admifis; a quibus tamen minutam \& imbellem noftram fpeciem fæpe deftrui verofimile eft. Ubique mares multoties copiofiores feminis obfervavi. - In betuletis Sibiriæ inter Obum \& Ienifeam longe ab agris Septembri abundare vidi, ubi folitarii circa vias, inepte currentes confpiciebantur; nec majores Volgenfibus, velleris vero intenfo colore pulcriores. Et credo fine certis nidis vagos vivere, neque magis, quam $M$. agrarium \& fylva. ticum, a frigore torpefcere fenfi. Adeo imbelles autem funt, ut etiam a Mure vago (vix majore) fefe defendere non poffint, quemadmodum fupra relato exemplo conftat. Parvitas xque, ac color intenfe fulvus, fine dorfali fria, $a b$ affinibus evidenter, diftinguunt, præter alia ex icone \& defcriptione perfpicienda.

\section{DESCRIPTIO

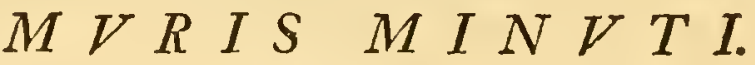

Tab. XXIV. B.

Corpus fere dimidio minus, quam M. Mufculo adulto; at caput paulo groffius \& hirfutius.

$N a f u s$ acutiufculus, fupra hirfutie fufcus, ad angulum labii pallidus. Dentes primores antice lutefcentes.

Myftaces tenerrimi, extremo canefcentes, quinque ordinum. Verruca multipilis fub oculis, unipilis in fuperciliis.

Oculi nafo paulo propiores. Auriculce minufculx, vellere femilatentes, fuborbiculatæ, planæ, poftice nudx, intus gryfeo canoque fubpilof : trago lato, elliptico, margine nudo, meatum protegente. 
Corpus teretius, quam Mufculo; artus tenuiores. Palma tetradactylæ unguiculo pollicari obtuffifimo. Planta pentadactylæ, interiore multo breviore. Ungues albicantes.

Cauda brevior, tenuiorque, quam in Mufculo, fed craffior longiorque, quam in M. agrario, pauloque pilofior, fubfiliformis, teneriter annulata (CXXX.) fupra longitudinaliter fufca, fub. tus cana.

Color velleris fupra fulvus, portice intenfior, in dorfo longitudinaliter magis minusve fufcefcens, latcribus dilutior, fubtus $a b$ ore ad caudam cano - albus. Pedes fupra gryfei, folcis utrinque cano-fimbriatis. - Variat colore obfoletiore, magisve fufco, \& fulvidiore fubtusque candidiore. Sibirici intenfe fulvi, fubtus candidi. Feminis plerumque color exfoletior fordidiorque.

Mammarum papillæ VI. æquidiftantes, abdominales IV. pectorales II. Clitoris papillaris minutifima.

\section{ME N S V R A E.}

Pondus vulgo infra fefquidrachmam, plerumque drachmæ cum fcrupulo, rariffimis ultra didrachmam; Feminis femper minus. Longitudo a nafo ad ortum caudx

- capitis ad nucham

- caudæ

- brachiorum

- palmæ

- tibiarum

- plantæ

Difantia oculorum a nafo - aurium ab oculis

Circumferentia capitis ante aures

- thoracis

- roftri

Aurjum altitudo paulo ultra - latitudo

Circumfèrentia carpi 
Circumferentia tarfi

- caudx bafi

Longitudo dentium fuperiorum minus

c. $2 \frac{1}{2}$.

- . - inferiorum

\section{A N A T O M E. \\ Tab. $X X V$. fig. $17 \cdot 190^{\circ}$}

Glandula abdominalis fubcutanea non verfus hypochondria, fed fere in inguine fita.

Hepar ( $f i g$. I 7.) feptemlobum: finiftro omnibus reliquis majore. Spigeliani fubtus duo difcoïdei. Cy/tis omnino nulla.

Lien lanceolato - oblongus, extus planiufculus.

Ventriculus (fig. I 8.) fundo minus amplo, quam in $\mathbf{M}$. agrario, itidem tenuiore membrana facto; at pars pylorica glandulofiore membrana facta, gibbofior, quam in eodem. Plica intus circularis, utramque tunicarum fubftantiam difterminans. Cbymus plerumque feminum pulmentum albiffimum.

Inteftinuln tenue 9." in majoribus ad fummum $11 . "$ 6." Ccecum (fig. I 9.) pollicare, in circulum curvatum, apice lumbriciformi, fubacuminato. Portio frilata fimplici arcu curvata, cum reliquo excretorio inteftino moleculis ellipticis articulata. 2." $6 . "$ " æquans.

Ren dexter anterior. Glandulce lumbares verfus pelvim remotx. Penis 3." vix filo grofliori æqualis. Uteri cornua in fe. minis ufque ad renes extenfa.

Sceletor ut in præcedente. Cranilmm offibus roftri brevius \& argutius. Molares ut in eodem \& M. Mufculo tuberculofi.

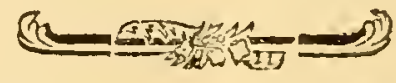




\section{- \\ ILLVSTRATIONES \\ Q VAEDAM \\ I $\mathrm{N}$ S C I V R E V M G E N V S. \\ $S$ C I V R I \\ $V O L A N T E S$ G ENERATIM.}

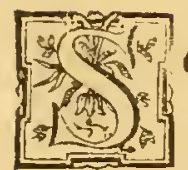

cimrorum velo inter pedes tenfo corpus in aëre librantium, tres mihi conftare videntur $\int p e c i e s$, pluribus adtributis \& conftantibus notis diverfe, quot etiam LINNAEVS, confufis tamen fynonymis, diftinxerat, alii vero Zoologi etiam magis obfufcarunt, \& BVFFonIvs ad unicam fere fpeciem, quam folam prius norat, redegit.

Prima fpecies, quæ in ultimis Orientis infulis hofpitatur, quamque poft meam in Mifcellaneis Zoologicis defcriptionem illuftrarunt A. vosmaer \& Amiciff. pennant, immo nuper etiam in Supplementis agnovit \& produxit Ill. BVFFonivs, (Supplen. vol. III. p. I 5I. t. 2 I.), omnium Sciurorum eft maxima, \& nominc olim impofito, scivin petaurifte,

- hic quoque ftabit.

Secunda, mihi apprime nune cognita, Sciuri volatica pelle inftructi fpecies illa eft, qux ab Europa boreali ufque in ultimum Afix aquilonaris angulum fylvas \& betuleta freY y 
quens colit, primumque a GESNERO muris pontici vel fcythici nomine defcripta fuit. Hrc, deinceps accuratiore deferiptione illuftranda, nomen jam fatis inolitum scIvRI colantis mihi quoque fervabit.

Tertiam fpeciom, quan \& in Mufeis fxpius \& vivam, prafertion nuper Mofcua, ubi apud Nobil. procop. DEMIDof late multiplicat, videre licuit, quamque D'AVBENTONVs graphice defcripfit, scivevm Volucellam cognominabo.

Proince fpeciei Synonymis, utpote paucis, vix opus eft ut inhæreamus. Animal extremis Indici oceani infulis peculiare, in eadem remota patria, quæ Lemmemn, fic dictum, volantem, \& Draconem alit, pauci obfervarunt, pauciflimaque Mufea cuftodiunt "). In Belgio quum verfarer, tria omnino, e numerofis curioforum Mufeis, hujus Sciuri exuvias gloriabantur; quibus fi fpecimen Mulei reg. Societ. Londinenfls a p ENNANTo defcriptum, \& illud quod BVFFonso nunc inferviit addideris, habebis forte omnia quæ noftra Eufopa vidit rariflınæ quadrupedis exempla.

a) Itineratorum, qui Scimi petauriface mentionem fecerunt, primus ni fallor eft N 1 EV HOF I S $(Z e e$ - cn Landreize door Oofindien $p, 2 S z$.) cujus feles rolewtes huic animali optime refpondent. Dein nomine Civettae volantis defcriplit v ALENTYN (Oud en Niluev. Oofindie t.0. 3. p. 269). Pottremo de eo retulerunt Mifionarii Ieluitae (Lettres édifi. antes) quorum nurratio cum Icose tranfit in Hifoi:e generale des loyages vol. $X V . p .51 . \&$ fine eadem in Mimoires gèagraphe phyj, ct hifforiques (Paris $1-6 \zeta$ ). vok. 2. p. 194. Ibi nomen gentile Taguan. quod CAMELLI inter fynonyma Lcmuris volantis retulit, huic animali.tribuicur, \& pro eodem fignificando etiam a BVFFONIO adoptatum eft. Pri. ruam bonam animalis defcriptionem de. derat Cel. allamand in Ejitome operis Briffoniani (quadrup. p. 112.). Dẽin polt lloftram (in Mifcell Zoolog. p 54 . tab. Il.) Vos MAERII prodiit mo. nographia, \& novifime Amic. PEN: NANT defcriptio in fyn. quadr. p. 292. fupraque adlegata BVFFONII, in fuP: plementis. 
Maxima vero confufin fecunde terticeque Speciei fynonyma premit, quan intactam rolinquere haud poffum. KLEINIVS has fpecies non diftinxit; quem enim ex icone sE. BAE "Sciurum virginianum, petauriftam, vocat (qundr. difpof. p. 55.), ut ftatim dicctur, plane aliud eft animal, in quo SEBAE aliquantum vacillat fides. - BRISSONIVS tamen, huic etiam. confifus, tres. Sciuros volantes adoptavit: hane ipfam nempe anomalam fpeciem sebar (thef. $\boldsymbol{l}$. $t$. 44. fig. 3.); dein Scintrmin fibiricnn voluntem; cujus genuina fynonyma (Gefnerianum, Kleinianum, aliaque) perperam ad tertiam fpeciem (Volucellam noftram) retulit, qux ipfi Sciurns volans fimpliciter dicta eft, quamque in Europa \& America boreali xque vivere autumat. His in Epitome Briffoniani laboris quartam, adjecit fpeciem (Sc. petanırifan noftrum) Cel. aldamand. - Ill. Linnaevs in pofterioribus Syftemutis editionibus primus Sciurum volantem Americanum (Valncellam, ut videtur, noftrum) inter Mures retulit \& $M$. volantem appellavit; Sciuros inter, præter fibiricum (Sc. volantem LiN. \& nobis), recenfuit etiam Sagittam, petaurifte noftro affinem, attamen, fi recte intelligo, minime cum codem confundendum, quo circa argumenta deinde faltem probabilia adferam. Quod vero Americanum animalculum Murem compel-. laverit LINNAEVs, videtur e fpecimine nondum advito necdum villis in cauda diftichis inftructo, factum fuifle, quale $V$ ir $\mathrm{Ill}$. in Mufei Adolpho-Frideric. Part. II. p. Io. ita defcripfit, ut mihi vix fuperfit dubium; nec alias intelligi facile poteft, quare potius hunc, quam Gliren Romanorum \& Sc. volantem ipfum ad murinum genus referre maluerit. Quanam vero ratione ductus ad Murem colantem fuum citaverit suBae (thef. I. t. 44. fig. 3.) 
atque EDWARDSI ( $(2 . t$. I9I.) icones, cauda evidenter villofa, difticha inftructas, isemque RAJvm, qui Sciuro volanti fuo diferte caudam planan \& latam tribuit; hoc quidem apprime ignorare me fateor. - Candidiff. EDWARds certiflime Sc. Volucellam noftrum delineavit, quem neque cauda tereti (nifi in juniore rtate, ut in Sc. volante quoque vidcbinus) neque pelle a collo ad armos tenfa preditum effe, accuratifima deferiptio D'AVBENTONI extra dubium ponit, fi etiam propriis oculis confidere nollem. Etiam sЕвАE anomala ifta icon, quam LINNAEVS ad Murem volantem citat, caudam late villofam habet, fi forte hanc pellis a collo tenfa ideam Linnæo fuppeditaffe crederes. - Dcinde vero catesbaei picturas, Sc. Volncellann fplendide exprimentes, cum Sc. volante Americano brissonir ad Sc. Volantem citavit Idem, \& hunc Amcrice communem fecit, qui mihi ultra terminos Afix haud videtur proceffitfe.

Contraria facilitate $\mathrm{I} / \mathrm{l}$. BvfFonivs, quem fecutus eft $\mathrm{Cel}$. PENNANT, quæcunque apud auctores invenit, interque ea GESNERr quoque notitian \& KLEßNi defcriptionem (in Act. angl. vol. 38. p. 32. tab.2.), qux polonico animali, adeoque Sciuro volanti noftro debentur, ad Volucellam, quem folum norat, Americanum traxit eumque Polonico etiam momine ${ }^{b}$ ) dotavit; de diftinguendis vero hifec animalculis ne fomniavit quidem, licet in SEBAE anomala figura, cui fidem derogare fuduit, aliquantum hæreat (bift. nat. edit. min. Vol. XX. p. I 28.).

b) Nomen Polatucia, ut foribit B v F. lonia forte ufitatum. Ipfumque IIl. ViFonivs, vel ad genium lingure rectius rum incertum fuifte inde liquet, quod Poleticha (quod fere Volucellæe confo. Ruficum nomen \& Mofcoviticum diftil. num eft) non eft Rilicum, fed in Po. xerit. 
Dicam quod res eft: Sciurus Volncella eft animalculum gregarium, a Sc. Volante Europx \& Sibirix, conftanter folitario, colore, proportíonibus moribusque diverfum penitus \& Americæ feptentrionali ita proprium, ut alter $\Lambda$ fiæ boreali eft \& Europx. Equidem Sc. volantem in Americam transfrctalle non obnixe negaverim, inter auctores tamen qui Americanum animal defcripferunt, nullos Sc. volantem fibiricum innuife certus fum; quosque ipfe ex America miffos vidi, omnes Sciuri Volucellæ fuerunt; qui quantum a Sc. volante fibirico differant, defcriptionem hujus meam, cum D'Aubentoniana Volucellæ conferentibus fatis fuperque patebit. Quumque in peragrata mihi \& antecefforibus Sibiria univerfa nunquan alia fpecics, quam Sc. volans nofter, ubique frequens, fucrit ob̨ervatus; pcllesque nulla alix quam hujus $c$ remotiflimis. Sibiria plagis, Sciuris cincreis mixtæ adferantur; tuto concludi poffe arbitror, Sc. Voluccllam in Sibiriam non tranlifife.

Scimrum Sagittam, Linnatevs licet Iavenfem dixcrit, cuna Sc. petaurifta noftro non congrucre, collatæ defcriptiones loquantur. S. Sagittæ Lin. Jtatura Sc. vulgaris tribuitur; at $S$. petauriftæ Cuniculum $f$. felem minorcm æquat. Ille habet cutem a capite ad armos cxtenfam, cujus nofter ne veftigium quidem præfert; candam ille longitudine corporis, adeoque palmarem, valde depreffam \& pilis lanceolatam, nofter corpore longiorem, plusquam fefquipedalem, villofo - teretem. Priori dentes fufci, aures veftita, color in mafculo ferrugineo - fufcus, fubtus pallidior; S. pctaurifte dentes primores fulvi, auriculæ parvæ, nudiufculæ, color in potiore fexu fupra niger, canis variegatus, lateribus caY y 3 
pitis artubusque caftaneo - rufus, fubtus fordide canus. Forte tamen vel fpeciminis Linnaani junioris, rel defcriptionis vitium fubeft. Quan in Mifcellaneis Zool. dedi fidam \& e pluribus fpeciminibus collectam clic fatis feio, \& nuperior quoque BYFFONI confirmat, e mafculo fpecimine rufo, aibo, nigroque fupra mixto, adornata.

Ceterum LINNAEI defcriptio magis convenire viderur cum Scinro iolante majore ex America hyperborea transmillo, quem $C e l$. Forster in Aftor. angl. vol. LXII. p. 379. breviter adumbravit: "magnitudine Sc. vulgaris, vel , majorem, vellere longo intus fufco, extus ferrugineo (tawny „, brown), fubtus flavefcenti - album, cauda villofifima, de„preffa, concolore, fed pelle tantum inter pedes tenfa." Quæquidem fpecies, fub latitudine boreali $51^{\circ}$. circa Sinum Iacobi abuvdans, a tribus enumeratis diverfa certe ${ }^{\circ} \mathrm{ct}$, ulterioremque illuftrationem pofeit.

Aninal denique illud paradoxon, quod seBa (thef. ¿ol. I. tab. 44. fig. 3.) e Vincentiano Mufeo ad tria fpecimina, delineari fecit, a Sciuris volantibus aque ac Lemure diverfum mihi videtur; neque enim fictum dixerim, quum locum indicarit auctor, unde petita icon, eaque ipfa fatis affibre picta, immo figuræ Sc. volantis, quam tab. 4I. fig. 3. dedit, longe præferenda fit. Habet auten labium non fciureo modo fifum, \& dentes potius ferini in icone apparent; auricula dein majores, palma omnes pentadactyla \& pellis volatica a collo verfus palmas inftar cuculli extenfa pingitur, quod in nullo mihi cognitorum animalium, præter Lemurem volantem: contra vero nulla pellis a femoribus ad caudx ufque apicem, ut in 
eodem. Forte novis obfervationibus aliquis Zoologix hoc refituat animal.

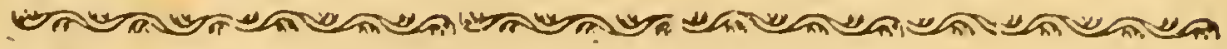

\section{S C I V R V S \\ $\begin{array}{lllllll}V & O & L & A & N & S .\end{array}$}

Scimrlm volantem C. onswero e Lithuania miferat Anton. schnlabergarvs \& Polonicum nomen, latino ifto confonum - (Popyelycza lätayac $\sim a$ ) adjecerat (de Quadrup. p. 743.). Poftea ufque ad kLesniva fere Zoologos latuit hec fpccics, excepto quod $C l$. Dvvernoy in $\mathrm{V}$. Volnmine Commentarionzm Acad. Petropolitance inquilinum Ruffix defcripfit fine addita icone. KLEINI1 relatio \& icon, que in Actor. amglicor. Vol. XXXVIII. prodiit, in Toml. IV. Playfice Sacree a scineveirzero translata eft. In opere Witfeniano autem defcriptio tantum ex pelle, cum imaginaria icone extat (Noord - en Ouft - Tatar. Edit. II. vol. 2. p. 785.) quæ vix citari meretur; quemadmodum \& illa peffima eft, quam nuper dedit Fiscrier (Verfluch einer Nuturgefch. von Livland, Leip: I $778.8^{\circ}$ p. 62.). $\Lambda$ uctores reliqui omnino omnes, qui Sciuri fpeciem pellibus volaticis inftructam tractarunt, de Volucella americano funt intelligendi, adcoque fynonymiftx, ctiam novifimi, corrigendi itidem omnes.

Eft enim intra Europæ fines rariffimum animalculum, 1icet in Lithuanix, Livonix, Fennonix, Lapponiæque betuletis 
inquilinum vere efle, e RCZACZINSKI, KLEINII, FISCHEri, dvvernoy, Faunce fuecica, kalmique ) teltimoniis fatis conftet. Multo copiofius uralenfes fylvas colit, \& in omnibus Sibiriæ betuletis, pinu mixtis etiam rarioribus \& per campos sparfis lucis, abundat. Tidulatur in cavis truncorum qua poteft altifime a terra remotis, ubi nidum e congeftis mufcis mollifimum parat. Semper, excepto foturæ tempore, folitarii occurrunt, \& interdiu nunquam apparent; quibus maxime a'Sc. Volucella, gregariam vitam agents ${ }^{d}$ ) differt. Præcipuum Sc. volantis alimentum funt Betularum gemmæ, turiones atque Iuli; Pini etiam turiones \& gemmæ; quibus contęntus in inteftinis chymus virefcente flavus adeo fit refinofus odore \& natura, ut ficcatus, æque ac excrementa, murinorum formam oblongam xmulantia, ad candelam facile accendantur, claraque \& conftanti flamma comburantur, cum odore pinex frondis combutte. - Ea excrementa ad arborum, in quibus nidulantur, radicem copiofe \& ita jacent depofita, ut animalculum videatur pro egerenda alvo illuc defcendiffe. Certum inde fignum is qui animalculum in fylvis quærunt. - Conftat eos hyeme monnifi tepida tempeftate nido prodire. Non tamen obtorpefcunt, licet glandulas inftas, thymo fubanalogas, quæ fopitis per hycmem animalibus adeo copiofæ \& prolix $x$

con-

c) Befkrifning üfver Cajaneborgs. Atar foliorum a ventoabreptorum transvehi, liin. Refpondente Eric. c A S T rè A Abo. denos vel duodenos fimul, c A T E S B A E1754. 4. p. 58. Ibi inter alia relatum legi- v s docet (nat. hif. of Carolina vol.11. tab. tur, Sciuros volantes vulgarem Sciurum e $\left.p .7^{6} 6.77\right)$. Et ultra duodecim in eodem nido fuo expellere, quem fibi adaptent, trunco cavo, uno nido \& communi in dum ipfi ftruendis nidisfint inepti. Quod hyemalem cibum penu obfervari, totaque equidem pro vero affumere vix poflum.

d) Interdiu ex arbore in arborem in- nat. hil. of North-Carolina p. 1-29. 
contigerunt fub axillis \& ad collum habeat, minori quidem mole. Vefci autem hyeme, argumento fuerunt inteftina fub rigidifimo Decembris \& Ianuarii frigore adlatorum chymo refertifima; neque tota hyeme, ut Voluccllæ faciunt, in nido delitefcere, collectoque ibi victu fuftentari, fatis exinde apparet, quod in decipulas pro Sciuris ftatutas, \& ficco pifce plerumquc inefcatas, fatis frequentes incidant, multo minore tamen numero, quam ipfi Sciuri. Exinde quoque fit, ut a callida venatorum plebe pelles Sciurorum volantium, qux tenuitate fua \& velleris flacciditate ignobiles \& inutiles fere funt, bonis Sciurorum pellibus, quippe quæ fubverfæ plerumque venduntur, immifceri foleant, immo ad Lenam integræ ex tenellis hifce pellibus confuuntur veftes \& ad Sinas a mercatoribus deferuntur, dimidio circiter Sciurorum pretio venales, $\& a b$ omni humore facile corrumpendx. - Quod pro volatu vulgo habetur, fatis jam notum eft non effe volatum, fed animalis faltus audaciores, pellibus laterum inter divaricatos pedes tenfis, \& corpus in aëre fulpendentibus ita adjutos, ut ad 20 \& ultra orgyas e cacumine unius, verfus alterius arboris medium oblique ferantur. Hisque faltibus ita confidunt, ut raro, nifi pro deponendis fæcibus in terram defcendant. Captos in media fylva experimenci gratia humi depofui, \& ineptiffine, erecta cauda, quafi per faltus fugientes vidi; fimulac vero arboren adtigerant, velociffime \& quafi fubfultim in altum enitebantur fcandentes, cauda modo re. jecta in dorfum, modo demiffa. Ex altiore trunci parte dejecti, excipiebant fefe velis fuis \& in aëre varie librabant atque motu caudæ dirigebant corpus. - Dum vero in Betuiis prefertim vitam agunt, fapienter a Natura profpectum eft, 
ut onni tempore anni exalbido - cancfeentem colorcm velleris fervent, quo cortici betularum ita fiunt fimiles, ut fcandentes vix, imo fub diluculum, quo tempore prefertin excurrunt, plane non confpici eminus poffint, coque ab avibus rapacibus nocturnis fecuriores funt.

Pulli nafcuntur fub initium vel certe ante medium Maji, \& pletumque duo, tres, rarove quatuor cum fingulis matribus reperiuntur. Durante itinere Matrem cum duobus pullis adhuc nudis \& coccis d. $\frac{1 \pi}{22}$ Maji adlatis, per plures hebdomades alui, betulinis maxime julis, \& mores, quantum in angufto carcere fieri poterat, obfervavi $\left.{ }^{\circ}\right)$. Pel totam diem mater quafi incubabat pullis, eosdem velis fuis, tanquam ftoreis obvolvens." Occidente demum fole nidum, cui de die quafi adfixa hærebat, relinquens, mufco nidi cooperiebat pullos diligenter \& pabulum quafitura per ergaftulum vagabatur, tota nocte inquicta. Etiam oculorum conftitutio, quos fimillimos habent Strygi Aluconi, noctivagos cffe indicant. Pulli, qui jam fatis magni ad me delati funt $\mathcal{S}$, ut faltem biduo majores viderentur, lente crefcebant; \& poft fex demum dies dentes primores exferere, pilisque veftiri cœperunt. Manferunt autem cœci ufque ad tredecimum diem, tumque apertis quidem oculis, fed (poft frigidulam tunc forte noctem) mortuí, imo a matre, quæ brevi poft obiit, jam arrofi reperti funt: ut ergo ultra quartum decimum diem cocos effe con-

c) Vid Itinerar. Vol. Il. p. 440 .

f) Alter mafculıs pondere fuit $6 \frac{3}{4}$ diachmarum; altera femella $5 \frac{5}{5}$ drachn. Vmbilici cicatrix necue in his, nec aliis poftea adlatis ulla apparuit. At papil. loe mammaruin utrinque quatuor 2 co. ftis fpuriis ufque ad inguina æequidiftan. tes in fomina evidentifimin, obfoletiores in pullo mafuculo. Cutis, procter nafum, tarfos palpebrarum, \& lunulam fub meatibus auditivis fufcam, tota alba, 
ftet, quod vix in alia quadrupede obfervatum effe credo. Cæterum mordaculi funt Sciuri volantes, fed vitæ tenerrimæ, unde rarifine vivi Petropolin delati fucre; in captivitate enim leviflima e caufa moriuntur; præfertin quia pabulum non fatis nature accomodatum exhiberi poteft. Sedent \& incedunt, conglobato fatis trunco, cauda vel circa clunes circinnato - contorta vel in dorfum reflexa \& arctc adplicata. Palmis lavant $\&$ pabulum ori admovent clunibus infidentes, fere ut Sciuri. Clamor rariffimus doloris, murinus; iracundi tantum muffitant.

Collatis fpeciminibus, quæ media partim æftate, partim Decembri \& Ianuario effarcta mihi funt, vix ullam in altitudine \& denfitate velleris, quoad colorem vero omnino nullam differentiam invenio. Cauda in pullis teres, adultis cxpanfo denfifimo villo fit plana, circumfcriptione oblonga, latior quam in Glire Romanorum, quem alias vellere magis referunt Sciuri volantes, quam Sciurum vulgarem, quamvis huic forma capitis \& indole fimiliores, \& Sciureo generi omnino relinquendi, a quo Glis habitu \& natura alienus eft. - A Sciuro Volucella differunt noftri magnitudine plus tota tertia parte excedente; colore non in flavum inclinante, fed fupra candide leucophæo, fubtus candidiffmo, caudaque fupra vix fufco inumbrata; forma capitis brevio re \& globofiore; callda breviore paucioribus vertebris compofita, vix dimidiam corporis longitudinem excedente, dum in Volucella ad $\frac{3}{4}$ accedit; oculis nafo propioribus circulo magis atro cinctis; artubus anticis brevioribus, at pofticis tibiis (fiquidem D'Aubentonianæ menfuræ errore vacant) longioribus. Cæterum tota conformatione, pellibus ad brachia in alulam radio tenfilem dilatatis, antriculis nudis, brevibus, latiufculis, palmis tetradactylis, numcroque coftarum \& vertebrarum lumbarium. 
Supereft ut nomina gentilia Sc. volantis recenfeam. Rufficum Ljetgga volatile fignificat ipfo lingux fenfu, neque derivativim eft. Tatari aliud non habent quam Saar - TienKanat (Sciurus alatus pallens); ad Ienifeam nomen Babarchàn adoptarunt, a monticolis Samojedicx ftirpis, qui Abarghán appellant, translatum. Iacutis Ilnchön, quati inflatus, audit, quod durante faltu expanfus inflari videatur. Nomina Oftjacorum fecundum tribus varia, Berefovienfibus TochlyngLangi, Eftelicæ ftirpis ad Obum Imit - Lanki, Trtincnfibus Inve - Lanki, Surgutenfibus Pailan - langi itemque Vogulenfia ad Obum Touln - Leyn vel Tanling - Lengen \& Samojedicum Tirta - Trrek, omnia Sciurum volantem vel alatum fonant. Ortjacis ad Narym aliud Poëfe, \& Vogulis Verchoturienfibus Bobontóll in ufu eft. Votjaci Pulob, Permiani Kïfniir, Sirjäni Pall, Mongoli Olbo, Tungufi Uldjngi, Tanguti denique Bfhamabfli vocarunt. In Kantfchatka \& ultima Sibiria trans - Icnana quandoquidem nulli fere rcpcriuntur Sciuri volantes, nulla quoque, apud illas gentes nomina obtinent, faltem mihi non innotuerunt.

\section{DES CR I P T IO \\ SCIVRI VOLANTIS.}

Magnitudo inter Sciurum vulgarem \& ftriatum media. Caput fciurino retufius \& cum vellere globofius, roftro breviore.

Nuflıs latus, gibbus, villofus, plica cutis transverfa, mobili obtegente finum nudum, transverfum, in quo nares lumulatæ, fepto lato, profunde fulcato diremtæ. 
Os vix oris labiorum nudis, fupcriore ufque ad feptum bipartito. Bucce aliquantulum faccatæ, pifi majoris circiter capaces. Dentes primores fulvi, planiufculi. Linglaa fubcus ad frænum utrinque caruncula acutiufcula.

Myftaces quinque ordinum, nigri, rigidi, capite longiores $\left(2 \frac{5}{3} . "\right)$. Pilus fupcrciliaris fupra anticum oculorum canthum geminus; paratici \& gulares nulli.

Oculi magni, protuberantes. Palpebrarum ambitus albus, fed margo ciliaris aterrimus citculo nigro oculum includens. Pariopl tholminm membranula curta, nigro angulo tcrminata, in cantho oculi latitans. Irides nigra; pupilla ampla.

Am iculce breves, fubrotundæ, tentiffimx, patula, raritis, nec ubique villor $x$.

Corpus (quam Sciuro) depreffius \& brevius. Collım breve utrinque cute laxiufcula, verfus armos latefcente plica. tum. Nlia duplicatura cutis latifima, corpori concolor, ab artuhus primoribus orta, per latera, femorumque anticum marginem decurrens; ad carpum in alillam dilatata fubrotundam, radio peculiari offeo, ad carpum articulato, tenfilem, margine fimbriato - fufcefcentem. Denique inter femora \& caudam clltis item laxiufcule plicata \& tenfilis ambitum corporis abfolvit.

Artus clongati, præfertim primores. Verruca in poftico inferoque latere antibrachii verfus carpum, oblonga, decem pilis tendini fere innatis obfita ${ }^{g}$ ). Palmce tetradactylx,

g) Extcrius, in laxo vellere, hac rum pilorum bulbi in nodum coagmen. quidem vix ac ne vix apparent, fed quan. tati tendinibus flexoribus inhrent, \& do pellis ab antibrachio deglubitur, ho. pellen relinquunt foraminulis pertufam. 
tuberculo carpi pollicari, magno, convexo, interiore latere fubcallofo. Radius carpi, alam tendens, fefquipollicaris, arcuatus. Subtus palmæ fubvillofæ, tuberculis nudis, triplici ad digitos \& majore carpino, cum pollicari tubere confluente.

Plantce villofifimæ, pentadactylæ, introrfum verfatiles; digitisque (ut in Vefpertilione) fubæqualibus \& uno verfu, ad fcandendum, imbricatis. Subtus tubercula quatuor ad digitos, \& horum apices inter villos nuda; unguiculi albidi villis abfcondit:.

Cauda corpore brevior, plerumque circa clunes retortilis, longo villo lanata, plana, circumfcriptione oblonga.

Vellus denfifimum, tenerum, mollifimum, in dorfo ufque ad 9." altum, intus fufcum, fuperficic cano exalbidum, apicibus pilorum albentibus, demum canis. Subtus totum (vix ultra 5." altum) niveum, lanugine ad ipfam cutim fufcefcentc. Velum utrinque laterale, ab alula carpi ad hypochondria, \& margo lateralis colli, brachiumque longitudinaliter gryfeo - fufcefcente fimbria marginata, quæ fupcriorem canam faciem, ab inferiore alba difterminat. Extremi pedes albidi. Caudce lana albet, fupra pallido - canefcens, pilisque longioribus, apice nigricantibus inumbrata.

Mamma, 'nifi lactentibus, ob altitudinem velleris numerari nequeunt; papilla tunc conicx, majufcula, quatuor parium, a coftis fpuriis ufque ad inguina æquidiftantium. Vlll$v a$ ano proxima fimplex, clitoride vix notabili. - Scrotum (maribus) extra venerem confpicuum nullum. Praputinn ab ano pollicari fpatio remotum. Anus fub cauda villo latens, fcybala extra pelvim, velut in cloaca fecundaria colligens. 
MENSVRAE.

Pondus hyeme, quum non plus pinguedinis quam xftate habeant, tantun fecundum ætatem \& fexum variat. Mares a trium fere cum dimidia unciarum, ad quatuor unciarum cum aliquot drachmis; feminæ femper ponderofiores, fæpe ultra quinas uncias fefquiternis vel quaternis drachmis excedunt, licet vix mole majores videantur. Menfurce hic propofitæ funt fpeciminis feminci, cujus pondus fuit $5^{\frac{1}{2}}$ unc. \& unius ferupuli, quodque pro Anatome quoque ferviit.

Longitudo a fummo nafo ad ortum caudx

- caudie fine villo

- excedentis lanæ

- capitis a fummo nafo ad nucham

Intervallum narium f. craffities fepti

Latitudo nafi transverfa

Circumferentia oris ab angulo ad angulum

- capitis inter oculos \& aures

Diftantia oculi a nafo

- auris ab oculo ${ }_{\text {- }}$ -

- - circinno

- canthorum oculi antic. filo

- eadem circinno

Fiffura oculi

Apertura oculi

Auricularum altitudo a bafi

- ad verticem

- latitudo major

Longitudo antibrachii

- palmæ a carpo ad extremos ungues

- digitorum longiorum palma fere

- unguiculorum

- tibia

- planta ad extremos item ungues

- digiti longioris plantz fine ung.

- unguiculorum
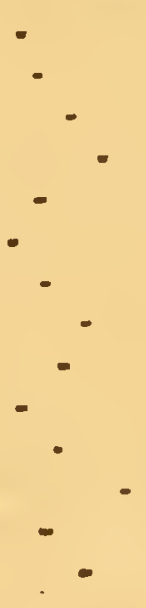

-

$=$
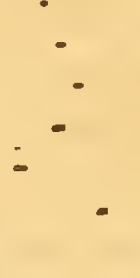

I. 4
I. $3 \frac{2}{3}$
0. $4 \frac{\pi}{3}$.
. $1 \frac{\pi}{3}$.

3. 10.

I. 2.

I. 8 .

․ 7.

2. $\frac{1}{3}$.

o. 8 .

2. II.

o. $\int \frac{\pi}{2}$.

o. $3 \frac{\mathrm{I}}{2}$.

I. 2 .

o. $10 \frac{1}{2}$.

o. 10.

- $8 \frac{1}{2}$.

o. $4 \frac{\pi}{2}$.

o. $3 \frac{2}{3}$.

D. $8 \frac{1}{2}$.

O. $5 \frac{\pi}{3}$.

o. $7 \frac{1}{2}$.

1. 5 .

c. I0.

o. 5 .

o. I.

I. 4

I. $3 \frac{2}{3}$.

a. $1 \frac{\pi}{3}$. 


\section{A N A T O MT E.}

Mufculi cutanei, propter pellem per corpóris ambitum dilatatam, varii. A circumferentia fibrofo - mufculari oris \& buccarum falcia mufculofa (platysmamyoüs) utrinque defecndit, marginem legens inter collum \& armos extenfarum plicarum, tandeinque in tendinem exilem, filiformem adtenuatus carpo interius inferitur. Dein mufe. fubaxillaris infignis, radiatim difperfus verfus pellem inter armos \& femora dilatatam, cujus duplicaturan fibris oblique longitudinalibus pervadit. (Glandulla lymphatica plana, tritici mole, huic mufculo inhret ipfo loco ubi fpargi incipit.) - Marginem velorum lateralium, inde a calcare carpi, legit tonioln mufculuris, perque tibiam fubcutanea defeendit, breviffimo tendine inferta ad ipfam bafin offis metatarfi medii. - Denique ultima $f_{l l}$ Sica cutulnea tenuiffimo, 4." longo tendine a calcaneo orta, per laxam inter flexuram femoris \& caudam curim decurrit, ad tertiam caudæ vertebram tendinefcens exilique tendine per candem decurrens. His mufculis vela \& plicas partim tendi, fubaxillari vero contrahi, in propatulo eft.

Vltime quoque fafcix ad ipfim genu flexuram adjacet glandula lymphatica, fubaxillari fimilis. Stria offcularis $\mathrm{ab}$ inguine utrinque verfus latera adfeendens (qua Glirium ordini communis fere eft) exilis, eique extremæ inhærens glan. dula itiden minuta, papaveris granulum referens.

Pectorales mufculi haud robuft, exterior infigni fafciculo in abdominales tendens. Neroi utrinque a tertia ad decimam coftam a coftalibus, per mufculos intercoftales eniffi, paralleli, in panniculum mufcularem velorum lateralium \& adjacentes fcapulix mufculos fparguntur. 
Glundule thymo analogæ axillares exiles, ut ambo vix 3 granorum pondus xquent; ad collum infigniores, paroticx, pondere juncto 21 granorum. Ipre parotides utrinque bipartitæ fub mandibulx bafi, \& granorum pondere.

Ad Linguce bafin adnatam utrinque limbus longitudinalis, ciliis reclinatis mollibus fcrratus; præter papillam fub frænulo gemellam.

Alous verfus pelvim anguftior. Omentum vix ullum; \& quicquid ejus adeft, fub ventriculo collećtum jacet, cujus pofticum obvelat latus. Omenta quoque lumbaria nulla, neque circa renes pinguedinis veftigium, ne quidem hyeme. Ventriculi fitus obliquus, ita ut fundo, diaphragmati obverfo, fummum hypochondrii finiftri occupet, curvatura deorfum \& dextrorfum tendat, antroque pylori dextram partem epigaftrii teneat. Hepar intra thoracem retractum, diaplsragmate tenui a penultima cofta vera ad antepenultimam fpuriam adhwrente, ita tamen, ut a dextris paulo ulterius defcendat. Siniftram totam alvum occupat cœcum in cochleam compofitum, cui fupra ipfam fpinam Ileon inferitur. Colon ad dextram fpinæ contortuplicatum \& furfum deorfumque ter procedens, arcu demum verfus finiftra facto defcendit.

Hepar quinquelobum, pondere drachme cum 12. circiter granis. Lobus finifer maximus; tertius ab hoc, (lub quo cyftis mediocris \& plerumque vacua), magnitudine proximus; dexterrimi pyramidato - irregulares.

Lien exilis, pone ventriculum ad finiftras coftas oblique longitudinalis omento laxe inhærens; membranulisque renis vertici conncxus, triquetro - complanntus, medio coarctatus, extremitatibus fpathulatis, longitudine ir."' pondere fefquitertii grani. 
Fentriculus ampliufculus, membranaceus, circularibus maxime fibris confpicus, a fundo amplifimo fenfim angultatus verfus antrum pylori, inaquale, $\&$ in minorem arcum recurvatum. Oifoplongus ventriculo oblique inferitur, fundoque per cellulolam longitudinaliter adfrietus. Circumferentia ventriculi a cardia per majorem arcum ad pylorum uique $4 . "$ " 4 " led axis a fundo recta

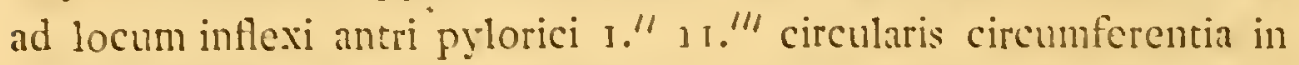
loco amplifimo $3 . "$ in anguftifimo $1 . "$ 4." ipfisque pylori $6 . " 1$

Intefinm tenue aquabile, a pyloro ad ceeum longitudine 2.' I0." vel fubtripedale; amplitudine calami feriptorii.

Crecm fubcellulofo - annulatum, in tres fpiras compofitum, apice fubulato brevi terminatum, digiti annularis fere amplitudine, circumferentia J." $6 . "$ longitudine $-\frac{\mathrm{r}}{2}$ pollicum (Fig. $\nabla$ litt. $a-$ b.).

Coli pars prior $\left(a-c, c-d_{.}\right)$contortuplicata, biglomerata medio quafi itthmo coarctata, ( $e_{\text {. }}$ ) extricata rquat.$- "{ }^{\prime \prime}$ " in medio anguftior, verfus rectum, ubi latefcit, circumferentia pollicari; reliqua pars coli ter reduplicata, parallelo fere fitu furfum deorfum procedens, dein verfus rectum arcuato - defecndens, tota ufque ad anum longitudine hujus partis 2.1 2." 5."l In prima reduplicatione coli excrementa moleculatim difcedunt, in fecunda in oblonga feybala compinguntur.

Ren dexter dimidia longitudine anterior finiftro, ultime coftx proximus, idemque oblongior \& dorfi fpina magis aldftrictus; finifter a dorfali latere planiufculus. Singuli pondus circiter gr. IX. Glandulde renales oblongo - cylindrica, vix 2:" lutex, grano uno leviores. 
Vefica urinaria amplifima, ovi pafferini forma \& molc, laxa; collo, quod ftrictura diftinctum eft, feu initio urethre intra pelvim pariter dilatato, urinifero.

Teftes hyeme exiles mafculis, in facculo annuii mufculofo fiti \& epididymidi adnati. Penis tenuis, longus, glande indiftincta, fubulata, terminara Spina offea infigni \& mucrone fub illa breviore, a dorfo carinata linea criftre galli fimili, denticulis callofis ferrata.

In feminis nterzls a vagina vix diftinetus, a clitoride ad cornuum divifuram 7." comma $\sigma_{3}^{\frac{1}{2}}$." fed cxtremitate adtenuata, in tres quatuorve gyros crifpata, quibus accubat ovarinn (hyeme) bullula una alterve notatum.

Plllmo finifter indivifus, dexter quadrilobus, lobo quarto azygo a dorfo cordis pofito. Admiranda, qux circa laryngem in Commentur. Petropol. Vol. $V$. p. 232. Seq. cxpofuit DVVERNOY, ad folitam in ordine glirium ftructuram redire vidi.

Sceleton fimillimum deferipto per Cel. D'A B BNTONVM Sc. Volucellx fceleto. Roffrum in cranio brevius atque craffius, orbitæ majores, dente fupraorbitali in proceffum producto fubulato $2 \frac{1}{2}$." olla poftice magis rotundato; immo totum cranium fupra convexius. Os bregmatis unicum, nulla futlra longitudinali divifum; frontale antice a nafalibus fifura integerrima aliquoufque divifum, poftice item integrum. Molares colliculofi fupra infraque fubæquales quatuor; at fuperius ante iftos minutus acceflorius quintus, fimplex \& obtufus. Coftarmm numerus duodenarius, ut in Volucella, quarum feptem utrinque veræ, ultimis duobus paribus articulationi enfis fterni infertis. Cofte primæ robufte, cartilagine folito longi-

$$
\text { A a a } 2
$$


ore ampliorem circulum efficiunt. Manubrium fterni latum; triangulo - truncatum; corpus vertebris tribus majoribus, \& minore enfi contermina compofitum. En/ls cartilagine lata orbiculata fpathulatus. - In artubus anticis clavicule-longe; radius multo robuftior cubito, qui fere ad proportionem fibulie pofticorum tenuatus, radio verfus carpinam extromitatem coadunatur. Carpo exterius, ejusque offi pifformi, ginglymo adarticulatur calcar offeum, tereti adtenuatum, calcari alaudæ fimile, radii fere longitudinem rquans, quod alulis explicandis infervit. Pofticorlm artuum offa nihil minora anticis; fibula tenuifima, ultima quarta parte longitudinis in tibiam deficiens. Vertebra lumbares 7; Sacri unica articularis lata, \& duæ pelvi non adarticulatæ; cande vertebræ 18. quarun fex priores proceflibus transverfis alatæ, reliqua teretes. Menfuras ecce, datis a DAVBentono e Volucella, comparatas.

Longitudo cranii integra

Latieudo maxima cranii ad zygomata

- ollæ pone zygomata

- inter orbitas ad incifuram

Longitudo offitm nafi eadergque roftri

Eorundem latitudo communis antice circinno

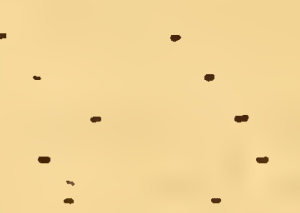

I." 5.111

- per convexitatem paulo ultra

Diftntia inter aperturam nafi \& marginem orbita

Diameter orbitie longitudinalis

Longitudo maxilla fine dentibus

Latituco ejusdem furmma ad apoph. latam

- ad molares

- ante molares

Longitudo inciforum inferiorum extra maxillam

- - - fuperiorum

Latitudo foraminis ovalis

- atlantis

Longitudo vertebræ dorfalis ultima

- omniun vertebrarun colli

o. 11.

o. 8 .

o. 4 .

o. $\quad 5 \frac{\pi}{2}$.

o. 3 .

o. 4 .

o. $4 \frac{2}{5}$.

0. $6 \frac{2}{5}$.

o. $9 \stackrel{x}{5}$.

o. 5 .

o. $2 \frac{2}{3}$.

o. $1 \frac{3}{4}$.

o. $2 \frac{1}{2}$.

o. $2 \frac{\mathrm{T}}{6}$.

o. $\frac{x}{4}$.

C. 4 .

o. 2 .

o. $5 \frac{\pi}{4}$. 
Longitudo omnitum vertebrarum dorfalium

- vertebrarum lumbarium

- lumbaris vertebræ fextæ longiffima

- ollis facri fere

Longitudo coftie octava

- - manubrii fterni

- corporis

- enfis offei

- ollum pelvis

- ilci a margine cotulæ

Diameter cotulit articularis

Longitudo ifchij ad cotulam

Foraminis ovalis longitudo

- laciundo

Diftantia inter ifchia

Longitudo fcapulæ

Latitudo ejusdem fumma

- minima colli fcapuløe

Longitudo claviculæ

Longitudo humeri

- radii inter articulos

- cubiti ab olecrano fummo ufquedum adnafcitur -

- calcaris carpinj

- metacarpi mediorum

- phalangis primæ fere

- phalangis fecundæ

- femoris

- tibix

- - fibulæ ufquedum adnafcitur

- calcanei

- offium metacarpi mediorum

- phalangis prima fere

- phalangis fecundx
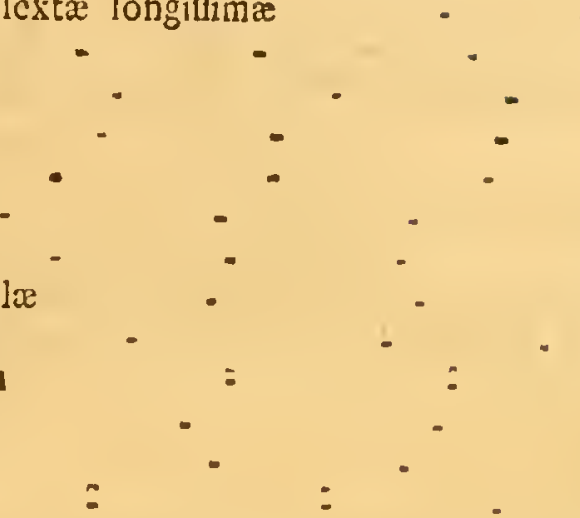


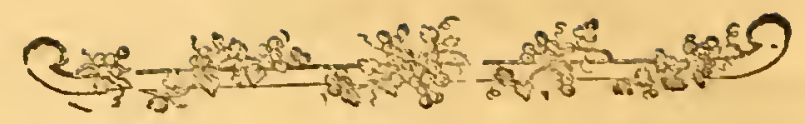

\section{S C I V R O R V M}

SPECIES QVAEDAM ILLVSTRATAE.

I InNaevs fpecies Sciurorum, quotquot norat, recte $\&$ ca1 fte diftinxit. Sed alii inter recentiffmos Zoologos in quibusdam lapfi funt, quas adtigiffe non inutile crit, quoufque mihi liquent.

BVFFonivs primum, credidit Scinmlm amcricanum cinerezm etiam in Afie \& Europæ borealioribus dari, immo Sciuri vulgaris varietatem $f$. larvam hyemalem cinerean ad eandem fpeciem pertinere \& a Sciuro rufo altivo fpecifice differre pronunciavit (bift. nat. ool. X. p. I I 7. edit min. XX. p. I 52. feqq.) contraria auctorum teftimonia variis argumentis infirmans, qux extra facundiam Auctoris vix quidquam ponderis habent.

Celeber\%. penNant in eandem fententiam inclinafic videtur, dum majorem varictatem, hycme exalbidam Sciurorum in quibusdan Sibirix regionibus inveniendorum, cum Sc. amcricano cinereo convenire credidit $\left(\int y m\right.$. of quadr. p. 2S2.) itidemque nigrefcentem varietatem, alpinam \& orientalem Sibiria, cum Sciuro nigro americano conjunxit (ibid.p.284.). Alios minus celebratos \& graves auctores nihil moror.

Contra vero iftos non poffum non afferere, per onmem æque Europam borealem, per totam Ruffam, ctiam temperatiorem, perque univerfam Sibiriam fpeciem tantum unicam Sciurorum hyeme cincrafcentem occurrere, qua a Sciuro rufo 
Europx temperatx ita plane non differt, ut $x$ ftivo tempore etian rufo colore, uti cxteris omnibus, conveniat penitus; quemadmodum e contrario Sciuri Germanix, fi frigido loco cicurati alintur, hyemalem pilum fatis evidenter cinerafcentem, multa cum rufedine licet mixtum, induunt.

Opinionibus originem dedit, quod Scimms vulgaris, fecundum regiones, varietatibus plurimis ludit, quas non futis curiofe determinaverant itincratores, quæ tamen omnes auriculis barbatis \& proportionibus à $S c$. cincren $\Lambda$ mericano funditus differunt. Media facies eft Sciurorum Succix, Rufix borcalioris \& Sibirix planioris, ad Obum, imo Icnifcam ufque fluvium: horum xftiva facics ab Europæis rufis, magnitudine paribus, plane non diftinguitur; fed incunte hyeme omnes, etiam in calidis conclavibus cnutriti, colorem cœrulcfcente - cincrcum, quafi pulveratum, paulove obfcuriorem induunt, \& tunc maxime, propter pelles, a venatoribus capiuntur, ceffante captura, quan.. do ingruente vere denuo rufo pilo contaminantur. In occidentalioribus \& auftralioribus hycmales pelles plus rufefcentis fervant \& ad gryfeum color cincreus, prafertim tergoris, inclinat, in frigidioribus pulcrior puriorque evadit.

Succefivam mutationem coloris in hac vulgari varictatc præfertim Krafnojari ad Ienifeam obfervavi, ubi tamen aliqui jampaulo obfcuriores, xftate fufcido-rufefcentes occurrunt, folitaque magnitudine corporis (a nafo ad caudans) circiter $-\frac{1}{2}$ poll. xquat. Initio \& medio Allgufti adlatos habui fupra rufos, fufco per medium dorfum, magis minusve adumbratos, verfus latera in.cnfore colore. Pedes omnibus toti rufi; aures fepe vix barbate, rufx; prona facies alba; cauda plerumque nitide nigra, nonnifi 
pilorum radicibus aliquantum rufescentibus. - Initio Seltembris (Styl. vet.) intra quatriduum tres adlati funt Sciuri ma.. culi, quorum duo (forte juniores) fupra toti rufo erant colore, quem etiam paulo faturatiorem prætulit cauda; folis malis \& initio cauda cinerafcentibus. Vnus tamen, medio inter iftos tempore occifus, per medium capite \& tergore jam erat cinereus, verfus latera interque aures adhuc fuperftite rufo con lore, pedibus rufis \& cauda (extremo nigræ) initio, auriumque antica facie \& penicillis, quos hycme omnes valde infignes habent. - Septembris XII. ${ }^{\text {mo }}$ tres mafculos totidemque foeminas -adtulerunt: ex his duæ totæ adhuc rufæ, cauda faturatiore, imo fere brunnea; mafculi duo alii ab initio cauda cinerafcere coperant, \& in horum altero cinereus color jam per majorem partem dorfi rufo erat immixtus, caudaque nigrefcebat, pedibus \& capite adhuc intemeratis rufis. Vnus mas, unaque famina totam pofticam partem dorfi cum initio caudx \& externa femorum facic habuere cineream, reliquo dorfo rufo, caudaque rufa, extremo cinerafcente. His pili rufi æque ac cinerei, defluebant. Etiam XIV. Scptembris rufus adhuc fuit captus mafculus, cui vix cauda cinerafcere coperat; at in alio d. XV. Sept. capto fumma capitis pars, auricula, humeri, pedes, latera, caudaque rufa; male \& interna facies aurium cinereo imbuta, dorfum medium \& initium 'caudæ tota fere cinerea, nifi quod apices cauda hinc inde rufefcebant. Denique XXVIII. Septembr. alio loco adlatum habui mafculum, capite rufo cinereoque nebulofum, auribus rufis nigro barbatis, toto dorfo cinereo, cauda nigra rufo mixta, crepidine pectoris ventrisque fubtus dilute rufa, ut \& interna pedum facie. Exeunte hyeme ibidem circa finem Maji capti Sciuri, plerumque exhibebant 
caput totum cum auriculis, pedes caudamque jam rufa, dum in reliquo corpore fupino pilos rufos ubique fub cinereis ad. huc latentes.

Cum fupra memoratis d. XII. Septembr. cefis, etiam vivus adlatus fuit Sciurus, totus ruftis, quem in tepido concla. vi affervavi; huic circa IV. Octobr. demum tota corporis pedumque fupera \& externa facies, vertex inter aures, oculorum regio \& initium caudæ cinerafcere incoperunt, \& quum IV. Novembr. mortuus effet, totum corpus fupra fatis obfcure cinereum, pedes plirimam partem adhuc rufi (uti multis tota hyeme mancnt), multumque rufedinis circa faciem \& aures fupererat; cauda villi bafi cinerafcentes, extremo rufefcente fufci, auriumque penicilli nigri.

Ex his fatis apparet variabilis color \& inconftans terminus modusque, quo cinereus rufo fuccedit. Locales varictates nunc ulterius perfequamur. A Ienifeja fl. orientem verfus, in borealibus Ienifeenfis provincix, ut \& in Alpino tractu ab auftro Sibiriam claudente, plurimi Sciuri magis magisque nigrefcunt \& præfertim circa Baikalem \& fuperiorem Angaram, inque alpeftribus inter Selengam \& Argunum, ut \& in omni tractu Lenæ fl. omnes æftate occurrunt brunnei, feu fuliginofo - rufefcentes, imo vellere penitus furco nigricante, apicibus tantum, pilorum rufis, caudis atris, nitiois; atque hyeme omnes, eodem fere, ut fupra de vulgaribus dictum eft, tempore, eademque inconftantia, fufco - cinereo feu plumbeo mutantur colore: quæ pelies in denfifimis alpeftribus fylvis, Cembra \& aliis acerofis frequentibus maxime collectr, apud Europæos maxime, fed a Chinenfibus parum eftimantur, earumque caudx, ob fplendidam nigredinem, ad pratexendas veftes adhibentur.

$\mathrm{B} b$ b 
374 SCIVRORVM SPECIES QVAEDAM ILLVSTRATAE.

Contra apud Sinas magno in pretio eft, triploque fere in Sibiria coëmitur varietas exalbida, quæ in Pinetis raris camporum Barabenfium, inter Irtin \& Obum, itemque inter Tfchulymi confluentes \& Ienifeam \& fecundum tractum Ifettæ fluvii, ut \& in Ruflia ad Samaram fl. eique conterminum Volgæ fylvofum tractum, localis vivit, \& fere nunquam extra iftas regiones apparet. Hæc non folum paulo major eft Europæis \& Sibiricis aliis omnibus, fed etiam fe diftinguit egregie vellere hyberno pulcherrimo, molliffimo, exalbido canefcente feu leucophæo, Larorum dorfis fere fimili, fed fubundulato, quem reftivus excipit dilutiflime rufus feu fulvus in junioribus, in fenioribus frpe fufco - rufus, lateribus quandoque nigrefcentibus \& extremis pedibus atris, quales pondere fxpe ad fefquilibram medicam accedere deprehendi, longitudine a nafo ad caudam 8." 2"l cauda 7." (prater villum 2." $3 \cdot{ }^{\prime \prime}$ ) excedentes. - Huic varietati pelle hyemali finillimi Sciuri, fed minores fere vulgaribus, e regione Kafym, Berefovienfis ditionis adferuntur.

Hæ funt tres præcipuæ varietates Sciurorum per Impcrium Rufficum vulgatiores, inter quas tamen prima (vnlgaris) latiffme patet, ultima (exalbida) minime omnium abundat \& exiguis tractibus inclufa eft. Hæc enim, pariter ac nigra vari*tas, a loci \& pabuli natura ita pendent, ut extra folitas regiones rarifime, nec nifi coacta quadam infolitaque migratione apparcant, qualem de nigricantibus Sajanenfum \& Altaïcarum alpium Sciuris, per planas regiones inter Obum \& Ienifeam, in Itinerarii mei Vol. II. p. 660. adnotavi. In Bargufinenfi tractu vix centefimus Sciurus eftate rufus apparet, quos ibi venatores, inter folitos, brunneo - nigricantes, tanquam transfugas fporadicos confiderant \& obfervant maxime in cavis arbo- 
tum abfcondi, dum nigricantes omnes in ramorum bifurcationibus \& fummitate pinuum nidos e mufco fructos habent. In regionibus contra nonnullis, qua inter prafcriptos varietatibus iftis limites intermediæ \& migrationibus carum expofitæ funt, ut eft v. gr. tractus Kani vel Tomi fluviorum, ibi quotannis fere promifcue capiuntur cxalbidi, plumbicolores \& vuls gares cinerei; immo cinereo - rufefcentes quoque immifcentur, quos juniores plerumque cfie crediderim. In genere autem Sciuri per omnem Sibiriam \& finitimas regiones alpinas, ad Sinas \& Bucharos ufque, adeoque faltem ad $40^{\text {manm }}$ laticudinis borealis gradum, in Ruffia vero faltem ufque ad quinquagefimum verfus aufrum, hyeme cineream veftem induunt, dum in reliqua Europa nonnifi in terris fub fexagefimo fere gradu pofitis eam coloris mutationem hyemalem fubeant.

Sporadica varietates, inter hos noftros Sciuros, hyeme cinereos, præfertim ad album colorem totæ vel pro parte degenerantes, haud ita raro præfertim in Sibiria, occurrunt, ubi contra nunquam plane atra individua obfervata fuife fcio. Satis frequen. tes occurrunt, qui hyeme pariter \& aftate toti albi apparent, vel parte tantum capitis, \& fæpe macula hinc inde corporis rufi f. cinerei funt. Ad Tf́chulymum infignem pulcritudine \& fatura Sciurum, varietatis exalbidæ, obtinui fab finem Septcmbris 1771 . cui dimidium caput, area magna alterius lateris, cauda tota pedesque nivei crant, reliqua partim hyberno colore leucophæa, partim rufo picta erant. Aliam ex Obenfi tractu ultra Berefovam adlatam habui varietatem hyemalem, medio tantum tergore longitudinaliter exalbido - canefcentem, lateribus \& fubtus albam, pedibus intenfus canis, pofticorum metatarfo fupra cano fufcefcenteque inixto, cxterius nigricante, digitis tamen totis albus; auriculis porro penicillo nigri- 
cantibus, cauda bafi cinerea, hine nigricante, cxtremo alba, preter floccum fummi apicis nigrum. E quibus facile liquet, Scimrim fibricium albim brissoxio pro frecie pofitum, me. ram ejusmodi accidentalem rarictatem fuiffe.

Crterum Sciurorum notabilis, \& non fatis a Zoologis adnotatus mos innotuit mihi ex autopfia \& venatoribus Sibirix vulgo notus eft. Scilicet quod autumno, dum pluviofa tempeftate Fungi varii in fylvis abundant, agaricos varios, quos in deliciis habent, \& quorum prxcipuum, Lapponibus etiam notum, in Flora Lapp. p. 367 . indicavit LINNAEvs, copiofe colligant, \& in arboribus prefertim illis, in quibus nidum, pro duobus tribusve fæpe communem, ftruxerunt, corticis rimis \& ramorum furcis vel prefractis apicibus inferant \& infigant, ut ad hyemalem cibum ficcatos fervent. - Contra vero de celebrata aliisS ciurorum navigatione apud noftros nulla mentio.

Quemadmodum perfuafus fum, omnes iftos fupra memoratos Sciuros, hyeme vario gradu cinereos, vel accidentaliter albos, noftri Europei efle varietates, neque cum Americano "etiam æeftate cinereo Sciuro, multo majore \& auriculis imberbibus conftanter diverfo conjungi poffe credo; ita contra plane non concedere pofium Scimmm? Indfonizm, quem forsterrs. (Act. angl. vol. LXIT. p. 3 , 8.) \& Celeberr. ecian ті. PENNANT primus poft inmortalem $1 \mathrm{AJVM}$, Anglorum folidus Zoologus (Syn. qliadr. p. 280. a. tab. 26. fig. I.) pro varietate Sciuri vulgaris pofuerunt, fub hac fpecie militare poffe, licet eidem maxime affinis, ctiam moribus, utique videatur. Accepi quatuor e Labradoria in cxuviis farctos, qui differentias hujus fpecici fatis evidenter monfrant, \& de quibus adjecta. fichedula monet, quod aftivo pariter ac hyemali tempore eodem 
colore cincreo, ftictico, per medium dorfum fulvefcente, fubtus cinerafcente, obfervantur. Aures quoque plane imberbes, rotundatæ, caput oblongius, caudaque haud difticha, $\lceil c d$ villofo teres annulatim variegata, diftinguunt; ut alia minutiora, \& proportiones hic non exponam, quæ mclius in recenti animali alius obfervaverit.

Addam hac occafione aliam ex India orientali quondam mihi oblatam in Belgio fpeciem, quam apud recentifimos Zoologos fiuftra quæfivi. Poffet hæc

scivrvs erytbrcells appellari. Defcriptum fpecimen magnitudine crat Sciuri vulgaris, vel paulo forte majus. Color corporis fere qui in Cavia $\Lambda$ cuti obfervatur, luteo fufcoque mixti pilis; fubtus longitudinaliter fanguineo - fulvus feu faturatifime rufus. Idem color eft contia tereti - villofx, \& quam fafcia fupcrne longitudinalis nigricans legit. Palmee tetradactylæ, verruca infigni, loco pollicis, notatx. Plante pentaductylo. Auricule fubbarbatx. - Diverfa omnino videtur fpecies a Sciuro javenfi, quem Cl. sparmann nuper in Actis Soc. Gotboburgenlis defcripfit, ut ct ab il10, quem in montibus Hyrcaniac obfervavit GMELINvs nofter, \& in Itinerat. vol. III. p. 379. tab. 43. notam fecit; quae quidem ad hancec noftram proximx ftare debent.

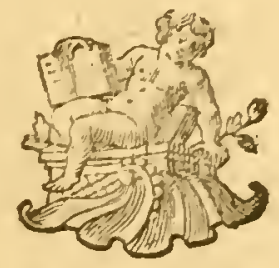

$\begin{array}{llllll}B & b & b & 3\end{array}$ 


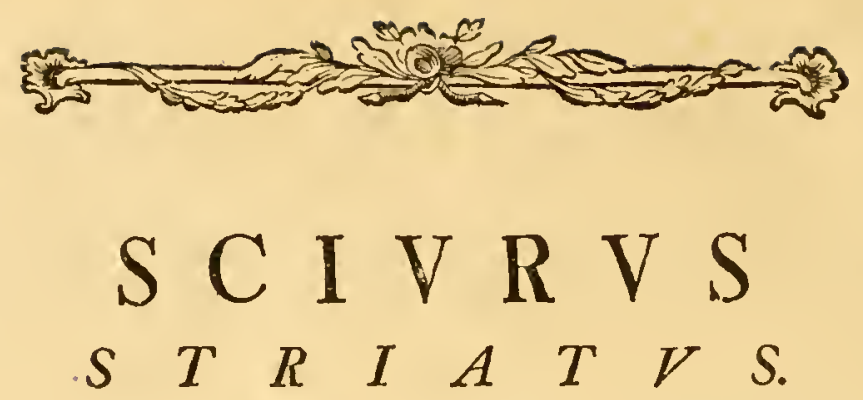

Hec fpecies vere Afix noftra cum America communis eft \& jam ufque in Europam, fcilicet per omnem Kamæ fluvii tractum, \& ad Dvinam fefe explicavit, quemadmodum per omnes Vralenfium montium frigidiores fylvas copiofe paffim occurrit. Sola hæc, præter Sciuri vulgaris varietates \& Sc. volantem, per Sibiriam reperitur, neque alia ulla Sciurei generis fpecies. In fylvis acerofis totius Sibirix \& finitimi tractus montani, imo in Betuletis quoque fpiffioribus nufquam defunt Sciuri ftriati; frequentifimi funt ubi Cembra abundat, vel ubi in fylvofa regione inchoati agri pabuli prebent abundantiam, ad promptuaria praefertim pro hyeme condenda. Ibi circa pagos mira copia domici.. lia figunt et frumentis vel Cembræ nuculis granaria fua replent, pullulantque numcrofa prole. Abfunt tantum in maxime arcticis, deficientibus fylvis, uti \&, propter eandem caufam, ultra Anadyr fluvium. Ideo etiam in omni Kant fchatka, licet Ccmbræ proventu felicifima, abfunt, pariter ac Sciuri vulgares \& volantes; quos omnes fylvis denudata ultra Kowymam, fexagefimum inter et 58 gradum, regio coërcuit, \& per aprica transmigrare impedivit.

In fylvis, quamvis uliginofis, tamen humi, circa truncos præfertim arborum \& in tuberibus clatis antra fua fodiunt, nunquam, exemplo congenerum, in truncis ramisve arborum ftabulantur, licet extra antrum perturbati egregie fcandant, perque truncum \& ramos expedite curfitent. Antra finguli parant fatis inordinata, 
fpithamx profunditate canali flexuofo adeunda, alterne coarctata atque dilatata, vel varias in cameras cohærentes difpertita, quarum una pro nido, reliquac frpe duæ vel tres pro promptuariis ferviunt. Hæc promptuaria autumno maxime replent, ideoque ad Octobrin ufque, fubfrigida licet tempeftate, continua per totas dies diligentia vagantur, \& tunc circa vias, ubi plantarum femina, imo grano ex equorum ftercore, colligere polfunt, nullum frequentius animalculum, maxime inter Obum \& Ienifam, occurrat. Qui tunc extra antra capiuntur, facculos buccales, quibus hxc fola inter Sciuros fpecies, inftar Criceti, capaciffimis inftructa eft, feminibus variis refertiffimos gerunt; inter quæ, præter arborum acifoliarum femina, Heraclei fibirici \& Polygoni avicularis frequentifima effe folent. In fylvis nobili Cembræ proventu frequentibus folos fere hujus nucleos congerunt, tanta fape copia, ut ex uno antro decem, imo XV. librarum acervum lectiffimorum effodi viderim. Decidente deinde nive in antra hacce fua fe condunt, \& nufquam apparent, collecto penu viventes.

Sicut his moribus \& facculis buccalibus Criceto \& $\mathrm{Ci}_{i-}$ tillo affinis eft Sciurus ftriatus, ita \& nafo convexo fofforio pofteriorem refert. Toto etiam habitu a Sciuris arboreis aliquantum difcrepat, adcoque cum reliquis Sciuris ftriatis peculiarem generis phalangem conftituit. Caput oblongius habet, quan vulgares, aures nudas rotundatas; caudam villofo - teretiufculam, quam minus crebro reflectit, corpus denique gracilius \& artus breviores; vellus quoque perbreve \& minus tenerum, murino generi fimilius. Attamen diurnum vitæ genus \& quod hyeme fine fopore lateant, cum Sciuris potius commune habent. 
Inclufi Sciuri ftriati facile \& diu nutriri poffunt, nucle: is \& vegctabilibus alimentis variis, carnes etian crudas oblatas avide devorant, \& fi plures in eodem carcere, caudas fibi invicem prorodunt. Omne autem pabulum fciureo more in palnas accipiunt \& clunibus infidentes rodunt, fique multum offeratur, totas buccas fufferciunt avidifime. Cicurari perfecte nunquam poffunt, fecus ac Sciuri vulgares, femperque manent timidi, latebrofi, fugaces \& mordaculi, vincula \& ligneos carceres ftrenue rodentes. In libertatem reftituti velocifime afcendunt arbores, \& miris promptisque faltibus Sciuros fere xquant. Vocein incluforum rarifime audias, \& quam vi illata quandoque edunt, ratti fcreatui fubfimilis fere eft.

Capiuntur, propter pelles ignobiliores, plerisque locis negligentius, frequenter vero ad Lcnam \& in Kufnecenfi tractu, ubi vellere paulo preftantiore funt. Partim in arboribus obtufis fagittis occiduntur, partim decipulis comprefloriis aliisque capiuntur. Ad Lenam Iacutorum pueri otiofi in fylvis fonum vocis femellæ, neftri tempore vernali, poft truncum arboris ftantes, lamella betulini corticis in os inferta imitantur \& undique accurrentes cæea libidine mares fuftibus cædunt. Tergora, tæniis cleganter picta, fi cum felectu artificiofus confuta fucrint, pulcherrimas adfpectu, fed admodum infirmas veftes prebent, quæ fatis copiofe Sinis mercatoribus venduntur, rarius Petropolin perveniunt, ubi tunc fatis caro conftant, licet ad Lenam in mille pelles vix fex, octove Rublonibus æftimari foleant.

Nomina Sciuri ftriati apud gentes Ruffici imperii \& Afiaticas rel. fequentia ufitatiora didici: 
Rufficum, Burunduk.

Barchkirorum, DJjulali.

Tatarorum ad Ienifeam, Kïgeriik vel Köbrök.

Buraticum, Dfbyrykiz.

Mongolicum, Dfbyraki.

Indicum, Kätbo (notante messerschm.)

Tunguficum, Uldïnki \& Ulbilki.

Wogulenfe, Wabrte, ad Sofvam Konfer.

Wotjacorum, Ulirda.

Oftjacorum Surgutenfium, Scböpe; ad Narym, Schépek; ad Jas, Koop; ad Ienifeam, Denka.

Kamåchinzis, Nógai.

Arinzis, Lappje.

Samojedis, Pifeku.

Monticolis Sajanenfibus, Orom.

Iacutis, Kurtechuges $\int$ (i. e. Iineatus) \& Mochotóy.

Americanos Sciuros ftriatos ipfe nunquam vidi; fed ex auctorum defcriptionibus fatis apparet, ejusdem fpecici cum fibirico noftro effe. Habent iftos RAIVs, cATESBAEVS, EDWARDsivs ${ }^{b}$ ), \& itineratores varii. De Sibirico egere gmeLINVS, DE BRVYN, BVFFONIVS ${ }^{c}$ ), cujus figura optima dicenda eft. Sed nemo horum accuratam recentis animalculi

b) Sciurus Lifteri R A J. (yn. p. 216 . Ground - Squirrel C A T ES 13. carol. 11 . tab. pag. 75. Sciurus carolinienfis minor ED IV A R B S av. IV.tab.181. B R IS S ON quadr. p. I55. С H A RLEVOIX hift. de la notu. France $V$. p. 198. В R I C K EL L sat. hif. of. N. Caroline p. 129. cet.

c) guedin Nov. Com. Petrop. Tom. $V$. p. 34t. Sciurus minor virgatus. DE URVyN Reize over Mofcorien $\rho$. 467. tab. 11.257. peffima. Born - doefkic, B VFF O hift. nat. Tom $X$. p. r26. edit. min. $X X$, p. 186. tab. 28. Le Suiffe.

C c c 
defcriptionem dedit, quam hic fuperaddo, fed abfque anatome, qua cafu periit, \& eo minus neceffaria videtur, cum nihil omnino infoliti occurrife bene meminerim.

\section{ES C R I P T IO \\ $S C I V R I S T R I A T I$.}

Caput paulo oblongius, roftumque conicum, maxilla. fuperiore productius, quam in Sciuro vulgari. Nafus ultra dentes primores longius productus, rotundatus, pubefeens, fola narium apertura feptoque didymo nudis.

Labium fuperius ufque ad feptum difciffum; oris anguli reliquo labio pilofiores. Dentes primores antico latere plani, lutei, fubtilifime ftriati. Molares tuberculofi, fupra utrinque V. primo minimo; infra IV. Sacculi buccarum ufque ad parotides extenfi.

Myftaces quinque ordinum, exiles, capite breviores, nigri. Setule 2 lupra anticum canthum oculi; gemina in buccis fub cantho fere poltico fita; fub gula pili quatuor tenelli albi. Pills longior in medii brachii latere poftico \& duo verfus carpum, paulo exteriores, albidi.

Octri majufculi, protuberantes, nigricantes; palpebrarum limbus nudus fufcus; Periophthalmium plica brevis, margine cartilagineo fufca.

Auricule breves, oblongo - rotundatx, brevifimo vellere veftire, intus capiti concolores, extus antice nigricantes, poftice albidre. Meatus auditorius trago bafeos a poftico margine arcte connivens. 
Corpus forma sciuri. Artus poftici longiores. Palme tetradactylx, verruca pollicari obtufa, fuperius lamella cornea incruftata. Plante pentadactylx. Volce pedum nudæ, albæ, callis albis, digiti fubtus nudi, fufci, transverfis veftigiis rugofi. Ungues furci.

Carda longitudine trunci, undique villofa, in vivo animali fubdifticha, cute (ut in murina cauda) annulata.

Vellus haud altum, quale fere Criceto, imo fere rùdius. Color in capite fuperne, cervice, humeris, femoribus, lateribusque gryieo - lutefcens, pilis longioribus raris nigris, apice albicantibus mixtus. Gula, corpus fubtus, artus interiore latere e canefcenti alba, tranfparente bafi pilorum cum cute furca. Latera capitis linea a bafi per fupercilia, alia item a palpebra ad aurium bafin ufque pallidae, cum duabus fafciis ferrugineis alternæ, quarum altera infimo, altera inter pállidas fafcias, a cantho oculi ad aurem ducta. Dorfum fafciis quinque nigris, longitudinalibus ftriatum, quarum media a nucha ad caudam, proximæ a cervice ad clunes, extimæ a fcapulis ad femora protenduntur; interjecta fafcix ad mediam pallido-lutefcentes, exteriores albo - pallidæ. Cauda fupra nigricantior, fubtus obfolete lutefcens, villis omnibus verfus extremitates nigris, apice vero canis, ita ut expanfa cauda quafi tribus lineis nigris in longitudinem varia vidcatur.

\section{E N S V R A E.}

Pondus unciarum $2 \frac{\mathrm{r}}{+}$ vel trium.

Longitudo a fummo nafo ad anum -

- caudæ fine filo

- villi excedentis

- capitis ad nucham

1. $1=\frac{5}{2}$ 
Intervallum narium

Diftantia oculi a nafo - auris ab.oculo

Circumferentia oris

Prominentia nafi ultra incifores

Fiflura oculi

Inte, vallum inter canthos ocul. filo

$$
\text { - circinno }
$$

- aurium per verticem filo

- - - recta

Altitudo auris a bafi

- - - a vertice

Latitudo ejuscem explanata

Circumferentia nafi ante dentes

- roftri ante oculos

- capitis inter oculos \& aures

Longitudo colli

Circumferentia colli

- - thoracis ad armos

- in medio corpore

- ad ilia

- bafeos caudr

Longitudo humeri

- - antibrachii

- - digiti medii (fine ungue $1 \frac{1}{2}{ }^{\prime \prime \prime}$ )

- femoris

- tibix

- plantæ totius

- digitorum trium mediorum fubæqualium (demto ungue $\left.\mathrm{I} \frac{2}{3},{ }^{\prime \prime \prime}\right)$

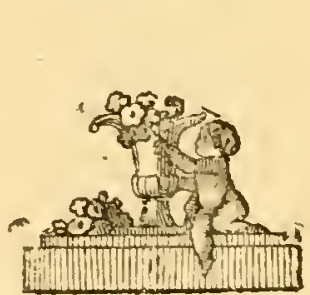




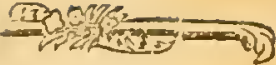 \\ E X P L I C A T I O \\ I $\quad \mathrm{C} \quad \mathrm{O} \cdot \mathrm{N}^{\mathrm{N}} \mathrm{M}$.}

Tab. I. Lepus pufillus. pag. 37. Tab. II. Lepus alpinus. p. 52. Tab. III. Lepus Ogotona. p. 64 . Tab. IV. A. Fig. 1. 2. Lep. variabilis \& Lep. Tolai Fœtus. p. 59.

- - Fig. 3. Lep. pufilli auricula. p. 38.

- Fig. 4. Ejusdem cranium a fron. te. p. 37 .

- Fig. 5. Ejusdem fceleton. pag. $37 \cdot 44$.

: - Fig. 6. Ejusdern hepar. p. $4 \mathrm{r}$.

- Fig. 7. Vid. tab. req.

- Fig. 8. A. Rugæ cœci ejusdem animalis cum fimbriis. p. 43 .

- Fig. 8. B. Superficies interna in. fundibuli coli reticulata. ibid.

- : Fig. 8.C. a. Superficies interna ultimæ portionis coli trifa. riam cellulofx, ibid.

: - Fig. 9. Vid. tab. feq.

- Fig. 1o. Lep. alpini hepar.

- Fig. 11. 12. Vid. tab. req.

- Fig. 13. A. Lep alpini craniam a latere. p. 13 .

- Fig. 13. B. idem a fronte, ibid.

- Fig. 14.15. Vid. tab. feq.

- Fig. 16. A. Lep. Ogotona cranium a latere, p. 68.

- Fig. 16. $B$. idem a fronte, ibid.
Tab. IV. B. Fig. $z$. Lep pufilli ven. triculus \& inteftina. p. $4 \mathrm{~T}$.

- Fig. 9. Fjusden renes, vefica \& partes genitales mafculine. p. 43.44.

- Fig. ${ }_{1 I}$. Lep. alpini sentriculus. p. 56.

- Fig. 12. Ejusdem inteftina craf. fa. p. $5^{6}$.

- Fig. 14. Eadem Lep. Ogotonæ. p. 60.

- Fig. 15. Ejusd. renes, vefica urin. \& genitalia mafculina. p. 67.

$T a b, V$. Mus ArEtomys. p. IIr.

Tab. Vl. Muris Citilli varietas major. p. 126.

Tab. VI. B. Muris Citilli varietas guttata. p. 124 .

Tab. VII. Mlus capenfis, p. J73.

Tab. VIII. Nlus Typhlus. p. I58.

Tab. IX. Fig. J. Caput M. ArEto. myos a fronte, naturali magnitudine. p. ru.

- Fig. 2. A. B. Ejusdem animalis palmæ corfum \& vola. P II2.

- Fig. 3. Ejusdem planta. ibid.

- Fig. 4. Ejusdem inteft. cœecum. p. $n 6$.

$\mathrm{Ccc} 3$ 
Tab. 1.Y. Fig. 5. Fjusdem genitalia I,Tab. Yl'll. Fig. r. item $A$. \& $B$. matculina. p. 116.

- Fig. 6. Muris Cirilli inteft. re.

Ei portio infima cum orificio. p. 148 .

: Fig. 7 . Muris Citilli inteft. cce. cum \& colon. p. 148 .

Muris Criceti genitalia mafculina. p. S4.

Fig. s. A. Caftoris Fibri glans. b. c. d. cjus oficulum. p. 85 . Fig. 3. Muris talpini ventriculus. p. 183 .

Fig. 8. g. ro. Ejusdem genitalia mafcnlina. P. I 49 .

- Fig. 11. vid. tab. XXVi.

- Fis. $1 I^{*}$. vid. tab. XXVII.

- Fig. I2. Muris Typhli ventriculus, cum portione duodeni. p. $x 62$.

- Fig. 13. Ejusdem cœcum. p.163.

- Fig if. vid, tab. XXVI.

- Fig. 15. -vid. tab. XXVI.

- Fig. 16. vid. tab, XXVII.

- Fig. 17. vid. tab. XXVI.

- Fig. $\nabla$. Sciuri volantis inteft. ccecum \& colon. p. 366.

Tab. $X$. Nus Afpalax. p. 168.

Tai. Xl. A. Mus talpinus. p. Iso.

Tab. XI. B. Mus torquatus. p. 206.

Tab. XII. A. Mus Lemmus, norvagicus. p. Igr.

Tab. X7I, $B$. Mluris Lemmi var. e La. ponia ruffica. p. 192.

Tab. XIII. A. Nus Lagurus. p. 213.

Tab. XIII, $B$. Mus focialis, p. 220 .

Tab. XIV. A. Mus ceconomus. p. $23+$.

Tab. XIV. B. Mus rutilus. p. 248 .

Tab. $X I Y . C$. Mus alliarins, p. $=53$.

Tab. $X V . A$. Mus phæus. p. 262.

Tab. XV. B. Mus Furunculus. p. 274 .

Tab. XVI. A. Nus arenarius. p. 266.

Tab. XVI. B. Mus fongarus. p. 270 .

Fig. 4. Ejusdem cœcum cum portione coli. p. 194 .

- Fig. 5. Ejusdem craniun. p.ist.

- Fig. 6. 7. Mluris Lemmi ventriculus. $y_{0} 203$.

- Fig. S. Ejusdem inteftina crafia. p. 203 .

- Fig. g. Vid. tab. XXVII.

- Fig. so. Lemmi maris palma. p. 200. vid. in ead. tab.

- Fig. II. Muris Laguri hepar. p. 215 .

Fig. 12. छ 12. 6. Ejusdem rentriculns tam inflatus quam jejunus. p. 215.

- Fig. 13. Ejusdem inteftina craf. fi. p. 216 .

- Fig. :f. Muris focialis ventrica. lus. p. 223 .

- Fig. 15. Ejusdem inteftium cx. cum \& feq. p. 223 .

Fig. 16. Muris aconomi hepar. p. 236 .

Fig. I. $^{-}$Ejusdem ventriculus. p. 236 .

Fig. 1S. Ejusdem intert. cocum \& rel. crafta. p. 236.237.

- Fig. 19. Vid. tab. XXVIl.

- Fig. 2o. Muris gregalis dentes primores. p. 242 .

Fig. $20 *$. Vid. tab. XXVII.

Fig. $2 r$. Nuris rutili ventriculas, p. $25^{\circ}$. 
Tab. XVII. Fig. 22. Fjusdem inteft. cœecum cum feq. p. 250 .

- Fig. 22*. Vid, tab. XXVII.

- Fig. 23. Muris arenarii hepar. p. 268 .

- Fig. $2+$ In opere tabulisque dectt.

- Fig. 25. 26. 27. Muris arenarii ventriculus. p. 268 .

- Fig. 28. Ejusdem inteftinum cœ. cum \& fpirale. p. 268.

- Fig. 29. (in tab. male 39). Mu. ris fongari hepar. I. 272 .

- Fig. 3o. Ejusdem ventriculus. ibid.

- His.3r. Ejusdem cœcum cum fpirali inteft. ibid.

- Fig. ㅇ Vid. tab. XXVII.

Tab. XVIII. A. Mus Accedula. p. 258. Tab. X/111. B. Mus longipes. p. 316. Tab. XIX. Nus tamaricinus. p. 323 . Tab. XX. Mus Iaculus. p. 292. Tab. XXI. Nus Sagitta. p. 308 . Tab. XX11. Fig. r. Mus betulinus. p. 333 .

- Fig. 2. Mus vagus. p. 329.

Tab. XXlII. A. Mus Caracn. p. 336. Tab. XX111. B. Mus faxatilis, p. 256. Tab. $X X I V . A$. Mus agrarius. p. $3 t^{2}$. Tab. XXIV. B. Mus minutus. p. $3+8$. Tab. $X X V$. Fig. 1 . Nuris Iaculi ventriculus cum duodeno. p. 200.

- Fig. 2. Ejusdern inteft. coecum cum ftriato \& excretorio. p. 200.

- Fig. 3. Ejusdem hepar, ibid.

- Fig. 4. \& Fig. 4*. Vid. tab. XXVII.
Tab. XXV. Fig. 오. Vid. tab. XXVII. - Fig. 5. Vid. tab. XXVI.

- Fig. 6. Muris longipedis ventri. culus. p. 319 .

Fig. ?. Ejusdem inteft. cœcum cum ftriato. p. 320 .

Fig. 3. Vid. tab. XXVII.

- Eig. s. Vido p.

- Fig. 9. Muris tamaricini ventriculus. p. 326 .

- Fig. ro. Ejusdem inteft. coecum \& feq. p. 326.

Fig. 11. Ejusdem partes genitales mafculinae. p. $3 \approx 7$.

Fig. I2 Muris vagi ieutriculus. p. 332 .

Fig. 13. Ejusdem inteft. cocum \& reliqua crafia. p. 332.

- Fig. 14. Muris agrarii hepar. P. $3+4$.

- Fig. 15. Ejusdem ventriculus. ibid.

- Fig. 16. Ejusdem inteft. coecum $\&$ ftriatum p. $3+5$.

- Fig. 17. Muris minuti hepar. p. $3+8$.

- Fig. 18. Ejusdem ventriculus. ibid.

- Fig. 19. Ejusd. inteft, cocum. ibud.

Tab. XXVl. Fig. 1X.?. Muris Ci. tilli fulcrum offeum penis. p. 149

- Fig. Xlrll. rq. Muris Typhli fceleton. p. I63.

- Fig. YVII. 15. Ejusdem cranium. ibid.

- Fig. XI'Il. 17. Muris capenfis cranium. p. 15.5.

Fig. $X X Y$. 5. Muris Sagittre feleton. p. 311 . 
Tab. XXV1. Fig. A. B. C. Muris Tab. XXVII. Fig. XVII. $20^{*}$. A. B. hudfonii palma. p. 209.

Muris gregalis cranium. p. $2+2$.

Tab. XXYII. Fig. IX. II*. Muris - Fig. XVII. 22*. Muris alliarii Citilli cranium. p. $\mathbf{r}^{2} 2$. cranium. p. $5_{54}$.

- Fig. IX. 16. Muris A fpalacis of. fa pedum anteriorum. p. 172 .

- Fig. XVI1. g. A. B. Muris Lem. mi cranium. p. 204.

- Fig. XVII. ro. Muris Lemmi maris ofla ped. ant. p. 200.

- Fig. XVII. ㅇ. Muris Lemmi duo offa penis. P. 204.

- Fig. XVII. 19. A. B. Muris = " Fig. XXV. 8. Muris longipedis œconomi cranium. p. 237. cranium. p. $3 \geq 0$.

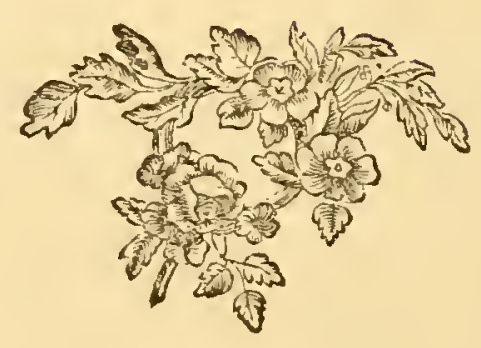


'Tint.I.

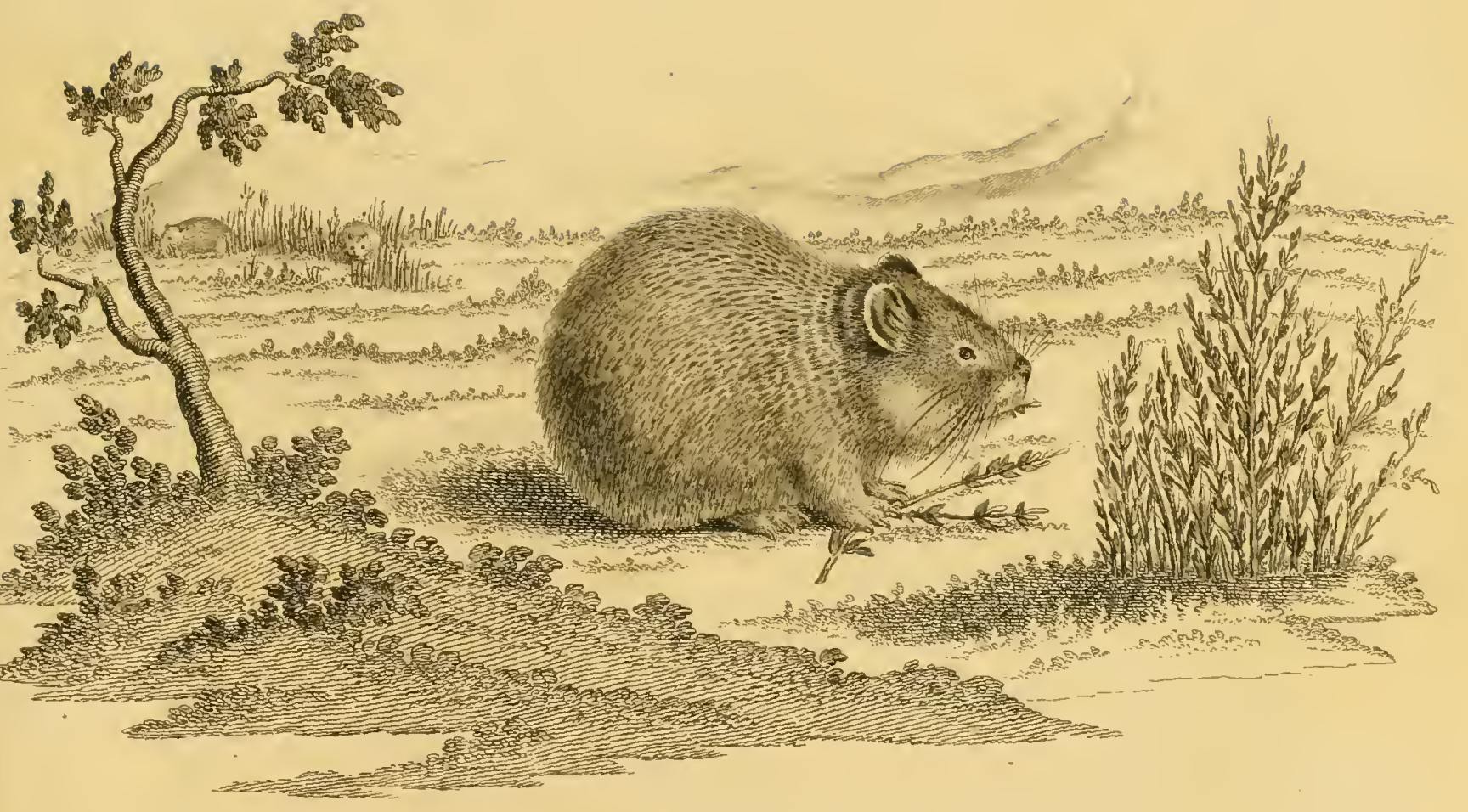





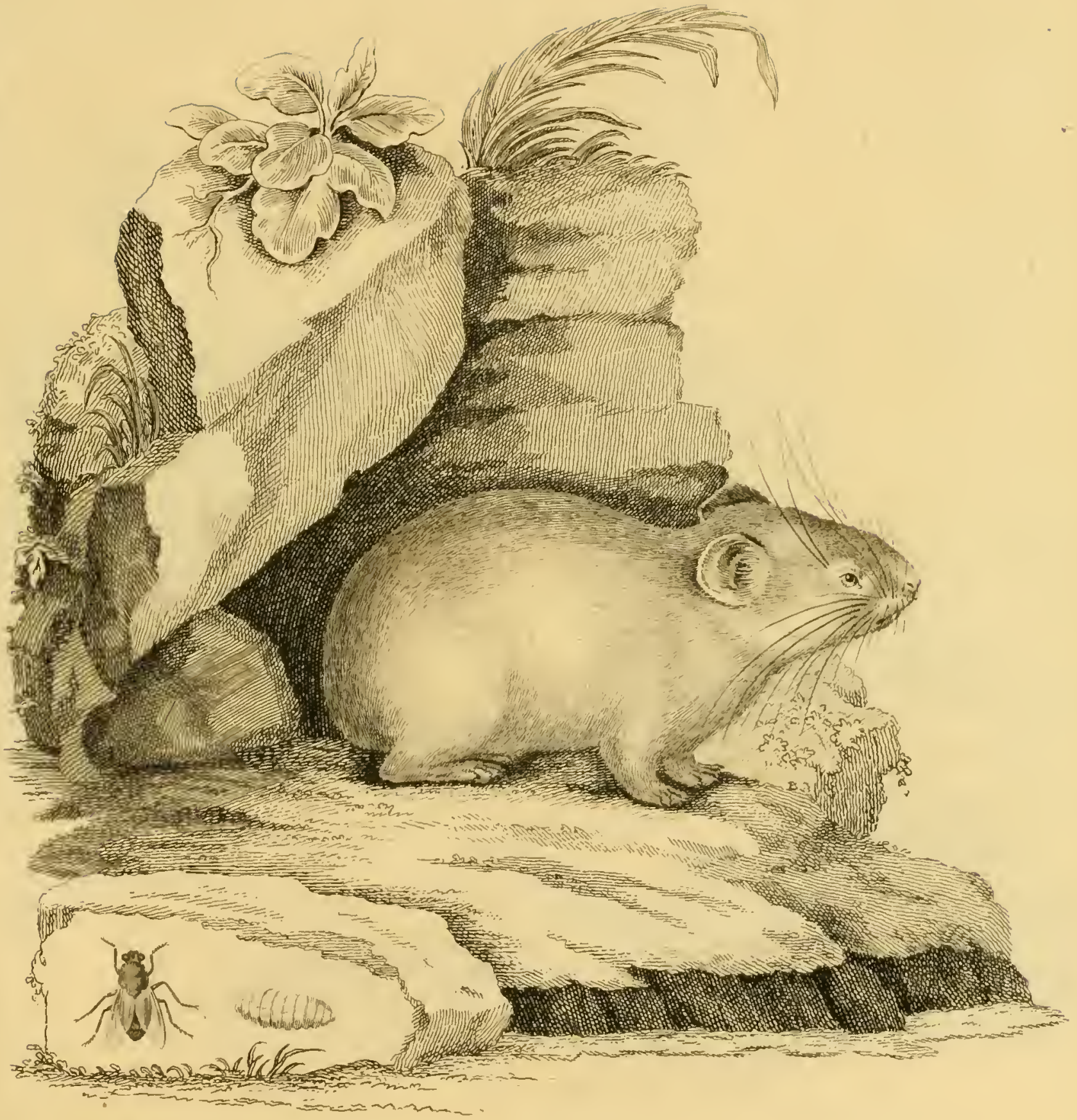





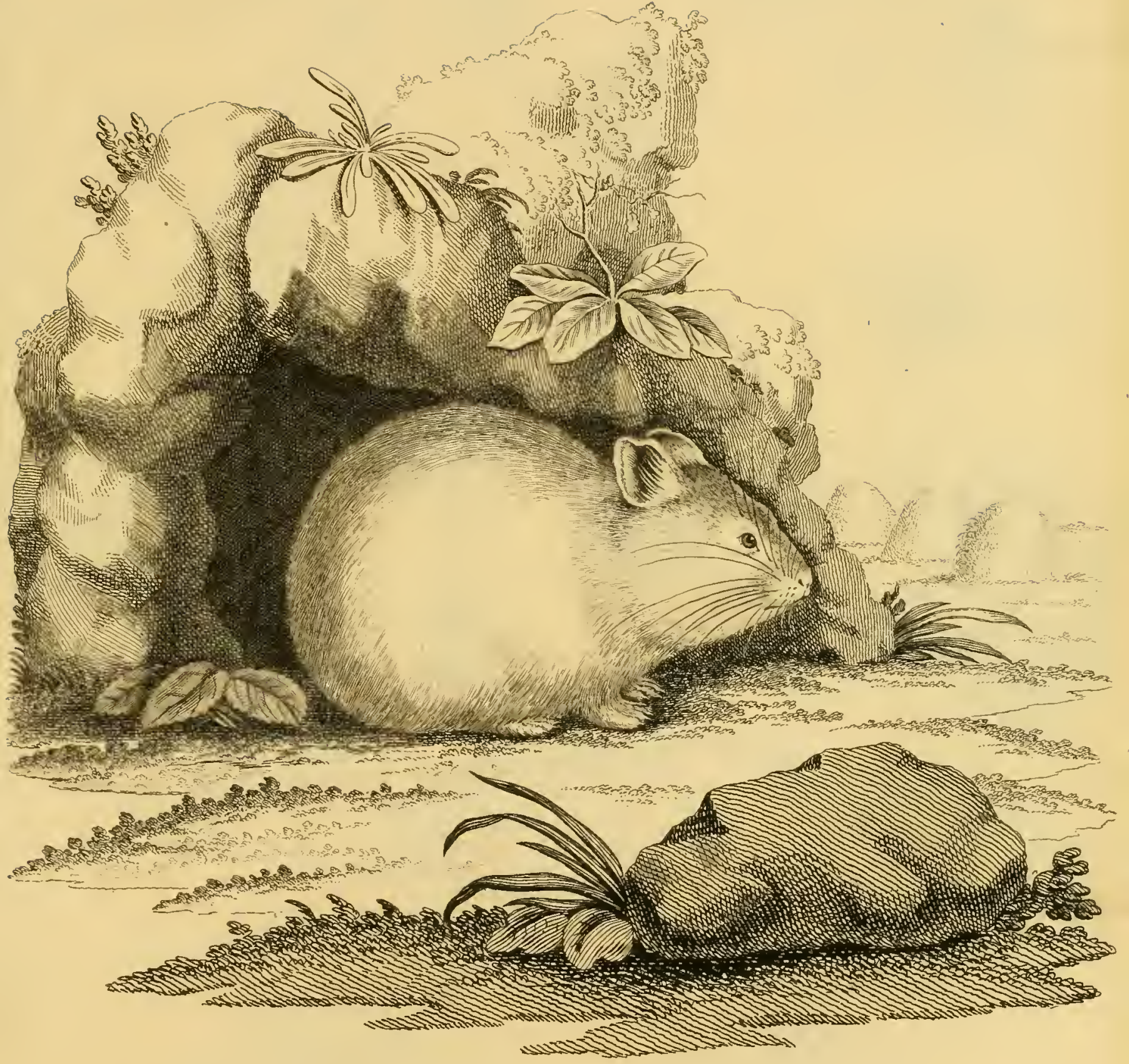





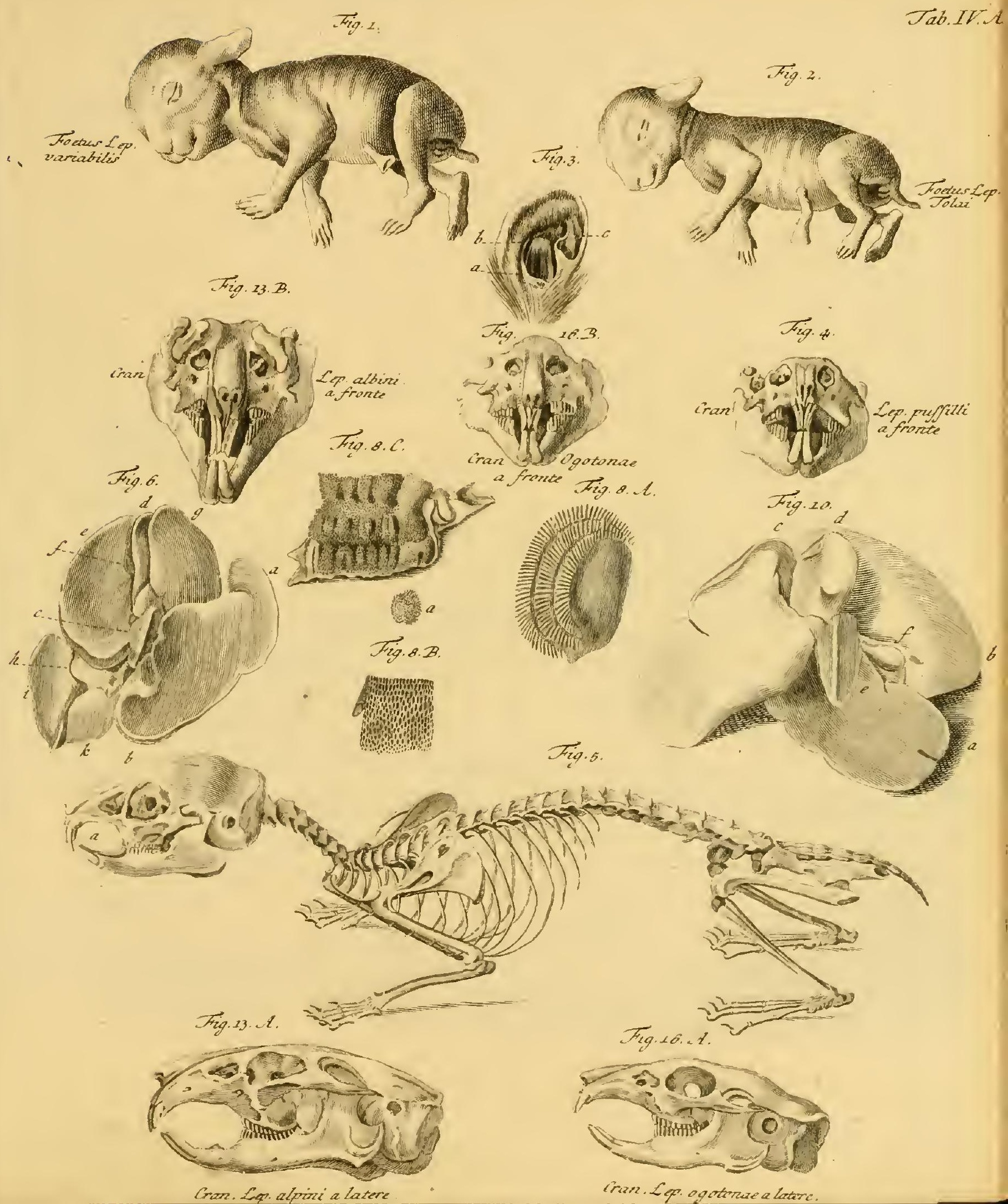


- 
Tat, V.

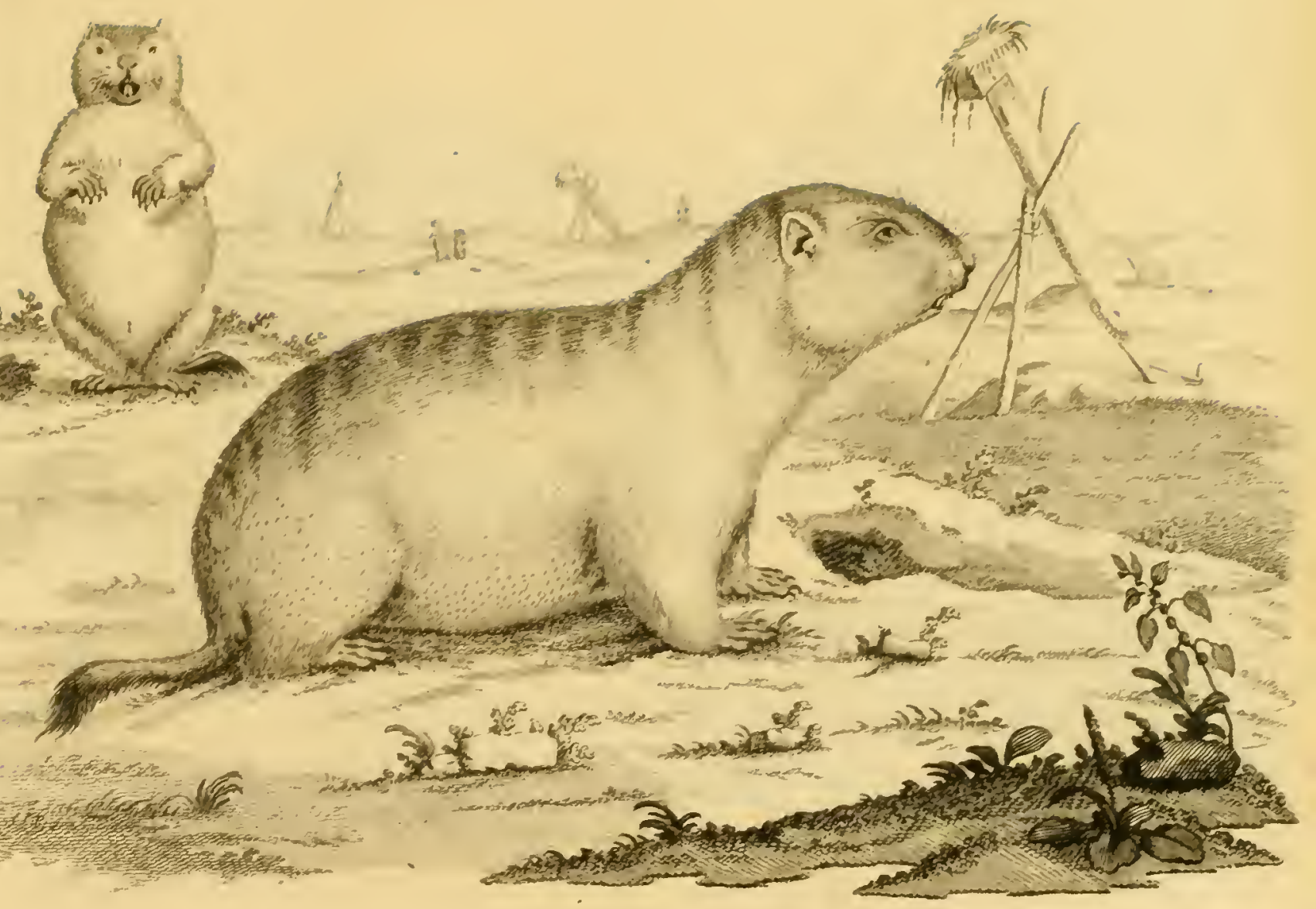



Tab.VI.

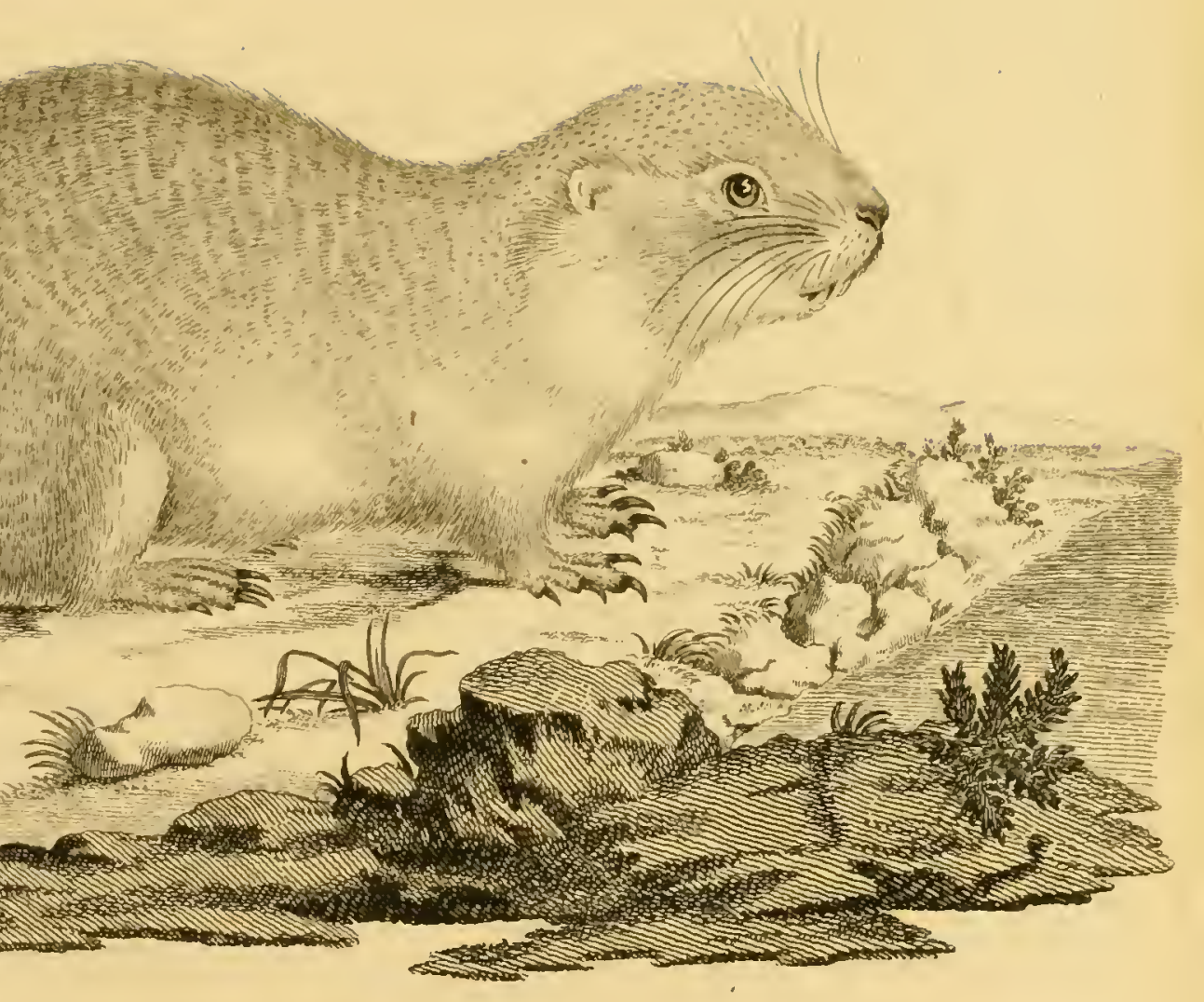



Tab. VI.

B.

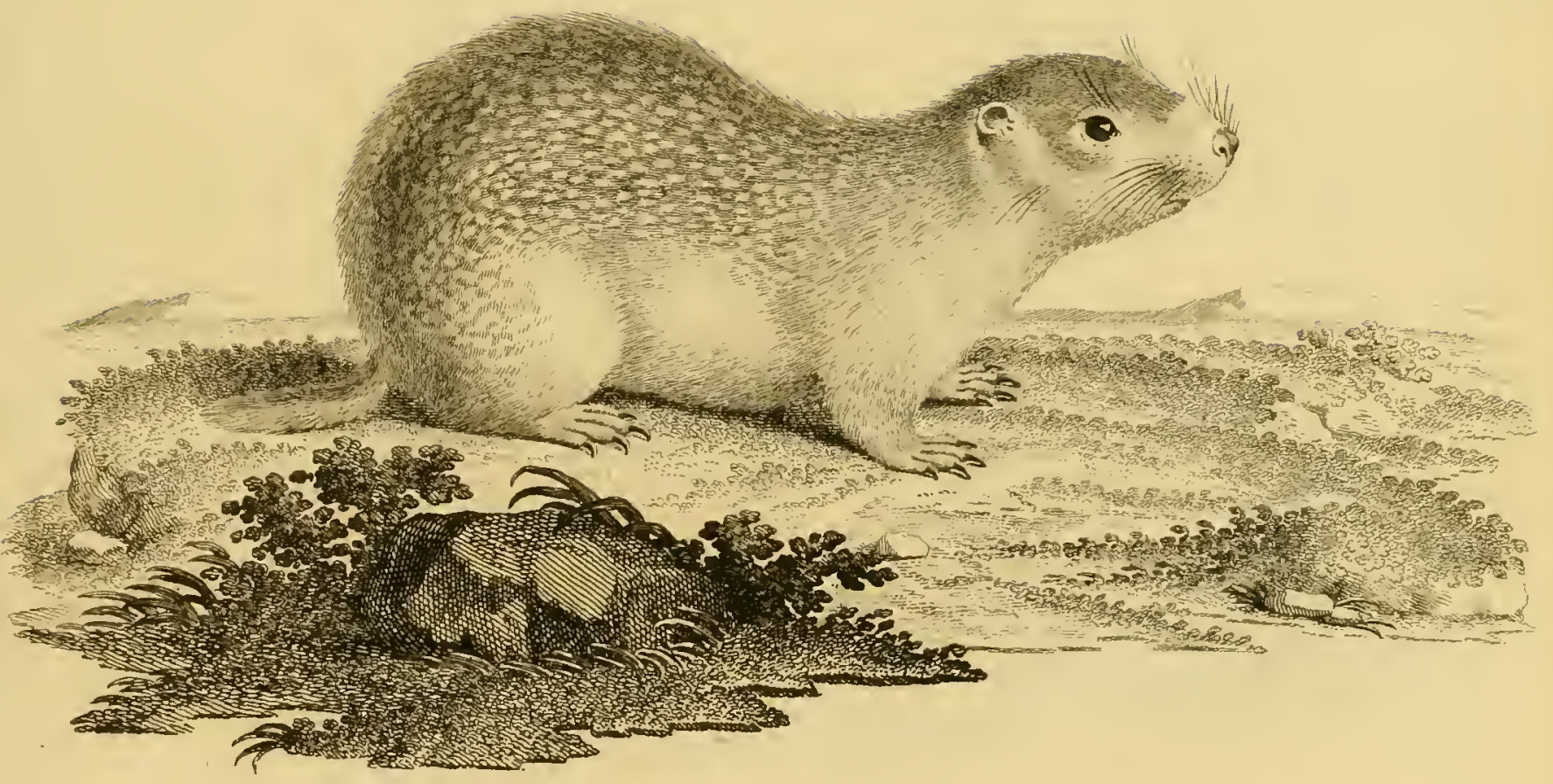





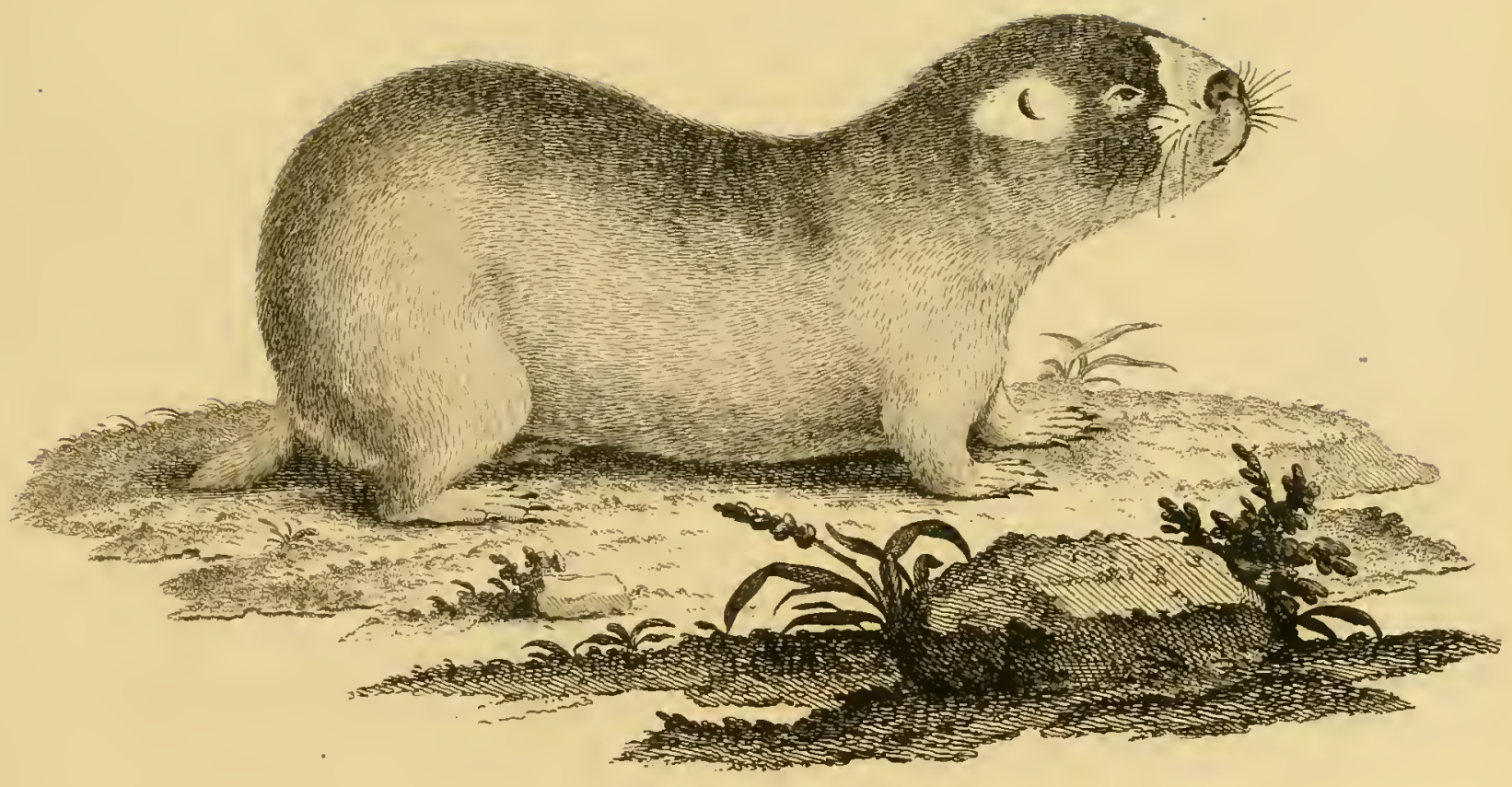



Tat.VIII,

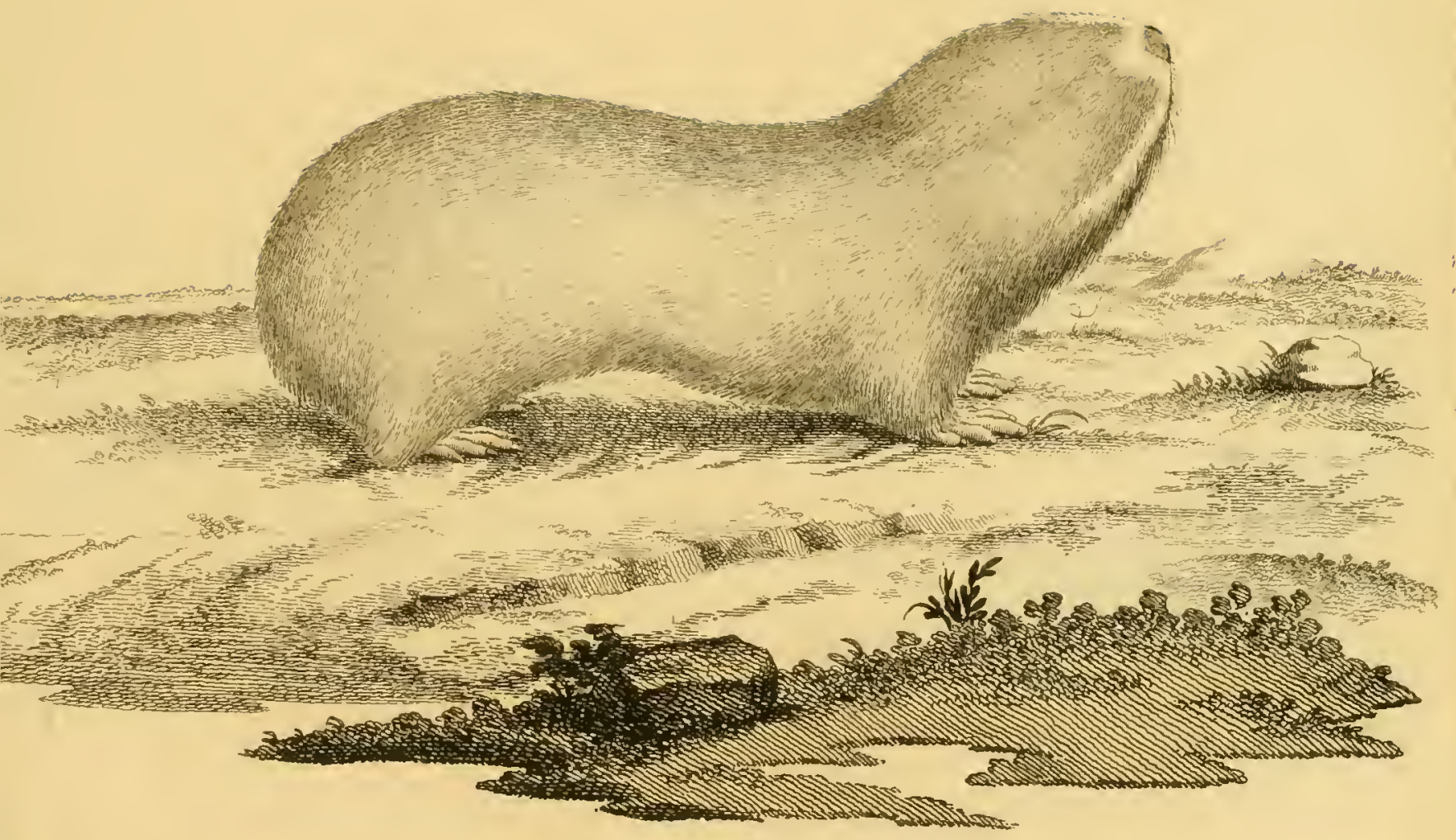



Tab.X.

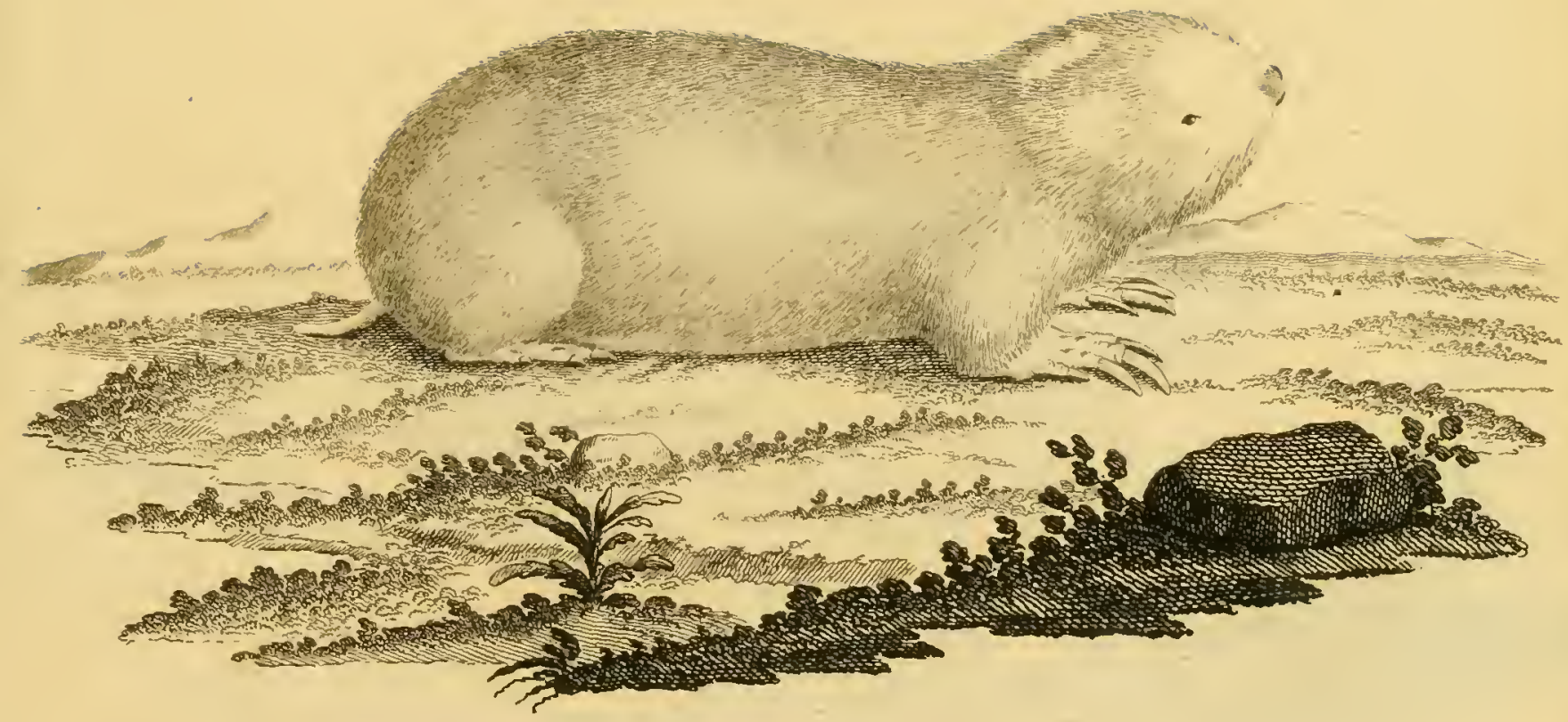



'Tab.XI.

A.

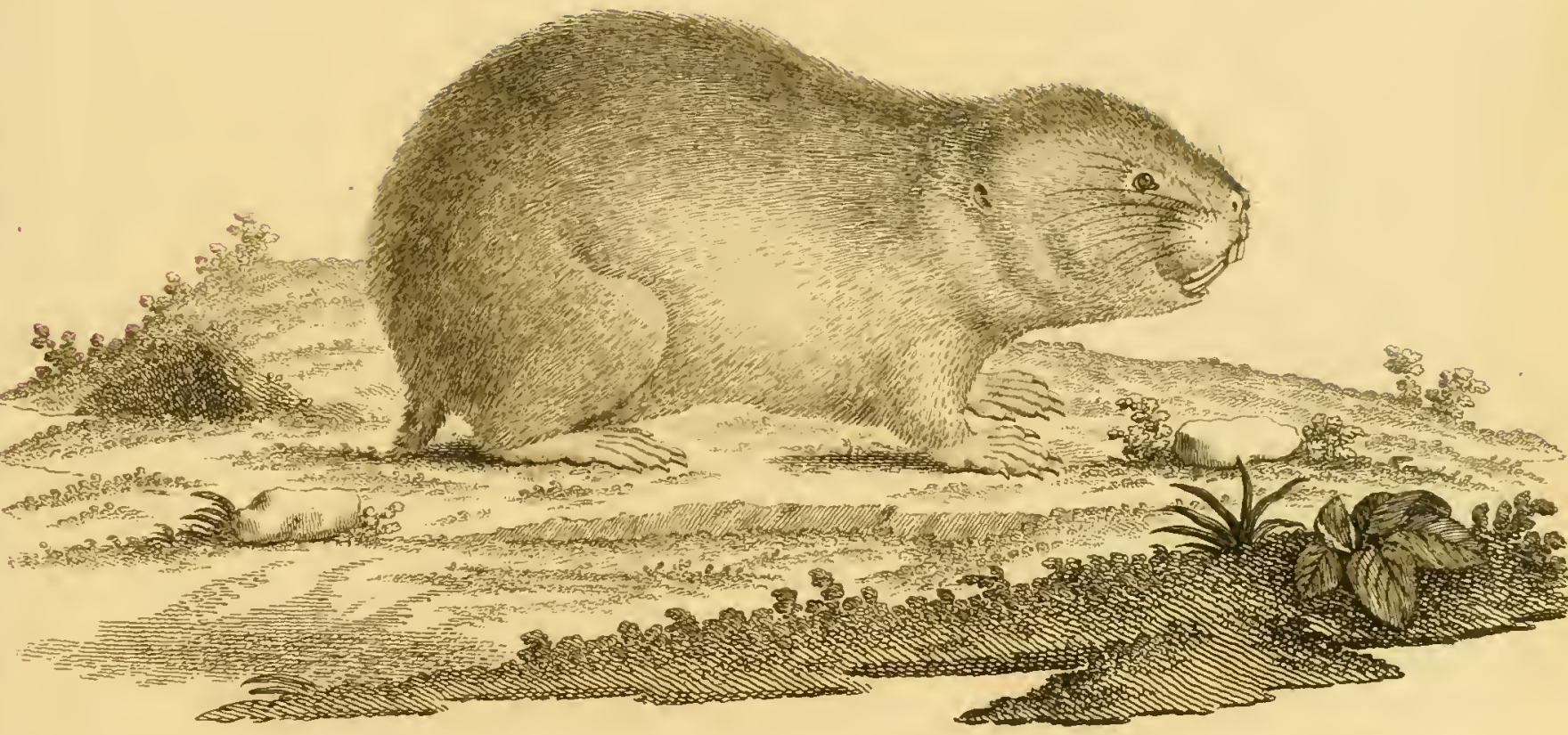






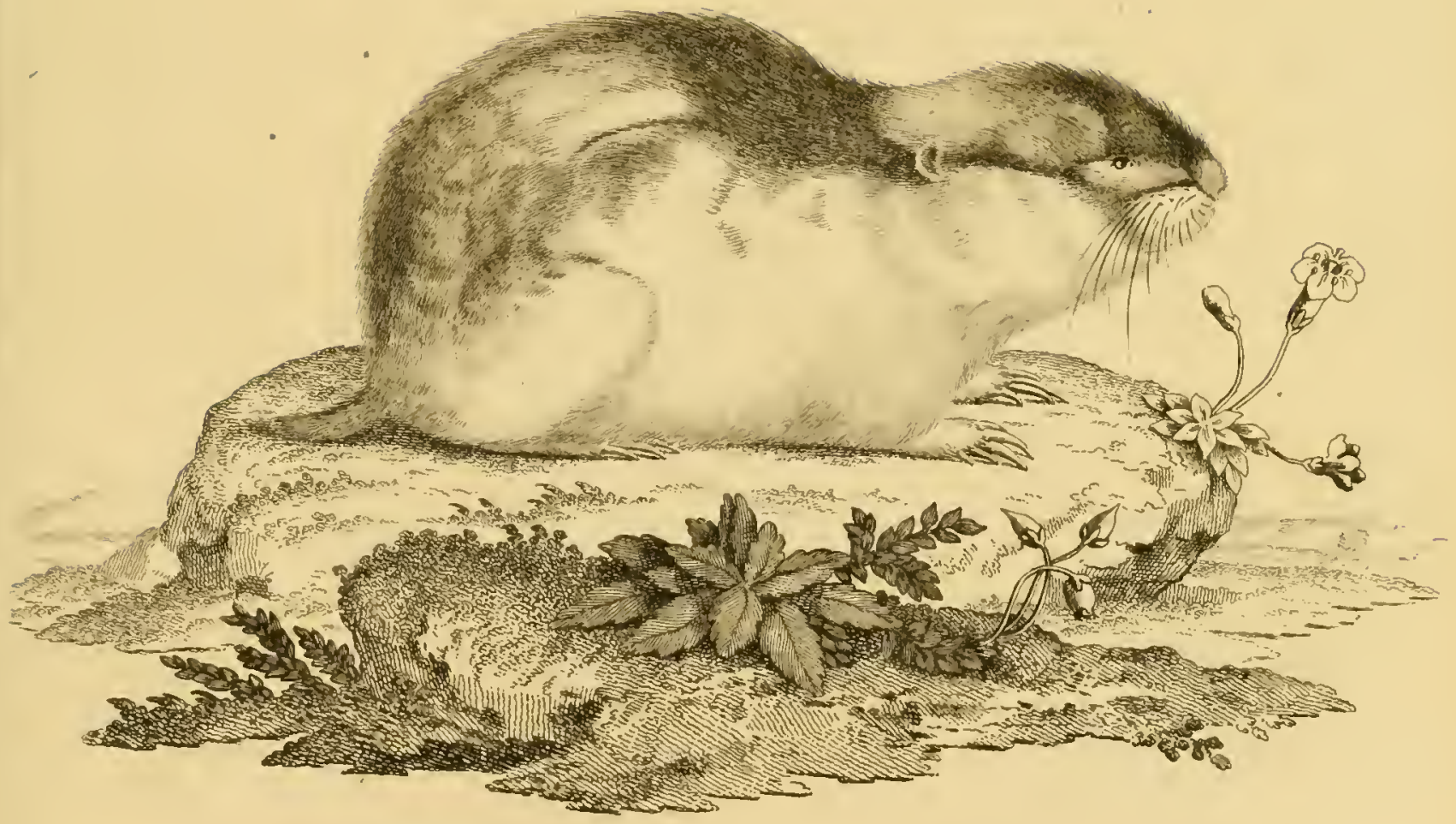



Tab. XII

$B$.

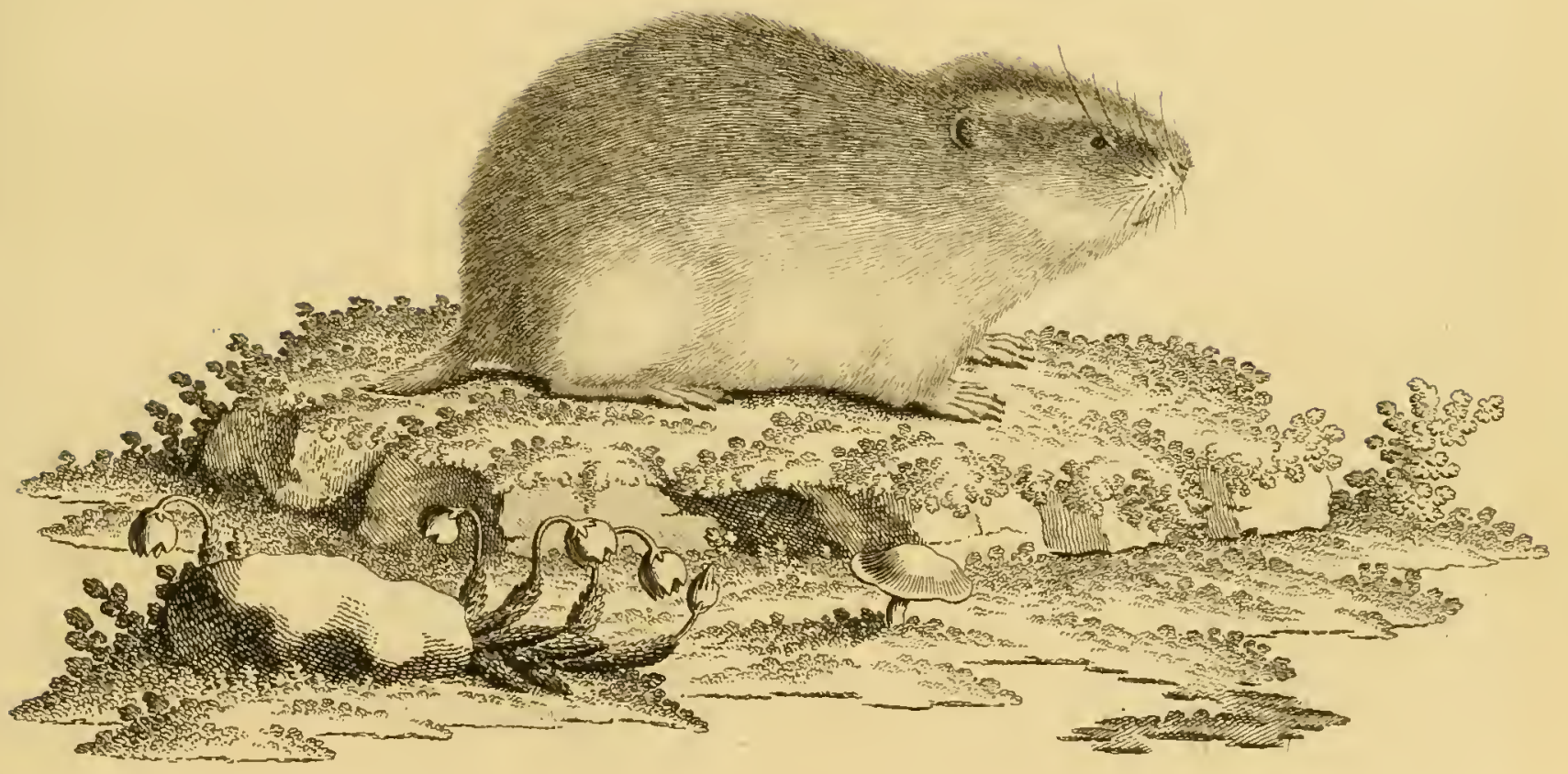





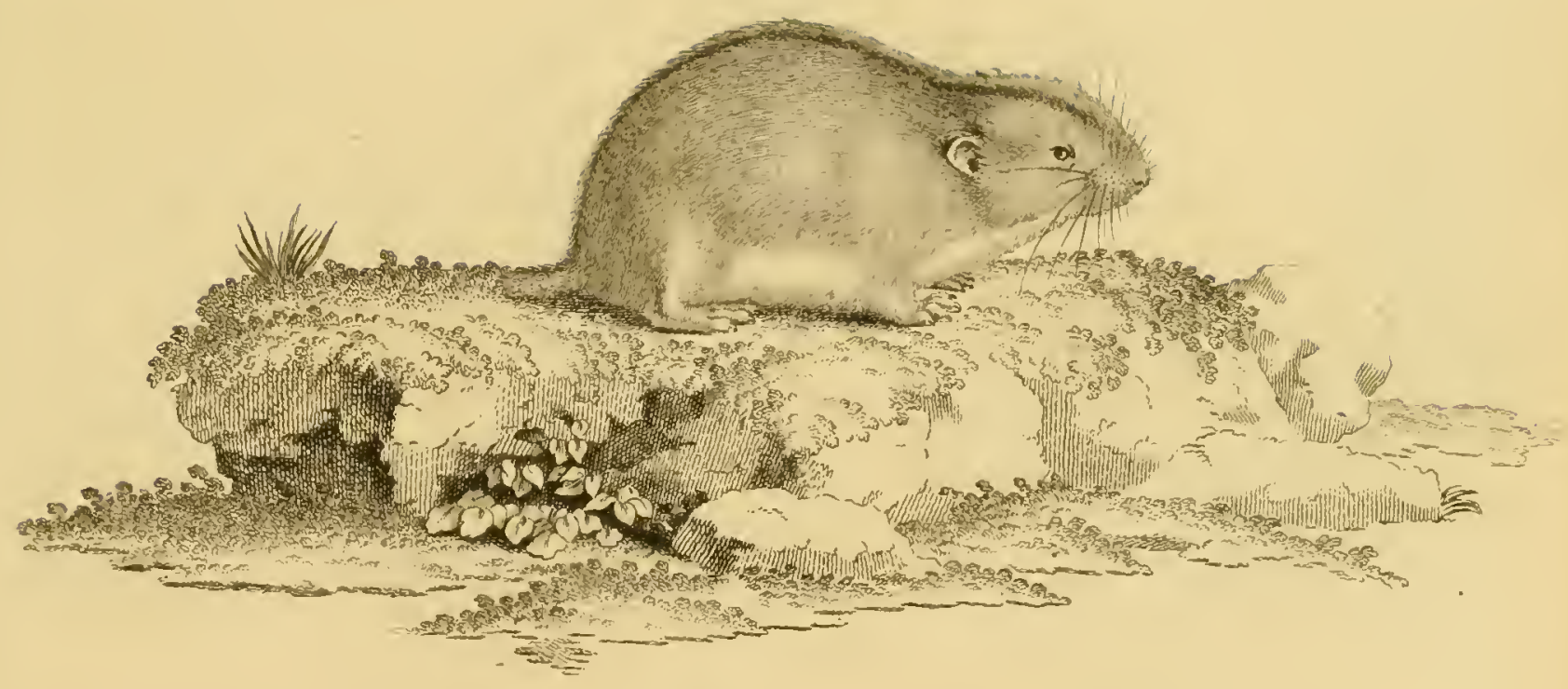



Tab. XIIL I3

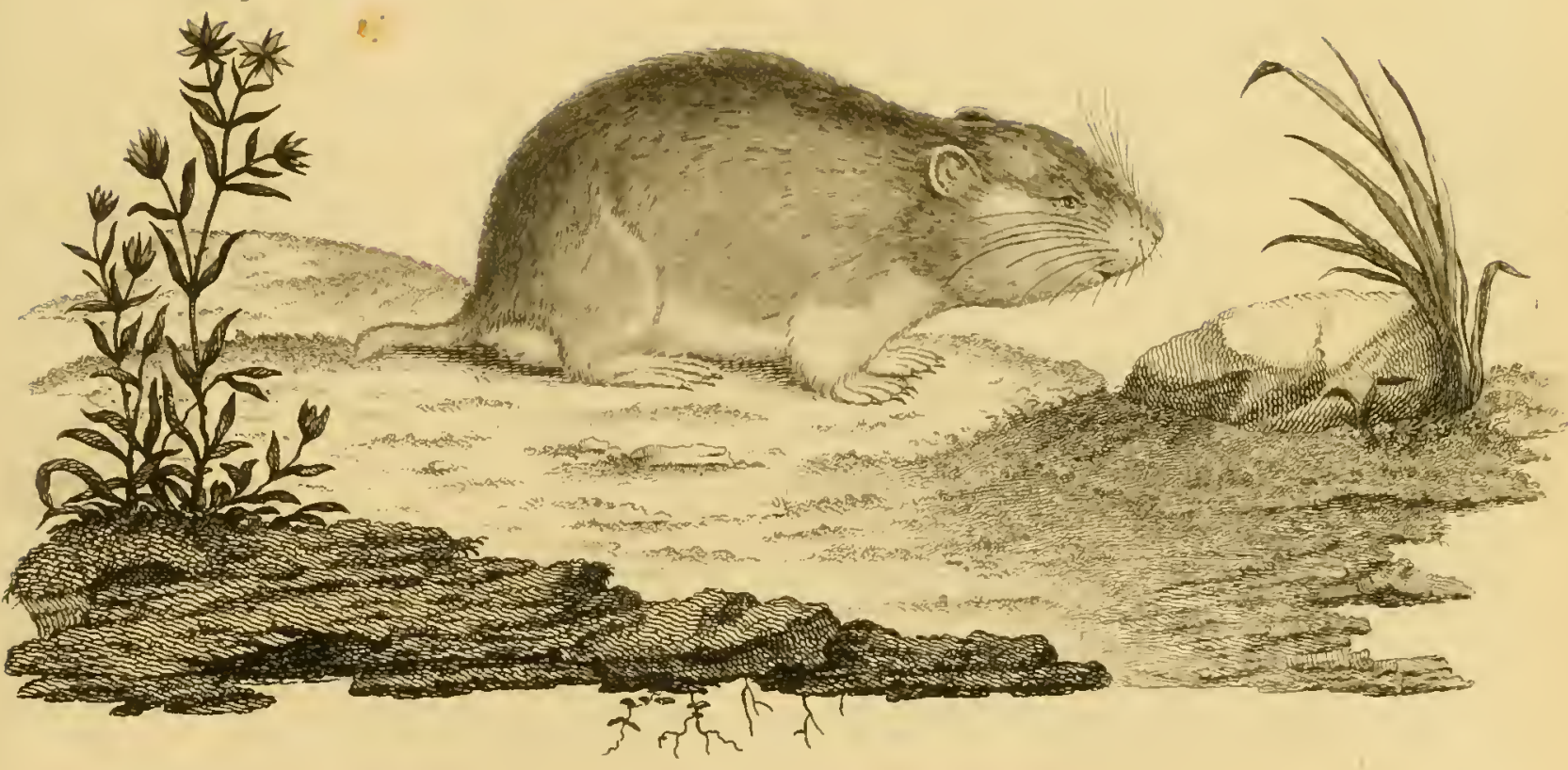





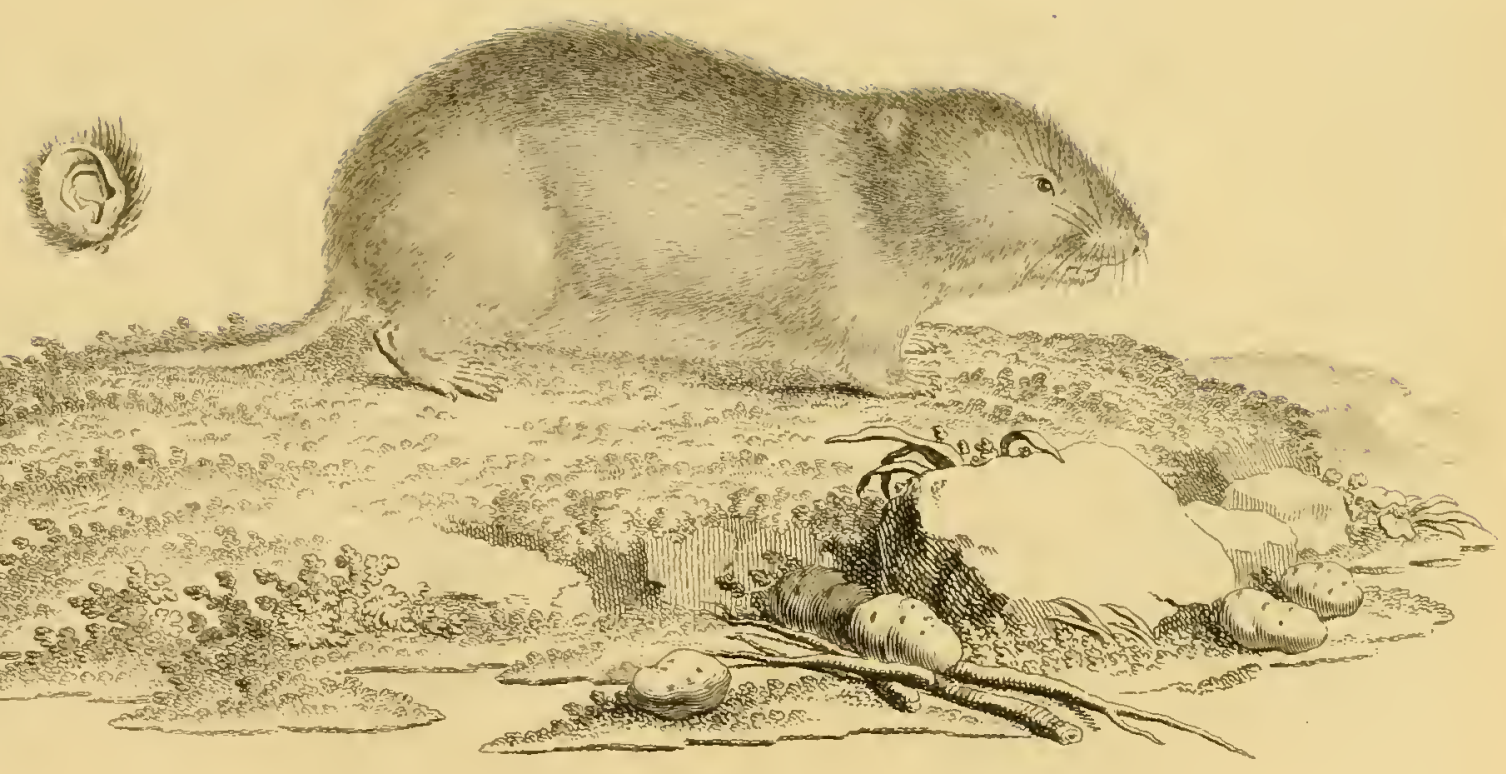





Tab. XIV.

C.

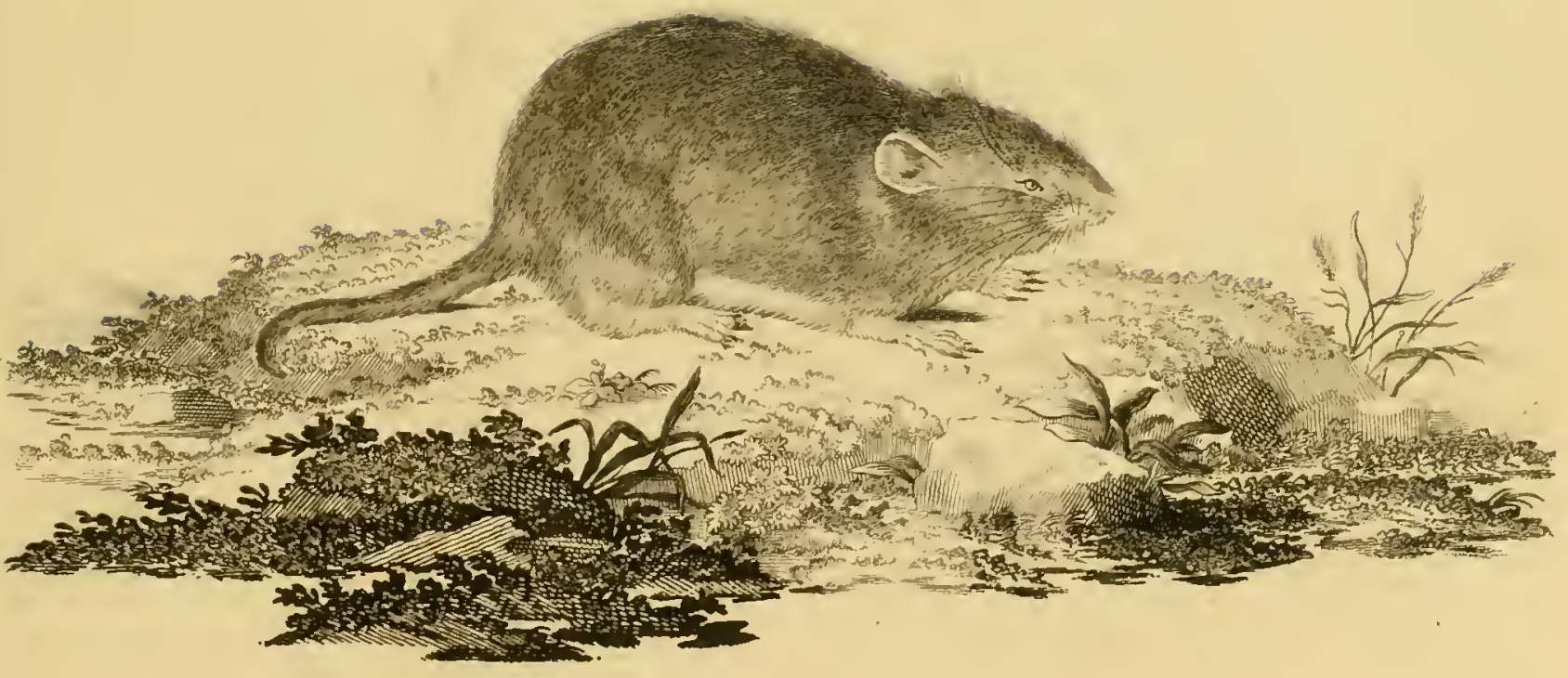





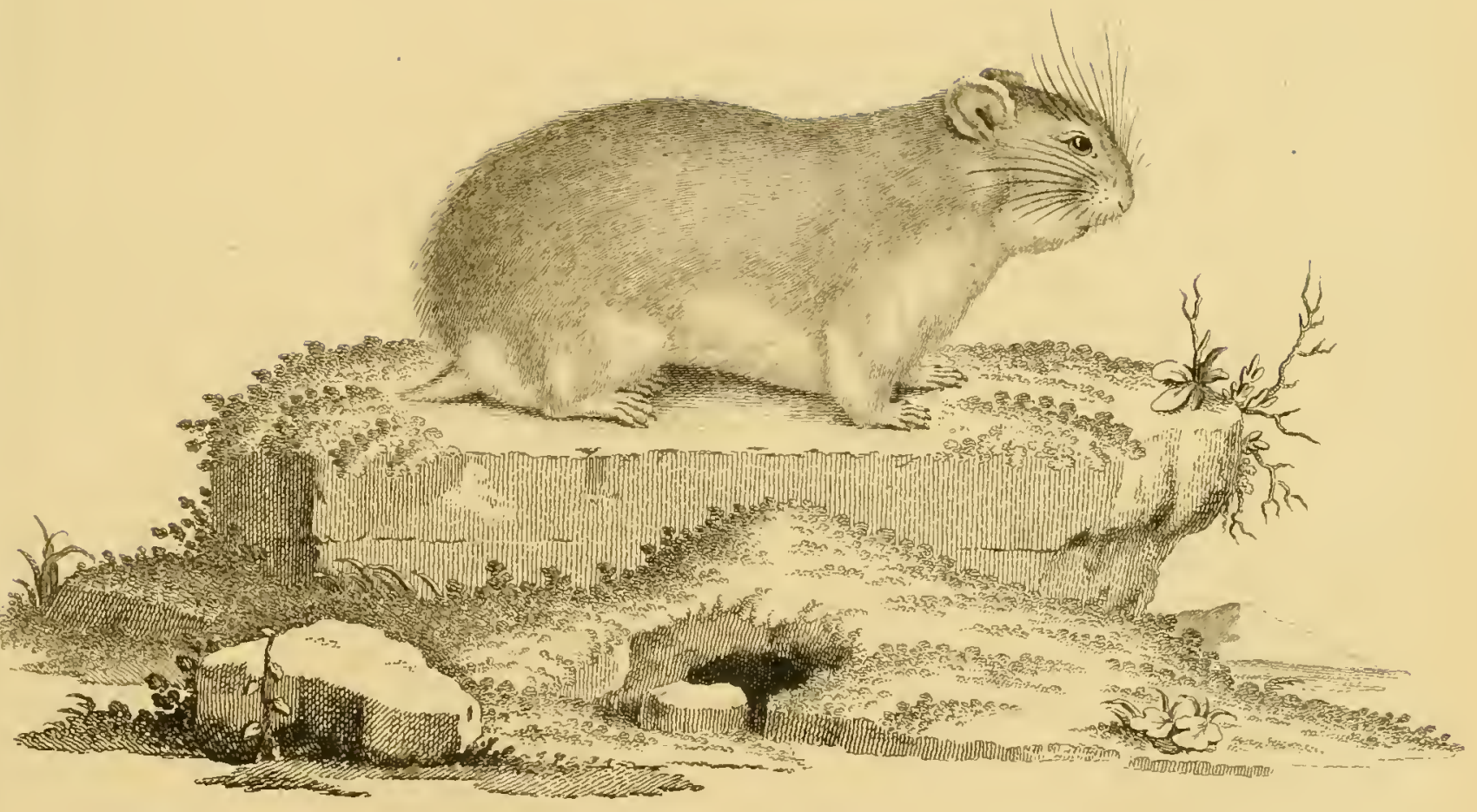





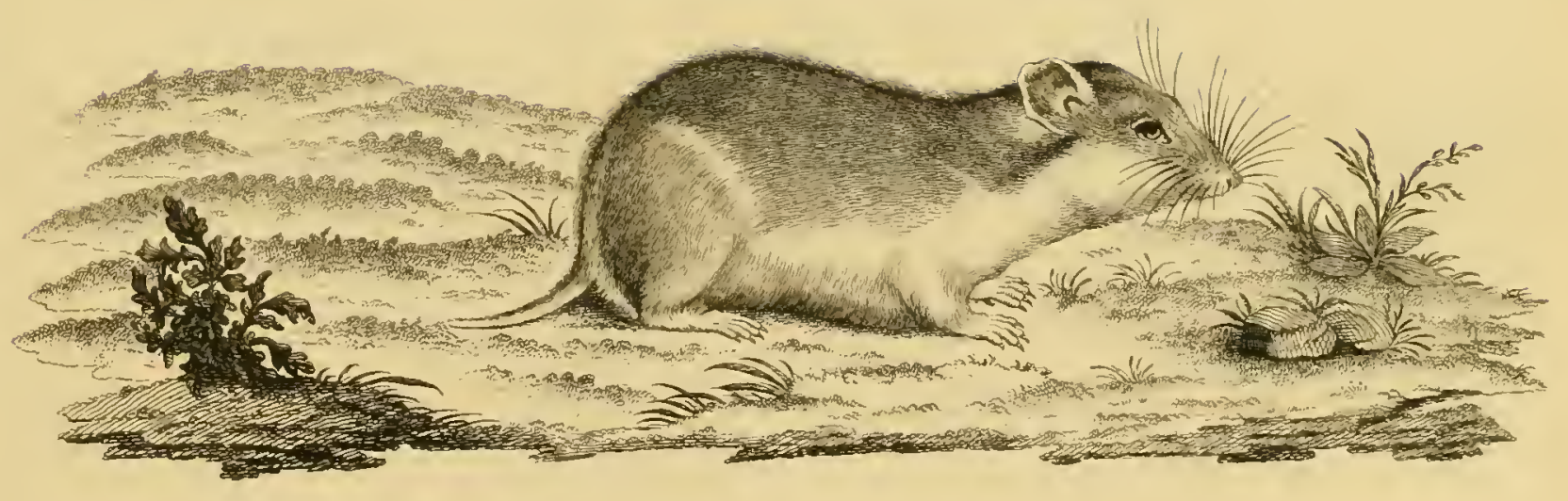



Tab.XVI.

A.

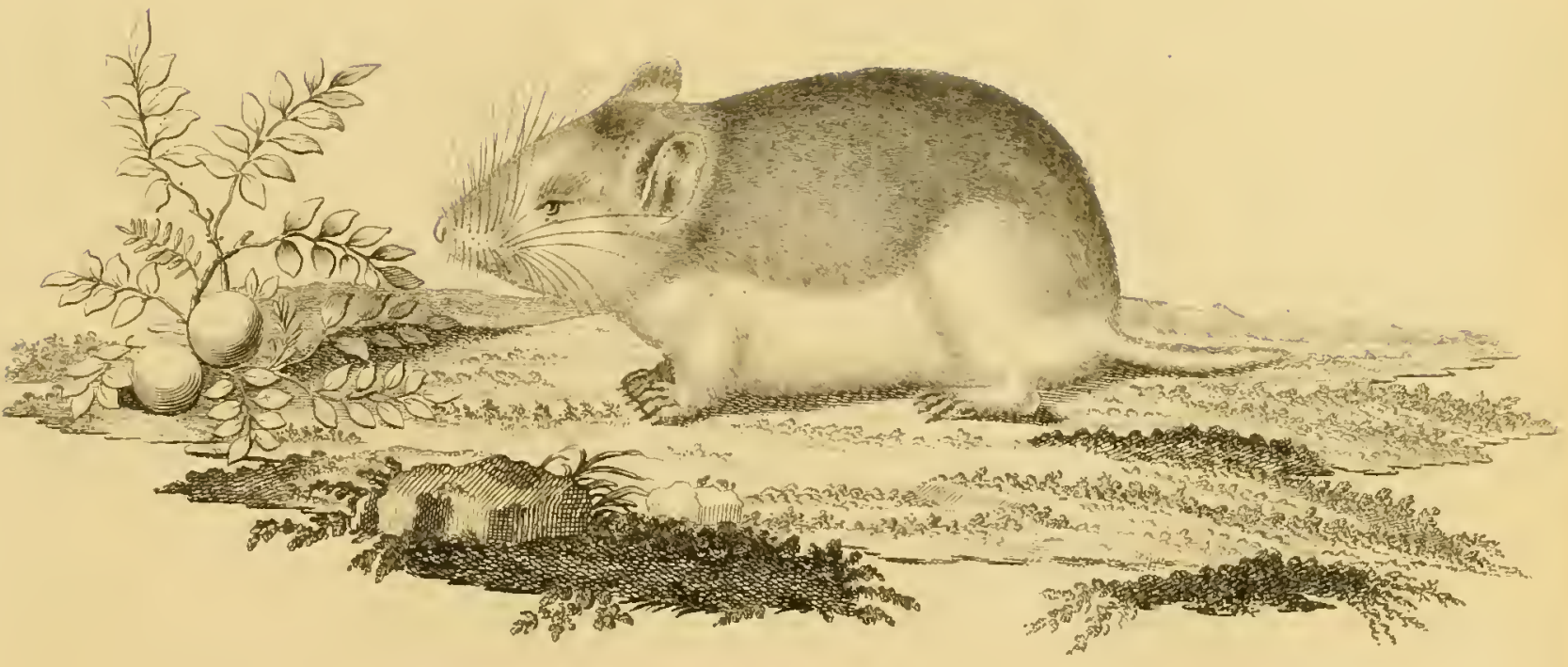



Tab.XVI .

$B$.

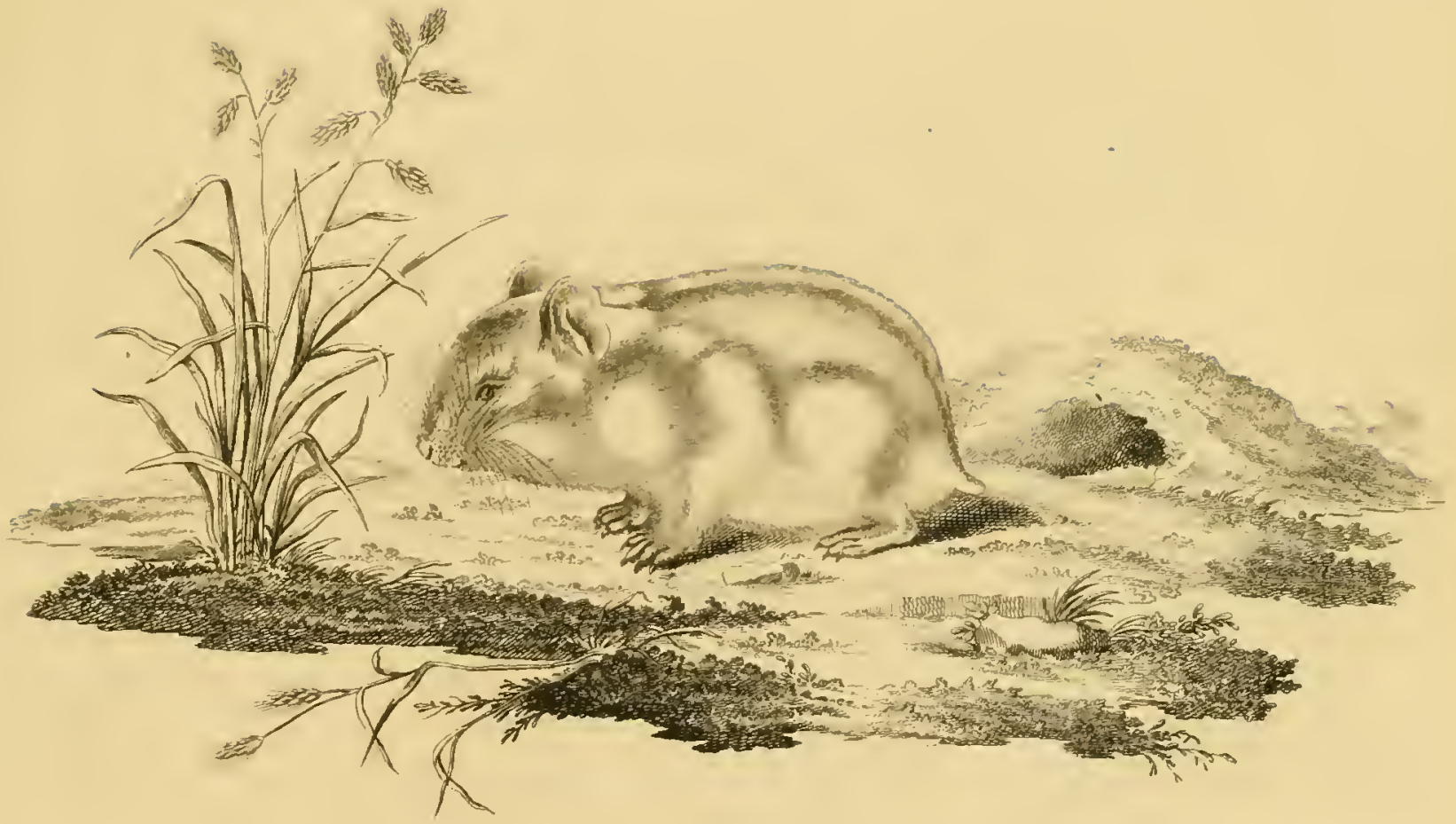



Jab. XVIII

A.

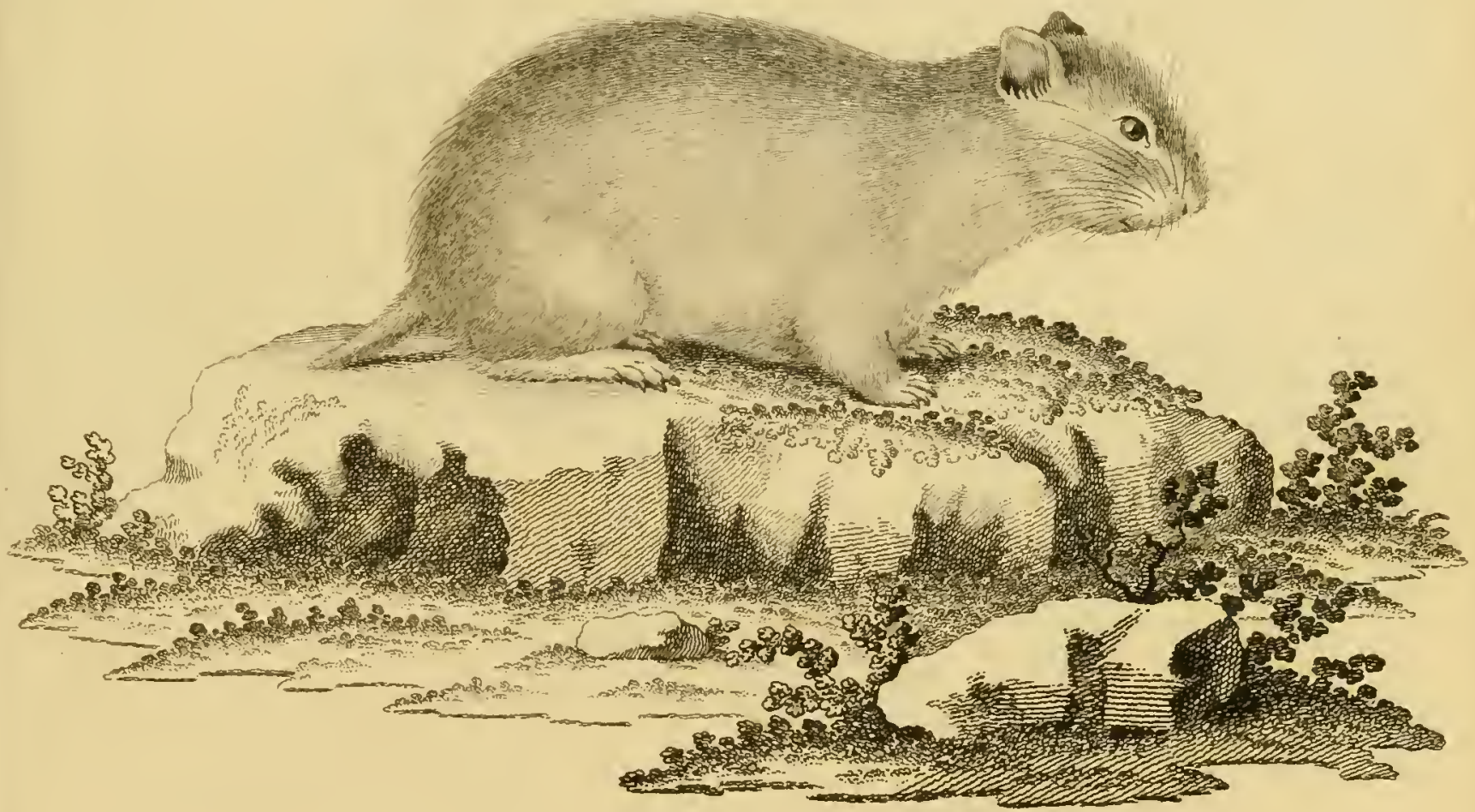



Tab. XVIII. 3 .

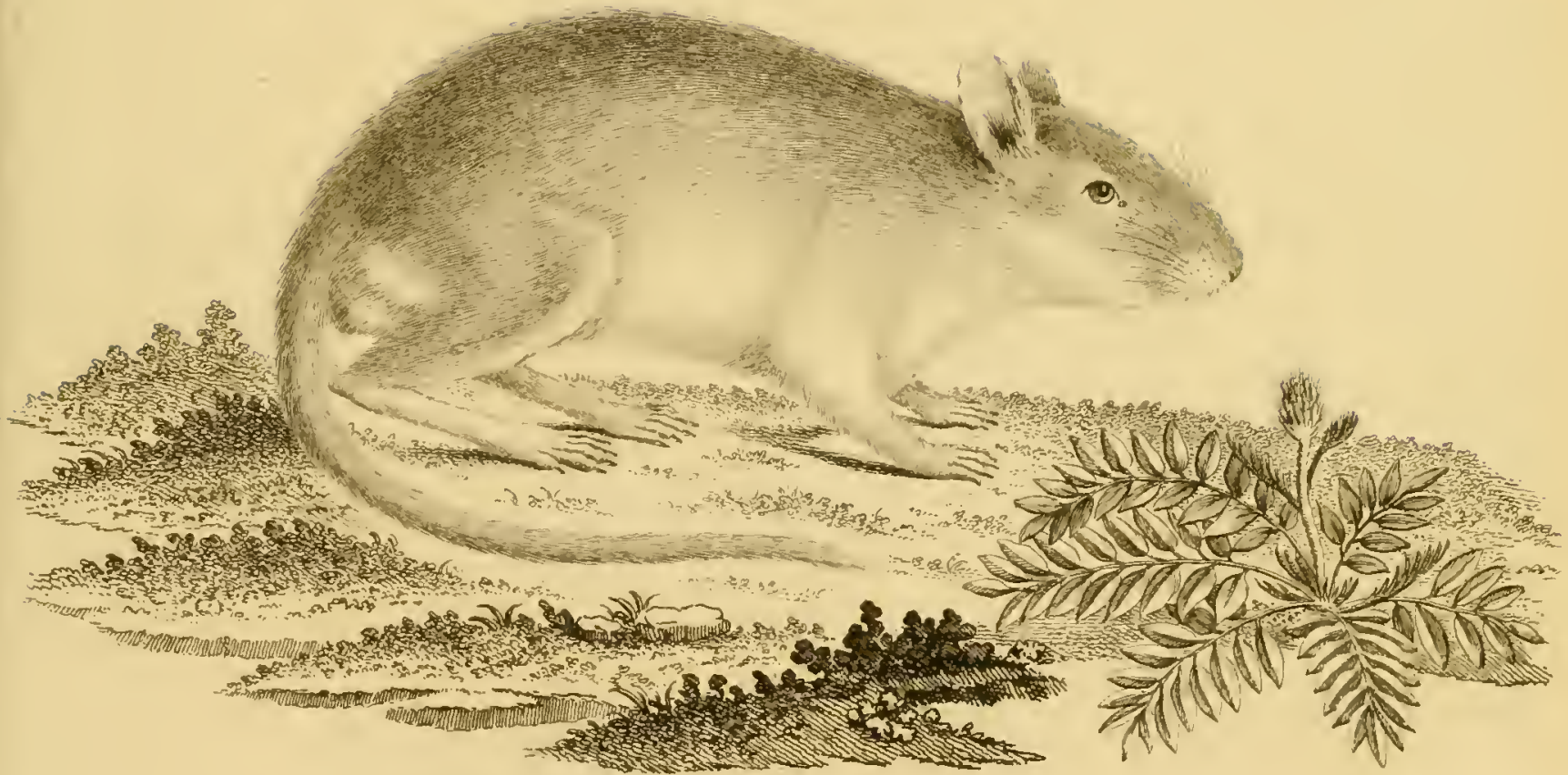



Tab. XIX

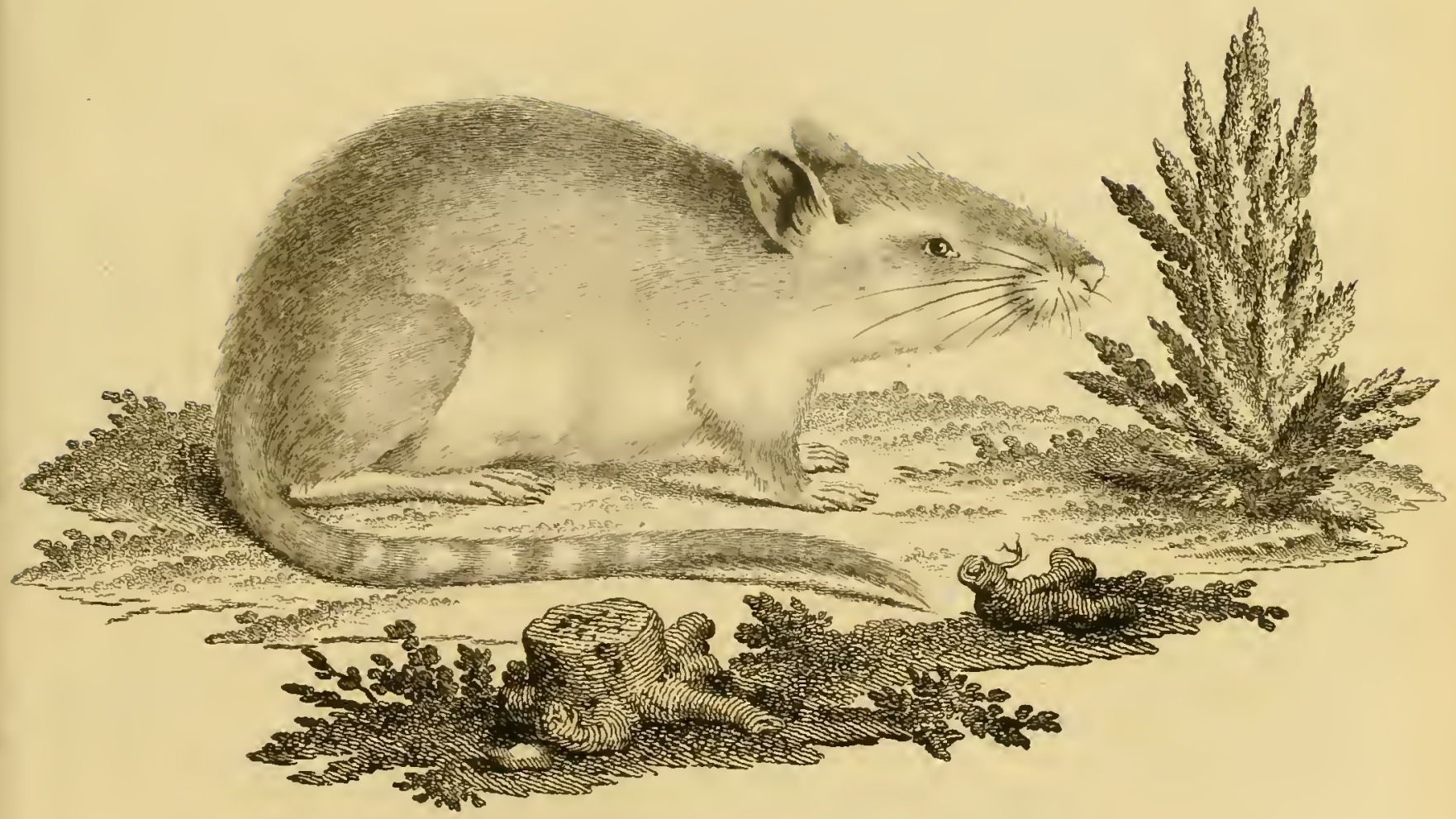



Tab.IX.

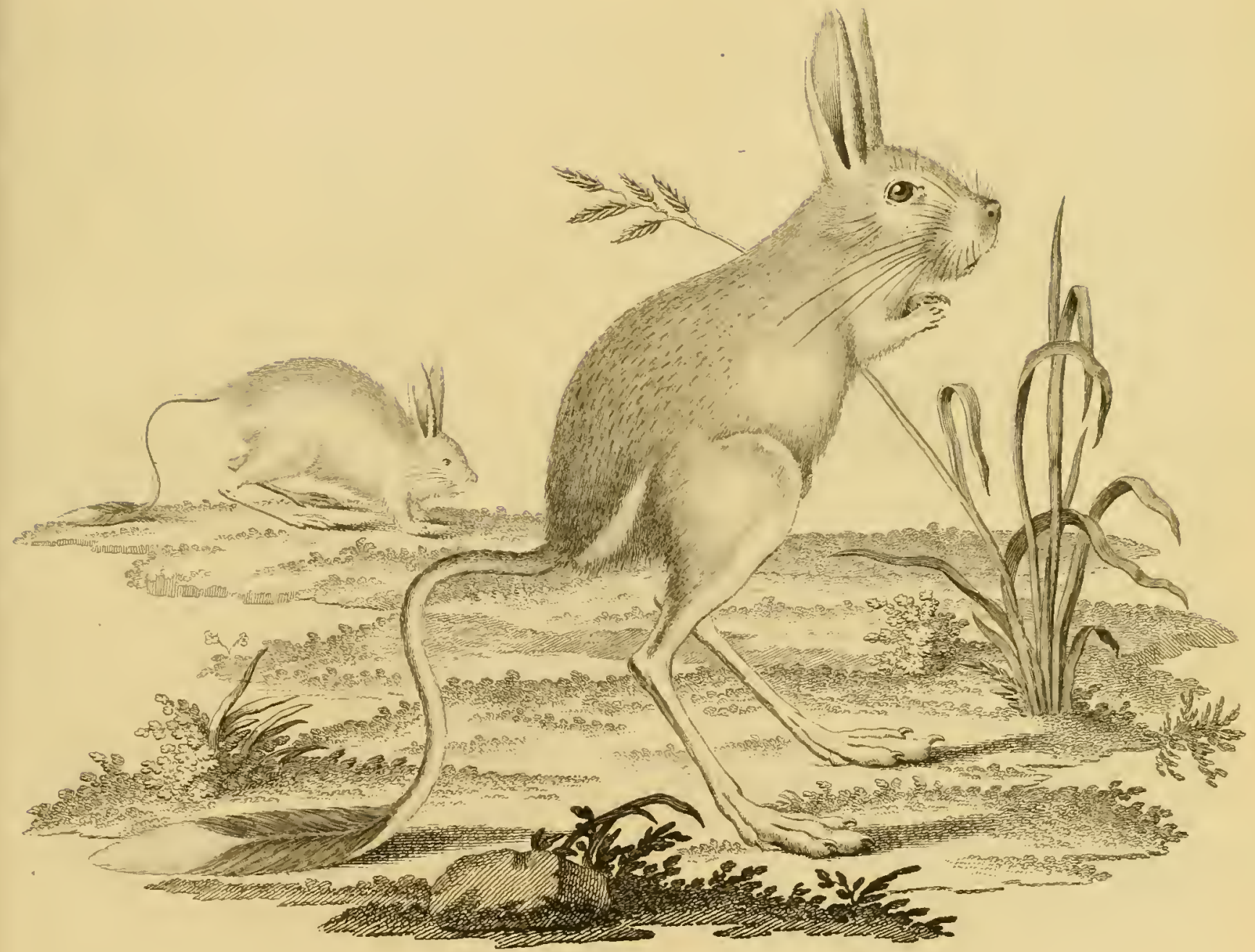



'Tab. XXI.

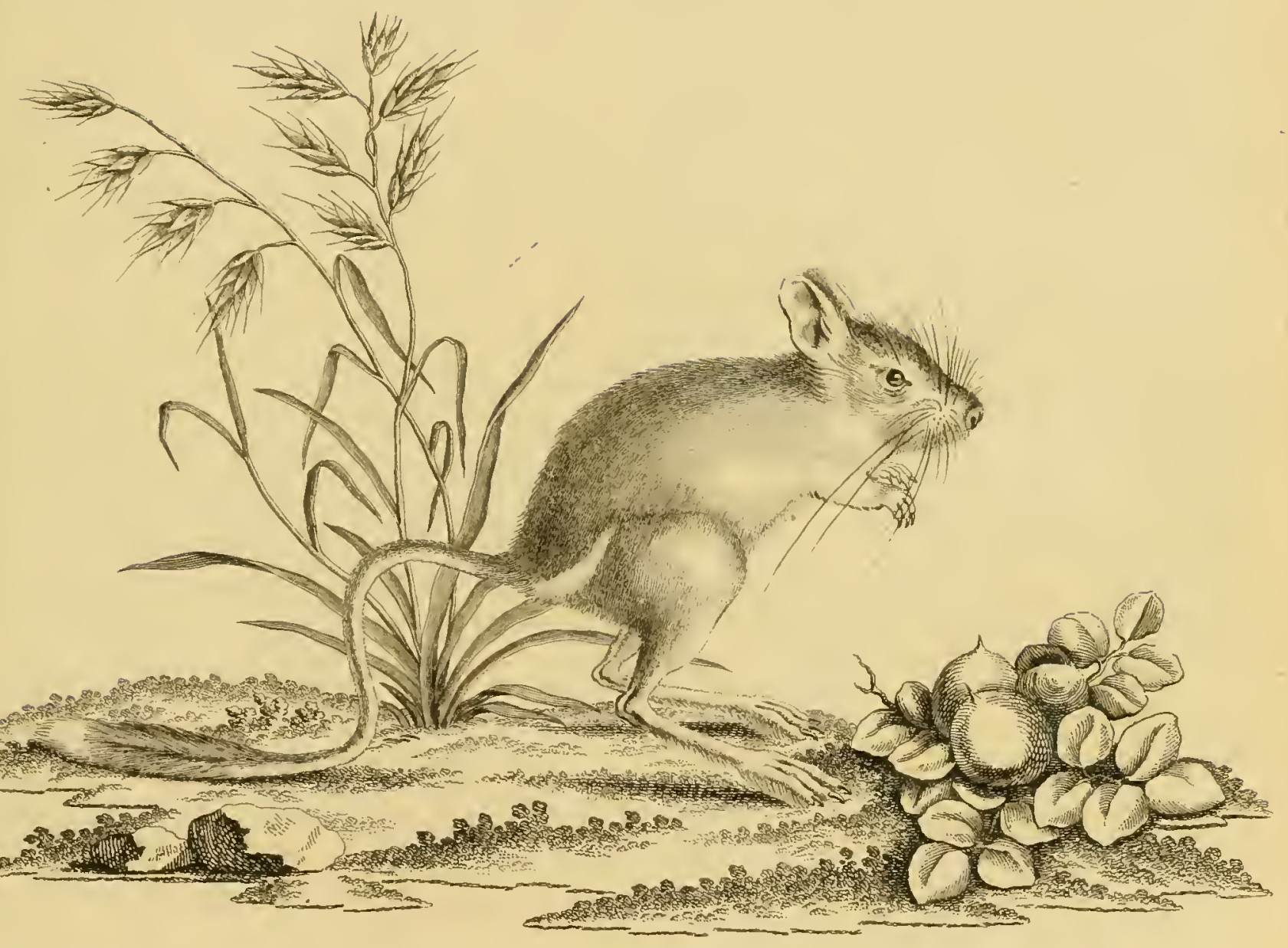




Jab.XXIII.

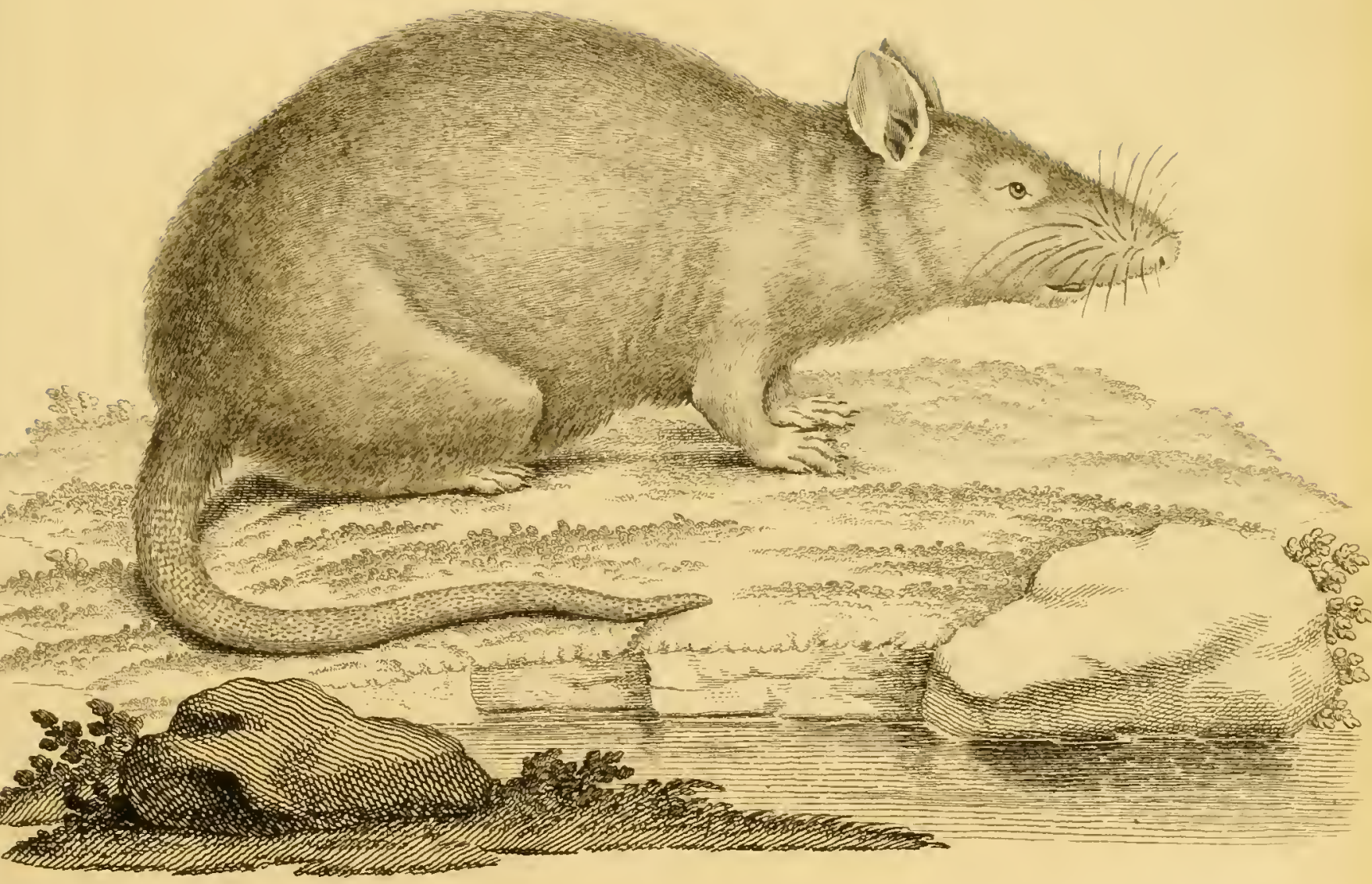





\section{Tab. IX]II}

B.

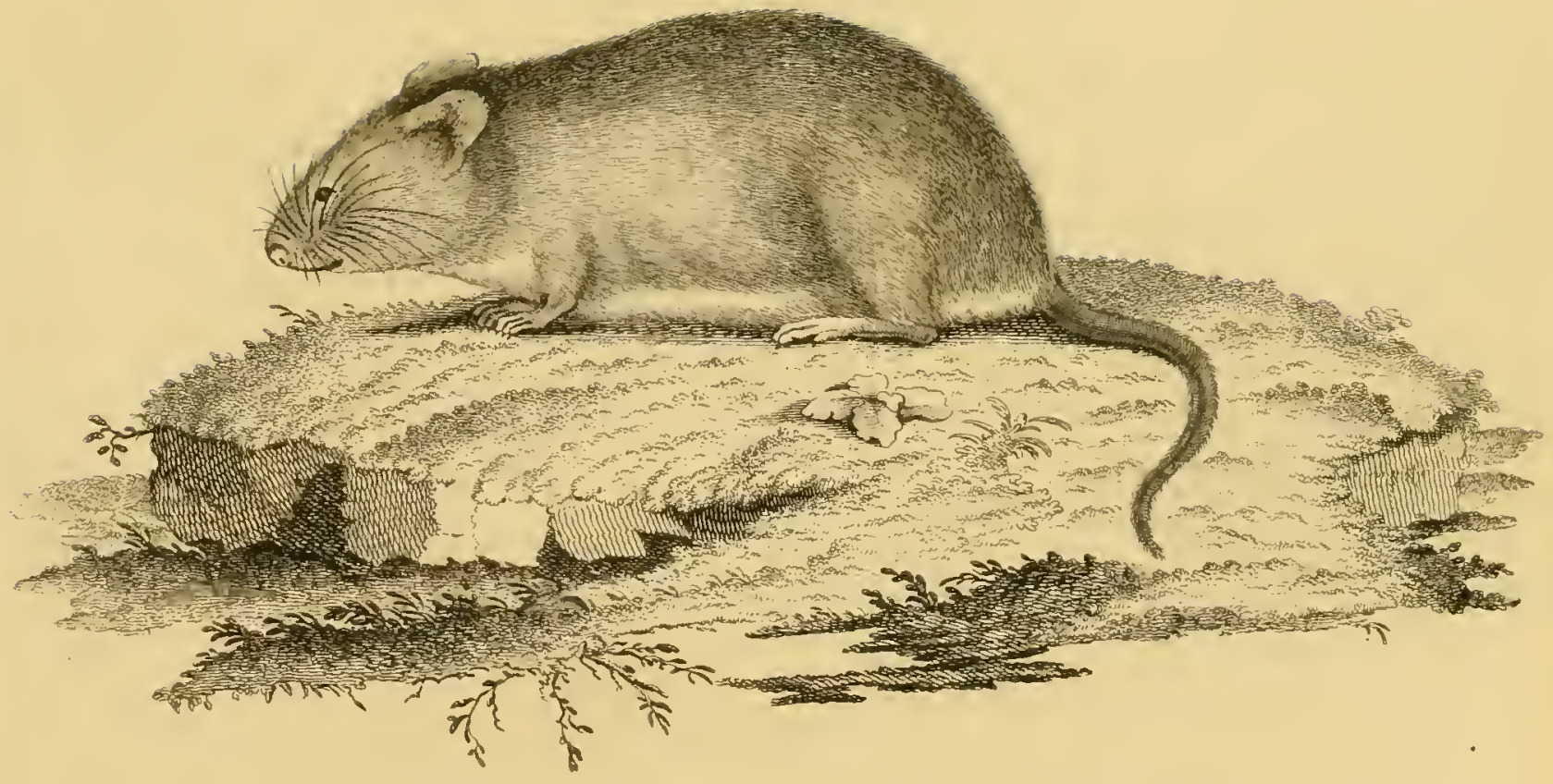



A.

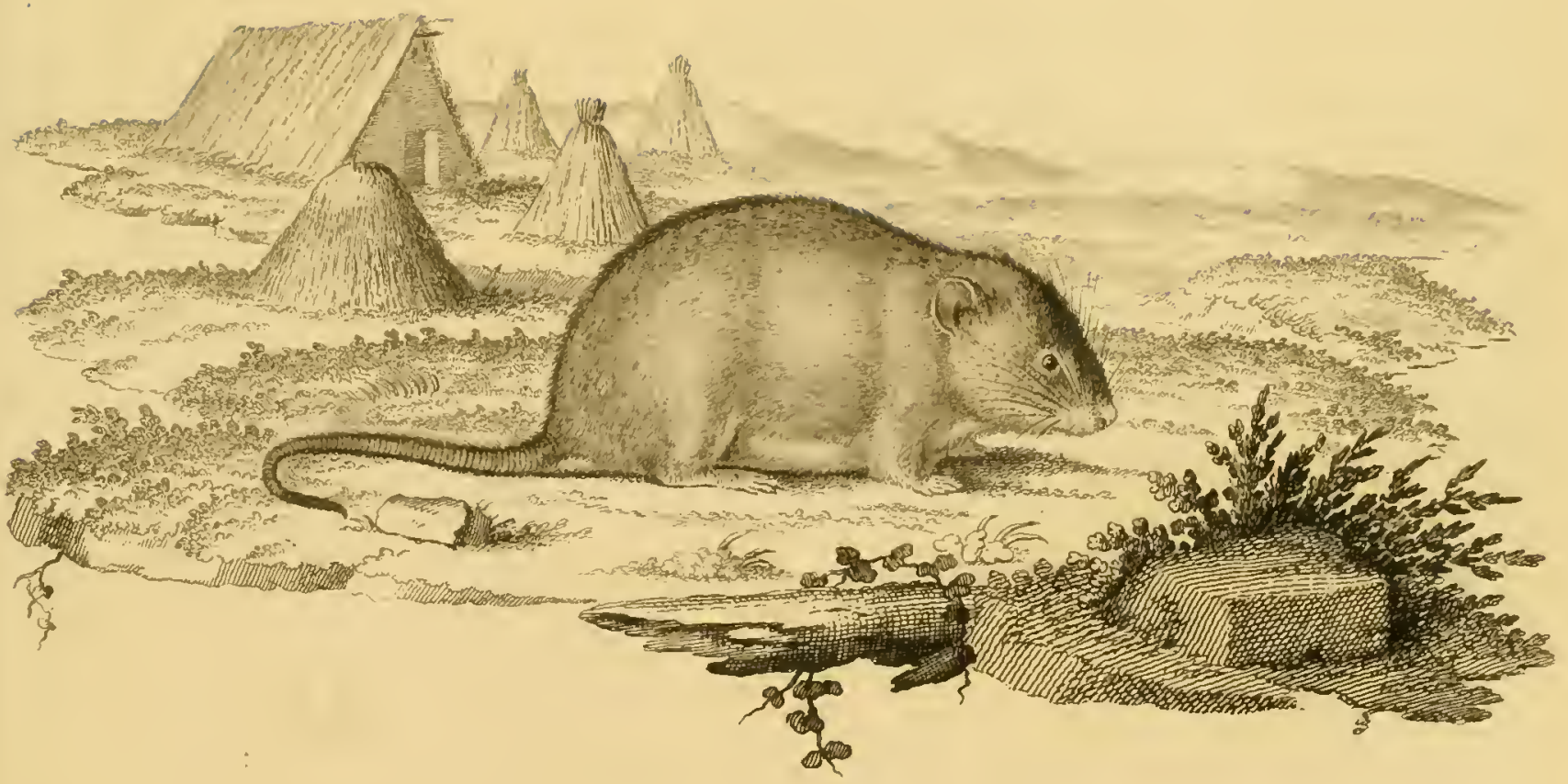



Jiab. NXIV.

13.

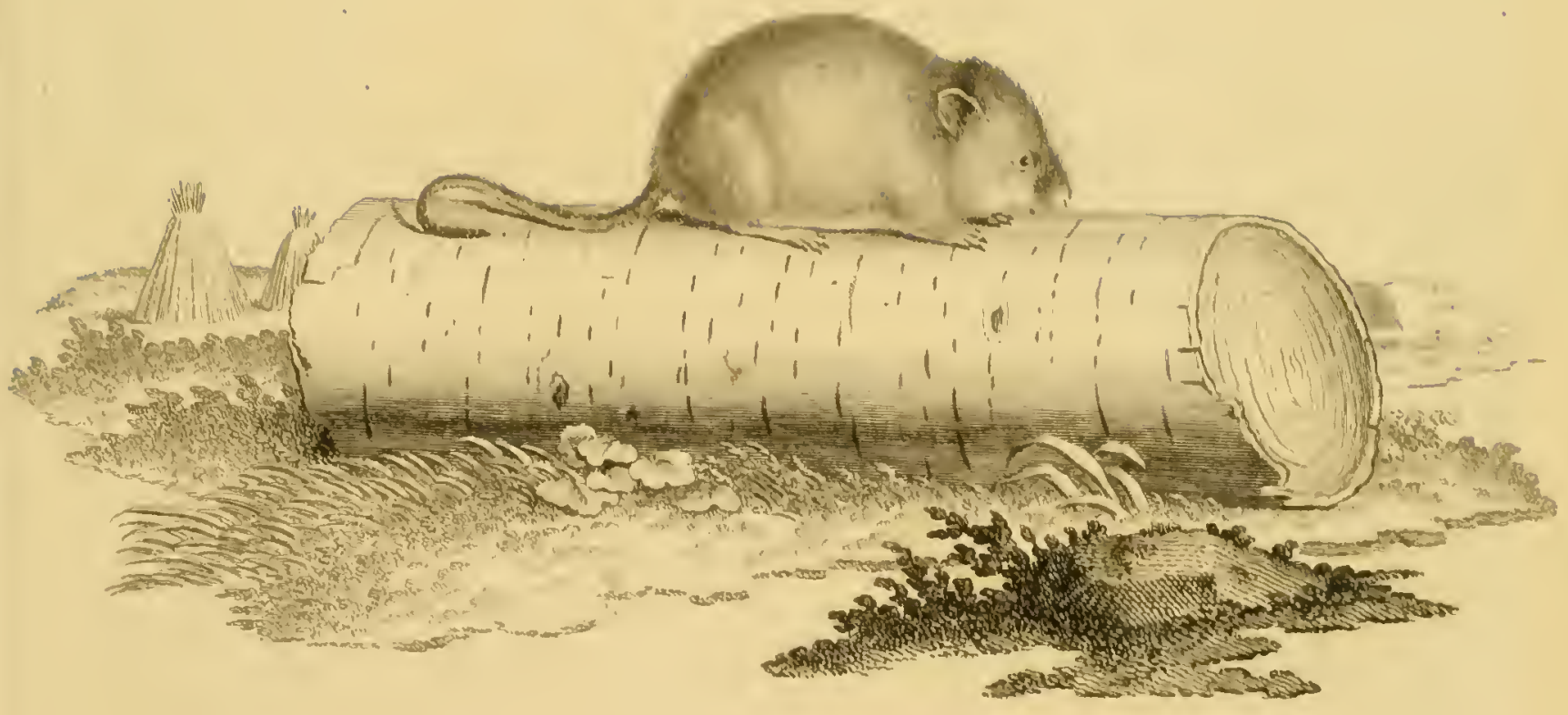




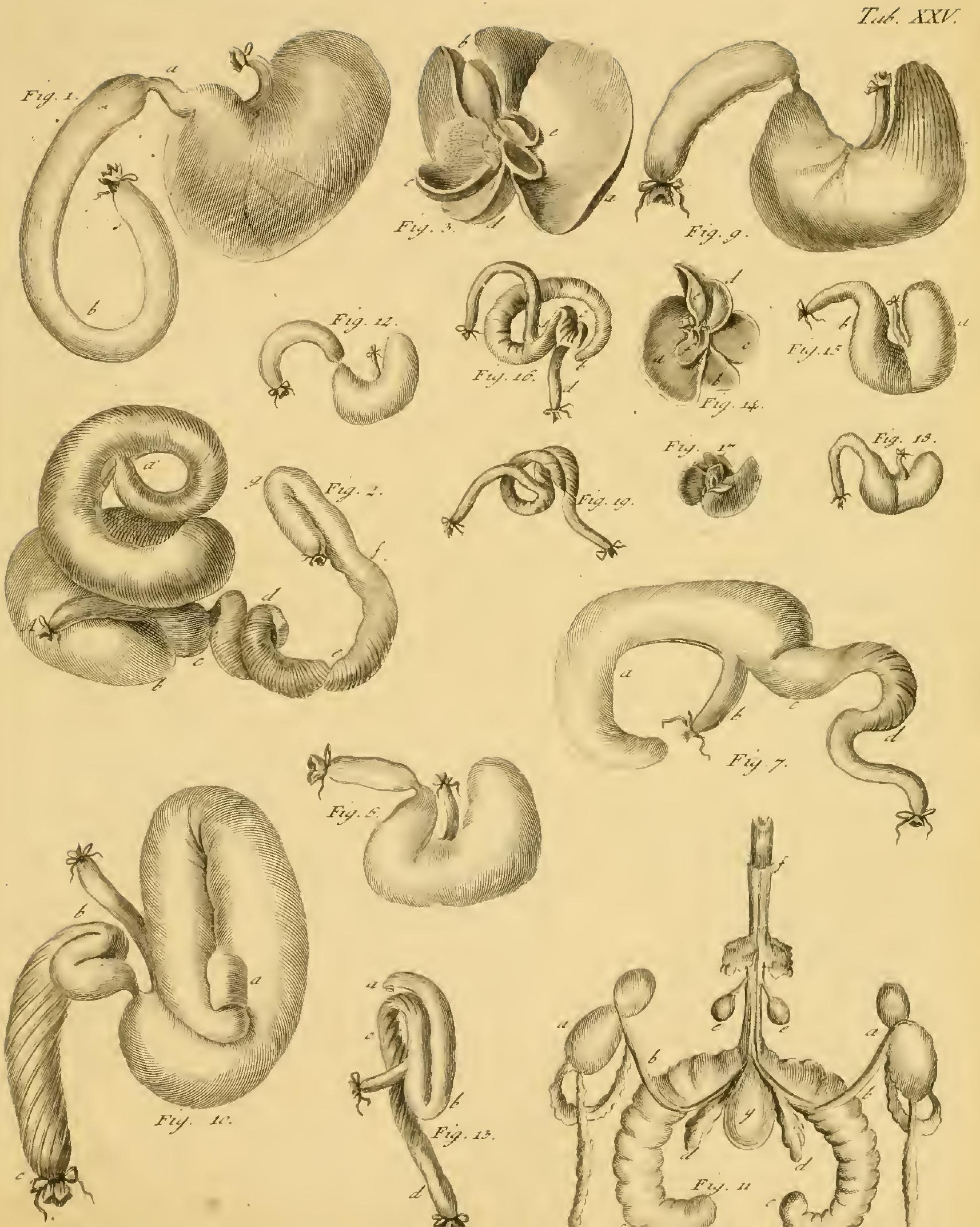



'Iab.XXVI.
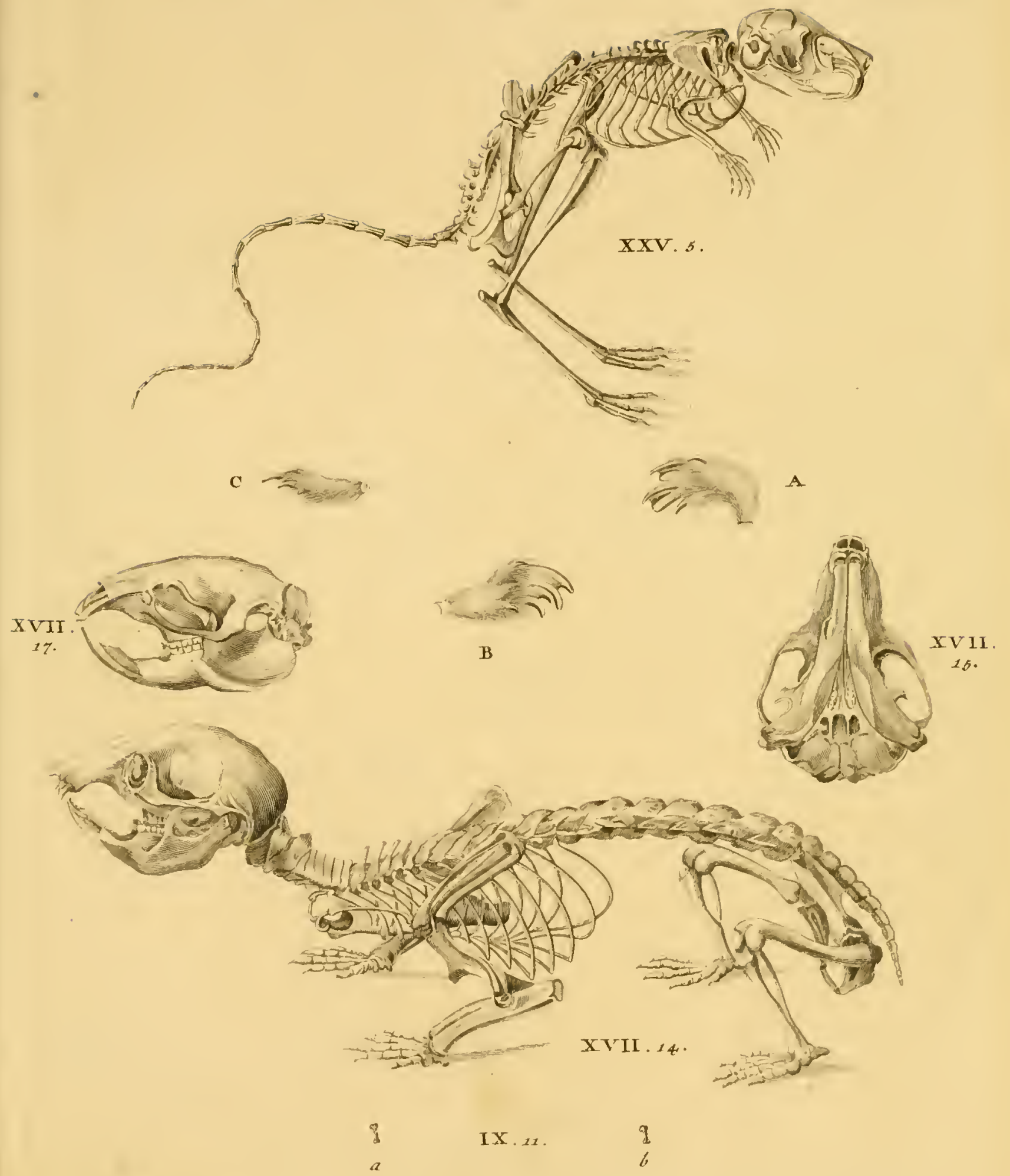
Andonins wampotaie. givl

kepew x'x

offinis J:" qu

og Nona

scielew .... 3

tot

vaunbili...,

3, accedue …25\%

agrarius... 34

$x$ Ciarius ... 25

areuaries ... $=\frac{5}{5}$

aepalar. . 165

sहtulinus ... 332

capensis...172

caraco.... 335

citeches... 119

decumanum 919

qualis...2 238

gandi-9. qud sonicus.. 208

raculur ... ₹ 55

lagurue... 210

lemmus.. $18 \bar{G}$

cregiper... B,

riruthis. 345

secore onuur 225

b.124....2.261

intilug ... 245

vagitta...300

kxaticis...255

sucial is ... 018

mequend... - 9 moes tialperies ,

trukriaine in

loramitus nos

top. Hew is

ragut 32 ?

"ciums ciucreus syo

emythraens 377

muelsonicios $3 r 6$

striatus óng

rolatev 355 


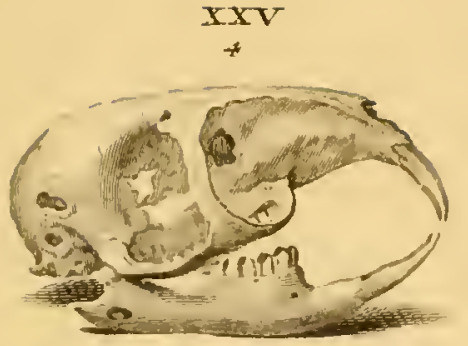

$X V I I 20 B$

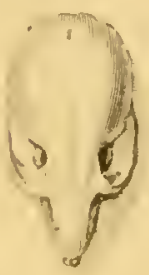

XVII $\Leftrightarrow A$

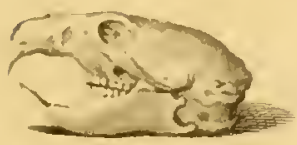

XVII 9
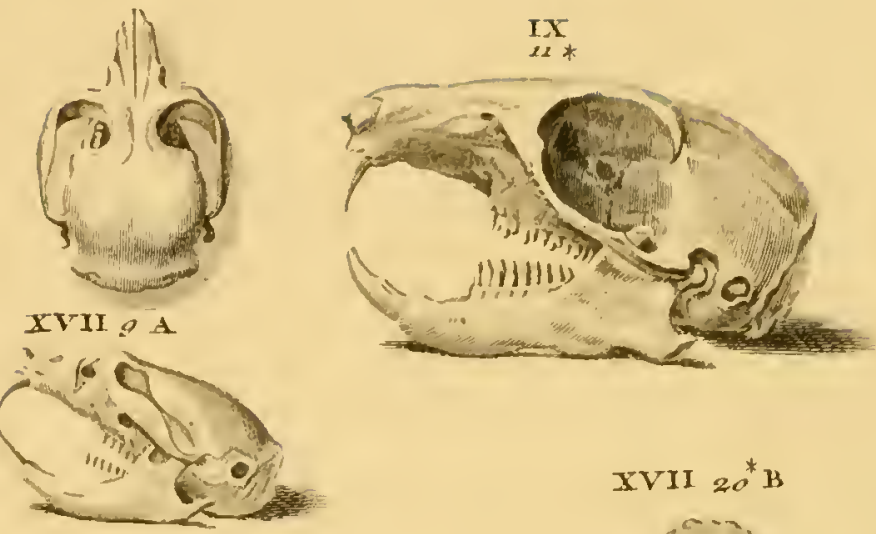

XVII $20^{*} \mathbf{B}$

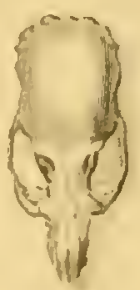

XVII $20^{*} \mathrm{~A}$

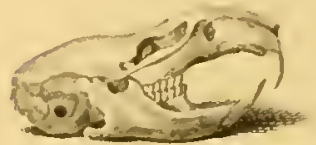

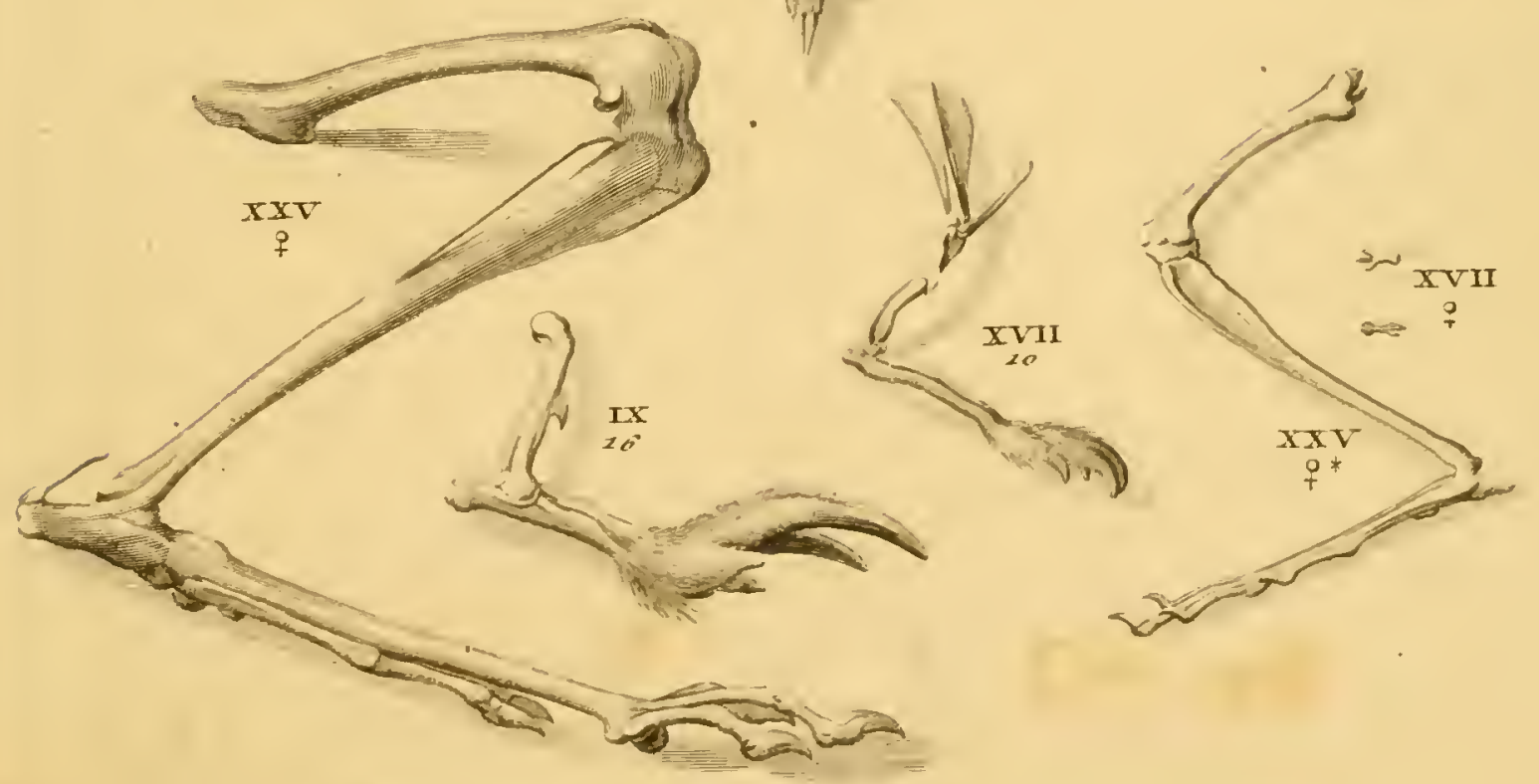




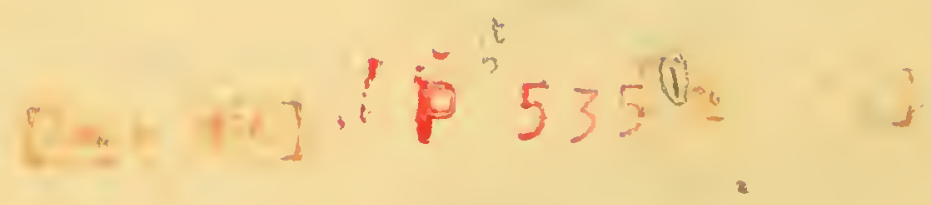






